\title{
Chemistry of the Subalkalic Silicic Obsidians
}

U.S. GEOLOGICAL SURVEY PROFESSIONAL PAPER 1523 


\section{AVAILABILITY OF BOOKS AND MAPS OF THE U.S. GEOLOGICAL SURVEY}

Instructions on ordering publications of the U.S. Geological Survey, along with the last offerings, are given in the current-year issues of the monthly catalog "New Publications of the U.S. Geological Survey." Prices of available U.S. Geological Survey publications released prior to the current year are listed in the most recent annual "Price and Availability List." Publications that are listed in various U.S. Geological Survey catalogs (see back inside cover) but not listed in the most recent annual "Price and Availability List" are no longer available.

Prices of reports released to the open files are given in the listing "U.S. Geological Survey Open-File Reports," updated monthly, which is for sale in microfiche from U.S. Geological Survey Book and Open-File Report Sales, Box 25425, Denver, CO 80225.

Order U.S. Geological Survey publications by mail or over the counter from the offices given below.

\section{BY MAIL}

\section{Books}

Professional Papers, Bulletins, Water-Supply Papers, Techniques of Water-Resources Investigations, Circulars, publications of general interest (such as leaflets, pamphlets, booklets), single copies of periodicals (Earthquakes \& Volcanoes, Preliminary Determination of Epicenters), and some miscellaneous reports, including some of the foregoing series that have gone out of print at the Superintendent of Documents, are obtainable by mail from

\section{U.S. Geological Survey, Book and Open-File Report Sales Box 25425 Denver, CO 80225}

Subscriptions to periodicals (Earthquakes \& Volcanoes and Preliminary Determination of Epicenters) can be obtained ONLY from

\section{Superintendent of Documents \\ U.S. Government Printing Office Washington, DC 20402}

(Check or money order must be payable to Superintendent of Documents.)

Maps

For maps, address mail orders to

$$
\begin{gathered}
\text { U.S. Geological Survey, Map Sales } \\
\text { Box 25286 } \\
\text { Denver, CO } 80225
\end{gathered}
$$

Residents of Alaska may order maps from

$$
\begin{aligned}
& \text { U.S. Geological Survey, Map Sales } \\
& 101 \text { Twelfth Ave. - Box } 12 \\
& \text { Fairbanks, AK } 99701
\end{aligned}
$$

\section{OVER THE COUNTER Books}

Books of the U.S. Geological Survey are available over the counter at the following U.S. Geological Survey offices, all of which are authorized agents of the Superintendent of Documents.

- ANCHORAGE, Alaska--4230 University Dr., Rm. 101

- ANCHORAGE, Alaska--605 West 4th Ave., Rm G-84

- DENVER, Colorado--Federal Bldg., Rm. 169, 1961 Stout St.

- LAKEWOOD, Colorado-- Federal Center, Bldg. 810

- MENLO PARK, California--Bldg. 3, Rm. 3128,345 Middlefield Rd.

- RESTON, Virginia--National Center, Rm. 1C402, 12201 Sunrise Valley Dr.

- SALT LAKE CITY, Utah--Federal Bldg., Rm. 8105, 125 South State St.

- SAN FRANCISCO, California--Customhouse, Rm. 504, 555 Battery St.

- SPOKANE, Washington--U.S. Courthouse, Rm. 678, West 920 Riverside Ave.

- WASHINGTON, D.C.--U.S. Department of the Interior Bldg., Rm. 2650, 1849 C St., NW.

\section{Maps}

Maps may be purchased over the counter at the U.S. Geological Survey offices where books are sold (all addresses in above list) and at the following Geological Survey offices:

- ROLLA, Missouri--1400 Independence Rd.

- FAIRBANKS, Alaska--New Federal Building, 101 Twelfth Ave. 


\section{Chemistry of the Subalkalic Silicic Obsidians}

By RAY MACDONALD, ROBERT L. SMITH, and JOHN E. THOMAS

U.S. GEOLOGICAL SURVEY PROFESSIONAL PAPER 1523

Compilation of analyses of subalkalic silicic obsidians, assessment of compositional variations in terms of tectonic setting and genetic mechanisms, and systematic discussion of element distribution in these rocks

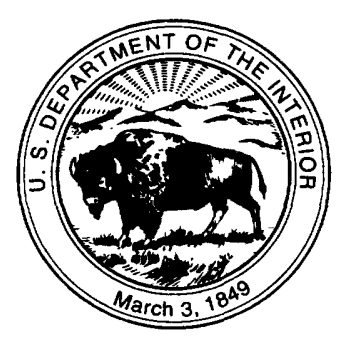

UNITED STATES GOVERNMENT PRINTING OFFICE, WASHINGTON : 1992 


\title{
U.S. DEPARTMENT OF THE INTERIOR
}

\author{
MANUEL LUJAN, JR., Secretary
}

\section{U.S. GEOLOGICAL SURVEY}

DALLAS L. PECK, Director

Any use of trade, product, or firm names in this publication is for descriptive purposes only and does not imply endorsement by the U.S. Government

\section{Library of Congress Cataloging-in-Publication Data}

Macdonald, Ray.

Chemistry of the subalkalic silicic obsidians / by Ray Macdonald, Robert L. Smith, and John E. Thomas. p. $\quad$ cm. - (U.S. Geological Survey professional paper ; 1523)

Includes bibliographical references (p. )

Supt. of Docs. no.: I 19.16:1523

1. Obsidian-Composition. I. Smith, Robert L. II. Thomas, John E. III. Title. IV. Series. QE462.028M33 $\quad 1991$

552 '.2-dc20

For sale by Books and Open-File Sales, U.S. Geological Survey, Federal Center, Box 25286, Denver, CO 80225 


\section{CONTENTS}

Abstract

Introduction

Acknowledgments

The data bank

Description and geographical distribution of analyzed samples

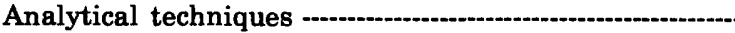

Major-element analyses -

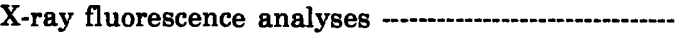

Instrumental neutron-activation analyses ..............

Other analytical methods

Presentation of the data bank

Completeness of the data bank

Representativeness of samples

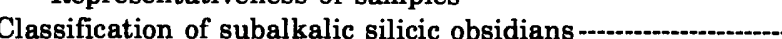

Classification used in this paper

Obsidians not accommodated by the classification scheme

Comparison with the rhyolite groupings of Ewart (1979)

Relations among $\mathrm{SiO}_{2}, \mathrm{Al}_{2} \mathrm{O}_{3}, \mathrm{CaO}$, and $\left(\mathrm{Na}_{2} \mathrm{O}+\mathrm{K}_{2} \mathrm{O}\right)$ in subalkalic obsidians

The terms calcic, calc-alkalic, and alkali-calcic -..-Relations among $\mathrm{Al}_{2} \mathrm{O}_{3}, \mathrm{CaO}$, and $\left(\mathrm{Na}_{2} \mathrm{O}+\mathrm{K}_{2} \mathrm{O}\right)$ and the significance of normative corundum -............

Normative Q-Ab-Or- $\mathrm{H}_{2} \mathrm{O}$ and $\mathrm{Or}-\mathrm{Ab}-\mathrm{An}-\mathrm{H}_{2} \mathrm{O}$ plots -

Notes on the occurrence, geology, and petrography of the obsidian subgroups

Group I: Obsidians from the early stages of arc development

Group II: Obsidians of mature island arcs ...................

Group III: Obsidians of active continental margins --.---

Group IV: Obsidians of the continental interiors -...-.....

Group V: Obsidians from islands overlying oceanic

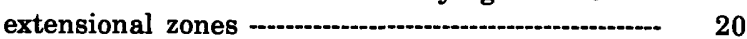

Geochemistry

Introduction

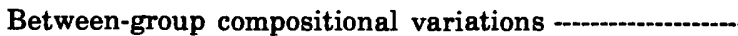

Tectonomagmatic discrimination diagrams -

Assessment of standard variation diagrams ..........

Trace-element discrimination plots -

Geochemical features of main obsidian groups -............

Group I: Obsidians from primitive island arcs --..-.

Group II: Obsidians from mature island arcs ........

Group III: Obsidians from the continental margins -

Group IV: Obsidians from the continental interiors

Group V: Obsidians from oceanic extensional settings

Unclassified obsidians

Magmatic differentiation processes in silicic systems -.........

Introduction

Relative roles of CLPD and CIPP

Some terms
Page
Magmatic differentiation processes in silicic systems-

Continued

Relative roles of CLPD and CIPP-Continued

Difficulties of recognizing CIPP magma

compositions

Criteria for the identification of CIPP

compositions -

Application to the whole body of obsidian data -......

Magma mixing and assimilation

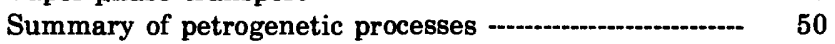

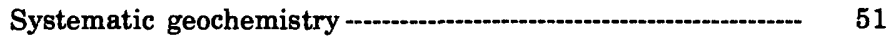

Silicon -

Aluminum - -

Iron -

Total $\mathrm{Fe}$ as $\mathrm{FeO}\left(\mathrm{FeO}_{t}\right)$

$\mathrm{FeO} /\left(\mathrm{FeO}+\mathrm{Fe}_{2} \mathrm{O}_{3}\right)$ ratios --.- 58

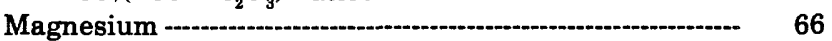

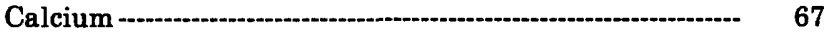

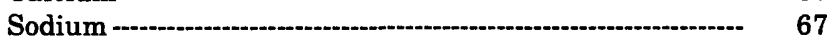

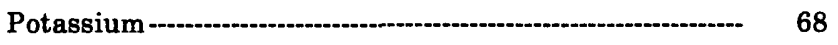

$\mathrm{Na}_{2} \mathrm{O}+\mathrm{K}_{2} \mathrm{O}$ -

$\mathrm{Na}_{2} \mathrm{O} / \mathrm{K}_{2} \mathrm{O}$ ratios -..-...-. 68

Water and the isotopes of hydrogen and oxygen ---.-.-. $\quad 69$

Water -..-..-.- 70

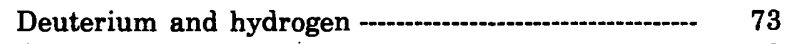

Oxygen isotopes -...........- 73

Titanium - -

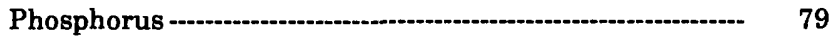

Manganese -

Chlorine --

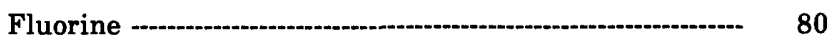

$\mathrm{Cl} / \mathrm{F}$ ratios - -.....- 80

Barium -

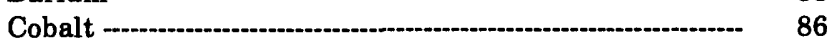

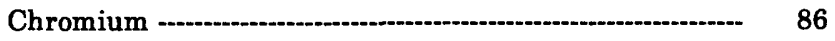

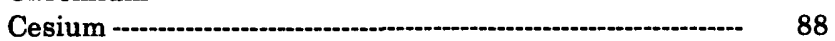

Niobium and tantalum -

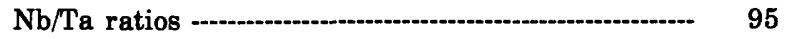

Lead - -

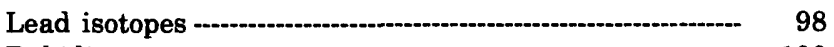

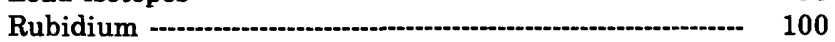

K/Rb ratios - - 100

Antimony -.-.- 100

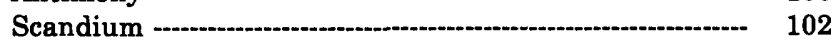

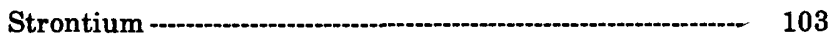

Strontium isotopes -...-...- 105

Thorium and uranium -

$\mathrm{Th} / \mathrm{U}$ ratios - - 110

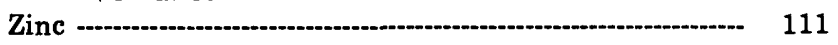

Zirconium and hafnium - -

$\mathrm{Zr} / \mathrm{Hf}$ ratios - - 113

Rare-earth elements and yttrium --.--.--.-- 115

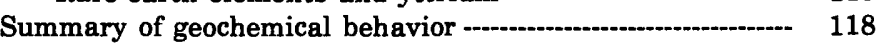

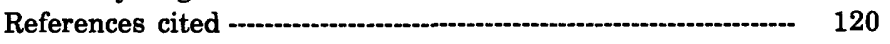




\section{ILLUSTRATIONS}

1. Graph of $\mathrm{CaO}$ versus $\mathrm{Na}_{2} \mathrm{O} / \mathrm{K}_{2} \mathrm{O}$ in subalkalic silicic obsidians having $\mathrm{CaO}$ less than 2 percent by weight -.....

2. Frequency diagram showing volume percent of phenocrysts in 124 samples of porphyritic obsidians -........... 3-5. Graphs of:

3. $\mathrm{SiO}_{2}$ versus $\mathrm{CaO} /\left(\mathrm{Na}_{2} \mathrm{O}+\mathrm{K}_{2} \mathrm{O}\right)$ showing overall similarity of calcic and calc-alkalic suites in high-SiO ${ }_{2}$ compositions

4. $\mathrm{CaO}$ versus $\mathrm{SiO}_{2} /\left(\mathrm{Na}_{2} \mathrm{O}+\mathrm{K}_{2} \mathrm{O}\right)$ showing distribution of silicic subalkalic obsidians into calcic, calcalkalic, and alkali-calcic types

5. $\mathrm{CaO}$ versus $\mathrm{SiO}_{2} /\left(\mathrm{Na}_{2} \mathrm{O}+\mathrm{K}_{2} \mathrm{O}\right)$ showing trends of various suites crossing field boundaries

6-8. Ternary diagrams of:

6. Molecular proportions of $\mathrm{CaO},\left(\mathrm{Na}_{2} \mathrm{O}+\mathrm{K}_{2} \mathrm{O}\right)$, and $\mathrm{Al}_{2} \mathrm{O}_{3}$ in silicic obsidians

7. CIPW normative proportions of quartz, albite, and orthoclase showing fields and averages for obsidian groups

8. CIPW normative proportions of anorthite, albite, and orthoclase showing fields and averages for obsidian groups

9. Diagram of geochemical patterns, normalized to ocean ridge granite, for average obsidian from different tectonic settings

10-12. Graphs of:

10. $\mathrm{SiO}_{2}$ versus $\left(\mathrm{Na}_{2} \mathrm{O}+\mathrm{K}_{2} \mathrm{O}\right)$ showing distribution of obsidians in fields of the tholeitic, high-alumina, and alkalic basalt series of Kuno (1966)

11. $\mathrm{SiO}_{2}$ versus $\mathrm{K}_{2} \mathrm{O}$ content of obsidians in fields of high-K, calc-alkalic, and low-K rhyolites of Ewart (1979)

12. Log alkali/lime ratio versus $\mathrm{SiO}_{2}$ for obsidians, showing changes associated with generation in increasingly sialic crust

13. Ternary diagrams showing obsidian data plotted on hafnium-thorium-tantalum discrimination diagram of Wood (1980) and with fields adjusted for more accurate obsidian group discrimination than those of Wood (1980)

14-21. Graphs of:

14. $\mathrm{Rb} / \mathrm{Zr}$ versus $\mathrm{Nb}$ showing compositional fields of the obsidians

15. $\mathrm{Rb}$ versus $(\mathrm{Y}+\mathrm{Nb})$ for obsidian types, showing fields determined by Pearce and others (1984) for granites

16. Ta versus $\mathrm{Yb}$ for obsidian types, showing fields determined by Pearce and others (1984) for granites

17. $\mathrm{Nb}$ versus $\mathrm{Ta}$ covariation in obsidians

18. $\mathrm{Nb}$ versus total iron (as $\mathrm{FeO}$ ) showing compositional fields of various obsidian groups

19. $\mathrm{Nb}$ versus total iron (as $\mathrm{FeO}$ ), with boundaries between obsidian fields taken from figure 18 , showing

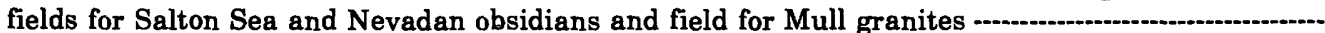

20. Sr versus Th showing fields occupied by selected subgroups of obsidians of Western United States continental margin

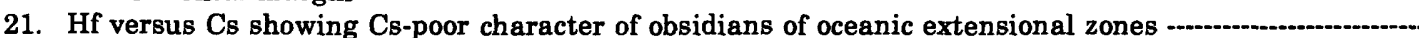

22. Diagram of $\mathrm{Nb}$ evolution in upper part of evolving, silicic magma chamber, showing base-level liquids and

real, total, and apparent fractionation factors

23-28. Graphs of:

23. $\mathrm{SiO}_{2}$ versus $\mathrm{Nb}$ showing relations between fractionation factors and magmatic affinity of systems -....

24. $\mathrm{K} / \mathrm{Rb}$ versus $\mathrm{Eu} / \mathrm{Eu}^{*}$ showing the relations between composition and dominant genetic processes -......

25. $\mathrm{K}_{2} \mathrm{O}$ versus $\mathrm{Rb}$ showing fields occupied by CLPD and CIPP silicic obsidians

26. $\mathrm{SiO}_{2}$ versus total iron (as $\mathrm{FeO}$ ) and versus $\mathrm{CaO}$ for various rock-glass pairs

27. $\mathrm{K}$ versus $\mathrm{Rb}$ showing that $\mathrm{CIPP}$ forms a link between crystal-liquid processes and hydrothermal activity

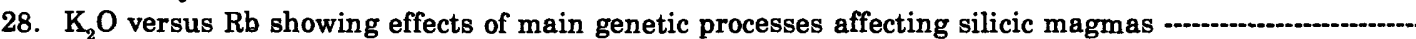

29. Histograms showing major-element distribution in obsidians

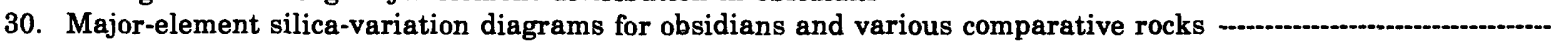

31. Graph of $\mathrm{SiO}_{2}$ versus total iron as $\mathrm{FeO}$ for obsidians of island arcs and for selected CLPD obsidians from United States continental interior

32. Histogram showing distribution of $\mathrm{FeO} /\left(\mathrm{FeO}+\mathrm{Fe}_{2} \mathrm{O}_{3}\right)$ ratio in obsidians

33. Histogram showing distribution of $\mathrm{Na}_{2} \mathrm{O} / \mathrm{K}_{2} \mathrm{O}$ ratio in obsidians

34. Graph of $\mathrm{SiO}_{2}$ versus $\mathrm{Na}_{2} \mathrm{O} / \mathrm{K}_{2} \mathrm{O}$ for obsidians and various comparative rocks

2 
35. Histogram showing $\mathrm{H}_{2} \mathrm{O}^{+}$data from all major studies of $\mathrm{H}_{2} \mathrm{O}$ in obsidians -

36. Histogram showing total $\mathrm{H}_{2} \mathrm{O}^{+}$data from four groups of obsidians shown in figure 35

37. Graph showing relations between $\mathrm{H}_{2} \mathrm{O}^{+}$and $\delta \mathrm{D}$ for obsidian and obsidian-hydrated glass (perlite) pairs --a-a- 75

38. Plot of $\delta^{18} \mathrm{O}$ of whole rock and glass samples of obsidians

39. Graph of $\mathrm{Cl}$ versus $\mathrm{F}$ for obsidians -

40. Histograms showing distribution of trace elements in obsidians

41. Graph of $\mathrm{Ba}$ versus $\mathrm{Sr}$ for obsidians and various comparative rocks

42. Graph of $\mathrm{CaO}$ versus $\mathrm{Co}$ for obsidians and various comparative rocks -

43. Trace-element silica-variation diagrams for obsidians and various comparative rocks - 89

44-47. Graphs of:

44. $\mathrm{K}_{2} \mathrm{O}(\mathrm{K})$ versus $\mathrm{Cs}$ for obsidians and various comparative rocks

45. $\mathrm{Rb}$ versus $\mathrm{Cs}$ showing generalized relations between $\mathrm{Rb} / \mathrm{Cs}$ ratio and tectonic setting

46. $\mathrm{CaO}$ versus $\mathrm{Ta}$ for obsidians and various comparative rocks

47. $\mathrm{SiO}_{2}$ versus $\mathrm{Nb}$ showing behavior in various systems controlled by crystal-liquid processes -.................

48. Histogram showing distribution of $\mathrm{Nb} / \mathrm{Ta}$ ratio in obsidians -

49. Graph of ${ }^{208} \mathrm{~Pb} /{ }^{204} \mathrm{~Pb}$ versus ${ }^{208} \mathrm{~Pb} /{ }^{204} \mathrm{~Pb}$ and ${ }^{207} \mathrm{~Pb} /{ }^{204} \mathrm{~Pb}$ versus ${ }^{206} \mathrm{~Pb} /{ }^{204} \mathrm{~Pb}$ for obsidians -........................

50. Graph of ${ }^{206} \mathrm{~Pb} /{ }^{204} \mathrm{~Pb}$ versus ${ }^{87} \mathrm{Sr} /{ }^{86} \mathrm{Sr}$ ratios for obsidians

51. Histogram showing distribution of $\mathrm{K} / \mathrm{Rb}$ ratio in obsidians -

52-55. Graphs of:

52. Cs versus $\mathrm{Sb}$ relations in obsidians from selected areas -

53. $\mathrm{MgO}$ versus $\mathrm{Sc}$ for obsidians and various comparative rocks

54. Sc versus Ta showing possible effects of CIPP on silicic magmas

55. $\mathrm{Sr}$ versus $\mathrm{CaO}$ and $\mathrm{Rb}$ for obsidians and various comparative rocks and $\mathrm{Sr}$ versus $\mathrm{Ta}$ showing tectonomagmatic discrimination

56. $\mathrm{K} / \mathrm{Th}$ versus $\mathrm{K} / \mathrm{U}$ for obsidians and various comparative rocks

57. Histogram showing distribution of $\mathrm{Th} / \mathrm{U}$ ratios in obsidians

58-60. Graphs of:

58. $\mathrm{Zn}$ versus $\mathrm{Yb}$ showing possible effects of CLPD in CIPP silicic systems

59. $\mathrm{Zr}$ versus $\mathrm{Hf}$ for obsidians and various comparative rocks showing that CIPP forms a link between - crystal-liquid processes and hydrothermal activity

60. Zr versus total iron (as $\mathrm{FeO}$ ) for obsidians and comparative rocks

61. Histogram showing distribution of $\mathrm{Zr} / \mathrm{Hf}$ ratios in obsidians

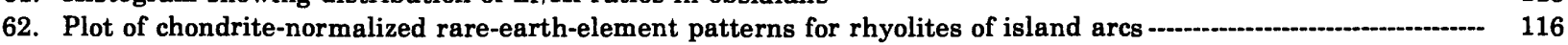

63. Plots of chondrite-normalized rare-earth-element patterns for obsidians of various groups -

64. Graph of $\mathrm{Ce} / \mathrm{Yb}$ versus $\mathrm{Eu} / \mathrm{Eu}^{*}$ for $\mathrm{CIPP}$ obsidians

\section{TABLES}

TABLE 1. Comparison of alkali determinations from published studies and the present paper

2. Comparison of trace-element data for obsidian from Big Glass Mountain, Medicine Lake highlands, California -----.-.

3. Comparison of trace-element data for Talasea obsidian

4. Summary of generalized localities and type of occurrence of samples compiled in appendixes I-IV

5. Generalized phenocryst assemblages of obsidian groups

6. Comparison, for the high- $\mathrm{SiO}_{2}$ rhyolites of certain orogenic and oceanic areas, of the classification scheme of this paper and the groupings of Ewart (1979)

7. Ranges and average compositions of the various obsidian groups

8. Average compositions of calcic and calc-alkalic obsidians from mature island arcs -

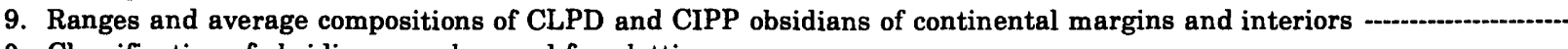

10. Classification of obsidian samples used for plotting purposes

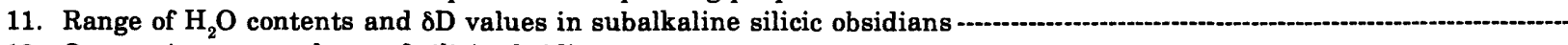

12. Oxygen isotope analyses of silicic obsidians -

13. Lead isotopic ratios in silicic obsidians

14. Strontium isotopic ratios in silicic obsidians -

15. Rare-earth-element characteristics of obsidians -

16. Correlation coefficients for the rare-earth elements and other elements with $r>0.60$

17. Attempt to isolate, for each element, those factors causing compositional variations in the obsidians; on an $\mathrm{SiO}_{2}$-normalized basis 


\section{APPENDIXES}

Appendix I. Chemical analyses of subalkaline silicic obsidians -

II. Chemical analyses of secondarily hydrated subalkaline silicic obsidians

III. Compilation of published major-element analyses of subalkaline silicic glasses --and

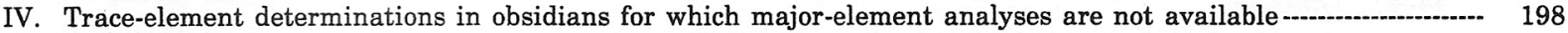

V. Additional analyses of rhyolites of primitive island arcs -

VI. Correlation matrix -

VII. Phenocryst assemblages and modal analyses of porphyritic obsidians

\section{ABBREVIATIONS}

CLPD Crystal-liquid processes dominated

CIPP Complex interaction of petrogenetic processes 


\title{
CHEMISTRY OF THE SUBALKALIC SILICIC OBSIDIANS
}

\author{
By Ray Macdonald, Robert L. Smith and John E. Thomas
}

\begin{abstract}
Nonhydrated obsidians are quenched magmatic liquids that record in their chemical compositions details of the tectonic environment of formation and of the differentiation mechanisms that affected their subsequent evolution. This study attempts to analyze, in terms of geologic processes, the compositional variations in the subalkalic silicic obsidians $\left(\mathrm{SiO}_{2} \geq 70\right.$ percent by weight, molecular $\left.\left(\mathrm{Na}_{2} \mathrm{O}+\mathrm{K}_{2} \mathrm{O}\right)<\mathrm{Al}_{2} \mathrm{O}_{3}\right)$. New major- and trace-element determinations of 241 samples and a compilation of 130 published major-element analyses are reported and interpreted.

Obsidians from five different tectonic settings are recognized: (1) primitive island arcs, (2) mature island arcs, (3) continental margins, (4) continental interiors, and (5) oceanic extensional zones. Tectonomagmatic discrimination between these groups is successfully made on $\mathrm{Nb}-\mathrm{Ta}, \mathrm{Nb}-\mathrm{FeO}_{\mathrm{t}}$, and $\mathrm{Th}-\mathrm{Hf}-\mathrm{Ta}$ plots, and compositional ranges and averages for each group are presented. The chemical differences between groups are related to the type of crust in which magmas were generated. With increasingly sialic (continental type) crust, the obsidians show overall enrichment in $\mathrm{F}, \mathrm{Be}, \mathrm{Li}, \mathrm{Mo}, \mathrm{Nb}, \mathrm{Rb}, \mathrm{Sn}, \mathrm{Ta}, \mathrm{U}, \mathrm{W}, \mathrm{Zn}$, and the rare-earth elements, and depletion in $\mathrm{Mg}, \mathrm{Ca}, \mathrm{Ba}, \mathrm{Co}, \mathrm{Sc}, \mathrm{Sr}$, and $\mathrm{Zr}$. They become more potassic, have higher $\mathrm{Fe} / \mathrm{Mg}$ and $\mathrm{F} / \mathrm{Cl}$ ratios, and lower $\mathrm{Zr} / \mathrm{Hf}, \mathrm{Nb} / \mathrm{Ta}$, and $\mathrm{Th} / \mathrm{U}$ ratios. Higher values of total rareearth elements are accompanied by light rare-earth-element enrichment and pronounced negative Eu anomalies.

An attempt is made to link obsidian chemistry to genetic mechanism. Two broad groups of rocks are distinguished: one generated where crystal-liquid processes dominated (CLPD types), which are the products of crustal anatexis, possibly under conditions of low halogen fugacity, \pm crystal fractionation \pm magma mixing; and a second group represented by rocks formed in the upper parts of large magma chambers by interplays of crystal fractionation, volatile transfer, magma mixing, and possibly various liquid-state differentiation mechanisms, or in other words a complex interaction of petrogenetic processes (CIPP types). Such rocks may also form by volatile-fluxed partial melting of the wallrocks, and subsequent mixing into the magma reservoir. Compositional ranges and averages for CLPD and CIPP obsidians are given.

It is shown by analogy with well-documented, zoned ash-flow tuffs that obsidians fractionated by CIPP have very low $\mathrm{Mg}, \mathrm{P}$, $\mathrm{Ba}$, and $\mathrm{Sr}$ contents, flat rare-earth-element patterns with extensive $\mathrm{Eu}$ anomalies, low $\mathrm{K} / \mathrm{Rb}$ and $\mathrm{Zr} / \mathrm{Nb}$ ratios, and relatively high $\mathrm{Na}_{2} \mathrm{O} / \mathrm{K}_{2} \mathrm{O}$ ratios. There is, however, considerable compositional overlap between CLPD and CIPP obsidians. The effects of magma mixing, assimilation, and vapor-phase transport in producing compositional variations in the obsidians are briefly assessed.

The geochemistry of the subalkalic silicic obsidians is described on an element-by-element basis, in order to provide a data base for silicic magma compositions that will hopefully contribute to
\end{abstract}

Manuscript approved for publication March 21, 1991. studies of granitic rocks. Attempts are also made to isolate the geochemical effects of tectonic environment and genetic mechanism for each element, by comparison with data from crystalliquid equilibria-controlled systems, from ash-flow sheets zoned by CIPP, and from mixed-magma series. A final tabulation relates the complexities of obsidian geochemistry to all the tectonic and genetic variables.

\section{INTRODUCTION}

This study of the chemistry of obsidians has been undertaken primarily to further our understanding of granitic igneous rocks. The literature on the chemistry of granites, rhyolites, and related rocks is extensive; much of it is useful, much is controversial, and much is totally useless. The study of granites per se is handicapped by difficulties inherent in sampling techniques and the recognition of significant samples, in obtaining accurate and precise chemical analyses, and in the distinct probability that many granites, though clearly of magmatic origin, may or may not represent liquid magmatic compositions, but instead reflect postmagmatic alteration or partial cumulate conditions.

This study of obsidians (nonhydrated rhyolitic glasses) is therefore a study of quenched, liquid, magmatic compositions. Its main aims are:

1. To determine the range of major- and trace-element compositions of subalkalic (mol. $\left.\left(\mathrm{Na}_{2} \mathrm{O}+\mathrm{K}_{2} \mathrm{O}\right)<\mathrm{Al}_{2} \mathrm{O}_{3}\right)$ rhyolitic liquids as expressed by obsidians. Although certain volatile constituents are lost before obsidian forms (for example, $\mathrm{H}_{2} \mathrm{O}, \mathrm{S}, \mathrm{CO}_{2}$, and perhaps $\mathrm{Cl}$ in some cases), most elements are relatively undisturbed, and thus obsidian represents a very close approximation to original rhyolitic melt.

2 . To relate compositional variations in the obsidians broadly to tectonic setting and, more specifically, to the type of crust in which the rhyolites were generated.

3. To interpret the data in terms of the main differentiation mechanisms operative in silicic magmas and to suggest preliminary criteria whereby the effects of each process might be identified.

4. To provide a comprehensive, systematic, element-by-element discussion of the data which will be the first of its kind specifically devoted to high-silica rocks. 


\section{ACKNOWLEDGMENTS}

We are deeply indebted to S.A. Malik (University of Reading) for the enormous effort in producing the major-element analyses, and to P.A. Baedecker (USGS, Reston) and J.O. Bowman (University of Lancaster) for INAA and XRF determinations, respectively. We also thank, for analytical results, E. Campbell (USGS; $\mathrm{Be}, \mathrm{Cl}, \mathrm{Mo}$, and $\mathrm{Nb}$ ), P. Aruscavage and J. Kane (USGS; Sn), W. D'Angelo (USGS; W), A. Neuville (USGS, Li), H. Smith (USGS, F), and D. Whitehead (Reading, F and Cl), with support from A. Childress, W. Daugherty, M. Doughten, D. Kobilis, and L. Schwartz (all USGS).

Obsidian samples were kindly provided by so many individuals that we deemed it best to acknowledge these critical contributions separately, in the annotated locality lists in appendixes I-IV.

David Gottfried provided unpublished data on the Woodson stock, and a wealth of geochemical experience. R.J. Banks, B. Robinson and T.L. Wright helped with computing problems. Karen Gray and Susan Russell-Robinson kept the project on the road, in many ways. Frank Dodge and Jim Rytuba provided detailed, constructive reviews of the manuscript.

J.E.T. thanks the University of Reading for financial support. R.M. was financed by the Natural Environment Research Council (U.K.) and the U.S. Geological Survey.

\section{THE DATA BANK}

An initial objective of this project was to collect from the literature all good-quality analyses of nonhydrated obsidians and glasses having $\mathrm{SiO}_{2} \geq 70$ percent and to assess the chemical variations in terms of rhyolite petrogenesis. Analyses were screened using the following criteria for rejection:

1. The total weight percent for major oxides did not lie within the limits $99-101$ percent.

2. Any one of the oxides $\mathrm{SiO}_{2}, \mathrm{Al}_{2} \mathrm{O}_{3}, \mathrm{Fe}_{2} \mathrm{O}_{3}, \mathrm{FeO}$, $\mathrm{CaO}, \mathrm{Na}_{2} \mathrm{O}, \mathrm{K}_{2} \mathrm{O}$, and $\mathrm{H}_{2} \mathrm{O}^{+}$was not reported.

3. Two or more of the oxides $\mathrm{TiO}_{2}, \mathrm{MnO}, \mathrm{MgO}$, and $\mathrm{P}_{2} \mathrm{O}_{5}$ were not reported.

4. $\mathrm{H}_{2} \mathrm{O}^{+}$content exceeded 1 weight percent. The original conclusion of Ross and Smith (1955), that obsidians with more than 1 percent $\mathrm{H}_{2} \mathrm{O}$ have been secondarily hydrated, has been confirmed by stable isotope studies (Friedman and Smith, 1958; Taylor, 1968) $)^{1}$.

'More recent studies have shown that nonhydrated obsidian pyroclasts may contain up to about 3 percent $\mathrm{H}_{2} \mathrm{O}$. The significance of these results to this work is discussed in the section "Water and the Isotopes of Hydrogen and Oxygen."
More than 200 major-element analyses were assembled. Despite the screening, it was apparent that the quality of many analyses was suspect, particularly alkali determinations.

Our experience with American silicic obsidians led us to expect a broad positive correlation between $\mathrm{CaO}$ contents and $\mathrm{Na}_{2} \mathrm{O} / \mathrm{K}_{2} \mathrm{O}$ ratios. The compilation of published analyses showed many exceptions to this rule. Comparison of our new data bank with the published analyses clearly demonstrates this (fig. 1). Published data may include chemical variants not sampled by our analytical program, but our reanalyses of glasses from some of the same localities that had previously provided "suspect" analyses have invariably indicated more normal alkali values for those rocks (table 1). In these examples, $\mathrm{Na}_{2} \mathrm{O}$ determinations appear to be more in error than those of $\mathrm{K}_{2} \mathrm{O}$. The series of analyses of obsidians presented by Friedman and Long (1976), on the other hand, have systematically low $\mathrm{K}_{2} \mathrm{O}$ values, by an average of about 10 percent, compared with our new data.

Other analytical problems may be suspected. For example, the analysis of an obsidian from Talasea, New Britain, given by Lowder and Carmichael (1970, sample 343) shows considerably higher $\mathrm{Fe}_{2} \mathrm{O}_{3}$ than $\mathrm{FeO}$ contents ( 1.58 pct, 0.88 pct, respectively; $\mathrm{FeO}_{\mathrm{t}}=2.30$ pct), a reversal of the situation in most obsidians. This unusual oxidation ratio is coupled with a rather high analytical total (100.46 pct). A high Fe determination seemed possible and

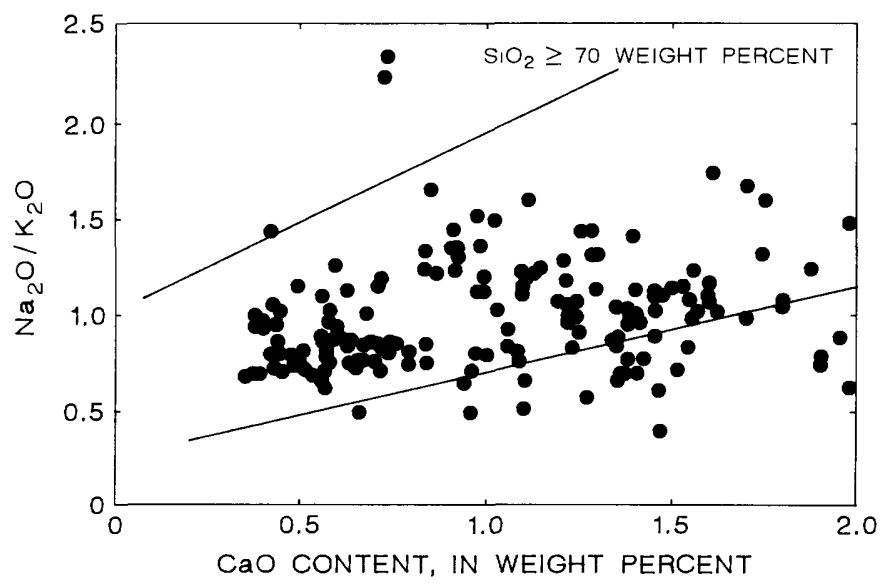

Figure 1.- CaO content versus ratio of $\mathrm{Na}_{2} \mathrm{O} / \mathrm{K}_{2} \mathrm{O}$ in subalkalic silicic obsidians having $\mathrm{CaO}$ less than 2 percent by weight. Rocks analyzed as part of this project fall between solid lines; dots represent published analyses: 27 rocks ( 15 percent) fall outside field bounded by solid lines. 
THE DATA BANK

TABLE 1.-Comparison of alkali determinations from published studies and the present paper

[Values are in weight percent]

\begin{tabular}{|c|c|c|c|c|c|}
\hline & \multicolumn{2}{|c|}{$\mathrm{Na}_{2} \mathrm{O}$} & \multicolumn{2}{|c|}{$\mathrm{K}_{2} \mathrm{O}$} & \multirow{2}{*}{ Reference (published; this paper) } \\
\hline & Published & New & Published & New & \\
\hline $\begin{array}{l}\text { Wadatoge, Japan } \\
\text { Kawago daira, Japan - } \\
\text { Hrafntinnuhryggur, Iceland -- } \\
\text { Rocche Rosse, Italy }\end{array}$ & $\begin{array}{ll}- & 2.84 \\
- & 5.16 \\
- & 3.36 \\
- & 3.7\end{array}$ & $\begin{array}{l}3.97 \\
3.85 \\
4.42 \\
4.23\end{array}$ & $\begin{array}{l}3.37 \\
2.12 \\
2.80 \\
5.1\end{array}$ & $\begin{array}{l}4.50 \\
2.40 \\
2.70 \\
5.05\end{array}$ & $\begin{array}{l}\text { Kawano, 1950; app. I, No. } 188 \\
\text { Kurasawa, 1959; app. I, No. } 189 \\
\text { Wright, 1915; app. I, No. } 175 \\
\text { von Platen, 1965; app. I, No. } 180\end{array}$ \\
\hline
\end{tabular}

indeed our reanalysis of Talasea obsidian gives $\mathrm{FeO}_{\mathrm{t}}=1.12$ percent. Smith and Johnson (1981) have also redetermined Talasea obsidian and found $\mathrm{FeO}$ to be 1.14 percent. Lowder and Carmichael's total Fe value would seem to be in error, and doubt is immediately cast upon other $\mathrm{Fe}$ determinations in that suite of analyses, including a glassy rhyodacite having $\mathrm{SiO}_{2}=72.19$ percent (their sample 279B).

The situation regarding trace elements proved equally unsatisfactory. Many available determinations were made for purposes of archaeological characterization and, for various reasons, were of limited use in our study.

1. Major-element analyses of the samples were not presented (for example, Cann and Renfrew, 1964; Renfrew and others, 1965, 1966, 1968; Jack and Carmichael, 1969; Jack, 1971; Rutherford, 1978).

2. Only a small number of supposedly diagnostic trace elements were determined (Gordus and others, 1968; Griffin and others, 1969; Stevenson and others, 1971).

3. Many samples were poorly located, geographically and (or) geologically (for example, Stevenson and others, 1971).

Interlaboratory consistency of data proved to be variable. Selected data from various studies of the Big Glass Mountain flow, Medicine Lake, California, indicate that for many elements interlaboratory agreement is good, but for others (for example, $\mathrm{Ce}, \mathrm{Co}$, and $\mathrm{Nb}$ ) rather less satisfactory (table 2). Although this flow has been contaminated by incorporation of mafic rocks, the close similarities of the $\mathrm{Ba}, \mathrm{Rb}$, and $\mathrm{Zr}$ values suggest that analytical problems, rather than natural contamination, are the main cause of the discrepancies in the data.

A comparison of the trace-element analyses of the Talasea obsidian, New Britain, published by Lowder and Carmichael (1970) and Smith and Johnson (1981), and presented in this paper (sam- ple 215), also shows some notable differences (table 3). As Smith and Johnson (1981, p. 10261) point out, Lowder and Carmichael's (1970) $\mathrm{Ni}, \mathrm{Ba}$, light rare-earth-element, and $\mathrm{Th}$ values are too high. Our $\mathrm{Y}$ and $\mathrm{Zn}$ determinations may be slightly on the high and low sides, respectively, but our $\mathrm{Pb}$ value is closer to Lowder and Carmichael's than to Smith and Johnson's.

Other inconsistencies in the published data, almost certainly due to analytical error, are noteworthy. For example:

1. The analysis of an obsidian from Forgia Vecchia, Lipari, presented by Cann and Renfrew (1964), does not lie within the limits for this unit given by Belluomini and Taddeucci (1971) for $\mathrm{Nb}, \mathrm{Rb}, \mathrm{Y}$, or $\mathrm{Zr}$.

2. The reanalysis by Wright and Gordus (1969) of Ronfrew and others' (1966) specimens 82 and 83 from eastern Turkey show satisfactory agreement for $\mathrm{Rb}$ but not for La. We suspect that Renfrew and others' La results are all, in fact, systematically too high.

3. The Y data of Higgins (1973) for obsidians from the Newberry Volcano, Oregon, are consistently higher than those of Jack and Carmichael (1969) for the Newberry rocks. Jack and Carmichael's (1969) $\mathrm{Zn}$ determinations, by contrast, are lower than those given by Laidley and McKay (1971) for Newberry glasses.

In view of these difficulties with the published analyses, we decided to build up a major- and trace-element data bank of subalkalic silicic obsidians, utilizing, for each element, the most precise analytical method available to us on a routine basis. Using our own collections and donated specimens, the number of samples reached 226 . Major-element (including $\mathrm{F}$ and $\mathrm{Cl}$ ) analyses and determinations of 32 trace elements were made on all samples, except for a very few where the small sample size resulted in certain elements being undetermined. Trace-element determinations only were subsequently made on a further 15 samples. 
TABLE 2.-Comparison of trace-element data for obsidian from Big Glass Mountain, Medicine Lake highlands, California

[All values in parts per million; -, not determined]

\begin{tabular}{|c|c|c|c|c|c|c|c|}
\hline \multirow[b]{2}{*}{$\mathrm{Ba}$} & \multirow{2}{*}{$\begin{array}{c}\begin{array}{c}\text { Jack and } \\
\text { Carmichael } \\
(1969)\end{array} \\
850\end{array}$} & \multirow{2}{*}{$\begin{array}{c}\begin{array}{c}\text { Stevenson } \\
\text { and others } \\
(1971)\end{array} \\
850\end{array}$} & \multirow{2}{*}{$\begin{array}{c}\begin{array}{c}\text { Condie and } \\
\text { Hayslip } \\
(1975)\end{array} \\
856\end{array}$} & \multirow{2}{*}{$\begin{array}{c}\begin{array}{c}\text { Sample } 42 \\
\text { (this } \\
\text { paper) }\end{array} \\
855\end{array}$} & \multirow{2}{*}{$\begin{array}{c}\text { Sample } 43 \\
\begin{array}{c}\text { (this } \\
\text { paper) }\end{array} \\
810\end{array}$} & \multicolumn{2}{|c|}{$\begin{array}{l}\text { Various authors, } \\
\text { in Flanagan } \\
(1976)\end{array}$} \\
\hline & & & & & & 705 & -826.7 \\
\hline $\mathrm{Ce}$ & 60 & - & - & 44 & 45 & 46.3 & $-\quad 60.4$ \\
\hline Co -...... & 15 & - & 2.6 & 2.1 & 1.9 & 1.76 & 7.2 \\
\hline Cs -...- & - & - & 11 & 10.5 & 9.7 & 10.3 & \\
\hline $\mathrm{Cu}$ & 10 & - & 18 & - & - & 10.2 & $-\quad 16.5$ \\
\hline La ...... & 30 & - & 29 & 23 & 24 & 27.0 & \\
\hline $\mathrm{Nb}$ & 5 & $<30$ & - & 9 & 9.4 & 5.44 & 9.44 \\
\hline $\mathrm{Pb}$ & 25 & - & - & 22 & 22 & 20.9 & $-\quad 21.2$ \\
\hline $\mathrm{Rb}$ & 155 & 140 & 157 & 156 & 154 & 96.3 & -193 \\
\hline Sc -...... & - & - & - & 4.5 & 4.36 & 4.60 & $-\quad 6.3$ \\
\hline $\mathrm{Sr}$ & 105 & 121 & 95 & 115 & 115 & 100.1 & -132 \\
\hline $\mathrm{Ta}$ & - & - & - & 1.00 & 1.03 & 0.54 & - $\quad 0.90$ \\
\hline Y -....... & 20 & 35 & - & 23 & 28 & 23.8 & $-\quad 26.7$ \\
\hline $\mathrm{Zn}$ & 25 & - & - & 30 & 28 & 21.5 & - $\quad 38.9$ \\
\hline Zr - & 215 & - & 192 & 206 & 212 & 205 & -304 \\
\hline
\end{tabular}

TABLE 3.-Comparison of trace-element data for Talasea obsidian

[All values in parts per million, - , not determined]

\begin{tabular}{|c|c|c|c|}
\hline & $\begin{array}{c}\text { Lowder and } \\
\text { Carmichael } \\
\text { (1970) }\end{array}$ & $\begin{array}{c}\text { Smith and } \\
\text { Johnson } \\
\text { (1981) }\end{array}$ & $\begin{array}{l}\text { Sample } 215 \\
\text { (this paper) }\end{array}$ \\
\hline Ba - & 645 & 480 & 540 \\
\hline Cr - & 5 & 4 & $<6$ \\
\hline $\mathrm{Cu}$ & 20 & 3 & - \\
\hline $\mathrm{Nb}$ & - & 2 & 3 \\
\hline $\mathrm{Ni}$ & 40 & $<1$ & - \\
\hline $\mathrm{Pb}$ & 20 & 8.5 & 19 \\
\hline Rb - -.... & 55 & 55 & 55 \\
\hline Sc - & - & 5 & 4 \\
\hline $\mathrm{Sr}$ & 200 & 206 & 216 \\
\hline Th -..... & 10 & 2.5 & 2.7 \\
\hline V-.............. & 35 & 6 & - \\
\hline Y …...... & 20 & 21 & 27 \\
\hline$Z_{n}$ & 40 & 38 & 31 \\
\hline $\mathrm{Zr} \ldots$ & 150 & 150 & 162 \\
\hline $\mathrm{Ce}$ & 50 & 29 & 24 \\
\hline La -..... & 20 & 13 & 13 \\
\hline Nd --.--- & 20 & 13 & 14 \\
\hline
\end{tabular}

\section{DESCRIPTION AND GEOGRAPHICAL DISTRIBUTION OF ANALYZED SAMPLES}

This report compiles geochemical information on silicic volcanic glasses. The majority of analyses has been made on obsidian. Though the term obsidian simply means pristine volcanic glass, it has popularly been used for material of sufficient size and quality to be worked as artifacts. As such, obsidian occurs in lava flows, in extrusive domes, and as blocks in pyroclastic deposits.
Silicic volcanic glass may, of course, occur in other forms: as pumiceous glassy carapaces on crystalline flows and domes, as remnant obsidian nodules (apache tears, marekanite) in secondarily hydrated flows and pyroclastic deposits, as vitreous facies of welded ash-flow tuffs, and as a range of tephra from coarse pumice to ash. In all these forms, especially as tephra, the glass tends to be rapidly hydrated after emplacement and may show variable amounts of chemical modification.

Nevertheless, incorporating nonhydrated glasses from this wider range of occurrences extended the number of samples of natural volcanic glass relevant to this compilation. Details of the mode of occurrence of individual specimens are given in the annotated sample lists accompanying various tables. Table 4 summarizes these data and also the general geographic localities of the analyzed specimens.

The rationale of selecting nonhydrated obsidians for analysis is that they represent magmatic liquid compositions. Sixty-one (61) percent of the 297 rocks for which petrographic information is available are porphyritic, however, and it might be argued that accumulation of crystals modified liquid compositions. A histogram of modal phenocryst proportions (fig. 2) indicates that 71 percent of the porphyritic samples have less than 3 percent phenocrysts, whereas only 17 percent of the samples have greater than or equal to 6 percent phenocrysts. Almost all compiled specimens are, therefore, crystal poor. Furthermore, there is no evidence of any systematic chemical differences 
TABLE 4.-Summary of generalized localities and types of occurrence of samples compiled in appendixes I-IV (excluding peralkaline rocks and those with $\mathrm{SiO}_{2}<70$ ) weight percent)

\begin{tabular}{|c|c|c|c|c|c|}
\hline Locality & $\begin{array}{l}\text { Lava flow } \\
\text { or dome }\end{array}$ & $\begin{array}{l}\text { Ash-Flow tuff } \\
\text { or agglutinate }\end{array}$ & $\begin{array}{l}\text { Fragments in } \\
\text { pyroclastic falls }\end{array}$ & Float & No information \\
\hline \multicolumn{6}{|c|}{ U.S.A. } \\
\hline \multicolumn{6}{|c|}{ Alaska } \\
\hline Oregon & 37 & 1 & - & 1 & - \\
\hline Californ & ... 70 & - & - & - & - \\
\hline Nevada & $\ldots$ & - & - & 2 & - \\
\hline Idaho - & -.- & 2 & - & - & - \\
\hline Wyomin & $\ldots 13$ & 2 & - & - & - \\
\hline Utah -.. & 16 & - & - & - & - \\
\hline Colorad & $\ldots \quad 2$ & - & - & - & - \\
\hline Arizona & $\ldots 6$ & - & 一 & - & - \\
\hline New $\mathrm{Me}$ & $\ldots 13$ & - & - & - & - \\
\hline
\end{tabular}

Central \& South America

\begin{tabular}{|c|c|c|c|c|c|}
\hline Mexico & 8 & 1 & 1 & - & 5 \\
\hline Guatemala & 2 & - & - & - & — \\
\hline Colombia - & 1 & - & - & - & - \\
\hline Ecuador - & 1 & 3 & - & - & - \\
\hline Peru & - & - & - & 9 & 1 \\
\hline Bolivia & - & 一 & - & 1 & 一 \\
\hline Chile - - & 5 & 一 & 一 & - & - \\
\hline \multicolumn{6}{|c|}{ Africa } \\
\hline Cameroon - & 一 & - & 一 & 1 & - \\
\hline
\end{tabular}

\begin{tabular}{|c|c|c|c|c|}
\hline \multicolumn{5}{|c|}{ Europe } \\
\hline 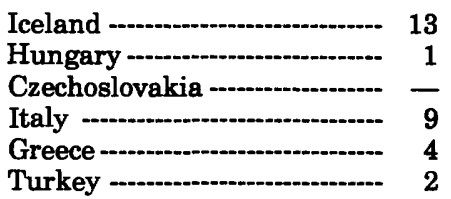 & $\begin{array}{l}- \\
- \\
-\end{array}$ & $\begin{array}{l}1 \\
- \\
- \\
-\end{array}$ & $\begin{array}{l}- \\
- \\
-\end{array}$ & $\begin{array}{r}-1 \\
1 \\
2 \\
-1\end{array}$ \\
\hline \multicolumn{5}{|c|}{ Asia } \\
\hline 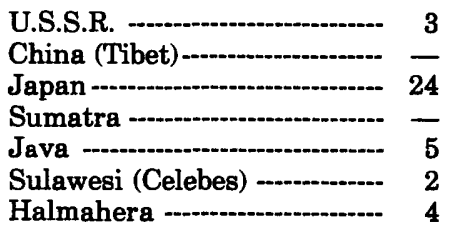 & $\begin{array}{l}- \\
- \\
-\end{array}$ & $\begin{array}{r}- \\
- \\
- \\
-\end{array}$ & $\begin{array}{l}- \\
- \\
- \\
-\end{array}$ & $\begin{array}{r}1 \\
1 \\
3 \\
1 \\
- \\
-\end{array}$ \\
\hline \multicolumn{5}{|c|}{ Australasia } \\
\hline 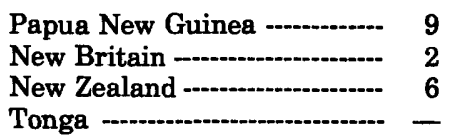 & - & $-\frac{}{1}$ & - & $\begin{array}{l}- \\
-\end{array}$ \\
\hline Total & 10 & 6 & 14 & 17 \\
\hline
\end{tabular}

Other types of occurrence, including sample numbers: dikelike mass intruded into maar, Mexico (146, 147, 279). There are also 9 glass separates in the compilation, from Alaska (5), Oregon $(10,12,14,16,18)$, Japan (187), Halmahera (210), and Tonge (371) 
between porphyritic and aphyric rocks. The data bank is therefore confidently taken to represent magmatic compositions (compare with Macdonald and Bailey, 1973, p. N4).

Some of our specimens were microvesicular. None was sufficiently rich in vesicles to be permeable, however, and we note that there is no relation between the degree of vesicularity of obsidians and the systematics of major- and minor-element chemistry.

\section{ANALYTICAL TECHNIQUES}

\section{MAJOR-ELEMENT ANALYSES}

Automated colorimetry, utilizing a Technicon Auto Analyzer, was used at the University of Reading, United Kingdom, to determine $\mathrm{SiO}_{2}$ and $\mathrm{Al}_{2} \mathrm{O}_{3}$ concentrations in solutions prepared by sodium hydroxide fusion of $100-\mathrm{mg}$ portions of sample powder; total iron (as $\mathrm{Fe}_{2} \mathrm{O}_{3}$ ), $\mathrm{TiO}_{2}, \mathrm{P}_{2} \mathrm{O}_{5}$ and $\mathrm{MnO}$ in solutions prepared by $\mathrm{HF}-\mathrm{HClO}_{4}$ digestions of 500 -mg portions of sample powder; and total iron (as $\mathrm{Fe}_{2} \mathrm{O}_{3}$ ) and $\mathrm{FeO}$ after cold dissolution of $500-\mathrm{mg}$ portions of powder with a mixture of $\mathrm{HF}$ and $\mathrm{H}_{2} \mathrm{SO}_{4}$ in the presence of ammonium metavanadate (Whitehead and Malik, 1975). No significant difference was found between total iron (as $\mathrm{Fe}_{2} \mathrm{O}_{3}$ ) determined by the alternative methods. The $\mathrm{Fe}_{2} \mathrm{O}_{3}$ content was calculated from the total iron (as $\mathrm{Fe}_{2} \mathrm{O}_{3}$ ) and $\mathrm{FeO}$ determinations. The basic colorimetric methods used in the automated colorimetry are as follows:

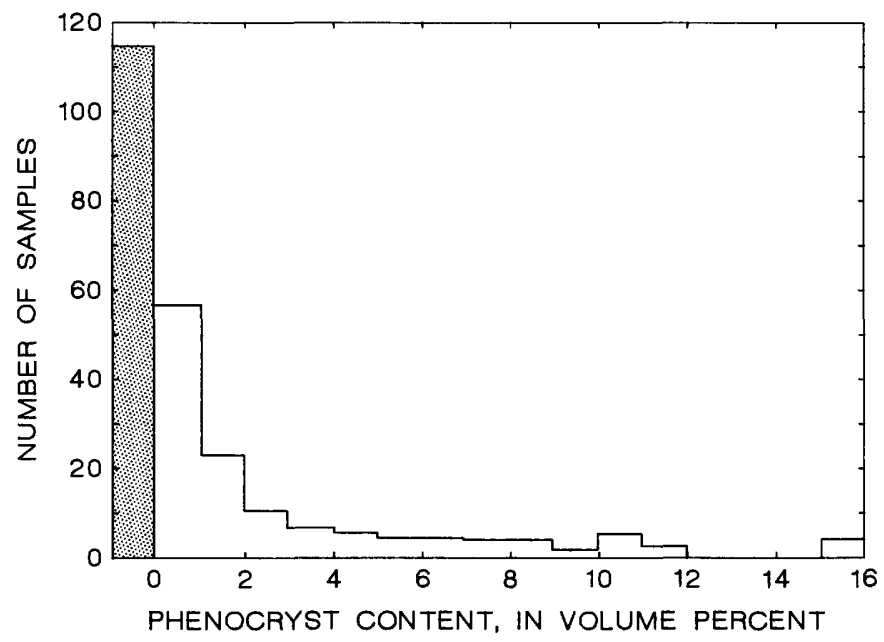

Figure 2.-Frequency diagram showing volume percent of phenocrysts in 124 samples of porphyritic obsidians. Shaded area represents 115 aphyric samples. Peralkaline and hydrated rocks and those having $\mathrm{SiO}_{2}$ less than 70 percent are excluded. Specimen 246, with 27 percent phenocrysts, is excluded.

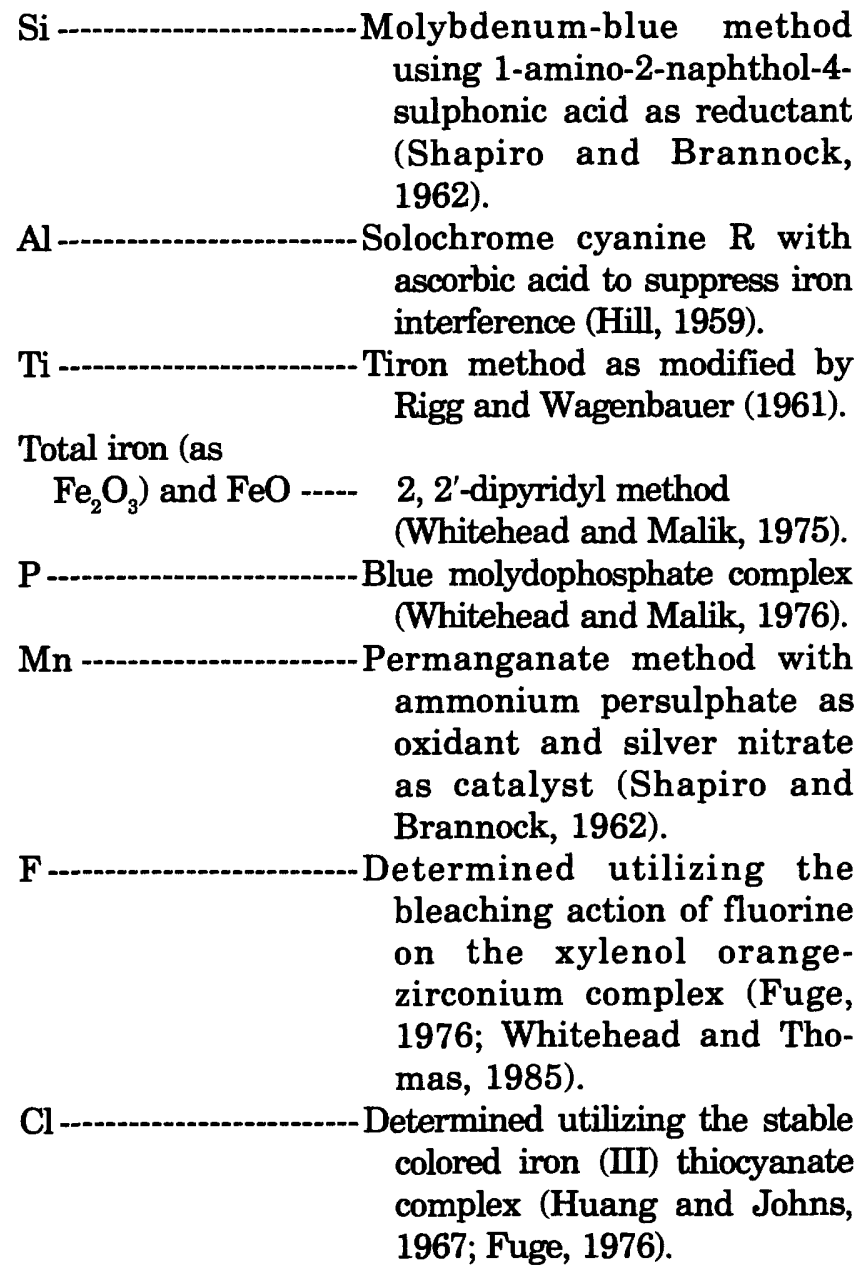

Most $\mathrm{F}$ and $\mathrm{Cl}$ determinations were made on 100 mg portions of sample powder using a pyrohydrolytic separation technique followed by selective-ion determination of $\mathrm{F}$ and automated colorimetric determination of $\mathrm{Cl}$ (Whitehead and Thomas, 1985). Initially, F and $\mathrm{Cl}$ were determined by an automated colorimetric method modified from Fuge (1976), but subsequently the pyrohydrolytic technique was preferred.

All portions of sample powders were dried for 2 hours at $110{ }^{\circ} \mathrm{C}$ before analysis. Atomic absorption spectrometry was employed for the determination of $\mathrm{Na}_{2} \mathrm{O}$ and $\mathrm{K}_{2} \mathrm{O}$ (with addition of $\mathrm{CsCl}$ as ionization buffer) and $\mathrm{CaO}$ and $\mathrm{MgO}$ (with addition of $\mathrm{LaCl}_{2}$ as releasing agent) using the solutions prepared by the HF-HClO digestions. Total water $\left(\mathrm{H}_{2} \mathrm{O}^{+}\right)$content was determined by a modified Penfield method similar to that described by Shapiro and Brannock (1955) except that a mixed lead oxide-lead chromate flux was used.

Duplicate portions of powder were analyzed for each sample, and the results reported are the mean of at least four determinations in the case of elements determined colorimetrically, two determina- 
tions for elements determined by atomic absorption spectrometry, and two determinations in the case of total water $\left(\mathrm{H}_{2} \mathrm{O}^{+}\right)$.

Analytical precision was monitored by including an obsidian from Pantelleria with successive batches of samples and also by including a sample from the preceding batch of test samples in with the next batch. The precision of results (in percent) is indicated by five replicate analyses of the Pantelleria rock : $\mathrm{SiO}_{2} 66.5$ (mean) \pm 0.11 (one standard deviation), $\mathrm{Al}_{2} \mathrm{O}_{3} 10.61 \pm 0.05, \mathrm{Fe}_{2} \mathrm{O}_{3} 2.23 \pm 0.13, \mathrm{FeO}$ $6.15 \pm 0.07, \mathrm{MgO} 0.15 \pm 0.004, \mathrm{CaO} 0.56 \pm 0.005, \mathrm{Na}_{2} \mathrm{O}$ $7.47 \pm 0.03, \mathrm{~K}_{2} \mathrm{O} 4.52 \pm 0.00, \mathrm{TiO}_{2} 0.64 \pm 0.007, \mathrm{P}_{2} \mathrm{O}_{5}$ $0.058 \pm 0.04$, and $\mathrm{MnO} 0.34 \pm 0.005$.

The accuracy of the Reading data can be judged by comparing the analyses of specimens 42 and 43 (see appendix I). Both samples are from Big Glass Mountain, Medicine Lake, California, No. 42 having been prepared for this study and No. 43 being the USGS standard rock RGM-1. The agreement is good, except for $\mathrm{H}_{2} \mathrm{O}^{+}$. The four-fold difference between the values ( 0.08 and 0.34 ; respectively) is very much higher than those normally associated with the modified Penfield method used at Reading. The difference may be related to a nonuniform distribution of water in the flow, caused by superheating of the rhyolite by incorporation of dacitic and basaltic magma.

\section{X-RAY FLUORESCENCE ANALYSES}

Concentrations of $\mathrm{Ba}, \mathrm{Nb}, \mathrm{Pb}, \mathrm{Rb}, \mathrm{Sr}, \mathrm{Y}, \mathrm{Zn}$, and $\mathrm{Zr}$ were determined by X-ray fluorescence (XRF) spectrometry at the University of Lancaster, United Kingdom, using rock powders. Estimates of precision, reported as one standard deviation in percent of the amount present and based on repeated analysis of RGM-1, are: $\mathrm{Ba} 3, \mathrm{Nb} 5, \mathrm{~Pb} 5, \mathrm{Rb} 2, \mathrm{Sr} 2, \mathrm{Y} 3$, $\mathrm{Zn} \mathrm{3,} \mathrm{and} \mathrm{Zr} 2$.

\section{INSTRUMENTAL NEUTRON-ACTIVATION ANALYSES}

Determinations of $\mathrm{Co}, \mathrm{Cr}, \mathrm{Cs}, \mathrm{Hf}, \mathrm{Rb}, \mathrm{Sb}, \mathrm{Sc}, \mathrm{Ta}$, $\mathrm{Th}, \mathrm{U}$, and the rare-earth-element contents were made by instrumental neutron-activation analysis (INAA) at the USGS, Reston, Va. Estimates of precision, based on replicate analyses of RGM-1 and given here as one standard deviation in percent of the amount present, are: Co $30, \mathrm{Cr} 30$, Cs 3 , Hf 3 , Rb 10, Sb 15, Sc 4, Ta 5, Th 4, U 12, La 6, Ce 5, Nd 11, Sm 8, Eu 17, Gd 20, Tb 4, Tm 13, Yb 5, and $\mathrm{Lu}$ 3 . The $\mathrm{Rb}$ values determined by INAA were less precise than those determined by XRF; although both are reported in appendix I, only the XRF data are used in discussions of $R b$ geochemistry.

\section{OTHER ANALYTICAL METHODS}

Analyses of the rare metals, $\mathrm{Li}, \mathrm{Be}, \mathrm{Sn}, \mathrm{Mo}, \mathrm{Nb}$, and $\mathrm{W}$, by the USGS, Reston, were determined as follows:

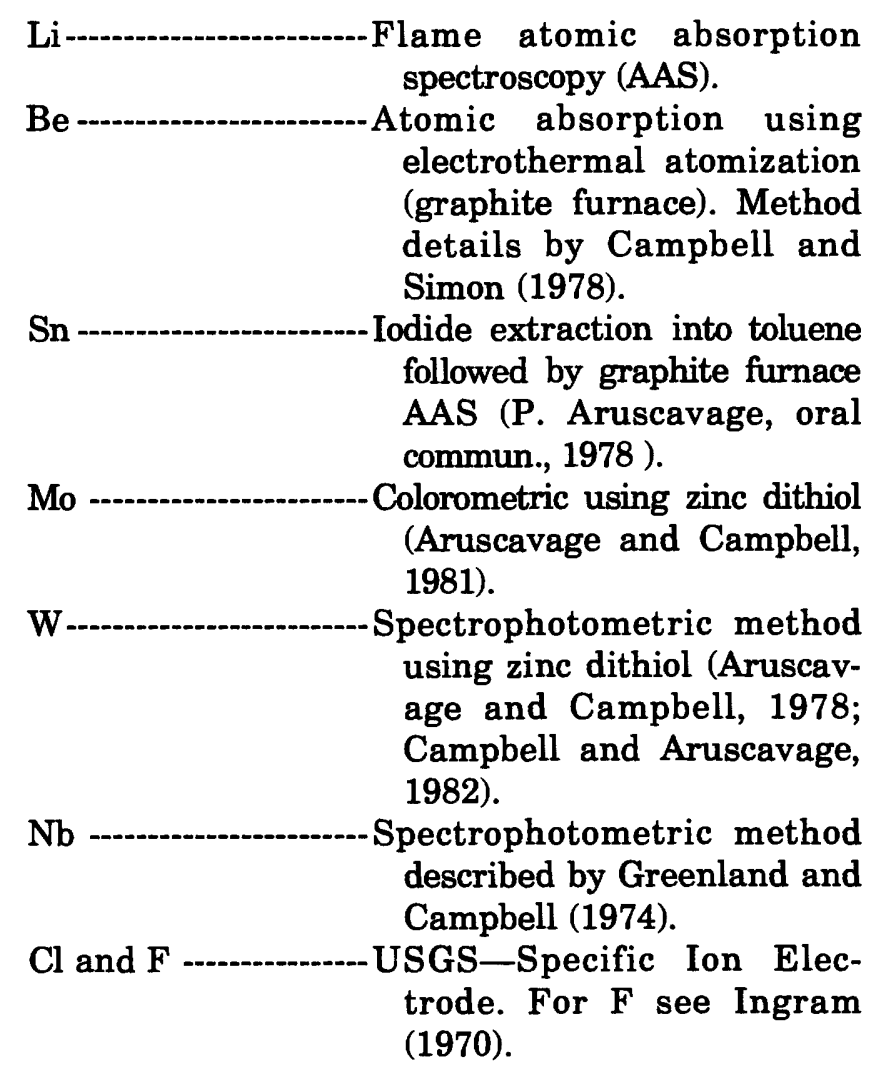

Both the USGS and University of Reading determinations of $\mathrm{F}$ and $\mathrm{Cl}$ are given in appendix $\mathrm{I}$. For some samples, the differences exceed those related only to the quoted precision of each method. We have no independent checks of which value is correct in such cases, so for the purposes of plotting on diagrams, calculations, and discussion, we have averaged the two values of $\mathrm{F}$ and $\mathrm{Cl}$ data.

\section{PRESENTATION OF THE DATA BANK}

The data presented in appendix I are of three kinds. The great majority (171 samples) are previously unpublished. A second category (29 samples) consists of analyses recently published or provided by USGS colleagues and made using similar analytical techniques to those of the present study for at 
least some elements. Thirdly, 17 analyses are of obsidians to which we have contributed part of the data. To this degree, appendix I thus provides an internally consistent body of data.

Certain specimens lie outside the arbitrarily imposed compositional limits of $\mathrm{SiO}_{2} \geq 70$ percent and molecular $\left(\mathrm{Na}_{2} \mathrm{O}+\mathrm{K}_{2} \mathrm{O}\right)<\mathrm{Al}_{2} \mathrm{O}_{3}$. For completeness, these have been included in the data tables but have not been used in any figures and computations. Specimens which proved to have more than 1 weight percent $\mathrm{H}_{2} \mathrm{O}^{+}$are given in appendix II; an exception is specimen 15, which is listed in appendix I because it is one of a whole rock-separated glass pair, and comparison is facilitated. Rocks for which traceelement data only are available are given in appendix IV. Analyses from appendixes II and IV are not used in illustrations or computations unless specifically stated.

Published major-element analyses which we consider reliable are listed in appendix III. In practice, this means that these data show compositions broadly similar to our new analyses; gross departure from the chemical range of the new data warranted suspicion and rejection from the compilation. This may have resulted in our omitting genuinely magmatic chemistries from appendix III, but, as mentioned above, where we have been able to reanalyze such rocks, the published analyses have invariably been found to be in error.

Because of the difficulties listed earlier, published trace-element determinations were not compiled. Instead, frequent referenced use is made in the text of any published data relevant to the discussion, except for the compilations of radiogenic and stable isotope determinations on silicic obsidians (see tables 13-16).

Modal analyses of porphyritic specimens are given in appendix VII. The new modes were determined using a single thin section per specimen. The number of counts varied between 500 and 2,500 , depending on the size of the section. We appreciate that a single thin section cannot give a truly representative value of the mode of an obsidian and, in some cases, may not even contain the full phenocryst assemblage. However, the modes are useful as an indication of the crystal-poor nature of the majority of specimens and in assessing the main mineralogical features of each obsidian group (table 5). In making intergroup comparisons, we acknowledge that phenocryst assemblages are partly a function of the degree of crystallinity. Sufficient multiphase samples are present from each group to promote modest confidence that apparent differences are real. Finally, there is some uncertainty about the optical identification of the acces- sory phases (for example, zircon) due to their very small size.

\section{COMPLETENESS OF THE DATA BANK}

The numbers of specimens in each group are as follows:

\begin{tabular}{|c|c|c|}
\hline \multirow[t]{2}{*}{ Obsidian groups } & \multicolumn{2}{|c|}{ Analyses } \\
\hline & New & Published \\
\hline Primitive island arcs & - & 1 \\
\hline Mature island arcs & 26 & 33 \\
\hline Continental margins & 66 & 53 \\
\hline Continental interiors & 80 & 28 \\
\hline Oceanic extensional zones --.- & 17 & 7 \\
\hline Other areas & 3 & 8 \\
\hline
\end{tabular}

The new data bank is least complete for calcic rhyolites from primitive and mature island arcs and, though published analyses (appendixes III, V) partially fill this gap, the number is still inadequate to describe fully the chemical variation in these rocks.

Though the lack of analyses of calcic varieties simply reflects absence from our collections, nonhydrated obsidians of this composition tend to be scarce in nature, as the most silica-rich members of calcic suites tend to be dacitic or rhyodacitic, with $\mathrm{SiO}_{2}<70$ percent. Even where higher silica calcic magmas exist, they are commonly erupted as ashes or as components of ash-flow tuffs. Furthermore, calcic rhyolites tend to be moderately porphyritic, a feature which promotes fracturing of the glass matrix and its subsequent rapid hydration.

It must also be noted that the data bank is heavily weighted toward rocks from the Western United States (57 percent of the total number of specimens). American samples comprise 85 percent of continental margin rhyolites and 77 percent of continental interior rhyolites, as defined below. There is no reason to believe that future analyses of obsidians from other areas will grossly modify the major-element compositional range established with this bias, but, in that every silicic province and complex are to some degree unique, the within-group ranges of trace-element abundances and ratios will almost certainly be extended.

\section{REPRESENTATIVENESS OF SAMPLES}

Many of the obsidian units described in this study are represented by a single specimen, consequently there is a question of how representative these specimens are of the eruptive units involved. 
TABLE 5.-Generalized phenocryst assemblages of obsidian groups

[Accessory minerals excluded. Pl, plagioclase; Opx, orthopyroxene; Cpx, clinopyroxene; Ox, Fe-Ti oxides; $\mathrm{Hb}$, amphibole; $\mathrm{Q}$, quartz; Ol, olivine; $\mathrm{Bi}$, biotite; $\mathrm{Kf}$, alkali feldspar]

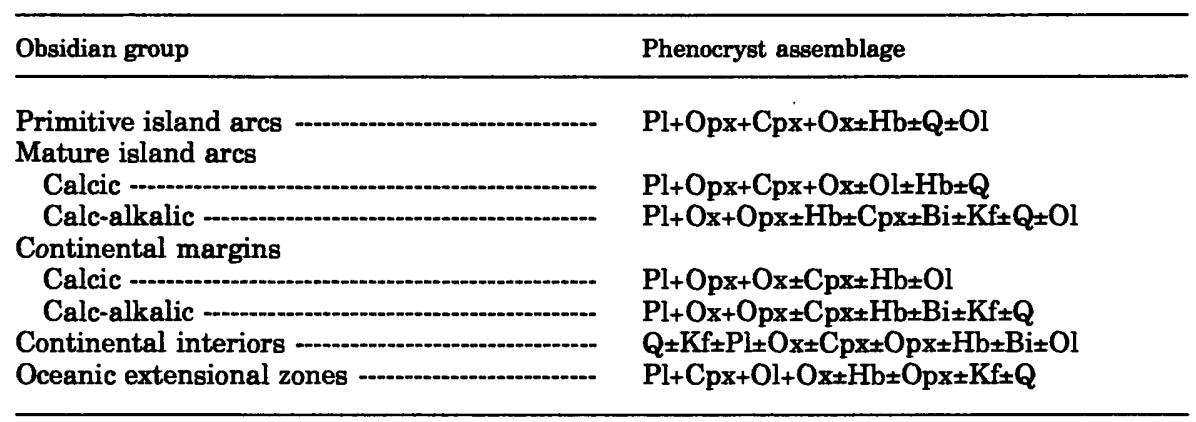

Two recent studies, employing high-precision analytical techniques, have indicated that some obsidian flows display within-flow variations in chemistry which are selectively marked for certain minor and trace elements. Laidley and McKay (1971) have concluded that though the "Big Obsidian flow" of Williams (1935) at Newberry Volcano, Oregon, has a high degree of homogeneity chemically, small but statistically significant differences do exist for such elements as $\mathrm{Zn}$ and $\mathrm{Rb}$.

In a study of Californian glass units, Bowman and others (1973) have shown that the Napa Glass Mountain unit is extremely homogeneous, any variation being below the analytical precision of their neutron-activation method. On the other hand, in the "Mt. Konocti obsidian flow" (rhyolite of Thurston Creek), two geographically distinct groups of analyses can be shown to be chemically distinguishable, though again the differences are very small.

However, more recent work (B.C. Hearn, oral commun., 1985) has shown that the rhyolite of Thurston Creek is actually composed of flows from more than one source vent, and thus a more logical explanation for the chemical distinction, between geographic groups of analyses, is simply that the "Mt. Konocti obsidian flow" is not a single unit of magma at the surface. Our samples 46 and 47 from Camel Back Ridge and Thurston Canyon, respectively, are from different flows of the rhyolite of Thurston Creek; whereas these samples show minor chemical variations, the differences are so small that it is doubtful that they are analytically significant on the basis of two samples.

Outside the United States, the Forgia Vecchia flow in Lipari, Italy, may also display compositional heterogeneity. Belluomini and Taddeucci (1971) present the following ranges for 14 specimens from the flow: $\mathrm{Rb}, 180-240$ ppm; Zr, $160-270$ ppm; Y, 80-110 ppm. Although the precision of the determinations is not given, such variation is outside the precision of the measurements commonly obtained by the XRF technique.

These examples serve to show that some, and perhaps many, obsidian flow units are not completely homogeneous chemically and that detailed study may reveal the nature and amount of any elemental variations present. Single specimens may not always give an accurate picture of the bulk chemistry of the unit being sampled. It should be stressed, however, that the California examples display element variations less than the precision usually obtained during routine, automated methods of analysis. Furthermore, in many examples from the Western United States (for example, Cove Creek, Utah; Bailey Ridge, Mineral Mountains, Utah; and the Mono Craters, California) the compositions of specimens collected from each of closely related groups of domes are virtually identical, indicating that variations within individual domes must be very small. We suggest that obsidian units are much more likely to be chemically homogeneous than heterogeneous and that where heterogeneity is present, it is normally visible in the field (for example, as xenoliths, as an uneven distribution of phenocrysts, or as evidence of the composite nature of the unit).

Finally, between-flow variations in trace-element abundances are many times greater than the withinflow variations revealed by the high-precision studies. Any geological conclusions reached are independent of such intraflow complications.

\section{CLASSIFICATION OF SUBALKALIC SILICIC OBSIDIANS}

\section{CLASSIFICATION USED IN THIS PAPER}

The reviews by Miyashiro (1974), Coleman (1975), Ewart and others (1977), Gill (1981), and various authors in Thorpe (1982) stressed the relations between the evolutionary stages of island ares and the character 
of the associated magmatism, using island arc in the broadest sense to include continental-margin settings. With increasing arc maturity, expressed by crustal thickening and increasingly sialic character, volcanism evolves from a low-K tholeiitic type to complex associations of tholeiitic, calc-alkalic, and alkalic rocks showing both geographic and temporal zonation.

Ewart (1979), Ewart and LeMaitre (1980), and Coulon and Thorpe (1981) provided further detail on the relations between magma associations and tectonic setting within orogenic belts. For example, Coulon and Thorpe (1981) tested the relations between the compositional characteristics of volcanic associations and such parameters as the rate of plate convergence, depth to the seismic zone, and the type and age of subducted and overriding lithosphere. They concluded that magma compositions are most strongly correlated with crustal thickness (Coulon and Thorpe, 1981). Because thickness, structure, and composition of developing continental-type crust are all interlinked, the magma composition is strongly related to the type of crust into which the magmas are emplaced (Smith and Macdonald, 1979).

Ideally, any classification of rhyolites should match rock composition to crustal environment. Chemistry can then be used to define the crustal type of ancient rhyolitic rocks as well as refine our knowledge of the structure of complex modern tectonic settings, such as mature island arcs and continental margins where more than one crustal component of quite different character may be involved. Unfortunately, knowledge of the composition, structure, and thickness of the deeper parts of the crust is so inadequate that formulation of a precise classification of this type-though it may be a longer term aim of our obsidian studiesis currently very difficult.

The classification of subalkalic rhyolitic obsidians used in this paper is a compromise. Rocks are assigned to broad, traditionally recognized, tectonic settings:

\begin{tabular}{|c|c|c|}
\hline & Group & Normal occurrence of obsidians \\
\hline Related to subduction & $\begin{array}{r}\text { I } \\
\text { II } \\
\text { III }\end{array}$ & $\begin{array}{l}\text { From primitive island arcs } \\
\text { From mature island arcs } \\
\text { From active continental margins }\end{array}$ \\
\hline Related to extension & $\begin{array}{l}\text { IV } \\
\text { V }\end{array}$ & $\begin{array}{l}\text { From extensional zones in cra- } \\
\text { tonic continental interiors } \\
\text { From extensional zones in } \\
\text { ocean basins }\end{array}$ \\
\hline
\end{tabular}

The rhyolites from each group are chemically distinct, because each tectonic setting is characterized by the host crust (and thus magma compositions). Hence, rhyolites of group IV normally occur in areas underlain by Precambrian crust, whereas the deep crust of mature island arcs generally is no older than Paleozoic. In certain complex arcs, such as Japan, however, slivers of Precambrian crust occur. On the other hand, in continental interiors there may be areas of continental-margin-type crust lacking a Precambrian component. Rhyolites generated within such areas have the compositional characteristics of the crust rather than those of the broad tectonic setting. For example, rocks having group III compositions (continental margins) may occur in the continental interior or on an island arc. Thus, although rhyolites are generally classified into the correct crustal type, that is if sufficient geological information is available to estimate the type of the basement crust, the classificatory terms may be tectonically imprecise.

We recognize that a genetic classification might be considered out of place in a paper of geochemistry data, but we feel that in spite of the overlaps and uncertainties, this kind of classification conveys the profound significance of rhyolite geochemistry.

\section{OBSIDIANS NOT ACCOMMODATED BY THE CLASSIFICATION SCHEME}

The rhyolites within each tectonic group have compositional characteristics that distinguish them from rhyolites of the other groups. Certain obsidians, however, have compositions unlike the main body of rhyolites; we have not included them in our classification scheme, even though their tectonic setting may be known. The chemical features which distinguish these glasses are described in a later section.

\section{COMPARISON WITH}

THE RHYOLITE GROUPINGS OF EWART (1979)

In a comprehensive review of the mineralogy and chemistry of sialic volcanic rocks of Tertiary to Holocene age, Ewart (1979) presented a dendrogram showing the interrelations and groupings between high-SiO, ( $>73$ percent) rhyolites from a variety of orogenic and oceanic tectonomagmatic associations. The dendrogram was based on $\mathbf{Q}$-mode cluster analysis using correlation coefficients calculated from major- and traceelement concentrations, phenocryst occurrence, and modal data.

Ewart's (1979) groupings were not intended to be a formal classification, but, as they were based in part on chemistry and tectonic settings, as in our classification, it is of interest to compare the two (table 6). Direct comparison is hampered by the facts that Ewart was dealing with a wider range of rocks 
TABLE 6.-Comparison, for the high-SiO ${ }_{2}$ rhyolites of certain orogenic and oceanic areas, of the classification scheme of this paper and the groupings of Ewart (1979)

[NC, not classified]

\begin{tabular}{|c|c|c|}
\hline $\begin{array}{c}\text { Classification } \\
\text { scheme of this } \\
\text { paper }\end{array}$ & Subregions/associations & $\begin{array}{l}\text { Groupings of } \\
\text { Ewart (1979) }\end{array}$ \\
\hline IV & $\begin{array}{l}\text { Western U.S.A.--Eastern Belt (all data) } \\
\text { Western U.S.A.--Eastern Belt } \\
\text { biotite rhyolites }\end{array}$ & \\
\hline III & $\begin{array}{l}\text { Western U.S.A.--Western Belt } \\
\text { biotite rhyolites } \\
\text { Western U.S.A.--Western Belt (all data) } \\
\text { Western South America }\end{array}$ & $\begin{array}{l}\text { Potassic rhyolites of } \\
\text { orogenic associations }\end{array}$ \\
\hline $\mathrm{NC}$ & Mediterranean & \\
\hline III,IV & Middle America & \\
\hline IV & $\begin{array}{l}\text { Yellowstone and Snake River Plain } \\
\text { Mono Lake area (California) }\end{array}$ & $\begin{array}{l}\text { Potassic rhyolites of } \\
\text { bimodal associations }\end{array}$ \\
\hline I & $\begin{array}{l}\text { Low-K-rhyolites, Southwest Pacific } \\
\text { South Sandwich Islands pumice }\end{array}$ & \\
\hline $\begin{array}{c}\text { II } \\
\text { I,II,III,IV }\end{array}$ & $\begin{array}{l}\text { Low-K rhyolites, Japan-Kuriles-Saipan } \\
\text { Japan, all data }\end{array}$ & $\begin{array}{l}\text { Low-K and calc- } \\
\text { alkali orogenic rhyolites }\end{array}$ \\
\hline II & $\begin{array}{l}\text { Southwest Pacific (excluding New Zealand) } \\
\text { Taupo Volcanic Zone, New Zealand }\end{array}$ & \\
\hline III & $\begin{array}{l}\text { Medicine Lake (California) } \\
\text { High Cascades (excluding Medicine Lake)- } \\
\text { Alaska-Aleutians }\end{array}$ & \\
\hline V & $\begin{array}{l}\text { Iceland } \\
\text { Salton Sea (California) }\end{array}$ & $\begin{array}{l}\text { Less potassic rhyolites of } \\
\text { bimodal associations }\end{array}$ \\
\hline
\end{tabular}

(including secondarily hydrated and crystalline varieties) emplaced over a wider time spectrum (Tertiary to Holocene) and that he incorporated mineralogical data into his groupings. Nevertheless, many similarities may be noted. His "low-K and calcalkali orogenic rhyolites" are essentially groups I and II of our classification, although in some complex arcs, such as Japan, we recognize rocks of groups III and IV.

Ewart's "potassic rhyolites of orogenic associations" incorporate rocks of groups III and IV; we argue that many of the samples from his Eastern Belt of the Western United States (even those of Tertiary age) are intracratonic rocks not related to subduction. Ewart recognizes the existence of this continental interior type (group IV), calling them "potassic rhyolites of bimodal associations." The rocks within his "less potassic rhyolites of bimodal associations" are essentially those of group V of this paper.

\section{RELATIONS AMONG $\mathrm{SiO}_{2}, \mathrm{Al}_{2} \mathrm{O}_{3}, \mathrm{CaO}$, AND $\left(\mathrm{Na}_{2} \mathrm{O}+\mathrm{K}_{2} \mathrm{O}\right)$ IN SUBALKALIC OBSIDIANS}

We consider here aspects of the interrelations among the most abundant oxides in the various obsidian groups. Several terms are described as used in this report, and normative projections in the $Q$ $\mathrm{Ab}-\mathrm{Or}$ and Or-Ab-An systems are presented. 
THE TERMS CALCIC, CALC-ALKALIC, AND ALKALI-CALCIC

Peacock (1931) used alkali-lime relations to classify igneous suites into calcic, calc-alkalic, alkalicalcic, and alkalic. Alkalic, by definition, is not applicable to the obsidians compiled in this paper. The classification was based on the $\mathrm{SiO}_{2}$ content for which the concentration of $\mathrm{CaO}$ equals that of $\left(\mathrm{Na}_{2} \mathrm{O}+\mathrm{K}_{2} \mathrm{O}\right)$ in a genetically related, mafic to silicic suite of rocks. Because many rhyolites occur either as members of bimodal basalt-rhyolite associations or as masses commonly independent of more mafic rocks, Peacock's classification cannot be formally applied to such occurrences.

The terms have proved so useful that they are still commonly employed in the literature, but unfortunately, either undefined or with contrasting definitions. For example, Zielinski (1978) defines calc-alkalic rhyolites as "having atomic $\mathrm{Al}>(\mathrm{Na}+\mathrm{K})$ and with plagioclase as phenocrysts," whereas Tatlock and others (1976) consider the rhyolite from Glass Mountain, California, calc-alkalic "because of the high ratio of $\mathrm{CaO}$ to total iron and the relatively high *** An content of its normative plagioclase $\left(A n_{13-14}\right)$." Robinson and others (1976) employ the term "low $\mathrm{CaO}$, alkali rhyolite" for rocks "intermediate in composition between peralkaline comendites and metaluminous rhyolites." For apparently the same compositions, that is, "atomic $\mathrm{Al} \cong(\mathrm{Na}+\mathrm{K})$, plagioclase absent," Zielinski (1978) coins the term "transitional rhyolite". Clearly, it is desirable for continued employment of these terms in rhyolite geochemistry that, first, they are formally defined and, second, that to avoid confusion, definitions are in accord with the usage of Peacock (1931). Any attempt to define the terms for highly silicic rocks will run into severe difficulties, as the following examples show.

The ratio $\mathrm{CaO} /\left(\mathrm{Na}_{2} \mathrm{O}+\mathrm{K}_{2} \mathrm{O}\right)$ is plotted against $\mathrm{SiO}_{2}$ for obsidians from four volcanic complexes in the Western United States continental margin (fig. 3). On the basis of Peacock's classification, two complexes are calcic (Crater Lake: Williams, 1942; and Clear Lake: Anderson, 1936) and two are calc-alkalic (Newberry: Williams, 1935, Higgins, 1973; and Medicine Lake: Williams, 1935). Tielines connect whole rock and separated glass pairs from Crater Lake. Whole rock trends for a calcic granodiorite (Woodson stock, southern California: Tilling and Gottfried, 1969) and for a calc-alkalic granitoid suite (Tuolumne Intrusive Suite, California: Peck, 1980, data from Bateman and Chappell, 1979) are also shown. There is an overlap of calcic and calc-alkalic rock suites such that they are essentially indistinguish- able on this plot. The differences in the alkali-lime index utilized by Peacock are maximized in rocks of intermediate composition. As rock compositions trend toward the minima in the system Q-Or-Ab-An$\mathrm{H}_{2} \mathrm{O}$, intersuite differences in major-element abundances are made much less distinct.

It is possible to subdivide rhyolites into the various groups by erecting arbitrary boundaries at constant values of $\mathrm{CaO} /\left(\mathrm{Na}_{2} \mathrm{O}+\mathrm{K}_{2} \mathrm{O}\right)$ ratio rather than parallel to the tielines and rock trends. Individual rock suites could then show more than one affinity, which is unnecessarily confusing.

An alternative approach to the problem is shown in figure 4. As $\mathrm{CaO}$ and, even more so, the sum $\left(\mathrm{Na}_{2} \mathrm{O}+\mathrm{K}_{2} \mathrm{O}\right)$ show wide variations with changing $\mathrm{SiO}_{2}$ and at constant $\mathrm{SiO}_{2}$, the $\left(\mathrm{Na}_{2} \mathrm{O}+\mathrm{K}_{2} \mathrm{O}\right)$ values are normalized by calculation of the ratio $\mathrm{SiO}_{2} /\left(\mathrm{Na}_{2} \mathrm{O}+\mathrm{K}_{2} \mathrm{O}\right)$. Boundaries are drawn to be as consistent as possible with the nomenclature derived for relevant rocks using Peacock's (1931) scheme. The fields are termed alkali-calcic, calc-alkalic, and calcic and appear to have real geologic significance (fig. 4). Continental-interior rocks are overwhelmingly alkali-calcic. The calcic rocks of island arcs are largely those associated with tholeiitic volcanoes rather than calc-alkalic types associated with high$\mathrm{Al}_{2} \mathrm{O}_{3}$-series volcanoes (Miyashiro, 1974). There are also two groups of Icelandic rhyolites: a higher alkali group $\left(\mathrm{SiO}_{2} /\left(\mathrm{Na}_{2} \mathrm{O}+\mathrm{K}_{2} \mathrm{O}\right)<\sim 9\right)$ found in alkalic complexes and a lower alkali group ( $(\geq 2)$ associated with tholeiitic basalts.

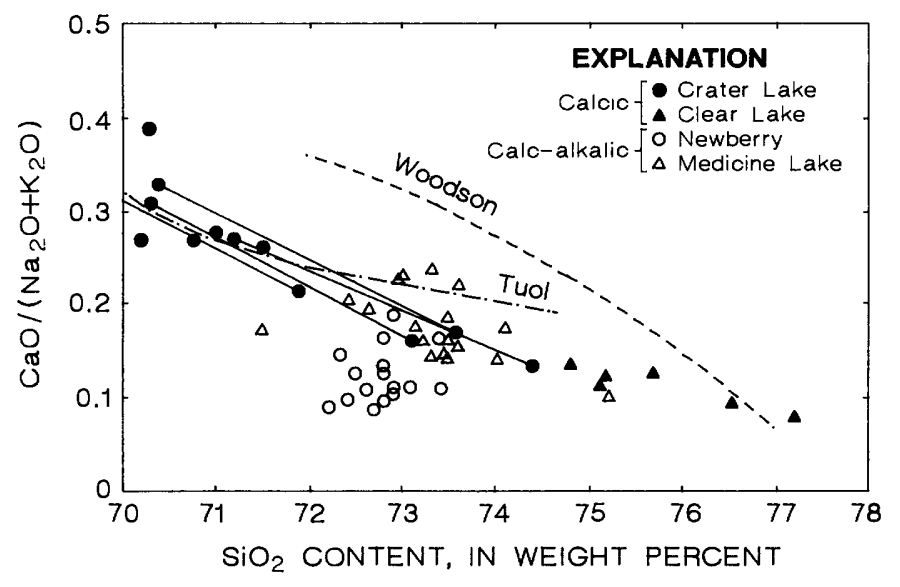

Figure 3.- $\mathrm{SiO}_{2}$ content versus ratio of $\mathrm{CaO} /\left(\mathrm{Na}_{2} \mathrm{O}+\mathrm{K}_{2} \mathrm{O}\right)$ showing overall similarity of calcic (Crater Lake and Clear Lake) and calc-alkalic (Newberry and Medicine Lake) suites in high-SiO compositions. Data from appendixes I and III. Trends for Woodson granodiorite stock and granitoids of the Tuolumne Intrusive Suite (Tuol) are given for comparison (data sources are same as figure 5). Solid tielines connect whole rock and separated glass pairs from Crater Lake. 
A drawback of the $\mathrm{SiO}_{2} /\left(\mathrm{Na}_{2} \mathrm{O}+\mathrm{K}_{2} \mathrm{O}\right)$ versus $\mathrm{CaO}$ plot is that individual suites cross field boundaries (fig. 5), as the Bandelier, Bishop Tuff, Tuolumne and Woodson trends, the Crater Lake tielines, and the Borax Lake mixed magma trend show. However, no other classificatory scheme based on $\mathrm{SiO}_{2}, \mathrm{CaO}$, and $\left(\mathrm{Na}_{2} \mathrm{O}+\mathrm{K}_{2} \mathrm{O}\right)$ can be devised entirely consistent with Peacock's (1931) original scheme. The terms calcic, calc-alkalic, and alkali-calcic are useful descriptive terms firmly established in the literature of granites and rhyolites, and we continue to use them, as defined on figure 4.

\section{RELATIONS AMONG $\mathrm{Al}_{2} \mathrm{O}_{3}, \mathrm{CaO}$, AND $\left(\mathrm{Na}_{2} \mathrm{O}+\mathrm{K}_{2} \mathrm{O}\right)$ AND THE} SIGNIFICANCE OF NORMATIVE CORUNDUM

Shand (1949) stressed the importance of the relations among $\mathrm{Al}_{2} \mathrm{O}_{3}, \mathrm{CaO}$, and $\mathrm{Na}_{2} \mathrm{O}+\mathrm{K}_{2} \mathrm{O}$ by using them as the basis of his subdivision of igneous

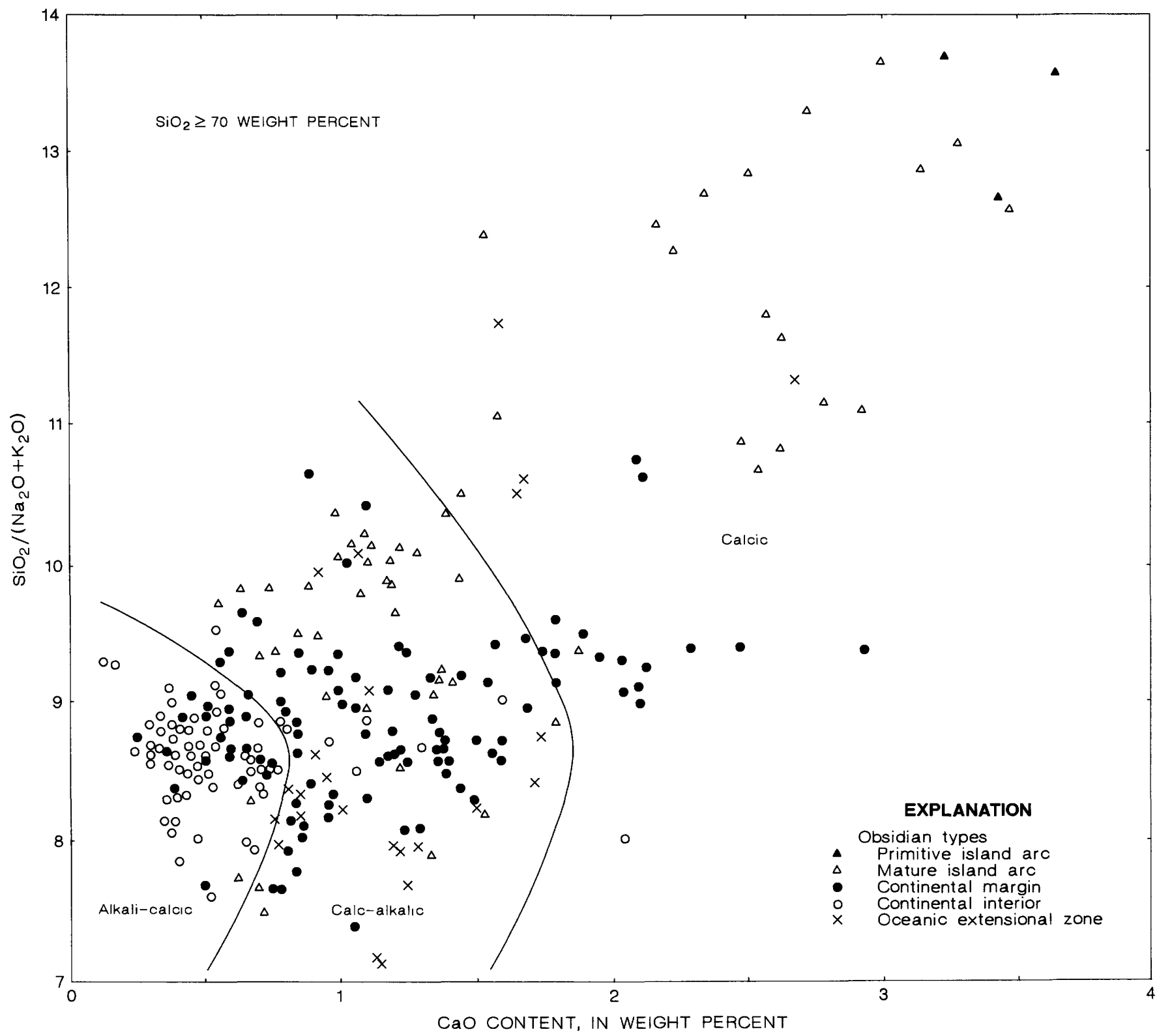

FIGURE 4.- $-\mathrm{CaO}$ content versus ratio of $\mathrm{SiO}_{2} /\left(\mathrm{Na}_{2} \mathrm{O}+\mathrm{K}_{2} \mathrm{O}\right)$ showing distribution of silicic subalkalic obsidians and their subdivisions into calcic, calc-alkalic, and alkali-calcic types. Boundaries between fields are drawn to coincide as nearly as possible with Peacock's (1931) scheme. Data from appendixes I and III (excluding samples 349, 351, and 371) and from appendix V (excluding samples A, F, and G). 
rocks into peraluminous, metaluminous, subaluminous, and peralkaline. The distinction between subaluminous and metaluminous rocks is largely mineralogic, depending on the $\mathrm{Al}$ contents of the ferromagnesian minerals. The distinction is difficult to apply in most obsidians, and the term subaluminous is not used here to avoid any possible confusion with peralkaline.

Chemical criteria

Peraluminous: molecular $\mathrm{Al}_{2} \mathrm{O}_{3} \geq \mathrm{CaO}+\left(\mathrm{Na}_{2} \mathrm{O}+\mathrm{K}_{2} \mathrm{O}\right)$

Metaluminous: molecular

$\left(\mathrm{Na}_{2} \mathrm{O}+\mathrm{K}_{2} \mathrm{O}\right)<\mathrm{Al}_{2} \mathrm{O}_{3}<\mathrm{CaO}+\left(\mathrm{Na}_{2} \mathrm{O}+\mathrm{K}_{2} \mathrm{O}\right) \quad$ [Normative an + di]

Peralkaline: molecular $\left(\mathrm{Na}_{2} \mathrm{O}+\mathrm{K}_{2} \mathrm{O}\right) \geq \mathrm{Al}_{2} \mathrm{O}_{3}$
CIPW normative mineral criteria

[Normative $\mathrm{C}+$ an]

[Normative ac+ns]
The fields occupied by each type and by the rhyolite groups on a molecular $\mathrm{CaO}-\mathrm{Al}_{2} \mathrm{O}_{3}-\left(\mathrm{Na}_{2} \mathrm{O}+\mathrm{K}_{2} \mathrm{O}\right)$ diagram are given in figure 6 . With the exception of the primitive-island-arc and oceanic-extensional groups, which are almost exclusively metaluminous, the main rhyolite groups contain both peraluminous and metaluminous varieties. The ratios of the number of specimens of the two varieties in the different groups are as follows:

Obsidian groups

Peraluminous/metaluminous

Primitive island arcs (I) -

Mature island arcs (II) -

Continental margins (III) -

Continental interiors (IV) -........ 0.72

Oceanic extensional zones (V) -

Peraluminous rocks are apparently very rare in areas overlying basaltic crust (groups I and V).

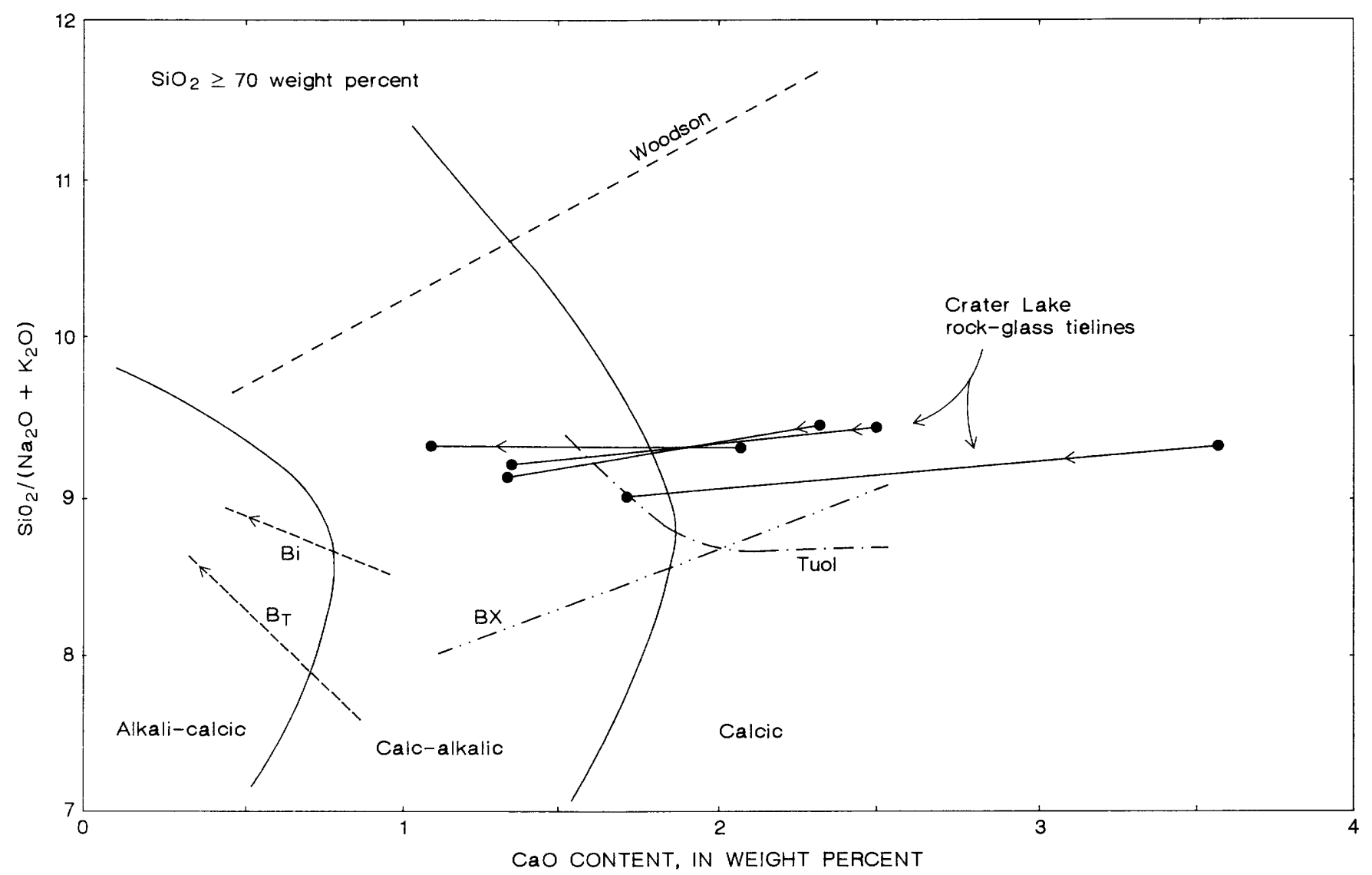

Figure 5.- $\mathrm{CaO}$ content versus ratio of $\mathrm{SiO}_{2} /\left(\mathrm{Na}_{2} \mathrm{O}+\mathrm{K}_{2} \mathrm{O}\right)$ showing typical trends of various suites crossing field boundaries. Crater Lake data from appendix I. Other data sources for this and subsequent diagrams: Woodson granodiorite (Tilling and Gottfried, 1969; David Gottfried, written commun., 1975); Tuol, granitoids of Tuolumne Intrusive Suite
(Peck, 1980, data from Bateman and Chappell, 1979); BX, mixed obsidian of Borax Lake (Bowman and others, 1973); $B_{T}$, Tshirege Member of the Bandelier Tuff, Valles Mountains, New Mexico (R.L. Smith, unpub. data); Bi, Bishop Tuff, California (Hildreth, 1979, 1981). Arrows indicate direction of liquid fractionation. 
Though it may be inferred that the presence of crust with a sialic component is necessary for the generation of peraluminous rhyolites, it must be noted that the proportion of such rhyolites is higher in arc obsidians than in those from the continental interior, indicating that degree of $\mathrm{Al}_{2} \mathrm{O}_{3}$-saturation is not simply related to crustal type.

A similar situation exists in individual volcanic complexes. Obsidians from Crater Lake and Coso are dominantly metaluminous; whereas at Medicine

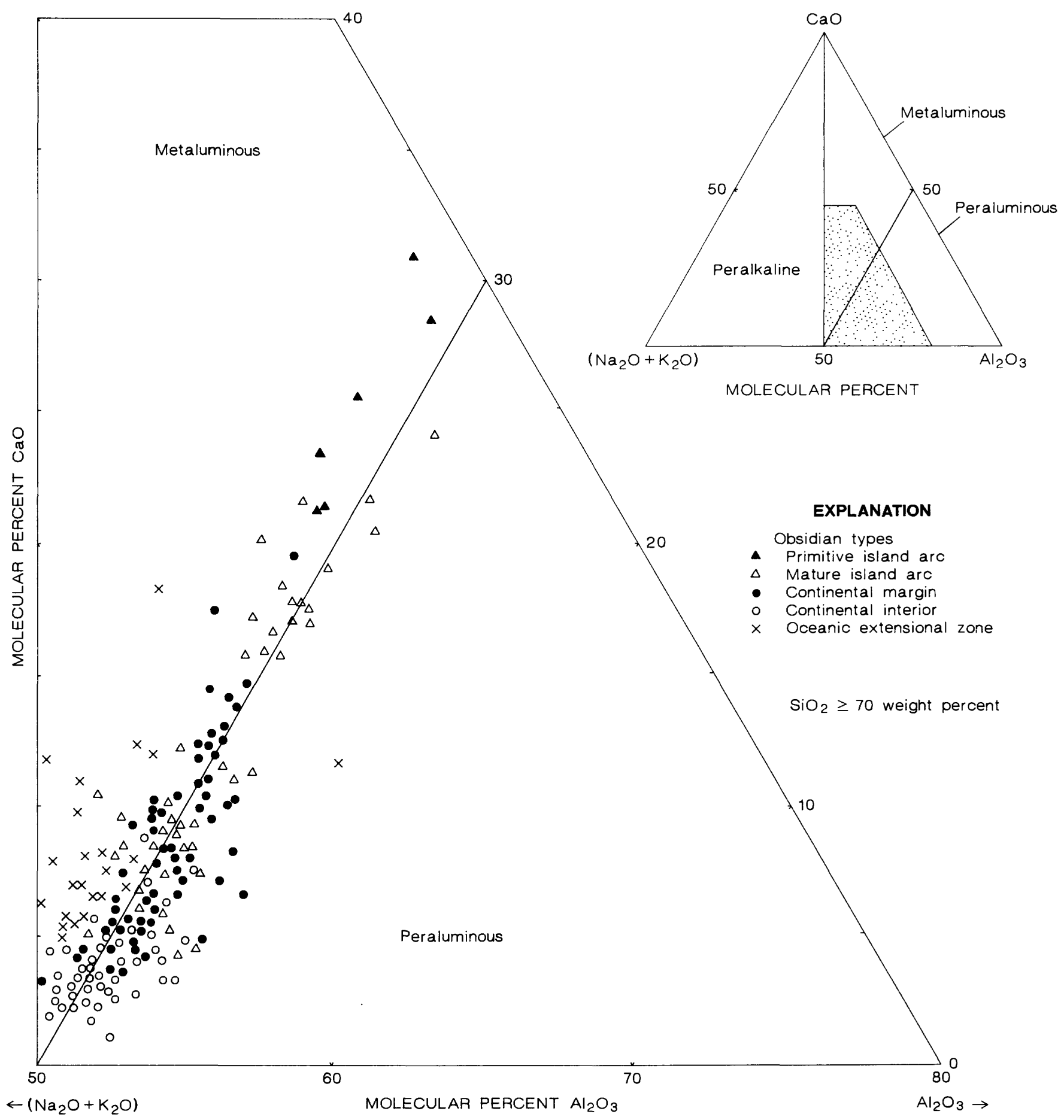

Figure 6.-Molecular proportions of $\mathrm{CaO},\left(\mathrm{Na}_{2} \mathrm{O}+\mathrm{K}_{2} \mathrm{O}\right)$, and $\mathrm{Al}_{2} \mathrm{O}_{3}$ in silicic obsidians. Inset shows compositional fields of peraluminous, metaluminous, and peralkaline rhyolites and field (stippled) occupied by larger diagram. Data from appendixes I, III, and V. 
Lake and Yellowstone, metaluminous and peraluminous varieties are present in about equal numbers. In the Newberry and Jemez Mountain complexes, the ratios of peraluminous to metaluminous obsidians are about $2: 1$ and 1:2, respectively.

There appears to be some doubt in the literature as to whether normative corundum actually exists in silicic magmas and, if so, in what amounts. Normative corundum (C) in volcanic rocks has traditionally been regarded as an indication of a faulty chemical analysis or of secondary alteration of the rocks. Chayes (1970, p. 181-182) states, "Whatever the detailed interpretation of $\mathrm{C}^{* * *}$ there seems little doubt that its occurrence in amounts of the order of 2 percent or less is either a consequence of surficial or hydrothermal alteration or a combined analyticalcomputational artifact."

Because posteruptive alteration can be discounted as having affected nonhydrated obsidians, it is of interest to examine the distribution of normative corundum in terms of the reality of its existence in silicic magmas and the magmatic affinities of the rocks in which it occurs. Of the 322 rocks compiled, 166 (52 percent) are peraluminous, that is, Cnormative. The normative corundum has either been produced by a "combined analytical-computational artifact" (Chayes, 1970) or is a genuinely magmatic feature (compare with Cawthorn and others, 1976). Because the analyses have been made by numerous analysts using a variety of techniques and because $\mathbf{C}$ is present in such a large proportion of the rocks, we suggest that normative corundum is a real feature of the relevant magmas and is related to the petrogenesis of the rocks.

Distribution of normative corundum (C)

\begin{tabular}{|c|c|c|c|c|}
\hline Range of $C$, in percent & $0-0.49$ & $0.5-0.99$ & $1.0-1.49$ & $1.50-1.99$ \\
\hline $\begin{array}{l}\text { Number of } \\
\text { analyses }\end{array}$ & 114 & 34 & 9 & 6 \\
\hline $\begin{array}{l}\text { Mature island } \\
\text { arcs (II) }\end{array}$ & 23 & 11 & 3 & 1 \\
\hline $\begin{array}{l}\text { Continental } \\
\text { margins (III) --. }\end{array}$ & 59 & 18 & 4 & 2 \\
\hline $\begin{array}{l}\text { Continental } \\
\text { interiors (IV) -- }\end{array}$ & 32 & 5 & 2 & 3 \\
\hline $\begin{array}{l}\text { Oceanic } \\
\text { extensional } \\
\text { zones (V) }\end{array}$ & 0 & 0 & 0 & 0 \\
\hline
\end{tabular}

It should be stressed that the amount of normative corundum is typically small, $(C<1$ percent in 90 percent of the samples that yield normative corundum, and $\mathrm{C}<0.5$ percent in 70 percent of those samples). Only three rocks have $\mathrm{C} \geq 2$ percent. The maximum value is 6.34 percent, recorded in a chemically unique glass block from Cameroon (No. 337). Thus, the majority of subalkalic obsidians contain neither a substantial excess nor deficit of mol. $\mathrm{Al}_{2} \mathrm{O}_{3}$ over $\left(\mathrm{CaO}+\mathrm{Na}_{2} \mathrm{O}+\mathrm{K}_{2} \mathrm{O}\right)$.

\section{NORMATIVE Q-Ab-Or- $\mathrm{H}_{2} \mathrm{O}$ AND Or-Ab-An- $\mathrm{H}_{2} \mathrm{O}$ PLOTS}

The fields and average compositions of each of the rhyolite groups are shown in the ternary quartzfeldspar and feldspar-feldspar plots in figures 7 and 8 and are compared to the various quartz-feldspar and two-feldspar boundary curves at $1 \mathrm{kbar} P_{\mathrm{H}_{2} \mathrm{O}}$ determined by James and Hamilton (1969). The distributions are similar to those established by Ewart (1979) in his review of the chemistry of Tertiary and Holocene silicic volcanic rocks.

The field for obsidians from the continental interiors straddles the quartz-saturated, two-feldspar boundary curve for $1 \mathrm{kbar} P_{\mathrm{H}_{2} \mathrm{O}}$ and lies just to the

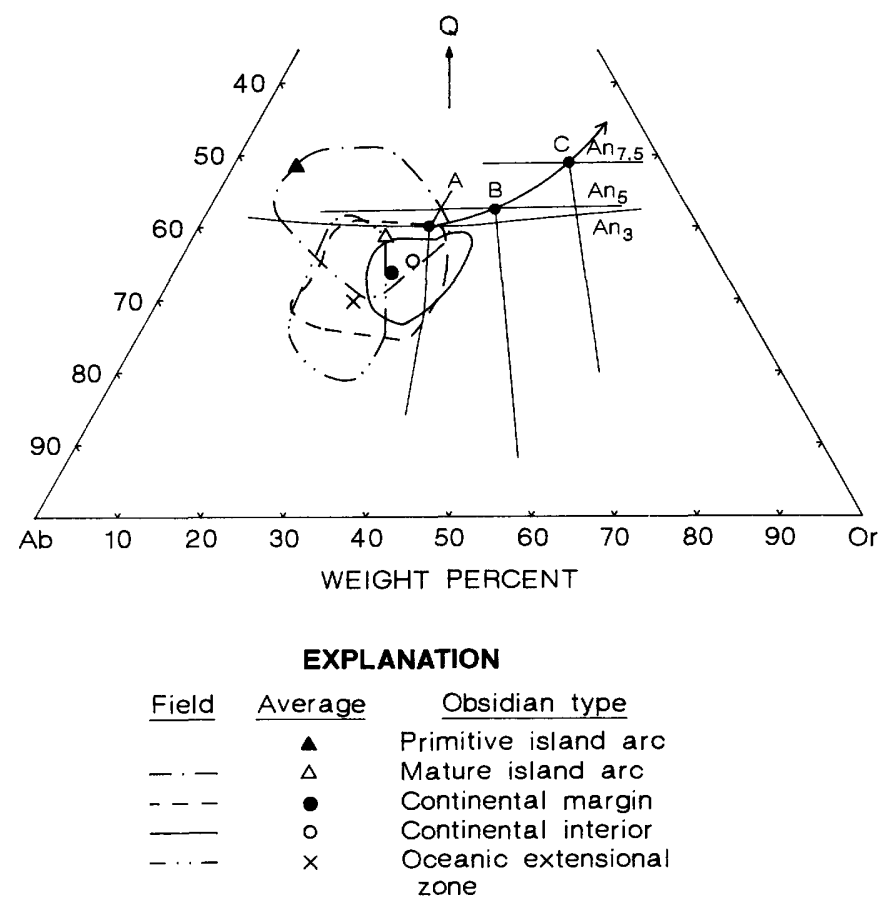

FIGURE 7.-CIPW normative proportions of quartz (Q), albite (Ab), and orthoclase (Or) showing fields (except that of primitive island arcs) and averages for obsidian groups. Also shown are quartz-feldspar and two-feldspar boundary curves at $1 \mathrm{kbar}$ $P_{\mathrm{H}_{2} \mathrm{O}}$ for compositions $\mathrm{An}_{3}, \mathrm{An}_{5}$, and $\mathrm{An}_{7.5}$ (from James and Hamilton, 1969). Points A-C mark trend of low-temperature piercing points with increasing An content (arrow). Diagram may be compared with similar plots by Ewart (1979, fig. 21). 
$\mathrm{SiO}_{2}$-poor side of the $\mathrm{An}_{3}$ piercing point in this system (point A, fig. 7). This is largely consistent with the observed phenocryst mineralogy, which commonly includes alkali feldspar \pm plagioclase \pm quartz. The presence of quartz phenocrysts suggests, however, that somewhat higher pressures than $1 \mathrm{kbar}$ were involved during the final equilibration of many of these magmas.

The field for obsidians from the continental margins overlaps the field for interior rocks for more potassic compositions, but extends to more sodic and calcic compositions. The rocks are not, however, richer in $\mathrm{SiO}_{2}$. The margin rocks as a group do not trend toward the ternary minimum. The field of most $\mathrm{SiO}_{2}$-rich types is elongate parallel to the quartz-sodic feldspar boundary curve for low An contents, and the field mainly projects into the sodic feldspar stability field. The position of the field is consistent with the relative scarcity of potassic feldspar in continental-margin rocks, magma compositions in most cases apparently reaching the quartzplagioclase saturation surface but not evolving to the two-feldspar+quartz surface.

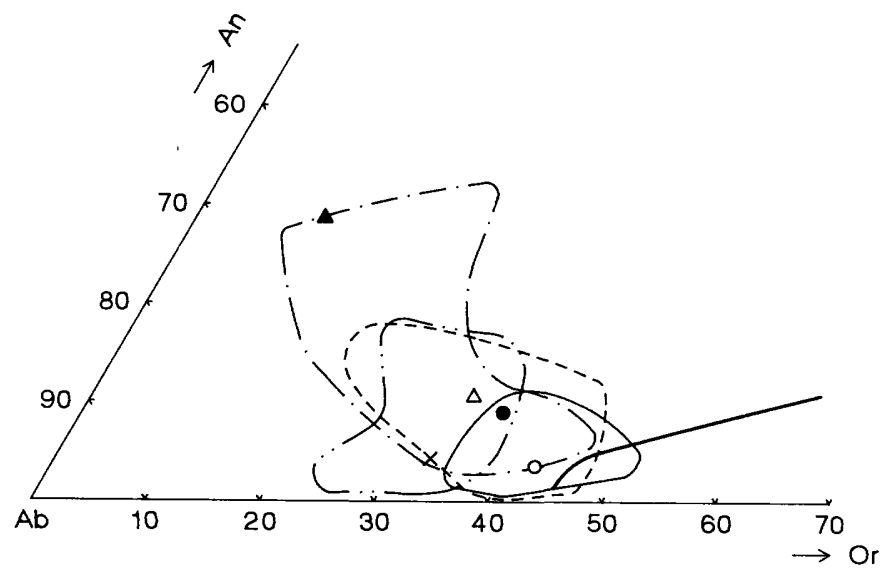

WEIGHT PERCENT

EXPLANATION

\begin{tabular}{|c|c|c|}
\hline Field & Average & Obsidian type \\
\hline & $\Delta$ & Primitive island arc \\
\hline & $\Delta$ & Mature island arc \\
\hline--- & $\bullet$ & Continental margin \\
\hline & $\times$ & $\begin{array}{l}\text { Oceanic extensional } \\
\text { zone }\end{array}$ \\
\hline
\end{tabular}

Figure 8.-CIPW normative proportions of anorthite (An), albite $(\mathrm{Ab})$, and orthoclase (Or) showing fields (except that of primitive island arcs) and averages for obsidian groups. Bold curve is projection of quartz-saturated two-feldspar boundary at 1 kbar $P_{\mathrm{H}_{2} \mathrm{O}}$ (from James and Hamilton, 1969). Diagram may be compared with similar plots by Ewart (1979, fig. 22).
The field for obsidians from mature island arcs partially overlaps those from the continental margins and interiors but extends to more quartz- and anorthite-rich compositions. As Ewart (1979, p. 74) points out, these can be grossly correlated with the shift of the quartz-feldspar boundary curve toward more quartz-rich compositions with increasing An content within the Q-Or-Ab-An- $\mathrm{H}_{2} \mathrm{O}$ system. The data field does not, however, follow the trend of lowtemperature piercing points (fig. 7) with increasing An content but plots well to the sodic side of the trend. This precludes the involvement of alkali feldspar in the higher temperature genesis of the majority of the rocks, because only a few of the obsidians plot close to the quartz+two-feldspar surface.

Absence of alkali feldspar from the phenocryst assemblages of the oceanic extensional rhyolites is consistent with their plotted fields (figs. 7, 8).

\section{NOTES ON THE OCCURRENCE, GEOLOGY, AND PETROGRAPHY OF THE OBSIDIAN SUBGROUPS}

\section{GROUP I: OBSIDIANS FROM THE EARLY STAGES OF ARC DEVELOPMENT}

Obsidians from the early stages of arc development are members of the magmatic association termed the "island arc tholeiitic series" by Jakes and Gill (1970) and "primitive island arc series" by Donnelly and Rogers (1980); they would be incorporated into the low-K group of rhyolites of Ewart (1979). They occur typically in areas of subcontinental and relatively young crust including intraoceanic island arcs that appear to be underlain by thin $(<20 \mathrm{~km})$ basaltic crust.

This magmatism represents the earliest stages of arc development, and it is implicit in many accounts that there is a structural and magmatic transition to the mature-arc phase. Bryan (1979, p. 598) specifically refers to the silicic members as "first cycle siliceous derivatives," implying a more or less direct origin from mantle materials.

Rhyolites of this group have been reported from the Tonga-Kermadec Islands (Ewart and others, 1977; Bryan, 1979), the South Sandwich Islands (Baker, 1978, 1982), the Caribbean arc (Donnelly and Rogers, 1980), parts of New Britain (Smith and Johnson, 1981, p. 10262), the southern Kuriles, the Huzi volcanic zone, Japan, and the Izu-Mariana Islands (Jakes and Gill, 1970; Baker, 1972; Ewart, 1979).

Silicic rocks, especially those with $\mathrm{SiO}_{2} \geq 70$ percent, are normally minor members of suites dominated by basalts and basaltic andesites (for 
example, in the Tonga-Kermadec arc and the South Sandwich Islands). Some exceptions do occur, however, such as the voluminous dacites and associated trondhjemitic plutons emplaced during Miocene time in Fiji (Gill and Stork, 1979). The eruptive products may be represented by massive lava flows and domes, but a considerable percentage of these products is pyroclastic.

The data bank contains too few examples of this group to generalize about phenocryst assemblages. According to Ewart (1979, p. 50), however, his low$\mathrm{K}$ rhyolites are dominated by plagioclase (Pl)hypersthene $(\mathrm{Opx})$-augite $(\mathrm{Cpx})$-Fe-Ti oxides $(\mathrm{Ox})$ assemblages, with amphibole $(\mathrm{Hb})$, quartz $(\mathrm{Q})$, and olivine (Ol) of more sporadic occurrence. Similarly, Gill and Stork (1980) report $\mathrm{Pl}+\mathrm{Ox} \pm \mathrm{Q} \pm \mathrm{Cpx} \pm \mathrm{Opx}$ (rare) $\pm \mathrm{Hb}$ (very rare) \pm apatite $(\mathrm{Ap})$ as a generalized phenocryst assemblage in the Undu dacite, Fiji. Particularly noteworthy is the absence of biotite and alkali feldspar as phenocrysts in group I rhyolites.

\section{GROUP II: OBSIDIANS OF MATURE ISLAND ARCS}

Rhyolites of the developing to mature island arcs show a range in compositions that at least partly reflects a zonation of magmatic associations within many such arcs (Miyashiro, 1974). Thus, a distinction has been made (Kuno, 1966; Miyashiro, 1974; Katsui and others, 1978) between rhyolites that are members of tholeiitic magmatic associations and those of calc-alkalic associations; the tholeiitic magmas are higher in $\mathrm{CaO}$ and lower in alkalis, particularly $\mathrm{K}_{2} \mathrm{O}$, at given $\mathrm{SiO}_{2}$ concentrations. The two subgroups plot in the calcic and calc-alkalic fields, respectively, of the $\mathrm{CaO}$ versus $\mathrm{SiO}_{2} /\left(\mathrm{Na}_{2} \mathrm{O}+\mathrm{K}_{2} \mathrm{O}\right)$ diagram (fig. 4). They show consistent chemical differences apparently related to the stage of arc development.

The calcic group of rhyolites is most commonly found on the trench side of developing or mature island arcs in zone 2 or on the border between zones 1 and 2 of Miyashiro's (1974) arc zonation. The crust is $20-30 \mathrm{~km}$ thick and is believed to be transitional from oceanic to continental (Miyashiro, 1974), though details of its structure and composition are poorly known. The rhyolites are normally members of a tholeiitic magmatic association, though they may be provincially (for example, Japan) or locally (for example, Hakone volcano) associated with rocks of calc-alkalic series.

Rhyolites of this group are present in Japan (Miyashiro, 1974; Katsui and others, 1978), the Kuriles (Gorshkov, 1970), and Indonesia and the Caribbean (Smith and others, 1980; Donnelly and Rogers, 1980).
The most common phenocryst assemblage in these rocks is $\mathrm{Pl}+\mathrm{Opx}+\mathrm{Cpx}+\mathrm{Ox}$, and the generalized assemblage $\mathrm{Pl}+\mathrm{Opx}+\mathrm{Cpx}+\mathrm{Ox} \pm \mathrm{Ol} \pm \mathrm{Hb} \pm \mathrm{Q}$ incorporates the majority of samples. Alkali feldspar (Kf) has not been recorded as a phenocryst in such rhyolites, and biotite (Bi) appears in only three specimens.

Rocorded phenocryst assemblages, excluding accessory phases, are as follows (sample numbers in parenthesis):

$\begin{array}{ll}\mathrm{Pl}+\mathrm{Opx}+\mathrm{Cpx}+\mathrm{Ox} & (189,193,194) \\ \mathrm{Pl}+\mathrm{Opx}+\mathrm{Cpx}+\mathrm{Ox}+\mathrm{Ol} & (205) \\ \mathrm{Pl}+\mathrm{Opx}+\mathrm{Cpx}+\mathrm{Ox}+\mathrm{Q} & (338,347) \\ \mathrm{Pl}+\mathrm{Opx}+\mathrm{Cpx}+\mathrm{Ox}+\mathrm{Hb} & (344) \\ \mathrm{Pl}+\mathrm{Opx}+\mathrm{Cpx}+\mathrm{Ox}+\mathrm{Hb}+\mathrm{Bi} & (341,342,343) \\ \mathrm{Pl}+\mathrm{Opx}+\mathrm{Cpx}+\mathrm{Ol}+\mathrm{Q}+\mathrm{Hb} & (350) \\ \mathrm{Pl}+\mathrm{Opx}+\mathrm{Ox}+\mathrm{Q}+\mathrm{Hb} & (195) \\ \mathrm{Pl}+\mathrm{Cpx}+\mathrm{Ox}+\mathrm{Ol} & (354) \\ \mathrm{Pl}+\mathrm{Opx}+\mathrm{Q} & (335,336,352) \\ \mathrm{Q}+\mathrm{Hb} & (340)\end{array}$

As the island-arc system develops, the underlying crust becomes thicker $(230 \mathrm{~km})$ and is increasingly of "continental-type" (that is, of more sialic composition). Recycling of such crustal materials becomes a distinct possibility and may contribute a significant percentage of silicic volcanic rocks. The circumPacific arcs and those of the lesser Antilles and Indonesia would be included in this category, which characteristically would be considered to represent orogenic volcanism. We include New Zealand and Java as arc systems, although some would consider them continental margins.

The main rocks of these arcs are andesites and dacites of the calc-alkalic association, though tholeiitic and alkalic lineages also occur (Miyashiro, 1974). The proportions of rhyolitic types vary but are generally low (Baker, 1972, fig. 2). Characteristically, much of the silicic volcanism occurs as pyroclastic deposits.

Petrographically, the calc-alkalic group II rhyolites vary greatly. Phenocryst assemblages recorded are:

$\begin{array}{ll}\mathrm{Pl}+\mathrm{Opx}+\mathrm{Cpx}+\mathrm{Ox} & (209) \\ \mathrm{Pl}+\mathrm{Cpx}+\mathrm{Ox} & (200,203) \\ \mathrm{Pl}+\mathrm{Opx} & (367) \\ \mathrm{Pl}+\mathrm{Opx}+\mathrm{Ox} & (204,206) \\ \mathrm{Pl}+\mathrm{Cpx}+\mathrm{Ol} & (2) \\ \mathrm{Pl}+\mathrm{Opx}+\mathrm{Hb}+\mathrm{Ox} & (208) \\ \mathrm{Pl}+\mathrm{Opx}+\mathrm{Cpx}+\mathrm{Hb}+\mathrm{Ox}+\mathrm{Q} & (201) \\ \mathrm{Pl}+\mathrm{Opx}+\mathrm{Hb}+\mathrm{Ox}+\mathrm{Q}+\mathrm{Kf} & (198) \\ \mathrm{Pl}+\mathrm{Hb} & (368) \\ \mathrm{Pl}+\mathrm{Hb}+\mathrm{Ox} & (199) \\ \mathrm{Pl}+\mathrm{Opx}+\mathrm{Ox}+\mathrm{Kf} & (216) \\ \mathrm{Pl}+\mathrm{Ox}+\mathrm{Kf} & (202) \\ \mathrm{Pl}+\mathrm{Ox}+\mathrm{Q}+\mathrm{Bi} & (186) \\ \mathrm{Pl}+\mathrm{Ox}+\mathrm{Kf}+\mathrm{Bi} & (190) \\ \mathrm{Pl}+\mathrm{Ox}+\mathrm{Hb}+\mathrm{Bi} & (1,192)\end{array}$


Thus, there is no single, common assemblage, although $\mathrm{Pl}+\mathrm{Ox}$ is virtually ubiquitous. A generalized assemblage could be written $\mathrm{Pl}+\mathrm{Ox} \pm \mathrm{Opx} \pm \mathrm{Hb} \pm \mathrm{Cpx} \pm \mathrm{Bi}$ $\pm \mathrm{Kf} \pm \mathrm{Q} \pm \mathrm{Ol}$, with the phases ordered by frequency of appearance. It is worthy of note that alkali feldspar appears in several specimens; biotite probably also is commonly present (Ewart, 1979, p. 51). In addition, a significant percentage ( $\sim 33$ percent) of the samples are aphyric.

\section{GROUP III: OBSIDIANS OF ACTIVE CONTINENTAL MARGINS}

Continental margins tend to have thicker (30$70 \mathrm{~km}$ ) crusts than island arcs, thereby producing more granitic (silicic) magmas. The tectonic distinction is rather arbitrary, as many margins may be island arcs accreted to continental crust. In some areas, active arcs that overlie oceanic crust may extend into continental areas where they overlie continental-type crust. For example, the Aleutian arc extends eastward into the Alaska Peninsula, and the Kurile arc continues into Kamchatka.

Included in the group of obsidians of active continental margins are the recent silicic volcanic rocks of the western Americas, extending from Alaska and Canada down through the Cascades and central California and linking, via Central America, to the Andes. The crust forming these areas consists largely of Paleozoic and younger geosynclinal materials of generally andesitic composition, including a large graywacke-type sedimentary component. Precambrian rocks, present in some cases, are not volumetrically important as crustal components. The scarcity of Precambrian rocks is a critical part of the definition of this group; crust, and therefore rhyolites, of this type may occur within continental interiors far from the continental margin. Thus, group III rhyolites occur in parts of Nevada (Nos. 76-79) where Precambrian crust is apparently missing. The example serves to stress the point made earlier that the chemistry of rhyolites is primarily dependent on the type of crust in which they were emplaced. It also, perhaps, suggests that the term "continental margin" is not totally satisfactory for this group, but the data required to construct a more ideal classification based on crustal type and thickness are not yet available.

Furthermore, the broad tectonic setting of continental margin may include areas where extensional tectonics have been superimposed on the subduction regime. These extensional zones may produce rhyolites with distinctive chemistries, such as those of the Brothers fault zone in Oregon, which include high-Fe, even peralkaline, varieties which are in some respects transitional to group $\mathrm{V}$ rhyolites of oceanic extensional zones. A possible explanation is that the crust in such zones is also transitional, perhaps due to intrusion into the sialic crust of substantial amounts of mafic material.

Continental-margin volcanism is dominated by andesites of calc-alkalic affinity, as is the case for the mature island arcs. An important difference is that rhyolitic volcanics are much more abundant on continental margins, much of the additional material being accounted for in voluminous pyroclastic deposits. Examples of large Cenozoic rhyolitic ash-flow provinces include the Central Andes $(\geq 70,000$ $\mathrm{km}^{3}$, Pichler and Zeil, 1972) and Central America $\left(\geq 10,000 \mathrm{~km}^{2}\right.$, Pushkar and others, 1972). The midTertiary ash-flow tuffs of the Sierra Madre Occidental of western Mexico, thought to have been part of a continental arc, cover an area of more than 250,000 $\mathrm{km}^{2}$ (Cameron and others, 1980).

As in the island-arc groups, there is a range of rhyolitic compositions within the active-continentalmargin group. Affinities range from relatively CaO-rich types, many of which belong to calcic associations as defined by Peacock (1931), through rhyolite of calc-alkalic associations to alkali-calcic, relatively potassic, rhyolites. Though the majorelement chemistry of the low-CaO types is comparable to rhyolites from epicontinental settings, the $\mathrm{Nb}$ and $\mathrm{Ta}$ abundances normally fingerprint them as of margin type.

The calcic rhyolites of the continental margins are more restricted geographically and volumetrically than their calc-alkalic associates. Their fullest development in Holocene time has been in the Cascades, Alaska, and Kamchatka. The alkali-calcic types have been found in several areas, including eastern Oregon, Mono Craters, north-western Nevada, Japan, and Turkey. They probably represent the highly differentiated end-members of calcalkalic suites.

$\mathrm{Pl}+\mathrm{Opx}+\mathrm{Ox}$ occur in all seven porphyritic, calcic specimens in the continental margin for which we have data, and the generalized assemblage $\mathrm{Pl}+\mathrm{Opx}+\mathrm{Ox} \pm \mathrm{Cpx} \pm \mathrm{Hb} \pm \mathrm{Ol}(?)$ describes all the samples. Only one calcic rhyolite of this group is aphyric (No. 243). Recorded assemblages (accessories excluded) are:

$\begin{array}{ll}\mathrm{Pl}+\mathrm{Opx}+\mathrm{Ox} & (8,9) \\ \mathrm{Pl}+\mathrm{Opx}+\mathrm{Ox}+\mathrm{Cpx} & (20,21) \\ \mathrm{Pl}+\mathrm{Opx}+\mathrm{Ox}+\mathrm{Hb} & (19,247) \\ \mathrm{Pl}+\mathrm{Opx}+\mathrm{Ox}+\mathrm{Cpx}+\mathrm{Hb} & (246) \\ \mathrm{Pl}+\mathrm{Opx}+\mathrm{Ox}+\mathrm{Cpx}+\mathrm{Hb}+\mathrm{Ol} ? & (13,15,17)\end{array}$


A notable feature of the calc-alkalic specimens from the continental margins is that 54 percent, generally the more silicic, of them are aphyric. The porphyritic specimens show a variety of phenocryst assemblages:

$\begin{array}{ll}\mathrm{Pl} & (45) \\ \mathrm{Pl}+\mathrm{Opx} & (279) \\ \mathrm{Pl}+\mathrm{Opx}+\mathrm{Ox} & (24,41,46,47,280) \\ \mathrm{Pl}+\mathrm{Opx}+\mathrm{Cpx}+\mathrm{Ox} & (22,278) \\ \mathrm{Pl}+\mathrm{Cpx}+\mathrm{Ox} & (261) \\ \mathrm{Pl}+\mathrm{Cpx} & (6) \\ \mathrm{Pl}+\mathrm{Opx}+\mathrm{Cpx} & (48) \\ \mathrm{Opx}+\mathrm{Cpx}+\mathrm{Ox} & (273) \\ \mathrm{Pl}+\mathrm{Opx}+\mathrm{Ox}+\mathrm{Bi} & (53) \\ \mathrm{Pl}+\mathrm{Ox}+\mathrm{Bi} & (4,154,328) \\ \mathrm{Pl}+\mathrm{Bi} & (36,329) \\ \mathrm{Pl}+\mathrm{Hb} & (31,162,166) \\ \mathrm{Pl}+\mathrm{Hb}+\mathrm{Ox} & (163) \\ \mathrm{Cpx}+\mathrm{Hb} & (248) \\ \mathrm{Pl}+\mathrm{Opx}+\mathrm{Cpx}+\mathrm{Hb} & (281) \\ \mathrm{Pl}+\mathrm{Opx}+\mathrm{Cpx}+\mathrm{Hb}+\mathrm{Bi}+\mathrm{Ox}+\mathrm{Kf} & (51) \\ \mathrm{Pl}+\mathrm{Opx}+\mathrm{Cpx}+\mathrm{Hb}+\mathrm{Bi}+\mathrm{Ox}+\mathrm{Kf}+\mathrm{Q} & (283,284) \\ \mathrm{Pl}+\mathrm{Opx}+\mathrm{Cpx}+\mathrm{Ox}+\mathrm{Kf}+\mathrm{Q} & (3) \\ & \end{array}$

There is an overall similarity to the assemblages recorded in the calc-alkalic rhyolites of mature island arcs. $\mathrm{Pl}+\mathrm{Ox}+\mathrm{Opx}$ occurs in a majority of specimens, whereas a generalized assemblage is $\mathrm{Pl}+\mathrm{Ox}+\mathrm{Opx}+\mathrm{Cpx}+\mathrm{Hb}+\mathrm{Bi}+\mathrm{Kf}+\mathrm{Q}$.

Twelve of the 19 alkali-calcic specimens are aphyric, and the remaining 7 are phenocryst-poor ( $\leq 1$ percent modal). The assemblages noted are:

$\begin{array}{ll}\mathrm{Pl}+\mathrm{Opx}+\mathrm{Cpx}+\mathrm{Ox}+\mathrm{Hb} & (188) \\ \mathrm{Pl}+\mathrm{Cpx}+\mathrm{Ox}+\mathrm{Bi} & (184) \\ \mathrm{Pl}+\mathrm{Ox}+\mathrm{Hb}+\mathrm{Bi}+\mathrm{Kf} & (54) \\ \mathrm{Opx}+\mathrm{Ox} & (285,287,288) \\ \mathrm{Ox} & (49)\end{array}$

\section{GROUP IV: OBSIDIANS OF THE CONTINENTAL INTERIORS}

Obsidians of the continental interiors are emplaced within stable continental cratonic areas. The crust varies in thickness from $25-50 \mathrm{~km}$, where its lower parts consist of Precambrian and (or) lower Paleozoic rocks. Though most commonly found in the stable continental interiors, such crust may also occur in complex arc/margin settings. For example, the obsidians of Wadatoge and Imari in Japan (Nos. 188, 191) occur in areas underlain by lower Paleozoic and (or) Precambrian crust (Doe and Zartman, 1982).

Rhyolites are part of several types of magmatic systems in the continental setting: basalt-andesitedacite-rhyolite suites, bimodal associations with basalts, entirely silicic dome fields, and enormous volumes of ash-flow tuffs. Associated basalts form a spectrum of compositions: tholeiitic, high- $\mathrm{Al}_{2} \mathrm{O}_{3}$, and alkalic types have all been recorded.

Group IV alkali-calcic rocks vary petrographically. Phenocryst assemblages recorded in the data bank are:

$\begin{array}{ll}\mathrm{Pl} & (98,105,109,141,146 \\ \mathrm{Cpx} & (147) \\ \mathrm{Ox} & (161) \\ \mathrm{Pl}+\mathrm{Ox} & (143) \\ \mathrm{Pl}+\mathrm{Cpx}+\mathrm{Ox} & (101) \\ \mathrm{Pl}+\mathrm{Cpx}+\mathrm{Bi}+\mathrm{Ox} & (178) \\ \mathrm{Pl}+\mathrm{Bi} & (107) \\ \mathrm{Pl}+\mathrm{Kf}+\mathrm{Ol} & (300) \\ \mathrm{Pl}+\mathrm{Kf}+\mathrm{Ox} & (119,124) \\ \mathrm{Pl}+\mathrm{Kf}+\mathrm{Opx}+\mathrm{Cpx}+\mathrm{Ox} & (85) \\ \mathrm{Pl}+\mathrm{Kf}+\mathrm{Opx}+\mathrm{Cpx}+\mathrm{Hb}+\mathrm{Bi}+\mathrm{Ox} & (121) \\ \mathrm{Kf}+\mathrm{Bi}+\mathrm{Ox} & (110,305) \\ \mathrm{Kf}+\mathrm{Bi} & (306) \\ \mathrm{Kf} & (295) \\ \mathrm{Q}+\mathrm{Pl} & (111) \\ \mathrm{Q}+\mathrm{Kfs} & (92,296,297,298,299) \\ \mathrm{Q}+\mathrm{Pl}+\mathrm{Kfs} & (89,102,116,294) \\ \mathrm{Q}+\mathrm{Pl}+\mathrm{Kfs}+\mathrm{Ox} & (90,95,108,303,304) \\ \mathrm{Q}+\mathrm{Pl}+\mathrm{Kfs}+\mathrm{Opx}+\mathrm{Ox} & (144) \\ \mathrm{Q}+\mathrm{Pl}+\mathrm{Kfs}+\mathrm{Opx}+\mathrm{Cpx}+\mathrm{Ox} & (84) \\ \mathrm{Q}+\mathrm{Pl}+\mathrm{Kfs}+\mathrm{Cpx}+\mathrm{Opx}+\mathrm{Hb}+\mathrm{Ox} & (310) \\ \mathrm{Q}+\mathrm{Pl}+\mathrm{Kfs}+\mathrm{Hb}+\mathrm{Ox} & (86) \\ \mathrm{Q}+\mathrm{Pl}+\mathrm{Kfs}+\mathrm{Bi}+\mathrm{Ox} & (87) \\ \mathrm{Q}+\mathrm{Pl}+\mathrm{Kfs}+\mathrm{Bi}+\mathrm{Hb}+\mathrm{Ox} & (88) \\ \mathrm{Q}+\mathrm{Pl}+\mathrm{Kfs}+\mathrm{Opx}+\mathrm{Cpx}+\mathrm{Hb}+\mathrm{Bi}+\mathrm{Ox}+\mathrm{Ol} & (307,308,309) \\ \mathrm{Q}+\mathrm{Pl}+\mathrm{Kfs}+\mathrm{Bi}+\mathrm{Hb} & (145) \\ \mathrm{Q}+\mathrm{Kfs}+\mathrm{Cpx}+\mathrm{Ox} & (91) \\ & \end{array}$

In addition, a simplified assemblage for 15 specimens from the Coso Range, California (Nos. 57-72, excluding 67) is $\mathrm{Q}+\mathrm{Kf}+\mathrm{Pl}+\mathrm{Ox} \pm \mathrm{Cpx} \pm \mathrm{Opx} \pm \mathrm{Hb} \pm \mathrm{Bi} \pm \mathrm{Ol}$.

Quartz and alkali feldspars are common phenocryst phases, and biotite is also more frequently present than in any other rhyolite group.

A large proportion (42 percent) of the samples are aphyric. These rhyolites have the highest average $\mathrm{SiO}_{2}$ (table 7), and the absence of phenocrysts may be a reflection of low solidus temperatures and high viscosities (Ewart and Le Maitre, 1980).

\section{GROUP V: OBSIDIANS FROM ISLANDS OVERLYING OCEANIC EXTENSIONAL ZONES}

Group V silicic rocks from islands overlying regions of high heat flow at or near spreading axes with relatively thin $(<25 \mathrm{~km})$ oceanic-type crust are most extensively developed on Iceland but are also found on the volcanic islands of St. Andrew Strait, Papua New Guinea, in the Bismarck Sea, a marginal basin where sea-floor spreading is apparently taking place (Johnson and others, 1978). Group V 
rhyolites have also been erupted from the Alcedo caldera, Galapagos Islands.

Included in this group are rhyolites forming a series of domes in the Salton Sea, California. These occur within an area of rapid, active spreading in a continental setting and are underlain by a crust intermediate in type between oceanic and continental. The chemistry of the Salton Sea rhyolites reflects this transition, but we consider them to be of group $\mathrm{V}$ affinity.

A feature of this group is that they almost invariably occur in bimodal association with basalt; where intermediate rocks are present (for example, in the tholeiitic centers of eastern Iceland), they are relatively uncommon.

Petrographically, group V rhyolites are rather uniform, and the phenocryst assemblage $\mathrm{Pl}+\mathrm{Cpx}+\mathrm{Ol}+\mathrm{Ox}$ is present in the majority of specimens. $\mathrm{Hb}, \mathrm{Opx}, \mathrm{Kf}$, and $\mathbf{Q}$ are less common phases. Recorded assemblages are:

$\begin{array}{ll}\mathrm{Pl}+\mathrm{Ox} & (213) \\ \mathrm{Pl}+\mathrm{Ox}+\mathrm{Cpx}+\mathrm{Opx} & (176) \\ \mathrm{Pl}+\mathrm{Cpx}+\mathrm{Ox} & (171,321) \\ \mathrm{Pl}+\mathrm{Cpx}+\mathrm{Ox}+\mathrm{Ol} & (156,157,158,174,178) \\ \mathrm{Pl}+\mathrm{Cpx}+\mathrm{Ol} & (319) \\ \mathrm{Pl}+\mathrm{Ox}+\mathrm{Ol} & (214) \\ \mathrm{Pl}+\mathrm{Cpx}+\mathrm{Ox}+\mathrm{Ol}+\mathrm{Hb} & (172) \\ \mathrm{Pl}+\mathrm{Cpx}+\mathrm{Ox}+\mathrm{Ol}+\mathrm{Q} & (169,170) \\ \mathrm{Pl}+\mathrm{Cpx}+\mathrm{Ox}+\mathrm{Ol}+\mathrm{Hb}+\mathrm{Kf} & (74) \\ \mathrm{Pl}+\mathrm{Cpx}+\mathrm{Ox}+\mathrm{Hb}+\mathrm{Kf} & (73)\end{array}$

\section{GEOCHEMISTRY}

\section{INTRODUCTION}

The ranges of elemental abundances in the obsidians are given in table 7 . Despite the restricted range of major-element abundances imposed by the 70-percent- $\mathrm{SiO}_{2}$ lower limit, the minor and trace elements can show order-of-magnitude variations (for example, $\mathrm{Ba}$ and $\mathrm{Sr}$ ). Compositional variations in the rhyolites are related to the type of crust through which the magma is emplaced and to the types and relative efficiencies of the genetic mechanisms operative on the silicic magmas, which may be specific to a given crustal environment. As previously stated, the type of crust through which the magma is emplaced forms the basis of the classification scheme used in this paper. The compositional variations must in some way be related either to the composition of the crust, its control on magma evolution, or to subcrustal processes themselves, which are related to the overlying crust.

One further level of chemical variation must also be mentioned. Numerous examples of restricted geo- chemical anomalies are apparent in the data bank. Three may be mentioned here. The obsidian from Xalapasquillo, Mexico (Nos. 146, 147) is unique in having $\mathrm{Th} / \mathrm{U}$ ratio $<1$. The obsidian from the U.S. Gypsum Company perlite mine in Nevada (No. 78) shows extreme HREE depletion, with $\mathrm{Yb}$ at almost chondritic levels. The Superior, Arizona, obsidian (No. 106) has notably low contents of $\mathrm{Cs}, \mathrm{Sb}, \mathrm{Th}$, and $\mathrm{U}$ for a continental interior rhyolite. Many more examples are provided in later sections. It is possible that these restricted anomalies are a result of source rocks of unusual composition, reflecting very localized modifications of crustal composition. Alternatively, they may be process-related in some way. Whatever their cause, they add some nonsystematic scatter to the within-group compositional variations.

\section{BETWEEN-GROUP COMPOSITIONAL VARIATIONS}

Ranges and average compositions for the obsidians from various settings are given in table 7 . The main features of the average analyses can be shown as geochemical patterns (fig. 9). The normalizing factor for these patterns is the hypothetical ocean-ridge granite (ORG) of Pearce and others (1984), which was calculated as the residual liquid after 75 percent fractional crystallization of average N-type MORB (normal midocean ridge basalt as opposed to E-type, enriched MORB). This calculation attempts to produce a model granitic liquid by simple fractionation from a basalt having a plagioclase-olivineclinopyroxene-magnetite assemblage, with no crustal interaction and without involvement of a dominant volatile phase. Any deviation from a flat pattern reflects a more complex magma genesis, which varies from setting to setting.

In general, the patterns show an overall slope from left to right (see fig. 9), that is, enrichment in $\mathrm{K}, \mathrm{Rb}, \mathrm{Ba}$, and $\mathrm{Th}$ relative to the other elements shown ( $\mathrm{Ta}, \mathrm{Nb}, \mathrm{Ce}, \mathrm{Hf}, \mathrm{Zr}, \mathrm{Sm}, \mathrm{Y}, \mathrm{Yb}$ ), though the details of the patterns are different. Those patterns from the continental-margin and mature-island-arc obsidians are the most similar. They show a slight depletion in $\mathrm{Ba}$ relative to $\mathrm{Rb}$ and $\mathrm{Th}$, and small troughs at $\mathrm{Nb}$ and $\mathrm{Ta}$ (especially in the matureisland-arc average) which mimic the $\mathrm{Nb}$ - $\mathrm{Ta}$ depletion typical of mafic rocks in subduction zones (Pearce, 1982, 1983). The combination of a deep Ba trough and low Ce concentrations relative to $\mathrm{Nb}$ distinguish the continental-interior average from that of the other groups. The oceanic-extensional-zone average closely follows those of the mature island arcs and continental margins from $K$ to $T h$ but is much higher in the Ce to $\mathrm{Yb}$ elements than the other types. 
TABLE 7.-Ranges and average compositions of the various obsidian groups

[First average $(X)$ in each column was calculated using new data only (appendix $I$ ); ranges and second average $\left(\mathrm{X}_{\mathrm{T}}\right)$ using all data. - , not determined]

\begin{tabular}{|c|c|c|c|c|c|c|c|c|c|c|c|c|c|c|c|}
\hline & \multicolumn{3}{|c|}{ Primitive island arcs } & \multicolumn{3}{|c|}{ Mature island arcs } & \multicolumn{3}{|c|}{ Continental margins } & \multicolumn{3}{|c|}{ Continental interiors* } & \multicolumn{3}{|c|}{ Oceanic extensional zones } \\
\hline & Range & $\mathbf{x}$ & $\mathbf{x}_{\mathrm{T}}$ & Range & $\mathbf{x}$ & $\mathbf{x}_{\mathrm{T}}$ & Range & $\mathbf{x}$ & $\mathbf{x}_{T}$ & Range & $\mathbf{x}$ & $\mathbf{x}_{\mathrm{T}}$ & Range & $\mathbf{x}$ & $\mathbf{x}_{\mathrm{T}}$ \\
\hline \multicolumn{16}{|c|}{ Major elements-(weight percent) } \\
\hline $\mathrm{SiO}_{2}$ & 70.1-73.5 & - & 71.6 & $70.6-77.2$ & 75.2 & 74.6 & $70.2-77.3$ & 74.5 & 74.1 & $70.6-77.5$ & 75.9 & 75.8 & $70.0-76.9$ & 72.9 & 73.1 \\
\hline 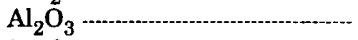 & $11.90-14.31$ & - & 13.04 & $11.39-15.26$ & 13.14 & 13.26 & $11.92-15.37$ & 13.58 & 13.65 & $11.90-16.30$ & 12.85 & 12.87 & $11.82-14.59$ & 13.21 & 13.13 \\
\hline $\mathrm{Fe}_{2} \mathrm{O}_{3}$ & $.69-1.57$ & - & 1.05 & $.04-1.52$ & .44 & .56 & $.09-1.67$ & .49 & .50 & $.09-1.33$ & .43 & .45 & .27-1.97 & .74 & .78 \\
\hline $\mathrm{FeO}$ & $1.84-4.84$ & - & 3.24 & $.37-4.03$ & 1.15 & 1.17 & $.32-2.62$ & .92 & 1.14 & $.12-1.76$ & .59 & .65 & $1.10-3.88$ & 2.00 & 1.94 \\
\hline MgO & $.50-1.1$ & - & .84 & $.07-1.38$ & .25 & .36 & $.01-.93$ & .21 & .24 & $.00-.66$ & .06 & .07 & $.00-.73$ & .22 & .23 \\
\hline $\mathrm{CaO}$ & $3.25-4.61$ & - & 3.80 & $.66-3.70$ & 1.34 & 1.64 & $.27-2.94$ & 1.00 & 1.11 & $.16-2.07$ & .51 & .54 & .48-2.79 & 1.20 & 1.25 \\
\hline $\mathrm{Na}_{2} \mathrm{O}$ & $2.81-4.88$ & - & 3.85 & $2.72-5.19$ & 4.13 & 4.13 & $3.40-5.38$ & 4.32 & 4.29 & $3.00-5.07$ & 4.14 & 4.05 & $3.16-5.93$ & 4.97 & 4.87 \\
\hline $\mathrm{K}_{2} \mathrm{O}$ & $.64-1.52$ & - & .92 & $.98-5.01$ & 3.46 & 3.22 & $2.43-5.26$ & 4.11 & 4.12 & $3.60-6.60$ & 4.61 & 4.73 & $2.30-4.43$ & 3.64 & 3.59 \\
\hline $\mathrm{H}_{2} \mathrm{O}^{+}$ & - & - & - & $.05-.78$ & .17 & .32 & $.04-1.10$ & .20 & .27 & $.01-.98$ & .24 & .25 & $.04-.63$ & .14 & .19 \\
\hline $\mathrm{TiO}_{2}$ & $.30-.58$ & - & .47 & $.08-.73$ & .22 & .27 & $.03-.54$ & .21 & .22 & $.00-.31$ & .10 & .11 & $.10-.92$ & 29 & .29 \\
\hline $\mathrm{P}_{2} \mathrm{O}_{5}$ & $.07-.12$ & - & .09 & $.01-.33$ & .03 & .08 & $.01-.22$ & .04 & .05 & $.00-.55$ & .02 & .02 & $.00-.44$ & .04 & .06 \\
\hline MnO & $.06-.14$ & - & .11 & $.01-.20$ & .08 & .08 & $.02-.12$ & .06 & .05 & $.02-.14$ & .06 & .05 & $.04-.18$ & .09 & .08 \\
\hline $\mathrm{Cl}$ & - & - & - & $.06-.19$ & .11 & - & $.01-.17$ & .07 & - & $.04-.20$ & .08 & - & $.03-.36$ & .17 & - \\
\hline F & - & - & - & $.02-.08$ & .05 & - & $.02-.12$ & .05 & - & $.05-1.36$ & .15 & - & $.05-.20$ & .12 & - \\
\hline $\mathrm{Fe}$ as $\mathrm{FeO}^{1}$ & $2.75-5.25$ & - & 4.28 & $.55-4.74$ & 1.54 & 1.80 & $.53-2.89$ & 1.33 & 1.58 & $.50-2.30$ & .99 & 1.06 & $1.40-4.79$ & 2.66 & 2.65 \\
\hline $\mathrm{FeO} /\left(\mathrm{FeO}+\mathrm{Fe}_{2} \mathrm{O}_{3}\right)^{1}$ & $.58-.86$ & - & .76 & $.35-.98$ & .72 & .68 & $.35-.95$ & .65 & .70 & $.08-.85$ & .58 & .59 & $.44-.87$ & .73 & .71 \\
\hline $\mathrm{Na}_{2} \mathrm{O} / \mathrm{K}_{2} \mathrm{O}^{1}$ & $2.16-7.51$ & - & 4.18 & $.71-4.51$ & 1.19 & 1.28 & $.68-2.16$ & 1.05 & 1.04 & $.47-1.13$ & .90 & .86 & $.98-2.15$ & 1.37 & 1.36 \\
\hline$\left(\mathrm{Na} \mathrm{O}+\mathrm{K}_{2} \mathrm{O}\right) / \mathrm{Al}_{2} \mathrm{O}_{3}{ }^{2} \ldots$ & $.46-.62$ & - & .56 & $.48-.94$ & .80 & .77 & $.73-1.00$ & .85 & .84 & $.66-.99$ & .92 & .92 & $.72-.98$ & .92 & .91 \\
\hline$\left(\mathrm{CaO}+\mathrm{Na}_{2} \mathrm{O}+\mathrm{K}_{2} \mathrm{O}\right) / \mathrm{Al}_{2} \mathrm{O}_{3}^{2}$ & $1.04-1.12$ & - & 1.09 & $.89-1.14$ & .99 & 1.00 & $.89-1.12$ & .98 & .99 & $.68-1.07$ & .99 & .99 & $1.02-1.17$ & 1.08 & 1.08 \\
\hline $\mathrm{CaO} /\left(\mathrm{Na}_{2} \mathrm{O}+\mathrm{K}_{2} \mathrm{O}\right)^{1}$ & $.61-1.19$ & - & .80 & $.07-.57$ & .18 & .22 & $.03-.39$ & .12 & .13 & $.03-.23$ & .06 & .06 & $.05-.42$ & .14 & .15 \\
\hline $\mathrm{Cl} / \mathrm{F}^{1}$ & - & - & - & $1.48-5.19$ & 2.2 & - & $.15-3.94$ & 1.4 & - & $.03-2.40$ & .5 & - & $.38-3.03$ & 1.4 & - \\
\hline \multicolumn{16}{|c|}{ Trace elements (parts per million) } \\
\hline Ba -..- & $68-610$ & & 286 & $392-1285$ & 637 & - & $13-1440$ & 730 & - & $1-1040$ & 164 & - & $400-880$ & 619 & - \\
\hline $\mathrm{Be}$ & - & - & - & $.86-3.2$ & 1.59 & - & $1.3-5.5$ & 2.62 & - & $1.8-32$ & 6.90 & - & $1.9-5.8$ & 4.67 & - \\
\hline Co & $2.8-10$ & - & 6.6 & $.2-4.6$ & 1.2 & - & $.1-4.5$ & 1.1 & - & $.09-3.9$ & .4 & - & $<.2-4.0$ & 1.29 & - \\
\hline $\mathrm{Cr}$ & - & - & - & $1.1-2.2$ & 1.7 & - & $1.1-10.7$ & 2.3 & - & $1.0-13.2$ & 3.2 & - & $.4-3.8$ & 1.4 & - \\
\hline Cs ‥-1 & - & - & - & $1.3-12.7$ & 6.2 & - & $1.8-21.1$ & 5.8 & - & $2.0-503$ & 6.4 & - & $.7-4.0$ & 1.5 & - \\
\hline Hf ‥-1- & - & - & - & $2.0-10.9$ & 4.7 & - & $1.9-11.5$ & 5.0 & - & $1.3-14.5$ & 5.6 & - & $7.6-21.8$ & 12.8 & - \\
\hline $\mathrm{Li}$ & - & - & - & $18-68$ & 35 & - & $25-110$ & 49 & - & $34-3400$ & 84 & - & $18-81$ & 32 & - \\
\hline Mo --1-1- & - & - & - & $1.2-4.7$ & 2.3 & - & $.58-8.1$ & 3.2 & - & $.26-9.9$ & 4.1 & - & $2.3-6.2$ & 4.2 & - \\
\hline Nb - & $.6-3$ & - & 2 & $3-15$ & 8.2 & - & $5-36$ & 13.8 & - & $14-288$ & 55.2 & - & $30-131$ & 68.5 & - \\
\hline $\mathrm{Pb}$ & 4-10 & - & 7 & 6-44 & 20 & - & $9-49$ & 21 & - & $15-101$ & 32 & - & $9-19$ & 14 & - \\
\hline $\mathrm{Rb}$ & $6.8-23$ & - & 16 & $23-200$ & 112 & - & $52-270$ & 135 & - & $103-1174$ & 232 & - & $62-158$ & 106 & - \\
\hline $\mathrm{Sb}$ & - & - & - & $<.1-2.3$ & .74 & - & $.2-1.9$ & .80 & - & $.1-3.9$ & .79 & - & $.3-.6$ & .48 & - \\
\hline Sc - & - & - & - & $1.72-12.4$ & 6.4 & - & $1.07-9.04$ & 3.6 & - & $.12-7.69$ & 2.0 & - & $.43-11.1$ & 3.9 & - \\
\hline Sn & - & - & - & $.5-3.6$ & 1.9 & - & $.7-7.9$ & 2.6 & - & $1.3-250$ & 5.6 & - & $2.2-8.4$ & 6.0 & - \\
\hline $\mathrm{Sr}$ & $110-255$ & - & 157 & $37-290$ & 125 & - & 2-402 & 120 & - & $<1-202$ & 23 & - & $25-128$ & 73 & - \\
\hline Ta & - & - & - & $.21-1.03$ & .60 & - & $.44-2.95$ & 1.24 & - & $1.93-29.4$ & 5.7 & - & $2.58-8.52$ & 4.9 & - \\
\hline Th - & $.7-4$ & - & 2.2 & $2.1-24.8$ & 10.6 & - & $4.9-26.6$ & 12.9 & - & $1.3-52.7$ & 23.6 & - & 7.3-20.8 & 12.7 & - \\
\hline
\end{tabular}




\begin{tabular}{|c|c|c|c|c|c|c|c|c|c|c|c|c|c|c|c|}
\hline U -...- & $.39-.84$ & - & .64 & $7-7.2$ & 3.1 & - & $2.1-13.2$ & 4.9 & - & $3.5-35.1$ & 10.9 & - & $2.1-5.7$ & 3.6 & - \\
\hline W & - & - & - & $.43-3.2$ & 1.7 & - & $.50-3.9$ & 1.8 & - & $1.0-76$ & 2.7 & - & $.94-3.3$ & 1.5 & - \\
\hline Y & $25-41$ & - & 34 & $10-85$ & 35 & - & $8-108$ & 30 & - & 8-245 & 55 & - & $31-155$ & 89 & - \\
\hline Zn - & $43-101$ & - & 69 & $8-108$ & 39 & - & $16-95$ & 38 & - & 18-282 & 54 & - & 42-179 & 97 & - \\
\hline Zr & $51-178$ & - & 98 & $39-420$ & 164 & - & $40-447$ & 165 & - & $22-367$ & 136 & - & $185-860$ & 526 & - \\
\hline La & - & - & - & $11-37$ & 22 & - & 9-90 & 28 & - & $1-95$ & 32 & - & 41-95 & 63 & - \\
\hline $\mathrm{Ce}$ & - & - & - & 24-79 & 43 & - & $18-142$ & 51 & - & 3-185 & 64 & - & $78-176$ & 130 & - \\
\hline $\mathrm{Nd}$ - & - & - & - & $11-46$ & 21 & - & 8-51 & 22 & - & 4-71 & 28 & - & $31-78$ & 59 & - \\
\hline Sm & - & - & - & $2.8-11.8$ & 5.0 & - & $2.0-10.5$ & 4.7 & - & $1.5-15.9$ & 6.7 & - & $6.4-17.9$ & 14.1 & - \\
\hline Eu & - & - & - & $.37-1.65$ & .76 & - & $.08-1.11$ & .55 & - & $.02-.98$ & .24 & - & $.94-3.29$ & 2.0 & - \\
\hline Gd -1 & - & - & - & $2.5-10.5$ & 4.6 & - & $1.6-10.8$ & 4.3 & - & $<2-16.6$ & 6.2 & - & $5.3-16.8$ & 11.7 & - \\
\hline Tb & - & - & - & $.32-2.01$ & .85 & - & $.24-2.25$ & .67 & - & $<.03-4.26$ & 1.28 & - & $.93-3.00$ & 2.18 & - \\
\hline Tm & - & - & - & $.26-1.29$ & .54 & - & $<.10-1.82$ & .45 & - & $<.20-3.22$ & .91 & - & $.60-1.96$ & 1.26 & - \\
\hline Yb & - & - & - & $1.7-8.9$ & 3.8 & - & $.2-11.7$ & 2.9 & - & $.3-23.6$ & 5.7 & - & $4.2-13.6$ & 8.3 & - \\
\hline Lu - & - & - & - & $.27-1.30$ & .56 & - & $<.1-1.66$ & .42 & - & $.04-3.04$ & .93 & - & $.62-1.87$ & 1.06 & - \\
\hline $\mathrm{Nb} / \mathrm{Ta}$ & - & - & - & $9.6-21.5$ & 13.7 & - & $7.4-21.2$ & 11.1 & - & $2.5-18.9$ & 9.7 & - & $11.0-15.5$ & 14.0 & - \\
\hline $\mathrm{K} / \mathrm{Rb}$ & $385-781$ & - & 540 & $167-571$ & 256 & - & 138-394 & 253 & - & $25-380$ & 165 & - & $220-356$ & 285 & - \\
\hline $\mathrm{Rb} / \mathrm{Sr}$ & $.04-.16$ & - & .11 & $.1-5.3$ & .9 & - & $.1-65$ & 1.1 & - & $.8-1533$ & 10.3 & - & $.5-5.8$ & 1.5 & - \\
\hline $\mathrm{Ca} / \mathrm{Sr}$ & $112-211$ & - & 176 & $40-149$ & 77 & - & 35-965 & 60 & - & $39-12863$ & 158 & - & 91-243 & 118 & - \\
\hline Th/U & $1.0-2.5$ & - & 1.8 & $1.4-9.1$ & 3.5 & - & $1.4-3.6$ & 2.6 & - & $.1-5.1$ & 2.2 & - & $3.0-4.1$ & 3.5 & - \\
\hline Zr/Hf & - & - & - & $20-48$ & 35 & - & $17-48$ & 33 & - & $10-43$ & 24 & - & $23-46$ & 41 & - \\
\hline $\mathrm{Ce} / \mathrm{Yb}$ & - & - & - & $6.4-24.5$ & 11.5 & - & $4.7-230$ & 18.0 & - & $2.4-12.0$ & 11.2 & - & $9.0-26.4$ & 15.6 & - \\
\hline $\mathrm{Eu} / \mathrm{Eu}^{*}$ & - & - & - & $.20-.78$ & .51 & - & $.04-.75$ & .38 & - & $.01-.56$ & .12 & - & $.32-.68$ & .48 & - \\
\hline \multirow{2}{*}{\multicolumn{2}{|c|}{$\begin{array}{l}\text { Maximum number of determinations: } \\
\text { major elements } \\
\text { trace elements }\end{array}$}} & & & & & & & & & & & & & & \\
\hline & & $\begin{array}{l}7 \\
5\end{array}$ & & & $\begin{array}{l}59 \\
26\end{array}$ & & & $\begin{array}{r}119 \\
66\end{array}$ & & & $\begin{array}{r}108 \\
80\end{array}$ & & & $\begin{array}{l}24 \\
17\end{array}$ & \\
\hline
\end{tabular}

1By weight
2Molecular

*Averages exclude $\mathrm{P}_{2} \mathrm{O}_{\mathrm{s}}, \mathrm{F}, \mathrm{Cs}, \mathrm{Li}, \mathrm{Rb}, \mathrm{Sb}, \mathrm{Sn}$, and $\mathrm{W}$ data for sample 160. 
The plot distinguishes elements which are potentially valuable at separating the obsidian groups, for example, $\mathrm{Nb}, \mathrm{Ta}$, and $\mathrm{Th}$ (although averaging tends to blur the value of $\mathrm{Th}$ ), from those less valuable, for example, $\mathrm{Zr}$ and $\mathrm{Hf}$. In fact, the overlap between the groups is sufficiently large that no one element or ratio can separate all five groups. Combinations of elements provide more successful discriminants, such as the $\mathrm{Nb}-\mathrm{Ta}, \mathrm{Nb}-\mathrm{FeO}$, and Th-Ta-Hf plots presented below.

The compositional differences must have petrogenetic significance, reflecting in some way the differ-

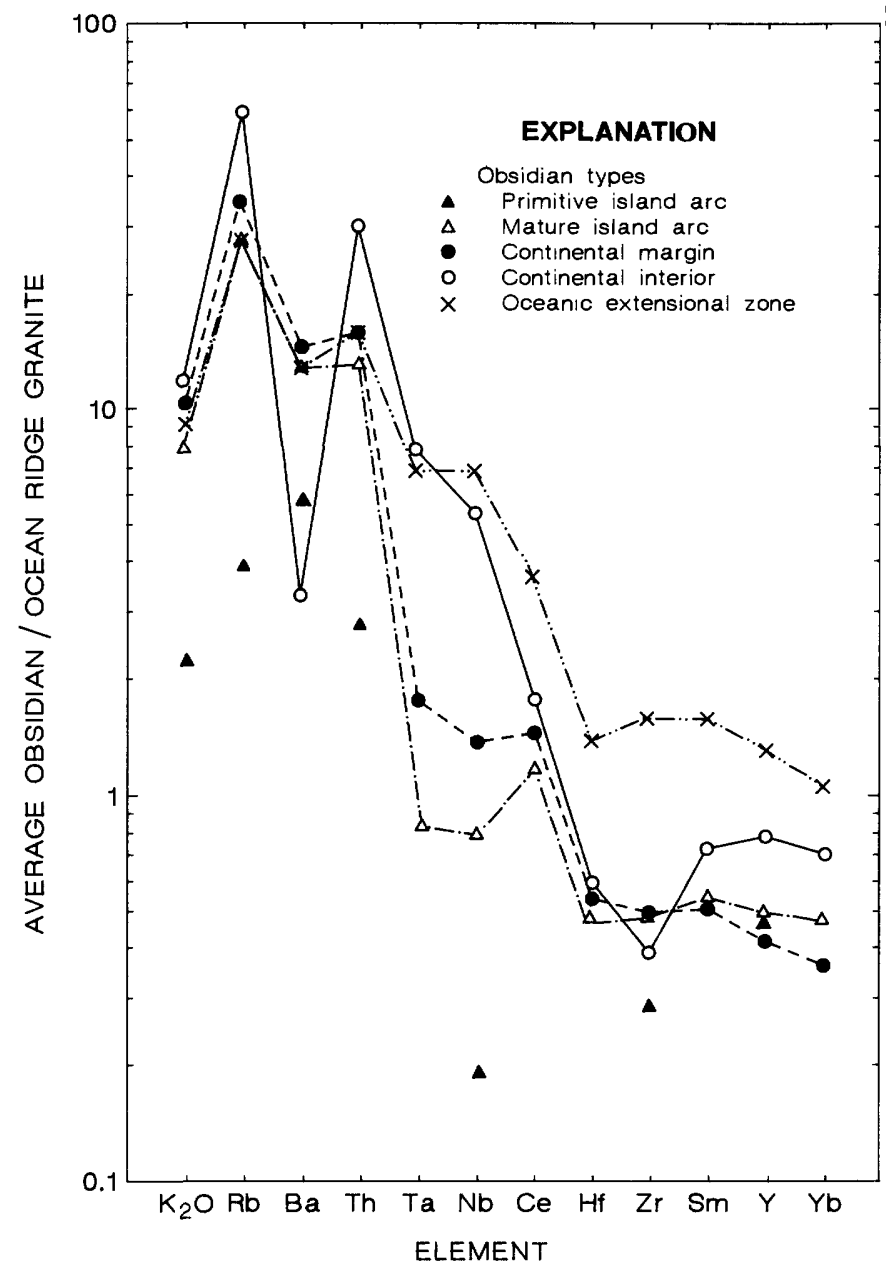

Figure 9.-Geochemical patterns, normalized to ocean ridge granite, for average obsidian from different tectonic settings (table 7). Available data for primitive island arcs are shown, but pattern is incomplete because values for several elements were not determined. Order of elements and normalizing values from Pearce and others (1984); values are: $\mathrm{K}_{2} \mathrm{O}, 0.4 ; \mathrm{Rb}, 4 ; \mathrm{Ba}, 50$; $\mathrm{Th}, 0.8 ; \mathrm{Ta}, 0.7 ; \mathrm{Nb}, 10$; Ce, 35; Hf, 9; $\mathrm{Zr}, 340 ; \mathrm{Sm}, 9 ; \mathrm{Y}, 70 ; \mathrm{Yb}$, 8 ( $\mathrm{K}_{2} \mathrm{O}$, in weight percent; others, in parts per million). The $\mathrm{Yb}$ value is incorrectly reported as 80 in Pearce and others (1984, table 3). ing source materials and evolutionary histories of the rhyolites in each setting. In the next section, we assess the usefulness of tectonomagmatic discrimination diagrams for silicic rocks, using some standard variation diagrams and plots based on stable traceelement abundances.

\section{TECTONOMAGMATIC DISCRIMINATION DIAGRAMS}

\section{ASSESSMENT OF STANDARD VARIATION DIAGRAMS}

The $\left(\mathrm{Na}_{2} \mathrm{O}+\mathrm{K}_{2} \mathrm{O}\right)$ content versus $\mathrm{SiO}_{2}$ content for obsidians, as shown in figure 10 , are plotted with respect to the fields for tholeiitic, high- $\mathrm{Al}_{2} \mathrm{O}_{3}$, and alkalic basalt series of Kuno (1966), although these fields are shown for reference only and carry no implication that the rhyolites are necessarily parts of differentiation sequences involving basaltic members. The plot demonstrates two points relevant to the relation between rhyolite chemistry and crustal maturity. (1) The obsidians show narrower ranges, in terms of total alkalis, in more sialic settings. Island-arc rocks are present in all three fields, continental-margin rocks plot in the alkalic and high-alumina fields, and the continental-interior rhyolites are mostly restricted to the alkalic field. (2) The proportions of each rhyolite type in the three series also vary widely, as the following tabulation stresses.

\begin{tabular}{|c|c|c|c|}
\hline \multirow[b]{2}{*}{ Obsidian group } & \multicolumn{3}{|c|}{ Number of specimens in each series } \\
\hline & Tholeiitic & High- $\mathrm{Al}_{2} \mathrm{O}_{3}$ basalt & Alkalic \\
\hline $\begin{array}{l}\text { Primitive island } \\
\operatorname{arcs}(\mathrm{I})\end{array}$ & 6 & - & - \\
\hline $\begin{array}{l}\text { Mature island } \\
\operatorname{arcs}(I I)\end{array}$ & 18 & 31 & 10 \\
\hline $\begin{array}{l}\text { Continental } \\
\text { margins (III) }\end{array}$ & - & 41 & 78 \\
\hline $\begin{array}{l}\text { Continental } \\
\text { interiors (IV) }\end{array}$ & - & 7 & 99 \\
\hline $\begin{array}{l}\text { Oceanic extensional } \\
\text { zones }(V)\end{array}$ & 2 & 5 & 17 \\
\hline
\end{tabular}

In a crude way, therefore, the arrow shown in figure 10 indicates the trend of increasingly sialic crust. Major exceptions are the rhyolites of oceanic extensional zones, the majority of which plot in the alkalic field and were emplaced on basaltic crust.

Use of the $\left(\mathrm{Na}_{2} \mathrm{O}+\mathrm{K}_{2} \mathrm{O}\right)$ versus $\mathrm{SiO}_{2}$ plot as a tectonomagmatic discrimination diagram is limited. Rocks from four rhyolite groups plot within the alkalic field; trace-element plots much more successfully separate these groups. The diagram can be used as an indicator of crustal type in a partly negative 
way, for example, rocks that plot below the alkalichigh alumina boundary are not likely to have originated in a within-plate continental setting, and rocks that plot below the high alumina-tholeiite line are not likely to have a substantial sialic component.

Increasing maturity of orogenic zones, expressed in terms of crustal thickening and increasingly sialic character, is matched by an evolution of the associated volcanism from low- $\mathrm{K}$ tholeiitic rocks to complex associations of tholeiitic, calc-alkalic, and alkalic rocks with chemical variations both along the zone and with vertical height within the stratigraphic sequence. This compositional evolution is often most notable in potassium and related elements, and certain workers (for example, Jakes and Gill, 1970; MacKenzie and Chappell, 1972; Peccerillo and Taylor, 1976) have employed $\mathrm{SiO}_{2}$ versus $\mathrm{K}_{2} \mathrm{O}$ plots as a simple classification scheme for orogenic volcanic rocks. Thus, Peccerillo and Taylor (1976) have recognized low-K, calc-alkalic, and high- $\mathrm{K}$ series on the basis of arbitrary boundaries on a $\mathrm{K}_{2} \mathrm{O}-\mathrm{SiO}_{2}$ plot.

Ewart (1979) divided rhyolites, which he defined as having $\mathrm{SiO}_{2} \geq 69$ percent by weight, into a series of regional groupings based on geography and (or) tectonic setting. The data were further divided into low-K, calc-alkalic, and high-K types (fig. 11) using chemical subdivisions slightly modified from those of Peccerillo and Taylor (1976). Obsidian data plot in the three fields as follows:

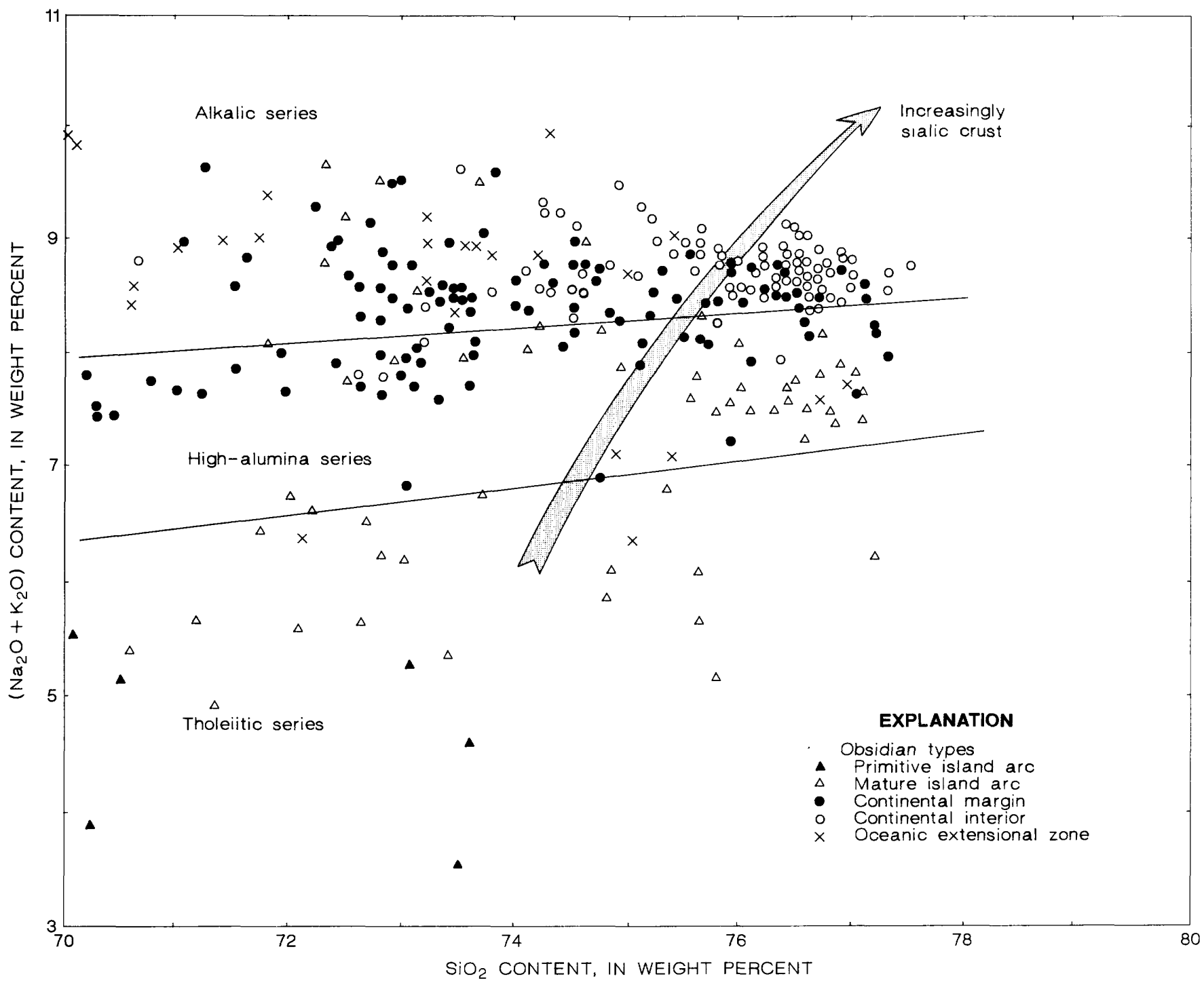

Figure 10.- $\mathrm{SiO}_{2}$ content versus $\mathrm{Na}_{2} \mathrm{O}+\mathrm{K}_{2} \mathrm{O}$ content showing distribution of obsidians in fields of tholeiitic, high-alumina, and alkalic basalt series of Kuno (1966). Data from appendixes I, III, and V (samples A, C-G). 


$\begin{array}{lccc}\text { Obsidian group } & \text { Low-K } & \text { Calc-alkalic } & \text { High-K } \\ \text { Primitive islands arc (I) --.-- } & 4 & 2 & - \\ \text { Mature island arc (II) --.-.-.- } & 3 & 21 & 36 \\ \text { Continental margins (III) --- } & - & 19 & 94 \\ \text { Continental interiors (IV) -.- } & - & - & 93 \\ \begin{array}{l}\text { Oceanic extensional } \\ \quad \text { zones (V) --.-.- }\end{array} & - & 10 & 14 \\ \quad\end{array}$

Percent of total -a--a- $\quad 2.4 \quad 17.6 \quad 80.0$

The data broadly confirm Ewart's (1979) conclusions, namely, that with increasingly mature crustal type, the ratios of the number of samples of high-K to calc-alkalic and of calc-alkalic to low- $K$ rhyolites increase. The $\mathrm{K}_{2} \mathrm{O}$ versus $\mathrm{SiO}_{2}$ plot is useful as a very general indication of crustal type, though it has severe limitations; for example, the extensive overlap of continental-margin and continental-interior rocks.

As a classification scheme for silicic rocks, the plot is less satisfactory for two main reasons. First,

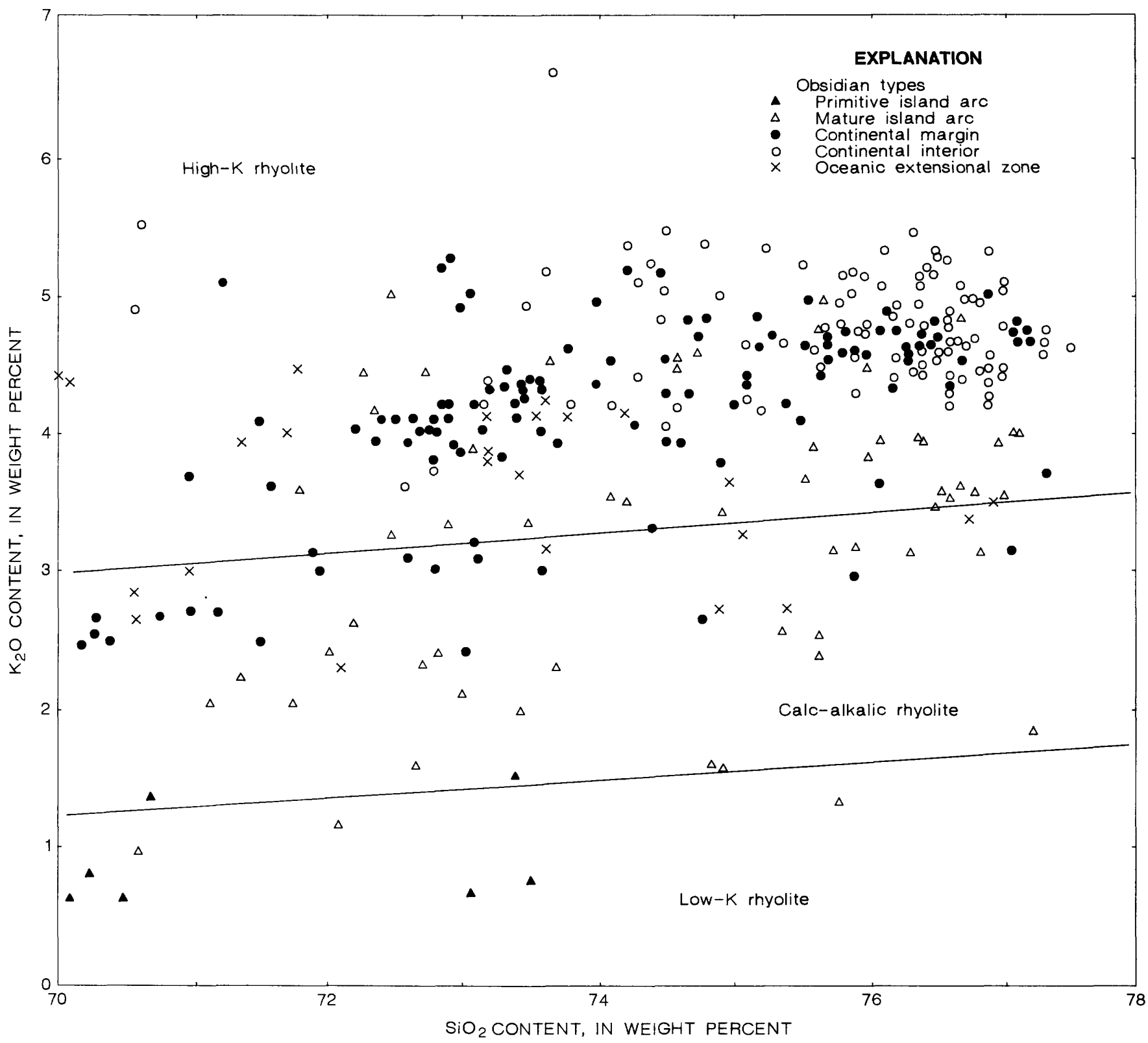

Figure 11.- $\mathrm{SiO}_{2}$ content versus $\mathrm{K}_{2} \mathrm{O}$ content of obsidians in fields of high-potassium, calc-alkalic, and low-potassium rhyolites of Ewart (1979). Data from appendixes I, III, and V (samples A-G). 
it may produce ambiguities with existing terminologies. Most obsidians from the continental margin of the Western United States plot in the high-K field, whereas others, such as Crater Lake and South Sister, plot in the calc-alkalic field. Yet, in Peacock's (1931) scheme, the former rocks are calcalkalic and the latter calcic. Second, and more importantly, the plot brings together rhyolites of quite different character, although they were generated in different settings. Thus, the term high-K rhyolite would be applicable to an Icelandic rhyolite and to one from the Yellowstone complex, rocks which are totally dissimilar in terms of traceelement chemistry. More generally, the mobility of alkalis during low-temperature alteration processes renders this plot possibly misleading for older, crystalline rocks and hydrated glasses.

In view of these restrictions, we prefer not to use the $\mathrm{K}_{2} \mathrm{O}-\mathrm{SiO}_{2}$ plot for classificatory purposes, even on an informal basis.

A plot of $\log _{10} \mathrm{CaO} /\left(\mathrm{Na}_{2} \mathrm{O}+\mathrm{K}_{2} \mathrm{O}\right)$ versus $\mathrm{SiO}_{2}$ (fig. 12) uses as its basis Peacock's (1931) method for classifying igneous rock suites. It has been employed in various forms by Christiansen and Lipman (1972), Petro and others (1979), and Brown $(1979,1982)$ mainly to classify igneous rocks and to identify tectonic environment. Brown (1982) presents the plot to show that with increasing maturity of arc systems, the $\mathrm{CaO} /\left(\mathrm{Na}_{2} \mathrm{O}+\mathrm{K}_{2} \mathrm{O}\right)$ ratio of the volcanic suites becomes lower, at given $\mathrm{SiO}_{2}$ content, as the proportions of calcic to calc-alkalic and calc-alkalic to alkali-calcic suites become smaller. The averages for each of the main rhyolite groups show this overall trend very clearly. There is, however, considerable overlap between groups, and the diagram is not an entirely successful indicator of tectonic setting. Again, concentrations of alkalis may also be disturbed in ancient rocks and hydrated glasses. Trace-element or combined trace- and major-element plots are more reliable discriminators.

\section{TRACE-ELEMENT DISCRIMINATION PLOTS}

Trace elements show much greater variations in abundance than major elements in obsidians from different tectonic settings (table 7) and thus provide better discrimination. The use of stable trace elements, that is, those believed to be immobile during metamorphism and (or) low-temperature alteration (Pearce and others, 1984), would make such discriminants particularly applicable to ancient silicic rocks.
A Th-Hf-Ta ternary plot (fig. 13), originally presented by Wood and others (1979), and later slightly modified by Wood (1980), was proposed as a means of tectonomagmatic discrimination. Though much of the discussion in those papers concerned mafic rocks, the diagram was also considered applicable to silicic rocks. Limited data on silicic rocks were available to Wood and his colleagues, however, and here we employ the obsidian data bank to evaluate the diagram's usefulness.

A diagram such as this, based on relative concentrations of elements, is potentially more useful than those using absolute concentrations, for example, $\mathrm{Nb}$ versus $\mathrm{Ta}$ or $\mathrm{Nb}$ versus $\mathrm{FeO}_{\mathrm{t}}$ graphs (see figs. 17, 18), in that the relative amounts are unlikely to change significantly over relatively small $\mathrm{SiO}_{2}$ intervals. Thus, it is not critical to know the original absolute, magmatic $\mathrm{SiO}_{2}$ content before plotting data, a point of much value in the discrimination of altered silicic rocks.

Wood (1980) discriminates rocks from the following tectonomagmatic environments:

$$
\begin{aligned}
& \text { A -----N-type MORB (common or normal MORB) } \\
& \text { B -.--E-type MORB (enriched MORB) and tholeiit- } \\
& \text { ic within-plate basalts and differentiates. } \\
& \text { C -.---Alkaline within-plate basalts and differentiates. } \\
& \text { D ----- Destructive plate-margin basalts and differ- } \\
& \text { entiates. }
\end{aligned}
$$

The relations among these groups and the obsidian terminology of this paper are as follows:

I -----Obsidians of primitive island arcs: $D(H f / T h \geq 3)$.

II -----Obsidians of immature and mature island arcs: D (Hf/Th 23$)$.

III ------Obsidians of continental margins: $D(\mathrm{Hf} / \mathrm{Th} \leq 3)$.

IV -----Obsidians of continental interiors: ?

V -.-.-Obsidians of oceanic extensional zones: $\mathrm{B}$ or $\mathrm{C}$, depending on affinity of volcanic center.

Group IV obsidians are the most difficult to fit into Wood's (1980) groups. They are "within-plate" and commonly associated with tholeiitic or alkaline basalts, in which case fields $B$ and $C$ might seem appropriate. However, it is by no means certain that they are differentiates of the associated basalts. In fact, these rhyolites occupy their own field on the Th-Hf-Ta diagram. 
The subduction-related rhyolites mostly fall within field D (fig. 13A), except for some continentalmargin rocks whose plotted position might justify a slight adjustment of Wood's (1980) field. Relatively calcic samples plot in more Hf-rich positions, as Wood predicts, and although data are too scarce to be sure, it appears likely that the subdivision of field D marked as "primitive arc tholeiites (and differentiates)" at $\mathrm{Hf} / \mathrm{Th}=3$ is also justifiable.

Several of the rhyolites from oceanic spreading zones plot within fields $\mathrm{B}$ and $\mathrm{C}$, as expected, but others lie to the left of field $C$. These points may be encompassed by expanding field $\mathrm{C}$, as suggested in figure $13 B$; this adjusted field, showing little overlap with adjacent fields, defines tectonic setting rather accurately. Important exceptions are the Salton Sea obsidians, noted earlier as having chemical features transitional between oceanic extensional zones and continental margin. The relatively high Th contents of these rocks result in their plotting in the continental-margin field.

Apart from an important overlap with field D, it is notable that the obsidians from continental interiors occupy a field on the Hf-Th-Ta diagram, not included by Wood (1980), reflecting the lack of relevant traceelement data prior to the present study.

It is possible, therefore, to modify Wood's diagram to produce three tectonomagmatic fields: subductionrelated, oceanic extensional, and continental interior, with an area of overlap between the subductionrelated and continental interior fields (fig. $13 B$ ). The distribution of the obsidian groups within each field is as follows:

Tectonomagmatic field

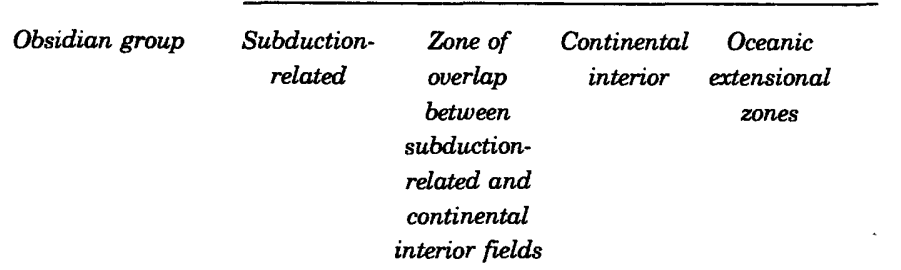

Primitive island

\begin{tabular}{|c|c|c|c|c|}
\hline $\operatorname{arcs}$ & 4 & 0 & 0 & 0 \\
\hline $\begin{array}{l}\text { Mature island } \\
\text { arcs }\end{array}$ & 22 & 4 & 0 & 0 \\
\hline $\begin{array}{l}\text { Continental } \\
\text { margins }\end{array}$ & 24 & 40 & $\mathbf{0}$ & 0 \\
\hline $\begin{array}{l}\text { Continental } \\
\text { interiors - }\end{array}$ & 0 & 45 & 33 & 0 \\
\hline $\begin{array}{l}\text { Oceanic exten- } \\
\text { sional zones ----- }\end{array}$ & 1 & 1 & 0 & 1 \\
\hline
\end{tabular}

Compared to the $\mathrm{Nb}-\mathrm{Ta}$ and $\mathrm{Nb}-\mathrm{FeO}_{\mathrm{t}}$ diagrams (see figs. 17, 18), the Hf-Th-Ta diagram has the disadvantages of being less able to distinguish mature-arc from continental-margin rhyolites and of there being an overlap between subductionrelated and continental-interior types. On the other hand, it is less sensitive to major-element variations, especially $\mathrm{SiO}_{2}$ content, and, thus, is applicable to a wider range of altered rocks.

A plot of $\log R b / \mathrm{Zr}$ versus $\mathrm{Nb}$ content (fig. 14) was used by Brown and others (1984) in their discussion of the geochemical characteristics of granites from various subduction-related settings. It utilizes the fact that though $\mathrm{Rb}$ and $\mathrm{Nb}$ both show striking increases in silicic rocks emplaced in increasingly sialic crust, $\mathrm{Zr}$ is less variable (table 7). The plot of obsidian data in figure 14, showing arbitrary field boundaries, is only partially successful as a discrimination diagram. There is almost complete overlap of mature- . island-arc and continental-margin rocks and substantial overlap of continental-margin and continental interior rocks. Eighteen specimens are incorrectly classified on the plot.

A possible problem regarding application to granites and crystallized and hydrated rhyolites is that $\mathrm{Rb}$ can be a mobile element, thus affecting the $\mathrm{Rb} / \mathrm{Zr}$ ratio.

Pearce and others (1984) have used various combinations of the elements $\mathrm{Rb}, \mathrm{Y}, \mathrm{Yb}, \mathrm{Ta}$, and $\mathrm{Nb}$ for tectonic discrimination of granites. Here we plot the obsidian data on two of their diagrams: Rb versus $(\mathrm{Y}+\mathrm{Nb}$ ) (fig. 15) and $\mathrm{Ta}$ versus $\mathrm{Yb}$ (fig. 16). The $\mathrm{Rb}-(\mathrm{Y}+\mathrm{Nb})$ plot (fig. 15) is moderately successful at discriminating subduction-related obsidians from continental-interior and oceanic-extensional-zone obsidians, chiefly a result of the higher $\mathrm{Nb}$ values in the latter two groups. Higher $\mathrm{Rb}$ concentrations in continental-interior rocks effectively separate them from those of the oceanic extensional zones. However, there is considerable overlap between the subduction-related and continental-interior data;

Figure 12.- $\mathrm{SiO}_{2}$ content versus $\log _{10} \mathrm{CaO} /\left(\mathrm{Na}_{2} \mathrm{O}+\mathrm{K}_{2} \mathrm{O}\right)$ for obsidians, showing changes associated with generation in increasingly sialic crust. Large circled symbols are averages for each rhyolite group; rhyolites of mature island arcs are subdivided into calcic (subscript $C$ ) and calcalkalic (subscript CA) varieties. Field of normal calc-alkalic rock series is from Brown (1982, fig. 2). Data from appendixes I, III, and V (samples A-G). For simplicity, individual data points for obsidians of oceanic extensional zones are not shown. 


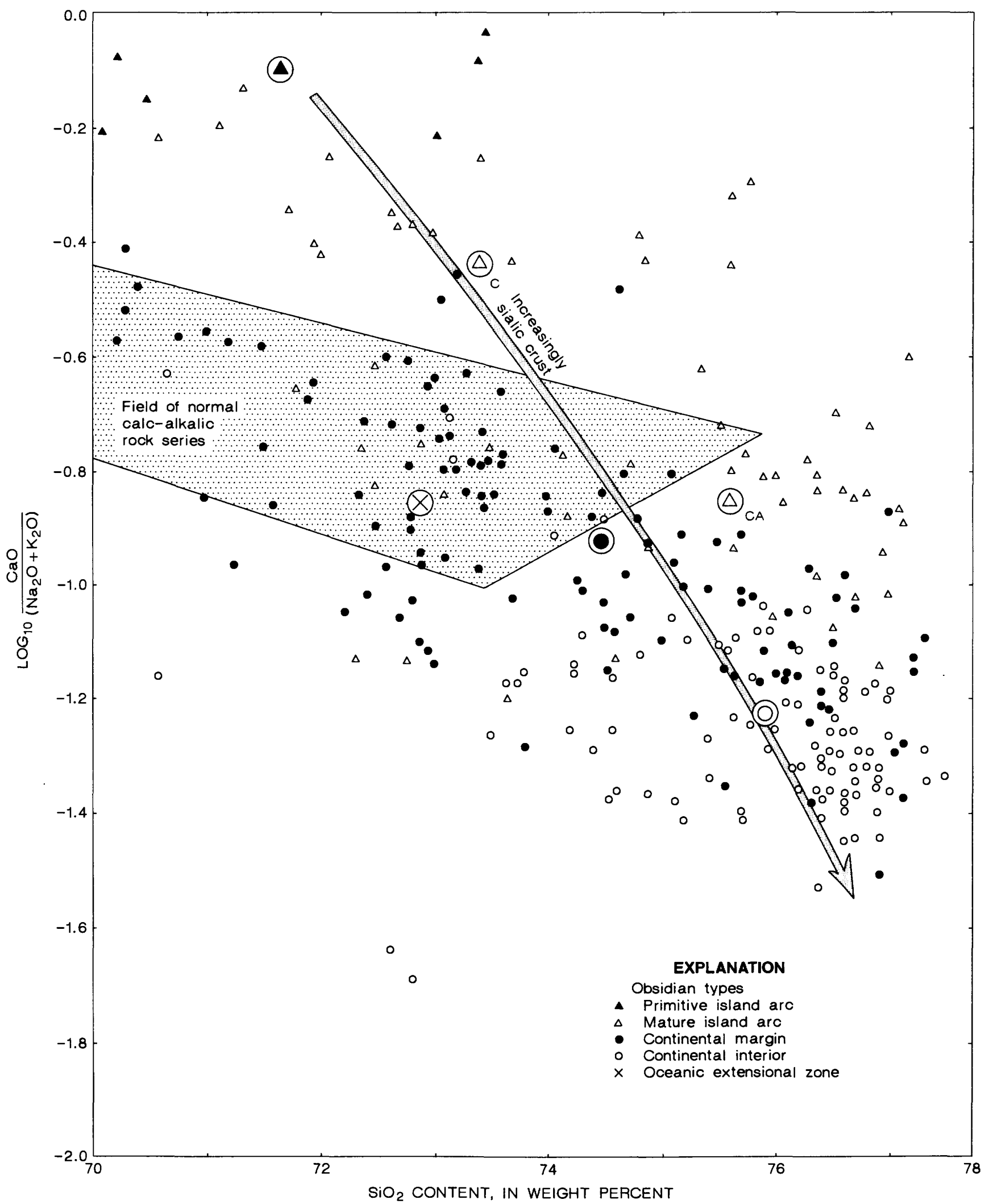


27 specimens plot in inappropriate fields using Pearce and others' (1984) boundaries. The applicability of this plot to crystalline silicic rocks is also limited by possible mobility of $\mathrm{Rb}$.

The Ta-Yb plot (fig. 16) is of limited value, mainly because $\mathrm{Yb}$ abundances show similar ranges in all the obsidian groups. Subduction-related obsidians plot in all four fields on the diagram and obsidians from the continental interiors and oceanic extensional zones are poorly discriminated. A total of 34 specimens are inappropriately classified.

$\mathrm{Nb}$ and $\mathrm{Ta}$ contents are particularly useful indicators of the tectonic setting of rhyolitic rocks (fig. 17; compare with Pearce and Gale, 1977). Values of

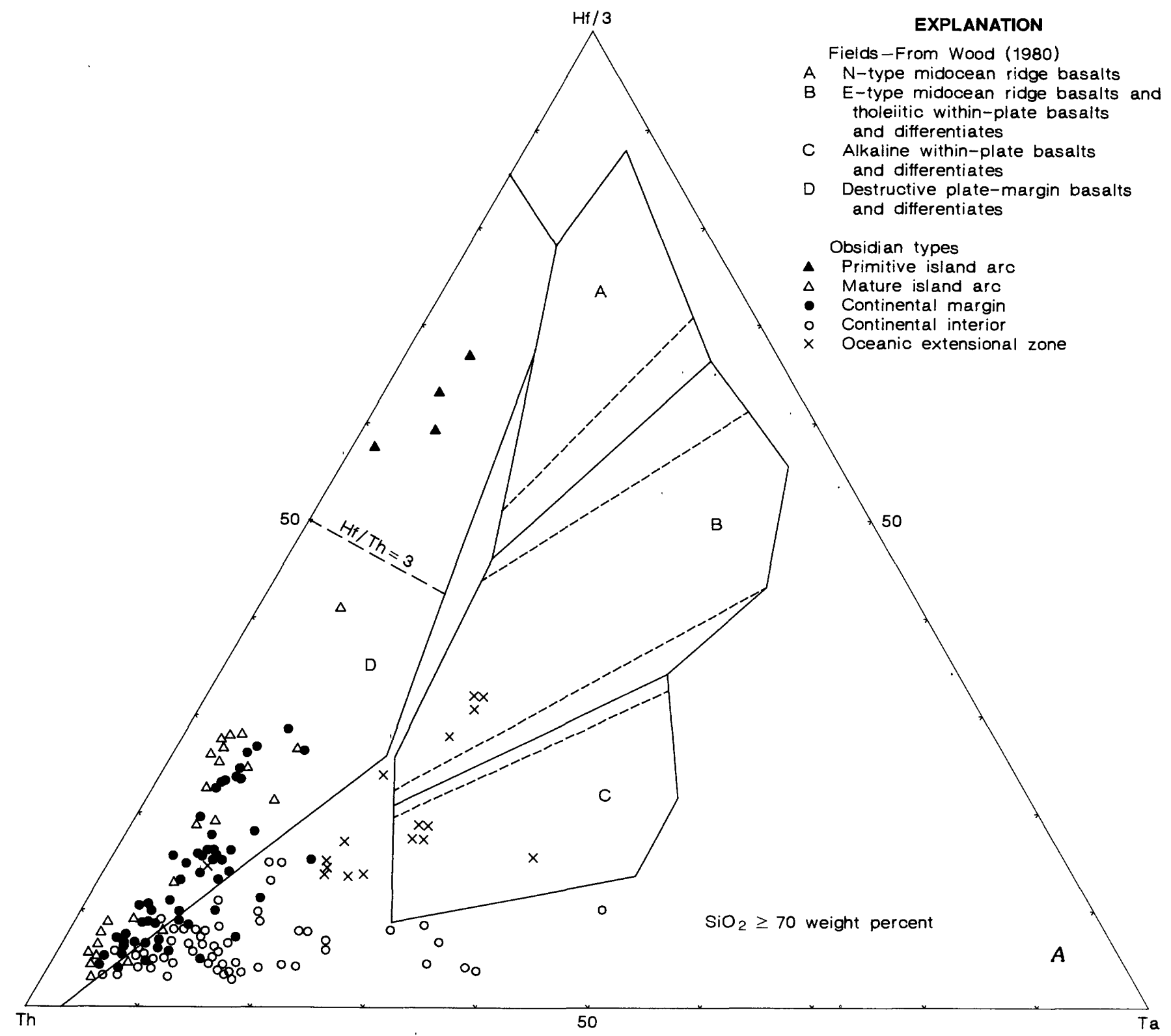

Figure 13.-Obsidian data plotted on $(A)$ hafnium (Hf)-thorium (Th)-tantalum (Ta) discrimination diagram of Wood (1980). Short-dashed lines indicate areas of overlap between fields $A$ and $B$ and fields $B$ and $C$ noted by Wood. Hf/Th ratio of 3 (long-dashed lines) separates rocks of primitive island arcs from those of more mature arcs. Data for primitive island arc rocks from appendix $V$ (samples $F, H, I$, and $J$ ). Ta values were not reported for these specimens and are calculated for this plot by assuming $\mathrm{Nb} / \mathrm{Ta}$ ratio of $15 . B$, Data plotted as in $A$, but with fields redefined for obsidian group classification used herein. 
$\mathrm{Ta}=1.5 \mathrm{ppm}$ and $\mathrm{Nb}=19 \mathrm{ppm}$ have been selected to separate rhyolites of subduction-related settings (lower) from extensional types (higher). Using these values, 161 specimens are, and 9 are not, assigned to the correct category, whereas 8 lie in an overlap zone where the concentration of either $\mathrm{Nb}$ or $\mathrm{Ta}$ is too high or too low for the rock category. We suggest, therefore, that this plot is a useful guide to the tectonic setting of ancient volcanic rocks, in that both elements are unaffected by either low-temperature alteration processes or by low-grade metamorphism. Its application to altered rocks is, of course, dependent on such rocks having magmatic $\mathrm{SiO}_{2} \geq 70$ weight percent, which may not be easily assessed. Its main disadvantage in obsidian studies is that it cannot distinguish continental-interior from oceanic-extensional-zone rhyolites. The latter are, however, notably higher in $\mathrm{FeO}_{\mathrm{t}}$; an $\mathrm{Nb}-\mathrm{FeO}_{\mathrm{t}}$ plot can be used to separate the two groups.

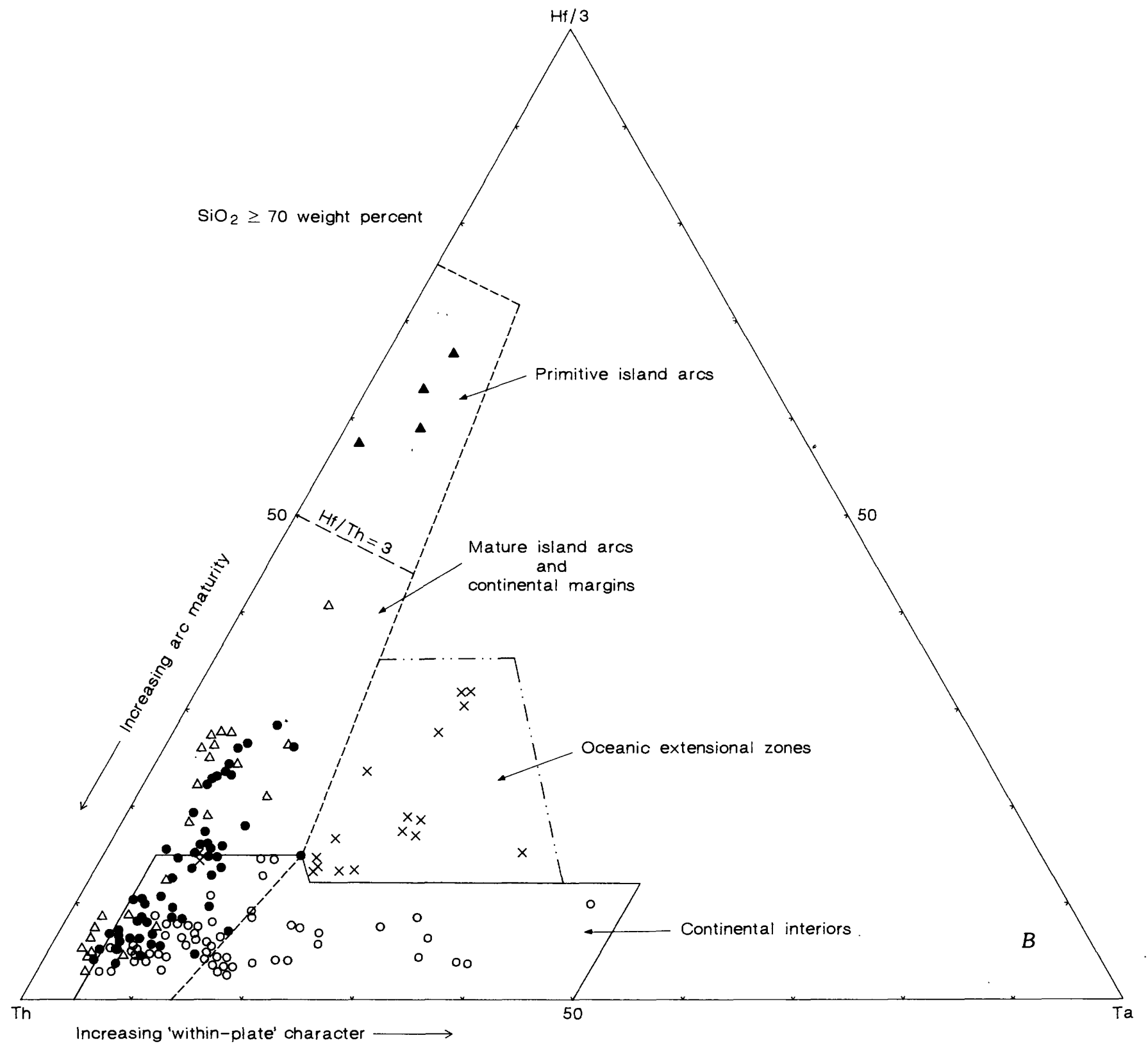

Figure 13.-Continued 
By plotting $\mathrm{Nb}$ versus $\mathrm{FeO}_{\mathrm{t}}$ (fig. 18) the boundaries between the obsidian fields can be estimated. There is a large overlap between the mature-island-arc and continental-margin types and between the continentalmargin and continental-interior types, as shown on the $\mathrm{Nb}-\mathrm{FeO}_{\mathrm{t}}$ plot. Allowing for that overlap, only four obsidians (two from the continental margin and one each from the continental interior and the oceanic extensional zone) plot outside their respective fields.

The combined use of the $\mathrm{Nb}-\mathrm{Ta}, \mathrm{Nb}-\mathrm{FeO}_{\mathrm{t}}$, $\mathrm{Nb}-\mathrm{Rb} / \mathrm{Zr}$, and Th-Hf-Ta plots allows an accurate classification of the subalkaline rhyolitic obsidians in terms of tectonic setting. The least satisfactory discrimination is between continental-margin and mature-island-arc obsidians, but, considering the similarity of the crustal materials, this is probably unavoidable in almost any chemical classification.

The plots may also be used to give a clearer indication of crustal type. It was noted earlier that rhyolites of the Brothers fault zone, Oregon, are chemically transitional between continental-margin and oceanic-extensional-zone types. We suggest that the underlying sialic crust might be substantially

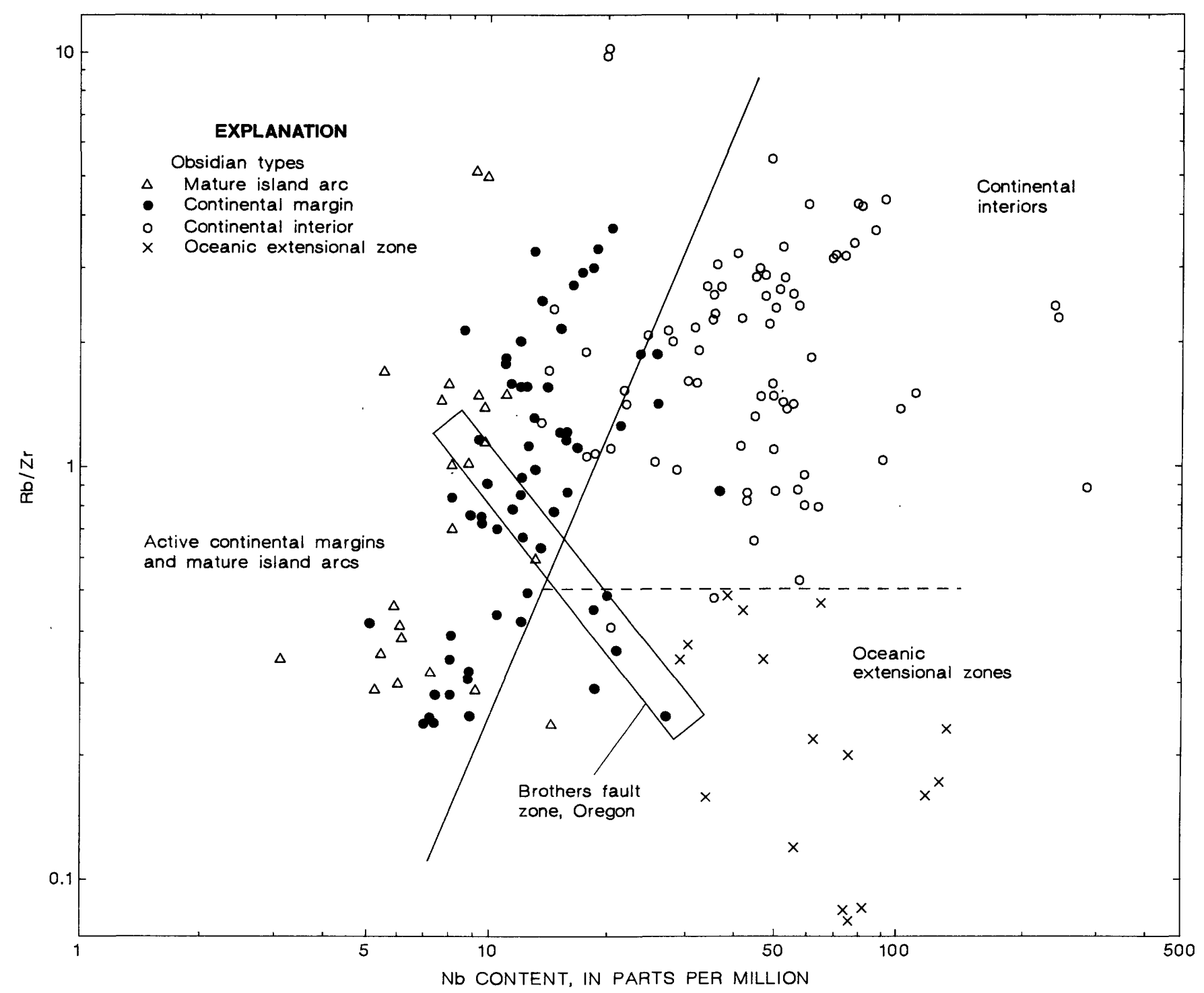

FIGURE 14.- $\mathrm{Nb}$ content versus ratio of $\mathrm{Rb} / \mathrm{Zr}$ showing compositional fields of obsidians. Boundaries are arbitrary. Data from appendix I; sample 160 is omitted to preserve scale. Rectangle encloses obsidians of Brothers fault zone, Oregon. Rocks from primitive island arcs are omitted because of uncertainties of some $R b$ values. 


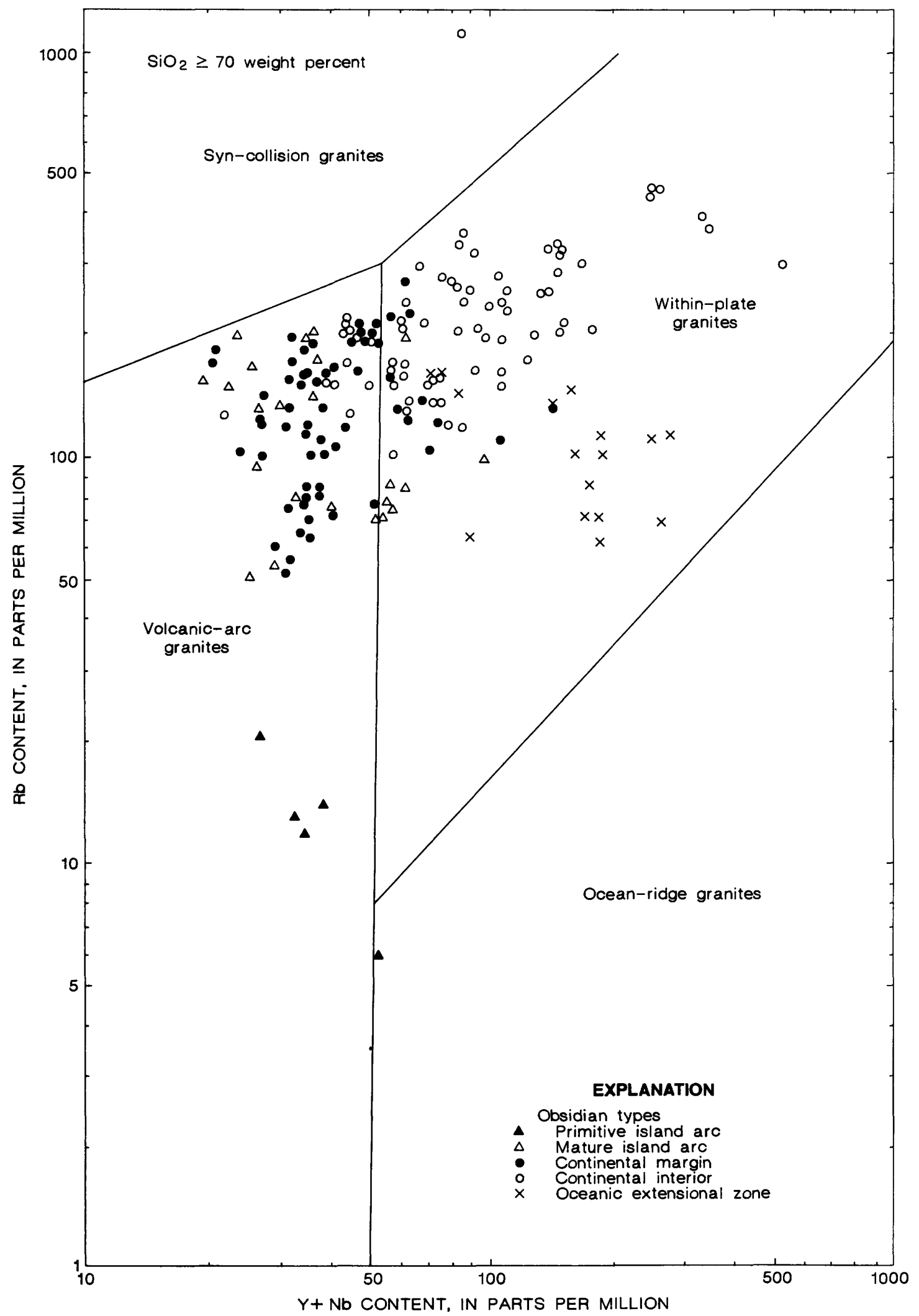

Figure 15. $-\mathrm{Y}+\mathrm{Nb}$ content versus $\mathrm{Rb}$ content for obsidian groups on discriminant plot devised by Pearce and others (1984) for granites. Data from appendix I. 
modified by the intrusion of mafic magmas. The multi-component nature of the obsidians is well shown on the $\mathrm{Nb}-\mathrm{Rb} / \mathrm{Zr}$ plot (fig. 14). Using the obsidian field boundaries from figure 18 , a $\mathrm{Nb}-\mathrm{FeO}_{\mathrm{t}}$ plot (fig. 19) shows that Salton Sea obsidians straddle the boundary between the oceanic-extensional-zone and continental-margin/continental-interior fields, consistent with their tectonic setting. The three Nevadan specimens classified as continental-margin types (based on their location west of the craton and affinity to Oregon subprovince types), although geographically in the continental interior, plot in the continental-margin field.

Rocks from the island of Mull in the British Tertiary province are used (fig. 19) to show the potential application to granites. The igneous centers of this province lie on mafic dike swarms, the activity possibly representing continental attenuation during aborted attempts to open the Atlantic Ocean. Many of the mafic rocks have been shown on isotopic

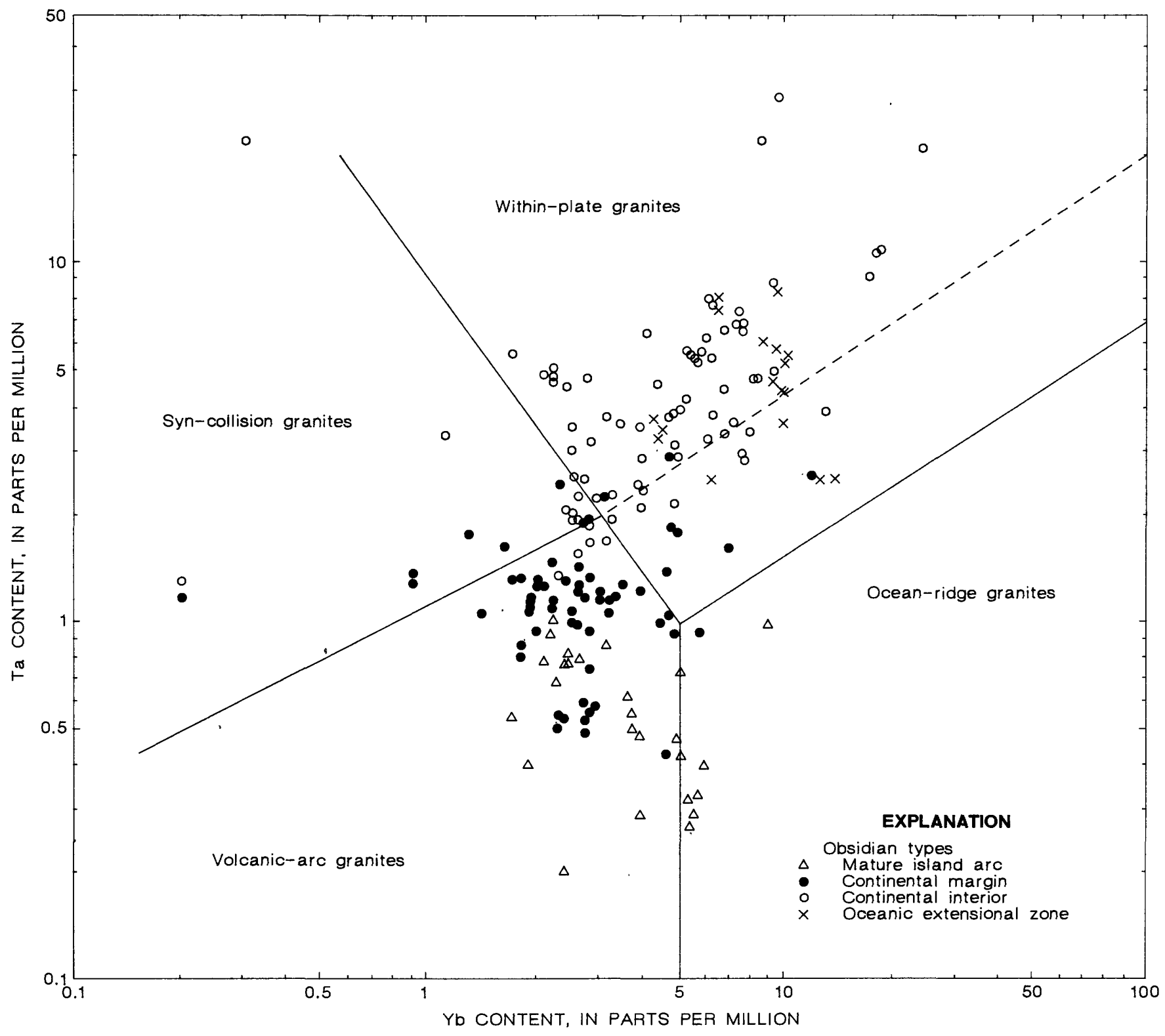

Figure 16.-Yb content versus Ta content for obsidian types. Fields were determined by Pearce and others (1984) for granites. Dashed line is upper compositional boundary for ocean-ridge granites from anomalous ridge segments. Data from appendix I. 
and trace-element grounds to have been contaminated with $\mathrm{Nb}$-poor, granulitic-facies rocks. The Mull granites straddle the oceanic-extensional-zone continental-margin boundary, consistent with derivation from mantle- and crustal-derived components.

The geological potential of these tectonomagmatic discrimination plots is considerable. For example, they might be used to trace, via the silicic igneous rocks, the development of cratonic areas from island-arc terrains and to record periods of crustal attenuation and fracturing which may not be decipherable from structural, stratigraphic, or geophysical evidence. Such studies are complementary to isotopic studies, for example DePaolo and Farmer's (1984) regional survey

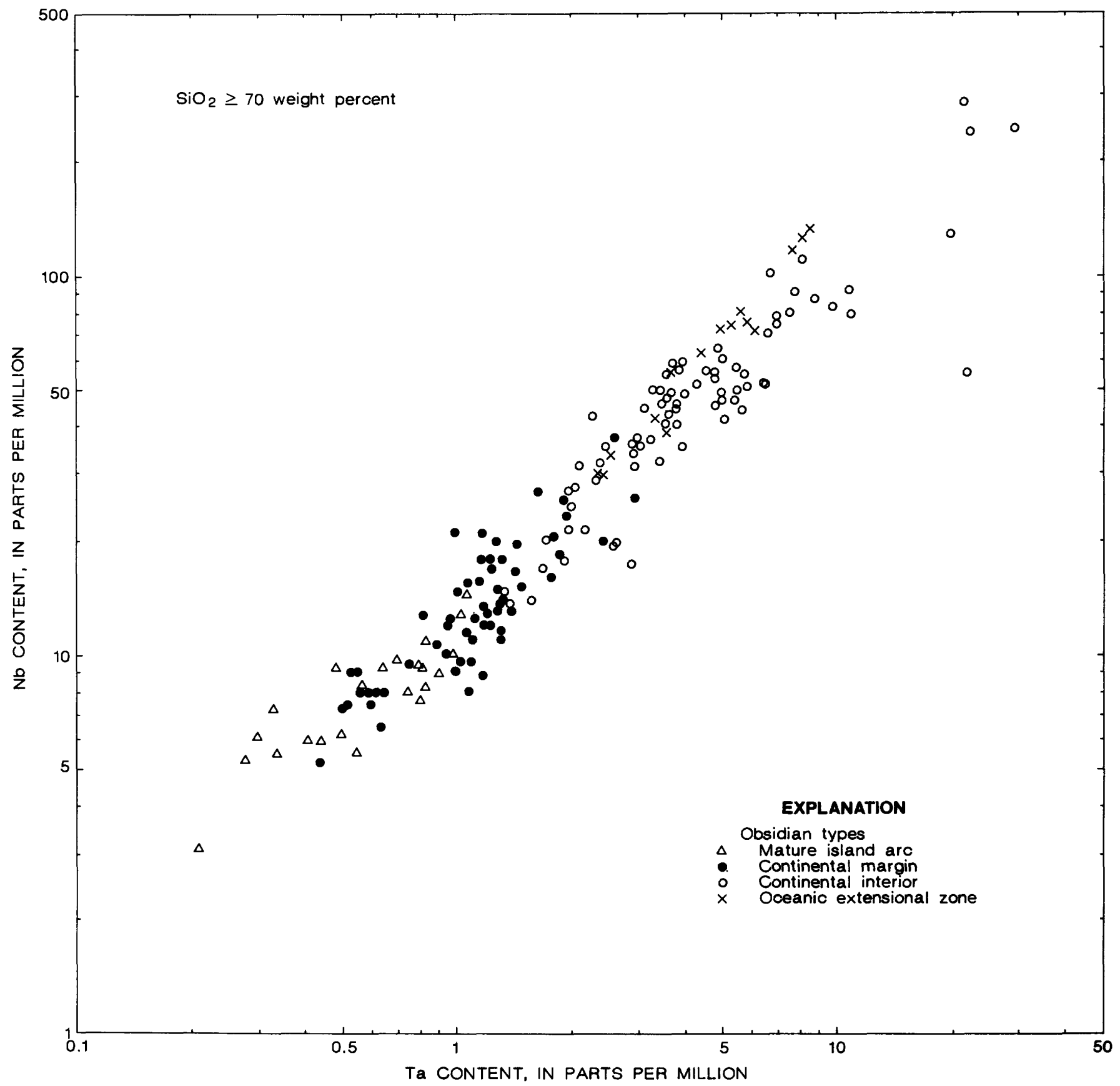

FIGURE 17.- Ta content versus $\mathrm{Nb}$ content in obsidians. These elements successfully distinguish subduction-related from within-plate types. Data from appendixes I and IV. 
of initial $\mathrm{Sr}$ and $\mathrm{Pb}$ isotopic compositions of granitic rocks in the Western United States, which showed that magma sources can be inferred from the systematic geographical variability of the $\mathrm{Nd}$ data in particular.

\section{GEOCHEMICAL FEATURES OF MAIN OBSIDIAN GROUPS}

\section{GROUP I: OBSIDIANS FROM PRIMITIVE ISLAND ARCS}

There is a noticeable lack of data on obsidians from primitive island arcs. The only sample available to us was a partially hydrated pumice (No. 220 , appendix II) from the South Sandwich Islands
(Gass and others, 1963). This rock is young, however, and its composition has probably been modified very little by hydration. Data are available in the literature for the residual glass of the Metis Shoal dacite (Melson and others, 1970; Ewart and others, 1973) and for recent pumices from Eua (Tonga) and Herald Cays, Queensland (Bryan, 1968,1971 ). We have also made use in table 7 of apparently glassy specimens from Deception Island (Weaver and others, 1979) and Curtis Island, Kermadec Islands (Ewart and others, 1977), and of a partial analysis of an obsidian from Tafahi, Tonga (Smith and others, 1977).

To aid discussion, selected published analyses of devitrified and (or) secondarily hydrated rhyolites

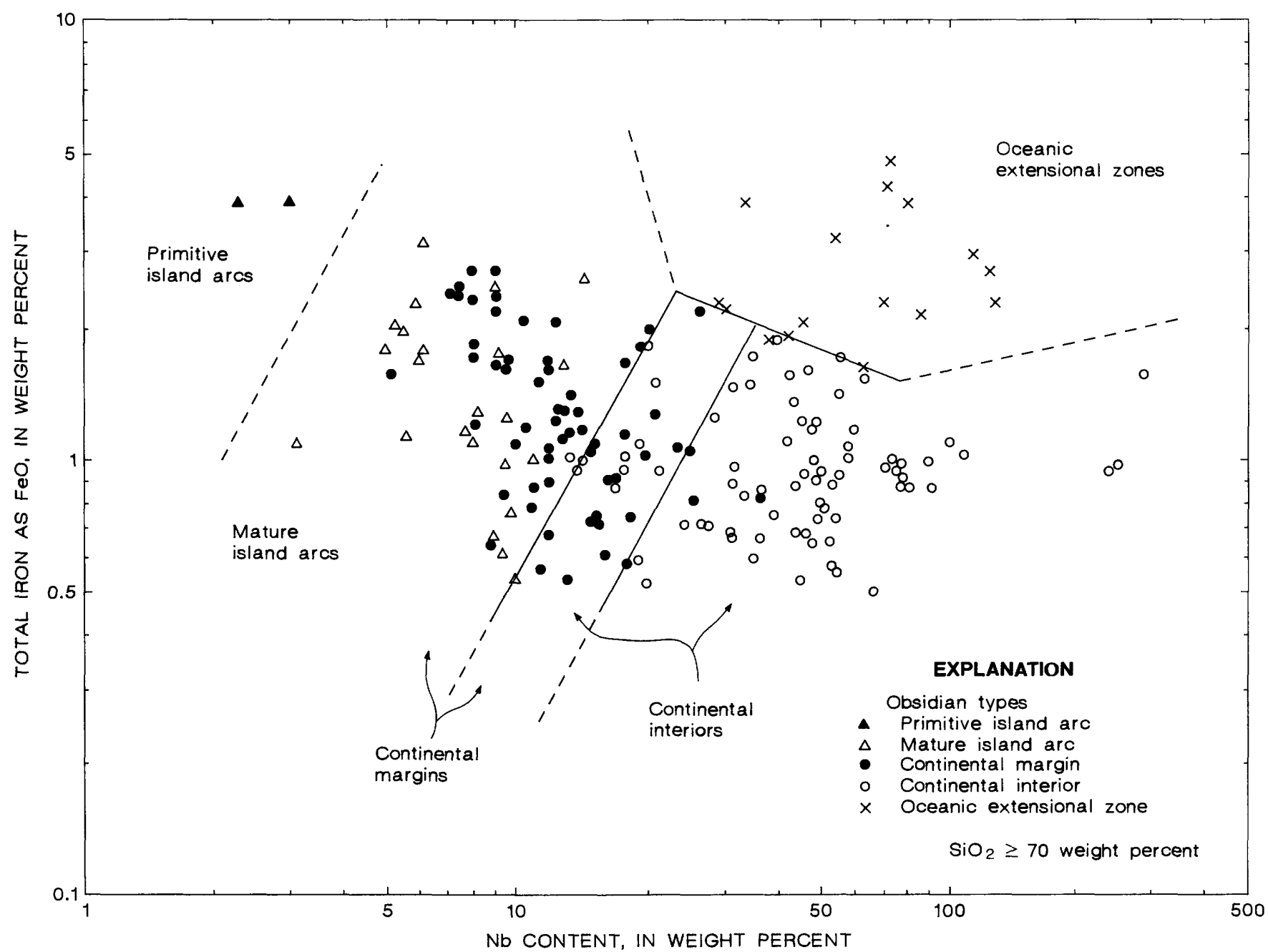

FIGURE 18.- Nb content versus total iron (as $\mathrm{FeO}$ ) showing compositional fields of various obsidian groups. Fields were drawn by eye and dashed where uncertain. Note clear separation of continental interior from oceanic extensional zone types. Data from appendixes I and V (samples D and G). 
are given in appendix $\mathrm{V}$, but these have not been included in any computations or diagrams.

A further problem is that many critical elements occur in very low abundance in primitive-arc rhyolites, thus creating severe analytical problems. For example, we do not have satisfactory values for $\mathrm{Ta}$ in the South Sandwich pumice (No. 220).

The rhyolites share the diagnostic chemical features of the association, namely, low contents of $\mathrm{K}_{2} \mathrm{O}, \mathrm{Nb}, \mathrm{Rb}, \mathrm{Ta}, \mathrm{Th}$, and $\mathrm{U}$. The values of $10 \mathrm{ppm}$ $\mathrm{Nb}$ and $4 \mathrm{ppm}$ Th obtained for Tafahi obsidian by Smith and others (1977) are probably too high. REE contents are low and the chondritenormalized REE patterns are characteristically flat, with Eu anomalies ${ }^{2}$ either absent or small and negative. $\mathrm{K} / \mathrm{Rb}$ ratios up to 1619 have been recorded from hydrated specimens, but such ratios almost certainly reflect $\mathrm{Rb}$ leaching. The relatively pristine rocks have a range of 385 to 781 , which, although high in relation to other rhyolite groups, are in line with high $\mathrm{K} / \mathrm{Rb}$ ratios in other members of the association (Baker, 1982). As noted by Donnelly and Rogers (1980), $\mathrm{Th} / \mathrm{U}$ ratios are unusually low in these rocks, values less than 2 being common. $\mathrm{Zr} / \mathrm{Hf}$ ratios are variable, four

2Eu anomalies are measured by $\mathrm{Eu} / \mathrm{Eu}^{*}$, where $\mathrm{Eu}^{*}$ is the chondrite-normalized Eu abundance calculated assuming a smooth REE pattern between Sm and Gd.

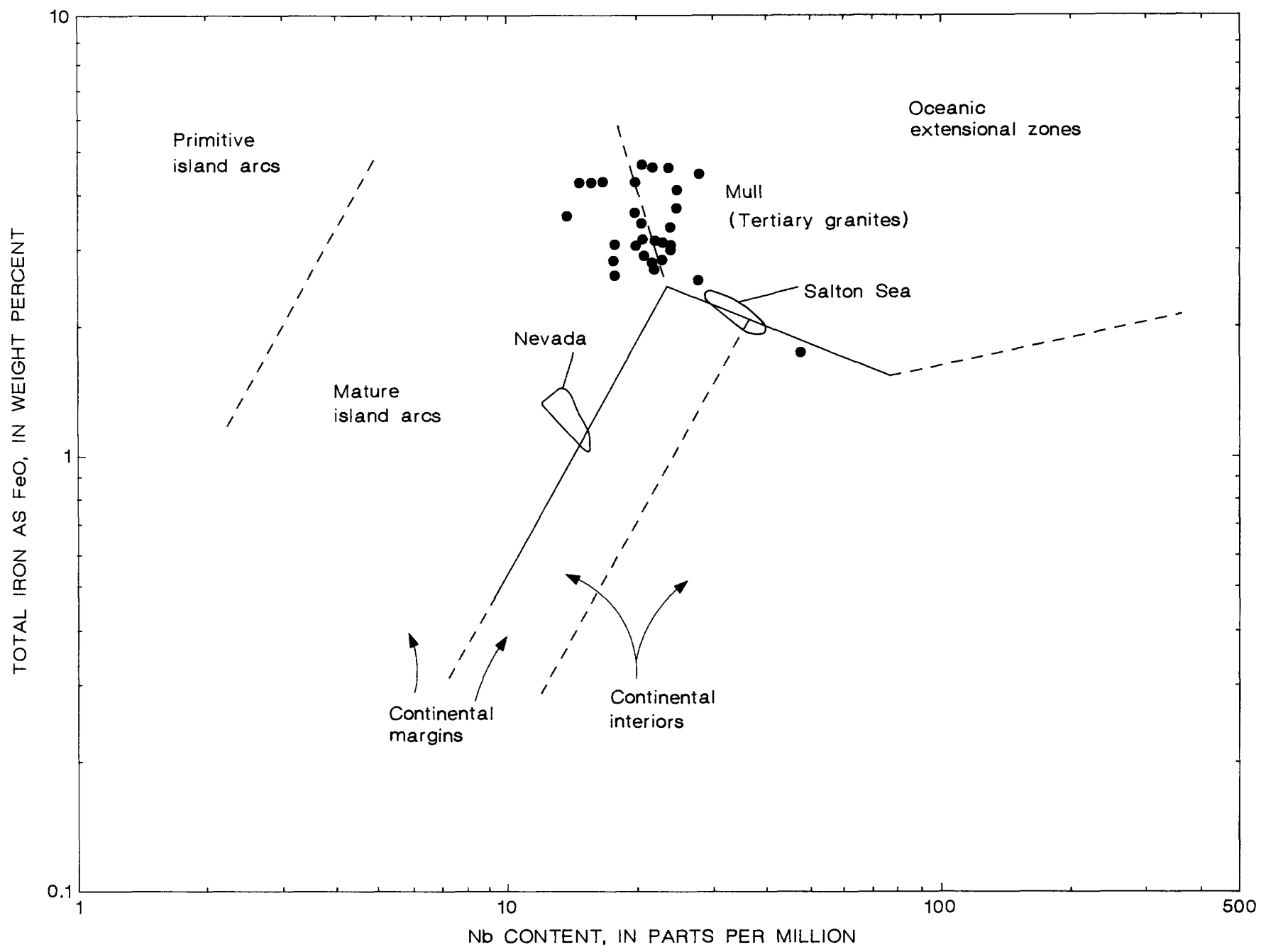

Figure 19.-Nb content versus total iron (as $\mathrm{FeO}$ ), with boundaries between obsidian fields taken from figure 18. Fields of Salton Sea and Nevadan obsidian data from appendix I (samples $73-75$ and $76-79$, respectively).
Data for Mull granites from Walsh and others (1979). This plot illustrates the application of the $\mathrm{Nb}-\mathrm{FeO}_{\mathrm{t}}$ diagram for additional insight into tectonomagmatic discrimination for specific data sets. 
samples range from 36 to 68 . Three of these are from Undu, Fiji, and vary from 41 to 68 ; however, analytical imprecision at low levels of $\mathrm{Hf}$ may be suspected. The values of $\mathrm{Nb} / \mathrm{Ta}$ and $\mathrm{Zr} / \mathrm{Hf}$ ratios in the rhyolitic magmas have not yet been established, although we have no reason to suspect that the $\mathrm{Zr} / \mathrm{Hf}$ ratio (36) of our sample 220 is an abnormal ratio.

High $\mathrm{SiO}_{2}$ values recorded from certain nonglassy rhyolites of this group are noteworthy; for example, on Undu, Fiji, values approaching 80 percent have been recorded (Gill and Stork, 1979). Petrographic evidence of silicification of many such specimens makes it clear that those high values are not magmatic. An upper magmatic $\mathrm{SiO}_{2}$ limit for primitivearc rhyolites has not yet been established.

Finally, an overall similarity of this group of rhyolites to oceanic plagiogranites has been recognized (Barker, 1979), though Donnelly and Rogers (1980, p. 353) claim that, in detail, there are important chemical differences between the two groups.

\section{GROUP II: OBSIDIANS FROM MATURE ISLAND ARCS}

Compared with primitive-arc types, the obsidians from more advanced stages of arc development have, on average, notably lower contents of $\mathrm{CaO}$ and $\mathrm{FeO}$ and higher $\mathrm{K}_{2} \mathrm{O}, \mathrm{Ba}, \mathrm{Cs}, \mathrm{Hf}, \mathrm{Nb}, \mathrm{Rb}, \mathrm{Ta}, \mathrm{Th}, \mathrm{U}$, and REE. $\mathrm{Na}_{2} \mathrm{O} / \mathrm{K}_{2} \mathrm{O}$ and $\mathrm{K} / \mathrm{Rb}$ ratios are lower and $\mathrm{Th} / \mathrm{U}$ ratios higher, on average. The average $\mathrm{Rb} / \mathrm{Sr}$ ratio is 0.90 , seven to eight times higher than in primitivearc rhyolites. The REE pattern shows distinct LREE enrichment, the $\mathrm{Ce} / \mathrm{Yb}$ ratio averaging 11.5.

There is notable compositional diversity within the group, the most significant being the division into calcic and calc-alkalic types. The distinction is partly one of differing stages of evolution of individual suites and partly one of genuine intrasuite differences. Averages for both types of mature island-arc rhyolites are given in table 8 . The lower $\mathrm{K}_{2} \mathrm{O}, \mathrm{Ba}, \mathrm{Cs}, \mathrm{Rb}, \mathrm{Ta}, \mathrm{Th}, \mathrm{U}, \mathrm{Zr}$, and LREE contents of the calcic varieties are noteworthy, and these rocks form a chemical, as well as spatial and time, transition between primitive-arc rhyolites and the calc-alkalic rhyolites of the mature-arc systems.

Another notable variant is the high-alkali type of island-arc rhyolite, such as those recorded from the Moresby Strait area, Papua New Guinea, by Smith and Johnson (1981). These have sufficiently high $\left(\mathrm{Na}_{2} \mathrm{O}+\mathrm{K}_{2} \mathrm{O}\right)$ contents that they plot in the alkalic field of Kuno's (1966) alkali-silica diagram and are, in fact, broadly associated with peralkaline varieties.

Their trace-element chemistry unequivocally characterizes them as of mature island-arc type. Consider-
TABLE 8.-Average compositions of calcic and calc-alkalic obsidians from mature island arcs

[First figures in each column calculated using new data only (appendix I); second column using all data (appendixes I, III), -, not determined]

\begin{tabular}{|c|c|c|c|c|}
\hline & \multicolumn{2}{|c|}{ Calcic } & \multicolumn{2}{|c|}{ Calc-alkalic } \\
\hline & $\mathbf{x}$ & $\mathbf{x}_{\mathbf{T}}$ & $\mathbf{x}$ & $\mathbf{x}_{\mathbf{T}}$ \\
\hline $\mathrm{SiO}_{2}-$ & 73.4 & 73.4 & 75.6 & 75.3 \\
\hline $\mathrm{Al}_{2} \mathrm{O}_{3}$ & 13.54 & 13.55 & 13.04 & 13.10 \\
\hline $\mathrm{Fe}_{2} \mathrm{O}_{3}$ & .59 & .80 & .40 & .42 \\
\hline $\mathrm{FeO}$ & 1.83 & 1.48 & .99 & 1.00 \\
\hline MgO & .61 & .64 & .16 & .20 \\
\hline $\mathrm{CaO}$ & 2.38 & 2.63 & 1.10 & 1.09 \\
\hline $\mathrm{Na}_{2} \mathrm{O}$ & 4.24 & 4.09 & 4.10 & 4.17 \\
\hline $\mathrm{K}_{2} \mathrm{O}$ & 2.25 & 2.05 & 3.75 & 3.87 \\
\hline $\mathrm{H}_{2} \mathrm{O}^{+}$ & .16 & .41 & .17 & .27 \\
\hline $\mathrm{TiO}_{2}$ & .39 & .42 & .18 & .19 \\
\hline $\mathrm{P}_{2} \mathrm{O}_{5}$ & .07 & 11 & .02 & .05 \\
\hline MnO & .10 & .09 & .08 & .07 \\
\hline $\mathrm{Cl}$ & .10 & - & .11 & - \\
\hline F - & .05 & - & .05 & - \\
\hline $\mathrm{FeO}_{\mathrm{t}}{ }^{1} \ldots$ & 2.37 & 2.55 & 1.35 & 1.38 \\
\hline $\mathrm{FeO} /\left(\mathrm{FeO}+\mathrm{Fe}_{2} \mathrm{O}_{3}\right)^{1} \ldots$ & .76 & .65 & .71 & .70 \\
\hline $\mathrm{Na}_{2} \mathrm{O} / \mathrm{K}_{2} \mathrm{O}^{1} \ldots$ & 2.15 & 2.27 & 1.13 & 1.11 \\
\hline$\left(\mathrm{Na}_{2} \mathrm{O}+\mathrm{K}_{2} \mathrm{O}\right) / \mathrm{Al}_{2} \mathrm{O}_{3}^{2}$ & .70 & .66 & .83 & .84 \\
\hline$\left(\mathrm{CaO}+\mathrm{Na}_{2} \mathrm{O}+\mathrm{K}_{2}^{2} \mathrm{O}\right) / \mathrm{Al}_{2} \mathrm{O}_{3}^{2}$ & 1.01 & 1.01 & .98 & .99 \\
\hline $\mathrm{CaO} /\left(\mathrm{Na}_{2} \mathrm{O}+\mathrm{K}_{2} \mathrm{O}\right)^{1}$ & .37 & .43 & .14 & .14 \\
\hline $\mathrm{Cl} / \mathrm{F}^{1}$ & 2.0 & - & 2.2 & - \\
\hline 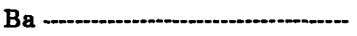 & 521 & - & 664 & - \\
\hline $\mathrm{Be}$ - & 1.3 & - & 1.6 & - \\
\hline $\mathrm{Co}$ & 3.2 & - & .7 & - \\
\hline $\mathrm{Cr}$ & 2.1 & - & 1.1 & - \\
\hline Сs & 2.8 & - & 7.0 & - \\
\hline Hf - & 4.7 & - & 4.8 & - \\
\hline $\mathrm{Li}$ & 27 & - & 27 & - \\
\hline Mo & 2.4 & - & 2.3 & - \\
\hline Nb & 7.0 & - & 8.4 & - \\
\hline $\mathrm{Pb}$ & 16 & - & 21 & - \\
\hline Rb - & 50 & - & 127 & - \\
\hline Sb - & .6 & - & .8 & - \\
\hline $\mathrm{Sc}$ & 12.5 & - & 5.0 & - \\
\hline Sn & 1.4 & - & 2.0 & - \\
\hline $\mathrm{Sr}$ & 183 & - & 111 & - \\
\hline Ta & .41 & - & .65 & - \\
\hline $\mathrm{Th}$ & 4.2 & - & 12.1 & - \\
\hline U & 1.5 & - & 3.3 & - \\
\hline W & 1.1 & - & 1.8 & - \\
\hline Y & 35 & - & 30 & - \\
\hline Zn - & 41 & - & 38 & - \\
\hline Zr & 139 & - & 169 & - \\
\hline La - & 15 & - & 23 & - \\
\hline $\mathrm{Ce}$ & 32 & - & 46 & - \\
\hline Nd - & 19 & - & 22 & - \\
\hline Sm - & 4.5 & - & 5.1 & - \\
\hline Eu & .88 & - & .73 & - \\
\hline$\overline{G d}$ & 4.1 & - & 4.8 & - \\
\hline $\mathrm{Tb}$ & .75 & - & .84 & - \\
\hline $\operatorname{Tm}$ & .52 & - & .55 & - \\
\hline Yb & 3.7 & - & 3.8 & - \\
\hline Lu w & .55 & - & .56 & - \\
\hline $\mathrm{Nb} / \mathrm{Ta}$ & 17.1 & - & 12.9 & - \\
\hline K/Rb & 374 & - & 245 & - \\
\hline $\mathrm{Rb} / \mathrm{Sr}$ & .3 & - & 1.1 & - \\
\hline $\mathrm{Ca} / \mathrm{Sr}$ & 93 & - & 71 & - \\
\hline $\mathrm{Th} / \mathrm{U}$ & 2.8 & - & 3.7 & - \\
\hline Zr/Hf & 30 & - & 35 & - \\
\hline $\mathrm{Ce} / \mathrm{Yb}$ & 8.6 & - & 12.1 & - \\
\hline $\mathbf{E u} / \mathbf{E u}^{*}$ & .62 & - & .46 & - \\
\hline Maximum number & & & & \\
\hline of determinations & 5 & 21 & 21 & 38 \\
\hline
\end{tabular}


able variations also exist in trace-element abundances in arc obsidians from different areas; for example, the Javan samples (Nos. 198-202) are relatively Cs-, Th-, and U-rich. Such features may be either source- or process-controlled and will be explained only after detailed future study of individual suites.

\section{GROUP III: OBSIDIANS FROM THE CONTINENTAL MARGINS}

Although obsidians of the continental margins are very similar to mature-island-arc obsidians, they do have somewhat higher average contents of $\mathrm{K}_{2} \mathrm{O}, \mathrm{Ba}$, $\mathrm{Li}, \mathrm{Mo}, \mathrm{Nb}, \mathrm{Rb}, \mathrm{Sn}, \mathrm{Ta}, \mathrm{Th}$, and $\mathrm{U}$ and lower Sc and $\mathrm{Zn}$. $\mathrm{K} / \mathrm{Rb}$ and $\mathrm{Zr} / \mathrm{Hf}$ ratios are about the same, $\mathrm{Nb} / \mathrm{Ta}, \mathrm{Ca} / \mathrm{Sr}$, and $\mathrm{Th} / \mathrm{U}$ ratios are lower, and $\mathrm{Rb} / \mathrm{Sr}$ ratios higher. The REE patterns are also very similar but, on average, are more LREE-enriched and have a more pronounced negative Eu anomaly.

The continental-margin obsidians contain several chemically distinct subtypes. In the Western United States, for example, at least three such subtypes can be distinguished: (1) Cascades, (2) southeastern Oregon (east of the Cascade Range), and (3) Clear Lake. On a Sr-Th plot (fig. 20), they' occupy minimally

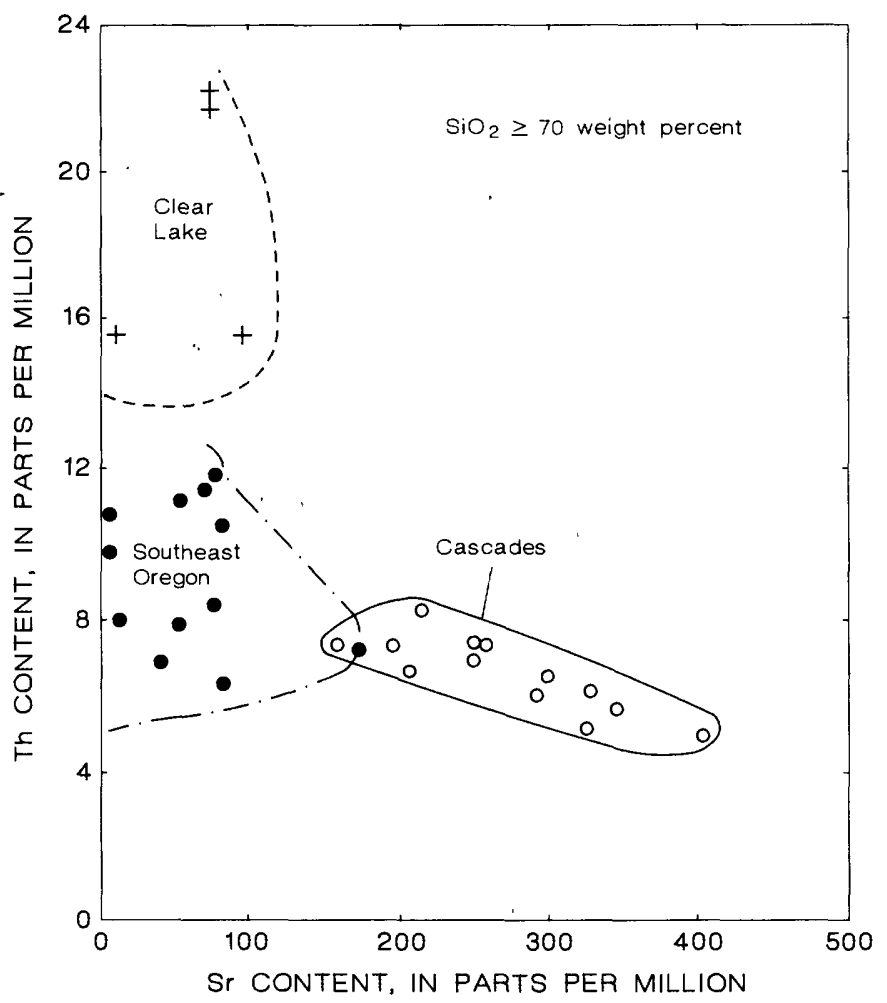

Figure 20,-Sr content versus Th content showing fields occupied by selected subgroups of obsidians of the Western United States continental margin. Data from appendix I. Specimens: Clear Lake, 45-48; southeastern Oregon, 22-28 and 30-34; Cascades, 8-10 and 12-21. overlapping fields. Other distinguishing features include the higher $\mathrm{Cs}$ contents of the Clear Lake rocks and the relatively high $\mathrm{Nb}$ and $\mathrm{Ta}$ contents of many of the Oregon subtype specimens.

These differences are partly $\mathrm{SiO}_{2}$-dependent; the chemical distinctions would be minimized at equivalent $\mathrm{SiO}_{2}$ contents. Partly also, they are related to tectonic setting. The Cascades volcanoes are genuinely subduction-related types, variably developing on thick prisms of Mesozoic geosynclinal sedimentary and volcanic rocks (for example, Lassen and Shasta) or on crust which is possibly partly of oceanic type (for example, Crater Lake and South Sister). The Oregon subtype rocks were erupted in extensional settings within the continental margin, in areas of thinned lithosphere which may be at least partly of oceanic type. Compositionally, they are a disparate set of rocks which contrast with other margin systems in having peralkaline associates. The Clear Lake complex is unique, situated on a transform fault within the continental margin; its relation between chemistry and tectonics, however, is obscure.

Minor- and trace-element compositions, with complementary $\mathrm{Nd}-\mathrm{Sr}-\mathrm{Pb}$ isotopic studies, of rhyolites within the continental margins will undoubtedly prove to be important tracers of crustal type and structure, but a full understanding of the mechanisms producing the chemical variations is not yet possible.

\section{GROUP IV: OBSIDIANS FROM THE CONTINENTAL INTERIORS}

Compared to the margin obsidians, the continentalinterior rocks have markedly higher $\mathrm{F}, \mathrm{Be}, \mathrm{Li}, \mathrm{Mo}$, $\mathrm{Nb}, \mathrm{Rb}, \mathrm{Sn}, \mathrm{Ta}, \mathrm{Th}, \mathrm{U}, \mathrm{W}, \mathrm{Zn}$, and REE contents and $\mathrm{FeO} / \mathrm{MgO}$ ratios and lower contents of $\mathrm{MgO}, \mathrm{CaO}, \mathrm{Ba}$, $\mathrm{Co}, \mathrm{Sc}, \mathrm{Sr}$, and $\mathrm{Zr}$. This is the only group to have average $\mathrm{Na}_{2} \mathrm{O} / \mathrm{K}_{2} \mathrm{O}$ and $\mathrm{Cl} / \mathrm{F}$ ratios $<1$. The average $\mathrm{Rb} / \mathrm{Sr}$ ratio is high (10), $\mathrm{K} / \mathrm{Rb}$ ratio low (165), and the $\mathrm{Zr} / \mathrm{Hf}, \mathrm{Th} / \mathrm{U}$, and $\mathrm{Nb} / \mathrm{Ta}$ ratios are lower than in continental-margin obsidians, indicating relative enrichment of the lower abundance element in each ratio. Though both LREE and HREE are higher than in margin types, the interior rhyolite pattern indicates considerably less LREE enrichment and a more pronounced negative $\mathrm{Eu}$ anomaly.

\section{GROUP V: OBSIDIANS FROM OCEANIC EXTENSIONAL SETTINGS}

Certain features of the oceanic-extensional zone obsidians are distinctive. The combination of high $\left(\mathrm{Na}_{2} \mathrm{O}+\mathrm{K}_{2} \mathrm{O}\right)$ and high $\mathrm{CaO}$ contents shown by 
many specimens is rare among the other rhyolite groups. Values of molecular $\left(\mathrm{CaO}+\mathrm{Na}_{2} \mathrm{O}+\mathrm{K}_{2} \mathrm{O}\right) / \mathrm{Al}_{2} \mathrm{O}_{3}$ (1.05-1.20) are among the highest in the data bank, and many rhyolites from this setting are actually peralkaline.

Notable also (table 7) is the combination of high $\mathrm{Hf}, \mathrm{Nb}, \mathrm{REE}, \mathrm{Ta}, \mathrm{Y}$, and $\mathrm{Zr}$ with low abundances of $\mathrm{Cs}$, Th, and $\mathrm{U}$; the $\mathrm{Cs}$ values, in particular, are among the lowest in the data bank (fig. 21). Such ratios as $\mathrm{Nb} / \mathrm{Th}$ and $\mathrm{K} / \mathrm{Cs}$ also display these characteristics particularly well. In a gross way, the oceanic extensional rhyolites show low ratios of LIL/HFS (Large Ion Lithophile/High Field Strength) elements (Saunders and others, 1980), the main exception being that the LREE are relatively enriched, rather than depleted, in these rocks compared to other rhyolite groups.

Within the group, Johnson and others (1978) recognized that many of the geochemical features of the Icelandic rhyolites are shared by obsidians from St. Andrew Strait, Papua New Guinea. Certain differences also exist. $\mathrm{Al}_{2} \mathrm{O}_{3}$ concentrations are generally not as low as in the Icelandic specimens, $\mathrm{Cl}$ contents are notably higher, REE are less enriched, and $\mathrm{K} / \mathrm{Rb}$ ratios are higher.

Johnson and others (1978) also alluded to the similarities between the Icelandic and Salton Sea

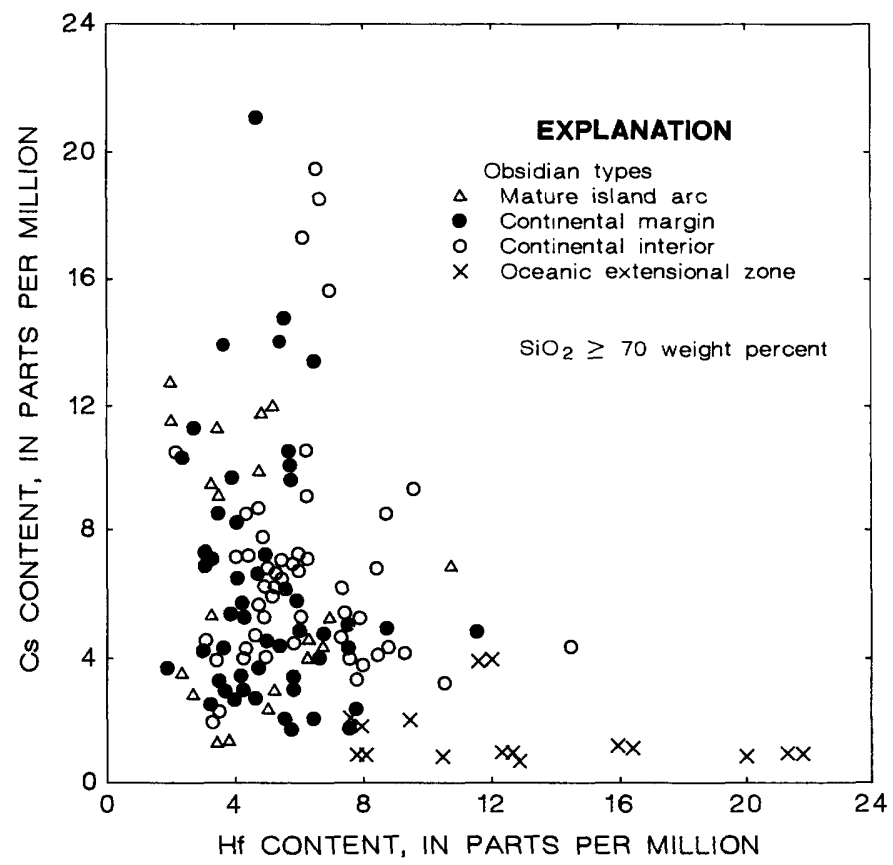

Figure 21.-Hf content versus Cs content showing Cs-poor (and relatively Hf-rich) character of obsidians of oceanic extensional zones. Data from appendix I. rhyolites. There are new analyses of only three of the five small domes in the geothermal field, but the rapid-rock analyses of Robinson and others (1976) suggest that variation within the domes is small and that the new analyses are typical.

The major-element chemistry of the Salton Sea rocks is typically of group V type, but the trace elements are less similar. The $\mathrm{Zr}$ group of elements does not show the very high values, or the $R b$ group the low values, of the Icelandic rocks. The traceelement proportions are in many respects transitional between Icelandic and continental-margin types.

It is tempting to see the Icelandic-St. Andrew Strait-Salton Sea rocks as a sequence, where a "primitive" magma of Icelandic type becomes progressively contaminated with sialic crust, the amount of contamination approximately reflecting the proportion of continental crust in the tectonic setting. Such a mechanism would not by itself explain the lower HFS element concentrations in combination with increased contents of K-related elements, and more complex petrogeneses are indicated.

\section{UNCLASSIFIED OBSIDIANS}

Certain obsidians are sufficiently distinctive chemically to not readily fit into the classification scheme used in this paper. In terms of numbers of analyses, the most important of these occur in the Eolian arc, Italy. The arc has been interpreted (Barberi and others, 1974) as a complex zone of interaction between a marginal basin (Tyrrhenian abyssal plain) and a westnorthwest-dipping subduction zone under the arc. The volcanoes are apparently developed on thin continental crust, itself perhaps underlain by a wedge of oceanic crust (Keller, 1982, fig. 2).

Obsidians from Lipari and Vulcano (Nos. 180-182) have distinctive compositions, notably extremely high concentrations of K-group elements ( $R b, C s, U$, $\mathrm{Th}$ ) in combination with high LREE, $\mathrm{Nb}$, and Ta. The average $\mathrm{Ce} / \mathrm{Yb}$ ratio is the highest of any of the rhyolite groups.

In terms of the classification of this paper, these Eolian rocks plot close to the boundary of the oceanic-extensional and continental-interior fields on critical compositional diagrams. Their chemistry seems, therefore, to reflect their transitional tectonic affinity between continental and oceanic settings, but superimposed on this is the regional effect of high K-group elements.

Obsidians collected from Monte Lentia, Vulcano (Nos. 322-325) also have unusual chemistry. The low 
abundances of $\mathrm{SiO}_{2}$ and high $\mathrm{FeO}_{\mathrm{t}}, \mathrm{MgO}$, and $\mathrm{CaO}$ are comparable to the calcic obsidians of mature island arcs, but the high $\left(\mathrm{Na}_{2} \mathrm{O}+\mathrm{K}_{2} \mathrm{O}\right)$ content and low $\mathrm{Na}_{2} \mathrm{O} / \mathrm{K}_{2} \mathrm{O}$ ratio are not. The low $\mathrm{Na}_{2} \mathrm{O} / \mathrm{K}_{2} \mathrm{O}$ ratios and high $\mathrm{MgO}$ contents distinguish them from rhyolites of oceanic extensional zones. Unfortunately, trace-element data are unavailable to allow a full characterization of these interesting rocks.

Obsidian blocks of uncertain derivation found on Mont Manengouba, Cameroon (Tchoua, 1970) also have a unique chemistry (No. 337); low total alkalis relative to $\mathrm{SiO}_{2}$ and $\mathrm{Al}_{2} \mathrm{O}_{3}$ yield the highest value of normative corundum in the data bank, and this sample has a high normative ratio of quartz: (orthoclase+albite). This unusual rock clearly has an unusual petrogenesis, and traceelement and isotopic study would be meaningful. An obsidian from Garove Island in the Bismark Sea (No. 364) has "mixed" chemical features. The low concentrations of $\mathrm{Ba}, \mathrm{Cs}, \mathrm{Pb}, \mathrm{Rb}$, and $\mathrm{Th}$, the high $\mathrm{FeO}_{\mathrm{t}}$ and $\mathrm{CaO}$ contents and $\mathrm{K} / \mathrm{Rb}$ ratios, and the relatively unfractionated REE pattern $\left(\mathrm{Ce}_{\mathrm{N}} / \mathrm{Yb}_{\mathrm{N}}=1.57 ; \mathrm{Eu} / \mathrm{Eu}^{*}=0.76\right)$ resemble features of rhyolites from primitive island arcs (app. V). $\mathrm{Na}_{2} \mathrm{O}$ content (5.7 percent), however, is very near the maximum (5.93 percent) recorded in the data bank; $\mathrm{Nb}, \mathrm{Zr}$, and $\mathrm{Hf}$ concentrations are higher than in other primitive-arc rocks.

\section{MAGMATIC DIFFERENTIATION PROCESSES IN SILICIC SYSTEMS}

\section{INTRODUCTION}

No single differentiation mechanism can be generally applicable over the whole evolutionary history of a silicic complex; different mechanisms probably dominate at different stages. Hildreth (1977) and Pitcher (1979, p. 638) provide the following summary of mechanisms effective at different stages: (1) During partial melting and coalescence: establishment of crystal-liquid equilibrium; (2) during ascent and high-level emplacement: reequilibration between liquid and crystal fractions and the removal of the $\mathrm{Ca}, \mathrm{Fe}$, and $\mathrm{Mg}$ in mafic mineral clots; (3) in the resulting high-silica caps to plutons (the potentially caldera-forming magma chambers): diffusive exchange during roofward concentration of dissolved volatiles presumably by coupled convective-diffusive internal transport; and (4) during consolidation: re-establishment of crystal-liquid equilibria, effected both by convection-aided marginal accretion of phenocrysts and by diffusion, with vapor-transport becoming significant in the latest stages.

To these may be added the effects of wall-rock contamination before and after magma emplacement, and of the possibility of magma mixing during any except the latest stages of pluton consolidation. It should also be stressed that the above mechanisms are not exclusive to any particular evolutionary stage, nor are they mutually exclusive.

Obsidians represent melts expelled from magma chambers at different stages of evolution and undergoing different genetic mechanisms. The relative importance of such mechanisms varies, not only with evolutionary stage, but with the type of system (Smith, 1979; Hildreth, 1981). The chemistry of the rhyolites is the only means by which the evolutionary stage of the magma reservoir in many volcanic fields may be judged. This in turn determines our ability to predict the reservoir's future development. An important goal, therefore, is to link rhyolite chemistry to genetic mechanism. In this section, brief notes are made of the types of chemical evidence used to fingerprint the effects of the major differentiation mechanisms.

The processes believed operative in silicic magma chambers are crystal-liquid fractionation, magma mixing, wall-rock reaction, vapor-phase transfer, and thermogravitational diffusion. The last process was proposed, and briefly discussed, by Shaw and others (1976) as an alternative to crystal fractionation to explain the strong trace-element gradients that sometimes occur in the tops of magma chambers, usually with rather limited variations in major-element compositions. The development of the concept as it applies to silicic magmas is due mainly to Hildreth $(1979,1981)$ and Mahood $(1981 \mathrm{a}, \mathrm{b})$. This process, popularly known as TGD, is still not well understood, a point acknowledged by Mahood and Hildreth $(1983$, p. 11). It involves not only convection-aided diffusion within magmatic liquids but also volatile complexing under volatile oversaturated and undersaturated conditions.

The TGD concept has been criticized by several workers. Michael (1983), Miller and Mittlefehldt (1984), and Baker and McBirney (1985) argue that compositional zonation of the type seen in the Bishop Tuff can be generated by fractionation of crystals at the sidewalls of magma chambers, with convective uprise of the lower density, residual liquids toward the roof zone of the chamber. Walker and others (1981) and Lesher and others (1982) present experimental evidence to show that Soret diffusional gradients for many elements run 
counter to those ascribed to TGD in the natural magma chambers.

The fact that some process, or combination of processes, other than crystal fractionation has acted to differentiate the upper parts of many silicic systems can hardly be doubted (Smith, 1979; Hildreth, 1979, 1981; Bacon and others, 1981; Mahood, 1981a, b; Crecraft and others, 1981). However, it is premature in a descriptive geochemistry paper to classify all highly fractionated obsidians as solely the products of TGD, as presently understood, or of any other single genetic mechanism.

We distinguish chemically two broad groups of obsidians. One group has compositional variations which are judged on the basis of comparison with whole rock-separated glass pairs and trends in granitoid plutons to have been generated dominantly by crystal-liquid processes, such as crystal fractionation, restite separation, and partial melting of source rocks and chamber walls under conditions of low halogen activity. Magma mixing is a minor but common differentiation mechanism also. We refer to these rocks as CLPD compositions (that is, formed where crystal-liquid processes dominated).

The second group is systematically different, chemically, from the first and shows chemical variations comparable to those recorded in some voluminous, silicic ash-flow tuffs. The petrogenesis of these rocks has not been fully resolved but probably involves interplays of crystal fractionation, wall rock reactions, vapor-phase transfer, maxma mixing, and various liquid-state differentiation mechanisms, such as volatile complexing. Although such compositions may be generated in the uppermost parts of large magma chambers, they may also result from the direct partial melting of crustal rocks under conditions of high halogen fugacities, a process probably akin to the volatile fluxing mechanism of Bailey $(1970,1974$, 1980), Bailey and Macdonald (1970, 1975), and Macdonald and others (1970). We refer to such rocks as the result of a complex interaction of petrogenetic processes (CIPP).

We shall show below that it is not possible to define precisely CLPD and CIPP compositions. These vary between systems and with time within the same system. Some experience with the data base is required to appreciate fully the systematics of rhyolite geochemistry and to apply the terms CLPD and CIPP to individual specimens. Much of the following discussion is preliminary, but it is felt to be an important step toward maximizing the usefulness of the systematic, element-by-element treatment of the final section.

\section{RELATIVE ROLES OF CLPD AND CIPP}

\section{SOME TERMS}

Our usage of the terms "base-level magmas," "base-level liquids," and "real, total, and apparent fractionation factors" may be described with reference to an evolving silicic magma chamber, where a high-silica cap differentiating by CIPP lies above a dominant magma volume, of quartz latitic or rhyodacitic composition. $\mathrm{Nb}$ is used as a monitor element to describe the system's chemical evolution and is assumed to have a solid-liquid partition coefficient of zero.

Note that there is no specific composition, volume, or degree of crystallinity of base-level magmas: these vary between magmatic systems and with time in single systems. They can be defined only rather vaguely as the magmatic condition immediately prior to onset of CIPP. The hypothetical system is assumed to have evolved by CLPD to a state where the magma is substantially crystallized, in this case 50 percent (fig. 22). This magma is the base-level magma (with a given $\mathrm{Nb}$ content of $10 \mathrm{ppm}$ ).

As the base-level magma fractionated, a cap of nonporphyritic liquid overlying a crystal-rich bed was produced. As the result of 50 percent crystallization of base-level magma (and the zero solid-liquid partition coefficient for $\mathrm{Nb}$ ), the nonporphyritic cap contained $20 \mathrm{ppm} \mathrm{Nb}$ presumably formed by CLPD. This nonporphyritic magma is the base-level liquid which existed in the magma chamber at time $t_{1}$. (The interface between the crystal-rich layer and the base-level liquid is variably sharp: in some systems, a sharp interface will be shown as a notable composition gap (Smith, 1979) in the erupted products; in some others, a transitional passage will reveal no compositional hiatus. In CLPD systems, notable $\mathrm{SiO}_{2}$ gaps are common, whereas in CIPP systems, with high-silica magma, minor element gaps are more likely to be observed.)

Subsequent CIPP differentiation builds up the concentration of $\mathrm{Nb}$ in the most fractionated top of the silicic cap to $60 \mathrm{ppm}$ (point $\mathrm{X}$ at time $t_{2}$, fig. 22). Eruption occurs, tapping the magma chamber along the path $\mathrm{X}-\mathrm{Y}$. As recorded in the eruptive products, the $\mathrm{Nb}$ fractionation factor is 2 . However, this is an apparent fractionation factor because the full compositional range for CIPP fractionation (20-60 ppm $\mathrm{Nb})$ was not tapped during the eruption. The real fractionation factor relative to the base-level liquid, between times $t_{1}$ and $t_{2}$, is 3 , whereas the total fractionation factor relative to the base-level magma is 6 . 
Along path $\mathrm{Y}-\mathrm{Z}$, the system regenerates the compositional gradients, reaching a maximum $\mathrm{Nb}$ of 55 ppm. A second eruption occurs, this time tapping deeper in the chamber into the crystal-rich layer $(\mathrm{Z}-$ P). The apparent fractionation factor is now 3.7, higher than that in the first cycle, despite the lower real fractionation factor. These factors are therefore critically dependent on the balance between the extent of drawdown and the concentration gradients established between eruptive episodes.

Determining base-level liquid and base-level magma compositions may be exceedingly difficult. Multicyclic systems may or may not tap base levels.
A further complication is that in multicyclic systems, removal of high-silica fractions must inevitably result in up-element ${ }^{3}$ depletions at or near the liquid crystal-rich layer interface, such that base-level compositions change with time.

In general, only detailed reconstruction of the histories of individual systems will allow the recognition

studies of compositionally zoned ash-flow sheets have shown that during differentiation of the roof zone magmas, some elements (for example, $\mathrm{Rb}, \mathrm{Ta}$ ) concentrated upwards into lower temperature melts, while others (for example, Ba, Sr) concentrated in higher temperature liquids of deeper levels. They are conveniently referred to as up-elements and down-elements, with no implication as to the genetic mechanism. Note that some elements (for example, Mn, Sc) can be either up- or down-elements, depending on the affinity of the magmatic system.

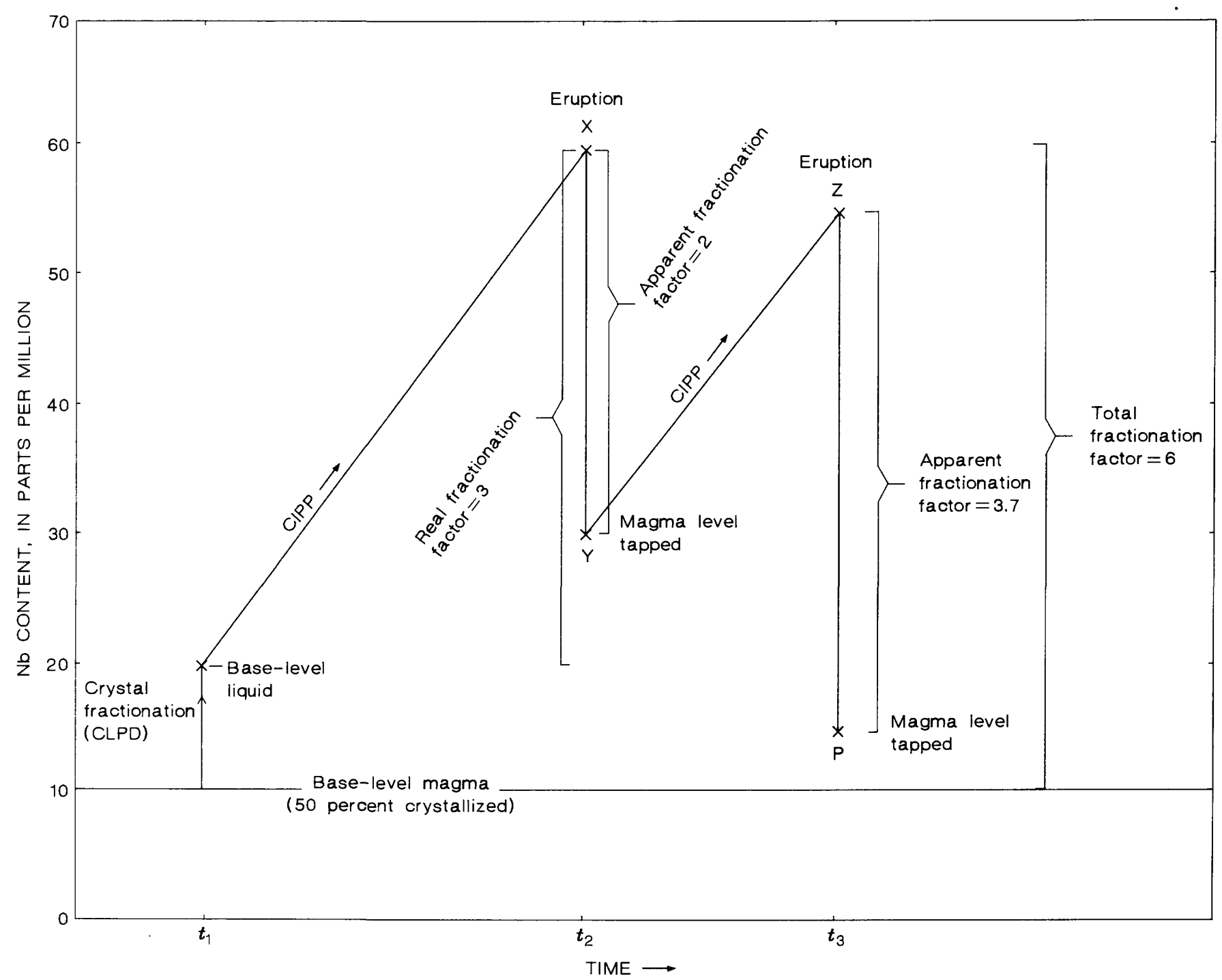

Figure 22.- $\mathrm{Nb}$ evolution, by CLPD and CIPP, in upper part of silicic magma chamber, showing base-level liquid and real, total, and apparent fractionation factors. See text for discussion of system along path denoted by arrow and at points $X, Y, Z$, and $P$. 
of base-level compositions. Such an approach is clearly impossible in volcanic fields of isolated rhyolitic domes or of bimodal basalt-rhyolite systems. For many, probably most, silicic systems, base-level liquid and base-level magma compositions lie variably within the field of crystal-liquid processes. In others, base-level liquids, in the sense of being the most primitive in the system, may actually have CIPP compositions.

It is relevant to note, at this point, certain other factors which bear on the determination of enrichment factors in CIPP systems. First, they are very dependent on the quality of the analytical data. As an example, consider a system in which Sn abundances for top and bottom magmas are $12 \mathrm{ppm}$ and $1 \mathrm{ppm}$, respectively, but which are reported as 10 $\mathrm{ppm}$ and $1.5 \mathrm{ppm}$, respectively-deviations from the true values not atypical in our experience. The real enrichment factor for the system is $12(12 / 1=12)$, the reported factor $6.7(10 / 1.5=6.7)$.

For certain elements, particularly those prone to secondary hydration, the problems of establishing real enrichment factors may be related not only to possible analytical imprecision but to sample quality also. Consider a zoned magma, erupted as an air-fall ashflow sequence, which originally had top and bottom $F$ abundances of 2,000 and $200 \mathrm{ppm}$, respectively (real enrichment factor $=10$ ). The sequence becomes hydrated after eruption, such that the most differentiated sample available is an air-fall pumice which loses 50 percent F (1,000 ppm). The "bottom" sample is a hydrated glass which loses only 20 percent $F(160 \mathrm{ppm})$. Although $F$ variation in the sequence appears to be systematic, the observed enrichment factor (6.3) is much lower than the real factor (10).

Considering all the problems, we urge great caution in the establishment and interpretation of enrichment factors in zoned systems. In particular, any petrogenetic conclusions based on the similarity or dissimilarity of elemental enrichments must be based on data known to be highly precise and on elements known to have preserved original magmatic abundances.

\section{DIFFICULTIES OF RECOGNIZING CIPP MAGMA COMPOSITIONS}

The steep trace-element gradients which characterize CIPP are normally found when $\mathrm{SiO}_{2}$ contents exceed 74 percent (Hildreth, 1979). It is tempting to suppose that these systems are approaching a natural minimum melting composition, where differentiation by crystal-liquid processes is inefficient, and other mechanisms become predominant. However, the rec- ognition of probable CIPP effects in peralkaline magmas (Noble and others, 1979; Mahood, 1981a, b) indicates that no single minimum composition can be applicable over the whole spectrum of rhyolite chemistries. In fact, CIPP may not be restricted to silicic systems. Detailed search may reveal its operation in intermediate or even mafic magmas.

The critical factors determining the composition at which the dominant fractionation process changes are not known but may include any or all of the following: Bulk composition of the system, melt structure, volatile species and their activities, and magma dynamics. Detailed studies of many more relevant systems are required to assess the importance of each variable and, in particular, the CLPD compositions in each system must be identifiable.

CLPD compositions differ in magmas of different affinity. Thus, a CLPD liquid at 76 percent $\mathrm{SiO}_{2}$ in an island-arc volcano may contain $10 \mathrm{ppm} \mathrm{Nb}$, in a continental-interior volcano 3 times as much. Even though both systems may subsequently experience similar CIPP fractionation histories, the factor of 3 difference in absolute $\mathrm{Nb}$ abundances will be maintained. Note that in figure 23 the $\mathrm{Nb}$ content of the

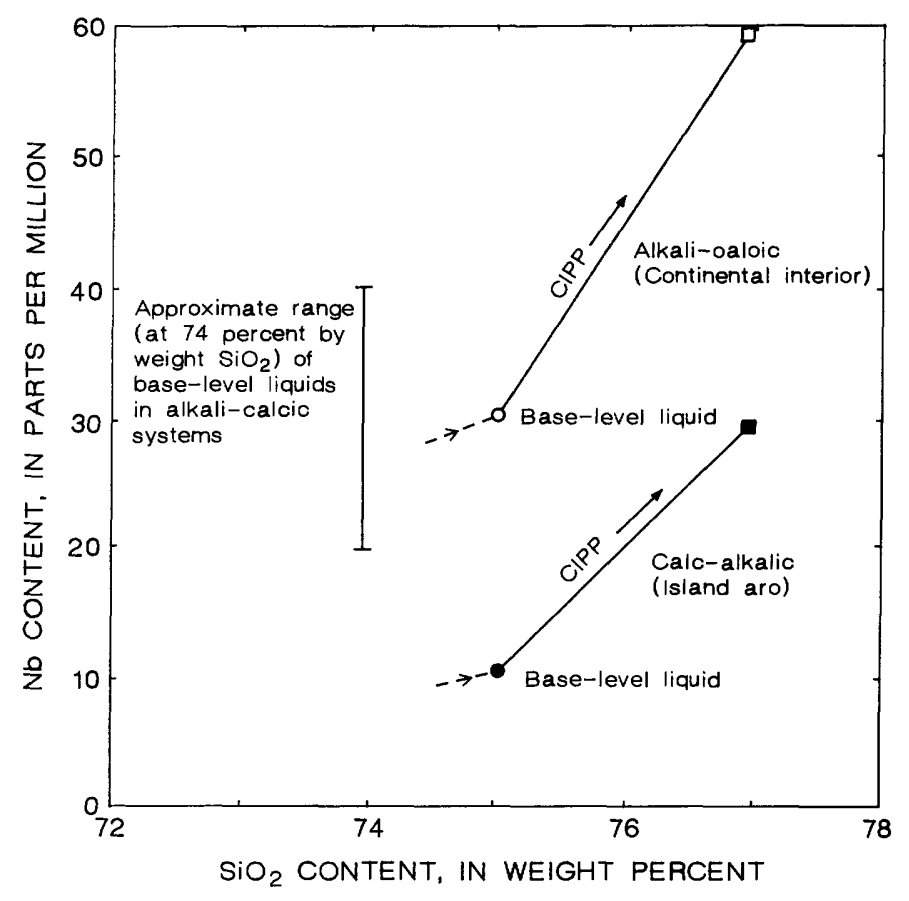

Figure 23.- $\mathrm{SiO}_{2}$ content versus $\mathrm{Nb}$ content showing relation between fractionation (enrichment) factors and magmatic affinity of system for proposed CIPP fractionation. Arrows indicate direction of enrichment; squares indicate maximum enrichment for given systems. 
most strongly differentiated arc rock equals that of the CLPD continental-interior liquid. It must be emphasized that the arc system has become more evolved than the interior and that the absolute concentration of an element in silicic systems is a function of both the degree of evolution and the base-level compositions. A rock with low concentrations of lithophilic elements may be quite highly evolved.

A further complication is imposed by variable source rock compositions. There are real variations in minor- and trace-element chemistry resulting from geographical location even within systems of equivalent major-element chemistry in the same tectonic setting. Thus, in the continental interior of the United States, CLPD silicic magmas may show, at equal $\mathrm{SiO}_{2}$ contents, variations of more than a factor of 2 in Th and $U$ abundances.

\section{CRITERIA FOR THE IDENTIFICATION OF CIPP COMPOSITIONS}

A critical problem is how to distinguish chemically those rocks which have evolved dominantly by crystalliquid processes from those which are CIPP controlled. Though end-member compositions are fairly easily recognized, it may, in fact, be difficult to distinguish mildly fractionated compositions unless they are part of a suite of compositions where the chemical trends and gradients support the CIPP concept.

Hildreth $(1979$, p. 71$)$ suggests: "The most easily obtained indications that the thermogravitational process has become dominant in a rhyolitic chamber are increases in the $\mathrm{Na} / \mathrm{K}$ ratio and the Mn concentration of successive eruptive products, and impoverishment of $\mathrm{Ba}, \mathrm{Sr}, \mathrm{P}$, and $\mathrm{Mg}$ to levels lower than 100 ppm each."

Such an approach is less viable in areas of isolated rhyolitic extrusive rocks where sequences of composition are unknown. Here an absolute indicator of CIPP is required. It follows from the foregoing discussion that absolute concentrations of elements are not entirely satisfactory because of intersuite variability and the consequent overlapping of base-level compositions. Elemental ratios and REE characteristics prove to be more useful. Hildreth's (1979) criteria for thermogravitational processes (TGD) can be expanded to suggest, therefore, that subalkalic rocks fractionated by CIPP will have, among other things, very low $\mathrm{Ba}, \mathrm{Sr}, \mathrm{P}$, and $\mathrm{Mg}$ contents, gentle to flat REE patterns with prominent $\mathrm{Eu}$ anomalies, low $\mathrm{K} / \mathrm{Rb}$ and $\mathrm{Zr} / \mathrm{Nb}$ ratios, and relatively high $\mathrm{Na}_{2} \mathrm{O} / \mathrm{K}_{2} \mathrm{O}$ ratios. Some of these features may be combined to provide a fingerprint of the process.
One attempt to define the relevant compositions of CIPP rock is shown in figure 24. It utilizes the observation that extreme depletion of $\mathrm{Eu}$ and the development of low $K / R b$ ratios characterize the CIPP process. A rather arbitrarily defined band separates rocks suspected of having been part of a CIPP system at some stage in their evolution from those for which a crystal-liquid control only is more tenable. The trend lines for the Bandelier and Bishop Tuffs cross the boundary and serve to stress that this diagram is, in reality, defining a compositional limit for crystal-liquid only processes. Rocks from the higher temperature parts of certain CIPP systems overlap CLPD rocks compositionally; definitive criteria to separate these are not yet available.

\section{APPLICATION TO THE WHOLE BODY OF OBSIDIAN DATA}

If crystal-liquid processes alone cannot adequately explain the chemical variations in the Bandelier and Bishop Tuffs, then it may be assumed that they are equally untenable for any comparable silicic magmas. Consider the data for the Quaternary rhyolite domes of the Coso Range, California (Bacon and others, 1981). On a K-Rb diagram (fig. 25), averaged compositions for groups 3 to 7 of the domes form a trend parallel to, and intermediate between, the generalized Bandelier and Bishop trends, ${ }^{4}$ a position consistent with their intermediate magmatic affinity and intermediate tectonic setting at the epicontinental margin. The other chemical data, for the Coso rocks, show trends and gradients closely comparable to those in the Bandelier and Bishop sheets, and the differentiation processes were probably similar. Bacon and others (1981) concluded that the Coso rhyolites represent episodic leaks from a magma chamber (or chambers) evolving by thermogravitational diffusion, a conclusion we now would cautiously change to control by CIPP.

The analogy may be extended to all the obsidians. Those plotting close to the CIPP trends on a K-Rb diagram and having the other relevant chemical characteristics are considered to represent CIPP magmas. Those plotting in the CLPD field have evolved either by crystal fractionation of a more mafic parent or by crustal anatexis. Magma mixing,

In this and subsequent plots, these trends are taken to be linear between the end-member compositions. In detail, for many elements, the trends are not truly linear. This simplification does not affect the main purpose of employing the trends-to show the compositional ranges and gradients of established CIPP systems. 
vapor-phase transport, and contamination by wall rock may proceed in either field.

There is considerable overlap between the two main fields not only on a $\mathrm{K}-\mathrm{Rb}$ diagram but using any chemical parameters. Experience can commonly tell whether rocks in the area of overlap are CIPP or CLPD compositions, but only detailed knowledge of the evolution of the relevant magmatic system can provide a more objective assessment.

The compositional ranges and averages for CLPD and CIPP obsidians of the continental margins and interiors are presented in table 9 , and specimens being classified are listed in table 10 . Important features of the averages include the following.

1. Average abundances are higher in CIPP than in CLPD rocks for $\mathrm{F}, \mathrm{Be}, \mathrm{Cs}, \mathrm{Li}, \mathrm{Nb}, \mathrm{Pb}, \mathrm{Rb}, \mathrm{Sb}, \mathrm{Sn}, \mathrm{Ta}$, Th, U, W, Y, Zn, and HREE and for $\mathrm{SiO}_{2}$ in the continental-margin group.

2. Average abundances are lower in CIPP than in CLPD rocks for $\mathrm{FeO}_{t}, \mathrm{MgO}, \mathrm{CaO}, \mathrm{TiO}_{2}, \mathrm{P}_{2} \mathrm{O}_{5}, \mathrm{Ba}, \mathrm{Co}$,
Sc, Sr, $\mathrm{Zr}, \mathrm{LREE}$, and $\mathrm{Eu}$, and for $\mathrm{Al}_{2} \mathrm{O}_{3}$ in the continental-margin group.

3. Average abundances are about the same in CLPD and CIPP rocks for $\mathrm{MnO}, \mathrm{Cl}, \mathrm{Hf}, \mathrm{Mo}$, and for $\mathrm{SiO}_{2}$, $\mathrm{Al}_{2} \mathrm{O}_{3}$, and $\mathrm{K}_{2} \mathrm{O}$ in the continental-interior group.

4. The element behavior indicated by the averages may not reflect that, in individual silicic CIPP systems, elements including $\mathrm{Fe}, \mathrm{Sc}$, and $\mathrm{Zr}$ may behave as upward-concentrating elements.

5. Average ratios of $\mathrm{Zr} / \mathrm{Hf}, \mathrm{K} / \mathrm{Rb}, \mathrm{Ce} / \mathrm{Yb}$, and $\mathrm{Eu} / \mathrm{Eu}^{*}$ are lower and $\mathrm{Ca} / \mathrm{Sr}$ and $\mathrm{Rb} / \mathrm{Sr}$ ratios higher in CIPP compared to CLPD rocks for both groups.

6. The higher $\mathrm{Na}_{2} \mathrm{O} / \mathrm{K}_{2} \mathrm{O}$ ratio in CIPP continentalinterior obsidians compared to CLPD types from the same group mirrors the behavior of the ratio in individual CIPP systems. The lower ratio in CIPP margin rocks relative to equivalent CLPD rocks is probably anomalous, due to the relatively potassic nature of certain of the available CIPP systems (for example, Nos. $33,48,49,50$ ).

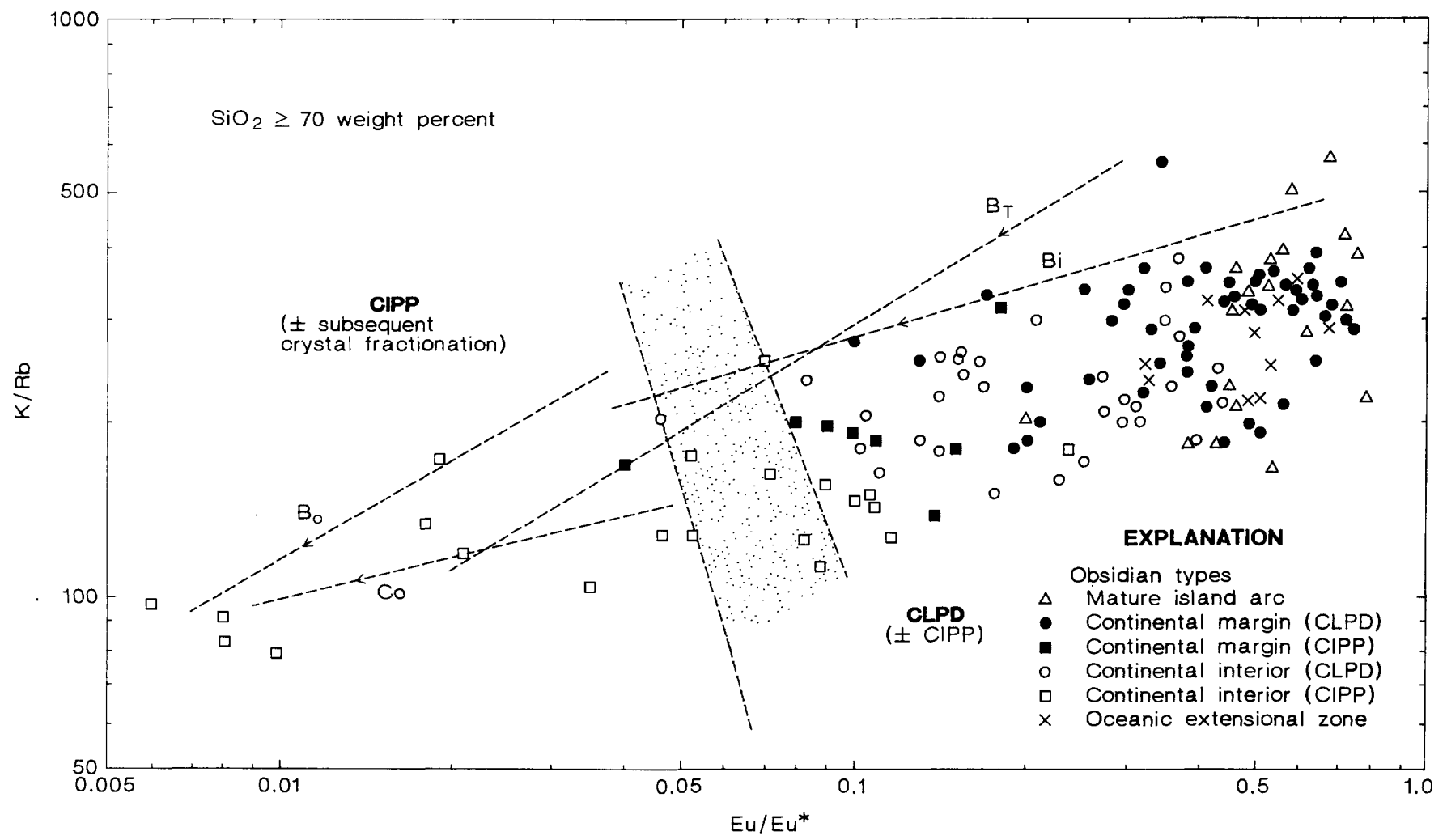

Figure 24.-Ratio of $\mathrm{Eu} / \mathrm{Eu}^{*}$ versus ratio of $\mathrm{K} / \mathrm{Rb}$ showing relation between composition and dominant genetic processes. Data from appendix I. Positions of the Bishop Tuff $(\mathrm{Bi})$ and Coso rhyolite $(\mathrm{Co})$ trends at lower values of $\mathrm{Eu} / \mathrm{Eu}^{*}$ are estimated due to uncertainties in Eu determinations. $B_{T}$ and
B are generalized trends for the Tshirege and Otowi Members of the Bandelier Tuff, respectively (R.L. Smith, unpub. data). Arrows indicate direction of liquid fractionation. Shaded band designates arbitrary and flexible field boundary. See text for discussion. 
7. The lower average $\mathrm{Nb} / \mathrm{Ta}$ and $\mathrm{Th} / \mathrm{U}$ ratios in CIPP interior obsidians again match behavior in individual systems. When more data are available, similar lower averages will probably be found for CIPP margin rocks.

\section{MAGMA MIXING AND ASSIMILATION}

Well-known examples of magma mixing in silicic systems include Novarupta, Valley of Ten Thousand Smokes (Fenner, 1923), the composite rhyolite-dacite flow on Big Glass Mountain, Medicine Lake Highlands (Anderson, 1933), the obsidian flow at Borax Lake, Clear Lake (Anderson, 1936; Bowman and others, 1973), and the Inyo Craters (Bailey and others, 1976). It is being increasingly recognized, however, that magma mixing is probably ubiquitous in silicic systems (Smith, 1979). For example, casual examination of Western United States obsidian flows reveals the almost universal presence of mafic inclusions, some of which represent quenched basaltic or andesitic magmas (R. Smith, personal observation). Such inclusions are also commonplace in the silicic members of island-arc volcanoes.

They are not, however, restricted to subductionrelated systems. Mafic inclusions have been reported from the Mineral Mountains, Utah (Lipman and others, 1978), and the Coso Range, California (Bacon and Metz, 1984). Magma mixing is also an important function of Icelandic systems (Sparks and others, 1977; Sigurdsson and Sparks, 1981).

Other silicic flows may carry xenoliths of mafic to intermediate rocks which represent fragments of preexisting flows. These occur in varying stages of disaggregation and have had the potential to contaminate the silicic host to varying degrees.

Several samples analyzed in this report carry megascopically or microscopically recognizable xenoliths of basalt, andesite, or dacite. Listed by

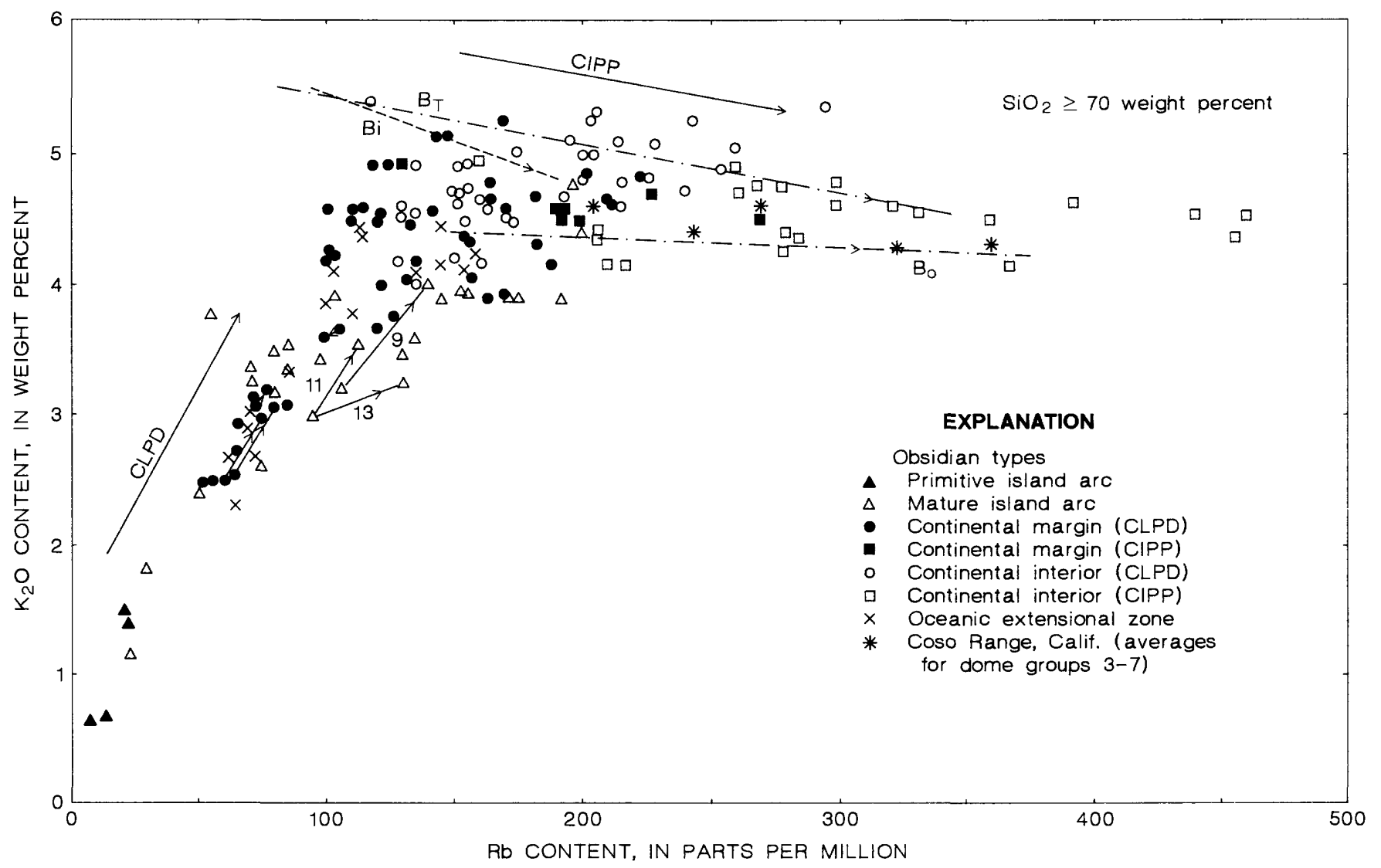

FIgURE 25.-Rb content versus $\mathrm{K}_{2} \mathrm{O}$ content showing fields occupied by CLPD and CIPP silicic obsidians. $\mathrm{B}_{\mathrm{T}}$ and $\mathrm{B}_{0}$ are generalized trends for the Tshirege and Otowi Members of the Bandelier Tuff, Valles Mountains, New Mexico, respectively (R.L. Smith, unpub. data); Bi, Bishop Tuff, California (Hildreth, 1979,
1981). Data from appendixes I and V (samples A, B, D, F, and G). Specimen 160 has been omitted to preserve the scale. Coso Range data from Bacon and others (1981). Solid tielines connect bulk rock-glass pairs; arrows point toward glass separate. Numbered tielines are data for Taupo, New Zealand (Ewart and others, 1968). 
tectonic setting, they are (sample number in parentheses):

Mature island arcs

Umnak, Alaska $(2,242)$

Nagrek, Java (199)

Mount Toduku and Mount Alon, Halmahera $(205,208)$

Continental margins

Novarupta, Alaska $(3,243,244)$

Big Glass Mountain, Medicine Lake (42, 43, 269273)

Orijana Canyon, Oregon (33)

Borax Lake, California $(48,281)$

Inyo Craters, California $(51,283,284)$

Wadatoge, Japan $(188,346)$

Continental interiors

Huckleberry Ridge Tuff, Yellowstone (89)

Ammon Tuff, Idaho (84)

Walcott Tuff, Idaho (85)

Oceanic extensional zones

Askja, Iceland (176)

Vatnajökull, Iceland (319)

Domadalshraun, Iceland (174)

Alcedo, Galapagos (158)

The specimen from Vulcano, Italy (182), also carries xenolithic fragments.

Samples 33, 84, 85, and 89 are welded tuffs, and the inclusions they carry are almost certainly accidental. Using data for the other rocks and for the mixed-magma series noted above, it is possible to examine the role of contamination in causing chemical diversity in the silicic obsidians.

Magma-mixing series will give straight-line trends on a two-axis, linear graph, whose slope and position are dependent on end-member compositions. Data for three mixed series are shown in figure 26. The nonlinearity of the Novarupta and Glass Mountain trends indicates either analytical error or the presence of a differentiation factor other than mixing; for example, phenocryst and (or) xenocryst redistribution. Nevertheless, the trends show that magma mixing can produce variations of similar magnitude to crystal-liquid effects, at least in terms of major elements.

Because rhyolitic magmas will, in general, mix with higher temperature magmas of the same series, the chemical variations produced will tend to mimic crystal-liquid trends. Recognition of the operation of magma mixing in single obsidian samples on purely chemical grounds is thus extremely difficult. One rock in which it may have occurred is an obsidian from White Mountain, Utah (No. 96, app. I). This rock has the chemical characteristics of a CIPP, continental-interior rhyolite, except for high $\mathrm{MgO}, \mathrm{CaO}, \mathrm{Co}$, and $\mathrm{Cr}$, consistent with contamination by mafic material. We have not identified such material in thin section, but the mode of occurrence of the rock, as a small isolated dome in a basaltic field, makes it a prime candidate for mixing with basalt, and basaltic inclusions do locally occur in the rhyolite.

A crude estimate of the amount of possible contamination of the obsidians by mafic magmas or xenoliths may be made using $\mathrm{Cr}$ concentrations. Though our $\mathrm{Cr}$ data are limited by poor precision at low abundance levels, virtually all the obsidians have $\mathrm{Cr}<4 \mathrm{ppm}$. The average $\mathrm{Cr}$ content in basalts is $162 \mathrm{ppm}$ (Prinz, 1968), suggesting that the maximum basaltic component in the rhyolites is much less than 5 percent. Correspondingly larger components are possible when the lower silica member is andesitic or dacitic, but it may be significant that only six obsidian samples have $\mathrm{Cr}$ contents as high $(29 \mathrm{ppm})$ as those from the Borax Lake mixed rhyolite-dacite obsidian flow (Bowman and others, 1973), and three of those probably reflect analytical error.

It is concluded that although magma mixing and assimilation of mafic rocks may affect significant chemical variations in silicic systems, there is no convincing evidence that those processes have been other than minor differentiation mechanisms in the obsidians.

\section{VAPOR-PHASE TRANSPORT}

An integral part of the thermogravitational diffusion model (Shaw and others, 1976; Hildreth, 1979) and accepted here as a likely CIPP component is the roofward migration and concentration of trace elements as hydroxyl, halide, or carbonate complexes. Hildreth (1981) has noted that thermogravitational diffusion may also include chemical exchange between liquid and a transient vapor phase. If, in silicic systems, the roof zone becomes saturated with

Figure 26. $-\mathrm{SiO}_{2}$ content versus total iron as $\mathrm{FeO}(A)$ and $\mathrm{CaO}$ $(B)$ content for various rock-glass pairs (solid tielines; appendix I; Ewart and others, 1968, pairs 9, 11, 12, 13); Borax Lake (Bowman and others, 1973), Novarupta (specimens 3, 243, 244), and Big Glass Mountain (specimens 264-268) mixed flows; Bishop Tuff, Bi (Hildreth, 1981); Bandelier Tuff, Otowi, $B_{\text {, }}$ and Tshirege, $B_{T}$, Members (R.L. Smith, unpub. data); and Woodson granodiorite stock (Tilling and Gottfried, 1969; David Gottfried, unpub. data). Arrows indicate direction of liquid fractionation. 


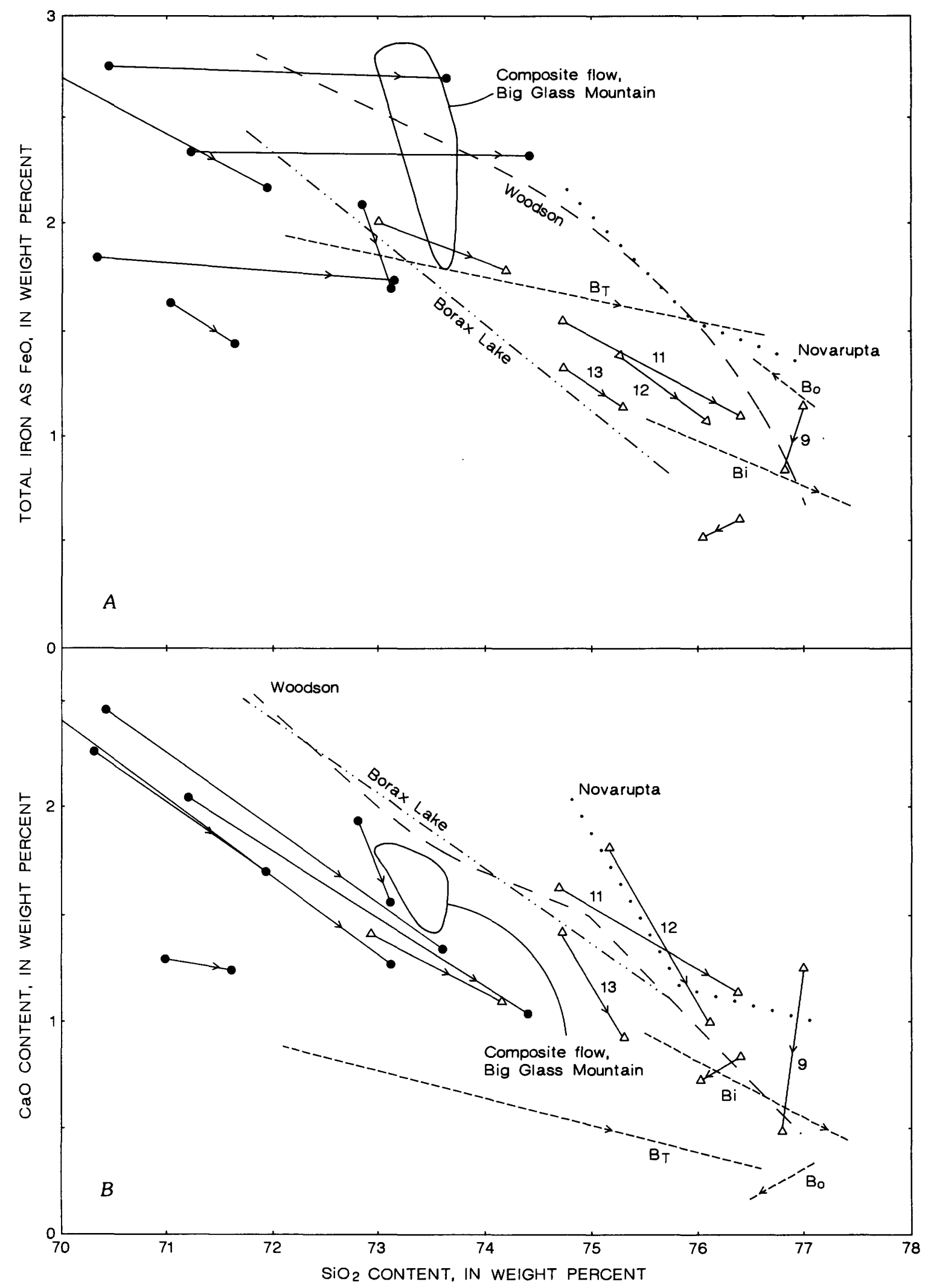


volatiles prior to eruption, with the evolution of a discrete vapor phase, partitioning of elements into this potentially fugitive volatile phase may be an important differentiation mechanism.

Unfortunately, there is no general agreement as to whether volatile saturation actually occurs in CIPP systems. Hildreth (1981, p. 10175), for example, argues from a review of pertinent petrographic and geochemical evidence that "the weight of evidence is against preeruptive water and halogen saturation in explosive rhyolitic magmas, but the transient effects of $\mathrm{CO}_{2}$-bearing vapor might be important to transport of some trace components." Similarly, Mahood (1981a, b) finds little evidence that the Tala Tuff magma chamber became saturated with volatiles prior to eruption.

Nevertheless, there is a natural progression during the plutonic stages from CLPD to liquid-vapor crystal-controlled processes in the roof zones of silicic systems, the latter being recorded, for example, in pegmatites, greisens, and other pneumatolytic deposits. Chemically, CIPP forms a transitional stage, as shown in figure 27 , in terms of $\mathrm{K}$ - $\mathrm{Rb}$ covariance. The crystal-liquid processes dominant (CLPD) field of this paper coincides with the "Main Trend" zone of Shaw (1968), whereas the complex interaction of petrogenetic processes (CIPP) field spans the composition range between the CLPD field and that defined by the pegmatite-hydrothermal trends of Shaw.

Ratios of other pairs of coherent elements may change significantly during CIPP. The effect is particularly clearly shown by the $\mathrm{Zr} / \mathrm{Hf}$ ratio. $\mathrm{Zr}$ is a

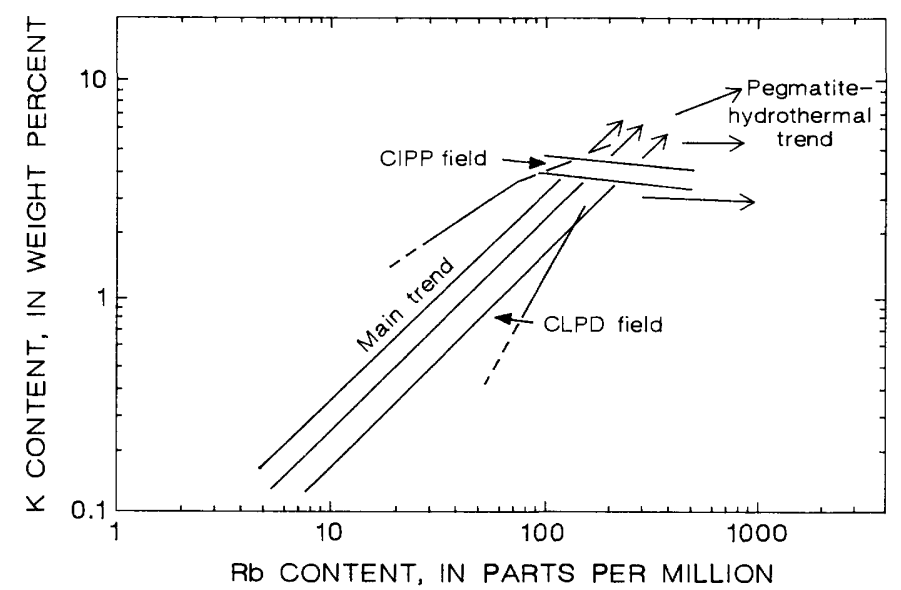

FIgURE 27.-Rb content versus $\mathrm{K}$ content showing that CIPP forms a link between crystal-liquid processes and hydrothermal activity. Main trend and pegmatite-hydrothermal trends are from Shaw (1968). Dashed lines express uncertainty of field boundaries. "down" element whereas Hf concentrates "upward." Obsidians strongly fractionated by CIPP have low $\mathrm{Zr} / \mathrm{Hf}$ ratios, commonly less than 20. During the pegmatitic-hydrothermal stages, $\mathrm{Zr} / \mathrm{Hf}$ fractionation may be even more marked, to the extent of producing hafnon-bearing pegmatites. The $\mathrm{Nb} / \mathrm{Ta}$ ratio is also decreased by CIPP, though less markedly than the $\mathrm{Zr} / \mathrm{Hf}$ ratio (table 9), and again CIPP forms a bridge to the postmagmatic processes.

Although the role of vapor-phase transport in redistributing elements within silicic magma chambers cannot yet be quantified (Hildreth, 1981), one important result of the bleeding of volatile-rich solutions into the roof rocks of magma chambers would be the attainment in the magma of apparent fractionation factors lower than the real factors achieved prior to volatile evolution as shown by the Bandelier and other data.

\section{SUMMARY OF PETROGENETIC PROCESSES}

A summarization, in terms of $K$ and $R b$, of the compositional fields in which each petrogenetic process has played a dominant or important role is shown in figure 28 . The following points may be noted:

1. The "crystal-liquid" field encloses the range of compositions of base-level magmas whose evolution has been controlled either by crystal fractionation or by crustal anatexis. The inflection in the zone is ascribed to a change either in the fractionating assemblage from mineralogies dominated by plagioclase to those dominated by plagioclase and alkali feldspar, or in the type of source rocks, for example, from oneto two-feldspar-bearing sources.

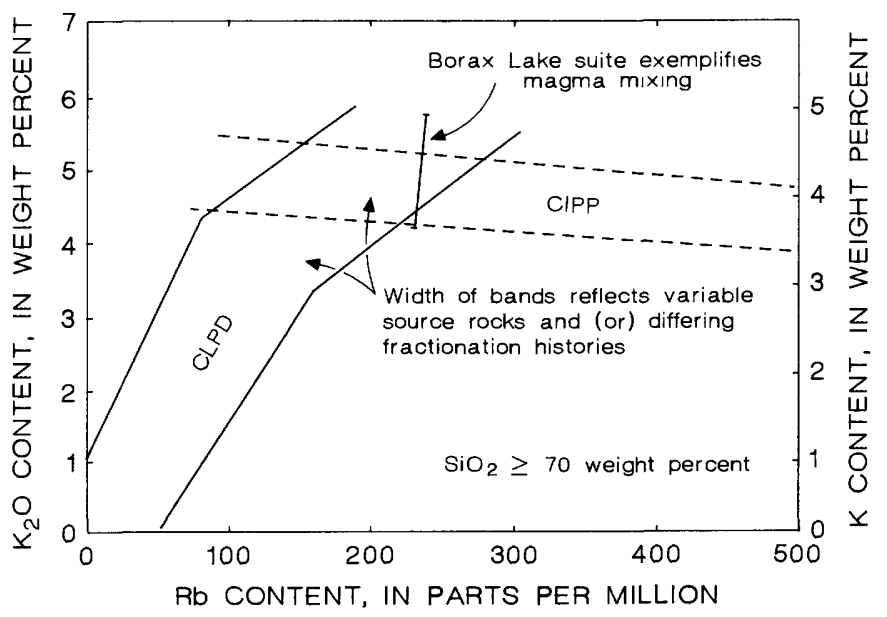

Figure 28.-Rb content versus $\mathrm{K}_{2} \mathrm{O}$ content showing effects of main genetic processes affecting silicic magmas. 
2. The CIPP field encompasses the range of the Bishop and Bandelier ash-flow sheets and of several obsidians inferred to have evolved dominantly by similar processes. The field overlaps that of crystalliquid processes, such that a distinction between processes cannot be made on the basis of $K$ and $R b$ contents within this field. Thus, $\mathrm{Rb}$ contents in the most evolved members of the Bishop system are lower than those in most CLPD continental-interior rocks. It is, of course, likely that true base levels for many interior systems probably lie below the Bishop maximum, but these values may occur in magmas having $\mathrm{SiO}_{2}<70$ percent (Smith, 1979, fig. 8). Subsequent crystal fractionation within diffused systems may result in extension of, and spread within, the CIPP field.

3. The width of the base-level zones reflect three factors. Most important are variations in source rock composition. Secondly, minor differences in partial melting trends and fractionation trends also exist, because the extensive parameters under which the magmas evolved must also have varied. Thirdly, some scatter has resulted from magma mixing and wall-rock contamination. Thus, the data for the mixed obsidian at Borax Lake form a crosstrend on the $\mathrm{K} / \mathrm{Rb}$ diagram.

4. We stress that, at present, our understanding of the chemistry of CIPP magmas and of the process itself is heavily dependent on the studies of the Bandelier and Bishop Tuffs. As Hildreth (1979, p. 69) points out, more complete documentation is required of zoned systems of a range of bulk compositions over a spectrum of volumes, temperature ranges, and phenocryst and volatile contents.

\section{SYSTEMATIC GEOCHEMISTRY}

In this section, the geochemistry of the subalkalic silicic obsidians is described element by element. A first aim is simply to present data in histogram form to show the elemental ranges for each rhyolite group and to indicate those elements which are most closely covariable in the obsidians. A second aim is to explain the variations in terms of the genetic mechanisms described in the previous section. The obsidian analyses are compared with data from rockglass pairs and granitic plutons (representing crystal-liquid-controlled compositions), from compositionally zoned ash-flow tuffs thought to have evolved dominantly by CIPP and from mixed-magma series where data permit.

For purposes of discussion, the rocks are divided (table 10) into those whose evolution had been con- trolled by CLPD or CIPP, respectively, using criteria outlined in the section entitled "Magmatic Differentiation Processes in Silicic Systems." This study represents the first detailed attempt to relate the complexities of rhyolite geochemistry to all the tectonic and genetic variables.

The elements are discussed, more or less, in the order they appear in the tables of analyses; the coherent pairs Nb-Ta, Zr-Hf, and Th- U are linked together; and the rare metals $\mathrm{Be}, \mathrm{Li}, \mathrm{Mo}, \mathrm{Sn}$, and $\mathrm{W}$ are included in appendixes I and II to make the data available in the broader context of the tabular data base. However, these data were acquired for an independent study by Smith and D. Gottfried and are not discussed in detail in this paper. The presentation varies somewhat from element to element but normally the data are given as histograms (for example, see figs. 29,40 ), as $\mathrm{SiO}_{2}$-variation diagrams (see figs. 30,41), and as correlation matrices for relevant elements. $\mathrm{SiO}_{2}$-variation diagrams are not suitable for trace elements which show orders-ofmagnitude variations, and another element is then used as a basis of comparison.

Correlation coefficients for all pairs of the following variables have been computed (app. VI): all major and trace elements, $\mathrm{FeO}_{t}$, and $\mathrm{Na}_{2} \mathrm{O} / \mathrm{K}_{2} \mathrm{O}$ ratio. In order to maximize the value of the coefficients, only rocks with both major- and traceelement data were used (app. I). Hydrated (app. II) and peralkaline samples, those samples with $\mathrm{SiO}_{2}<70$ percent, and the quite exceptional macusanite sample (No. 160) were also excluded from the calculations. The maximum degrees of freedom, that is, for rocks in which all elements had been satisfactorily determined, were 193; any correlation $>0.2$ is significant at the 1 percent level. In the following discussion, a value of $r= \pm 0.60$ was selected to isolate the most important interelement correlations, and these are listed in the section for each element. This value means that correlations are significant at better than the 0.1 percent level even for those elements for which the fewest determinations are available.

\section{SILICON}

The $\mathrm{SiO}_{2}$ values range from an arbitrary lower limit of $\mathbf{7 0}$ percent to $\mathbf{7 7 . 5}$ percent. The upper limit is almost identical to that (77.4 percent) suggested by Hildreth (1981) as a likely maximum for unaltered rhyolites, and there are sufficient obsidian analyses (11 samples) bearing $\mathrm{SiO}_{2}>77$ percent to be confident that such liquids do occur in nature. 
TABLE 9.-Ranges and average compositions of CLPD and CIPP obsidians of continental margins and interiors

[First averages in each column calculated using new data only (appendix I); ranges and second averages using all data (appendixes I, III); --, not determined]

\begin{tabular}{|c|c|c|c|c|c|c|c|c|c|c|c|c|}
\hline & \multirow{2}{*}{\multicolumn{6}{|c|}{ Continental margins }} & \multirow{2}{*}{\multicolumn{6}{|c|}{ Continental interiors }} \\
\hline & & & & & & & & \multicolumn{2}{|c|}{ CLPD } & \multicolumn{3}{|c|}{ CIPP } \\
\hline & Range & $\mathbf{x}$ & $\mathrm{x}_{\mathrm{T}}$ & Range & $\mathbf{x}$ & $\mathbf{x}_{\mathrm{T}}$ & Range & $\mathbf{x}$ & $\mathbf{x}_{\mathrm{T}}$ & Range & $\mathbf{x}$ & $\mathbf{x}_{\mathrm{r}}$ \\
\hline \multicolumn{13}{|c|}{ Major elements (weight percent) } \\
\hline $\mathrm{SiO}_{2} \ldots$ & $70.2-77.3$ & 74.2 & 73.8 & $74.5-77.2$ & 76.4 & 77.3 & $70.6-77.3$ & 75.8 & 75.7 & $70.7-77.5$ & 75.9 & 76.0 \\
\hline $\mathrm{Al}_{2} \mathrm{O}_{3} \ldots$ & $12.30-15.37$ & 13.73 & 13.79 & $11.92-12.96$ & 12.50 & 12.35 & $11.9-14.63$ & 13.20 & 13.01 & $12.09-16.30$ & 12.78 & 12.93 \\
\hline $\mathrm{Fe}_{2} \mathrm{O}_{3}$ & $.09-1.67$ & .51 & .52 & $.19-.51$ & .36 & .35 & $.21-1.3$ & .46 & .47 & $.09-1.33$ & .40 & .42 \\
\hline $\mathrm{FeO}$ & $.32-2.62$ & .96 & 1.20 & $.39-.93$ & .63 & .68 & $.12-1.76$ & .64 & .73 & $.19-1.31$ & .53 & .52 \\
\hline MgO & $<.01-.93$ & .23 & .27 & $.01-.27$ & .04 & .05 & $.00-.66$ & .09 & .10 & $.00-.44$ & .02 & .03 \\
\hline $\mathrm{CaO}$ & $.44-2.94$ & 1.07 & 1.19 & $.27-.79$ & .48 & .53 & $.31-1.61$ & .60 & .59 & $.16-2.07$ & .44 & .47 \\
\hline $\mathrm{Na}_{2} \mathrm{O}$ & $3.40-5.38$ & 4.35 & 4.32 & $3.52-4.38$ & 4.08 & 4.07 & $3.00-4.98$ & 3.96 & 3.90 & $3.30-5.07$ & 4.31 & 4.28 \\
\hline $\mathrm{K}_{2} \mathrm{O}$ & $2.43-5.26$ & 4.04 & 4.05 & $4.50-4.95$ & 4.62 & 4.64 & $4.01-6.60$ & 4.76 & 4.90 & $3.60-5.53$ & 4.45 & 4.48 \\
\hline $\mathrm{H}_{2} \mathrm{O}^{+}$ & $.04-1.10$ & .19 & .26 & $.09-.71$ & .25 & .34 & $.03-.68$ & .18 & .22 & $.01-.98$ & .31 & .30 \\
\hline $\mathrm{TiO}_{2}$ & $.03-.54$ & .22 & .23 & $.05-.13$ & .09 & .08 & .02-.31 & .13 & 14 & $.00-.15$ & .07 & .06 \\
\hline $\mathrm{P}_{2} \mathrm{O}_{5}$ & $.01-.22$ & .04 & .05 & $.008-.03$ & .01 & .01 & $.00-.09$ & .02 & .02 & $.00-.55$ & $.01^{*}$ & $.01 *$ \\
\hline MnO & $.02-.12$ & .06 & .05 & $.02-.10$ & .06 & .05 & $.02-.14$ & .06 & .05 & $.02-.13$ & .05 & .05 \\
\hline Cl & $.01-.17$ & .07 & - & $.03-.10$ & .06 & - & $.04-.13$ & .08 & - & $.04-.20$ & .09 & - \\
\hline F & $.02-.11$ & .05 & - & $.05-.12$ & .07 & - & $.05-.12$ & .09 & - & $.07-1.36$ & $.20^{*}$ & - \\
\hline $\mathrm{FeO}_{\mathrm{t}}{ }^{1}$ & $.53-2.89$ & 1.38 & 1.67 & $.74-1.20$ & .95 & 1.00 & $.50-2.30$ & 1.05 & 1.15 & $56-1.71$ & .89 & .90 \\
\hline $\mathrm{FeO} /\left(\mathrm{FeO}+\mathrm{Fe}_{2} \mathrm{O}_{3}\right)^{1}$ & $.35-.95$ & .65 & .70 & $.45-.83$ & .64 & .66 & $.08-.84$ & .58 & .61 & $.24-.85$ & .57 & .55 \\
\hline $\mathrm{Na}_{2} \mathrm{O} / \mathrm{K}_{2} \mathrm{O}^{1}$ & $.68-2.16$ & 1.08 & 1.07 & $.74-.96$ & .84 & .85 & $.61-1.13$ & .83 & .80 & $.60-1.23$ & .97 & .96 \\
\hline$\left(\mathrm{Na}_{2} \mathrm{O}+\overline{\mathrm{K}}_{2} \mathrm{O}\right) / \mathrm{Al}_{2} \mathrm{O}_{3}{ }^{2}$ & $.73-1.00$ & .84 & .83 & $.86-.97$ & .94 & .93 & $.80-.99$ & .88 & .90 & $.66-.99$ & .93 & .92 \\
\hline$\left(\mathrm{CaO}+\mathrm{Na}_{2} \mathrm{O}+\mathrm{K}_{2} \mathrm{O}\right) / \mathrm{Al}_{2} \mathrm{O}_{3}{ }^{2}$ & 89-1.12 & .98 & .99 & $.96-1.03$ & 1.01 & 1.01 & $.90-1.07$ & .97 & .99 & $.68-1.04$ & .99 & .98 \\
\hline $\mathrm{CaO} /\left(\mathrm{Na}_{2} \mathrm{O}+\mathrm{K}_{2} \mathrm{O}\right)^{1}$ & $.05-.39$ & .13 & .14 & $.03-.10$ & .06 & .06 & $.03-.20$ & .07 & .07 & $.02-.23$ & .05 & .05 \\
\hline $\mathrm{Cl} / \mathrm{F}^{1}$ & $15-3.94$ & 1.5 & - & $.35-1.23$ & .9 & - & $.36-2.40$ & .90 & 1.19 & $.03-1.21$ & .5 & - \\
\hline \multicolumn{13}{|c|}{ Trace elements (parts per million) } \\
\hline (1) & 13-1440 & 814 & - & $13-415$ & 121 & - & 6-1040 & 287 & - & $1-70$ & 16 & - \\
\hline Be - & $1.3-3.4$ & 2.5 & - & $3.1-5.5$ & 3.9 & - & 18-7.3 & 3.8 & - & 4.6-32 & 11 & - \\
\hline Co & $.1-4.5$ & 1.1 & - & $<.2-.4$ & .3 & - & $.1-3.7$ & .5 & - & $.1-3.1$ & .4 & - \\
\hline Cr & $1.1-10.7$ & 2.3 & - & $1.7-3.5$ & 2.4 & - & $1.0-13.2$ & 3.1 & - & $1.3-9.0$ & 1.6 & - \\
\hline Cs & $1.8-14.8$ & 5.1 & - & $4.7-21.1$ & 10 & - & $2.0-15.7$ & 5.3 & - & $3.7-503$ & 7.6* & - \\
\hline Hf & $1.9-11.5$ & 5.0 & - & $2.7-6.7$ & 4.7 & - & $2.3-10.6$ & 5.3 & - & $1.3-14.5$ & 5.8 & - \\
\hline $\mathrm{Li}$ & $28-81$ & 45 & - & $42-110$ & 68 & - & $32-170$ & 56 & - & $\mathbf{3 6 - 3 4 0 0}$ & $116^{*}$ & - \\
\hline Mo - & $.58-6.5$ & 3.2 & - & $.96-8.1$ & 3.4 & - & $1.6-9$ & 4.5 & - & $.26-9.9$ & 3.6 & - \\
\hline Nb - & 5.2-27 & 13 & - & $14.5-37$ & 23 & - & $14-65$ & 37 & - & $20-288$ & 77 & - \\
\hline Pb & 9-34 & 21 & - & $17-49$ & 25 & - & $15-50$ & 26 & - & 20-101 & 38 & - \\
\hline Rb - & $52-223$ & 126 & - & $130-270$ & 202 & - & $103-296$ & 179 & - & $160-1174$ & 291* & - \\
\hline Sb --1- & $.2-1.9$ & .8 & - & $.6-1.3$ & 1.0 & - & $.1-1.3$ & .5 & - & $.3-2.9$ & $.9^{*}$ & - \\
\hline Sc - - & $1.1-8.4$ & 3.7 & - & $1.57-5.15$ & 2.8 & - & $1.03-4.23$ & 2.4 & - & $.12-3.85$ & 1.6 & - \\
\hline Sn - & $.7-6$ & 2.2 & - & $3.1-7.9$ & 4.7 & - & $1.3-9.4$ & 3.4 & - & $2.4-250$ & $8.2^{*}$ & - \\
\hline Sr & $9-444$ & 135 & - & $2-40$ & 14 & - & 2-202 & 41 & - & $.3-20$ & 4 & - \\
\hline Ta & $.44-1.82$ & 1.13 & - & $1.02-2.95$ & 2.01 & - & $1.33-5.69$ & 3.13 & - & $2.57-29.41$ & 7.67 & - \\
\hline Th & $4.9-26.6$ & 12 & - & $9.8-26.4$ & 18 & - & $4.2-45.6$ & 22 & - & $1.3-52.7$ & 30 & - \\
\hline U - & $2.9-8.3$ & 4.7 & - & $4.2-13.2$ & 6.8 & - & $3.5-14.4$ & 7.2 & - & $5.3-35.1$ & 12.9 & - \\
\hline
\end{tabular}




\begin{tabular}{|c|c|c|c|c|c|c|c|c|c|c|c|c|}
\hline W - & $.5-3.5$ & 1.6 & - & 2.1-3.9 & 2.8 & - & $1.0-3.5$ & 2.2 & - & $1.4-76$ & $3.4^{*}$ & - \\
\hline Y - & $8-80$ & 27 & - & 26-108 & 43 & - & $8-93$ & 37 & - & $25-245$ & 78 & - \\
\hline Zn & $16-89$ & 35 & - & 30-95 & 47 & - & 18-101 & 41 & - & 33-282 & 65 & 一 \\
\hline Zr & $40-447$ & 171 & - & $52-260$ & 123 & - & $52-367$ & 147 & - & $22-338$ & 125 & 一 \\
\hline La …- & 9-90 & 28 & - & $19-40$ & 25 & - & $10-95$ & 45 & - & 1-72 & 22 & - \\
\hline $\mathrm{Ce}$ & $18-142$ & 51 & - & 41-71 & 51 & - & 18-185 & 84 & - & 3-132 & 48 & 一 \\
\hline Nd - & $8-51$ & 22 & - & $15-30$ & 23 & - & $7-71$ & 30 & - & $4-56.9$ & 25 & - \\
\hline Sm - & $2.0-9.0$ & 4.5 & - & $3.3-10.5$ & 6.0 & - & $2.6-15.9$ & 6.6 & - & $1.5-15.6$ & 6.6 & - \\
\hline Eu - - & $13-1.11$ & .60 & - & $.08-.61$ & .22 & - & .14-.98 & .41 & - & .02-.31 & 10 & - \\
\hline 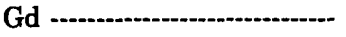 & $1.6-9.5$ & 4.1 & - & $3.1-10.8$ & 5.6 & - & $2.2-13.2$ & 5.7 & - & $<2-16.6$ & 7.8 & - \\
\hline Tb & $.24-1.53$ & 67 & - & $62-2.25$ & 1.1 & - & $<.03-2.44$ & 1.0 & - & $.17-4.26$ & 1.7 & - \\
\hline Tm & $<.10-1.10$ & .42 & - & $.32-1.82$ & .68 & - & $<.2-1.34$ & .67 & - & $.25-3.22$ & 1.1 & - \\
\hline Yb & $.2-6.9$ & 2.6 & - & $2.3-11.7$ & 4.6 & - & $1.1-8.0$ & 3.8 & - & .3-23.6 & 7.2 & - \\
\hline Lu & $.12-.98$ & .39 & - & $.32-1.66$ & .65 & - & $.15-1.10$ & .54 & - & $.04-3.04$ & .99 & - \\
\hline $\mathrm{Nb} / \mathrm{Ta}$ & $7.4-21.2$ & 11.5 & - & $8.1-14.2$ & 11.4 & - & $6.0-18.9$ & 11.8 & - & $2.5-15.4$ & 10.0 & - \\
\hline K/Rb & $180-394$ & 266 & - & 138-316 & 190 & - & $150-380$ & 221 & - & 25-257 & 127 & - \\
\hline Rb/Sr & $.1-15$ & .9 & - & $4.8-65$ & 14.4 & - & .8-ï173 & 4.4 & - & 14-1533 & 73 & - \\
\hline $\mathrm{Ca} / \mathrm{Sr}$ & 35-389 & 57 & - & $107-965$ & 245 & - & $38-1668$ & 105 & - & 429-12863 & 786 & - \\
\hline Th/U & $1.4-3.6$ & 2.6 & - & $1.9-3.6$ & 2.6 & - & $1.2-5.1$ & 3.1 & - & $.1-3.9$ & 2.3 & - \\
\hline Zr/Hf & $17-48$ & 34 & - & $17-41$ & 26 & - & $18-43$ & 28 & - & $10-36$ & 22 & - \\
\hline $\mathrm{Ce} / \mathrm{Yb}$ & $7.4-230$ & 19.6 & - & $4.7-18.6$ & 11.1 & - & $10-120$ & 22.1 & - & 2.4-21.5 & 6.7 & - \\
\hline $\mathrm{Eu} / \mathbf{E u}^{*}$ & $.10-.75$ & .43 & - & $.04-.18$ & .12 & - & .05-.56 & .20 & - & .01-.24 & .04 & - \\
\hline
\end{tabular}

Maximum number of determinations: major elements

\section{By weight
2Molecular}

*Averages exclude $\mathrm{P}_{2} \mathrm{O}_{5}, \mathrm{~F}, \mathrm{Cs}, \mathrm{Li}, \mathrm{Rb}, \mathrm{Sb}, \mathrm{Sn}$, and $\mathrm{W}$ data for sample 160 


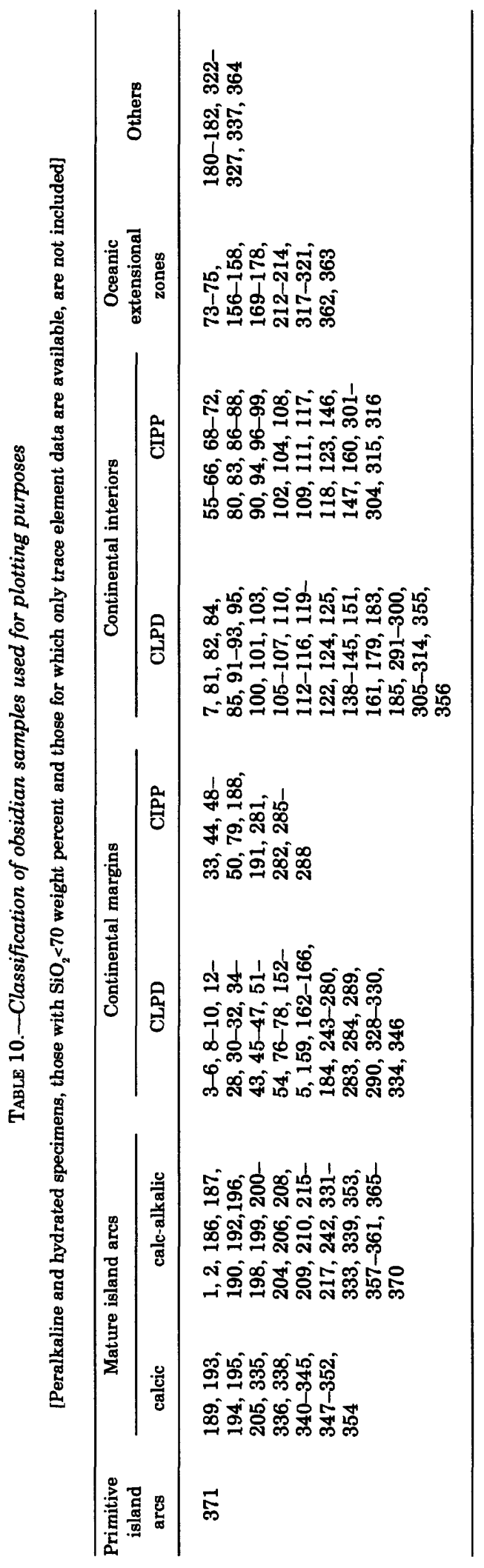

A histogram (fig. 29A) reveals increasing numbers of samples with increasing $\mathrm{SiO}_{2}$ contents. This increase presumably reflects the tendency of higher silica liquids to chill to glass.

No very high silica obsidians are known from primitive island arcs, which casts doubt on the magmatic nature of the high silica content (up to 80 percent) recorded in certain devitrified and secondarily hydrated specimens in this setting (see section "Geochemical Features of Main Obsidian Groups," group I). The bimodal character of silica distribution in mature-arc obsidians probably results from two effects. The lower silica peak represents the end-member compositions of the calcic rhyolites usually associated with tholeiitic complexes, which do not generally evolve to high- $\mathrm{SiO}_{2}$ compositions. The higher silica peak is formed by rocks of calc-alkalic type, the position of the peak again being determined by viscosity relations.

Base-level compositions (CLPD type) in continentalmargin obsidians show an approach to a normal $\mathrm{SiO}_{2}$ distribution, which probably reflects the overall distribution of silicic magma types in such settings. Although there are few samples in the data base, CIPP types are notably more silicic, reflecting $\mathrm{SiO}_{2}$ enrichment in lower temperature magmas. The magnitude of the shift relative to base-level rocks may be exaggerated, in that the CIPP nature of the lower $\mathrm{SiO}_{2}$ range of the Bishop Tuff, for example, is 75.5-77.4 percent, and this probably does not include base-level compositions (Hildreth, 1979).

There is a distinct scarcity of obsidians with $\mathrm{SiO}_{2}$ in the range 70-74 percent in the continental interiors. This may be partly due to the fact that the baselevel rocks are genuinely richer in silica, perhàps being derived by melting of more quartz-rich sources. The activity has not normally tapped deep enough levels within the relevant systems; the Bandelier Tuff, for example, ranges in composition from 72-77 percent $\mathrm{SiO}_{2}$.

Although there are fewer samples of the obsidians of the oceanic extensional zones, specimens are probably evenly distributed over the $\mathrm{SiO}_{2}$ range, as the histogram suggests.

Figure 29.-Distribution of major elements in obsidians. Obsidians of primitive island arcs and continental margins (CIPP types) are shown as ranges only. Arrows indicate average values. Data from appendixes I, III, and V. $A, \mathrm{SiO}_{2} . B$, $\mathrm{Al}_{2} \mathrm{O}_{3}$. C, Total iron as FeO. $D, \mathrm{MgO} . E, \mathrm{CaO} . F, \mathrm{Na}_{2} \mathrm{O} . G, \mathrm{~K}_{2} \mathrm{O}$ (sample 313 omitted to preserve scale). $H, \mathrm{Na}_{2} \mathrm{O}+\mathrm{K}_{2} \mathrm{O} . \mathrm{I}, \mathrm{TiO}_{2}$ (sample 176 omitted to preserve scale). $J, \mathrm{P}_{2} \mathrm{O}_{5}$ (samples 160 , 316,321 , and 351 omitted to preserve scale). $K, \mathrm{MnO}$ (sample 345 omitted to preserve scale). $L, \mathrm{Cl}$ (sample 212 omitted to preserve scale). $M, F$ (sample 160 omitted to preserve scale). Change of scale on $\mathrm{P}_{2} \mathrm{O}_{5}$ and $\mathrm{F}$ axes is intentional. 


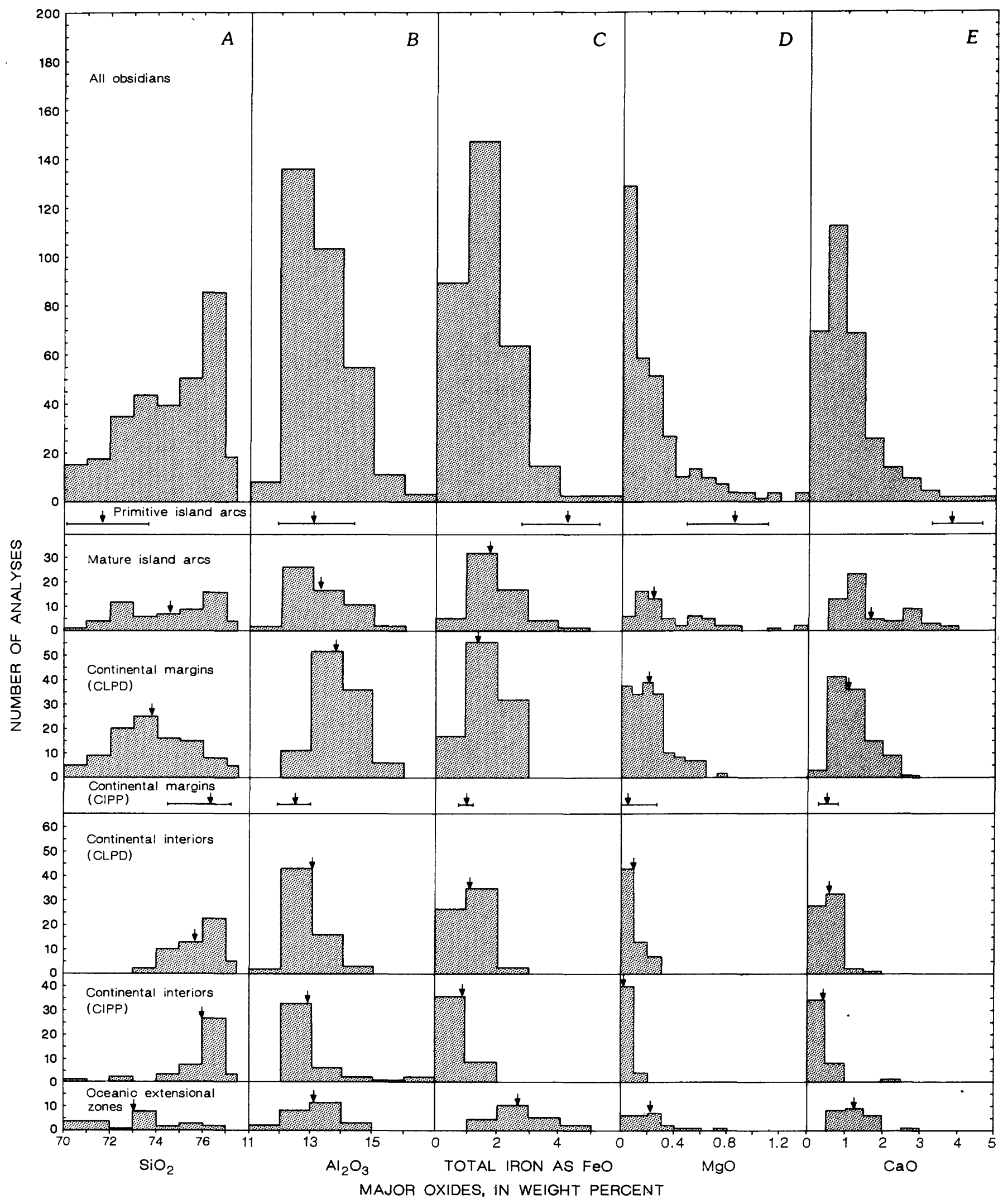




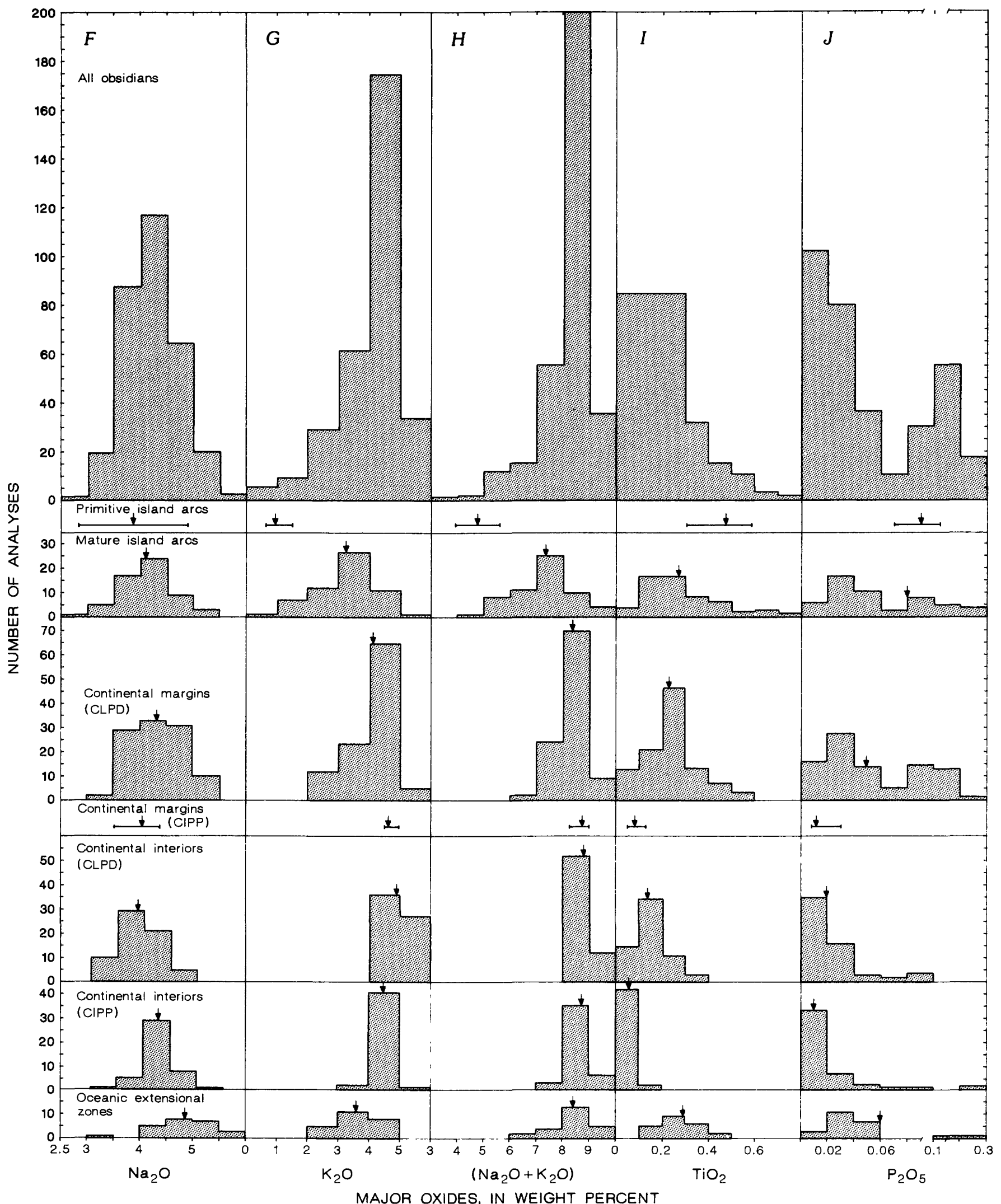

Figure 29.-Continued. 


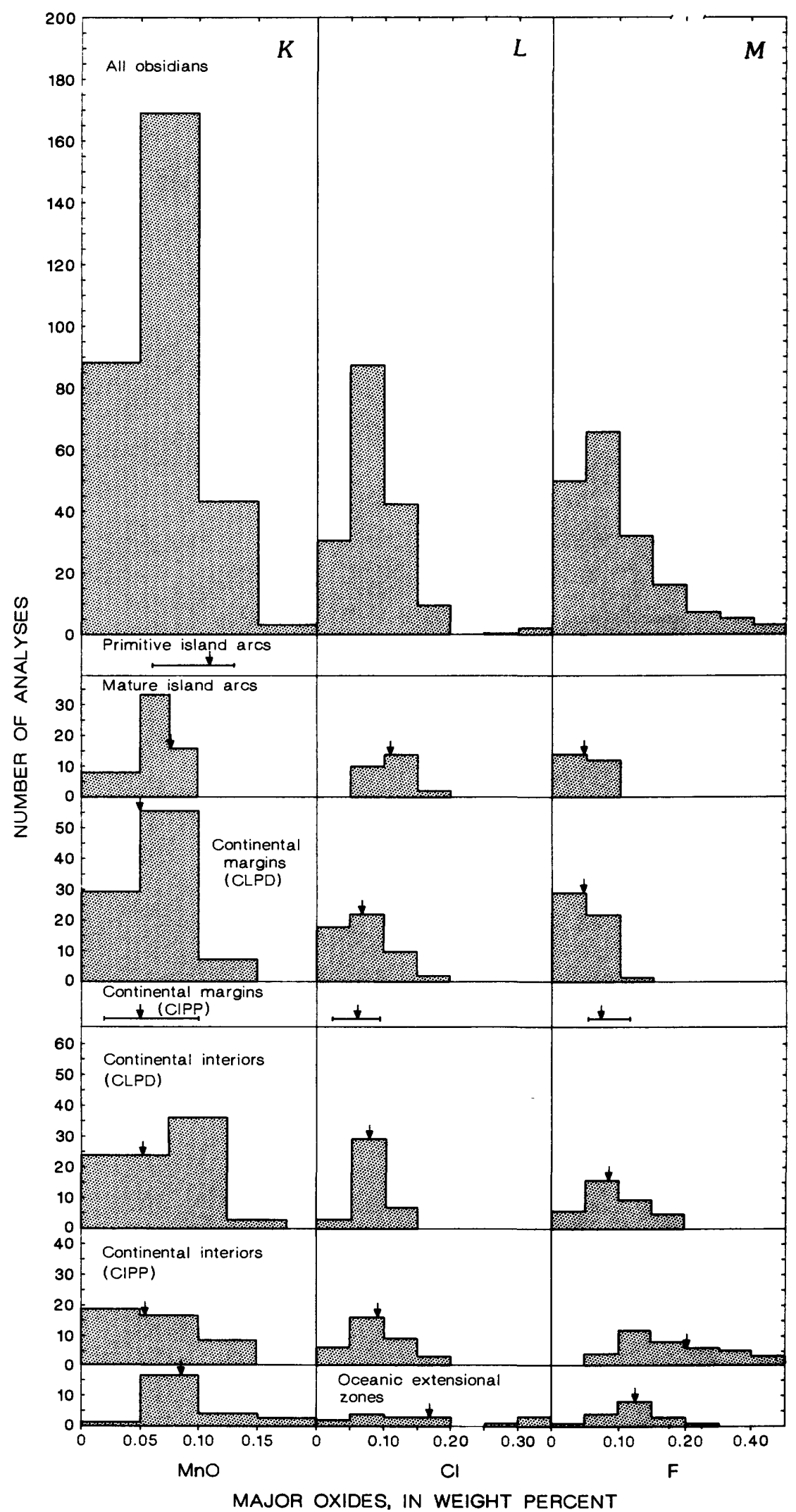

Figure 29.-Continued. 


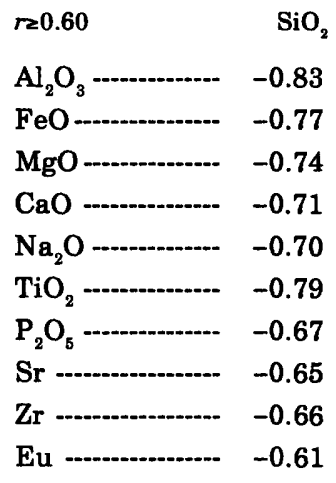

\section{ALUMINUM}

$\mathrm{Al}_{2} \mathrm{O}_{3}$ shows a very scattered, but significant $(r=$ -0.83), negative correlation with $\mathrm{SiO}_{2}$ (see fig. $30 A$ ). This imparts a skew in the $\mathrm{Al}_{2} \mathrm{O}_{3}$ histogram toward lower $\mathrm{Al}_{2} \mathrm{O}_{3}$ values (fig. 29B). Much of the spread at constant $\mathrm{SiO}_{2}$ results from variations between rhyolite groups. Rocks from primitive island arcs and oceanic extensional zones tend to have lower $\mathrm{Al}_{2} \mathrm{O}_{3}$ values than those of the other groups. Calcic varieties of island-arc obsidians tend to have lower $\mathrm{Al}_{2} \mathrm{O}_{3}$ abundances than calc-alkalic types at similar $\mathrm{SiO}_{2}$ contents.

Of the various rhyolite groups, continental-margin obsidians show the least scatter when plotted against $\mathrm{SiO}_{2}$ (fig. 30). The spread of points is generally parallel to the rock-glass tielines and to the trend of the Woodson granodiorite stock. Though this is compatible with their compositions having been controlled by crystal-liquid processes, the CIPP trends for zoned ash-flow tuffs are also parallel, such that there is gross overlap between the fields of CLPD and CIPP rocks on this diagram.

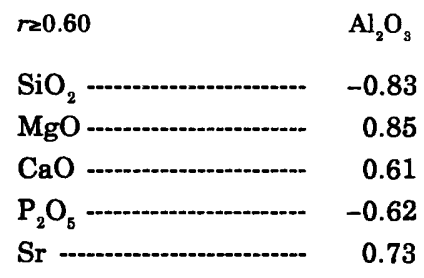

\section{IRON \\ TOTAL $\mathrm{Fe}$ AS $\mathrm{FeO}(\mathrm{FeO})$}

$\mathrm{FeO}_{\mathrm{t}}$ shows an overall negative correlation with $\mathrm{SiO}_{2}(r=-0.79)$. For any given $\mathrm{SiO}_{2}$ value, there is a three- to five-fold variation in $\mathrm{FeO}_{\mathrm{t}}$, the scatter resulting from two main effects. First, important intergroup differences exist in $\mathrm{FeO}_{\mathrm{t}}-\mathrm{SiO}_{2}$ relations. Thus, obsidians from primitive arcs and oceanic ex- tensional settings have higher $\mathrm{FeO}_{\mathrm{t}}$ contents than those from the other groups at equivalent $\mathrm{SiO}_{2}$ values. Second, there are variations within groups, two examples of which are shown in figure 31 . Within the arc setting, the calcic types (as defined in fig. 4) tend to have higher $\mathrm{FeO}_{t}$ than the calcalkalic types, again normalized to $\mathrm{SiO}_{2}$. In the continental interiors, CLPD obsidians of the Snake River Plain and Yellowstone systems have notably higher $\mathrm{FeO}_{\mathrm{t}}$ than similar rocks from Utah and New Mexico.

The behavior of Fe during CIPP is partially dependent on bulk composition. In the Bishop and Coso systems, Fe was a downward-concentrating element (Hildreth, 1979, 1981; Bacon and others, 1981); in peralkaline systems, especially Cl-rich types, it is normally an "up" element (Mahood, 1981a, b; Hildreth, 1981). Smith (1979, p. 14) omitted $\mathrm{Fe}$ from his list of element behavior in the Bandelier Tuff, because there is evidence of a more complex pattern, whereby $\mathrm{Fe}$ increased upward during CIPP episodes but was fractionated downward during intermittent periods of CLPD. As far as the body of obsidian data is concerned, CIPP has had the overall effect of lowering the mean $\mathrm{FeO}_{\mathrm{t}}$ content in CIPP as opposed to relevant baselevel rocks (fig. 29C) and, as a result, increasing the $\mathrm{SiO}_{2} / \mathrm{FeO}_{\mathrm{t}}$ ratio (fig. $30 \mathrm{~B}$ ).

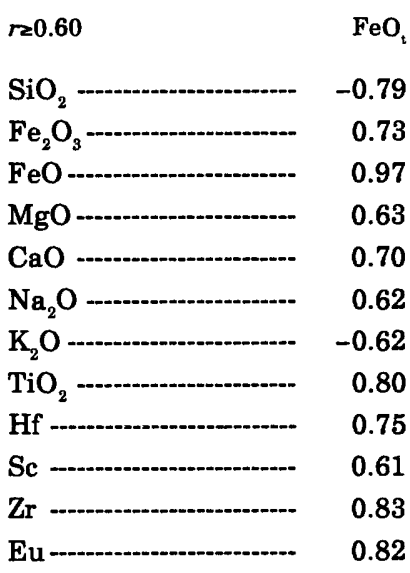

$$
\mathrm{FeO} /\left(\mathrm{FeO}+\mathrm{Fe}_{2} \mathrm{O}_{3}\right) \text { RATIOS }
$$

The iron oxidation ratio is prone to modification during even slight secondary hydration of glasses. Furthermore, analytical imprecision is probably an important problem, especially in older analyses. For example, the average $\mathrm{FeO} /\left(\mathrm{FeO}+\mathrm{Fe}_{2} \mathrm{O}_{3}\right)$ ratio in published analyses of obsidians from mature island arcs, especially the calcic varieties, is lower than that in 

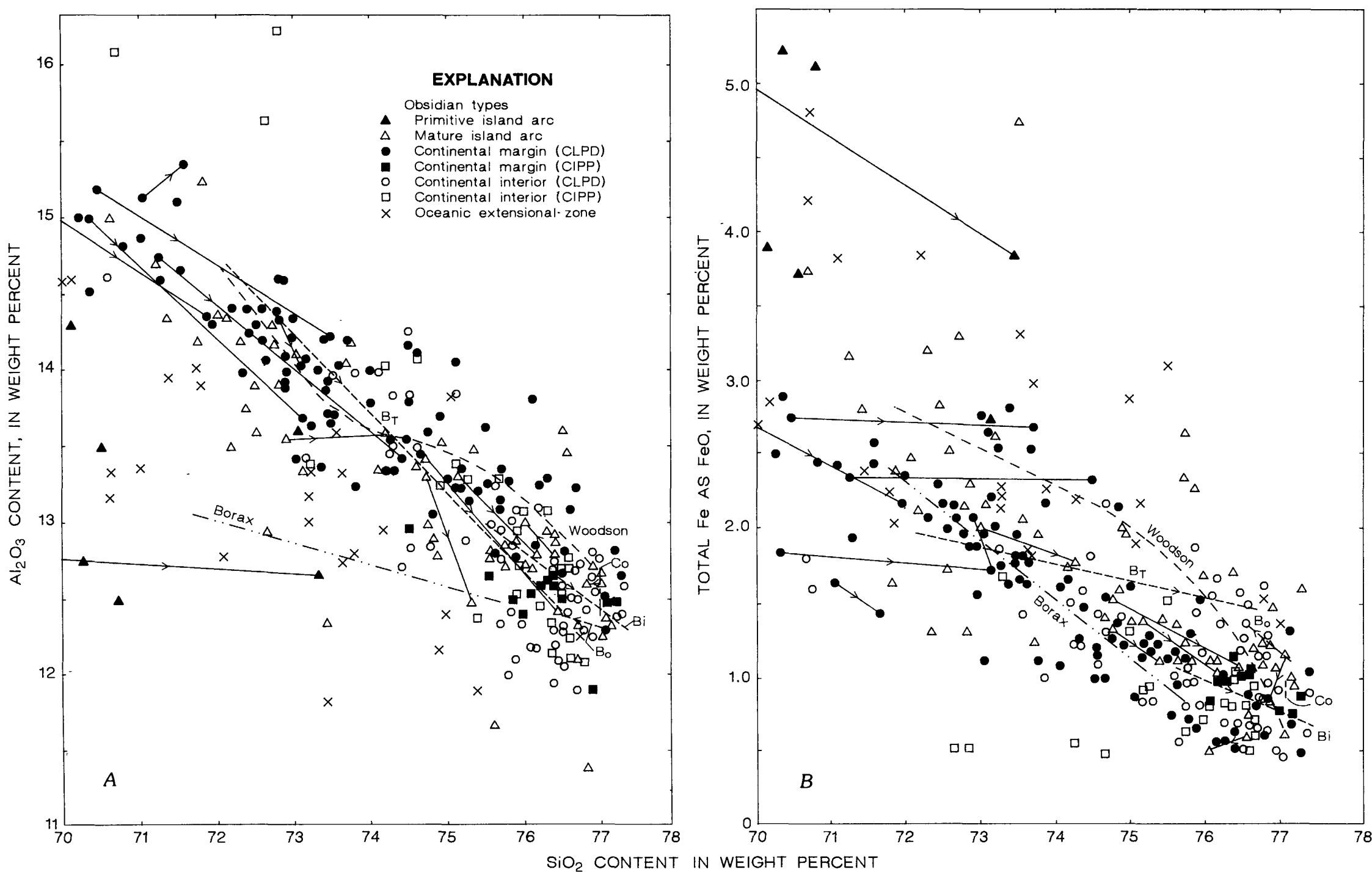

FIGURE 30.-Major-element silica-variation diagrams for obsidians and various comparative rocks. Data for obsidians from appendixes I, III, and V; others are same as for figure $5 . \mathrm{SiO}_{2}$ content versus: $A, \mathrm{Al}_{2} \mathrm{O}_{3} . B$, Total iron as $\mathrm{FeO}$. $C$, $\mathrm{MgO}$ (samples 350 and 351 omitted to preserve scale). $D, \mathrm{CaO} . E, \mathrm{Na}_{2} \mathrm{O} . F, \mathrm{~K}_{2} \mathrm{O}$ (sample 313 omitted to preserve scale). $G, \mathrm{Na}_{2} \mathrm{O}+\mathrm{K}_{2} \mathrm{O} . \mathrm{H}, \mathrm{TiO}_{2}, I, \mathrm{P}_{2} \mathrm{O}_{5} . J, \mathrm{MnO}$

$K, C l . L, F$ (sample 160 omitted to preserve scale). Solid tielines indicate rock glass pairs. Dashed lines indicate range of compositions of systems; Bishop Tuff (Bi); Bandelier Tuff (Otowi Member, $\mathrm{B}_{\mathrm{o}}$, Tshirege Member, $\mathrm{B}_{\mathrm{T}}$ ) Coso Range (Co); Borax Lake; and Woodson Granodiorite. References as in figure 5. All arrows indicate direction of fractionating liquid. 

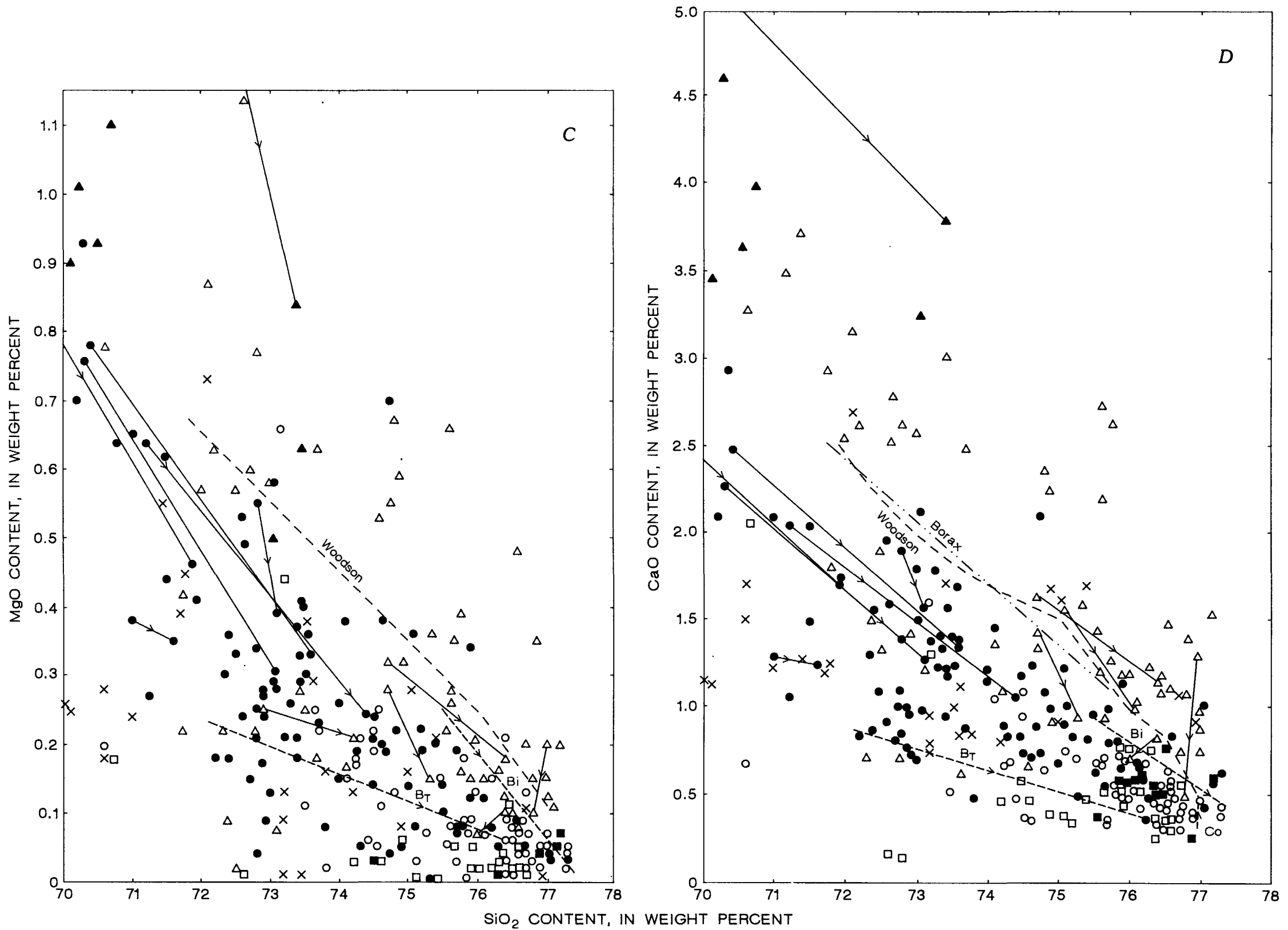

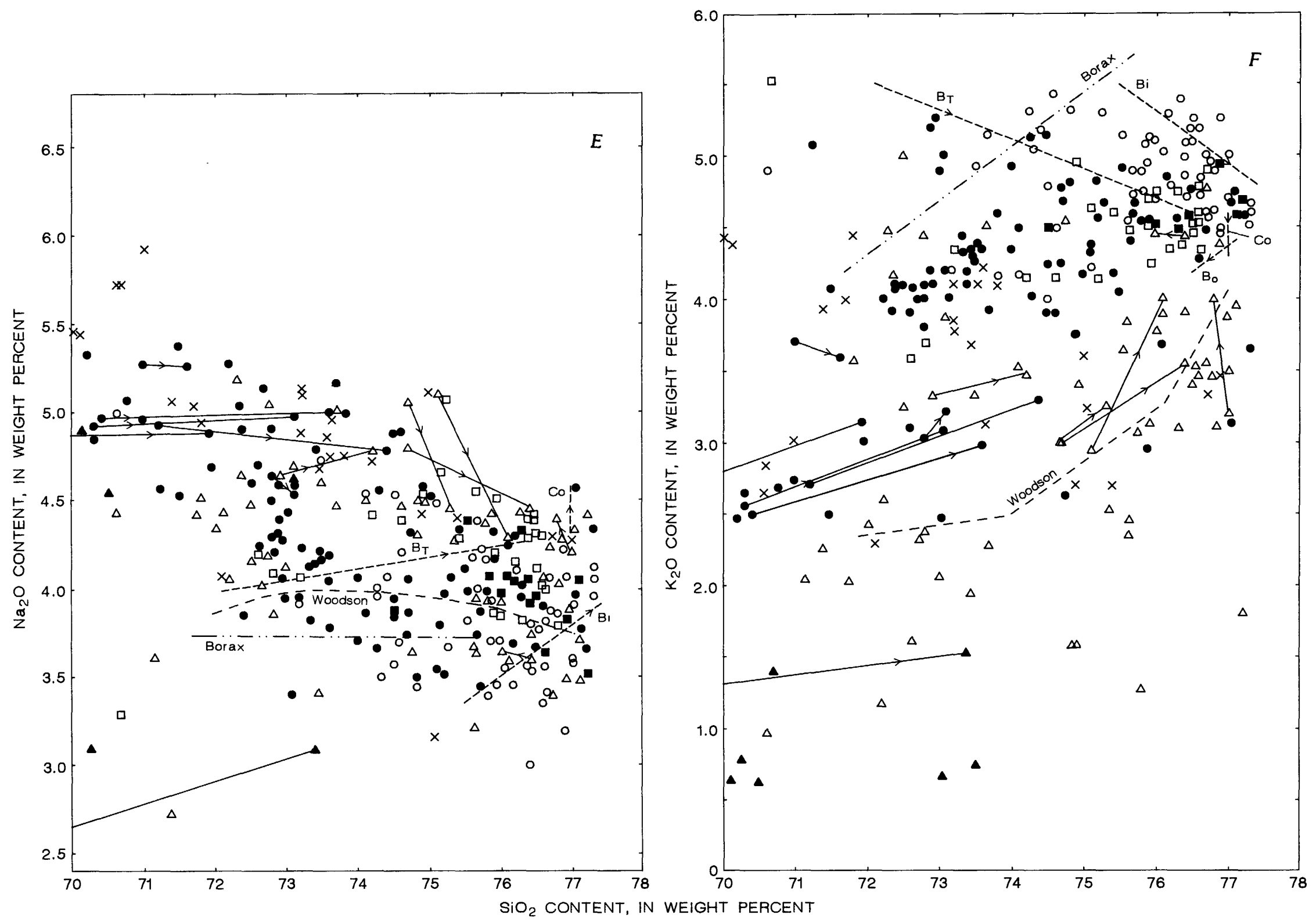

Figure 30.-Continued. 

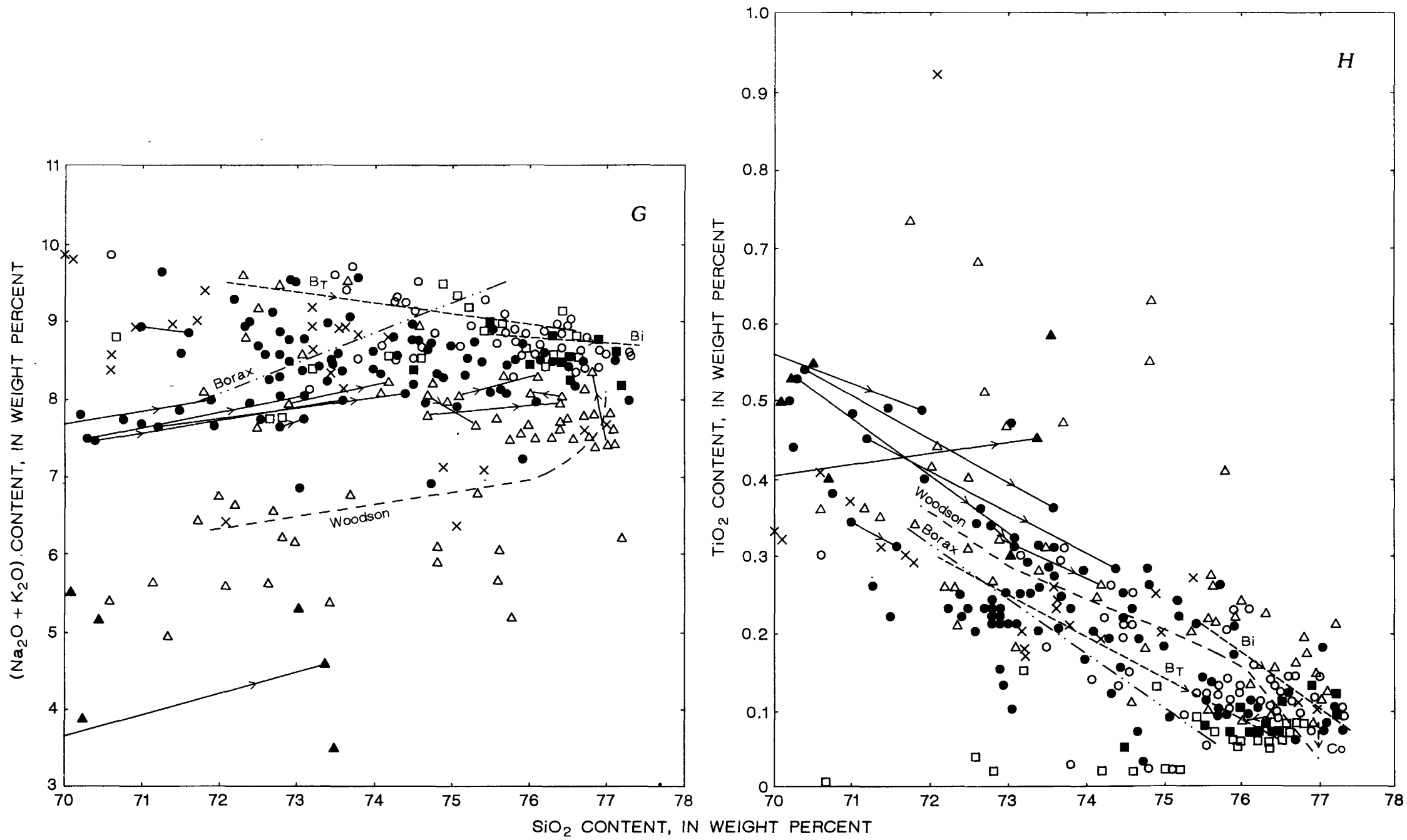



Figure 30.-Continued 


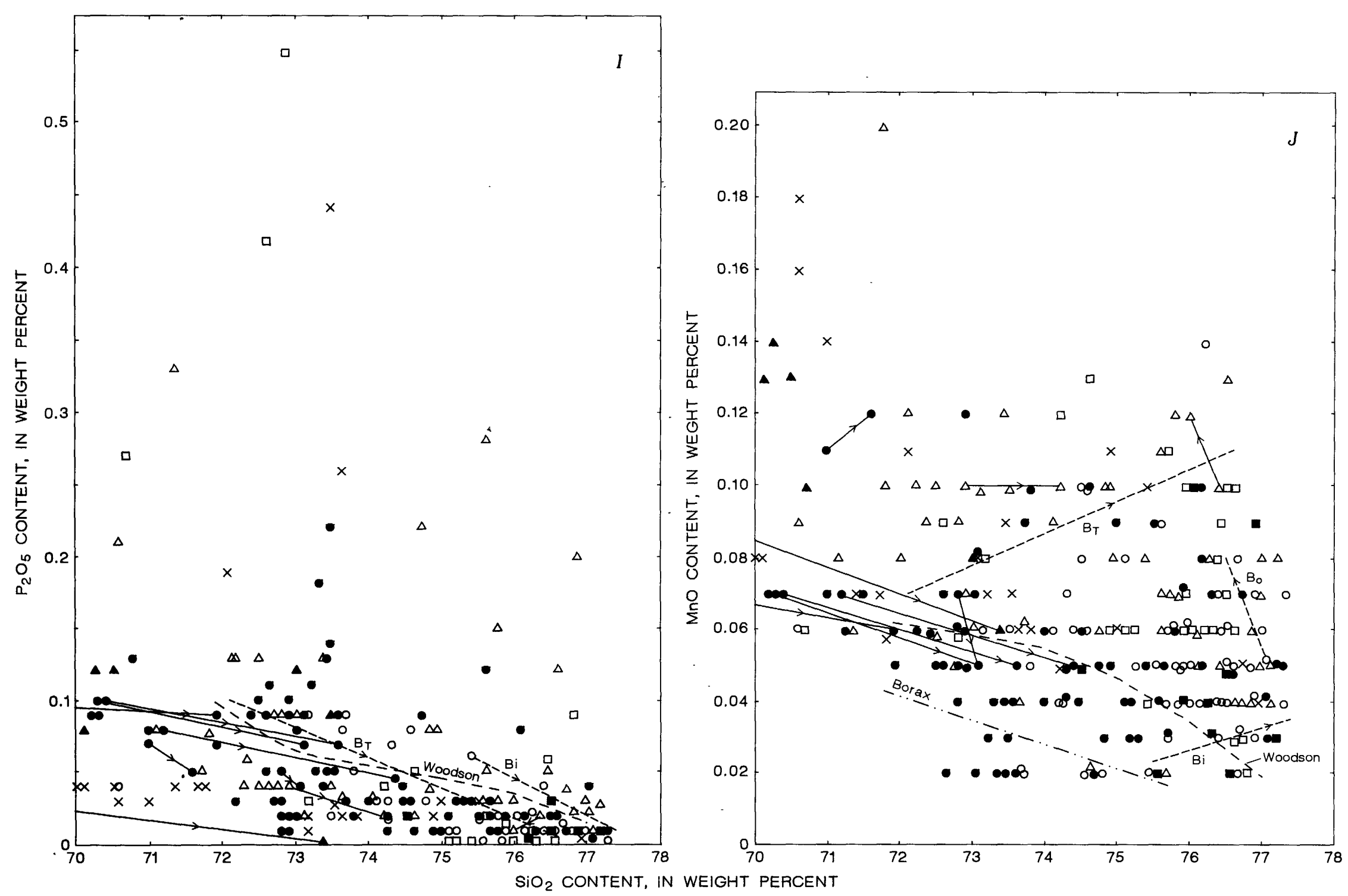

Figure 30.-Continued. 


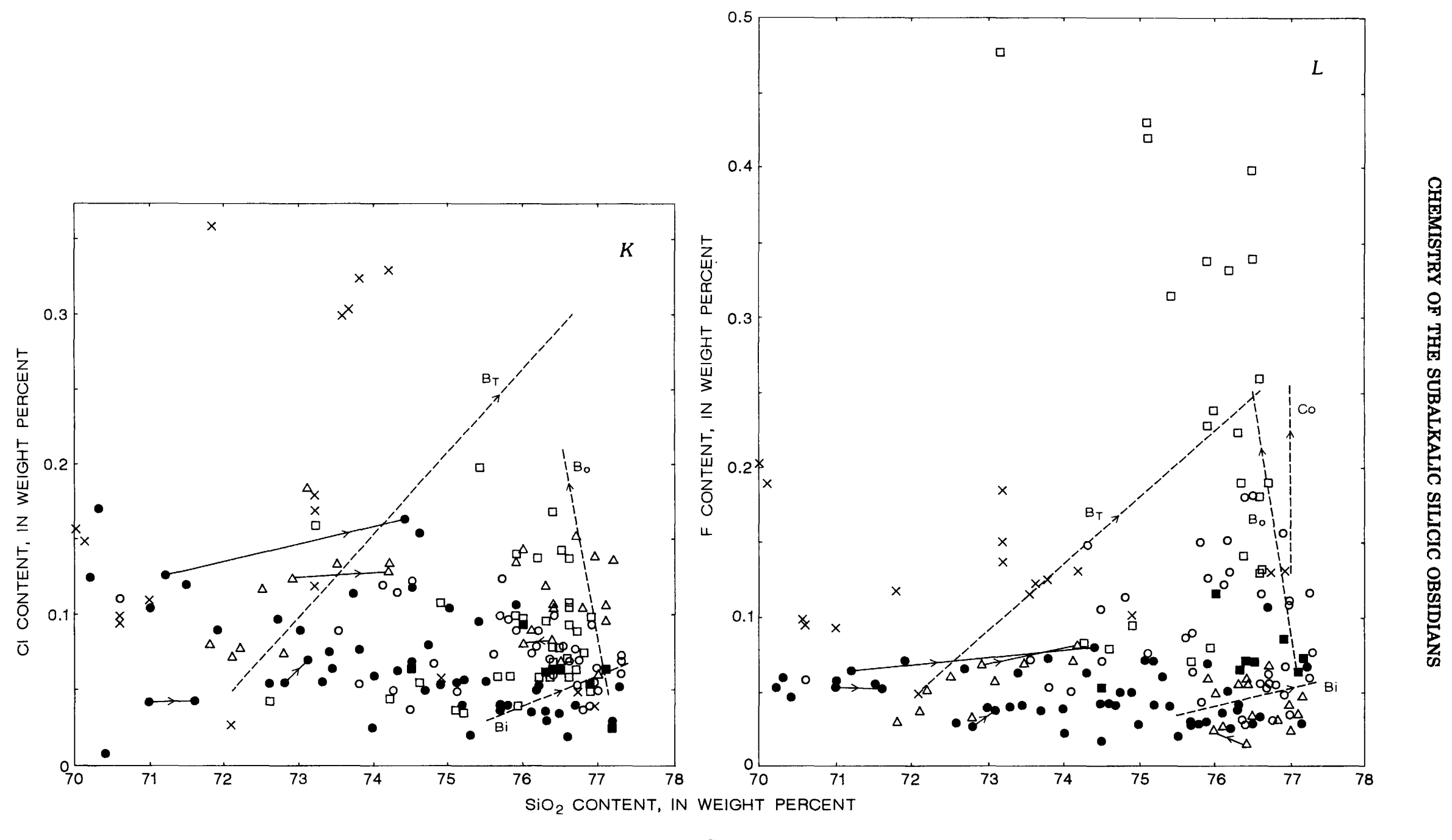

Figure 30.-Continued. 


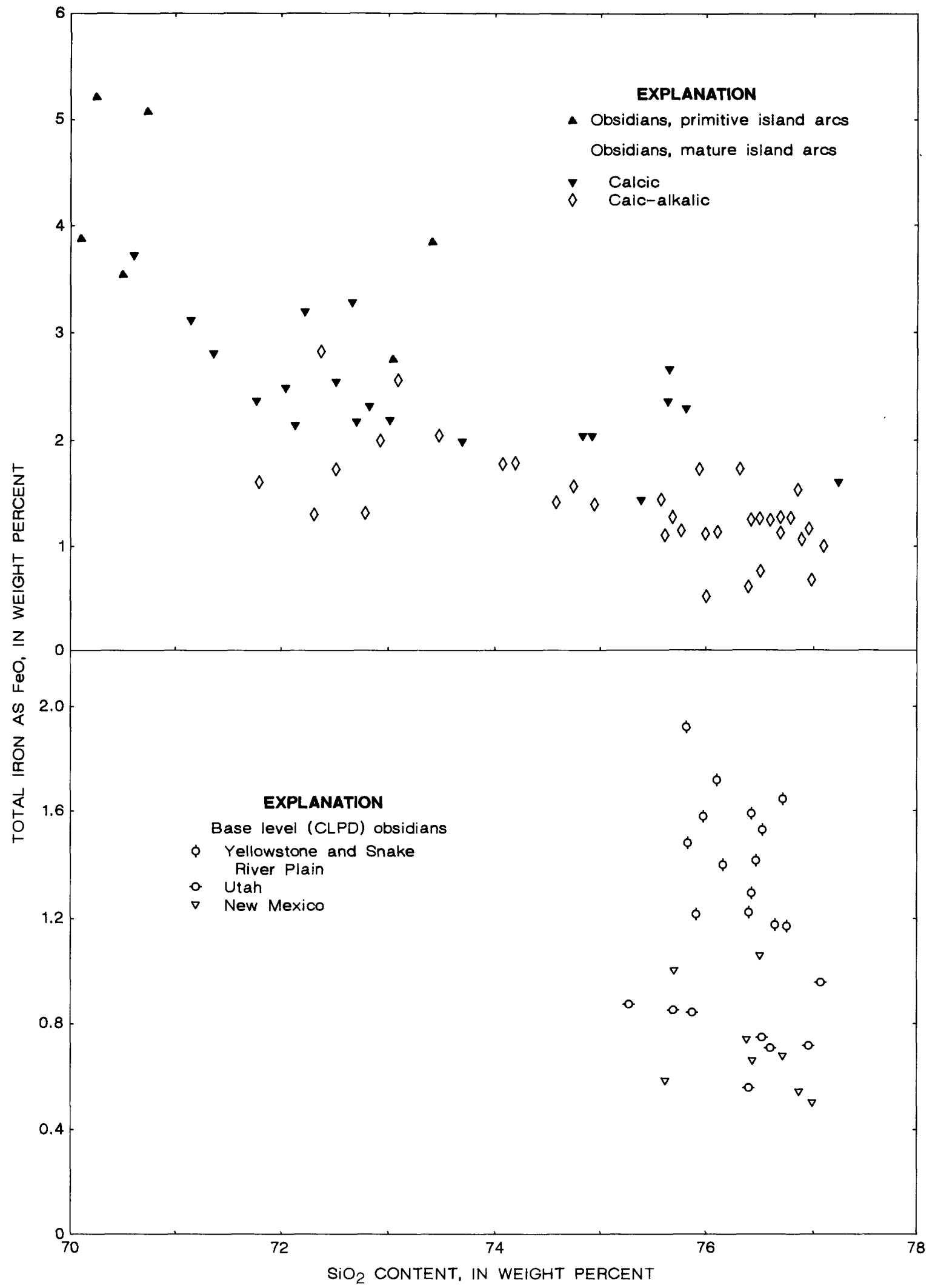

FIGURE 31.- $\mathrm{SiO}_{2}$ content versus total iron as $\mathrm{FeO}$ for $(A)$ obsidians of island arcs. Calcic rocks tend to have higher $\mathrm{Fe}$ contents, at equivalent $\mathrm{SiO}_{2}$ values, than calc-alkalic types. Data from appendixes I, III, and V. B, Selected CLPD obsidians from United States continental interior. Data from appendixes I and III. 


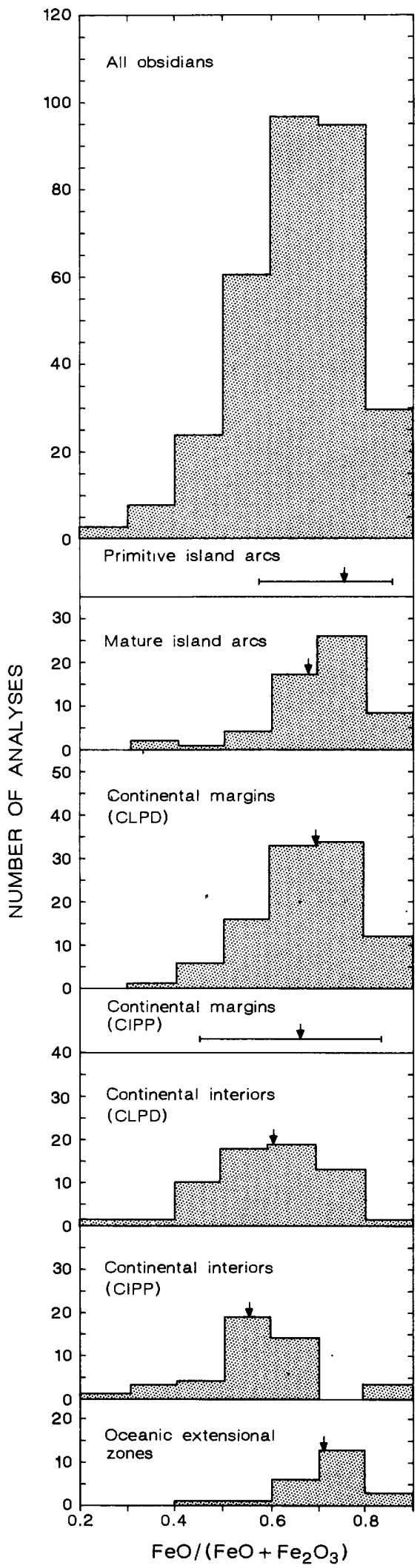

the new data (app. I). The peak of the histogram (fig. $32 A$ ) lies between 0.6 and 0.7 , and the average for the magmas probably lies toward the higher end of this range. The range and average are comparable to those in peralkaline silicic glasses (Macdonald and Bailey, 1973).

Values of $\mathrm{FeO} /\left(\mathrm{FeO}+\mathrm{Fe}_{2} \mathrm{O}_{3}\right)<0.4$ and $\geq 0.8$ (by weight) should be treated with caution. Many such values probably represent analytical error. Lower than average values may be determined on glasses from ash-flow tuffs, where oxidation of Fe can occur during tuff emplacement and consolidation. The average ratio for the whole-rock, welded-tuff obsidians in the compilation is 0.57 , the range $0.40-0.74$.

It is of interest to note that the average ratio calculated from the new analyses decreases in the sequence arc $\rightarrow$ margin $\rightarrow$ interior (table 7 ). Though the differences may not be significant in the light of possible hydration and analytical problems, it would be important genetically if silicic rocks from sialic areas truly were more oxidized than those from less mature crust.

\section{MAGNESIUM}

$\mathrm{MgO}$ has a compositional range of three orders of magnitude, from $<0.005$ percent to $>1$ percent. At the lower end of this range, analytical uncertainties are such that only broad generalizations are possible. At least some of the scatter at constant $\mathrm{SiO}_{2}$ results from intergroup differences. Obsidians from primitive arcs and calcic types from mature arcs are more magnesian than continentalmargin and continental-interior rocks (fig. 29D).

Hildreth $(1979$, p. 71$)$ noted that diffusion can result in impoverishment of $\mathrm{Mg}$.to levels below 100 ppm. The new data show that most obsidians with $\mathrm{MgO}<0.05$ percent are CIPP (fig. $30 \mathrm{C}$ ), but that CLPD magmas may also have extremely low $\mathrm{MgO}$ abundances ( 0.01 percent).

The strong positive correlations of $\mathrm{MgO}$ with $\mathrm{Al}_{2} \mathrm{O}_{3}, \mathrm{CaO}, \mathrm{TiO}_{2}, \mathrm{P}_{2} \mathrm{O}_{5}, \mathrm{Co}$, and $\mathrm{Sr}$ indicate that these oxides behave similarly in terms of both tectonic setting and genetic processes. All are depleted in lower temperature magmas. A slightly lesser correlation with $S c(0.63)$ results from the

Figure 32.-Distribution of $\mathrm{FeO} /\left(\mathrm{FeO}+\mathrm{Fe}_{2} \mathrm{O}_{3}\right)$ ratio in obsidians. Obsidians of primitive island ares and continental margins (CIPP types) are shown as ranges only. Arrows indicate average values. Data from appendixes I, III, and V. Samples 12, $15,194,266,271$, and 310 are omitted to preserve scale. 
complex behavior of Sc in CIPP systems where Sc and $\mathrm{Mg}$ may show different senses of enrichment. Both $\mathrm{K}$ and $\mathrm{Mg}$ are down elements during CIPP. Potassium shows much greater differences in rocks from different tectonic settings (table 7), and the overall relation between $\mathrm{K}$ and $\mathrm{Mg}$ is negative.

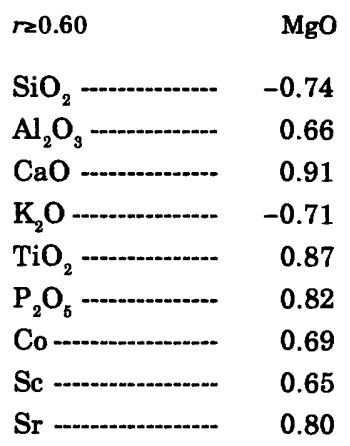

CALCIUM

$\mathrm{CaO}$ shows a large variation in the obsidians, from 0.15 to 4.61 weight percent (fig. $30 D$ ). Even at constant $\mathrm{SiO}_{2}$ there may be an almost order-ofmagnitude variation. The scatter is related mainly to crustal type. $\mathrm{CaO}$ broadly decreases in the sequence obsidians of primitive island arcs $\rightarrow$ mature island arcs $\rightarrow$ continental margins $\rightarrow$ continental interiors (table 7; fig. 30D).

Within each group, there is a finer scale of variation. By definition (fig. 4), the calcic obsidians of mature arcs and margins have higher $\mathrm{CaO} / \mathrm{SiO}_{2}$ ratios than associated calc-alkalic types. Within the continental margin group, the obsidians of Medicine Lake have higher $\mathrm{CaO}$, at given $\mathrm{SiO}_{2}$ values, than those of the Newberry volcanic complex. Rhyolites of oceanic extensional zones break down into two subgroups: a higher $\mathrm{CaO}$ subgroup commonly associated with tholeiitic centers and a lower $\mathrm{CaO}$ subgroup of rhyolites from more alkalic centers.

CLPD and CIPP lead to very low $\mathrm{CaO}$ concentrations $(\ll<1$ percent by weight) in high-silica rocks. Though a majority of specimens with $\mathrm{CaO}<0.5$ percent are inferred to be CIPP types, many CLPD rocks from continental margins and interiors also show such low abundances (fig. 30D).

The elements which correlate most strongly with $\mathrm{Ca}$ are the same as those which correlate with $\mathrm{Mg}$, with the addition of $\mathrm{FeO}$ and $\mathrm{Rb}$. The strong positive correlation with $\mathrm{Sr}$ is predictable because they form a chemically coherent pair. $\mathrm{Ca}$ and $\mathrm{Sr}$ are, however, partitioned by CLPD and CIPP.

The average $\mathrm{Ca} / \mathrm{Sr}$ ratio decreases in the sequence primitive island arc $\rightarrow$ mature island arc $\rightarrow$ continental margin (table 7), indicating relative enrichment of $\mathrm{Sr}$ as the crust becomes more continental in character. The much higher ratio in continental-interior obsidians largely reflects the much stronger downward concentrating tendency of $\mathrm{Sr}$ in CIPP systems. In the Bishop and Coso systems, for example, the $\mathrm{Ca} / \mathrm{Sr}$ ratio changed from 62 to $\geq 322$ and 463 to 1,634 , respectively, in lower temperature magmas (calculated from data in Hildreth, 1979, and Bacon and others, 1981); in the Tshirege Member of the Bandelier Tuff, the change was from 39 to $\geq 236$ (R.L. Smith, unpublished data).

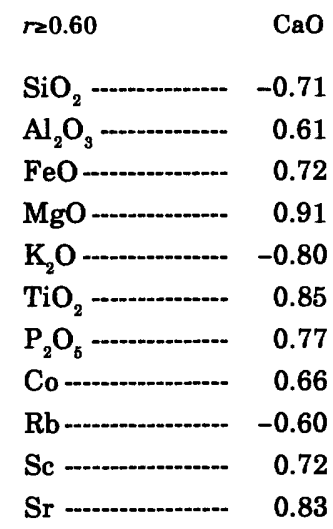

SODIUM

$\mathrm{Na}_{2} \mathrm{O}$ shows a relatively small range, from 2.72 to 5.93 weight percent, and 86 percent of the samples falls within the more restricted range of 3.5 to 5.0 weight percent (fig. $29 F^{\prime}$ ). At constant $\mathrm{SiO}_{2}$, there is considerable within-group variation (fig. $30 E$ ); for example, at approximately 73 percent $\mathrm{SiO}_{2}$, continental-margin obsidians nearly cover the complete spread of $\mathrm{Na}_{2} \mathrm{O}$ values, whereas continental-interior rocks do the same at 76.5 percent $\mathrm{SiO}_{2}$. Variations within groups are therefore of the same magnitude as variations between groups.

Further spread is caused by CIPP, which tends to reverse the negative correlation between $\mathrm{Na}_{2} \mathrm{O}$ and $\mathrm{SiO}_{2}$ resulting from crystal-liquid processes. $\mathrm{Na}_{2} \mathrm{O}$ is an upelement in all such systems yet described (Hildreth, 1979, 1981).

$\mathrm{Na}_{2} \mathrm{O}$ correlates strongly (that is, $r>0.60$ ) only with $\mathrm{SiO}_{2}, \mathrm{FeO}_{t}$, and $\mathrm{Zr}$. At a slightly lower level $(0.55-0.60)$, it also correlates with $\mathrm{Hf}$ and Eu. All these elements show similar geochemical behavior during crystal-liquid processes (see section on zirconium and hafnium).

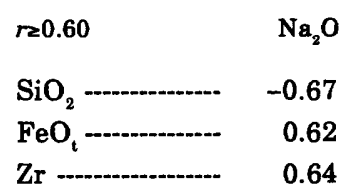




\section{POTASSIUM}

$\mathrm{K}_{2} \mathrm{O}$ is more variable than $\mathrm{Na}_{2} \mathrm{O}$, the range being 0.64 to 6.60 weight percent (fig. 29G). As discussed earlier, tectonic setting plays an important role in potassium geochemistry. On a $\mathrm{K}_{2} \mathrm{O}$ versus $\mathrm{SiO}_{2}$ plot (fig. $30 F)$ rocks from island arcs fall, albeit with several exceptions, in a separate field from rocks of the continental margins and interiors. Within-group divisions can also be made; thus, in both margin and arc settings, calcic types are less potassic than calc-alkalic types at similar $\mathrm{SiO}_{2}$ values (table 8). The lowest $\mathrm{K}_{2} \mathrm{O}$ values are found in obsidians from primitive island arcs (table 7), although they show some overlap with rhyolites from tholeiitic centers in more mature arcs.

Potassium is a downward-concentrating element during CIPP in contrast to sodium. Data from the rock-glass pairs and from the Woodson stock indicate $K$ concentration in residual liquids during crystal fractionation.

It is of interest that $\mathrm{K}_{2} \mathrm{O}$ shows only negative strong correlations $(r>0.60)$. The reason is two-fold: the strong crustal control on $\mathrm{K}$ distribution and the fact that during CIPP, $\mathrm{K}$ shows different behavior to otherwise coherent elements such as $\mathrm{Cs}, \mathrm{Rb}$, Th, and $\mathrm{U}$.

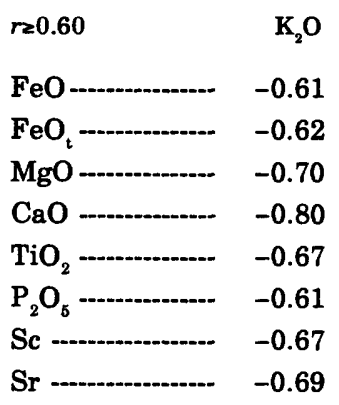

$$
\mathrm{Na}_{2} \mathrm{O}+\mathrm{K}_{2} \mathrm{O}
$$

The intergroup differences in $\mathrm{K}_{2} \mathrm{O}$ are reflected in $\left(\mathrm{Na}_{2} \mathrm{O}+\mathrm{K}_{2} \mathrm{O}\right)$ abundances (fig. $\left.29 \mathrm{H}\right)$. The lowest total alkali contents are found in arc (especially primitive arc) obsidians and in those from tholeiitic centers in oceanic extensional zones. As Miyashiro (1974) has stressed, however, mature-arc volcanoes can show a spectrum from low-alkali to high-alkali types, and arc rhyolites, in a few cases, may contain higher $\left(\mathrm{Na}_{2} \mathrm{O}+\mathrm{K}_{2} \mathrm{O}\right)$ abundances than continental-interior rocks of similar $\mathrm{SiO}_{2}$ content (fig. $30 G$ ). It is also difficult to separate continental-margin from interior rocks on the basis of alkali-silica relations.

Judging from the rock-glass pairs and the Woodson stock data, crystal fractionation more commonly produces a mild alkali enrichment in residual liquids. In the Bandelier, Bishop, and Coso CIPP systems, $\left(\mathrm{Na}_{2} \mathrm{O}+\mathrm{K}_{2} \mathrm{O}\right)$ values are about the same in lowest and highest temperature eruptions, suggesting that upward concentration of $\mathrm{Na}_{2} \mathrm{O}$ is about balanced on a weight basis by downward concentration of $\mathrm{K}_{2} \mathrm{O}$. On a molecular basis, however, the upward migration of $\mathrm{Na}$ and downward migration of $\mathrm{K}$ and $\mathrm{Al}$ results in a marked increase in the agpaitic index $\left(\left(\mathrm{Na}_{2} \mathrm{O}+\mathrm{K}_{2} \mathrm{O}\right) / \mathrm{Al}_{2} \mathrm{O}_{3}\right)$ upwards.

\section{$\mathrm{Na}_{2} \mathrm{O} / \mathrm{K}_{2} \mathrm{O}$ RATIOS}

There is a very wide range of $\mathrm{Na}_{2} \mathrm{O} / \mathrm{K}_{2} \mathrm{O}$ ratios, resulting mainly from variations in $\mathrm{K}_{2} \mathrm{O}$ abundances (fig. 33). Though the ratios show an overall negative correlation with $\mathrm{SiO}_{2}$ (fig. 34), there is a great deal of scatter, resulting from several effects.

1. Genetic processes. Rock-glass pairs, data from zoned plutons, and the data from base level rocks indicate that crystal-liquid processes tend to produce decreasing $\mathrm{Na}_{2} \mathrm{O} / \mathrm{K}_{2} \mathrm{O}$ ratios with increasing $\mathrm{SiO}_{2}$. Values as low as 0.6 have been recorded in CLPD obsidians from the continental interiors.

CIPP reverses the trend, however, such that $\mathrm{Na}_{2} \mathrm{O} / \mathrm{K}_{2} \mathrm{O}$ ratios increase in increasingly differentiated rocks. A magma series with a complex history may reach the same $\mathrm{Na}_{2} \mathrm{O} / \mathrm{K}_{2} \mathrm{O}$ ratio twice or more during its evolution. It is worth noting that CIPP may begin to operate in different systems at different $\mathrm{Na}_{2} \mathrm{O} / \mathrm{K}_{2} \mathrm{O}$ ratios. It is not possible to define a unique trend of base-level $\mathrm{Na}_{2} \mathrm{O} / \mathrm{K}_{2} \mathrm{O}$ ratios against relative $\mathrm{SiO}_{2}$, as they actually define a broad band. Some systems evolve to high-silica compositions before beginning to evolve by CIPP; for example, the Yellowstone complex magma was very rich in $\mathrm{SiO}_{2}$ and potassic at this stage. The Long Valley and Clear Lake systems may be inferred to have been undergoing CIPP at less silicic and more sodic compositions. It is tempting to suggest that this may be a general case (that is, calc-alkalic systems begin to evolve by CIPP at more "mafic" compositions than alkali-calcic systems), but there is as yet insufficient information on the true base-level compositions of most relevant systems to test this.

2. Tectonic environment. Clear effects of tectonic environment are related mainly to $\mathrm{K}_{2} \mathrm{O}$ variations. At given $\mathrm{SiO}_{2}$ values, $\mathrm{Na}_{2} \mathrm{O} / \mathrm{K}_{2} \mathrm{O}$ ratios decrease in the order of obsidians from primitive island arcs $\rightarrow$ calcic obsidians from mature island arcs $\rightarrow$ calc-alkalic obsidians from mature island arcs+calcic types from continental margins $\rightarrow$ calcalkalic obsidians of continental margins $\rightarrow$ obsidians from continental interiors. Rhyolites from oceanic extensional zones have ratios broadly comparable to those of the continental margins.

3. Within-group variations. Variations within groups also exist. The Newberry obsidians have 


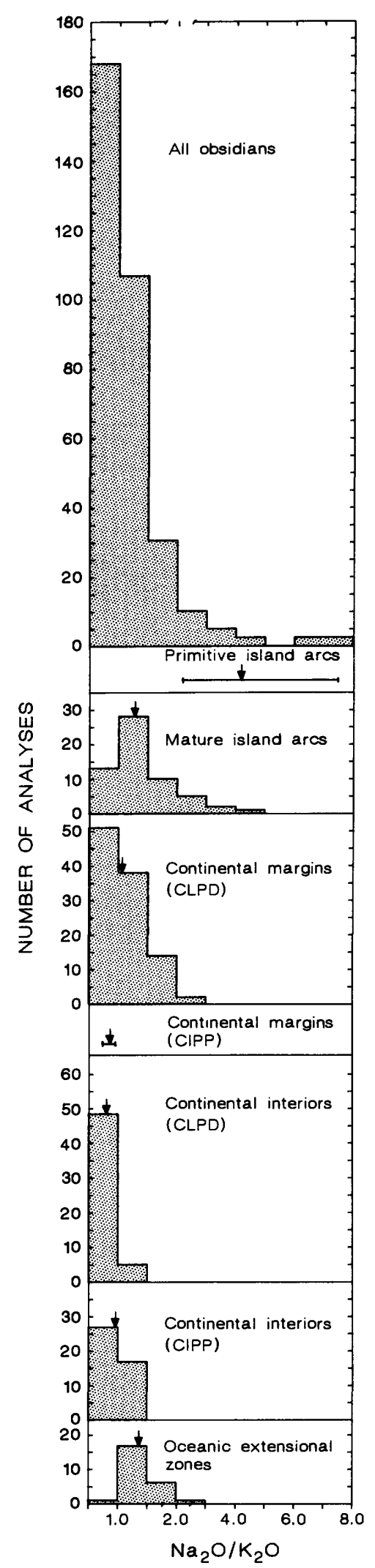

Figure 33.-Distribution of $\mathrm{Na}_{2} \mathrm{O} / \mathrm{K}_{2} \mathrm{O}$ ratios in obsidians. Obsidians of primitive island arcs and continental margins (CIPP types) are shown as ranges only. Arrows indicate average values. Data from appendixes I, III, and V. Note change of scale in ratio axis. higher $\mathrm{Na}_{2} \mathrm{O} / \mathrm{K}_{2} \mathrm{O}$ ratios than rocks of comparable $\mathrm{SiO}_{2}$ content from Medicine Lake. Ratios in CLPD glasses from the American continental interior may vary by a factor of two. The Java rhyolites are more potassic than those from New Zealand.

4. Magma mixing. Further variation in the $\mathrm{Na}_{2} \mathrm{O} / \mathrm{K}_{2} \mathrm{O}$ ratio is caused by magma mixing. The Novarupta rhyolites with $\mathrm{Na}_{2} \mathrm{O} / \mathrm{K}_{2} \mathrm{O}$ of $1.4-1.7$ (Nos. 3, 243, 244) represent somewhat more potassic rhyolites mixed with a more sodic, less silicarich member.

\begin{tabular}{|c|c|}
\hline$r \geq 0.60$ & $\mathrm{Na}_{2} \mathrm{O} / \mathrm{K}_{2} \mathrm{O}$ \\
\hline $\mathrm{SiO}_{2}$ & -0.62 \\
\hline $\mathrm{FeO}$ & 0.67 \\
\hline $\mathrm{FeO}_{\mathrm{t}}$ & 0.67 \\
\hline MgO & 0.70 \\
\hline $\mathrm{CaO}$ & 0.73 \\
\hline $\mathrm{Na}_{2} \mathrm{O}$ & 0.71 \\
\hline $\mathrm{K}_{2} \mathrm{O}$ & -0.90 \\
\hline $\mathrm{TiO}_{2}$ & 0.70 \\
\hline Sc - & 0.64 \\
\hline
\end{tabular}

WATER AND THE ISOTOPES OF HYDROGEN AND OXYGEN

WATER

Water in the obsidians ranges from 0.01 percent to approximately 1 percent by weight. Values consistently less than about 0.1 percent probably need some special explanation, either analytical or geological. Friedman and others (1963) showed from experimental work on viscosity and water content of rhyolite glass that obsidian lavas extruded at $900{ }^{\circ} \mathrm{C}$ would have no more than 0.1 percent $\mathrm{H}_{2} \mathrm{O}$ in equilibrium at atmospheric pressure. Because the solubility of $\mathrm{H}_{2} \mathrm{O}$ in obsidian increases with decreasing temperature at constant pressure, these authors concluded that the water content of obsidian equilibrated at $1 \mathrm{~atm}$ would be a function of the temperature of the obsidian. As most rhyolite obsidians are probably erupted at temperatures less than $900^{\circ} \mathrm{C}$, most will have water contents greater than 0.1 percent by weight.

Recent work by Eichelberger and Westrich (1983) on the solubility of $\mathrm{H}_{2} \mathrm{O}$ in rhyolitic magma suggests about 0.2 percent $\mathrm{H}_{2} \mathrm{O}$ in equilibrium with melt at $1 \mathrm{~atm}$ pressure. This work is essentially in agreement with that of Friedman and others (1963).

Our new data suggest that $\mathrm{H}_{2} \mathrm{O}^{+}$in rhyolite flows and domes rarely exceeds 0.5 percent and that higher values are found only in intrusive margins of domes, in dikes, or in clasts from pyroclastic deposits. 

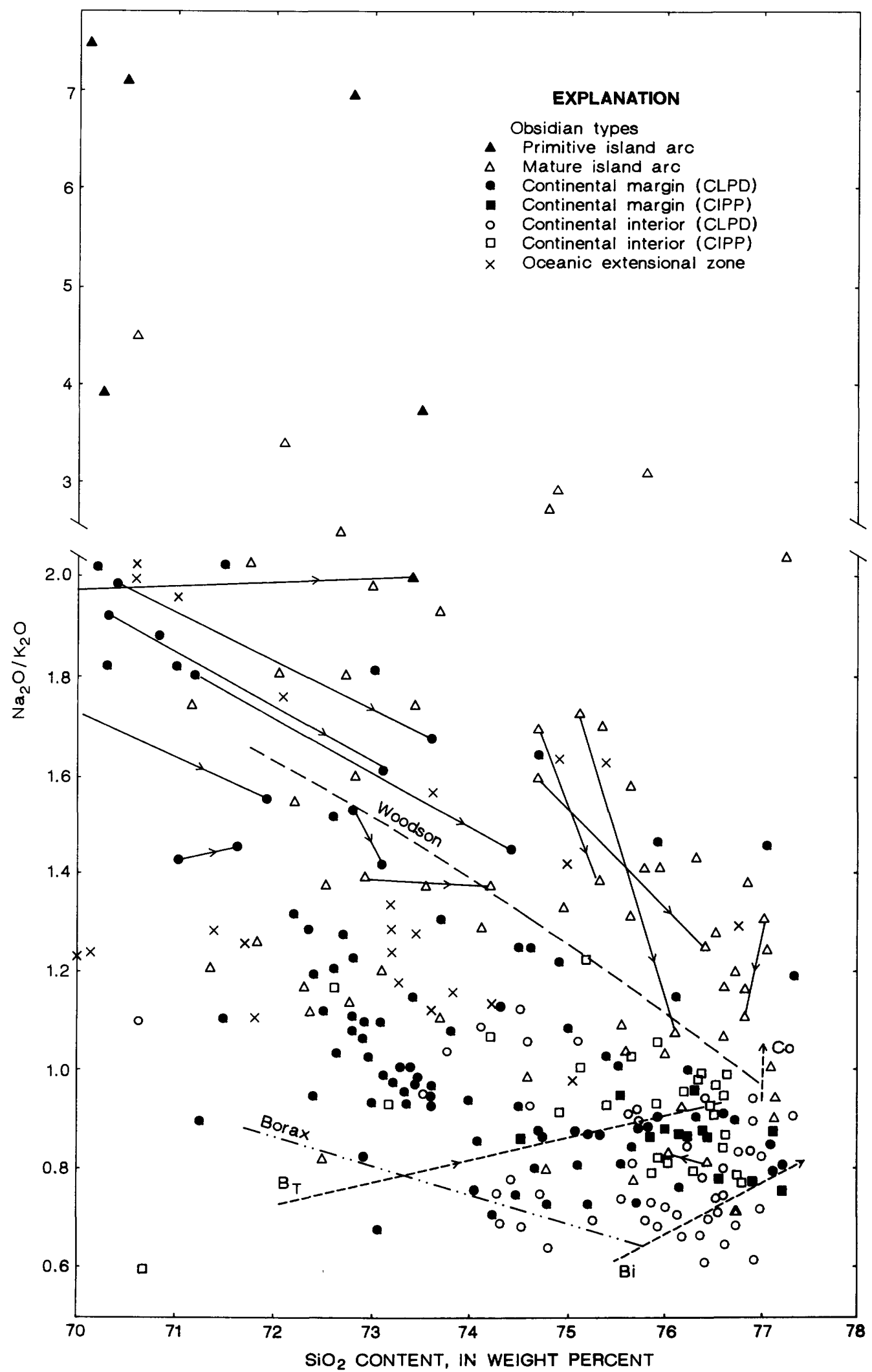

Figure 34.- $\mathrm{SiO}_{2}$ content versus ratio of $\mathrm{Na}_{2} \mathrm{O} / \mathrm{K}_{2} \mathrm{O}$ for obsidians and various comparative rocks. Data sources are same as for figure $5\left(\mathrm{Bi}\right.$, Bishop Tuff; Co, Coso Range; $\mathrm{B}_{\mathrm{T}}$,
Tshirege Member, Bandelier Tuff). Note change of scale on $y$ axis. Arrows on solid tielines and on dashed lines point in direction of liquid fractionation. 


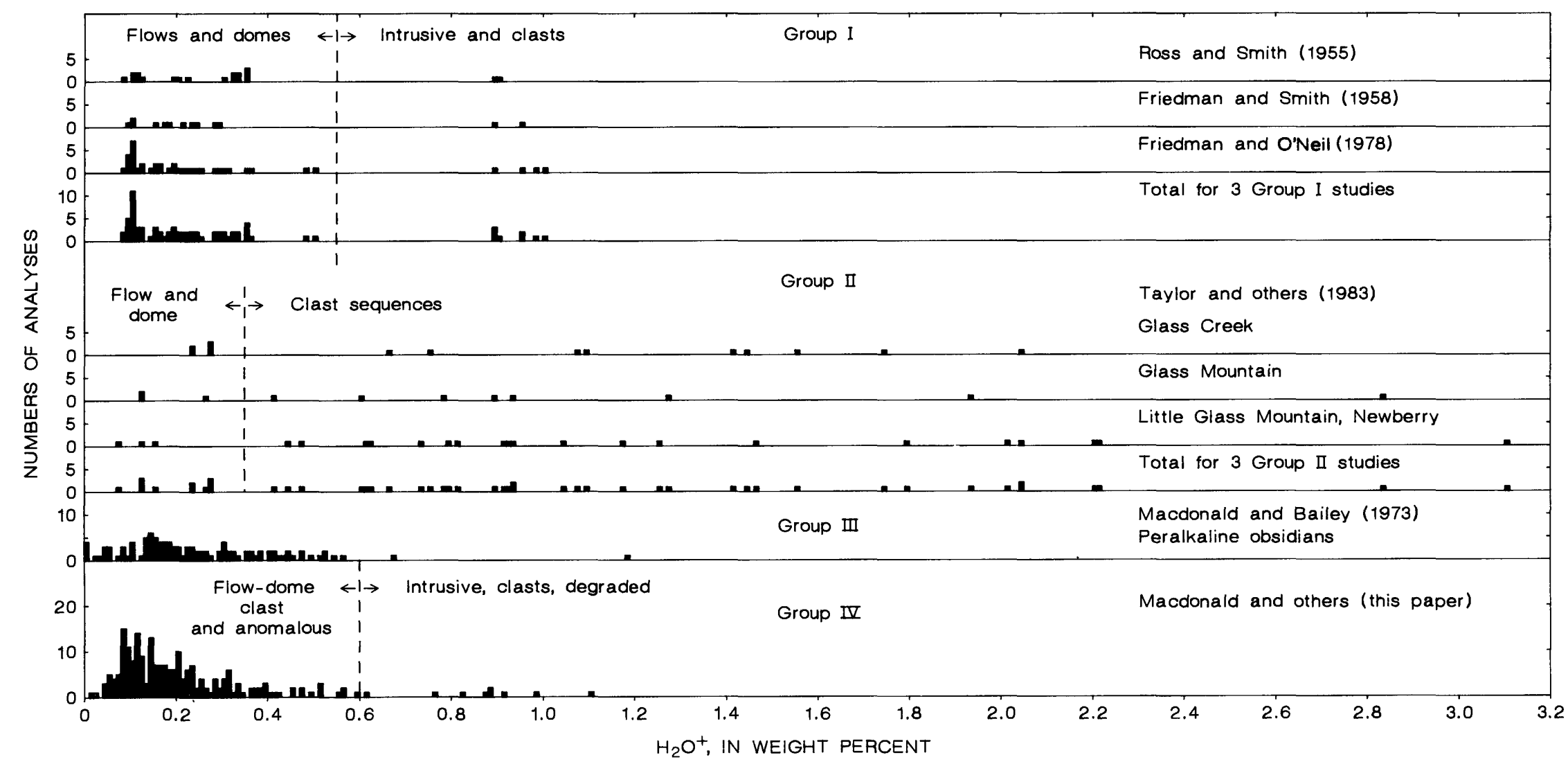

Figure 35.-Distribution of $\mathrm{H}_{2} \mathrm{O}^{+}$data from all major studies of $\mathrm{H}_{2} \mathrm{O}$ in obsidians. These studies are shown as four major groups. Group I, early studies emphasizing hydration of obsidian to form perlite and studies of deuterium/hydrogen $(\mathrm{D} / \mathrm{H})$ relations. Many of the same samples were used in all three studies. Group II, recent studies of clast sequences showing many samples of higher $\mathrm{H}_{2} \mathrm{O}^{+}$content than earlier studies. Group III, data on peralkaline obsidians. Group IV, data on subalkaline obsidians studied in this paper. 
Approximately 25 percent of the obsidians in the data base contain $<0.1$ percent $\mathrm{H}_{2} \mathrm{O}$. About half of these contain between 0.08 and 0.1 percent. On the basis of a comparison of our data with other data representative of modern water analyses by vacuum extraction methods (fig. 35), our obsidians appear to differ on the low side by at least 0.02 weight percent. We think that this difference is somehow related to differences in analytical techniques and is exaggerated in the water concentration range typical of the most highly annealed obsidians. In this range, vacuum extraction is probably the more efficient method for maximum water extraction. Below about 0.08 percent, there may be other reasons for very low amounts. These reasons include, as most likely causes, superheat and devitrification. Superheat may often be suspected from the presence of basaltic or andesitic xenoliths or xenocrysts that are commonly found in rhyolites of the rhyolite-basalt association and in agglutinates of rhyolitic and dacitic composition in andesitic stratovolcanoes.

Examples of such obsidians from appendix I are specimen 2, an agglutinate from Okmok caldera, Alaska, and specimen 176, an agglutinate from the 1875 eruption of Askja, Iceland, both having 0.05 percent $\mathrm{H}_{2} \mathrm{O}^{+}$. Specimen 96 from White Mountain, Utah, with 0.01 percent $\mathrm{H}_{2} \mathrm{O}^{+}$, the lowest in the data base, is also the sample nearest to total devitrification, as it is flecked with tiny, gray spherulites. This material may also be an example of superheated obsidian, because it is from a small rhyolite dome within a field of basalts; the rhyolite locally contains basaltic xenoliths. Aspects of the chemical composition of this rock are consistent with contamination by mafic magma (see section "Magma Mixing and Assimilation"). Obsidian sample 85, with 0.04 percent $\mathrm{H}_{2} \mathrm{O}^{+}$, is a welded facies of the Walcott Tuff, Idaho, and formed in a thin unit of very high temperature, fine-grained ash. We suspect that vacuum extraction of water from these samples would yield water contents slightly higher than those cited, but probably less than 0.08 percent.

Several obsidians in the data base, from flows or domes, were received from donors who had already prepared powders for analysis. Some of these samples appear to have anomalously high water values. We suggest that these samples have been degraded by adsorption of a few tenths of a percent $\mathrm{H}_{2} \mathrm{O}$ between sample preparation and analysis, not all the adsorbed $\mathrm{H}_{2} \mathrm{O}$ being driven off at $110^{\circ} \mathrm{C}$. This problem is common with obsidian chemistry, especially with older published analyses. Examples of such problems may be seen with Crater Lake samples 1118 , which range from 0.14 to 1.10 percent $\mathrm{H}_{2} \mathrm{O}^{+}$, compared with samples 19-21, which range from 0.10 to 0.19 percent $\mathrm{H}_{2} \mathrm{O}^{+}$. Samples $19-21$ were prepared directly for this study with water analyses in mind, whereas samples 11-18 were prepared some years before we analyzed them. The sample containers were not tightly sealed, allowing adsorption of water before analysis. The differences in the Llao Rock samples are particularly notable. It is doubtful that this difference is due to natural glass hydration, as the rocks are less than 7,000 years old. A similar contrast is seen in samples 110 and 111 from No Agua, New Mexico, with 0.15 and 0.91 percent $\mathrm{H}_{2} \mathrm{O}^{+}$, respectively. Sample 110 was prepared for this study, whereas 111 was from a stored tube sample.

We placed an upper limit of 1 percent $\mathrm{H}_{2} \mathrm{O}^{+}$on the data bank, because the geologic and isotopic evidence available at the time of data collection indicated that rhyolitic glasses containing more than 1 percent $\mathrm{H}_{2} \mathrm{O}^{+}$were overwhelmingly hydrated with meteoric water (Friedman and Smith, 1958; Taylor, 1968). However, Eichelberger and Westrich (1983) and Taylor and others (1983), during studies of obsidian clasts from pyroclastic deposits, have determined $\mathrm{H}_{2} \mathrm{O}^{+}$contents up to about 3 percent by weight. They interpret this water as primary, thus extending the known range of water in obsidian from 1 to 3 percent. Other, more recent, work (Newman and others, 1985; O'Neil and Taylor, 1985; Dunbar and Kyle, 1986) has extended the number of localities and samples of obsidian pyroclasts containing $\mathrm{H}_{2} \mathrm{O}^{+}$above 1 percent (table 11). More will surely be found.

Chemical changes related to low-temperature glass hydration are well covered in the literature and will not be repeated here (Truesdell, 1962, 1966; Lipman, 1965; Noble, 1967; Noble and others, 1967; Macdonald and Bailey, 1973; Stewart, 1979). To date, the variable water contents in high-water clasts have not been shown to be accompanied by any significant differences in the composition of the glass, other than the $\mathrm{D} / \mathrm{H}$ relations discussed below. There is no evidence, therefore, that the highly systematic nature of obsidian chemistry based on samples with $<1$ percent $\mathrm{H}_{2} \mathrm{O}^{+}$ would be complicated by inclusion of higher water rocks, even should they prove to be common geologically.

The discovery of high-water obsidians and the growing importance of obsidian studies for deciphering the chemistry of magmas make it mandatory that the distinction between hydrated and nonhydrated glass be fully recognized and understood. In most cases, visual examination is sufficient for the trained eye, but there are many 
TABLE 11.-Range of $\mathrm{H}_{2} \mathrm{O}$ contents and $\delta \mathrm{D}$ values in subalkaline silicic obsidians

\begin{tabular}{|c|c|c|c|c|}
\hline & $\begin{array}{c}\mathrm{H}_{2} \mathrm{O}^{+} \\
\text {(weight percent) }\end{array}$ & \multicolumn{3}{|c|}{$\begin{array}{c}\text { SD } \\
\text { (per mil) }\end{array}$} \\
\hline & $0.08-0.9$ & & - & \\
\hline Friedman and Smith (1958) & $.09-.95$ & -88 & to & -165 \\
\hline Friedman and O'Neil (1978) & $.07-$ & -90 & to & -180 \\
\hline *Taylor and others (1983) & $.10-3.1$ & -60 & to & -130 \\
\hline O'Neil and Taylor (1985) & $.23-.64$ & -91 & to & -134 \\
\hline Westrich and others (1985) & $.08-.65$ & -104 & to & -119 \\
\hline *Newman and others (1985) & $.12-\leq 2.6$ & -52 & to & -123 \\
\hline *Dunbar and Kyle (1986) & $.23-.64$ & & - & \\
\hline Macdonald and others (this paper) & $.01-1.1$ & & - & \\
\hline
\end{tabular}

*Clast sequences

glasses, such as those found in the group generally called pitchstones, where the field distinction may be more difficult and isotopic (see the subsection, "Deuterium and Hydrogen" below) or other chemical studies may be necessary to distinguish them.

Summing up the water data after allowing for a few samples degraded by adsorption of water before analysis, it seems possible to make the following generalizations regarding thermal history and provenance of subalkaline silicic obsidians based on $\mathrm{H}_{2} \mathrm{O}^{+}$ contents (see also fig. 36 ).

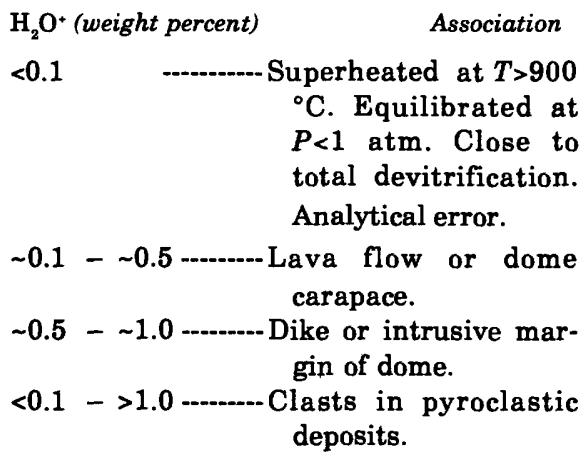

\section{DEUTERIUM AND HYDROGEN}

Deuterium (D)-hydrogen (H) relations in rhyolitic glasses were first studied by Friedman and Smith (1958). These authors found a significant difference in $\mathrm{D} / \mathrm{H}$ ratios between obsidian and perlite in pairs from the same outcrops; tielines in figure 37 connect coexisting pairs from several localities. The $\mathrm{D} / \mathrm{H}$ ratio in water extracted from perlites was a reflection of the $\mathrm{D} / \mathrm{H}$ ratio in meteoric water at that locality. The obsidians showed no such relation, and Friedman and Smith (1958) concluded that the water in obsidian was retained from the magmatic state, concurring with the ear- lier conclusions of Ross and Smith (1955). Taylor (1968) confirmed the Friedman-Smith study and strengthened it by oxygen isotope measurements, which led to the same conclusion.

More recent work by Taylor and others (1983), Newman and others (1985), and O'Neil and Taylor (1985) has shown a positive relation between $\mathrm{D} / \mathrm{H}$ ratio and total water in obsidians, with $\mathrm{D}$ enriched in high-water clasts (fig. 37; table 11). These authors interpret this relation as evidence of degassing of water from the magma and fractionation of $D$ to the vapor phase from beginning to end of a rhyolitic eruption. These studies, made on series of obsidian clasts from close-spaced pyroclastic beds, record a progressive decrease of $\mathrm{H}_{2} \mathrm{O}$ in clasts from earlier erupted beds, through the pyroclastic phase, to final degassed domes and lava flows. The sequence is accompanied by progressive decrease in $D / H$ ratios. The fractionation of $D$ from $H$ with decreasing water content is interpreted to be consistent with the Rayleigh distillation law.

The infrared studies of Newman and others (1985) on the $\mathrm{OH} / \mathrm{H}_{2} \mathrm{O}$ relations suggest that this ratio increases with decreasing total water, implying a preference for $\mathrm{OH}$ by the lighter isotope.

\section{OXYGEN ISOTOPES}

Taylor (1968) noted that, with respect to mafic, ultramafic, and many intermediate rocks, granites and rhyolites exhibit a very large range in $\delta^{18} \mathrm{O}$ values, the range being from -6.3 to +17.0 per mil. $\mathrm{He}$ arbitrarily divided the granitic rocks into five groups on the basis of $\delta^{18} \mathrm{O}$ contents and showed that, compared to the total range of values, nonhydrated obsidians show a rather restricted range, the majority of rocks falling between 5.5 and 7.7 per mil (fig. 38; table 12). 


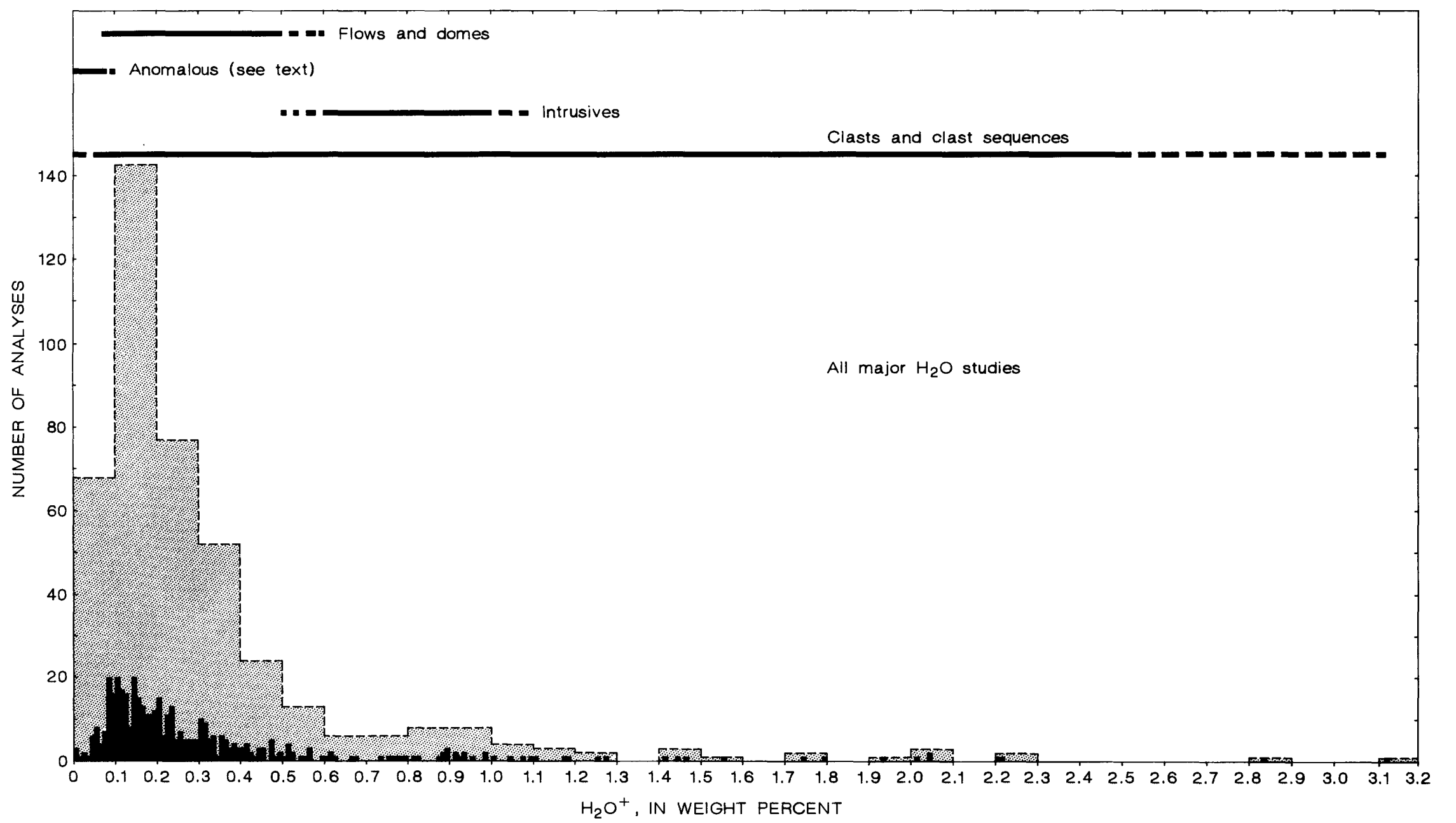

Figure 36.-Distribution of total $\mathrm{H}_{2} \mathrm{O}^{+}$data from four groups of obsidians shown in figure 35. Total data are shown in increments of 0.01 (solid bars) and 0.1 light shaded bars) weight percent $\mathrm{H}_{2} \mathrm{O}$, respectively. Horizontal bars show ranges (dashed where uncertain) of $\mathrm{H}_{2} \mathrm{O}$ by obsidian provenance: flows and domes, intrusives, clasts and clast sequences, anomalously low $\mathrm{H}_{2} \mathrm{O}$, and overlaps as suggested by total data base. 
In a later study, Muehlenbachs (1973) recorded the occurrence in Iceland of $10{ }^{18} \mathrm{O} /{ }^{16} \mathrm{O}$ rhyolitic obsidians. These have values from 2.8 to $4.4 \mathrm{per} \mathrm{mil}$ and belong to Taylor's (1968) LL group (see fig. 38), thus expanding the known compositional spectrum in obsidians.

Taylor (1968) suggested that silicic obsidians demonstrate a geographic distribution of ${ }^{18} \mathrm{O} /{ }^{16} \mathrm{O}$ ratios. Lgroup obsidians tend to be from either oceanic areas or continental-margin settings, whereas H-group glasses are from continental-interior areas (fig. 38). He noted some exceptions: two samples from the Jemez
Mountains, N. Mex., belong to the L group, and the Clear Lake, Calif., obsidians are peculiar in having $\delta^{18} \mathrm{O}$ values not only higher than other margin types but in fact higher than any other rhyolite obsidian.

Broadly speaking, this distribution was attributed to differing modes of evolution for the interior- and margin-type magmas (Taylor, 1968). The continental-margin varieties formed by differentiation of basaltic magma, whereas contamination by ${ }^{18} \mathrm{O}$-rich crustal material has played some role in the evolution of the interior-type magmas. However, on the basis of available data (fig. 38),

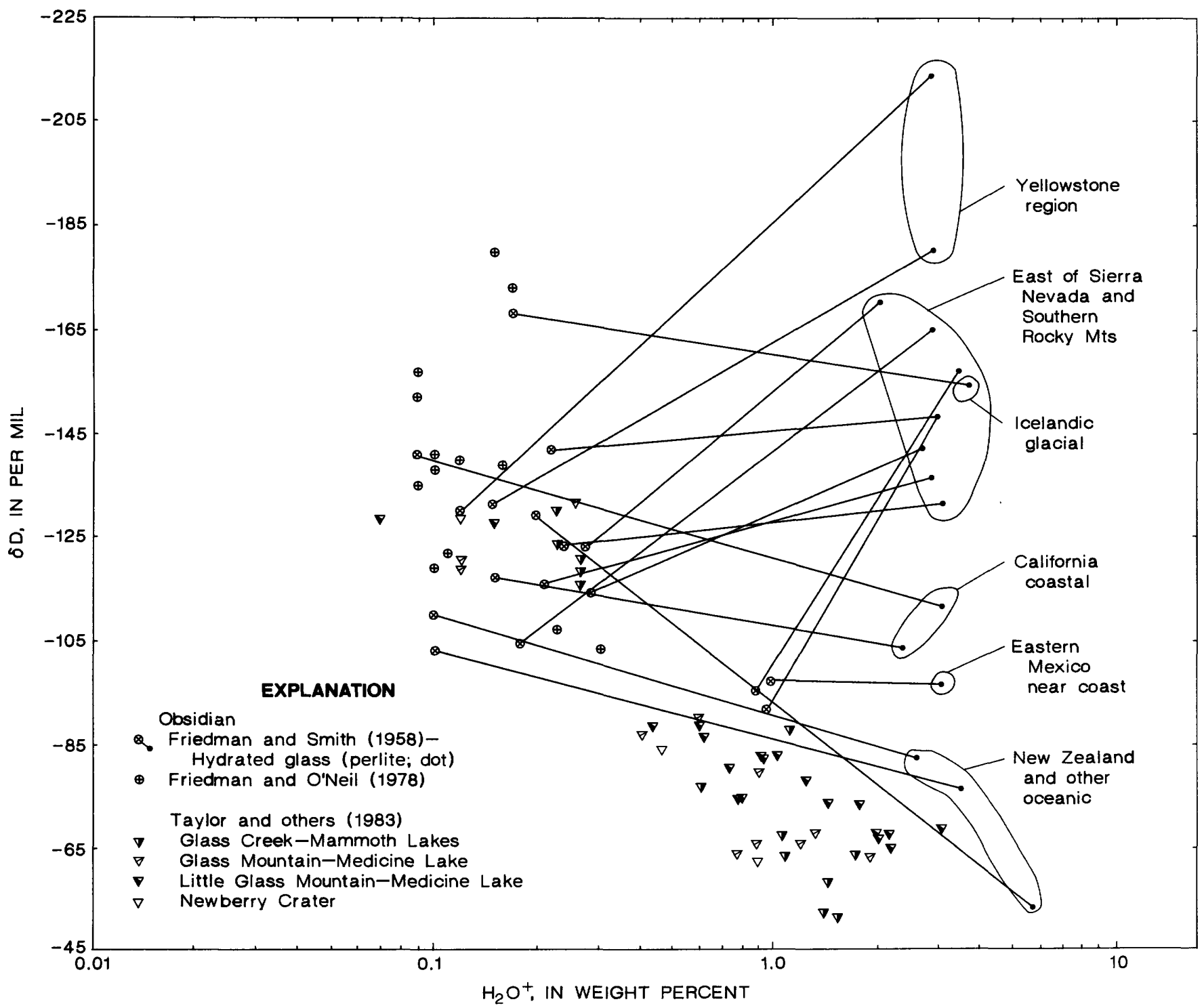

Figure 37. $-\mathrm{H}_{2} \mathrm{O}^{+}$content versus $\mathrm{\delta D}$ for obsidian and obsidianhydrated glass (perlite) pairs. Obsidian data show strong positive correlation between increasing $\mathrm{H}_{2} \mathrm{O}^{+}$and decreasing $6 \mathrm{D}$. Hydrated glass data are shown to reaffirm that there is a real difference between $\delta \mathrm{D}$ in most hydrated glass and $\delta \mathrm{D}$ in highwater obsidians, and that $6 \mathrm{D}$ in obsidian appears to relate to $\mathrm{H}_{2} \mathrm{O}$ content, whereas $\mathrm{H}_{2} \mathrm{O}$ in hydrated glass appears to relate to deuterium/hydrogen $(\mathrm{D} / \mathrm{H})$ composition of local meteoric waters. 


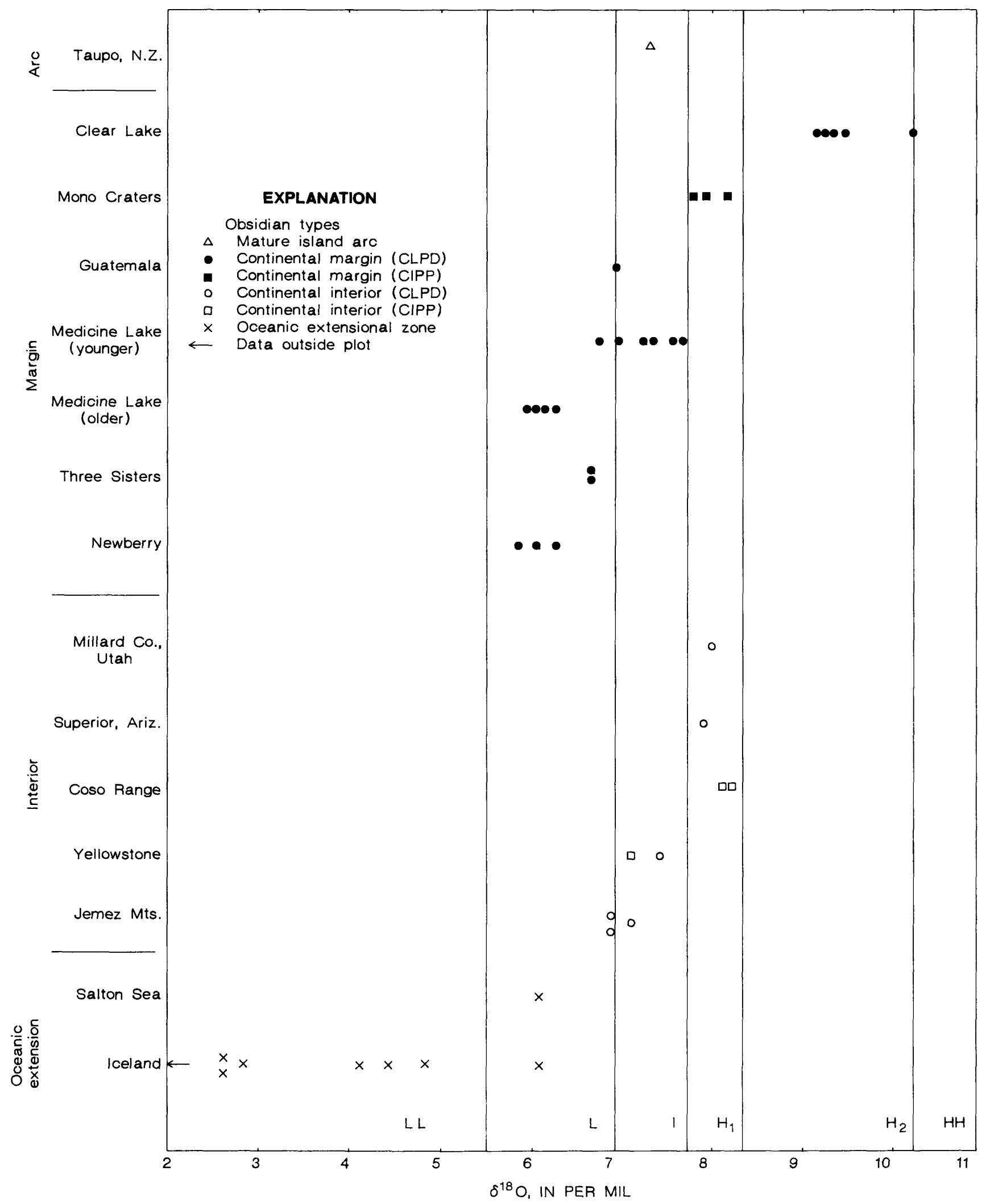

FIGURE 38.- $\delta^{18} \mathrm{O}$ of whole rock and glass samples of obsidians. Vertical lines separate arbitrary groups distinguished by Taylor (1968); limits are: LL, $\delta<5.5 ; \mathrm{L}, 5.5<\delta<7.0 ; \mathrm{I}, 7.0<\delta<7.8 ; \mathrm{H}_{1}, 7.8<\delta<8.4 ; \mathrm{H}_{2}, 8.4<\delta<10.2 ; \mathrm{HH}, \delta>10.2$. Data from appendix I. 
TABLE 12.-Oxygen isotope analyses of silicic obsidians

\begin{tabular}{|c|c|c|c|c|}
\hline Locality & $\begin{array}{l}\text { Published } \\
\text { specimen } \\
\text { number }\end{array}$ & $\begin{array}{l}\text { Material } \\
\text { analyzed }\end{array}$ & $\begin{array}{c}{ }^{18} \mathrm{O} \\
\text { (per mil) }\end{array}$ & Reference \\
\hline $\begin{array}{l}\text { Newberry Volcano, Oregon } \\
\text { Rhyolite dome, due S. of East Lake -ar obsidian flow, SE. corner of East Lake } \\
\text { Younger obsidian flow in caldera } \\
\text { Youngest obsidian }\end{array}$ & $\begin{array}{l}\text { PL-5-3 } \\
\text { PL-6-3 } \\
\text { PL-4-3 }\end{array}$ & $\begin{array}{l}\text { Whole rock } \\
\text { Whole rock } \\
\text { Whole rock }\end{array}$ & $\begin{array}{l}6.3 \\
6.1 \pm 0.0 \\
5.9 \pm 0.2\end{array}$ & $\begin{array}{l}(1) \\
(1) \\
(1)\end{array}$ \\
\hline 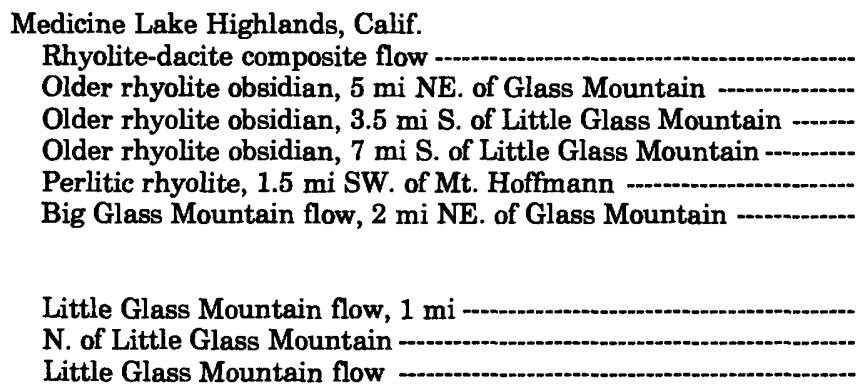 & $\begin{array}{l}\mathrm{ML}-55 \\
\mathrm{ML}-59 \\
\mathrm{ML}-65 \\
\mathrm{ML}-66 \\
\mathrm{ML}-17 \\
\mathrm{ML}-57 \\
\mathrm{ML}-57 \mathrm{a} \\
\mathrm{ML}-57 \mathrm{a} \\
\mathrm{ML}-63 \\
\mathrm{ML}-23 \\
\text { Doe-8 }\end{array}$ & $\begin{array}{l}\text { Whole rock } \\
\text { Whole rock } \\
\text { Whole rock } \\
\text { Whole rock } \\
\text { Whole rock } \\
\text { Whole rock } \\
\text { Black glass } \\
\text { Gray glass } \\
\text { Whole rock } \\
\text { Whole rock } \\
\text { Whole rock }\end{array}$ & $\begin{array}{l}7.4 \pm 0.2 \\
6.2 \pm 0.1 \\
6.1 \pm 0.1 \\
6.3 \pm 0.1 \\
6.0 \pm 0.2 \\
7.3 \pm 0.1 \\
7.3 \\
7.0 \\
7.7 \pm 0.2 \\
7.6 \pm 0.1 \\
6.8 \pm 0.2\end{array}$ & $\begin{array}{l}(1) \\
(1) \\
(1) \\
(1) \\
(1) \\
(1) \\
(1) \\
(1) \\
(1) \\
(1) \\
(1)\end{array}$ \\
\hline 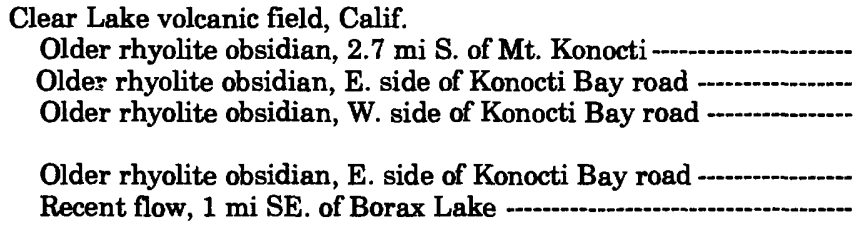 & $\begin{array}{l}\text { CL-20-3 } \\
\text { CL-9-3 } \\
\text { CL-10-3 } \\
\text { CL-10-3 } \\
\text { CL-19-3 } \\
\text { Doe-5 }\end{array}$ & $\begin{array}{l}\text { Whole rock } \\
\text { Whole rock } \\
\text { Black glass } \\
\text { Gray glass } \\
\text { Black glass } \\
\text { Whole rock }\end{array}$ & $\begin{array}{l}9.4 \\
9.3 \\
9.3 \\
9.5 \\
9.2 \\
10.2 \pm 0.1\end{array}$ & $\begin{array}{l}(1) \\
(1) \\
(1) \\
(1) \\
(1) \\
(1)\end{array}$ \\
\hline $\begin{array}{l}\text { Mono Craters, Calif. } \\
\text { Panum Crater } \\
\text { Dome, } 7 \text { mi SE. of Lee Vining } \\
\text { Flow, } 2 \text { mi E. of June Lake - }\end{array}$ & $\begin{array}{l}\text { T-807 } \\
\text { Mono-2 } \\
\text { Mono-7 }\end{array}$ & $\begin{array}{l}\text { Whole rock } \\
\text { Whole rock } \\
\text { Whole rock }\end{array}$ & $\begin{array}{l}8.0 \\
7.9 \pm 0.2 \\
8.2\end{array}$ & $\begin{array}{l}(1) \\
(1) \\
(1)\end{array}$ \\
\hline $\begin{array}{l}\text { Coso volcanic field, Calif. } \\
\text { Coso Hot Springs - } \\
\text { Salton Sea, Calif., Obsidian Butte }\end{array}$ & $\begin{array}{l}\text { T-341d } \\
\text { Coso-2 } \\
\text { W-772 }\end{array}$ & $\begin{array}{l}\text { Whole rock } \\
\text { Whole rock } \\
\text { Whole rock }\end{array}$ & $\begin{array}{l}8.2 \\
8.1 \\
6.1 \pm 0.2\end{array}$ & $\begin{array}{l}(1) \\
(1) \\
(1)\end{array}$ \\
\hline $\begin{array}{l}\text { Yellowstone volcanic field, Wyo. } \\
\text { Cougar Creek vent dome } \\
\text { Obsidian Cliff }\end{array}$ & $\begin{array}{l}\text { Doe-40 } \\
\text { YNP-3 }\end{array}$ & $\begin{array}{l}\text { Whole rock } \\
\text { Whole rock }\end{array}$ & $\begin{array}{l}7.4 \pm 0.1 \\
7.1\end{array}$ & $\begin{array}{l}(1) \\
(1)\end{array}$ \\
\hline Near Black Rock, Millard Co., Utah & Ward-obs. & Whole rock & $8.0 \pm 0.0$ & (1) \\
\hline Superior, Ariz., Marekanite nodules & Ariz-5 & Black obs. & $7.9 \pm 0.1$ & (1) \\
\hline $\begin{array}{l}\text { Jemez Mountains volcanic field, N. Mex. } \\
\text { Nodule in perlite, Arroyo Hondo } \\
\text { Obsidian, Los Posos - S. of Rio San Antonio } \\
\text { Jemez Creek Canyon, S. }\end{array}$ & $\begin{array}{l}\text { Doe-28 } \\
\text { Doe-29 } \\
\text { NM-4-4 }\end{array}$ & $\begin{array}{l}\text { Whole rock } \\
\text { Whole rock } \\
\text { Whole rock }\end{array}$ & $\begin{array}{l}7.1 \pm 0.2 \\
6.9 \pm 0.1 \\
6.9 \pm 0.1\end{array}$ & $\begin{array}{l}(1) \\
(1) \\
(1)\end{array}$ \\
\hline Guatemala Ixtepeque flow, Obrajuelo complex - & G-664 & Whole rock & $6.9 \pm 0.1$ & (1) \\
\hline 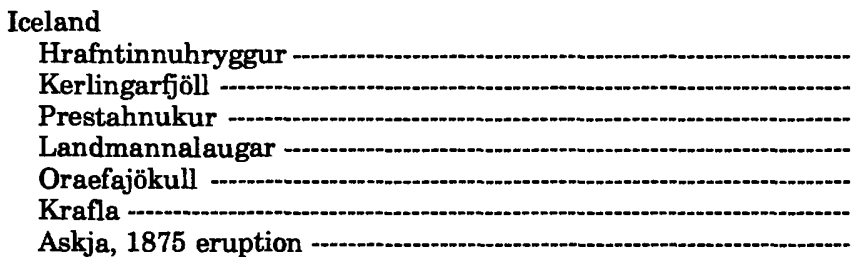 & $\begin{array}{l}\overline{-} \\
\overline{-} \\
\text { BMR } \\
\text { SAL-74 } \\
\text { KK-26 } \\
\text { A-1875 }\end{array}$ & $\begin{array}{l}\text { Whole rock } \\
\text { Glass } \\
\text { Glass } \\
\text { Whole rock } \\
\text { Whole rock } \\
\text { Whole rock } \\
\text { Whole rock }\end{array}$ & $\begin{array}{l}2.8 \pm 0.13 \\
4.8 \pm 0.13 \\
4.4 \pm 0.13 \\
2.8 \pm 0.13 \\
6.11 \\
2.88 \\
1.37\end{array}$ & $\begin{array}{l}(2) \\
(2) \\
(2) \\
(2) \\
(3) \\
(3) \\
(3)\end{array}$ \\
\hline Tau & $\mathrm{JH}-\mathbf{5 1 5}$ & Whole rock & $7.4 \pm 0.1$ & (4) \\
\hline
\end{tabular}

References:

(1) Taylor (1968)

(2) Muehlenbachs (1973)

(3) Condomines and others (1983)

(4) Blattner and Reid (1982) 
we feel that Taylor (1968) perhaps overemphasized the geographical control over ${ }^{18} \mathrm{O} /{ }^{16} \mathrm{O}$ ratios, and that no distinction can yet be made between obsidians of the continental margin and continental interiors.

Studies of individual volcanic centers reveal rather more complex petrogenetic relations. Thus, in the Medicine Lake Highlands, Taylor (1968, p. 44-47) showed that there is a general order of increasing ${ }^{18} \mathrm{O} /{ }^{16} \mathrm{O}$ ratios in the sequence andesite $\rightarrow$ basalt $\rightarrow$ rhyolite $\rightarrow$ dacite; that is, there is no simple relation between the ratio and $\mathrm{SiO}_{2}$ content. There is, however, a general increase in $\delta^{18} \mathrm{O}$ values of each rock type with decreasing age. Older, pre-Modoc, flows tend to belong to the $\mathrm{L}$ group while younger, recent flows are of I type (fig. 38).

These observations militate against any simple process of magmatic differentiation connecting the major rock types at Medicine Lake; at least two different mechanisms were operative. Taylor (1968, p. 47) specifically excludes the involvement of sialic crustal rock in the generation of the magma but allows the possibility of magma mixing as a partial cause of the isotope variations.

The $\delta^{18} \mathrm{O}$ data for the Newberry volcano also preclude crustal contamination with sedimentary rocks and (or) granites as an important mechanism in the formation of the rhyolites (Taylor, 1968, p. 48).

As well as being higher in $\delta^{18} \mathrm{O}$ than any other obsidians yet analyzed, the Clear Lake rocks also show a progression in ${ }^{18} \mathrm{O}$ content with decreasing age, from 8.8 per mil in a Pleistocene rhyodacite to 10.2 per mil in a younger obsidian. Again, no simple explanation of either observation can yet be offered. Closed-system fractionation of basaltic magma is precluded by these data.

Taylor's (1968) studies revealed how complex magmatic processes at individual centers are superimposed on broad regional patterns. Work by Lipman and Friedman (1975) stressed another complicating factor. They interpreted systematic oxygen isotope variations in the phenocryst phases of compositionally zoned ash-flow sheets and related flows in southern Nevada as being due to the influx of meteoric water into silicic magma chambers. Interaction of the water and the hot magma resulted in the magma becoming progressively lighter in ${ }^{18} \mathrm{O}$ with decreasing age. In contrast, Stuckless and O'Neil (1973) found no evidence of significant interaction between melts and meteoric water during the evolution of five ash-flow sheets in the Superstition-Superior area, Arizona. Measurement of ${ }^{18} \mathrm{O}$ in quartz phenocrysts of the Lava Creek Tuff showed that the Yellowstone magma chamber had a modest ${ }^{18} \mathrm{O} /{ }^{16} \mathrm{O}$ gradient at the time of this caldera-producing eruption (Hildreth, 1981) and that oxygen was systematically, isotopically lighter at the top of the chamber. These examples apparently point to the existence of isotopic variability in some, but not all, large chambers. The mechanisms generating the variability are still not understood.

However, in studies of zoned ash-flow sheets, great care must be taken in interpreting isotopic variations in glass samples that may have been secondarily hydrated. Six whole-rock samples covering the compositional range in the Bishop Tuff, California (Halliday and others, 1984), gave $\delta^{18} \mathrm{O}$ in the range 5.9-10.3 per mil, whereas the sanidine phenocrysts from the same rocks gave 6.7-7.9 per mil. The ${ }^{143} \mathrm{Nd} /{ }^{144} \mathrm{Nd}$ ratios were essentially constant at $0.51258 \pm 0.00001$. Halliday and others (1984) suggest that the extreme isotopic disequilibria resulted from low-temperature, post-eruptive interaction with meteoric water and that the magmas were isotopically uniform prior to eruption.

Muehlenbachs (1973) has reported the occurrence on Iceland of rhyolitic obsidians with $\delta^{18} \mathrm{O}$ values as low as 2.8 per mil. He suggests that at least some of these rhyolites were formed by the partial melting of hydrothermally altered basalts within the crust. It would be very valuable if low $\delta^{18} O$ values could be used to characterize basaltic source rocks in this way. Chemically, the Icelandic rocks are most similar to the St. Andrew Strait rhyolites and, somewhat less closely, to those from Salton Sea, California. No oxygen isotope data have been published for the St. Andrew Strait rocks, but one analysis is available for a Salton Sea rock (Taylor, 1968, table 1). The value of $6.1 \pm 0.2$ per mil, though by no means anomalously low, is among the lowest values for American obsidians.

\section{TITANIUM}

The range of $\mathrm{TiO}_{2}$ abundances is large, 0.02-0.9 weight percent. Its strongest positive correlations are with $\mathrm{FeO}_{t}, \mathrm{MgO}, \mathrm{CaO}, \mathrm{P}_{2} \mathrm{O}_{5}$, and, like those oxides and trace elements $\mathrm{Co}$ and $\mathrm{Sc}$, it shows negative correlations with $\mathrm{SiO}_{2}$ and $\mathrm{K}_{2} \mathrm{O}$.

The only clear effect of crustal type on $\mathrm{TiO}_{2}$ relative to $\mathrm{SiO}_{2}$ is that calcic obsidians from mature island arcs have higher $\mathrm{TiO}_{2}$ contents than the other rhyolite groups. The lower average $\mathrm{TiO}_{2}$ in continental-interior obsidians (table 7) is largely a function of the higher $\mathrm{SiO}_{2}$ in these rocks.

On a $\mathrm{SiO}_{2}-\mathrm{TiO}_{2}$ plot (fig. $30 \mathrm{H}$ ), the trends of rock-glass pairs, the Woodson stock, magma mixing 
series, and CIPP systems are subparallel, suggesting that they are all equally efficient in fractionating $\mathrm{TiO}_{2}$. Rocks having $\mathrm{TiO}_{2}<0.1$ weight percent are predominantly from CIPP systems, but several CLPD rocks from all the main rhyolite groups also show low values. No field unique to CIPP may thus be distinguished on this plot.

Within-group variations are relatively pronounced. The Newberry obsidians have lower $\mathrm{TiO}_{2}$ than those from Medicine Lake at equivalent $\mathrm{SiO}_{2}$. Yellowstone base-level rocks have rather high $\mathrm{TiO}_{2}$. Obsidians from the U.S. Gypsum mine, Nevada, Government Mountain, Arizona, and Xalapasquillo, Mexico, are all anomalously low in $\mathrm{TiO}_{2}$.

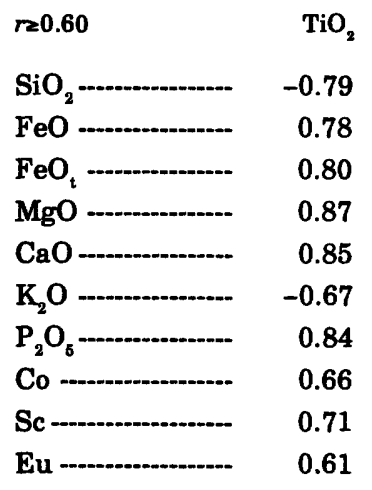

PHOSPHORUS

Although the range of $\mathrm{P}_{2} \mathrm{O}_{5}$ values is very large, $0.00 \mathrm{X}$ to 0.55 weight percent, approximately two-thirds of the samples have $<0.05$ percent $\mathrm{P}_{2} \mathrm{O}_{5}$ and about onethird have $<0.02$ percent $\mathrm{P}_{2} \mathrm{O}_{5}$. CIPP rocks in particular show extreme $\mathrm{P}$ depletion, few samples having more than 0.02 percent $\mathrm{P}_{2} \mathrm{O}_{5}$. Hildreth $(1979$, p. 71$)$ has already noted the tendency of CIPP to produce lowtemperature magmas with $\mathrm{P}_{2} \mathrm{O}_{5} \sim 230 \mathrm{ppm}$.

At such low levels, analytical uncertainty might contribute to disguising significant intergroup and intragroup variations. For example, there is a large difference in average $\mathrm{P}_{2} \mathrm{O}_{5}$ values in the new and published analyses of obsidians from mature island arcs (table 7), which is almost certainly due to overestimations of $\mathrm{P}_{2} \mathrm{O}_{5}$ contents in many older analyses. Even in the internally consistent data set of the obsidian data bank, it is difficult to distinguish chemically CLPD rocks from different tectonic settings (fig. 30I). It is possible that, at higher $\mathrm{SiO}_{2}$ levels, rocks of the arcs and continental margins show a much wider range of $\mathrm{P}_{2} \mathrm{O}_{5}$ values than those from the continental interiors. In lower silica rocks, obsidians from oceanic extensional zones tend to have relatively low $\mathrm{P}_{2} \mathrm{O}_{5}$ contents. The high $\mathrm{P}_{2} \mathrm{O}_{5}$ abundance in the macusanite glass (up to 0.55 percent, Nos. 160,315 ,
316) is one of the most puzzling features of this unusual material.

$\mathrm{P}_{2} \mathrm{O}_{5}$ shows strong correlations $(r \geq 0.6)$ only with $\mathrm{Al}_{2} \mathrm{O}_{3}, \mathrm{MgO}, \mathrm{CaO}, \mathrm{TiO}_{2}$, and $\mathrm{Sr}$ (positive) and $\mathrm{SiO}_{2}$ and $\mathrm{K}_{2} \mathrm{O}$ (negative).

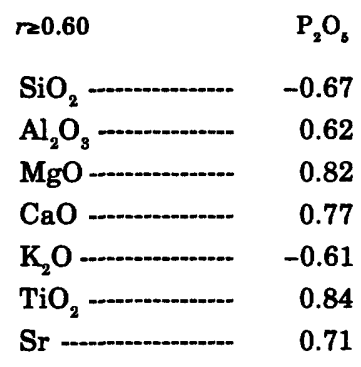

MANGANESE

In contrast to the other major oxides in the obsidians, $\mathrm{MnO}$ shows no correlation coefficient $>0.45$. This may partly be an analytical problem; the majority of specimens lie in the range 0.01 to 0.1 weight percent (fig. $29 \mathrm{~K}$ ), where analytical uncertainties will be relatively large (see the stepwise nature of the data in fig. $30 \mathrm{~J}$, and these might disguise significant relations. It may also be due in part to the behavior of Mn in CIPP systems. Though crystalliquid processes tend to produce a negative relation between $\mathrm{SiO}_{2}$ and $\mathrm{MnO}$ (see the relevant trends in fig. $30 \mathrm{~J}$, CIPP results in Mn enrichment in lower temperature magmas, at least in the Bandelier, Bishop, and Coso systems (Hildreth, 1979; Bacon and others, 1981). This reversal of behavior will have the result of lowering correlation coefficients with other elements.

The $\mathrm{MnO}^{-\mathrm{SiO}_{2}}$ plot (fig. $30 \mathrm{~J}$ ) shows no simple relation between $\mathrm{MnO}$ concentration and tectonic setting; neither do the mean concentrations of $\mathrm{MnO}$ in the various rhyolite groups (fig. $29 K$ ).

\section{CHLORINE}

Chlorine abundances in the obsidians range from 0.0 to 0.3 weight percent (fig. $29 L$ ). The correlation coefficient with $\mathrm{SiO}_{2}$ is low, -0.28 , owing to important differences between rocks of different tectonic settings.

Lack of reliable data for $\mathrm{Cl}$ in rhyolites of the primitive island arcs is a major shortcoming. In continental-margin obsidians, $\mathrm{Cl}$ shows a scattered, but real, negative correlation with $\mathrm{SiO}_{2}$. This is an apparent anomaly in that crystal-liquid processes, as judged from rock-glass tielines, tend to slightly enrich $\mathrm{Cl}$ in residual liquids. It is possible that the 
overall decrease against $\mathrm{SiO}_{2}$ is in some way related to the mobility of $\mathrm{Cl}$ in the magma chambers. It may be lost from more silicic magmas as a volatile phase or added to less silicic types by injection of mafic magma into the chamber. Alternatively, the effect may be related in some way to the sources of the rhyolites. Many of the lower silica, higher $\mathrm{Cl}$ margin rocks belong to the Cascades subtype (p. 39), whereas many rocks of the southwestern Oregon subtype contain higher silica and lower $\mathrm{Cl}$. The lower $\mathrm{Cl}$ values may be a result of relative $\mathrm{Cl}$ impoverishment of the sources which may have a substantial mafic component.

Some of the $\mathrm{Cl}$ scatter at constant $\mathrm{SiO}_{2}$ reflects areas of relatively high $\mathrm{Cl}$ abundances (for example, the Chilean obsidians). CIPP results in upward concentration of $\mathrm{Cl}$ and the average value in CIPP rocks is higher than in CLPD types. Hildreth (1981) refers to the scattered nature of $\mathrm{Cl}$ data in CIPP systems but suggests that enrichments of two are normal. This is certainly a minimum value, because in the Bandelier magma, enrichments of 4-6 are likely (R.L. Smith, unpub. data).

Continental-interior obsidians show no significant correlation with $\mathrm{SiO}_{2}$. CLPD continental-interior rocks show the same compositional range as CLPD continental-margin types. Certain CIPP specimens tend toward higher concentrations, up to 0.2 weight percent $\mathrm{Cl}$; but others, such as rocks from the San Francisco Peaks, Arizona (Nos. 108, 109), have low abundances, $<0.05$ weight percent. It is not yet known whether base-level $\mathrm{Cl}$ was low in this system or $\mathrm{Cl}$ was lost from the magma.

The highest $\mathrm{Cl}$ concentrations in the data bank are in the obsidians from the Eolian arc, Italy (Nos. 180, 181, 182, 326, 327) and in the oceanicextensional rhyolites. These latter rocks can be subdivided into those from the Admiralty Islands and the Salton Sea ( $\mathrm{Cl}>0.30$ percent) and those from Iceland ( $<0.20$ percent). The Icelandic rocks show the negative correlation between $\mathrm{SiO}_{2}$ and $\mathrm{Cl}$ noted for the continental-margin glasses. The low $\mathrm{Cl}$ content of the Askja mixed rock (0.02 weight percent, No. 176) suggests a potential mechanism for producing $\mathrm{Cl}$ depletion: loss, as a volatile phase, due to superheating on mixing with mafic magma.

$\mathrm{Cl}$ values of obsidians from mature island arcs overlap with the continental-margin types, but, at given $\mathrm{SiO}_{2}$ (fig. 30K), extend to higher values, a feature also indicated by the average abundances (table 7).

It is particularly notable that $\mathrm{Cl}$ has no correlation coefficient greater than 0.6 with any other element. Our prejudice is that this does not bear on the lack of systematic behavior of $\mathrm{Cl}$ in magmatic sys- tems but rather on the relative ease with which $\mathrm{Cl}$ can be added to, and removed from, the magmas. The highest coefficients, $0.3-0.4$, are with $\mathrm{FeO}, \mathrm{Hf}$, $\mathrm{Y}, \mathrm{Zr}$, and the REE excluding Eu. The coherence of this group of elements may be related to their ability to complex with $\mathrm{Cl}$.

\section{FLUORINE}

Fluorine shows a similar range as chlorine, 0.0 to 0.5 weight percent (fig. $29 M$ ). The distribution of $F$ is strongly related to geographic setting and geologic process, causing a correlation coefficient with $\mathrm{SiO}_{2}$ (0.11) even lower than that of $\mathrm{Cl}$. A marked aspect of $\mathrm{F}$ distribution is its strong enrichment in extensionrelated, as opposed to subduction-related, obsidian types. This enrichment of CLPD compositions is increased by CIPP, and only CIPP rocks have $F$ values above 0.19 percent. CLPD rocks from arcs and margins show a relatively restricted range, between 0.02 and 0.08 weight percent, which has no systematic variation with $\mathrm{SiO}_{2}$ (fig. $30 \mathrm{~L}$ ). Continental-interior rocks show a wider range, $0.03-0.18$ weight percent, with notable intergroup differences, for example, the high-F Yellowstone rocks and the low-F Jemez Mountain rocks.

In sharp contrast to $\mathrm{Cl}, \mathrm{F}$ shows many strong (>0.6) positive correlations with other elements. All of these have similar behavior in that they are enriched in interior obsidians, as opposed to subductionrelated rocks, and in that they are all up-elements during CIPP. The common factor may be their tendency to complex with $F$.

\begin{tabular}{|c|c|}
\hline$r \geq 0.60$ & $\mathbf{F}$ \\
\hline $\mathrm{Be}$ & 0.82 \\
\hline Nb & 0.72 \\
\hline Pb & 0.63 \\
\hline Rb - & 0.72 \\
\hline Sn - - & 0.76 \\
\hline Ta & 0.75 \\
\hline Th & 0.65 \\
\hline U & 0.63 \\
\hline Y & 0.69 \\
\hline $\mathrm{Tb}$ & 0.61 \\
\hline $\operatorname{Tm}$ & 0.70 \\
\hline Yb - & 0.71 \\
\hline Lu & 0.72 \\
\hline
\end{tabular}

Cl/F RATIOS

The averages of each rhyolite group (table 7) show that the continental-interior average has $\mathrm{Cl}<\mathrm{F}$, but the reverse is true in the other rhyolite groups. How- 
ever, use of averages disguises certain important features.

1. $\mathrm{Cl}$ is more abundant in all the obsidians from mature island arcs.

2. Though the average exceeds 1 , there are obsidians in the continental margins where the ratio $\mathrm{Cl} / \mathrm{F}<1$ (fig. 39), for example, in many of the eastern Oregon domes and in the Clear Lake field. Most CIPP continental-margin rocks have $\mathrm{Cl} / \mathrm{F}<1$.

3. Obsidians with $\mathrm{Cl} / \mathrm{F}>1$ are uncommon in the continental interiors (fig. 39). Notable exceptions are domes and flows from the Jemez Mountains volcanic complex, New Mexico.
4. The oceanic-extensional rocks have, on average, $\mathrm{Cl}$ in excess of $\mathrm{F}$. They form two subgroups, however, rocks from Salton Sea, Papua New Guinea, Alcedo, Galapagos, and Oraefajökull, Iceland, where $\mathrm{Cl}>\mathrm{F}$, and other Icelandic obsidians where $\mathrm{F}>\mathrm{Cl}$.

The data for the subalkalic obsidians are broadly consistent with the conclusions of Bailey (1980), based on peralkaline obsidians, that oceanic rhyolites (with the notable exception of Iceland) have $\mathrm{Cl}>\mathrm{F}$, but continental varieties have $\mathrm{Cl}<\mathrm{F}$. This fundamental difference is in some way related to the nature of the source rocks and (or) the processes involved in each setting. Given the different complexing affinities of different

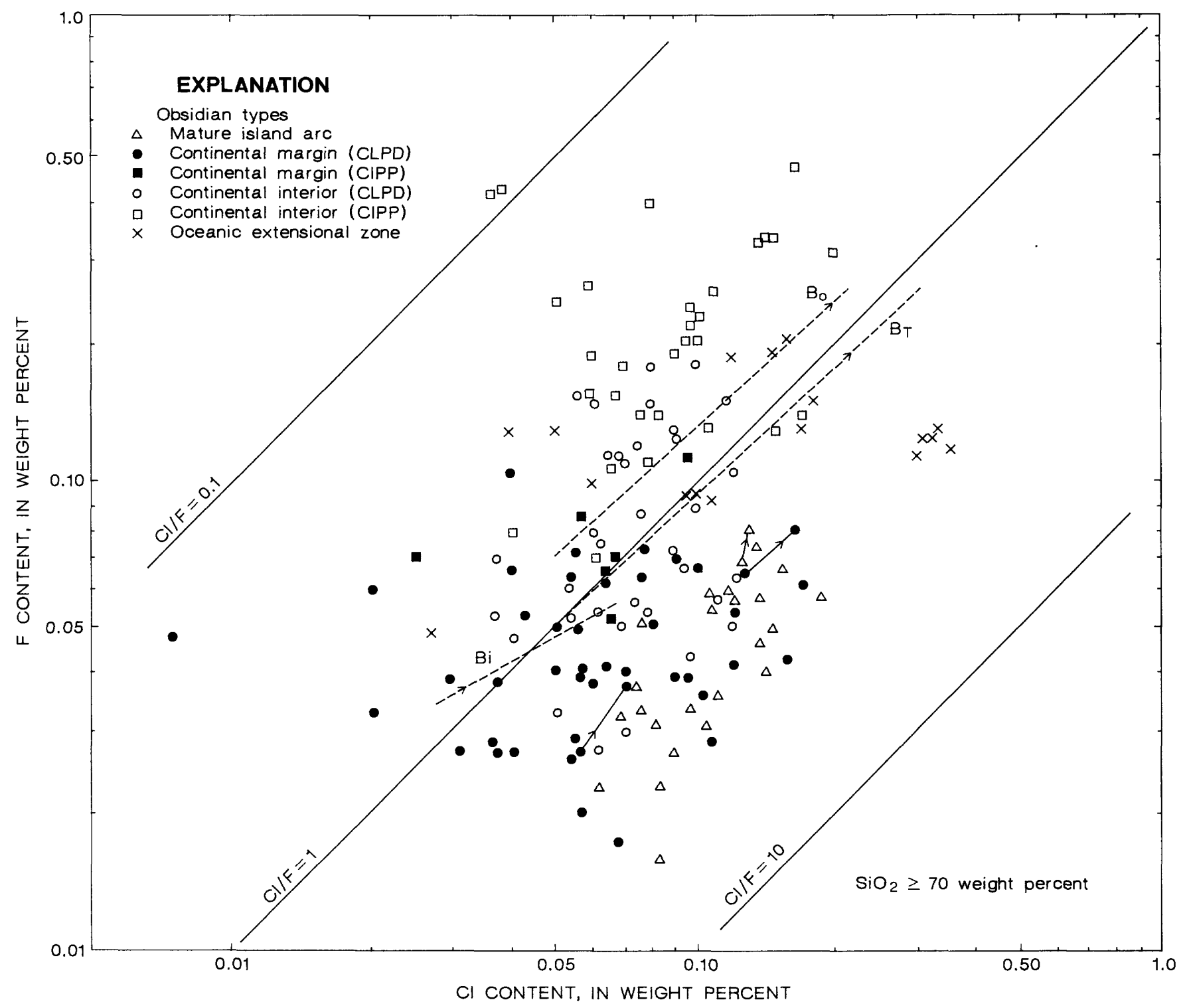

FIGURE 39.- $\mathrm{Cl}$ content versus $\mathrm{F}$ content for obsidians. Data sources are same as for figure 5. Solid tielines are rock-glass pairs; Bandelier Tuff (Otowi Member, $\mathrm{B}_{\mathrm{o}}$, and Tshirege Member, $\mathrm{B}_{\mathrm{T}}$ ); Bishop Tuff, Bi. Arrows indicate direction of liquid fractionation. 
elements for $\mathrm{F}$ and $\mathrm{Cl}$, the regional variations in $\mathrm{F}-\mathrm{Cl}$ relations may have important effects on the traceelement chemistry of the relevant silicic magmas.

It is also notable that within the limited data set for CIPP systems and CLPD rock-glass pairs (fig. 39) there seems no strong tendency for shifts in $\mathrm{Cl} / \mathrm{F}$ ratios with fractionation, and the trends are subparallel on the Cl-F plot. Slight deviations (for example, a slight increase in $\mathrm{Cl} / \mathrm{F}$ with increasing fractionation), as can be seen for both the Bishop and Bandelier systems, may be related as well to analytical or sample problems as to a real change in magmatic ratios.

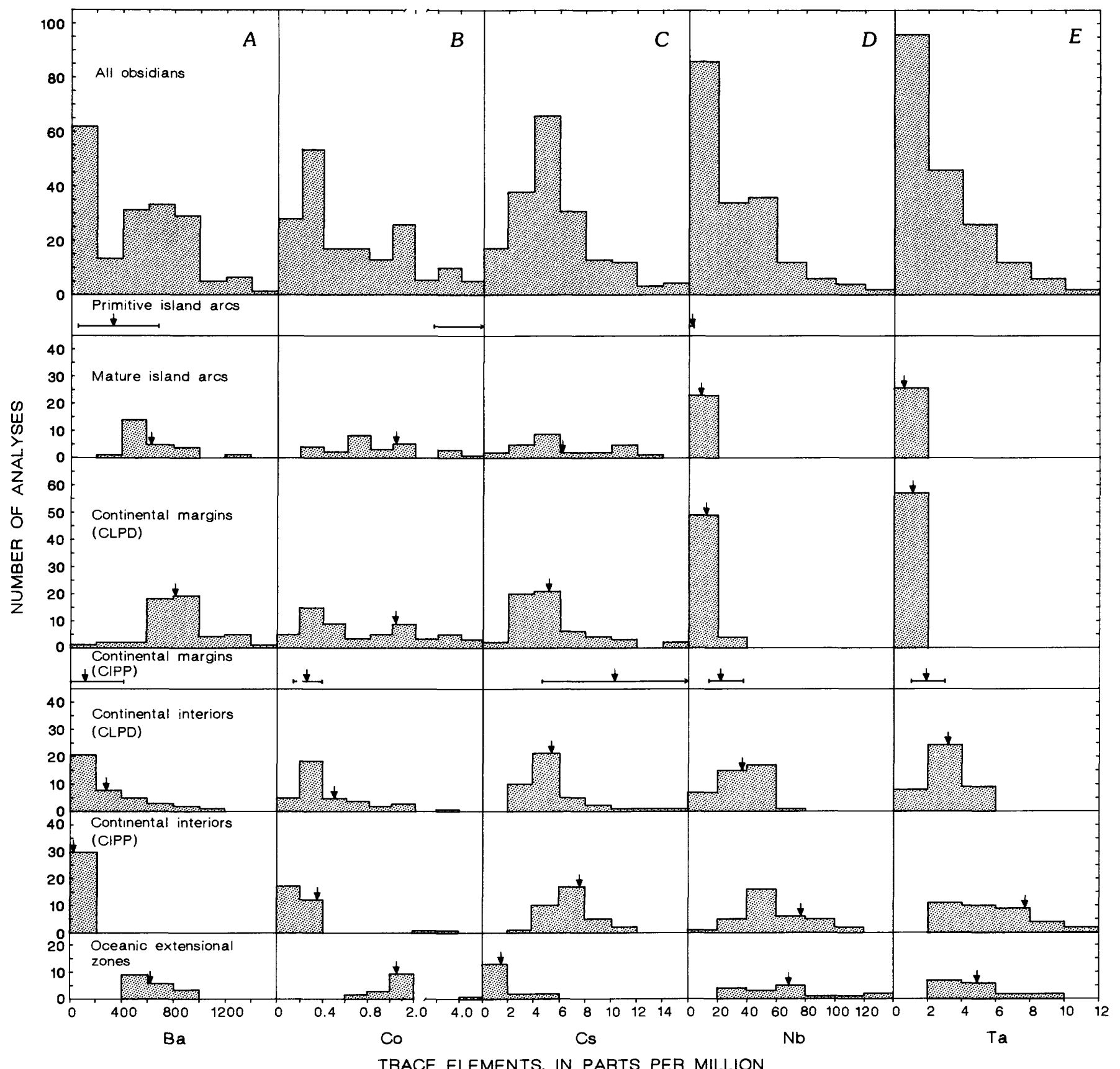

FIGURE 40.-Distribution of trace elements in obsidians. Obsidians of primitive island arcs and continental margins (CIPP types) are shown as ranges only. Primitive arc data missing on $C, E, H$, and $N$. Arrows indicate average values. Data from appendixes $I$ and V. $A, B a . B$, Co (note change in scale on Co axis). C, Cs (samples 86-88, 160, and 188 omitted to preserve scale). $D, \mathrm{Nb}$ (samples 83,108 , and 109 omitted to preserve scale). $E$, Ta (samples $83,108,109$, and 160 omitted to preserve scale, and sample 12 omitted 


\section{BARIUM}

In appendixes I, II, and IV, we report X-ray fluorescence determinations for $\mathrm{Ba}<5 \mathrm{ppm}$. Although these values were precisely determined, we have insufficient cross-checks using other analytical tech- niques to assess their accuracy. Until such checks are available, $\mathrm{Ba}$ values $<50 \mathrm{ppm}$ should be treated with caution.

$\mathrm{Ba}$ concentrations cover a 3-order-of-magnitude range, from 1 to $1,440 \mathrm{ppm}$. Averages and ranges are given in tables 7-9 and shown in figure $40 \mathrm{~A}$.

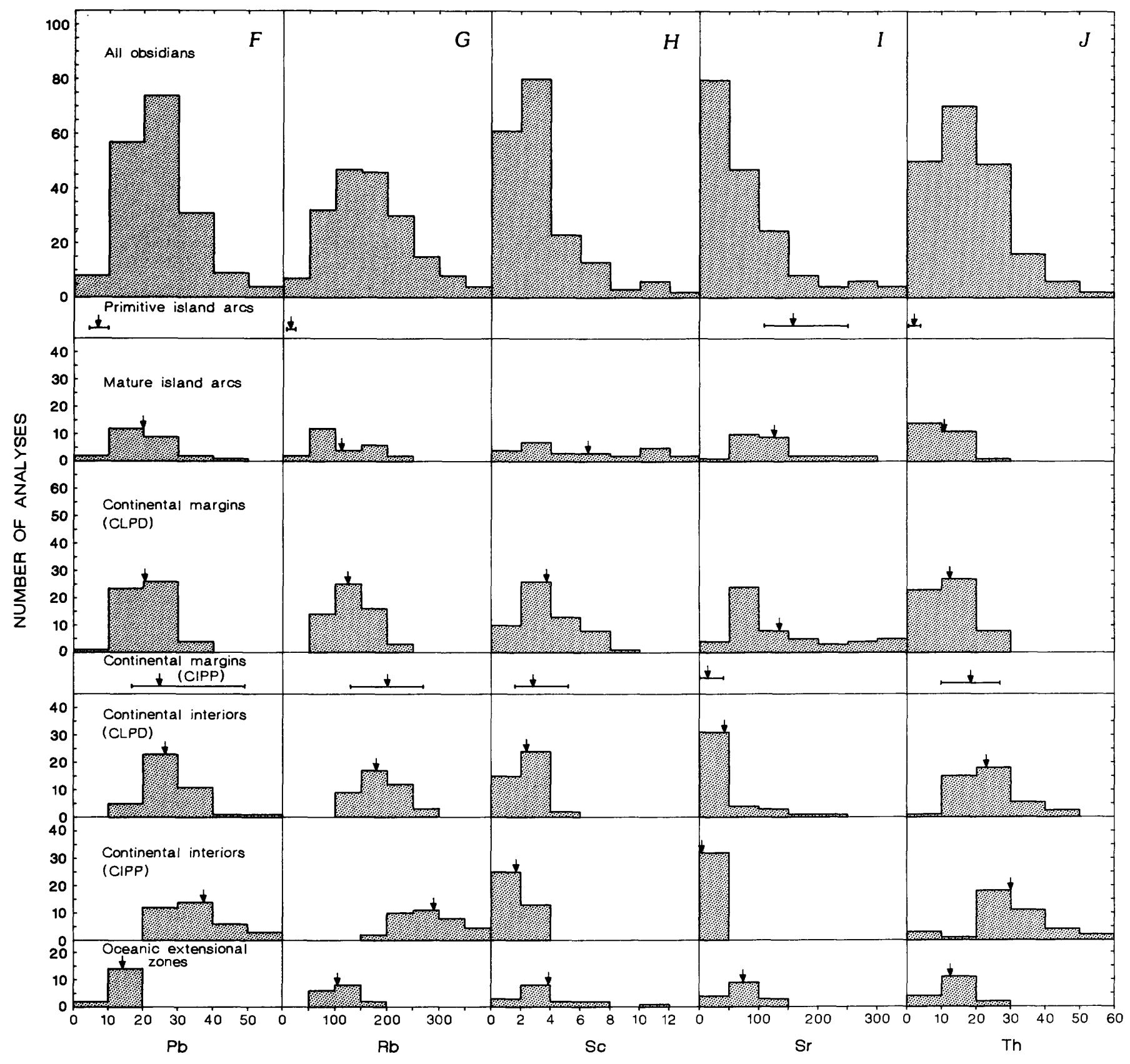

TRACE ELEMENTS, IN PARTS PER MILLION

because of suspected contamination). $F, \mathrm{~Pb}$ (samples 83,108 , and 109 omitted to preserve scale). $G$, Rb (samples $86-88$ and 160 omitted to preserve scale). $H$, Sc (sample 111 omitted-its high value may indicate analytical error or contamination of sample). $I$, Sr (sample 19 omitted to preserve scale). J, Th. K, U. $L, \mathrm{Zn}$ (sample 83 omitted to preserve scale). $M, \mathrm{Zr}$ (samples 156, 157, 172, 174 175, and 193 omitted to preserve scale). $N$, Hf. 
Obsidians from the primitive island arcs have the lowest $\mathrm{Ba}$ contents on a $\mathrm{SiO}_{2}$-normalized basis. Calcic rocks from the mature island arcs have values transitional between the primitive island arc rocks and the calc-alkalic types from mature arcs. These calc-alkalic rocks from mature island arcs have a range comparable to the rocks of the continental margins, with a lower average. This general increase of $\mathrm{Ba}$ contents from primitive arc to continental margin has been noted by Jakes and White (1972, p. 35). At $\mathrm{SiO}_{2}$ values $<75$ percent, base-level, continental- interior obsidians have clearly lower $\mathrm{Ba}$ abundances than mature-arc or continental-margin types. The difference persists at higher $\mathrm{SiO}_{2}$ levels, but rocks of all three groups can show extreme $\mathrm{Ba}$ depletion in this composition range. It is noteworthy that mature-island-arc rocks do not show the very low $\mathrm{Ba}$ contents found in continental rocks.

Obsidians from oceanic extensional zones show a range of $\mathrm{Ba}$ values, even on a $\mathrm{SiO}_{2}$-normalized basis. Rocks from Papua New Guinea and certain of the Icelandic complexes are relatively rich in $\mathrm{Ba}$, but those

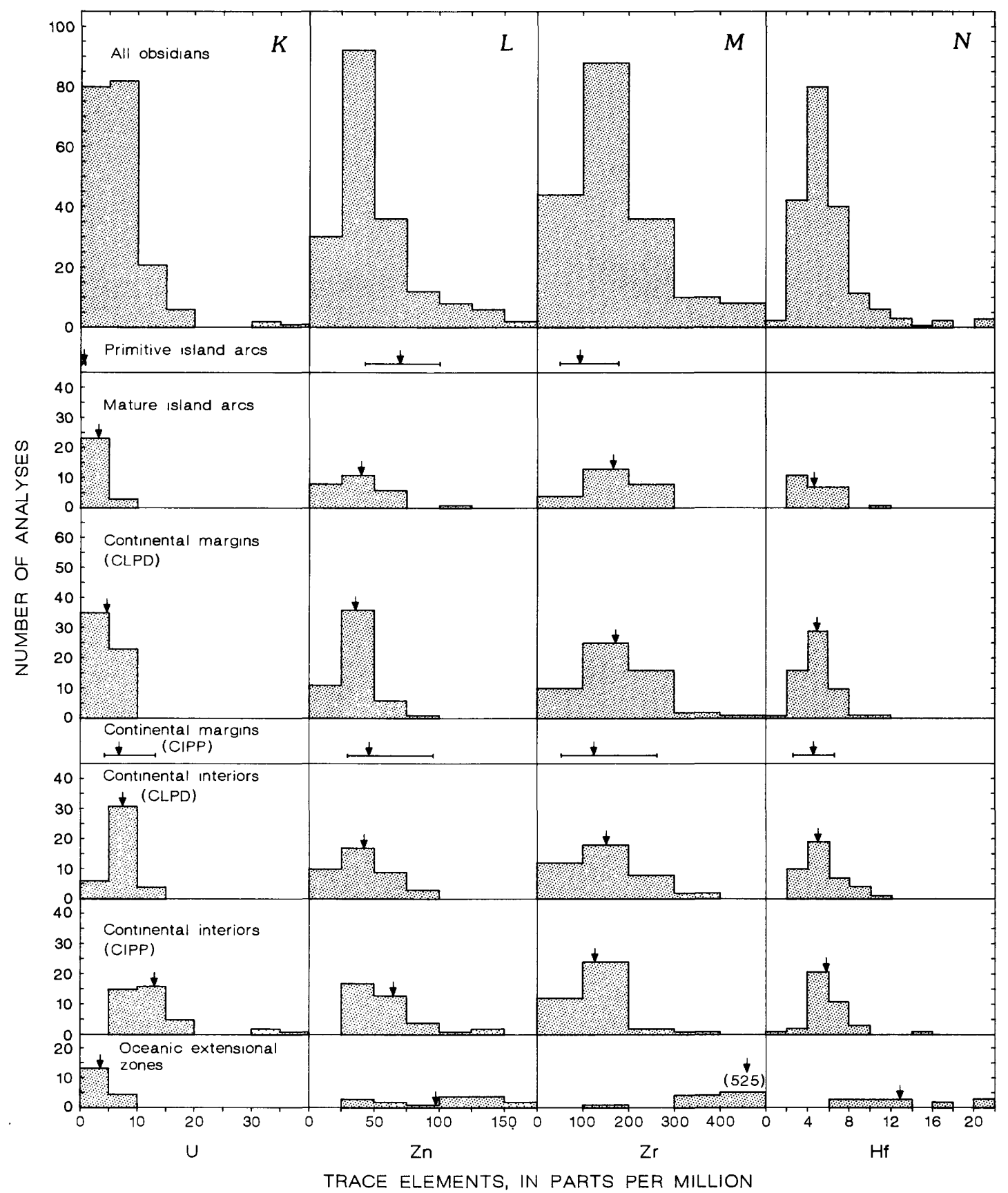

Figure 40.-Continued. 
from the Salton Sea, Alcedo, and the remaining Icelandic centers have very low $\mathrm{Ba}$ contents.

Within-group variations tend to be low, about a factor of 2 , in rocks with $\mathrm{SiO}_{2}<75$ percent but are up to two orders of magnitude in more silicic rocks. Certain specimens may be noted as rich in $\mathrm{Ba}$, even for subduction-related obsidians, for example, certain rocks from eastern Oregon (Nos. 26-28) and synresurgence rhyolites in the Long Valley caldera (data from Noble and others, 1972). The Ba enrichment is not accompanied by any apparently related anomaly and may represent Ba-rich source rocks.

The data for rock-glass pairs indicate either constant or increased $\mathrm{Ba}$ concentrations in residual liquids. This is broadly consistent with the absence of a highly significant correlation between $\mathrm{Ba}$ and $\mathrm{SiO}_{2}$ (app. VI), even in rocks with $\mathrm{SiO}_{2}<75$ percent.
The tielines for more silicic pairs (not illustrated) show $\mathrm{Ba}$ increase in the glass. A real petrogenetic problem is posed by the low $\mathrm{Ba}$ abundances in some CLPD obsidians ( $<20 \mathrm{ppm})$. As discussed by Hildreth (1981, p. 10169), those low abundances imply either sources abnormally depleted in $\mathrm{Ba}$, or very protracted feldspar fractionation from parental melts.

CIPP also produces extreme depletion of both $\mathrm{Ba}$ and $\mathrm{Sr}$ in lower temperature rocks (fig. 41). There is a variation of a factor of 60 from top to bottom in the Bishop Tuff (Hildreth, 1981); in the erupted part of the Coso system, the variation was 16 . Values of $\mathrm{Ba}<20 \mathrm{ppm}$ belong characteristically, but not exclusively, to CIPP rocks.

$\mathrm{Ba}$ has no strong $(r>0.60)$ correlation coefficient for another element. It is normally regarded as a

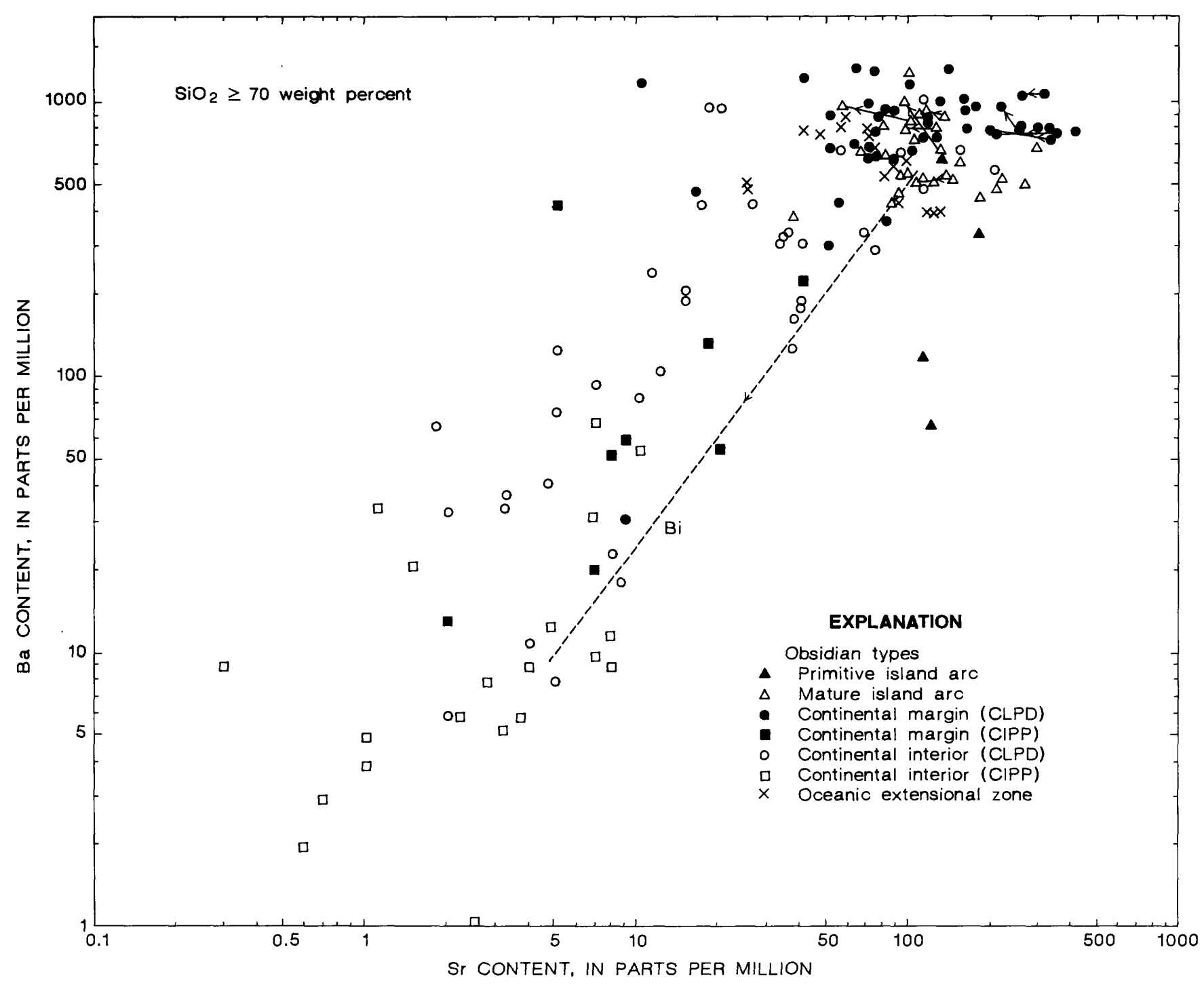

FiguRe 41.-Ba content versus Sr content for obsidians and various comparative rocks. Data sources are same as for figure 5. Solid tielines represent rock-glass pairs; dashed line represents Bishop Tuff $(\mathrm{Bi})$. Arrows indicate direction of liquid fractionation. 
K-related element, yet the two show dissimilar behavior in the obsidians. The sharp decrease in $\mathrm{Ba}$ in continental-interior rocks as opposed to subduction-related types stands in contrast to a $\mathrm{K}$ increase. CIPP depletes roof-zone magmas in $\mathrm{Ba}$ much more rapidly than $\mathrm{K}$, and high $\mathrm{K} / \mathrm{Ba}$ ratios characterize CIPP rocks.

\section{COBALT}

Cobalt occurs at very low levels $(<5 \mathrm{ppm})$ in the obsidians (fig. 40B), and analytical problems are

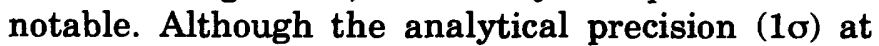
levels above $2 \mathrm{ppm}$ is estimated at 5 percent, at 0.2 ppm, it is 30 percent. Discussion of intersuite and intrasuite differences at low levels has to be made with caution. Interlaboratory comparison of data is even less rewarding. For example, the Co data obtained by Jack and Carmichael (1969) and Jack (1971) are higher than the INAA values for samples from the same localities by about an order of magnitude.

Contamination during sample preparation is an additional problem. Four Icelandic obsidians (Nos. $173,221,222,226$ ) have Co concentrations in the range 12-22 ppm. These values are not accompanied by unusually high $\mathrm{Cr}$ or Sc contents, which might indicate basalt contamination. Furthermore, comparison of one sample (173) with an otherwise almost identical rock (174) from the same complex shows Co values of 13.6 and $1.7 \mathrm{ppm}$, respectively. It may thus be suspected that these high Co samples were contaminated during sample preparation in tungsten carbide mills. Similarly, we suspect that the rock-glass pair from The Watchman, Crater Lake (Nos. 11, 12), has been contaminated, mainly on the basis of high $\mathrm{Ta}$ and $\mathrm{Cr}$ contents, as well as elevated Co abundances. These various samples are not used in computations or figures.

The new obsidian determinations are all less than $5 \mathrm{ppm}$, and the great majority $<1 \mathrm{ppm}$, Co (fig. 40B). Published data for rhyolites of primitive arcs are higher, up to $10 \mathrm{ppm}$. There is a broad, negative correlation $(r=-0.63)$ between $C_{0}$ and $\mathrm{SiO}_{2}$. The 40 times variation in Co concentrations makes it unsuitable for plotting against $\mathrm{SiO}_{2}$, so Co variation is here discussed on the basis of a Co$\mathrm{CaO}$ graph (fig. 42). Crystal-liquid trends and CIPP trends are approximately parallel, indicating that both processes are equally efficient in decreasing Co in lower-temperature magmas. Although CIPP rocks have Co in the range 0.1-0.4 ppm, many CLPD rocks have equally low abundances.
The average Co concentrations of silicic obsidians from mature island arcs, continental magmas, and oceanic extensional zones are very similar (table 7). The higher and lower averages for primitive-arc and continental-interior specimens, respectively, reflect their lower and higher $\mathrm{SiO}_{2}$ contents. There is no good evidence that the rocks from one setting are systematically different from any other, although such evidence may be masked by analytical imprecision.

Apart from $\mathrm{SiO}_{2}$, Co shows strong $(r>0.60)$ correlations only with $\mathrm{MgO}(0.69), \mathrm{CaO}(0.66)$, and $\mathrm{TiO}_{2}$ (0.66), as would be expected from an element whose distribution is controlled nore by bulk rock composition than by crustal or dominant genetic processes.

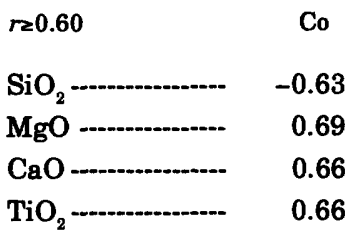

CHROMIUM

The data for $\mathrm{Cr}$ stress the unsatisfactory analytical uncertainties associated with the determination of this element at low concentrations (table 7).

1. The values of Johnson and others (1978) on $\mathrm{Cr}$ in obsidians from Papua New Guinea are about an order of magnitude higher than our new values. Because the samples were prepared in different laboratories, the higher values may alternatively indicate contamination.

2. Zielinski and others (1977) provide values for Rocky Mountain obsidians which are two or more times higher than our values.

3. Our value for Napa Glass Mountain is lower than that of Bowman and others (1973).

\begin{tabular}{|c|c|c|c|c|c|}
\hline Locality & $\begin{array}{c}\text { Specimen } \\
\text { No. }^{1}\end{array}$ & $\begin{array}{l}\text { This } \\
\text { paper }\end{array}$ & $\begin{array}{c}\text { Zielinski } \\
\text { and } \\
\text { others } \\
\text { (1977) }\end{array}$ & $\begin{array}{c}\text { Johnson } \\
\text { and } \\
\text { others } \\
\text { (1978) }\end{array}$ & $\begin{array}{c}\text { Bowman } \\
\text { and } \\
\text { others } \\
\text { (1973) }\end{array}$ \\
\hline $\begin{array}{l}\text { St. Andrew } \\
\text { Strait, } \\
\text { Papua New }\end{array}$ & $\begin{array}{l}\text { 25NG0011 } \\
(211)\end{array}$ & 2.7 & - & 26 & - \\
\hline Guinea & $\begin{array}{l}25 \mathrm{NG} 0025 \\
(213)\end{array}$ & $<7.0$ & 一 & 23 & 一 \\
\hline & 25NG0059 & $<6.0$ & - & 24 & - \\
\hline $\begin{array}{l}\text { Nathrop, } \\
\text { Colorado }\end{array}$ & $\begin{array}{l}\text { 66L-230A } \\
(104)\end{array}$ & $<6.0$ & 11 & - & 一 \\
\hline $\begin{array}{c}\text { Napa Glass } \\
\text { Mt., } \\
\text { California }\end{array}$ & $\begin{array}{l}\text { Average } \\
(44)\end{array}$ & $<5.0$ & - & - & 6.7 \\
\hline
\end{tabular}

'First number is published specimen number; the number in parantheses specimen number from this paper. 
Additionally, there is the problem that samples may be contaminated with $\mathrm{Cr}$ during grinding in materials such as tungsten carbide and colmonoy. We ascribe, for example, anomalously high $\mathrm{Cr}$ contents in specimens 11 and 12 to sample contamination.

Interlaboratory comparison of $\mathrm{Cr}$ results for obsidians appears to be unproductive at present. Though the data of this study provide at least an internally consistent body of results, replication of determinations at levels $<2 \mathrm{ppm}$ was in many cases unsatisfactory, varying by a factor of two or more in the worst cases. Reportable values were obtained for only 51 rocks. This precludes a detailed charting of $\mathrm{Cr}$ distribution in the obsidians, which is particularly unfortunate in that $\mathrm{Cr}$, like $\mathrm{Co}$, is potentially a useful element in assessing the amount of admixed mafic material in rhyolites.

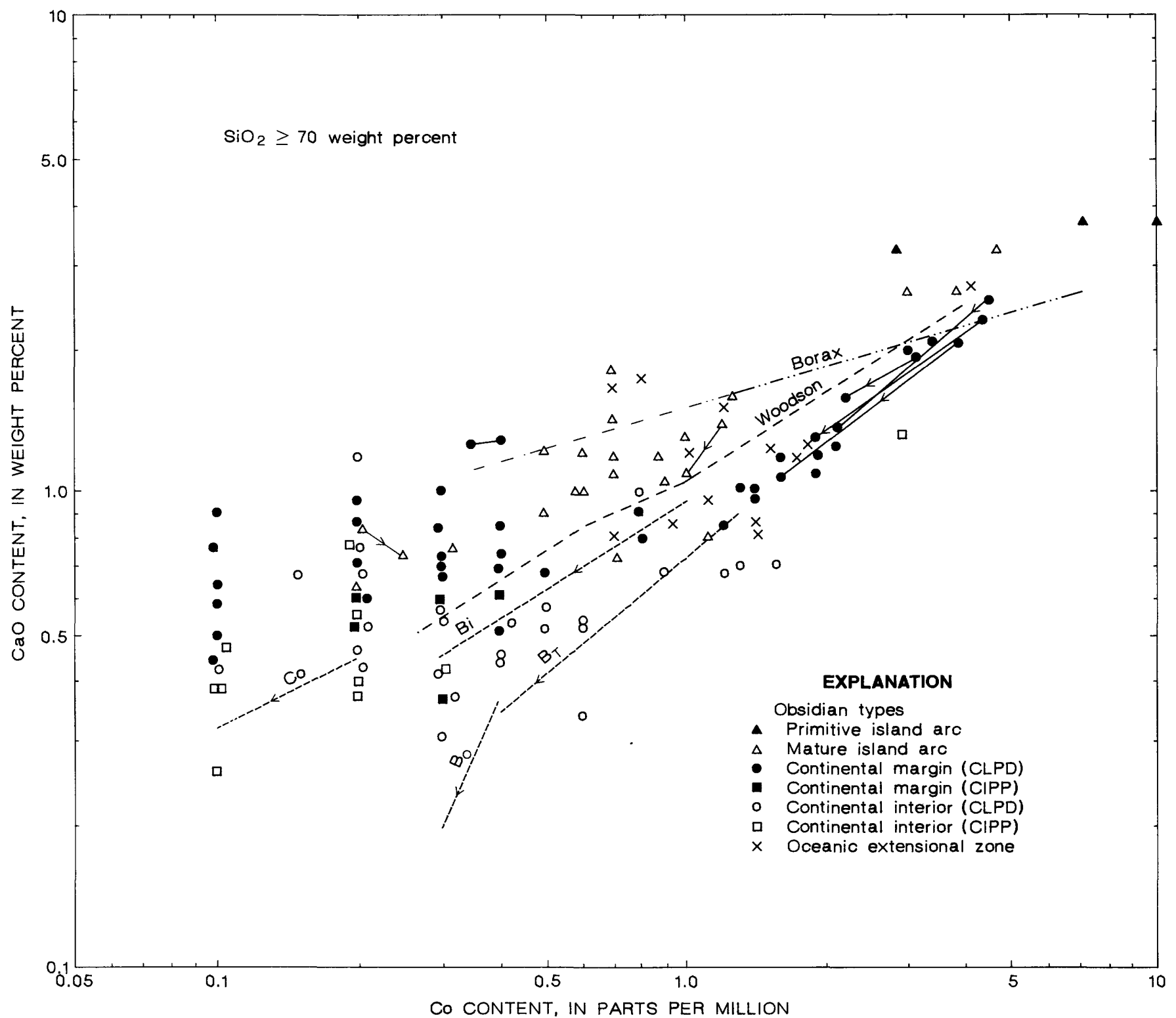

Figure 42.-Co content versus $\mathrm{CaO}$ content for obsidians and various comparative rocks. Data sources are same as for figure 5. Solid tielines indicate rock-glass pairs, arrows indicate direction of glass separate. Dashed lines indicate CIPP systems; Bishop Tuff (Bi);
Bandelier Tuff, Otowi $\left(B_{0}\right)$ and Tshirege $\left(B_{T}\right)$ Members; Coso Range (Co); arrows indicate direction of liquid fractionation and decreasing temperature. Also shown are the Borax Lake (Borax) mixed magma system, and the Woodson Grandiorite (Woodson) system. 
Field observations clearly demonstrate the ubiquity of this process, yet we are unable to test quantitatively the chemical effects of small amounts of such mixing.

The data bank seems to show the following features:

1. The majority of silicic obsidians contain $<4$ ppm Cr.

2. There are no confirmed values of $\mathrm{Cr}>11 \mathrm{ppm}$, except in rocks known to be contaminated with mafic material, for example, Borax Lake (Bowman and others, 1973).

3. It is possible that all high-silica obsidians having $\mathrm{Cr}>5 \mathrm{ppm}$ are mixed or contaminated rocks, for example, White Mountain, Utah (No. 96, $\mathrm{Cr}=9 \mathrm{ppm}$ ). The obsidian from US Gypsum perlite quarry, Nevada (No. 78), has several unusual geochemical features, including a high $\mathrm{Cr}$ value of $10.7 \mathrm{ppm}$.

\section{CESIUM}

Cesium abundances range from 0.5 to $21 \mathrm{ppm}$, with quite exceptional values of $500-550 \mathrm{ppm}$ in macusanite ${ }^{5}$ glass. The element's distribution in the obsidians is complex, showing important variations related to tectonic setting, genetic processes, and local causes.

The single available determination for rhyolites of primitive island arcs (No. 220) indicates that Cs levels are probably low (<1 ppm). Obsidians from other settings have Cs ranges and averages similar to each other, except for those from oceanic extensional zones where the maximum and average $\mathrm{Cs}$ concentrations are significantly lower (fig. 40C). This apparently is a characteristic feature of oceanicextensional-zone rhyolites, and though matureisland-arc rocks may have similarly low Cs levels, the $\mathrm{Rb} / \mathrm{Cs}$ ratio is lower in mature arc than in oceanic types.

Within-group variations account for much of the scatter of Cs data. The Cs contents of obsidians from Clear Lake and Medicine Lake, California, are among the highest in the data bank. Obsidians of Java have high Cs contents for mature-island-arc rocks. CLPD continental-interior rocks at 76 percent $\mathrm{SiO}_{2}$ show a range of $\mathrm{Cs}$ values from $<2$ to $16 \mathrm{ppm}$. It is not known whether these are features which char-

\footnotetext{
'Macusanite occurs as pebbles in gravel in the Macusani area, Peru. The un usual phenocryst assemblage includes high $\mathrm{Al}$ phases such as andalusite and sillimanite. It is also unusual chemically, in having very high concentrations of $A s, B$ and $\mathrm{Li}$, and high $\mathrm{Cs}, \mathrm{F}, \mathrm{Rb}, \mathrm{Sn}$, and Te (Barnes and others, 1970).
}

acterize all the volcanic products of these provinces or the silicic rocks only. The Cs enrichment of the subduction-related sequences relative to the other $\mathrm{K}$ related elements would suggest that it is a function of source-rock composition rather than being process controlled.

One of the four rock-glass pairs from the Taupo, New Zealand (Ewart and others, 1968), volcanics shows a positive correlation between $\mathrm{SiO}_{2}$ and $\mathrm{Cs}$, indicating enrichment of $\mathrm{Cs}$ in the residual liquids (fig. 43A). A similar relation exists for the Crater Lake pairs. In the remaining three Taupo pairs, the higher $\mathrm{Cs}$ occurs in the lower $\mathrm{SiO}_{2}$ rock, rather than in the glass. For one pair (Nos. 9R, 9A), the $\mathrm{SiO}_{2}$ difference is so small ( 0.2 percent) that analytical error in $\mathrm{SiO}_{2}$ determination or minor quartz fractionation may be suspected, a point apparently confirmed by the anomalous behavior of this pair on almost all diagrams. For the other two pairs, the negative relation between $\mathrm{SiO}_{2}$ and $\mathrm{Cs}$ is accompanied by a similar relation between $\mathrm{K}_{2} \mathrm{O}$ and $\mathrm{Cs}$ (fig. 44). This remains an anomaly. These rocks do not contain phenocrystic biotite, which might preferentially incorporate Cs (Ewart and others, 1968).

Alternative explanations are: (1) there is analytical error in at least one Cs determination, or (2) some Cs has been lost by leaching of the glass. The latter explanation seems unsatisfactory for pair 12, where the glass contains only 0.3 percent $\mathrm{H}_{2} \mathrm{O}^{+}$.

CIPP concentrates $\mathrm{Cs}$ in lower-temperature liquids. Enrichment factors of 3 to 4 have been recorded for the Bishop Tuff (Hildreth, 1979, 1981). The Bandelier Tuff (R.L. Smith, unpub. data) has an apparent enrichment factor of 6 and a probable enrichment factor of more than 10. The enrichment factors for $\mathrm{Cs}$ in the Bishop and Bandelier sheets are greater than those for $\mathrm{Rb}, \mathrm{Th}$, and $\mathrm{U}$, and the ratio of $\mathrm{Cs}$ to each of these elements increases with increasingly CIPP character (for example, see fig. 45).

Correlation coefficients between $\mathrm{Cs}$ and related elements of large ionic radius are given below:

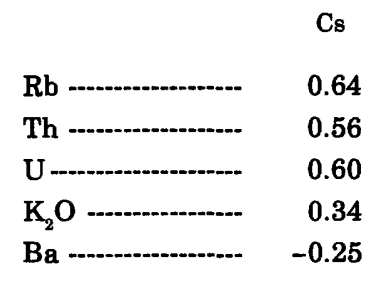

The low correlation coefficients with $\mathrm{K}_{2} \mathrm{O}$ and $\mathrm{Ba}$ result from differing behaviors during CIPP. Those with $\mathrm{Rb}, \mathrm{Th}$, and $\mathrm{U}$ are higher and positive, though the highest is only 0.64 . This is a function of the Cs 


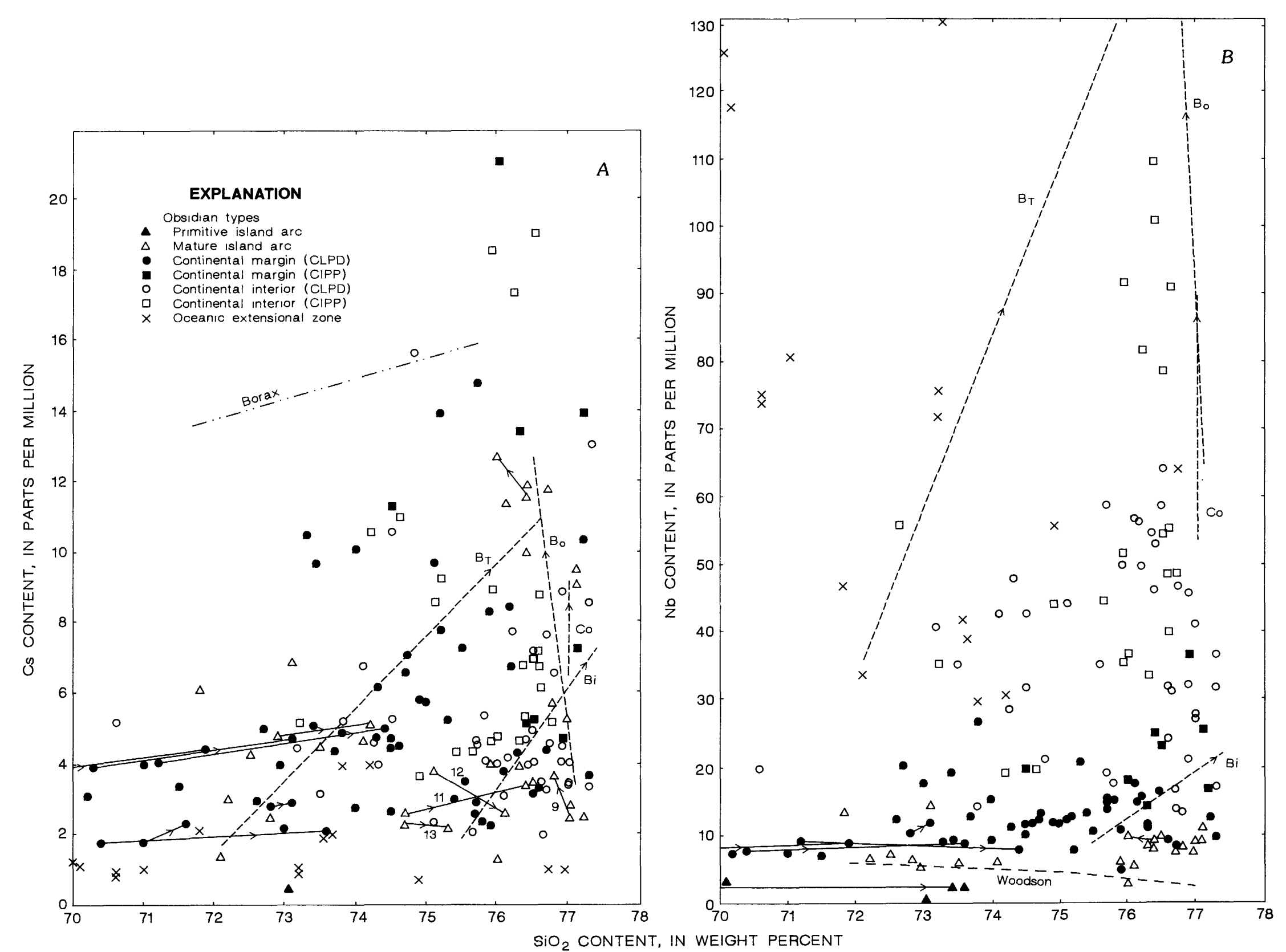

FIgURE 43.-Trace-element silica-variation diagrams for obsidians and various comparative rocks. Data sources are same as for figure 5. A, Cs (sample 160 omitted to preserve scale); numbered tielines: Taupo, New Zealand (Ewart and others, 1968, samples $9,11,12,13$ ). $B, \mathrm{Nb}$ (samples 83,108 , and 109 omitted to preserve scale). $C, \mathrm{~Pb}$ (rock-glass tielines are numbered as follows: 2, Halmahera [app. I, Nos. 209, 210]; 3, 4, 8, 9, Crater Lake [app. I, Nos. 15, 16, $17,18,11,12,13,14$ ]; 5, South Sister [app. I, Nos. 9, 10]; 6, Okushiri [app. I, Nos. 186, 187]; 7, Capital Mountain [app. I, Nos. 4, 5]). D, Rb (sample 160 omitted to preserve scale). $E$, Th. $F, \mathrm{U}$ (samples $86-88$ omitted to preserve scale) $G, \mathrm{Zn}$ (sample 83 omitted to preserve scale). $H$, Zr. $I$, Hf. Solid tielines represent rock-glass pairs; arrows point toward glass separate. Dashed lines represent rock systems; Bishop Tuff, Bi (Hildreth, 1981); Bandelier Tuff, Otowi, $B_{o}$, and Tshirege, $B$ Members (R.L. Smith, unpub. data); Coso Range, Co (Bacon and others, 1981); Borax Lake mixed magma, Borax (Bowman and others, 1973); Woodson Granodiorite stock, Woodson (D. Gottfried, written communication, 1975). Arrows indicate direction of liquid fractionation. 

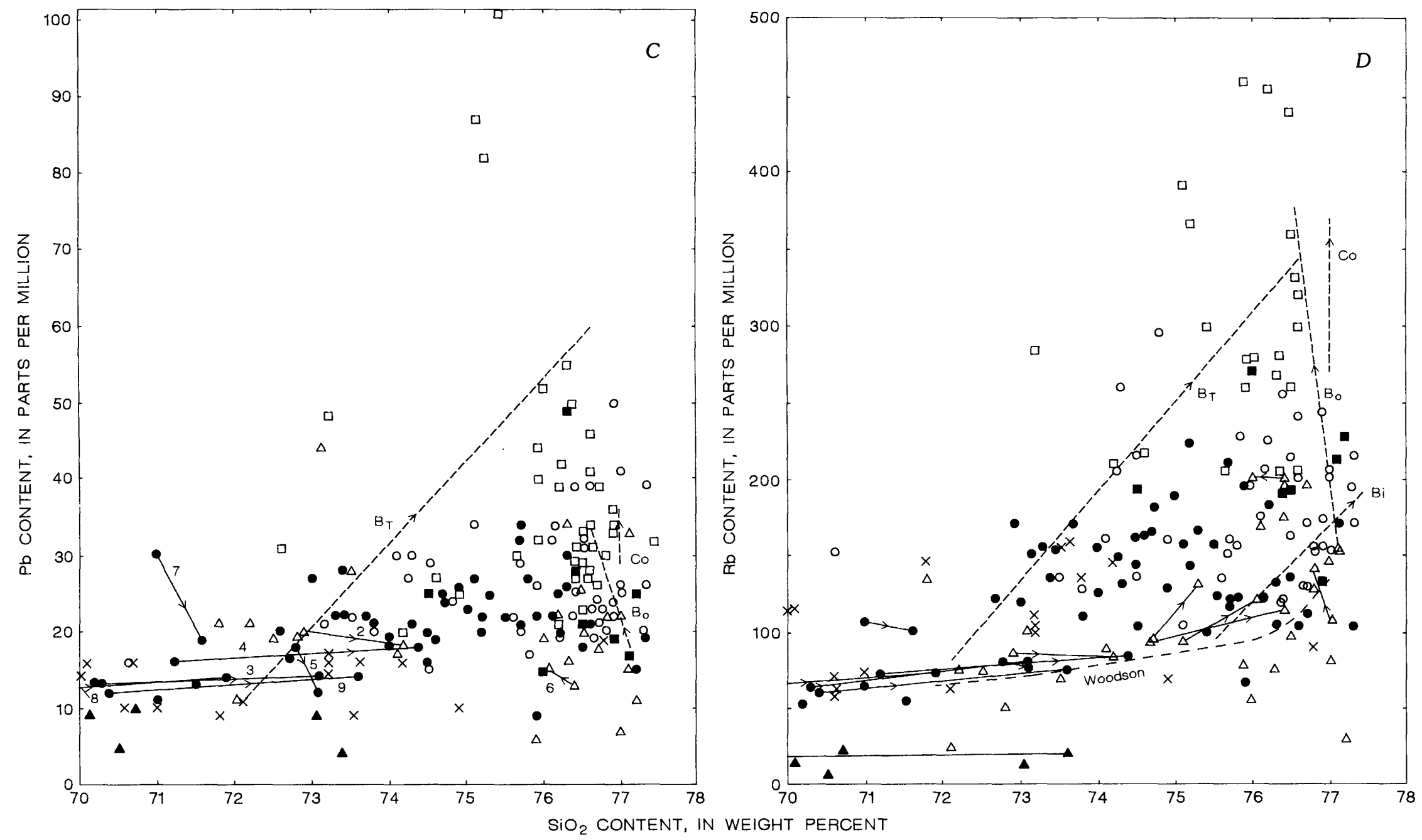

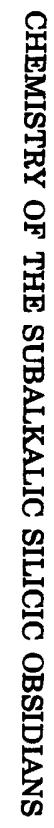

FiguRE 43.--Continued. 


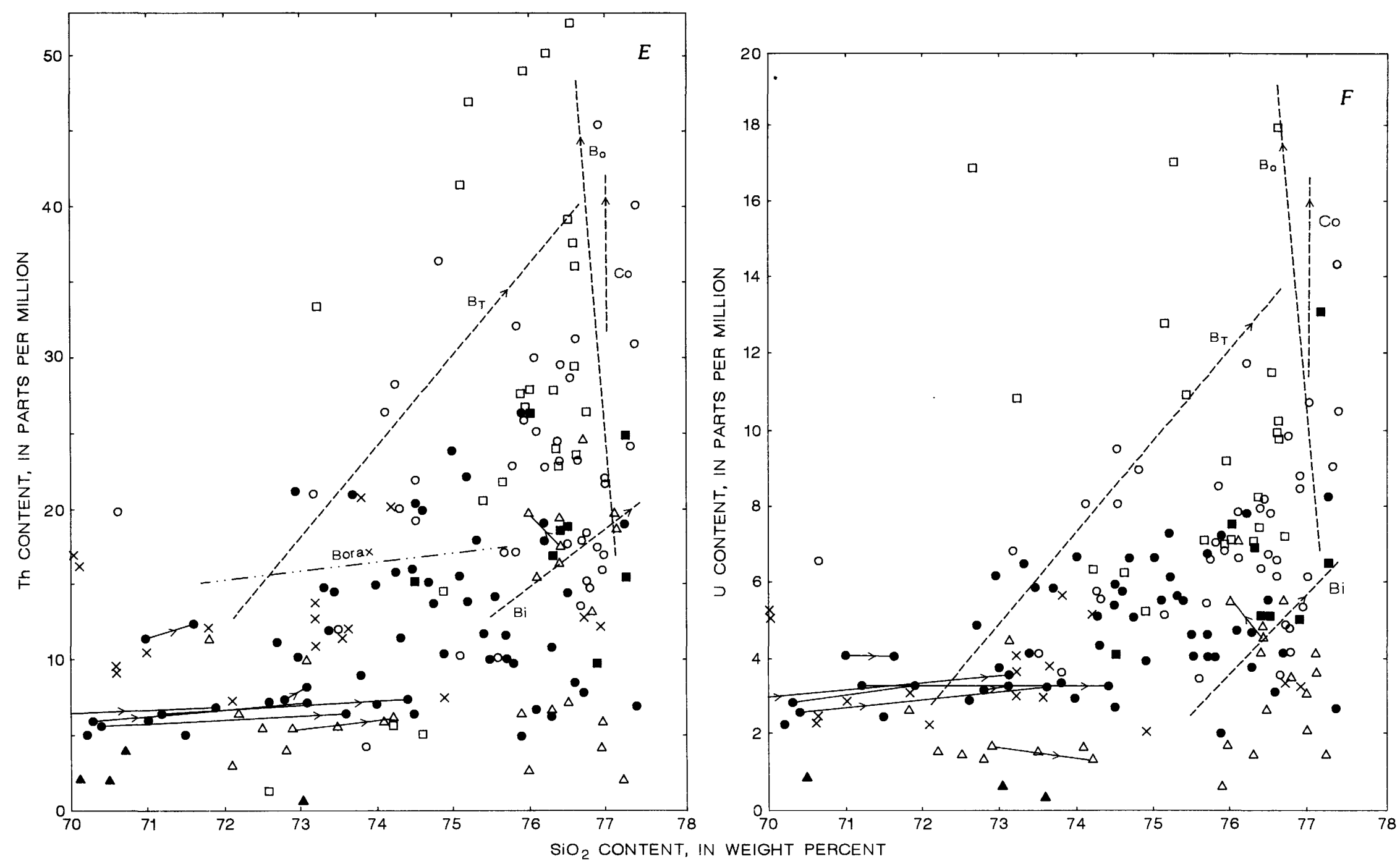

瓷

Figure 43.-Continued. 

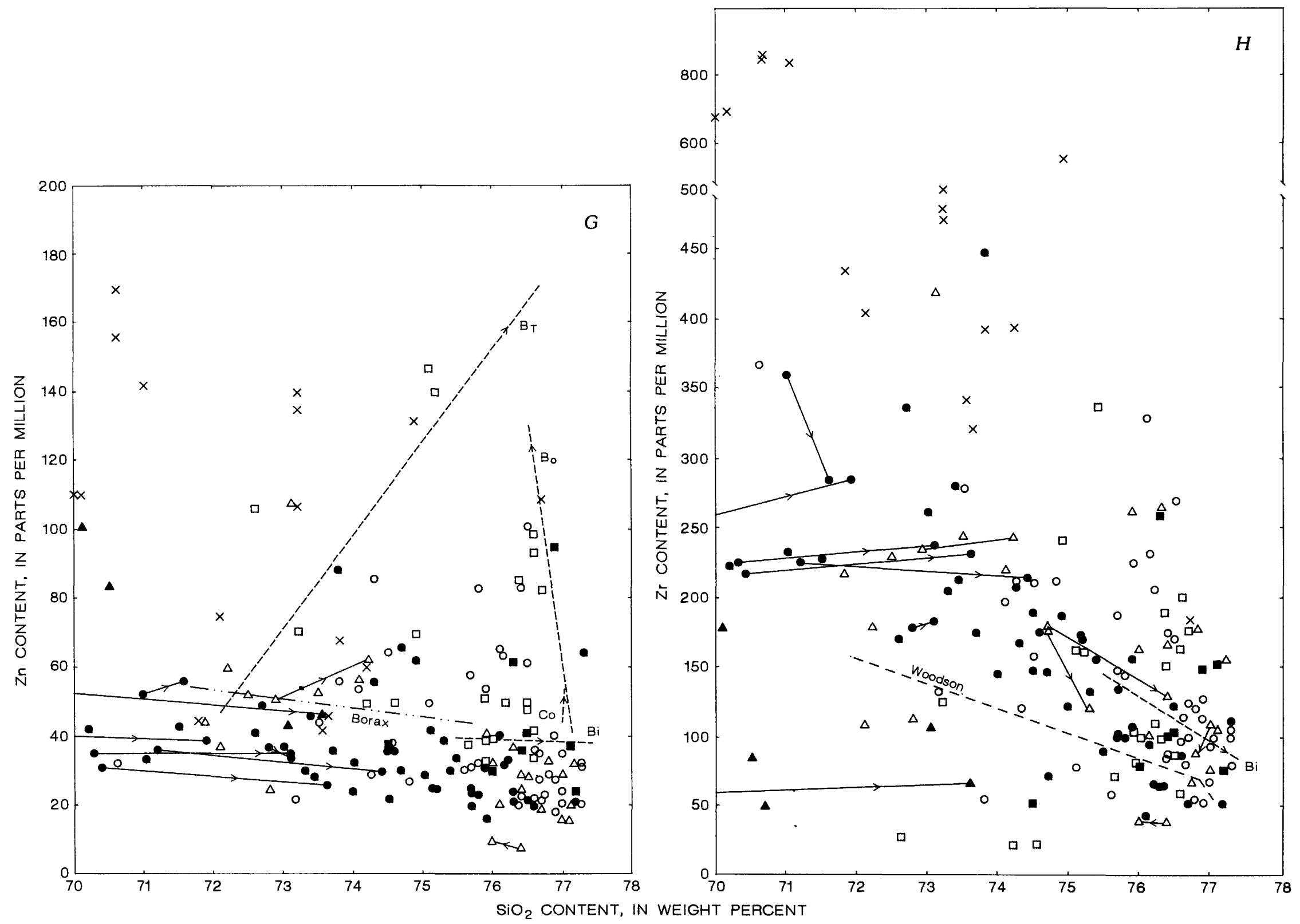

造

Figure 43.-Continued. 


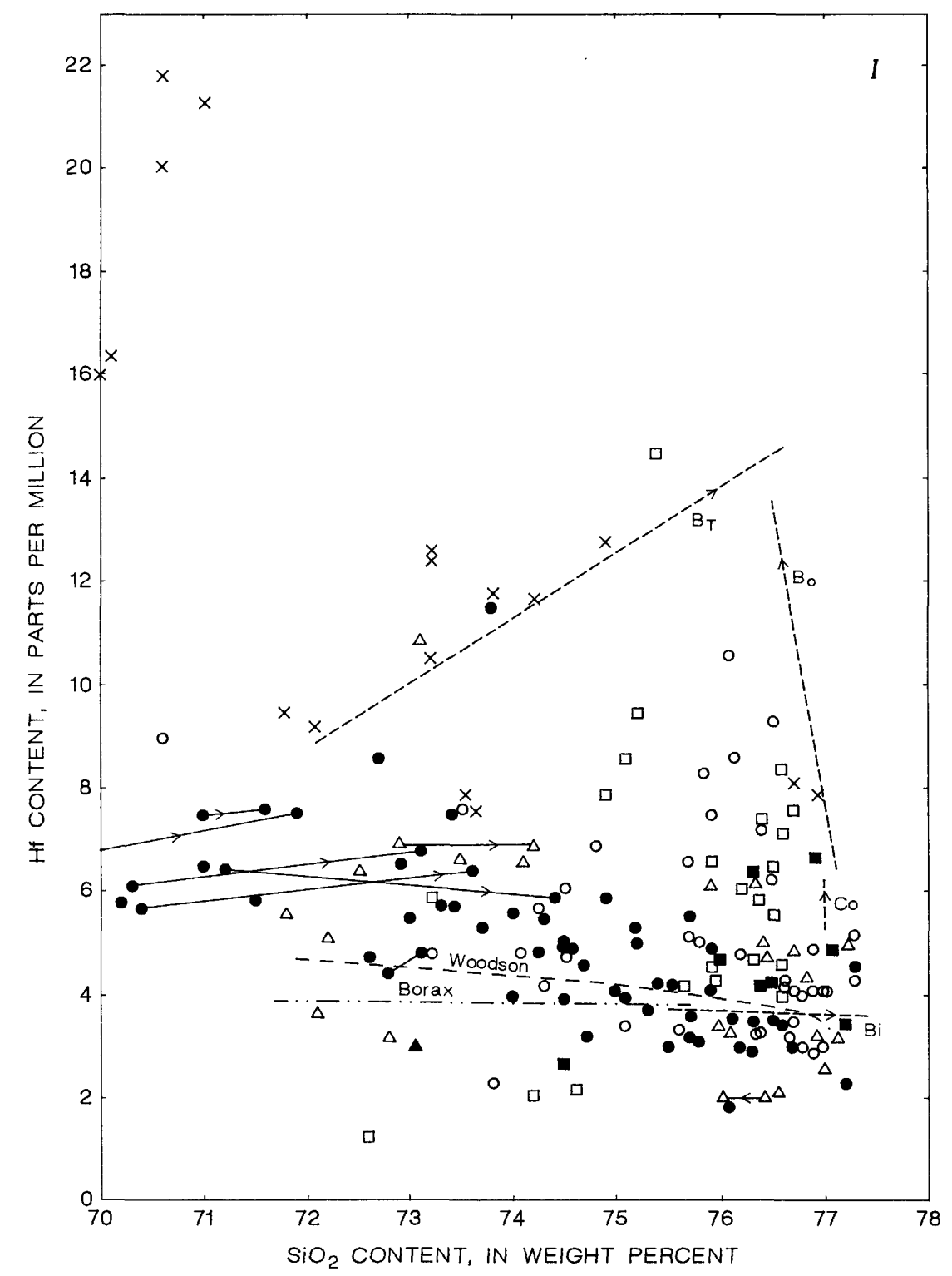

曷

Figure 43.-Continued 
enrichment of certain subduction-related obsidians, as noted above.

The Rb-Cs plot (fig. 45) illustrates many of the more important points of Cs geochemistry. There is a systematic relation between $\mathrm{Rb} / \mathrm{Cs}$ ratio and tectonic setting, the average ratio increasing in the sequence arc $\rightarrow$ margin $\rightarrow$ continental interior (compare with table 7). The process leading to this relative enrichment of $R b$ is as yet unidentified, but it contrasts with the effects of CIPP, which tends to decrease $\mathrm{Rb} / \mathrm{Cs}$ ratios.

The Rb-Cs plot also neatly shows an important aspect of the rhyolites of oceanic extensional zones. Their $\mathrm{Rb} / \mathrm{Cs}$ ratios indicate that the Cs depletion characteristic of such rocks is not accompanied by strong $R b$ depletion. Separation of this rhyolite group geographically stresses a point made in the section "Geochemical Features of Main Obsidian Groups," group V. The Iceland and Galapagos (Alcedo) rocks, generated entirely within oceanic crust, do not overlap the fields of arc and continental-margin obsidians. The Salton Sea rhyolites, on the other hand, have $\mathrm{Rb}$ and $\mathrm{Cs}$ contents closely comparable to margin types, their transitional composition reflecting their transitional tectonic setting. The Admiralty Islands glasses occupy an intermediate position on the plot, perhaps an indication that they were erupted in a complex tectonic zone where oceanic-type crust in a back-arc basin is related to an overall subduction regime.

The partly contrasting behaviors of $\mathrm{K}$ and $\mathrm{Cs}$ permit a qualitative description of $\mathrm{Cs}$ distribution. On a $\mathrm{K}_{2} \mathrm{O}$-Cs plot (fig. 44), a relatively "depleted" field (K/Cs greater than 16,600 ) contains the majority of oceanic extensional rocks plus a few CLPD arc and continental rocks. In a "normal" field (K/Cs=5,000-16,600), the majority of the obsidians show no significant correlation between $\mathrm{K}_{2} \mathrm{O}$ and $\mathrm{Cs}$, mainly due to the source effects in Cs abundances. An enriched field $(\mathrm{K} / \mathrm{Cs}<5,000)$ is comprised of CIPP specimens and highCs CLPD rocks.

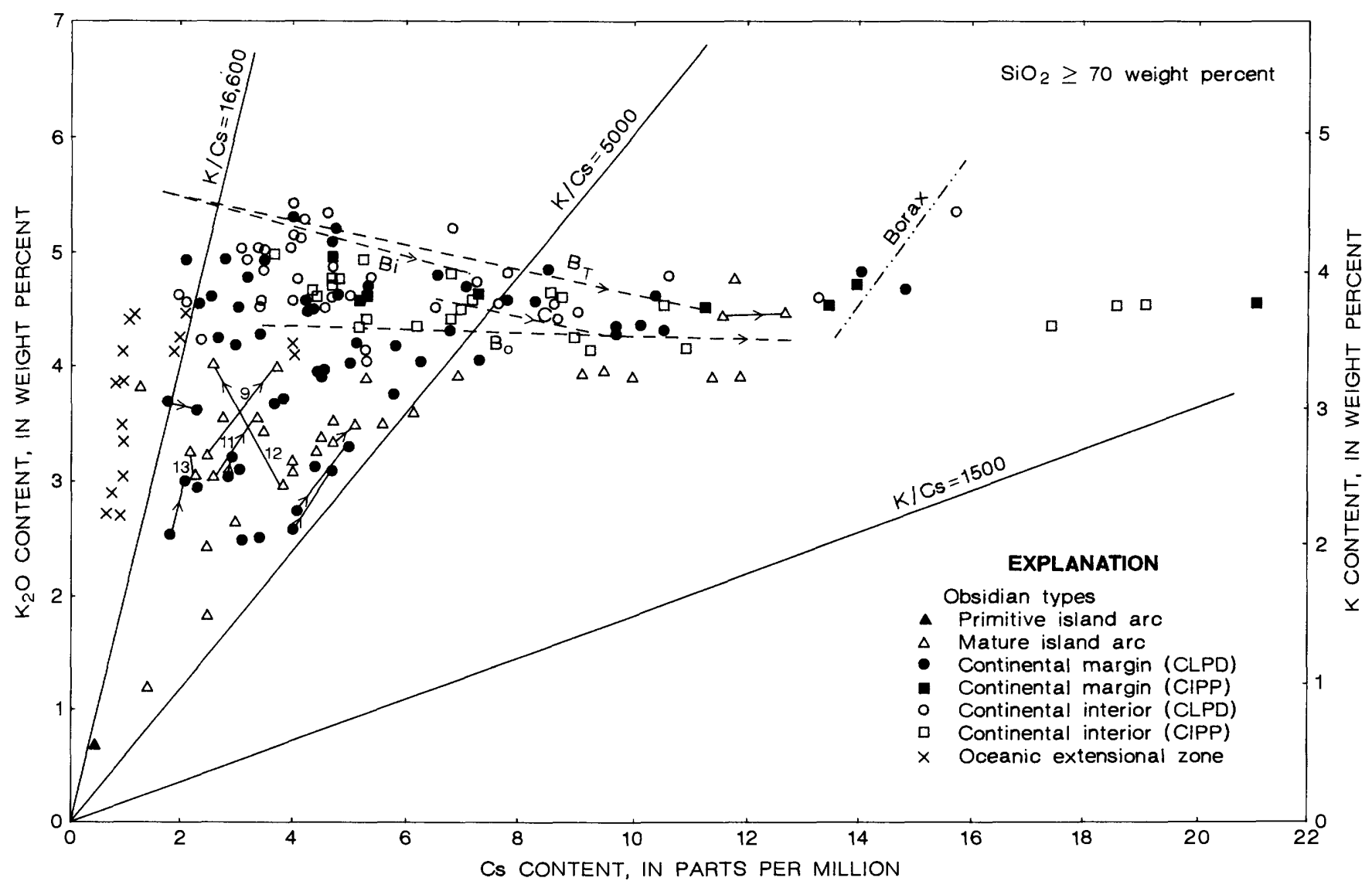

Figure 44. $-\mathrm{K}_{2} \mathrm{O}$ and $\mathrm{K}$ contents versus $\mathrm{Cs}$ content for obsidians and various comparative rocks. Data from appendix I. Sample 160 is omitted to preserve scale. Solid tielines connect rockglass pairs; arrows point toward glass separate. Numbered tielines: Taupo, New Zealand; data from Ewart and others

(1968). Dashed lines include Bishop Tuff, Bi (Hildreth, 1981); Bandelier Tuff, Otowi, $B_{0}$, and Tshirege, $B_{T}$, Members (R.L. Smith, unpub. data); Coso Range, Co (Bacon and others, 1981); and the Borax Lake, Borax, mixed magma (Bowman and others, 1973). Arrows indicate direction of liquid fractionation. 


\section{NIOBIUM AND TANTALUM}

Niobium and tantalum show wide variations in abundance in the obsidians, 0.6 to $258 \mathrm{ppm}$ and $<0.2$ to $30 \mathrm{ppm}$, respectively. The wide range and low abundances of Ta in many specimens make it unsuitable for plotting on a linear scale against $\mathrm{SiO}_{2}$, and the data are presented instead on a $\log \mathrm{CaO}-\log \mathrm{Ta}$ plot (fig. 46).

The abundances of both elements are strongly controlled by crustal type, which makes them useful as indicators of tectonomagmatic settings. The lowest $\mathrm{Nb}$ concentrations are found in the rhyolites of primitive island arcs (table 7, app. V). Values less than $3 \mathrm{ppm}$ are normal, and the $10 \mathrm{ppm} \mathrm{Nb}$ reported for a Tongan obsidian by Smith and others (1977) probably represents analytical error. There are no reported Ta determinations for these rocks; it almost certainly occurs in the $0.0 \mathrm{X}$ to $0 . \mathrm{X} \mathrm{ppm}$ range and presents severe analytical problems.

Although the average $\mathrm{Nb}$ and $\mathrm{Ta}$ abundances in mature-island-arc and continental-margin rocks are notably different (table 7 ; fig. $40 D, E$ ), there is extensive overlap in ranges. The overlap between continental-margin and continental-interior obsidians is much smaller and, in fact, there is no overlap if CLPD rocks only are considered.

The relative success of $\mathrm{Nb}$ and $\mathrm{Ta}$ as discriminants results from their behavior during crystal-liquid-

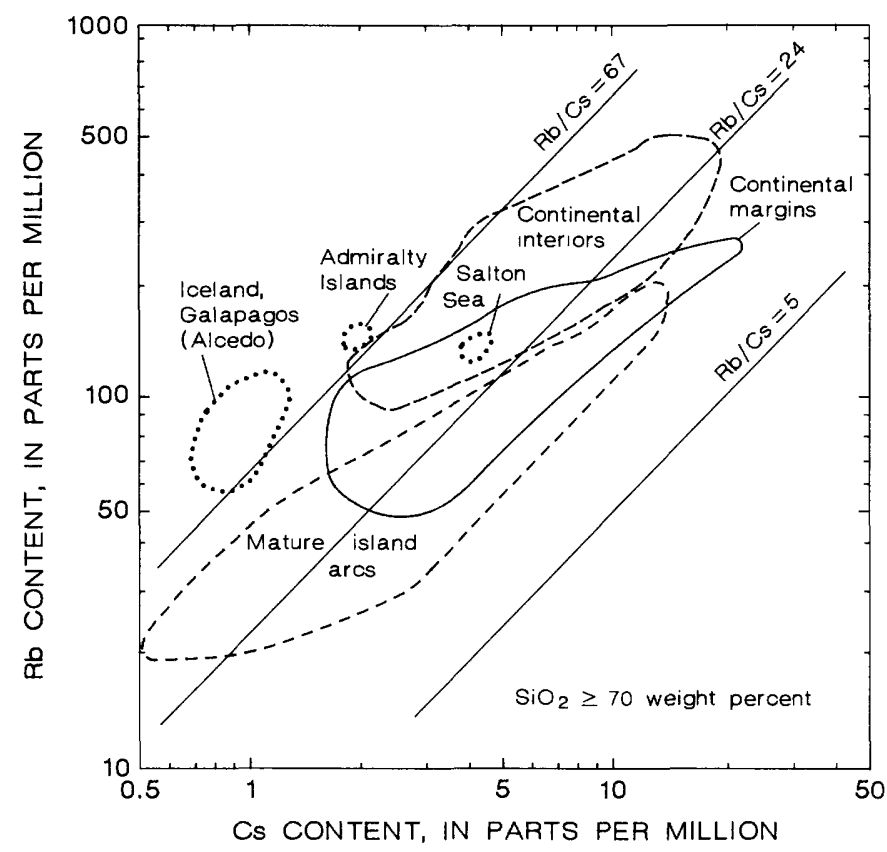

Figure 45.-Cs content versus $\mathrm{Rb}$ content showing generalized relations between $\mathrm{Rb} / \mathrm{Cs}$ ratio and tectonic setting. Obsidians from oceanic extensional zones are separated into three groups (Iceland-Galapagos, Admirality Islands, Salton Sea) according to locality. controlled processes, which is closely related to the chemical affinities of the rock series (Gottfried, in Parker and Fleischer, 1968, p. 24). Both elements tend to behave in an increasingly incompatible or residual manner in more alkalic magmas, reflecting their enhanced solubility in such magmas. Thus, during differentiation of calcic suites, $\mathrm{Nb}$ and $\mathrm{Ta}$ concentrations tend to stay constant or decrease slightly with increasing $\mathrm{SiO}_{2}$ concentrations, for example, the Woodson Stock trend and the Metis Shoal and Crater Lake rock-glass tielines (figs. $43 B, 47$ ). In calc-alkalic suites, they stay constant or increase slightly (for example, the Okushiri and Capital Mountain tielines, fig. 47), whereas in alkali-calcic sequences, they rise as $\mathrm{SiO}_{2}$ rises (Bandelier Tuff tielines, fig. 47). Even small intergroup differences in $\mathrm{Nb}$ and Ta contents at 70 percent $\mathrm{SiO}_{2}$ are thus maintained or exaggerated with further crystal-liquid differentiation.

$\mathrm{Nb}$ and $\mathrm{Ta}$ are strongly concentrated upwards during CIPP. A Nb-enrichment factor of about 6 has been recorded for the Bandelier Tuff (Smith, 1979) and a factor of 2-3 for Ta in the Bishop Tuff by Hildreth (1979). This process is very potent at enriching continental silicic magmas in $\mathrm{Nb}$ and Ta; though CLPD interior rocks have a maximum of $55 \mathrm{ppm} \mathrm{Nb}, \mathrm{CIPP}$ obsidians contain up to $270 \mathrm{ppm}$.

The strong controls over $\mathrm{Nb}$-Ta distribution exerted by crustal type and genetic process result in relatively small, intragroup variations. At constant $\mathrm{SiO}_{2}$ values, such variations are typically only a factor of two.

A correlation matrix for elements with which one or both of $\mathrm{Nb}$ and $\mathrm{Ta}$ show $r>0.60$ is given below. All are elements which concentrated in rhyolites of the continental interiors and which are up-elements during CIPP. Their strong correlations may reflect similar behavior during a variety of differentiation processes, rather than geochemical coherence, but there may be an important common link in their ability to complex with $\mathrm{F}$.

\section{$\mathrm{Nb} / \mathrm{Ta}$ RATIOS}

Analytical uncertainties are important in any discussion of variations of the $\mathrm{Nb} / \mathrm{Ta}$ ratio. In a rock for which $\mathrm{Nb}$ and $\mathrm{Ta}$ are reported as $8 \pm 1 \mathrm{ppm}$ and $0.5 \pm 0.1 \mathrm{ppm}$, respectively, the range of possible $\mathrm{Nb} / \mathrm{Ta}$ ratios is 11.7 to 22.5 , a considerable proportion of the whole range in the data bank (fig. 48). Subduction-related rhyolites may have abundances even lower than those in this example, and the problems of producing meaningful values of the $\mathrm{Nb} / \mathrm{Ta}$ ratio are severe. It is not possible at this stage, for example, to provide firm figures for $\mathrm{Nb} / \mathrm{Ta}$ ratios in rhyolites of primitive island arcs. 
The average ratios for the rhyolite groups may be significant (table 7). They seemingly indicate a progressively lower average in rhyolites from increasingly sialic settings. Breakdown of the data into CLPD and CIPP varieties complicates the issue a little. Baselevel obsidians in continental margins and continental interiors have similar ratios of 11.5 and 11.8, respectively. Those from mature island arcs and oceanic extensional zones have probably significantly higher averages of 13.7 and 14.0. Cratonization apparently results in Ta enrichment relative to $\mathrm{Nb}$.

The average CIPP obsidian from the continental interior has a distinctly lower $\mathrm{Nb} / \mathrm{Ta}$ ratio than CLPD obsidians. This suggests that the ratio tends to decrease during CIPP. Sufficiently precise data to test this are available only for the Bandelier Tuff (Smith and Gottfried, unpublished data). Here the ratio decreases with increasing differentiation from 12.9 to 11.5 in the Otowi Member and 14.9 to 11.2 in the Tshirege Member.

Despite the analytical uncertainties, it is possible to see variations in $\mathrm{Nb} / \mathrm{Ta}$ ratio on a complex or center basis. For example, four samples from Medicine
Lake, Calif., have low $\mathrm{Nb} / \mathrm{Ta}$ ratios in the range 7.4 to 9.4. By contrast, four glasses from Halmahera have high ratios between 16.2 and 21.5. These may represent the extremes of $\mathrm{Nb}-\mathrm{Ta}$ fractionation during crystal-liquid processes. Alternatively, they may be partial cumulates, in that they contain amongst the highest modal abundances of Fe-Ti oxides (app. VII).

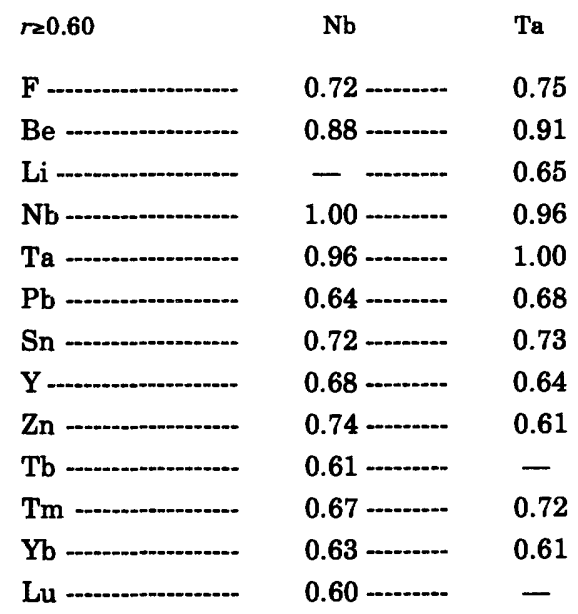

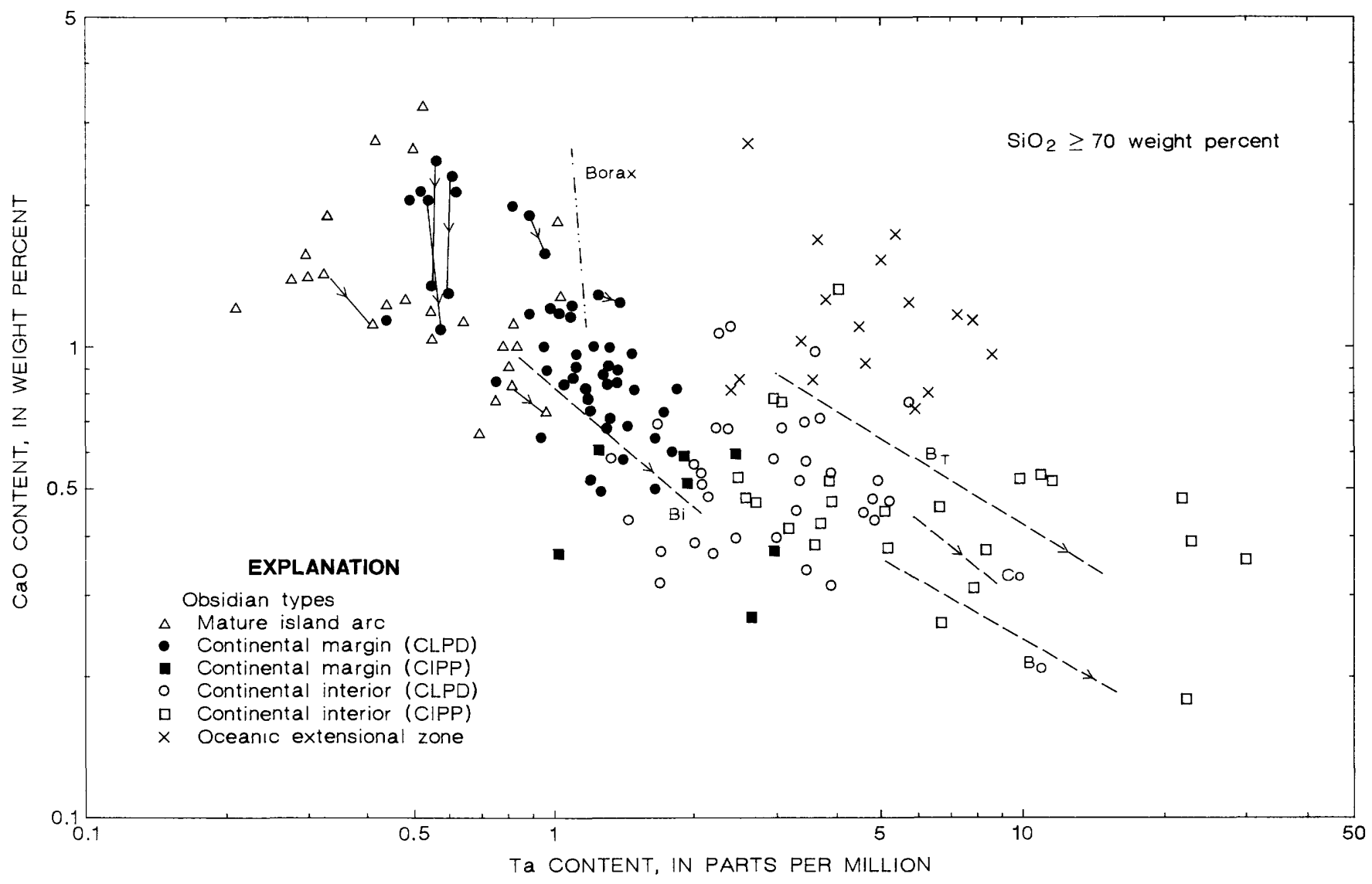

Figure 46.-Ta content versus $\mathrm{CaO}$ content for obsidians and various comparative rocks. Data from appendix I. Solid tielines represent rock-glass pairs with arrow pointing toward glass separate. Dashed lines: Bishop Tuff, Bi (Hildreth, 1981);
Bandelier Tuff, Otowi, $\mathrm{B}_{\mathrm{o}}$, and Tshirege, $\mathrm{B}_{\mathrm{T}}$, Members (R.L. Smith, unpub. data); Coso Range, Co (Bacon and others, 1981); and the Borax Lake, Borax, mixed magma (Bowman and others, 1973). Arrows indicate direction of liquid fractionation. 
LEAD

The range of $\mathrm{Pb}$ abundances is 4 to $101 \mathrm{ppm}$ (fig. $43 C)$. The lowest abundances $(<10 \mathrm{ppm})$ occur in rhyolites of primitive island arcs. Obsidians from mature island ares and continental margins have higher $\mathrm{Pb}$ contents but cannot be distinguished from each other on the basis of either their averages or ranges. The average base-level continental-interior rock has a $\mathrm{Pb}$ content of $26.4 \mathrm{ppm}$, probably not significantly different from the subduction-related group on a $\mathrm{SiO}_{2}-$ normalized basis. Oceanic-extensional rhyolites tend to have low $\mathrm{Pb}$ abundances; the range is 9-19 ppm and the average $14 \mathrm{ppm}$ (fig. $40 \mathrm{~F}$ ). This is consistent with the generally low levels of large-radius cations in these rocks.

The tielines for rock-glass pairs from Crater Lake and Okushiri show modest $\mathrm{Pb}$ enrichment in the glass

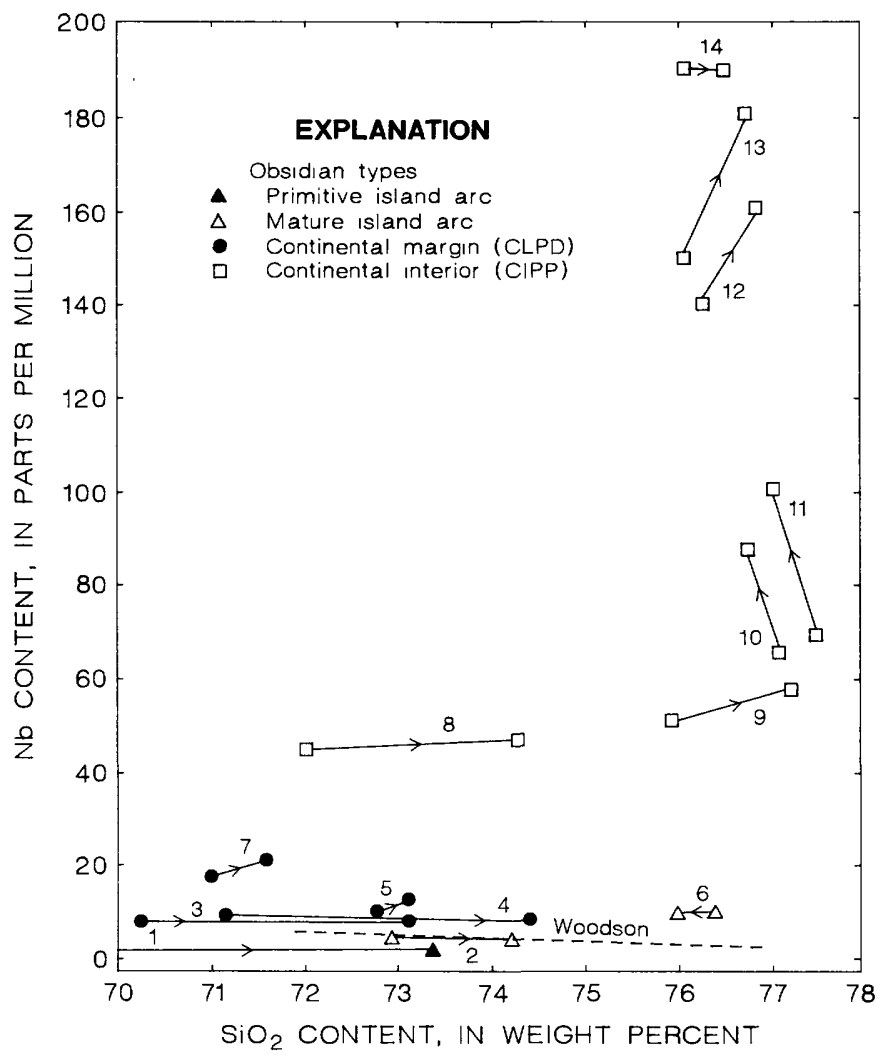

FIGURE 47.- $\mathrm{SiO}_{2}$ content versus $\mathrm{Nb}$ content showing behavior in various systems controlled by crystal-liquid processes. Rockglass tielines are numbered as follows: 1 , Metis Shoal, Tonga (app. V; David Gottfried, unpub. data); 2, Halmahera (app. I, Nos. 209, 210); 3, 4, Crater Lake (app. I, Nos. 15, 16; 17, 18); 5, South Sister (app. I, Nos. 9, 10); 6, Okushiri (app. I, Nos. 186, 187); 7, Capital Mountain (app. I, Nos. 4, 5); 8, 9, 12, 13 , from the Tshirege Member, Bandelier Tuff; 10, 11, 14, from the Otowi Member, Bandelier Tuff (R.L. Smith, unpub. data). Arrows indicate direction of liquid fractionation (glass). Woodson, Woodson Granodiorite trend (David Gottfried, unpub. data).

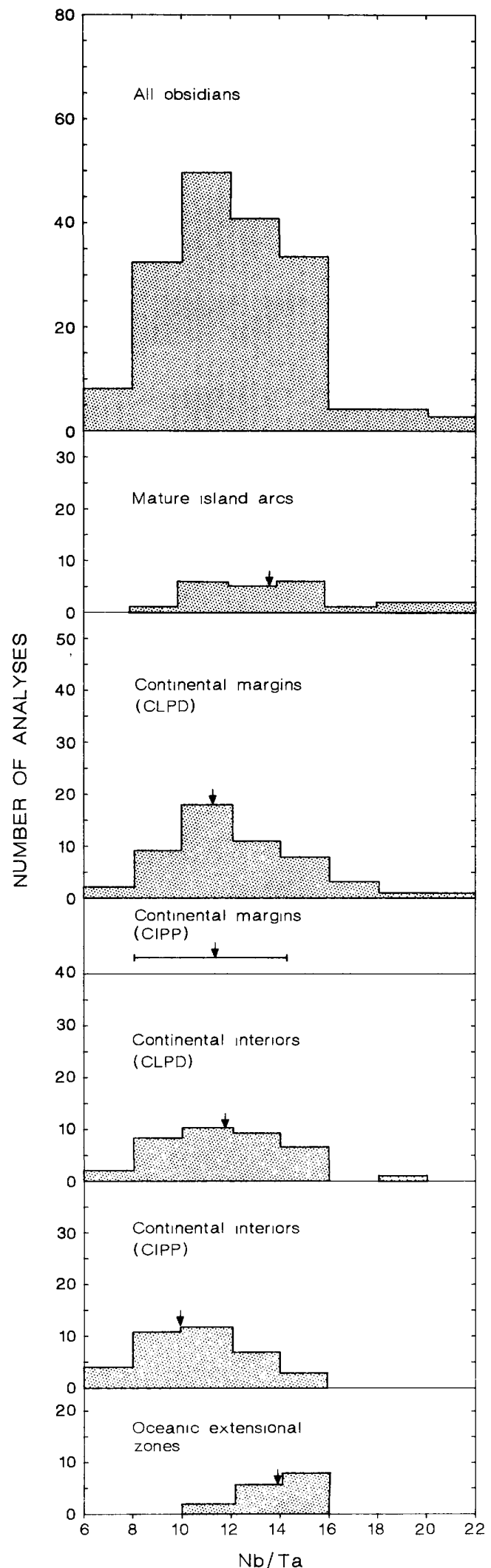

Figure 48.-Distribution of $\mathrm{Nb} / \mathrm{Ta}$ ratio in obsidians. Obsidians of continental margins (CIPP types) are shown as ranges only. Arrows indicate average values. Data from appendix I. Sample 160 is omitted to preserve scale. 
(fig. $43 C$ ), indicating a bulk distribution coefficient not much less than one for these samples. The decrease in $\mathrm{Pb}$ content in the glass for pairs from Capital Mountain, South Sister, and Halmahera requires an explanation. The Capital Mountain rock contains biotite phenocrysts, and it is possible that $\mathrm{Pb}$ has been strongly partitioned into that phase. The South Sister and Halmahera rocks have the phenocryst assemblages $\mathrm{Pl}+\mathrm{Opx}+\mathrm{Ox}$ and $\mathrm{Pl}+\mathrm{Opx}+\mathrm{Cpx}+\mathrm{Ox}$, respectively. None of these minerals has a distribution coefficient for $\mathrm{Pb}$ greater than 1 (Leeman, 1979), and their crystallization should have resulted in $\mathrm{Pb}$ increase in the residual liquids. A possible explanation is that a submicroscopic $\mathrm{Pb}$-sulfide phase is associated with the phenocryst minerals. Alternatively, there may be analytical error in the $\mathrm{Pb}$ determinations.

Evidence from the Coso (Bacon and others, 1981) and Bandelier (R.L. Smith, unpub. data) systems indicates that $\mathrm{Pb}$ is an upward-concentrating element during CIPP. In the obsidians, the highest values ( 235 ppm) have been recorded mainly from CIPP rocks, and the average CIPP continental-interior obsidian has a $\mathrm{Pb}$ content $(38.4 \mathrm{ppm})$ considerably in excess of the base-level rocks (26.4 ppm).

The behavior of $\mathrm{Pb}$ in the rhyolites thus seems to match that of such elements as $\mathrm{Nb}$ and $\mathrm{Rb}$, namely, modest increases in abundance within the crystalliquid field and sharp increases for limited majorelement variations when CIPP is the dominant differentiation mechanism. Another comparison with $\mathrm{Pb}$ is that within-group variations appear modest. At a given $\mathrm{SiO}_{2}$ level, within-group, base level $\mathrm{Pb}$ contents typically vary only by a factor of 2 or 3 . Occasional samples are somewhat anomalous; for example, the obsidian from Umnak (No. 2) has a high $\mathrm{Pb}$ content (44 ppm) for a base-level rock with 73.1 percent $\mathrm{SiO}_{2}$.

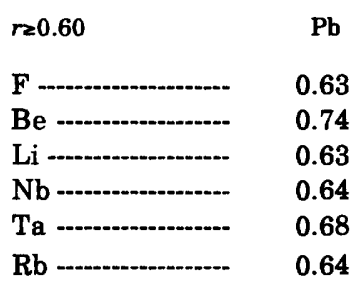

\section{LEAD ISOTOPES}

Inasmuch as secondary hydration may, by rockground water exchange, alter the lead isotopic composition of silicic rocks (for example, see Taylor and Forester, 1971), nonhydrated obsidians are a particularly valuable guide to the isotopic composition of the relevant magmas.
Available lead isotopic ratios are given in table 13. The range $\left({ }^{206} \mathrm{~Pb} /{ }^{204} \mathrm{~Pb}=16.58-19.16\right)$ indicates the glasses are variably radiogenic as regards lead content. This variation is discussed using as a basis the comprehensive review by Zartman (1974) as a basis.

Zartman (1974) divided the American cordilleran region into three geographical provinces on their characteristic lead isotopic patterns (fig. 49). The igneous rocks of field I, with rather low ${ }^{206} \mathrm{~Pb} /{ }^{204} \mathrm{~Pb}$, are comparatively unradiogenic; obsidians representative of this province are from the Jemez Mountains,

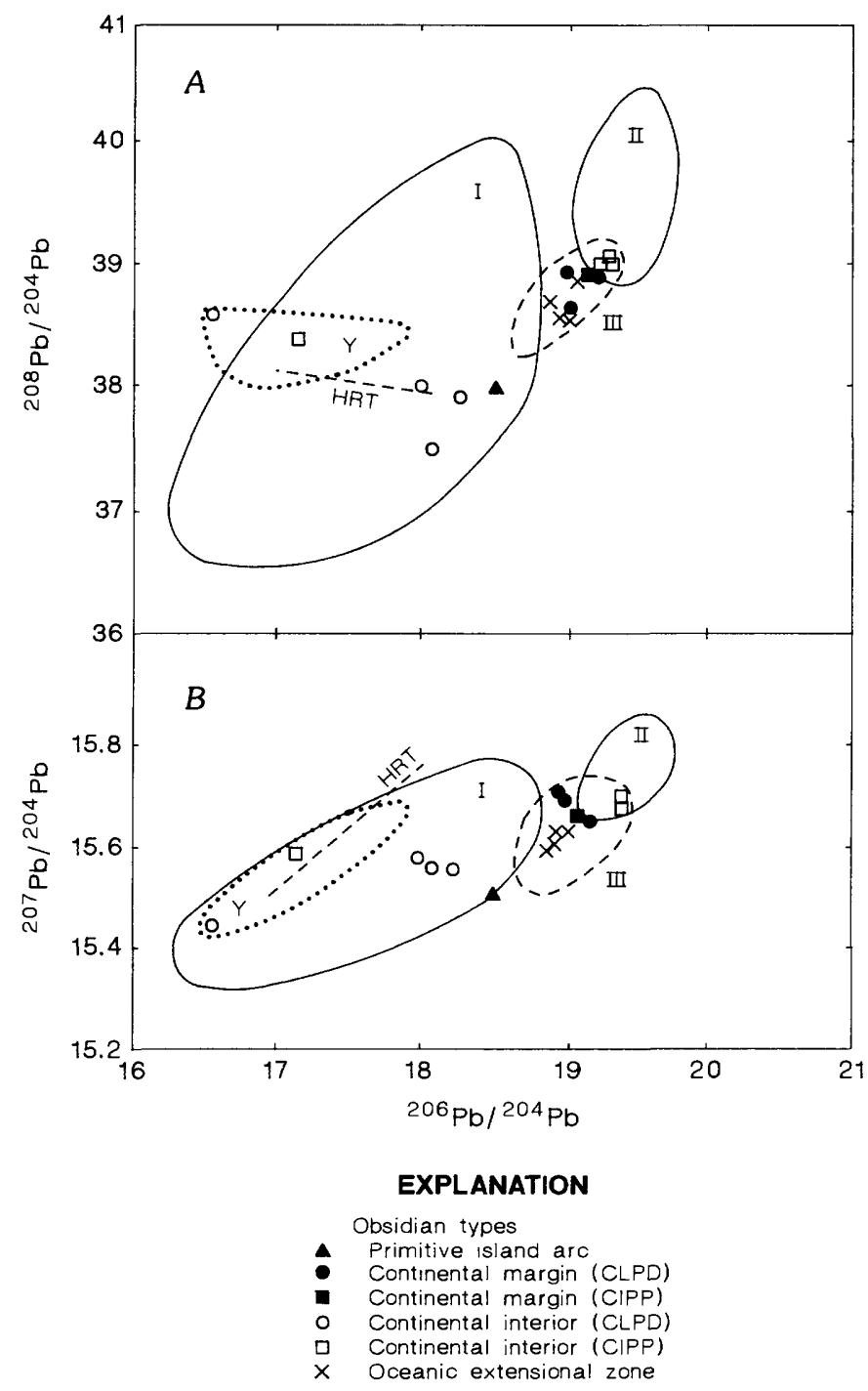

FIGURE 49. -Ratio of ${ }^{206} \mathrm{~Pb} /{ }^{204} \mathrm{~Pb}$ versus ratios of ${ }^{208} \mathrm{~Pb} /{ }^{204} \mathrm{~Pb}(A)$ and ${ }^{207} \mathrm{~Pb} /{ }^{204} \mathrm{~Pb}(B)$ for obsidians. Fields I to III are lead isotopic provinces in Western United States recognized by Zartman (1974). Field Y encloses rhyolites of Yellowstone volcanic complex (Doe and others, 1982). Line HRT connects analyses of the Huckleberry Ridge Tuff, Yellowstone (Doe and others, 1982). Data from appendix I. 
TABLE 13.-Lead isotopic ratios in silicic obsidians

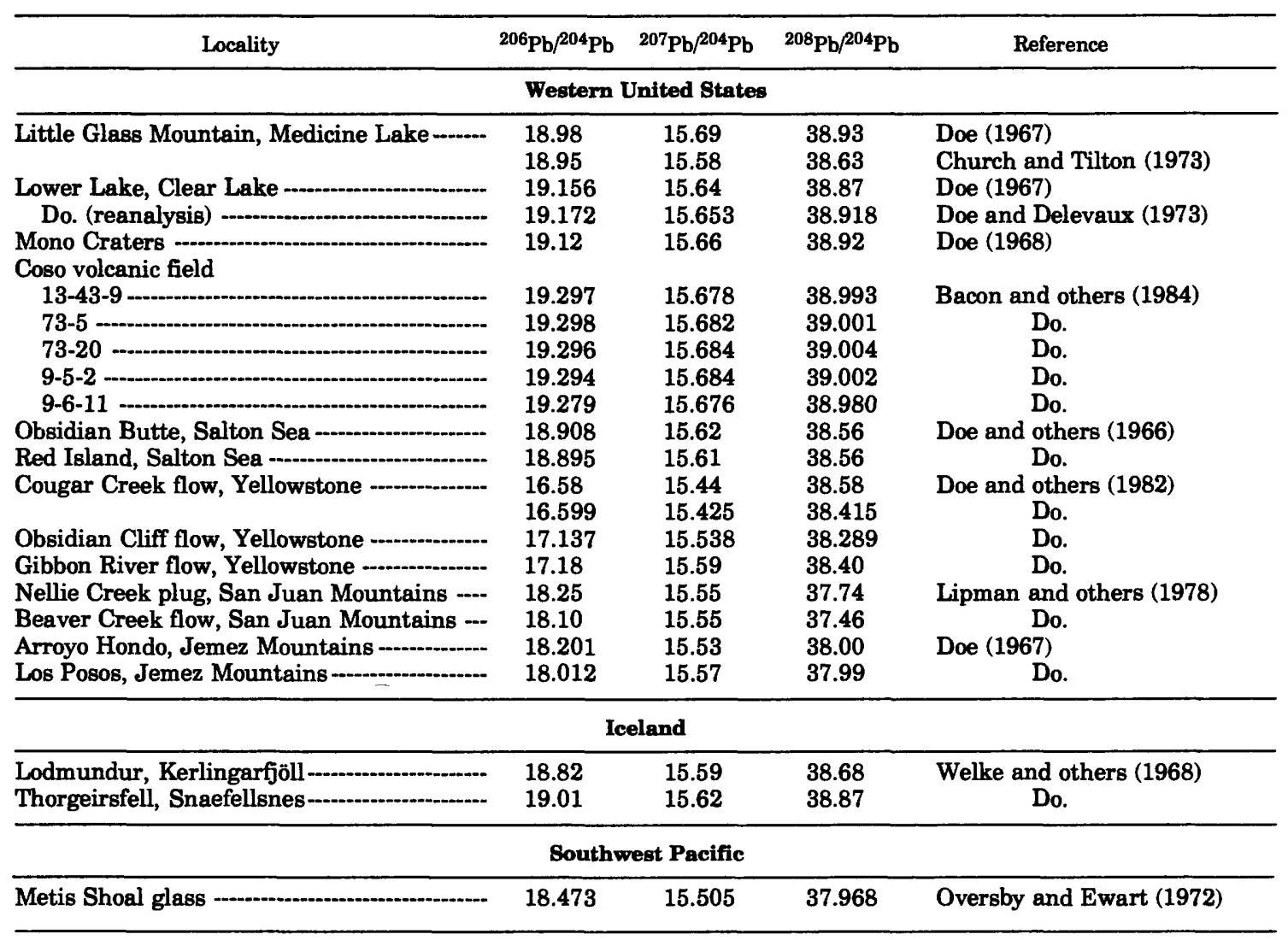

New Mexico, and Yellowstone Park, Wyoming, the continental interior of this report.

Rocks of Zartman's field III occupy a belt adjacent to the Pacific Ocean, the continental margin of this report. Field III igneous-rock lead isotopes are more radiogenic than those of Field $I$. The glasses plotted in field III in figure 49 come from Medicine Lake, Clear Lake, Mono Craters, and Salton Sea, all in California. The most radiogenic leads recognized by Zartman (field II) occur geographically between fields I and III. They are represented, among the obsidians, by the Coso rhyolites (Bacon and others, 1984).

Zartman (1974) suggests that the different lead patterns reflect different sources of the silicic magmas in each field. In field I, they have been derived from ancient (Precambrian) lower-crustal or possibly upper-mantle sources (compare with Lipman and others, 1978; Doe and others, 1982). The silicic rocks of field III have apparently been generated from thick eugeosynclinal piles, where subducted pelagic sediments and (or) basalts of the oceanic crust have recently contributed significant amounts of lead.

The non-American glasses plotted in figure 49 are from Metis Shoal (Oversby and Ewart, 1972) and
Iceland (Welke and others, 1968). Rocks from Iceland plot in field III; that is, they are moderately radiogenic. Because a contribution from subducted pelagic sediments would seem unlikely, the involvement of oceanic crust basalt (Zartman, 1974) during their evolution would seem to be a more viable alternative. The Metis Shoal glass is distinctly less radiogenic than other Tongan volcanics and actually plots in field $I$ of American rocks. Oversby and Ewart (1972) have proposed that the parental magma to the Metis Shoal dacite was formed by partial fusion of mantle which had previously been injected by basalt, with low ${ }^{206} \mathrm{~Pb} /{ }^{204} \mathrm{~Pb}$ ratio, from deeper, lithospheric sources. The $\mathrm{Pb}$-isotope data reflect this unusual mixed-source material.

The relation of this broad pattern of variation to that of $\mathrm{Sr}$ isotopes is noteworthy. Rocks of the continental interior are more radiogenic as regards $\mathbf{S r}$ than those of the oceanic extensional zones and subduction-related types (fig. 50). An overall negative correlation between ${ }^{87} \mathrm{Sr} /{ }^{86} \mathrm{Sr}$ and ${ }^{206} \mathrm{~Pb} /{ }^{204} \mathrm{~Pb}$ ratios is indicated by the obsidians. However, data from the Yellowstone volcanic field (Doe and others, 1982) show that the relation is not simple. For example, data for the Huckleberry Ridge Tuff, where 
$\mathrm{Sr}$ isotopic determinations were made on the potassic feldspars, suggest a positive relation between the ratios. The ratios show no positive covariance in the Yellowstone rhyolites either; two flows (field B, fig. 50) have higher values of both ratios than the majority of flows (field A). The wider spread of both initial ${ }^{87} \mathrm{Sr} /{ }^{86} \mathrm{Sr}$ and ${ }^{206} \mathrm{~Pb} /{ }^{204} \mathrm{~Pb}$ ratios in continentalinterior obsidians may reflect the greater variability of the source rocks and the establishment of isotopic gradients in CIPP magma chambers.

\section{RUBIDIUM}

There is a large range of $\mathrm{Rb}$ concentrations in the obsidians, 6 to $460 \mathrm{ppm}$. Rhyolites from primitive island arcs have distinctly low abundances $(<25 \mathrm{ppm}$; fig. 40G). Between the CLPD rocks of the other groups, there is a considerable amount of overlap, though the averages increase in the order mature arc $\rightarrow$ continental margin $\rightarrow$ continental interior (fig. $40 G$ ). Intragroup variations are low, typically a factor of two at a given $\mathrm{SiO}_{2}$ content (fig. $43 \mathrm{D}$ ).

All but two of the rock-glass pairs show Rb enrichment in the glass, indicating, as does the trend for the Woodson stock, that $\mathrm{Rb}$ concentrates in residual melts. One of the two pairs which have slight $R b$ depletion in the glass (Nos. 4, 5) is from a biotitephyric rock, and $\mathrm{K}_{2} \mathrm{O}$ and $\mathrm{Pb}$ are also slightly reduced in the glass, presumably as a result of partitioning of these elements into the mica. In the other pair (Nos. 9, 10) there is only a small difference $(2 \mathrm{ppm})$ in $\mathrm{Rb}$ content of rock and glass, and analytical imprecision may be suspected.

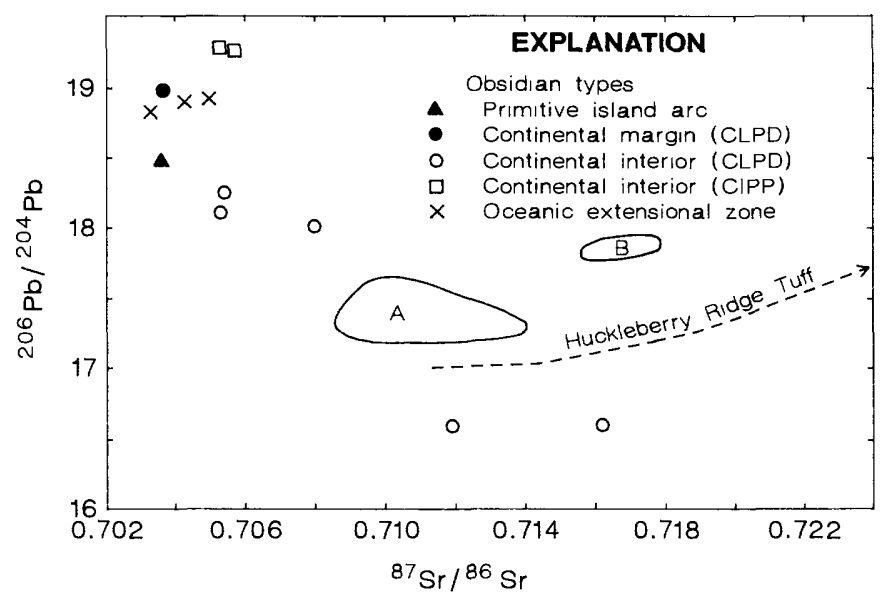

Figure 50.-Ratio of initial ${ }^{87} \mathrm{Sr} /{ }^{86} \mathrm{Sr}$ versus ${ }^{206} \mathrm{~Pb} /{ }^{204} \mathrm{~Pb}$ for obsidians. Biscuit Basin and Canyon flows of Yellowstone volcanic complex plot in field B; other Yellowstone rhyolites in field A. Data are from appendixes I and II. Yellowstone data, including Huckleberry Ridge Tuff, from Doe and others (1982).
$\mathrm{Rb}$ is an up-element in CIPP systems. Enrichment factors of 5 to 6 have been recorded for the Bandelier Tuff (upper member) by Smith and Bailey (1966) and 2 to 3 for the Bishop Tuff by Hildreth (1979). In the Coso system, the factor is 1.4. CIPP produces the highest $\mathrm{Rb}$ concentrations recorded from continentalinterior obsidians; all values greater than $300 \mathrm{ppm}$ are of CIPP type.

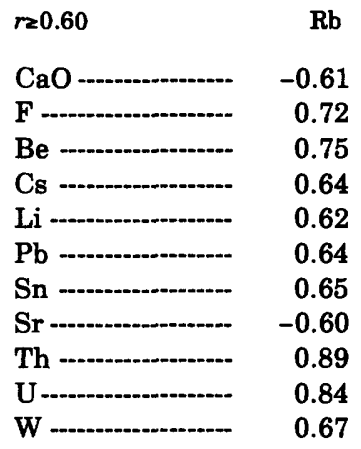

$\mathrm{Rb}$ shows strong $(>0.60)$ positive correlation with the rare metals $\mathrm{Be}, \mathrm{Li}, \mathrm{Sn}$, and $\mathrm{W}$, and with the large cations $\mathrm{Cs}$, $\mathrm{Th}, \mathrm{U}, \mathrm{Pb}$, and $\mathrm{F}$. Strong negative relations with $\mathrm{CaO}$ and $\mathrm{Sr}$ probably reflect feldspar control during crystal-liquid processes and antithetic behavior during CIPP. The correlations with the other elements may reflect, in part at least, a tendency to complex with $\mathrm{F}$.

\section{K/Rb RATIOS}

Crystal-liquid processes tend to maintain a positive correlation between $\mathrm{K}$ and $\mathrm{Rb}$, although the $\mathrm{K} / \mathrm{Rb}$ ratio of more potassic rocks may be as low as 150 . CIPP produces sharp changes in the ratio, invariably becoming lower in lower-temperature liquids, and all specimens with $\mathrm{K} / \mathrm{Rb}$ less than about 150 are CIPP rocks. The apparent contradiction to this statement, as shown by figure 51 , is an artifact of the histogram interval. As a graphic illustration of the problems of overlap of CLPD and CIPP compositions, the late-erupting magma of the Bishop Tuff and Tshirege sheet have two of the highest ratios (485 and 565, respectively) shown by the data bank (fig. 25).

\section{ANTIMONY}

Analytical problems were severe at the low levels (mainly $<2 \mathrm{ppm}$ ) of $\mathrm{Sb}$ found in the obsidians. Duplication of analyses was difficult, in the worst cases duplicate analyses differed 100-200 percent. Any detailed discussion of $\mathrm{Sb}$ variations, such as rock-glass tieline orientations and intragroup variations, is unwarranted. 


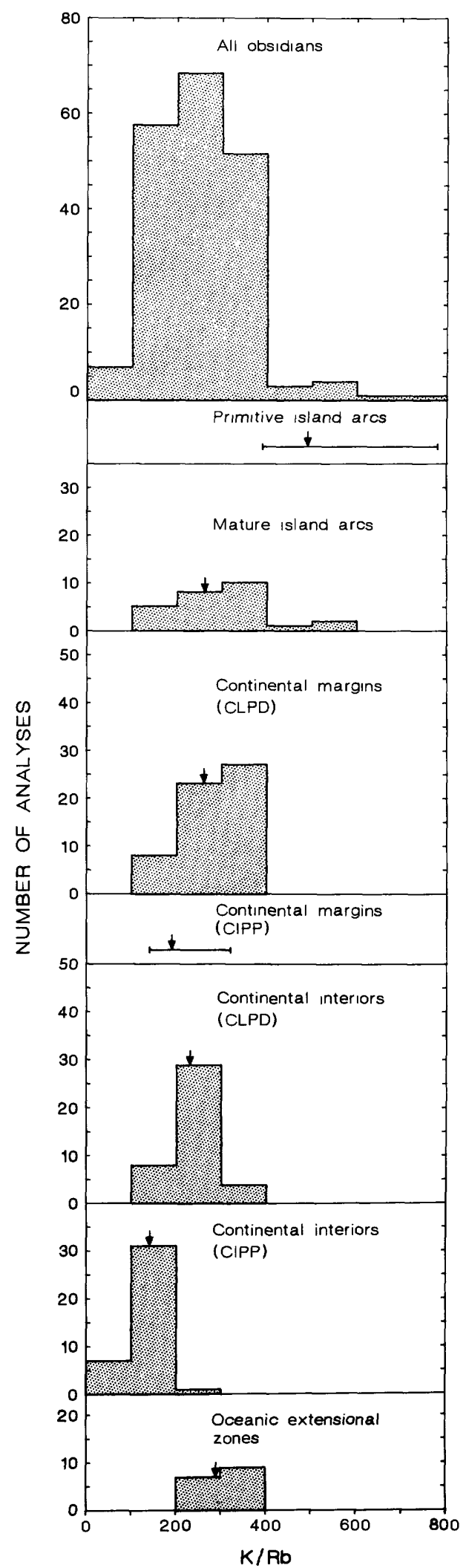

Figure 51.-Distribution of $\mathrm{K} / \mathrm{Rb}$ ratio in obsidians. Obsidians of primitive island arcs and continental margins (CIPP types) are shown as ranges only. Arrows indicate average values. Data from appendixes $I$ and $V$.
There are few published data with which to compare the new analyses. Tanner and Ehmann (1967) found $0.52 \mathrm{ppm} \mathrm{Sb}$ by neutron activation analysis in an obsidian from Big Glass Mountain, Calif., which is close to the $0.7 \mathrm{ppm}$ obtained on a sample of the flow prepared for this study (No. 42). However, for the USGS standard RGM-1, also from Big Glass Mountain, Katz and Grossman (1976) report $1.52 \mathrm{ppm} \mathrm{Sb}$ and Schwarz and Rowe (1976) give $1.30 \mathrm{ppm}$, whereas the updated USGS value determined by INAA (No. 43 ) is $1.20 \mathrm{ppm}$. Differences may be due both to analytical error and to sample heterogeneity in this mixed lava flow.

Bowman and others (1973) report a range of $0.93 \pm 0.10$ to $1.2 \pm 0.2 \mathrm{ppm} \mathrm{Sb}$ in the obsidian at Borax Lake, close to the value of $0.8 \pm 0.1 \mathrm{ppm}$ obtained on a separate sample for this study (No. 48). These various comparisons suggest that although our $\mathrm{Sb}$ data may be imprecise, they are of the right order of magnitude. The following comments are therefore offered with caution.

\begin{tabular}{|c|c|c|}
\hline Obsidian group & Sb range, in ppm & Sb average, in ppm \\
\hline Primitive island ares & (no data) & - \\
\hline Mature island arcs & $0.2-2.3$ & 0.7 \\
\hline \multicolumn{3}{|l|}{ Continental margins } \\
\hline CLPD & $0.3-1.9$ & .8 \\
\hline CIPP & $0.6-1.3$ & 1.0 \\
\hline \multicolumn{3}{|l|}{ Continental interiors } \\
\hline CLPD & $0.1-1.3$ & .5 \\
\hline CIPP & $0.3-2.9$ & .9 \\
\hline Oceanic extensional zones ---- & $0.3-0.6$ & .5 \\
\hline
\end{tabular}

The average data indicate that the highest CLPD compositions are in rocks from mature island arcs and continental margins, and the lowest in obsidians from oceanic extensional zones. Also judging from the averages, CIPP would appear to concentrate $\mathrm{Sb}$ in lower-temperature liquids. In the Bishop Tuff, Sb shows one of the highest enrichment factors of all upelements, about 3 (Hildreth, 1979); a slight enrichment from 1.0 to $1.3 \mathrm{ppm}$ was recorded in the Coso system by Bacon and others (1981). The highest value in the data bank, $39 \mathrm{ppm}$, was recorded in the macusanite glass, a rock inferred to have evolved strongly by CIPP.

Sb shows no correlation coefficient greater than 0.4. The largest values (0.36) are for $\mathrm{Cs}$ and $\mathrm{Li}$. These are at least partly due to intragroup variations, perhaps themselves related to variable source-rock compositions. Thus, the Utah obsidians (including both CLPD and CIPP rocks), already noted as being relatively depleted in $\mathrm{Cs}$ and $\mathrm{Li}$, have $\mathrm{Sb}$ contents lower than their group average (fig. 52). On the other hand, the Java obsidians, already noted for their high Cs contents, have $\mathrm{Sb}$ contents near or slightly higher than 
their group average. The Clear Lake or Medicine Lake high Cs obsidians are variable for $\mathrm{Sb}$ content but tend to confirm the general $\mathrm{Sb}-\mathrm{Cs}$ affinity.

\section{SCANDIUM}

The ranges and averages of Sc abundances in the rhyolites are as follows:
Obsidian group

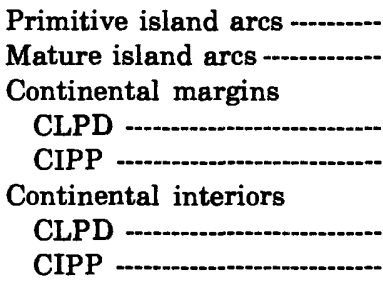

Oceanic extensional zones --
Sc range, in ppm Sc average, in ppm

10.2 (one sample)

$1.72-12.40$

1.1-8.4

1.57-5.15

$1.03-4.23$

$0.12-3.85$

$0.43-11.05$

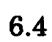

3.7

2.8

2.3

1.6

3.9
Sc concentrations in arc rocks are higher than those in CLPD continental-margin rocks, which in turn are higher than those in CLPD continentalinterior types, both in terms of averages and at similar $\mathrm{SiO}_{2}$ values. There are rather wide within-group variations, typically about a factor of 4 at constant $\mathrm{SiO}_{2}$ or $\mathrm{MgO}$ (fig. 53).

CIPP rocks have, on average, lower Sc contents than CLPD types in both continental-margin and continental-interior groups. The behavior of Sc in CIPP systems is, however, complex. In the Bishop Tuff system, Sc was an up-element, with an enrichment factor of 1.6 to 1.7 (Hildreth, 1979, 1981), but in both Bandelier sheets, it was a down-element. The possible relevance to the obsidian data bank is shown in an Sc-Ta plot (fig. 54). Ta is enriched upwards in all known CIPP systems. The spread of CIPP obsidian points suggests that Sc, as in the ashflow sheets, shows variable behavior from system to system. The reasons for this are not yet understood.

Scandium concentrations are also useful as indicators of contamination of silicic magmas by more mafic material. For example, the $\mathrm{SiO}_{2}$-poor end of the Borax Lake mixed-magma trend contains $10.48 \mathrm{ppm} \mathrm{Sc}$ (Bowman and others, 1973), higher than any other continentalmargin obsidian but comparable to island-arc types. Similarly, the Askja mixed obsidian (No. 176) contains about twice as much Sc as any other rhyolite from oceanic extensional zones. Wide variations in within-group CLPD abundances of Sc mean that it is impossible to generalize about the degree of contamination on the basis of Sc abundances alone. Careful evaluation of Sc data (and of $\mathrm{Co}, \mathrm{Cr}$, and $\mathrm{Ni}$ analyses) for individual suites should reveal anomalies consistent with mixing or assimilation.

The strongest ( $r>0.60)$ correlations shown by Sc are for the major elements $\mathrm{Fe}, \mathrm{Mg}, \mathrm{Ca}, \mathrm{K}$, and $\mathrm{Ti}$, reflecting concentration of $\mathrm{Sc}$ in the least silicic, highest $\mathrm{Ca}$ liquids. The MgO-Sc plot (fig. 53) provides a useful summary of Sc distribution in the silicic obsidians. CLPD rocks cover a broad, positive field, whose width represents mainly within-group variations in $\mathrm{Sc}$ abundances. In certain magmatic systems, CIPP results in upward-enrichment of Sc and a sharp increase in $\mathrm{Sc} / \mathrm{Mg}$ ratios. There is a concomitant tendency for the field of CIPP rocks to be displaced toward higher Sc/Mg ratios than CLPD types. Other CIPP rocks plot at very low $\mathrm{MgO}-\mathrm{Sc}$ values; these lie close to trend $\mathrm{Co}$ of figure 54 and are rocks where crystal-liquid controls have also affected $\mathrm{Sc}$ distribution.

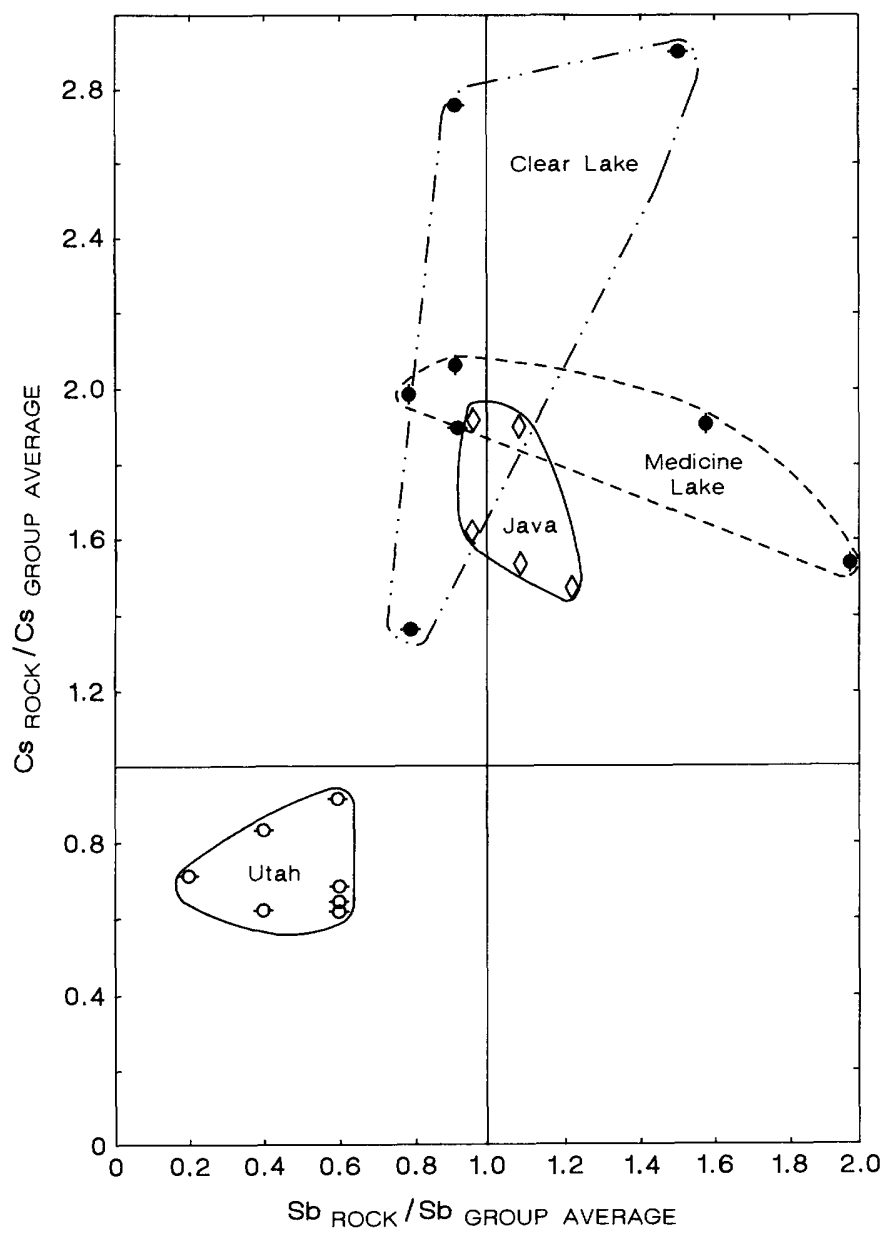

Figure 52.-Sb versus $\mathrm{Cs}$ relations in obsidians from selected areas. Element abundances were normalized by dividing by average value for each group. Fiducial lines, for each axis, separate positions of sample, or fields, relative to their respective group averages. Sample symbols simply differentiate geographic localities in overlapping fields. 


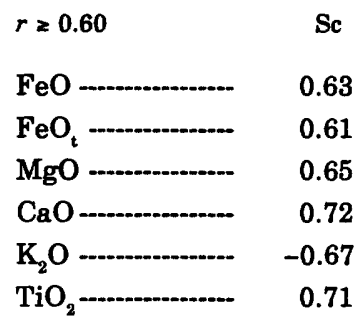

STRONTIUM

The range of $\mathrm{Sr}$ abundances, 0.3 to $402 \mathrm{ppm}$, is one of the largest in the data bank and makes a linear plot of $\mathrm{Sr}$ against $\mathrm{SiO}_{2}$ unsuitable. Ranges and averages for each of the rhyolite groups are given in tables 7-9. Obsidians from oceanic extensional zones have relatively low $\mathrm{Sr}$ abundances for CLPD rocks, on both average and $\mathrm{SiO}_{2}$-normalized bases. The rocks from primitive island arcs overlap the lower end of the field of specimens from mature island arcs (fig. 40I), the higher average value in the primitive-arc rocks reflecting their lower $\mathrm{SiO}_{2}$ contents. The averages and ranges for obsidians of mature island arcs and continental margins are very similar. Jakes and White (1972) have suggested that calc-alkalic volcanic rocks of island arcs generally have lower contents of $\mathrm{Sr}$ at the same $\mathrm{SiO}_{2}$ and $\mathrm{K}_{2} \mathrm{O}$ values than rocks from continental

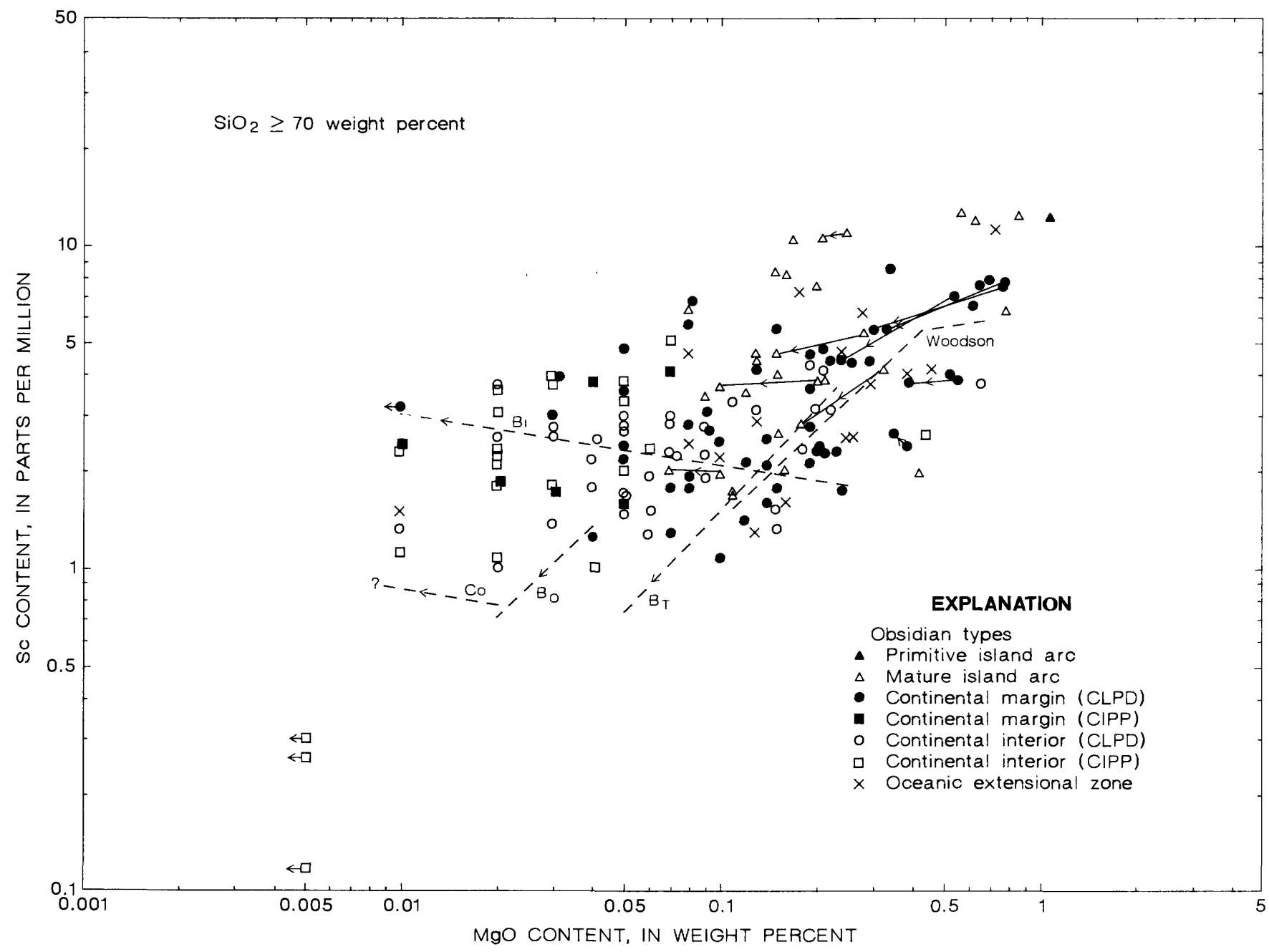

Figure 53.-MgO content versus Sc content for obsidians and various comparative rocks. Data sources are same as for figure 5. Sample 111 is omitted. Solid tielines represent rock-glass pairs, arrows point toward glass separate. Dashed lines represent various systems: Bishop Tuff, Bi
(Hildreth, 1981); Bandelier Tuff, Otowi, $B_{0}$, and Tshirege, $B_{T}$, Members (R.L. Smith, unpub. data); Coso Range, Co (Bacon and others, 1981); and Woodson Granodiorite, Woodson (D. Gottfried, unpub. data). Arrows indicate direction of liquid fractionation. 
margins. We cannot distinguish systematic differences between the two groups at equivalent $\mathrm{SiO}_{2}$ contents. The $\mathrm{K}_{2} \mathrm{O}-\mathrm{Sr}$ relation of Jakes and White (1972) possibly holds for higher $\mathrm{CaO}$ rocks but is more a function of lower $\mathrm{K}_{2} \mathrm{O}$ values in the arc rocks than lower Sr.

CLPD obsidians of the continental interiors have, on any basis, notably lower average $\mathrm{Sr}$ abundances than subduction-related obsidians. Levels of 1-2 ppm in certain of these rocks indicate that crystal-liquid processes may produce extreme $\mathrm{Sr}$ depletion in rhyolites (compare with Noble and others, 1972). Several mechanisms may be involved: extensive plagioclase fractionation from parental melts; retention of plagioclase as a residual phase in the source rocks during crustal anatexis; and (or) generation of the melts in $\mathrm{Sr}$-depleted source rocks, this condition being transmitted to the melts regardless of whether plagioclase is a residual phase after fusion.

The data for rock-glass pairs and the Woodson stock point to modest $\mathrm{Sr}$ depletion in residual liquids where $\mathrm{SiO}_{2}$ is less than 75-76 percent, but to very rapid depletion in more silicic liquids. Fractionation accentuates within-group variations, especially at the high-silica end, where factors of 3-4 are common. CIPP also results in extreme Sr depletion in lower-temperature liquids. Hildreth (1981) records a factor of 23 depletion in the Bishop Tuff. In the Coso rocks, the factor is about 5 (Bacon and others, 1981). Very low Sr abundances $(<1-10$

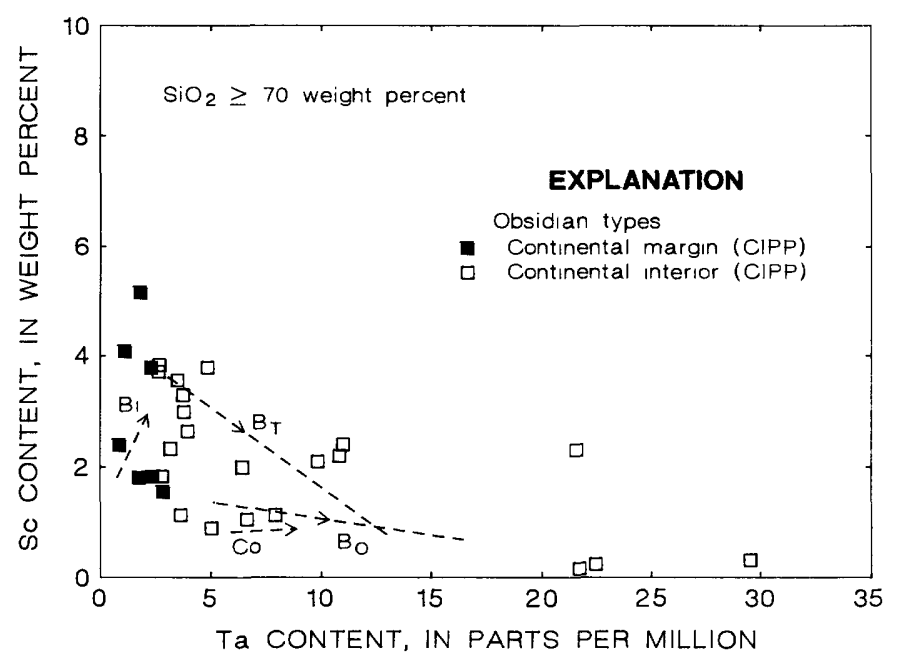

Figure 54.-Ta content versus Sc content showing possible effects of CIPP on silicic magmas. Data sources are same as for figure 5. Dashed lines represent CIPP systems: Bishop Tuff, Bi (Hildreth, 1981); Bandelier Tuff, Otowi, $B_{0}$, and Tshirege, $B_{T}$, Members (R.L. Smith, unpub. data); Coso Range, Co (Bacon and others, 1981). Arrows indicate direction of liquid fractionation. ppm, average $3.8 \mathrm{ppm}$ ) are characteristic of CIPP continental-interior rocks but, as noted above, are not exclusive to them.

Sr has high $(r>0.60)$ correlation coefficients mainly with certain major elements, reflecting its tendency to concentrate in the high $\mathrm{MgO}-\mathrm{CaO}$ rhyolites of the island arcs and continental margins. The highest value of $r$ is with $\mathrm{CaO}$, a relation predictable from classical considerations. A $\mathrm{CaO}-\mathrm{Sr}$ plot (fig. 55A) clearly shows the two main factors controlling $\mathrm{Sr}-\mathrm{Ca}$ covariation in the obsidians.

1. There is a tendency, indicated by the average values, toward lower $\mathrm{Ca} / \mathrm{Sr}$ ratios in the sequence obsidians of primitive island arcs (173) $\rightarrow$ calcic varieties from mature island arcs $(93) \rightarrow$ calc-alkalic varieties from mature island arcs (71) $\rightarrow$ CLPD continentalmargin rocks (56). The trend is reversed in the CLPD continental-interior obsidians, the average (103) indicating either that the source rocks of the rhyolites were depleted in $\mathrm{Sr}$ relative to $\mathrm{Ca}$, that $\mathrm{Sr}$ was preferentially retained by the source rocks during melting, or that the ratio was increased by substantial crystal fractionation.

2. In rocks with $\mathrm{CaO}$ greater than 1 percent and $\mathrm{Sr}$ greater than $100 \mathrm{ppm}$, crystal-liquid processes produce little change in the $\mathrm{Ca} / \mathrm{Sr}$ ratio of about 120 (fig. 55). However, in less calcic rocks, they can result in sharp increases in the $\mathrm{Ca} / \mathrm{Sr}$ ratio (see the Woodson trend, for example). CIPP has the same effect, in extreme cases giving $\mathrm{Ca} / \mathrm{Sr}$ ratios greater than $10^{4}$.

\begin{tabular}{|c|c|}
\hline$\geq 0.60$ & $\mathrm{Sr}$ \\
\hline $\mathrm{iO}_{2}$ & -0.65 \\
\hline $\mathrm{Al}_{2} \mathrm{O}_{3}$ & 0.73 \\
\hline MgO & 0.80 \\
\hline $\mathrm{CaO}-$ & 0.83 \\
\hline $\mathrm{K}_{2} \mathrm{O}$ & -0.69 \\
\hline $\mathrm{TiO}_{2}$ & 0.71 \\
\hline & 0.7 \\
\hline & -0 \\
\hline
\end{tabular}

$\mathrm{Rb} / \mathrm{Sr}$ ratios vary from $<0.1$ to $>1,000$ in the obsidians, the ratio increasing with increasing crystal fractionation and with increasing degrees of CIPP (fig. $55 B$ ). The majority of obsidians fall within a broad band elongated parallel to the various differentiation trends. Rocks from the primitive island ares fall to the $\mathrm{Rb}$-poor side of this band; a trend drawn from these rocks transverse to the main band follows a trend of increasing crustal maturity.

The Ta-Sr plot (fig. 55C) makes a useful tectonomagmatic discrimination diagram. The field boundaries are arbitrary and correctly assign 89.1 percent 
of obsidians to their respective groups as we have classified them. The general usefulness of this plot is unfortunately limited by the mobility of Sr during lowtemperature alteration processes.

\section{STRONTIUM ISOTOPES}

Initial ${ }^{87} \mathrm{Sr} /{ }^{86} \mathrm{Sr}$ ratios are compiled in table 14. The ranges in each obsidian group are:

\section{Obsidian group}

Primitive island arcs

Mature island arcs

Continental interiors

Oceanic extensional zones
Continental margins
${ }^{87} \mathrm{Sr} /{ }^{\mathrm{se}} \mathrm{Sr}$ range
(0.7038)
$0.7033-0.7045$
$0.7036-0.7064$
$0.7046-0.7162$
$0.7032-0.7050$

These values bear out the observation (Hedge and Peterman, 1974) that volcanic rocks emplaced through old sialic crust generally have higher and more variable initial ${ }^{87} \mathrm{Sr} /{ }^{86} \mathrm{Sr}$ ratios than those from island arcs and relatively young continental-margin settings. The proportion of continental crust to mantle components in its rhyolites is increasing as cratonization proceeds.

The ranges of ${ }^{87} \mathrm{Sr} /{ }^{86} \mathrm{Sr}$ ratios of five isotopically zoned, voluminous ash-flow sheets are also given in table 14. In each case, the ratios show an increase with inferred height in the magma chamber. The systematic nature of the increases suggests that the process is not random and that development of the isotopic gradients is an integral part of the zonation of the magma chamber (Hildreth, 1981).

Various mechanisms may have played roles in establishing isotopic variability in the melts, including isotopic exchange with wall and roof rocks (Noble and Hedge, 1969; Doe and others, 1982; Michael, 1983), interaction with high-temperature meteoric waters or hydrothermal fluids (Lipman and Friedman, 1975; Lipman and others, 1978; Doe and others, 1982), and inheritance of variable source-rock isotopic signatures (Hildreth, 1981), but the relative contribution of each mechanism remains unknown, even for individual magmatic systems. In some cases, posteruptive hydration of glassy samples may have contributed to isotopic variability. In the Bishop Tuff, California, Halliday and others (1984) reported initial ratios in glassy, whole-rock samples in the range 0.7061-0.7069. The variability in the whole-rock samples was ascribed to low-temperature, post-eruptive interaction with meteoric water (see "Oxygen Isotopes").

"These considerations indicate that it is dangerous to assume that the $\mathrm{Sr}^{* * *}$ isotopic variability of $\mathrm{a}^{* * *}$
TABLE 14. Strontium isotopic ratios in silicic obsidians

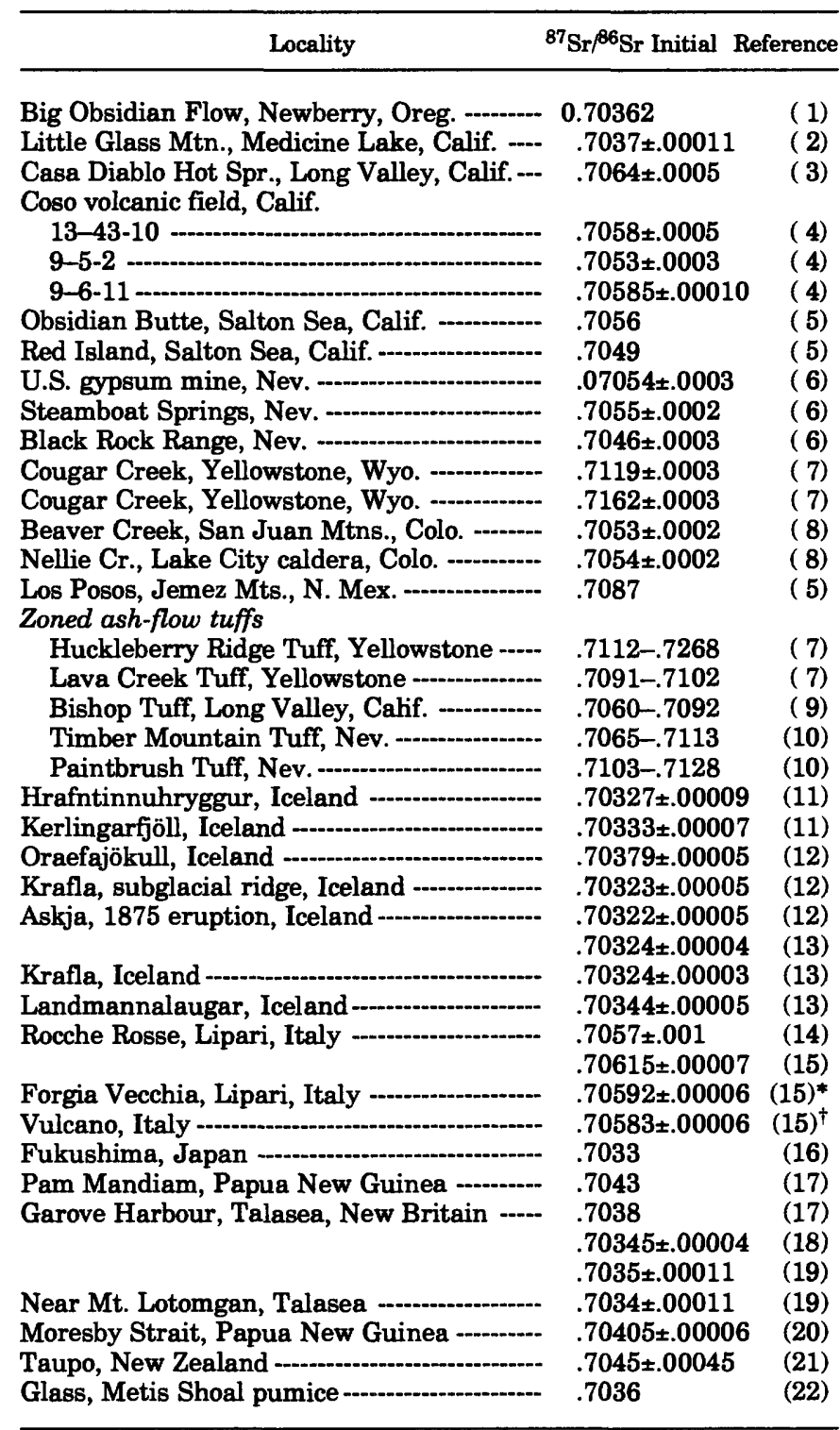

\begin{tabular}{|c|c|}
\hline & $\begin{array}{l}\text { Average of } 5 \text { determinations } \\
\text { Average of } 2 \text { determinations }\end{array}$ \\
\hline \multicolumn{2}{|c|}{ References: } \\
\hline (1) & M.W. Higgins (unpublished data) \\
\hline (2) & Peterman and others (1970a) \\
\hline (3) & Noble and others (1972) \\
\hline (4) & Bacon and others (1984) \\
\hline (5) & Doe (1968) \\
\hline (6) & Noble and others (1973) \\
\hline (7) & Doe and others (1982) \\
\hline (8) & Lipman and others (1978) \\
\hline (9) & Halliday and others (1984) \\
\hline (10) & Noble and Hedge (1969) \\
\hline (11) & O'Nions and Grönvold (1973) \\
\hline (12) & Condomines and others (1983) \\
\hline (13) & Wood and others (1979) \\
\hline (14) & Barberi and others (1974) \\
\hline (15) & Gale (1981) \\
\hline (16) & Shuto and Yashima (1974) \\
\hline (17) & Page and Johnson (1974) \\
\hline (18) & DePaolo and Johnson (1979) \\
\hline (19) & Peterman and others (1970b) \\
\hline (20) & Smith and Johnson (1981) \\
\hline (21) & Ewart and Stipp (1968) \\
\hline (22) & Ewart and others \\
\hline
\end{tabular}




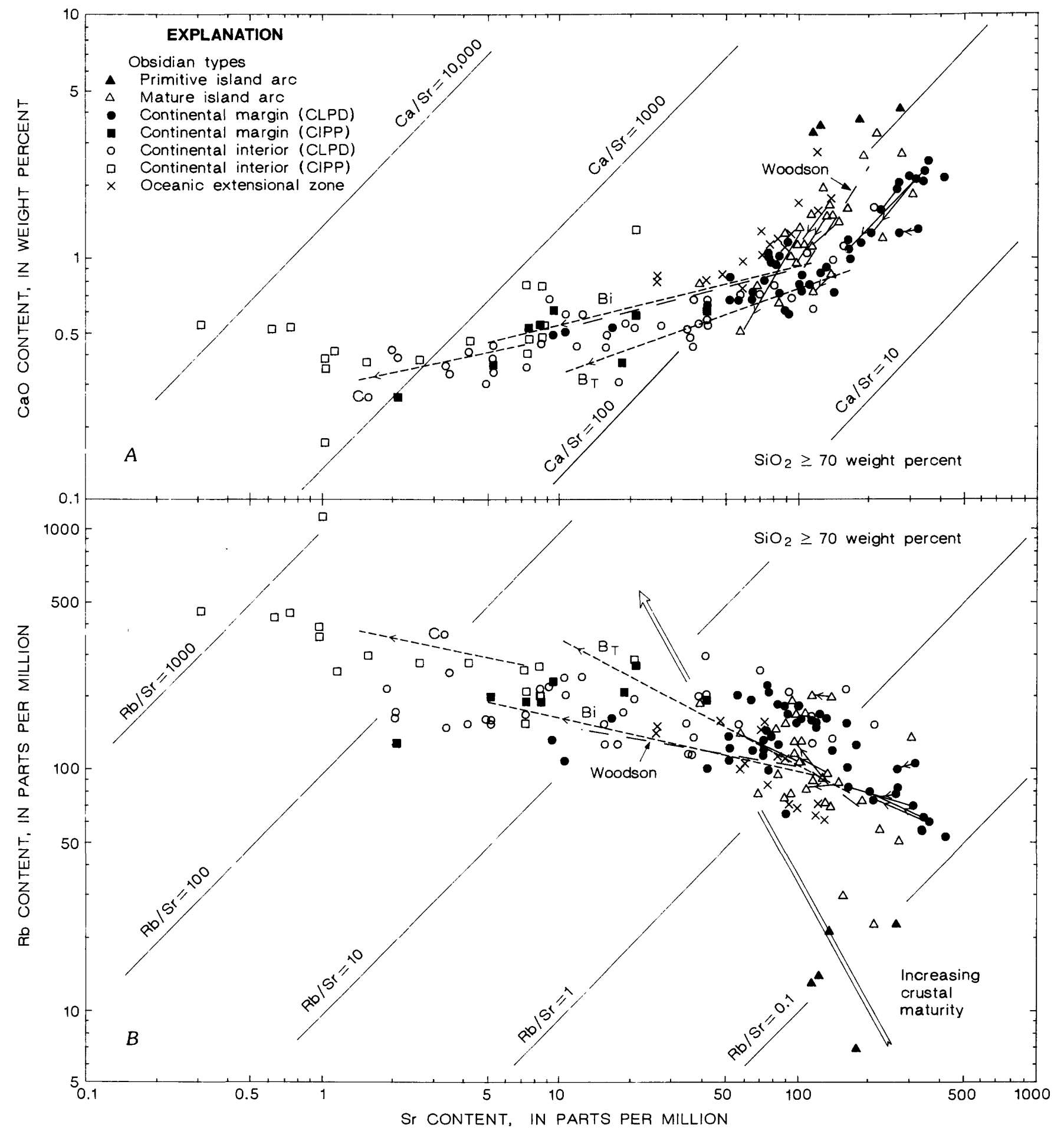

Figure 55.- $\mathrm{Sr}$ content versus $\mathrm{CaO}$ content $(A), \mathrm{Rb}$ content $(B)$, and Ta content $(C)$ for obsidians and various comparative rocks. Data sources are same as for figure 5. Solid tielines $(A, B)$ represent rock-glass pairs; arrows point toward glass separate. Dashed lines $(A, B)$ represent rock systems: Bishop
Tuff, Bi (Hildreth, 1981); Bandelier Tuff, Tshirege Member, $B_{T}$ (R.L. Smith, unpub. data); Coso Range, Co (Bacon and others, 1981); and Woodson Granodiorite, Woodson (D. Gottfried, unpub. data). Field boundaries in $C$ are arbitrary and dashed where questionable. 
volcano, or even a single eruptive unit is adequately represented by one or a few samples and that silicic magma may become isotopically distinct from some or all of the rocks that melted to produce it" (Hildreth, 1981, p. 10164). Use of ${ }^{87} \mathrm{Sr} /{ }^{86} \mathrm{Sr}$ ratios as indicators of the nature of the source rocks is premature until the factors causing isotopic variations within rhyolitic magma bodies are properly understood.

\section{THORIUM AND URANIUM}

The range of $U$ abundances is sufficiently large that the main features of $U$ distribution in the obsidians are not disguised by analytical imprecision. Detailed assessment of such variables as $\mathrm{Th} / \mathrm{U}$ is rather more difficult.

Some comparisons of the new data with published analyses are listed at the top of page 108.

With the exception of the Los Posos glass, the analyses are the same, within stated analytical pre- cisions. The reason for the discrepancy in the analyses for the Los Posos rocks is not known.

The ranges and averages for the two elements are given in figure $40 \mathrm{~J}, K$. The lowest abundances are found in rhyolites of primitive island arcs. At constant $\mathrm{SiO}_{2}$, there is a general increase in Th and $U$, reflected in the averages (tables 7 and 8 ) in the sequence calcic obsidians of mature island arcs $\rightarrow$ calc-alkalic mature island arcs $\rightarrow$ continental margin $\rightarrow$ continental interior (fig. $43 E, F$ ). The rhyolites of the oceanic extensional zones have $\mathrm{Th}$ and $U$ concentrations similar to those of the continental margins and mature island arcs. The obsidian data largely confirm the observations of Jakes and White (1972) and Ewart and others (1977) that Th and U contents of silicic rocks from areas underlain by thick continental crust are higher than those from areas of immature or primitive crust.

Data for Th and $U$ in differentiated plutonic series such as the Tuolumne Intrusive Suite (Peck, 1980, data from Bateman and Chappell, 1979) and

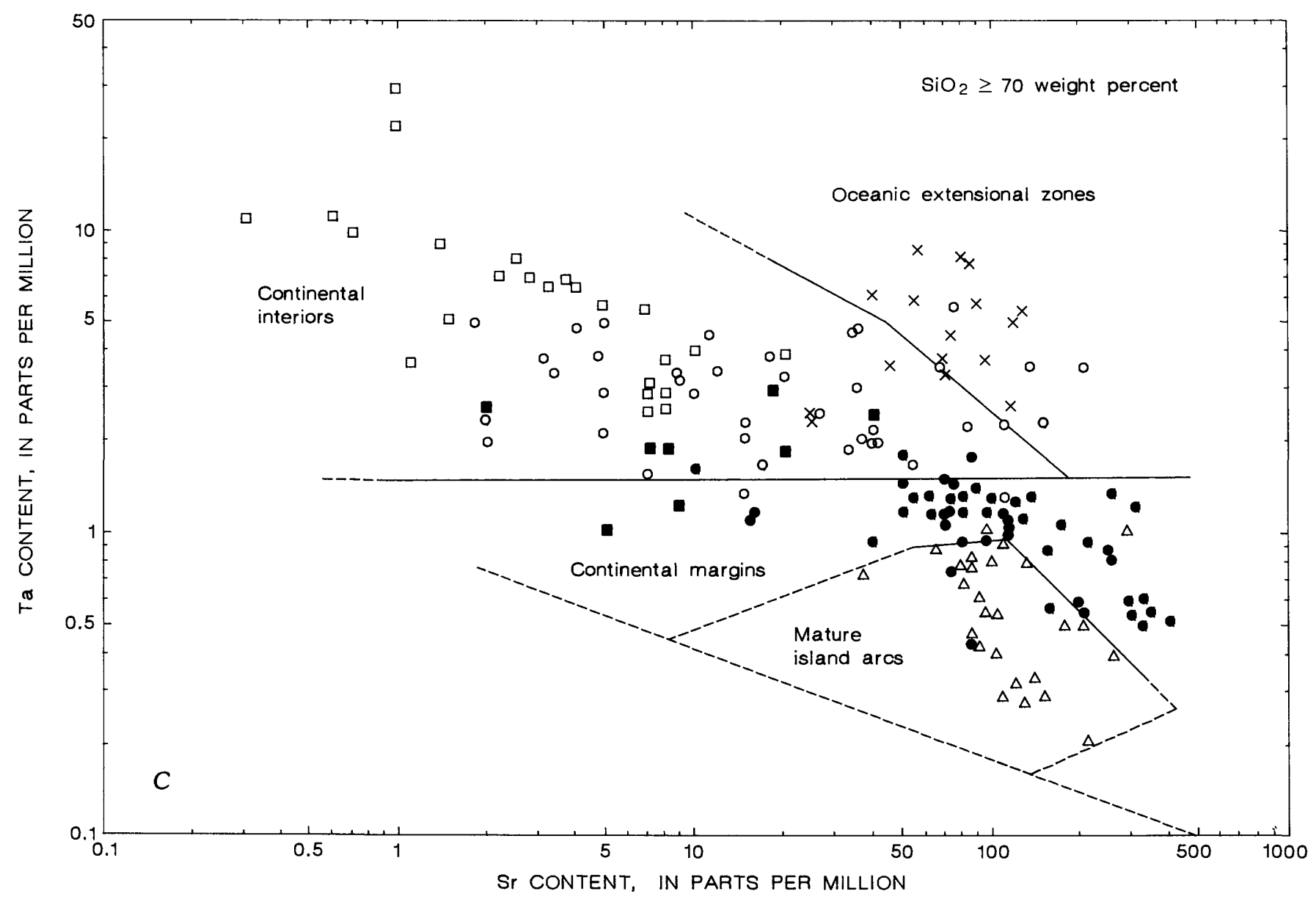

Figure 55.-Continued. 
Locality

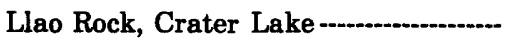

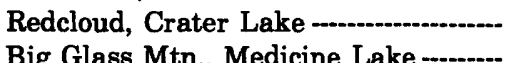

Big Glass Mtn., Medicine Lake -...........

Big Glass Mtn., (RLS-141) -............-

Borax Lake mixed flow, Clear Lake --

Obsidian Butte, Salton Sea -.-.-.-.-...-.

Shoshone Mtn., Nevada -

Obsidian Cliff, Yellowstone --.-.-.-.-.-.

Ruby Mtn., Colorado -..-..-..-...-

Grants Ridge, New Mexico -.-.-.--..-

Los Posos, Jemez Mts.

Rocche Rosse, Italy

Do. -..-...-...-

Do.
Th

Pub

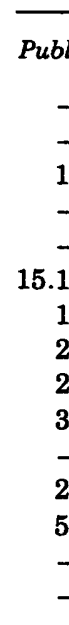

1-17.6

19.5

27.2

29.4

37.7

$\overline{24.8}$

24.8

$-$
New

- $\quad 5.1$

$-\quad 5.1$

$15.3-$

- $\quad 14.6$

14.8
14.8

15.6
20.8

20.8

26.4

37.7

23.2

17.7

$-$

$-$

55.7

\begin{tabular}{cc}
\multicolumn{2}{c}{$\mathrm{U}$} \\
\hline Published & New \\
2.94 & 2.9 \\
2.88 & 3.3 \\
5.68 & - \\
- & 5.9 \\
- & 6.5 \\
$5.77-6.75$ & 6.6 \\
6.06 & 5.7 \\
6.34 & 5.8 \\
7.19 & 7.3 \\
15.3 & 18.0 \\
8.2 & 8.1 \\
5.24 & 6.8 \\
17 & - \\
15.6 & - \\
- & 18.5
\end{tabular}

References

(published values; new values)

Noble and others (1980); No. 15

Noble and others (1980); No. 16

Rosholt and others (1971)

No. 43

No. 42

Bowman and others (1973); No. 48

Rosholt and others (1971); No. 73

Rosholt and others (1971); No. 82

Doe and others (1982); No. 94

Rosholt and others (1971); No. 104

Zielinski (1978); No. 219

Rosholt and others (1971); No. 120

Belluomini and Taddeucci (1970)

Gale (1981)

No. 180 the Woodson stock (Tilling and Gottfried, 1969) are sufficiently scattered when plotted against $\mathrm{SiO}_{2}$ that some secondary remobilization of these elements must be suspected. Nevertheless, the overall behavior of $T h$ and $U$ during differentiation of magmas is to increase in residual liquids (Rogers and Adams, 1969), and this is the type of behavior also indicated by the rock-glass tielines of this study. The Bishop (Hildreth, 1979, 1981), Bandelier (Smith and Bailey, 1966), and Coso (Bacon and others, 1981) systems all show strong upward enrichment of both elements. The Th and $U$ enrichment factors in the Bishop Tuff are 1.7 and 2.4, respectively, and in the Tshirege Member of the Bandelier Tuff are 3.2 and 4.9, respectively (R.L. Smith, unpub. data). Although the highest values reached are in CIPP continental-interior rocks, CLPD samples may have values sufficiently high that there is very substantial overlap of CIPP and CLPD fields for both Th and U.

It has been known for some time (see discussion in Phair and Gottfried, 1964) that there are lateral regional variations in $T h$ and $U$ distribution in the crust, lending to the concept of $T h$ and $U$ provinces. Notable examples are the high U concentrations shown by obsidians from the Rocky Mountain areagreater than $40 \mathrm{ppm} U$ in the specific case of the rhyolite of Nellie Creek, Colorado (Zielinski, 1978, table 1). This general Rocky Mountain high characterizes obsidians from New Mexico to Alaska but its cause remains enigmatic.

A convenient way of depicting rocks that are high or low in $T h$ and $U$ is by comparing them with the crustal averages for $\mathrm{K} / \mathrm{Th}$ and $\mathrm{K} / \mathrm{U}$ ratios of $3 \times 10^{3}$ and $1 \times 10^{4}$, respectively, suggested by Rogers and Adams (1969). Use of ratios rather than absolute abundances tends to normalize variations in abundances resulting from major-element variations. A $\mathrm{K} / \mathrm{Th}-\mathrm{K} / \mathrm{U}$ plot (fig. 56) shows, for example, the relatively high $\mathrm{Th}$ and $\mathrm{U}$ contents of obsidians from Chile and the low Th of many continental-margin rhyolites of the Oregon subtype. On a more local scale, the relative $T h$ depletion of the obsidians from Xalapasquillo, Mexico (Nos. 146, 147), and Macusani (No. 160; not shown on fig. 56) are notable.

The K/Th-K/U plot may also be used to make more general comments on $\mathrm{Th}$ and $\mathrm{U}$ distribution in rhyolites, though the large variation within the Bishop Tuff suggests that the comments are most relevant to CLPD rocks. The majority of obsidians have an excess of $\mathrm{Th}$ and $\mathrm{U}$ relative to common crustal materials. There are two partial explanations for this: first, the high-silica rocks of this study have higher $\mathrm{SiO}_{2}$ contents and thus higher Th and $\mathrm{U}$ contents than the average crustal rock used in computing the averages; and, second, many crustal rocks may have been leached of $T h$ and $U$ in the nearsurface environment during various low-temperature processes. Obsidians from continental margins show a roughly linear relation between $\mathrm{K} / \mathrm{Th}$ and $\mathrm{K} / \mathrm{U}$,

Figure 56.-Ratio of $\mathrm{K} / \mathrm{Th}$ versus ratio of $\mathrm{K} / \mathrm{U}$ for obsidians and various comparative rocks. Rocks of southeastern Oregon subtype are defined in text. Fields (for example, Th-U+) refer to rocks that have $T h$ and $U$ concentrations higher or lower relative to $K$ than average continental crust. Samples 145, 160, 203, 210, and 215 are omitted to preserve scale. Solid tielines represent rock-glass pairs; arrows point toward glass separate. Dashed lines represent CIPP systems: Bishop Tuff, Bi (Hildreth, 1981); Bandelier Tuff, Otowi, $\mathbf{B}_{\mathrm{o}}$, and Tshirege, $\mathbf{B}_{\mathrm{T}}$ Members (R.L. Smith, unpub. data); Coso Range, Co (Bacon and others, 1981). Arrows indicate direction of liquid fractionation. 


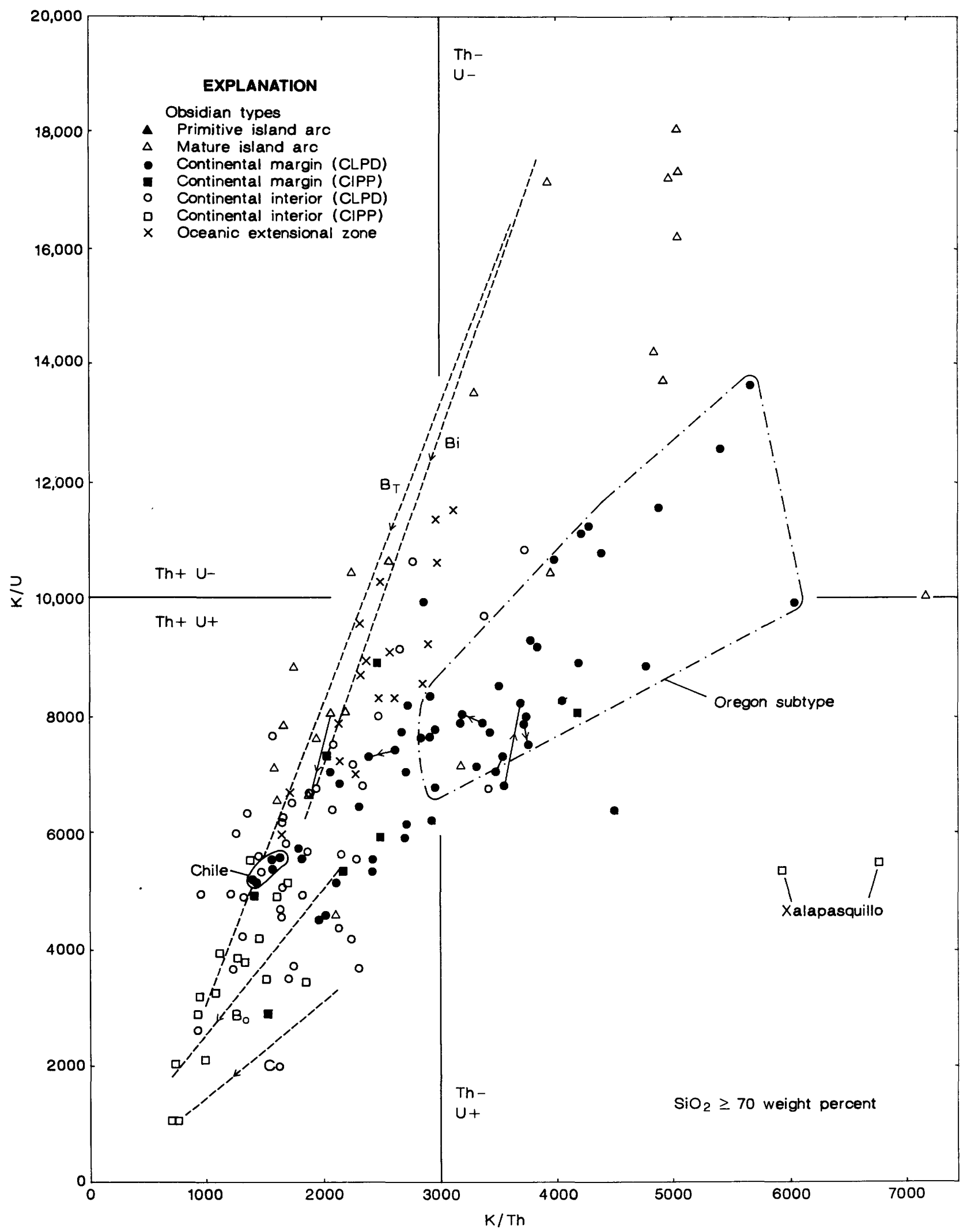


suggesting that though the absolute abundances of these elements vary widely within such obsidians, genetic processes did not significantly partition them. It is noteworthy that the range of values is from Th-U-excess to Th-U-depleted compositions, reflecting either the varying Th- $U$ chemistry of the source rocks or different behavior of the Th-U host phases during the melting process.

The majority of island-arc obsidians lie to the Upoor side of the margin rocks. Perhaps their source materials were relatively low in U. If continentalmargin volcanics represent a further stage in the cratonization process, then that process has resulted in $U$ enrichment relative to $K$.

Remobilization of $U$ in epicratonic settings is apparently indicated by the wide spread in $\mathrm{K} / \mathrm{U}$ values for the rhyolites from such settings.

\section{Th/U RATIOS}

Thorium and uranium are normally regarded as geochemically coherent in igneous-rock series. In the obsidians $(r=0.84)$, the effects of within- and betweengroup differences and analytical imprecision produce a significant range in $\mathrm{Th} / \mathrm{U}$ ratios, a total range from 1 to 6 .

The $\mathrm{Th} / \mathrm{U}$ ratio has been recorded as increasing, decreasing, or staying constant during the differentiation of igneous-rock series (Rogers and Adams, 1969). The $U$ data acquired in this study for rock-glass pairs are not sufficiently precise to assess changes in $\mathrm{Th} / \mathrm{U}$ ratio. Significant changes in the ratio are reported from CIPP systems; the trend in the Bishop, Bandelier, and Coso systems is toward lower $\mathrm{Th} / \mathrm{U}$ ratio in lowertemperature liquids. The respective values for each system are 5.00 to 3.13 (Hildreth, 1979), 4.50 to 2.93 (R.L. Smith, unpub. data), and 2.80 to 2.52 (Bacon and others, 1981). Hildreth (1981, p. 10177) has argued that for up-elements more highly charged than $3^{+}$, thermo-gravitational transport of volatile complexes is the most likely mechanism of enrichment. The relative enrichment of $U$ over Th reflects its enhanced ability to form complexes with halogens, especially in systems where $\mathrm{F}$ is a more important ligand than $\mathrm{Cl}$.

The great majority of silicic obsidians from continental margins have $\mathrm{Th} / \mathrm{U}$ ratios between 2 and 3 . CLPD rocks of the continental interiors have a slightly higher average ratio but also show a wider, and less unimodal, spread of ratios (fig. 57). Though the higher ratio may mean an overall increase in $\mathrm{Th} / \mathrm{U}$ ratio during the growth and development of continental crust (compare with Rogers and Adams, 1969), the wider spread indicates that continental-interior obsidians are probably derived from sources where substantial fractionation of Th and $U$ has taken place. Possible mecha-

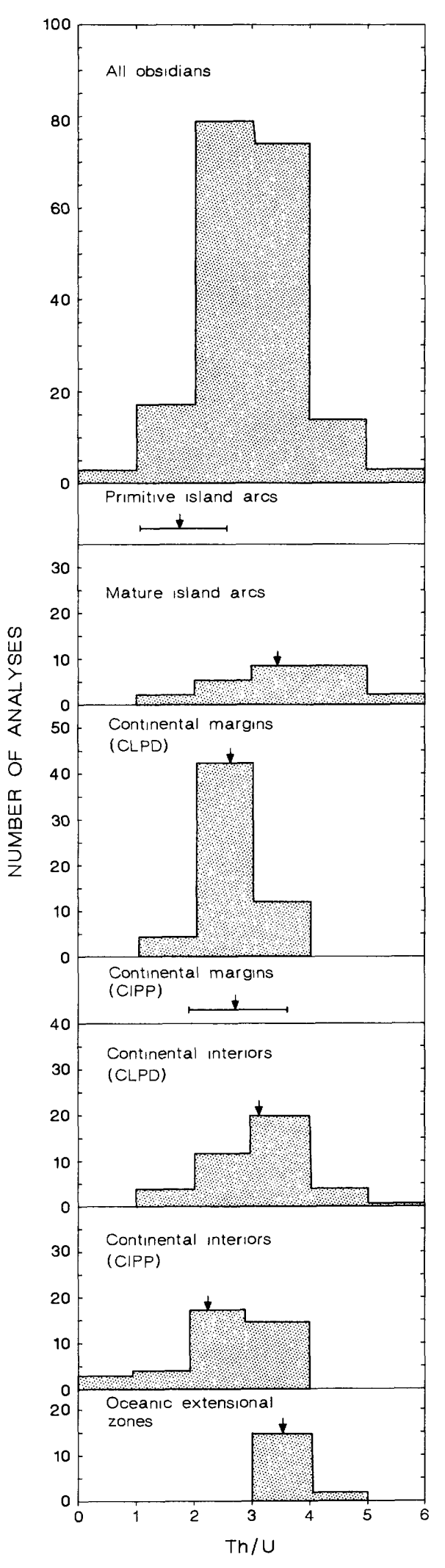

Figure 57.-Distribution of $\mathrm{Th} / \mathrm{U}$ ratios in obsidians. Obsidians of primitive island arcs and continental margins (CIPP types) are shown as ranges only. Arrows indicate average values. Data from appendixes I and V. Sample 203 is omitted to preserve scale. 
nisms include migration of both elements, and particularly $U$, to higher crustal levels during high-grade metamorphism and redistribution of $\mathrm{Th}$ and $\mathrm{U}$ by previous crustal fusion events.

Obsidians from mature island arcs also have a higher average $\mathrm{Th} / \mathrm{U}$ ratio than those of continental margins (compare with Jakes and White, 1972, table 3). Although data are scarce, obsidians from primitive island arcs are notable for low $\mathrm{Th} / \mathrm{U}$ ratios, commonly less than 2. There is thus no simple progression in $\mathrm{Th} / \mathrm{U}$ ratio to match the presumed tectonic progression, primitive arcs $\rightarrow$ mature island arcs $\rightarrow$ continental margins $\rightarrow$ continental interiors. The behaviors of Th and $U$ are different in some complex way during crustal development.

Thorium and uranium show the highest $(r>0.60)$ correlations with other elements of large ionic radius ( $\mathrm{Cs}$ and $\mathrm{Rb}$ ), with the rare metals $\mathrm{Be}, \mathrm{Sn}$, and $\mathrm{W}$, and with $F$. The common feature is probably the tendency to form complexes with $F$.

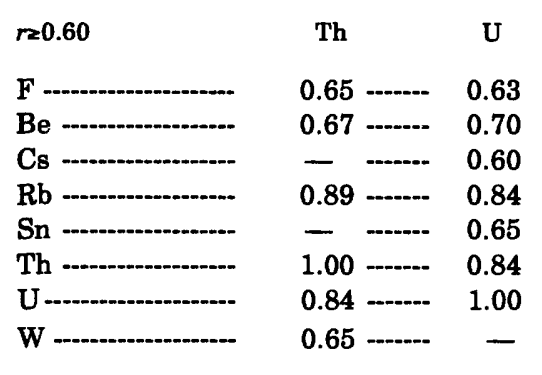

zINC

Zinc abundances show a large range, 8 to 282 ppm, although only one specimen contains more than $170 \mathrm{ppm}$. Four specimens from primitive arcs have $\mathrm{Zn}$ concentrations in the range $43-101 \mathrm{ppm}$, average $69 \mathrm{ppm}$. Obsidians of mature island arcs and continental margins are comparable in the spread of the data and the average (table 7; fig. $40 L$ ). CLPD obsidians of the continental interiors have a slightly higher average $\mathrm{Zn}$ concentration, but there is very extensive overlap between them and the subduction-related types on $\mathrm{a} \mathrm{SiO}_{2}-\mathrm{Zn}$ plot (fig. $43 G$ ). The rocks from oceanic extensional zones have higher $\mathrm{Zn}$ contents, on average, and $\mathrm{SiO}_{2}$-normalized bases. Within-group variations are high, commonly a factor of 4 at constant $\mathrm{SiO}_{2}$ values (fig. 43G).

Data from rock-glass pairs from Crater Lake and South Sister, which are calcic systems, indicate slight $\mathrm{Zn}$ depletion in residual liquids, a trend also found in the Tuolumne Intrusive Series (Bateman and Chappell, 1979). On the other hand, the calcalkalic rocks from Capital Mountain, Okushiri, and Halmahera demonstrate $\mathrm{Zn}$ enrichment in the glass.
The possibility that $\mathrm{Zn}$ behavior, like that of $\mathrm{Nb}$ and $\mathrm{Ta}$, is related to the magmatic affinity of the suite deserves further study.

The average $\mathrm{Zn}$ contents of CIPP rocks in the continental margin and interior groups are higher than those for the corresponding CLPD rocks (fig. 40L). Similar to $\mathrm{Sc}$, however, $\mathrm{Zn}$ behavior in CIPP systems is complex. In the Bishop system (Hildreth, 1979, 1981) Zn stayed about constant in all rocks, but in the Coso system it enriched upward slightly (Bacon and others, 1981) and in the Bandelier systems extreme enrichments of $\mathrm{Zn}$ occur (R.L. Smith, unpublished data). Some aspects of the complexity are displayed on a Yb-Zn plot (fig. 58), $\mathrm{Yb}$ being an up-element in all CIPP systems. Eightytwo percent of continental-interior CLPD obsidians plot within the marked field. Three possible types of $\mathrm{Zn}$ behavior are shown. Along trend $\mathrm{Y}, \mathrm{Zn}$ acts as a strongly upward-enriching element. CIPP rocks of this type include the San Francisco Peaks and Big Southern Butte. These are colinear with the Bandelier Tuff. Trend X connects the Big Pine and Olancha rocks and is roughly colinear with that of the Coso system, with which it may be connected. This type of trend, which also includes the Blackfoot domes, represents mild $\mathrm{Zn}$ up-enrichment during CIPP. The Bishop trend is developed in a continental margin system. This type of trend may be represented in the interior rocks by the Xalapasquillo

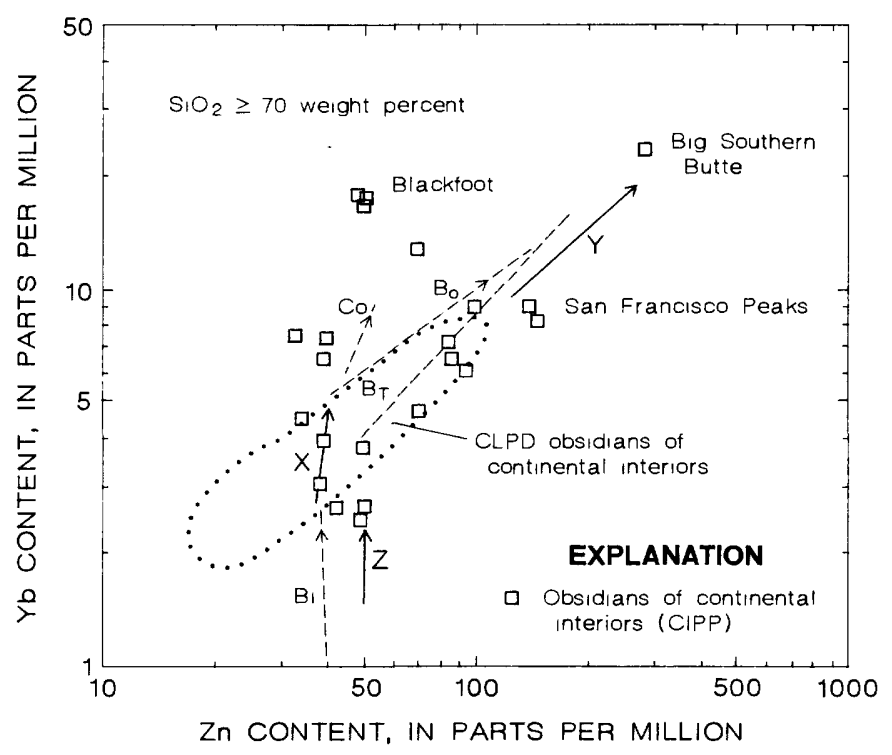

Figure 58.- $\mathrm{Zn}$ content versus $\mathrm{Yb}$ content showing possible effects of CLPD in CIPP silicic systems. Trends X, Y, and Z are discussed in text. Data from appendix I. Samples 145 and 160 are omitted to preserve scale. Dashed lines show CIPP system trends: Bishop Tuff, Bi (Hildreth, 1981); Bandelier Tuff, Otowi, $\mathbf{B}_{0}$, and Tshirege, $\mathbf{B}_{\mathrm{T}}$, Members (R.L. Smith, unpub. data); Coso Range, Co (Bacon and others, 1981). Arrows indicate direction of liquid fractionation. 
obsidians, Mexico, that is, trend $Z$ (fig. 58), which involves no significant $\mathrm{Zn}$ enrichment.

The reasons for the contrasting $\mathrm{Zn}$ behavior in different systems is not clear. Smith (1979) noted that $\mathrm{Zn}$ (along with lesser enrichments of $\mathrm{Zr}, \mathrm{Hf}$, and $\mathrm{La}$ ), after strong upward enrichment in the magma chamber preceding the eruptions of both Bandelier Tuff sheets, showed completely different concentration trends during the subsequent evolution of the Valles Rhyolite domes. He suggested that crystal fractionation of heavy minerals was probably involved as the thermal energy of the systems waned. Hildreth (1981) noted that strong partitioning of $\mathrm{Zn}$ into ferromagnesian phenocrysts relative to the coexisting liquid and crystal-liquid control superimposed on upward enrichment of $\mathrm{Zn}$ may explain $\mathrm{Zn}$ distribution.

The elements with which $\mathrm{Zn}$ shows strong $(>0.60)$ correlation fall into three groups: (1) $Y$ and the HREE, (2) Zr, Hf, Nd, and Sn, and (3) $\mathrm{Nb}$ and $\mathrm{Ta}$. Each correlation stresses different aspects of $\mathrm{Zn}$ behavior. Zinc shows good correlations (1) with $\mathrm{Y}$ and the HREE in CLPD obsidians and in those CIPP systems where it is an up-element, (2) with $\mathrm{Zr}$ and $\mathrm{Hf}$ in systems where it is a down-element and in CLPD rocks, and (3) with $\mathrm{Nb}$ and $\mathrm{Ta}$ in systems where it is an up-element and because all three have high abundances in obsidians of oceanic extensional zones.

\begin{tabular}{|c|c|}
\hline$r \geq 0.60$ & $\mathrm{Zn}_{\mathrm{n}}$ \\
\hline - & 0.74 \\
\hline n & 0.61 \\
\hline Zr - & 0.64 \\
\hline 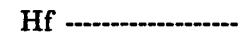 & 0.78 \\
\hline Y - & 0.75 \\
\hline Nd - & 0.65 \\
\hline $\mathrm{Sm}$ & 0.76 \\
\hline $\mathrm{Tb}$ & 0.78 \\
\hline Tm - & 0.68 \\
\hline Yb - & 0.68 \\
\hline ----.- & 0.67 \\
\hline
\end{tabular}

\section{ZIRCONIUM AND HAFNIUM}

The ranges of $\mathrm{Zr}$ and $\mathrm{Hf}$ abundances in the silicic obsidians are 22 to $860 \mathrm{ppm}$ and 1.3 to $21.8 \mathrm{ppm}$, respectively (fig. $40 M, N$ ). The spreads of $\mathrm{Zr}$ values in base-level rocks from mature island arcs, continental margins, and continental interiors are very similar, especially on a $\mathrm{SiO}_{2}$-normalized basis. The higher average value in the interior glasses reflects higher $\mathrm{SiO}_{2}$ contents (fig. $43 \mathrm{H}$ ). The comparability of $\mathrm{Zr}$ abundances in rocks from these tectonic settings precludes its use as a tectonomagmatic indicator. The situation for Hf is slightly different. Abundances in obsidians from mature island arcs and continental margins are similar but are higher in continentalinterior types, resulting in lower $\mathrm{Zr} / \mathrm{Hf}$ ratios (table 7; fig. 59A). Both $\mathrm{Zr}$ and $\mathrm{Hf}$ are relatively enriched in obsidians from oceanic extensional zones, on a $\mathrm{SiO}_{2}$-normalized basis and in terms of averages (table 7).

Within-group variations in $\mathrm{Zr}$ and $\mathrm{Hf}$ contents are substantial, commonly a factor of 4 at a given $\mathrm{SiO}_{2}$ value. Concentrations of both elements are very sensitive to small amounts of zircon fractionation and,

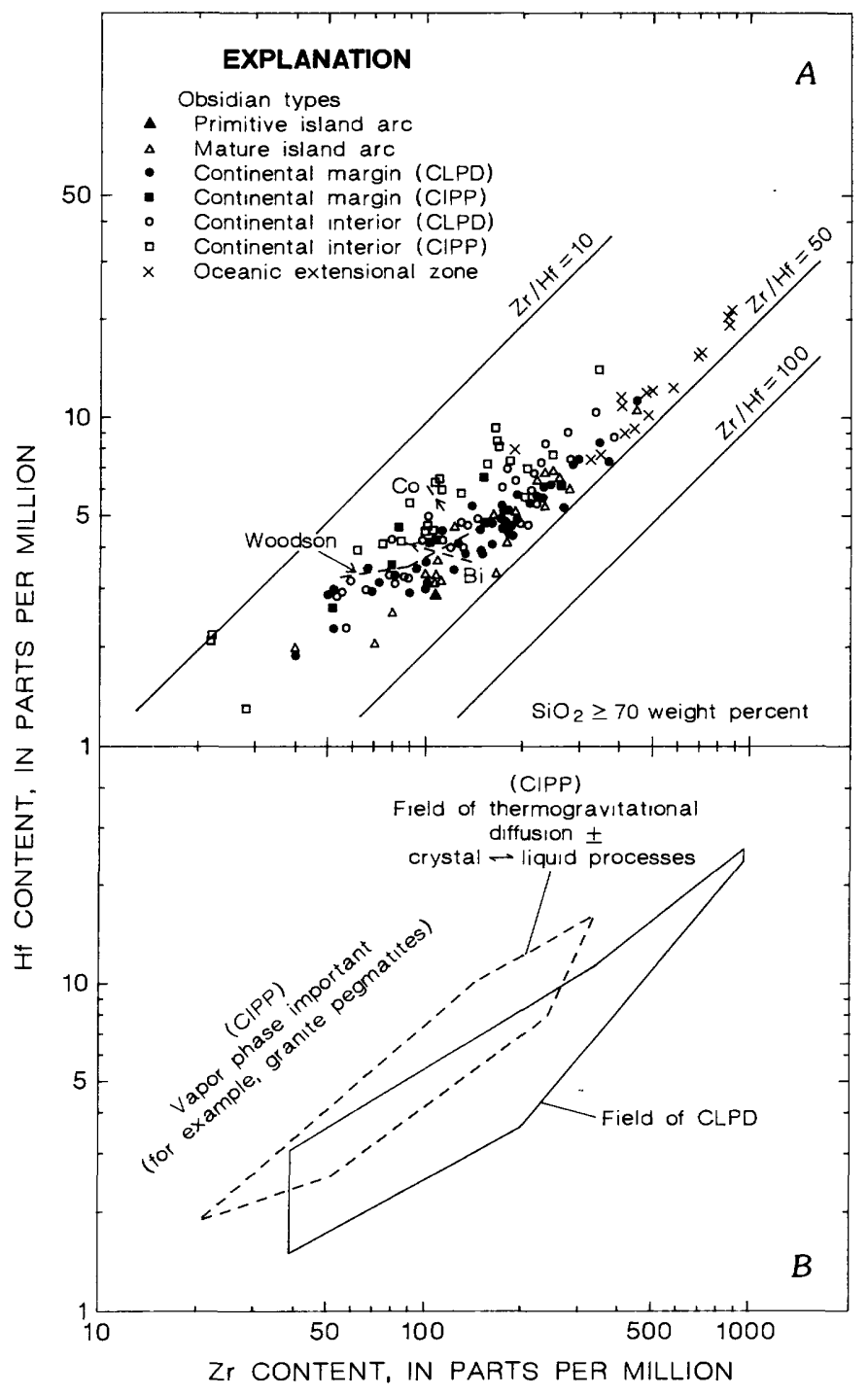

Figure 59. $-\mathrm{Zr}$ content versus $\mathrm{Hf}$ content for $(A)$ obsidians and various comparative rocks. Data sources are same as for figure 5. Dashed lines indicate CIPP systems: Bishop Tuff, Bi (Hildreth, 1981); Coso Range, Co (Bacon and others, 1981). Arrows indicate direction of liquid fractionation. $B$, Fields of thermogravitational diffusion and CLPD showing that CIPP forms a link between crystal-liquid processes and hydrothermal activity. 
given the common occurrence of zircon microphenocrysts in the obsidians (app. VI, VII), this may be a partial explanation of the spreads.

Data from rock-glass pairs in rocks with less than 74 percent $\mathrm{SiO}_{2}$ show only small changes in $\mathrm{Zr}$ and Hf concentrations, but there is greater $\mathrm{Zr}$ depletion in the glasses where the rocks have $\mathrm{SiO}_{2}$ greater than 74 percent $\mathrm{SiO}_{2}$. The Woodson granodiorite stock shows an overall depletion of $\mathrm{Zr}$ in more fractionated rocks and a less" strong depletion in $\mathrm{Hf}$, such that the $\mathrm{Zr} / \mathrm{Hf}$ ratio becomes progressively lower in more silicic samples.

The behavior of $\mathrm{Zr}$ and $\mathrm{Hf}$ during CIPP is complex. In the Bishop Tuff, $\mathrm{Zr}$ was depleted in roof-zone magmas, an effect unrelated to zircon fractionation (Hildreth, 1979).

Hafnium, on the other hand, showed no clear enrichment up or down. In the Coso system, Hf was an up-element, $\mathrm{Zr}$ a down-element (Bacon and others, 1981). Bulk rock data for the Bandelier Tuff indicate that $\mathrm{Zr}$ was a down-element. Analyses of glass separates show that $\mathrm{Zr}$ actually concentrated upward in the liquids (R.L. Smith, unpub. data). Apparently, zircon fractionation was being superimposed on upward concentration of $\mathrm{Zr}$ by CIPP.

If zircon is the major phase fractionating $\mathrm{Zr}$ and $\mathrm{Hf}$ in CIPP systems, its efficiency will be reduced in more alkalic systems due to increased solubility in the melt. The relative influences of crystal-liquid fractionation and CIPP on $\mathrm{Zr}$ and $\mathrm{Hf}$ distributions in CIPP systems may depend in part on the alkalinity of the melts.

The fractionation of $\mathrm{Zr}$ from $\mathrm{Hf}$ during CIPP in high-level silicic systems and in the transition from continental-margin- to continental-interior-type crusts is apparent in the lists of elements for which each shows strong $(r>0.60)$ correlations. The upward-concentrating nature of $\mathrm{Hf}$ means that it has less significant correlations with $\mathrm{SiO}_{2}$ (negative) and $\mathrm{FeO}$ (positive) and more significant correlations with $\mathrm{Y}$ and the HREE. The higher correlation coefficient for $\mathrm{Na}_{2} \mathrm{O}-\mathrm{Zr}, 0.64$, as opposed to 0.59 for $\mathrm{Na}_{2} \mathrm{O}$ $\mathrm{Hf}$, initially appears anomalous, because both $\mathrm{Na}$ and $\mathrm{Hf}$ are up-elements. The slight difference is probably caused by the enrichment of $\mathrm{Hf}$ relative to $\mathrm{Zr}$ in continental-interior rocks while $\mathrm{Na}_{2} \mathrm{O}$ decreases.

Both $\mathrm{Zr}$ and $\mathrm{Hf}$ show strong correlations with $\mathrm{FeO}_{\mathrm{t}}$, and a $\mathrm{Zr}-\mathrm{FeO}$ plot (fig. 60) is a useful way of summarizing $\mathrm{Zr}$ distribution in the rhyolites. Obsidians of primitive island arcs have $\mathrm{Zr}$ contents that overlap the lower to middle ranges of $\mathrm{Zr}$ abundances in the rhyolites of mature island arcs but that have distinctly higher $\mathrm{Fe} / \mathrm{Zr}$ ratios. The calcic rhyolites of the mature island arcs have $\mathrm{Fe} / \mathrm{Zr}$ ratios intermedi- ate to those of the calc-alkalic types. These latter rocks and CLPD rocks from the continental margins and interiors overlap almost completely on the $\mathrm{Zr}$ $\mathrm{FeO}_{\mathrm{t}}$ plot, but rhyolites of oceanic extensional zones have a lower average ratio, indicating relative $\mathbf{Z r}$ enrichment.

The broad, positive correlation between $\mathrm{FeO}_{\mathrm{t}}$ and $\mathrm{Zr}$ in CLPD obsidians has been noted earlier, in connection with $\mathrm{Fe}, \mathrm{Na}$, and $\mathrm{Cl}$ distributions. The positive relation is maintained by the trend of the Woodson granodiorite stock but only by some of the rock-glass pairs; several tieline orientations are present. Such within-group differences obviously contribute to the scatter of base-level data in this plot.

As discussed above, $\mathrm{Zr}$ and Fe behavior in CIPP systems is complex. No marked fractionation of $\mathrm{Zr}$ and $\mathrm{Fe}$ was achieved in the erupted parts of the Bishop and Coso systems. The tendency of CIPP rocks to plot to the Zr-rich side of the CLPD field is perhaps an indication, that in at least some systems, $\mathrm{Zr}$ is concentrated upward. In contrast, the CIPP rocks that plot on the Zr-poor side of the Woodson trend (fig. 60) must either have been derived from unusual base-level melts or underwent $\mathrm{Zr}$ depletion relative to $\mathrm{Fe}$, probably by zircon fractionation.

\begin{tabular}{|c|c|c|}
\hline$r \geq 0.60$ & $\mathbf{Z r}$ & Hf \\
\hline $\mathrm{SiO}_{2}$ & -0.66 & - \\
\hline $\mathrm{Fe}_{2} \mathrm{O}_{3}$ & 0.61 & - \\
\hline $\mathrm{FeO}$ & $0.81 \ldots$ & 0.73 \\
\hline $\mathrm{FeO}_{\mathrm{t}}$ & $0.83 \ldots$ & 0.75 \\
\hline $\mathrm{Na}_{2} \mathrm{O}$ & 0.64 & - \\
\hline Zn & 0.64 & 0.78 \\
\hline $\mathrm{Zr} \ldots$ & 1.00 & 0.94 \\
\hline Hf - & 0.94 & 1.00 \\
\hline -.......- & - -..... & 0.63 \\
\hline -..-.-.-.-. & $0.60 \ldots$ & 0.61 \\
\hline $\mathrm{Ce}$ - & 0.64 & 0.68 \\
\hline $\mathrm{Nd}-$ & 0.74 & 0.80 \\
\hline - & 0.72 & 0.83 \\
\hline -..-...-...- & 0.85 & 0.73 \\
\hline - & - - -... & 0.60 \\
\hline -...... & $-\cdots$ & 0.73 \\
\hline
\end{tabular}

Zr/Hf RATIOS

There are systematic variations in $\mathrm{Zr} / \mathrm{Hf}$ ratios with regard to tectonic setting and genetic process (fig. 61). The highest average ratio (41) is found in the obsidians of oceanic extensional zones. CLPD rocks from mature island arcs and continental margins have averages of 34.6 and 34.3, respectively, which are significantly higher than the value of 27 for CLPD 
continental-interior glasses. There is thus a negative relation between the $\mathrm{Zr} / \mathrm{Hf}$ ratio of rhyolites and the maturity of the crust in which they were emplaced.

Crystal-liquid processes, as exemplified by the Woodson trend and the tielines for rock-glass pairs, and CIPP both tend to produce lower $\mathrm{Zr} / \mathrm{Hf}$ ratios in more evolved (lower temperature) liquids. Very low
$\mathrm{Zr} / \mathrm{Hf}$ ratios of less than 20 can be achieved by both mechanisms. In this context, it is important to note that these low values overlap those found in granitic pegmatite bodies (Klemic and others, 1973), which we see as having formed during the lower temperature, vapor-dominated stages of the CIPP continuum (figs. 27, 59B).

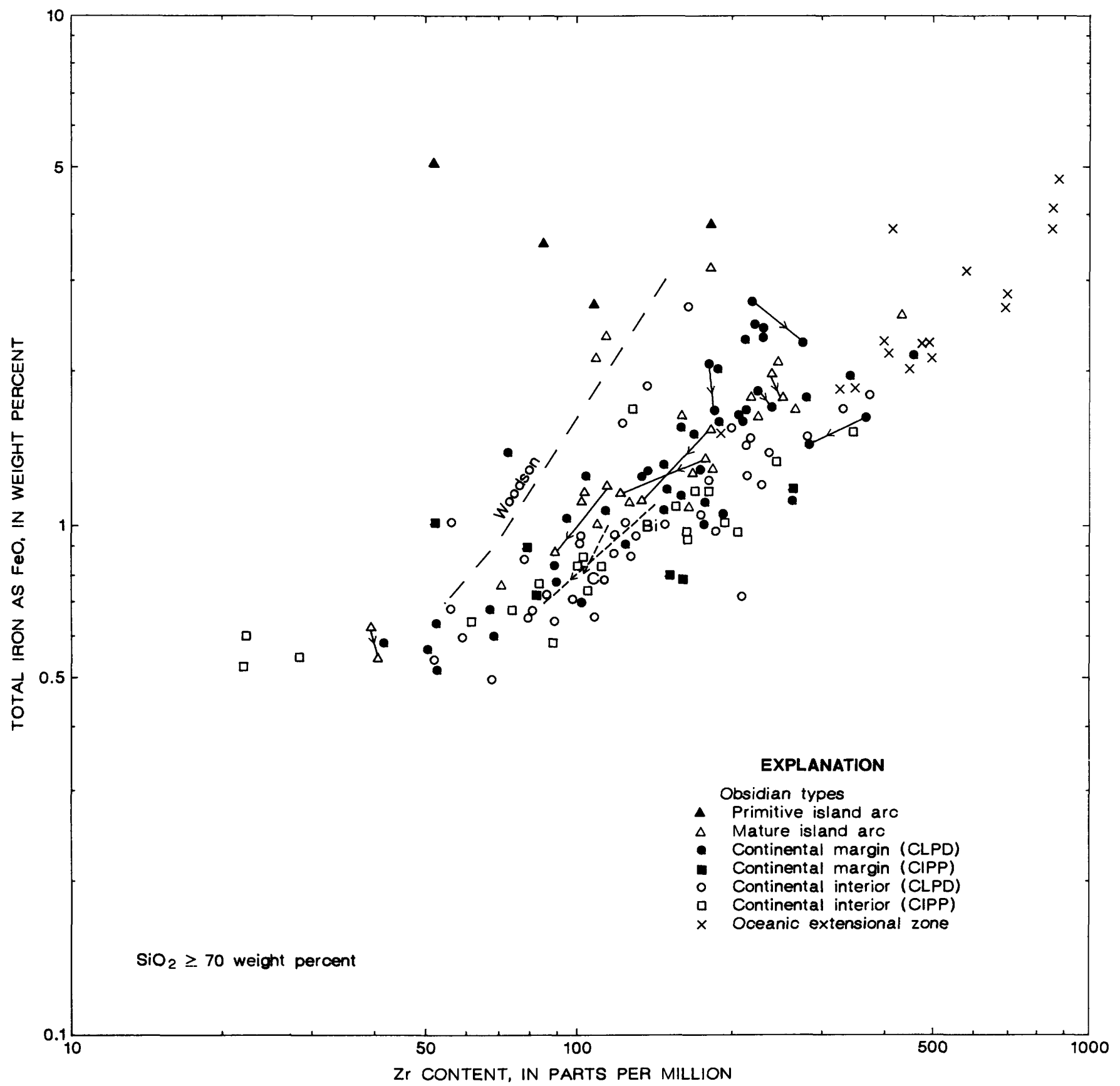

Figure 60.- Zr content versus total iron as $\mathrm{FeO}$ for obsidians and comparative rocks. Data sources are same as for figure 5 . Solid tielines represent rock-glass pairs, arrows point toward glass separate. Dashed lines represent CIPP systems: Bishop Tuff, Bi (Hildreth, 1981); Coso Range, Co (Bacon and others, 1981). Arrows indicate direction of liquid fractionation. 


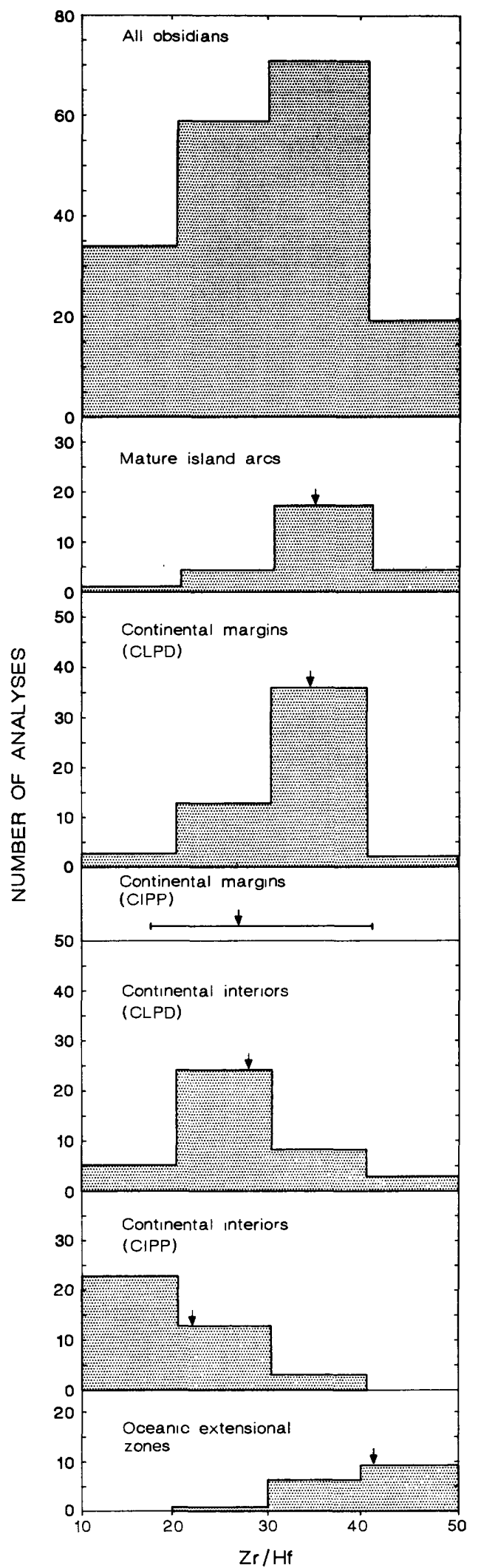

FIGURE 61.-Distribution of $\mathrm{Zr} / \mathrm{Hf}$ ratio in obsidians. Obsidians of continental margins (CIPP types) are shown as ranges only. Arrows indicate average values. Data from appendix I.

\section{RARE-EARTH ELEMENTS AND YTTRIUM}

The established procedure is to discuss $\mathrm{Y}$ with the HREE (Herrmann, 1970) and is fully justified for the rhyolites by the near-perfect correlation of $\mathrm{Y}$ and the HREE (app. VI). Ranges and averages in the different rhyolite groups are presented in tables 7-9 and summarized in table 15. For the sake of simplicity, $\mathrm{Ce}$ and $\mathrm{Yb}$ are used to show variations in the LREE and HREE, respectively, in the following discussion, whereas $\mathrm{Eu}$ is treated separately.

The greatest REE abundances occur in the obsidians of oceanic extensional zones. As a group, they are marked by LREE enrichment, between 100 and 300 times chondritic. $\mathrm{Ce}_{\mathrm{N}} / \mathrm{Yb}_{\mathrm{N}}$ ratios range from 2.2 to 6.0 , the lowest values found in the rocks from the Salton Sea (Nos. 73-75). There are marked negative $\mathrm{Eu}$ anomalies (average $\mathrm{Eu} / \mathrm{Eu}^{*}=0.48$ ).

In contrast, the lowest REE abundances occur in the obsidians of primitive island arcs. The chondrite-normalized pattern is characteristically flat $\left(\mathrm{Ce}_{\mathrm{N}} / \mathrm{Yb}_{\mathrm{N}} \sim 1\right)$ and, with the exception of a sample from Fiji (app. V, sample $H$ ), the Eu anomaly is either absent or negative and small.

There is a transition from early arc REE character to that in obsidians of mature island arcs. Masuda and others (1975) present data on a calcic rhyolite from Mashu, Hokkaido, which has a flat pattern, with $\mathrm{Ce}_{\mathrm{N}} / \mathrm{Yb}_{\mathrm{N}}<1$ and no Eu anomaly (fig. 62). A similar pattern has been recorded for a calcic rhyolite from Honsyu by Yajima and others (1972). The analyzed specimens in the data bank are slightly more fractionated: the average $\mathrm{Ce}_{\mathrm{N}} / \mathrm{Yb}_{\mathrm{N}}$ value is 1.97, and there is a distinct negative $\mathrm{Eu}$ anomaly $(\mathrm{Eu} / \mathrm{Eu}$ avg=0.64).

Such patterns are themselves transitional to the calc-alkalic rocks of mature island arcs, marked by increased LREE enrichment, to 60 times chondritic, higher $\mathrm{Ce}_{\mathrm{N}} / \mathrm{Yb}_{\mathrm{N}}$ values (average 2.75), and larger negative $\mathrm{Eu}$ anomalies (average $\mathrm{Eu} / \mathrm{Eu}^{*}=0.46$ ).

An increasingly fractionated stage is represented by the CLPD rocks of the continental margins. Although there is considerable overlap in REE abundances with the arc rocks, the average obsidian has a higher $\mathrm{Ce}_{\mathrm{N}} / \mathrm{Yb}_{\mathrm{N}}$ ratio (4.46) but a similar $\mathrm{Eu}$ deficiency $\left(\mathrm{Eu} / \mathrm{Eu}^{*}=0.43\right)$. CLPD obsidians of the continental interiors show an even more fractionated character, with higher average LREE abundances $\left(\mathrm{Ce}_{\mathrm{N}}\right.$ up to 209), increased LREE enrichment (average $\mathrm{Ce}_{\mathrm{N}} / \mathrm{Yb}_{\mathrm{N}}=5.08$ ), and a very substantial negative $\mathrm{Eu}$ anomaly $\left(\mathrm{Eu} / \mathrm{Eu}^{*}=0.20\right)$. There are also larger ranges of these values within the group.

The transition from primitive island arc to cratonic continental interior involves, therefore, (1) increasing LREE enrichment, (2) increasing development of 
TABLE 15.-Rare-earth element characteristics of obsidians

\begin{tabular}{|c|c|c|c|c|c|c|}
\hline \multirow{2}{*}{ Obsidian group } & \multicolumn{2}{|c|}{$\mathrm{Ce}_{\mathrm{N}}^{+}$} & \multicolumn{2}{|c|}{$\mathrm{Ce}_{\mathrm{N}} / \mathrm{Yb}_{\mathrm{N}}$} & \multicolumn{2}{|c|}{$\mathbf{E u} / \mathbf{E u}^{*}$} \\
\hline & Range & Average & Range & Average & Range & Average \\
\hline $\begin{array}{l}\text { Primitive island arcs } \\
\text { Mature island arcs }\end{array}$ & $13-26$ & 19 & $0.7-1.7$ & 1.3 & $0.38-0.97$ & 0.74 \\
\hline $\begin{array}{l}\text { Calcic - } \\
\text { Calc alkalic }\end{array}$ & $\begin{array}{l}28-49 \\
19-90\end{array}$ & $\begin{array}{l}36 \\
52\end{array}$ & $\begin{array}{l}1.5-3.3 \\
1.8-5.6\end{array}$ & $\begin{array}{l}1.9 \\
2.8\end{array}$ & $\begin{array}{l}.53-0.75 \\
.20-0.78\end{array}$ & $\begin{array}{l}.62 \\
.46\end{array}$ \\
\hline Continental margins & & & & & & \\
\hline $\begin{array}{l}\text { CLPD } \\
\text { CIPP }\end{array}$ & $\begin{array}{c}20-161 \\
47-81\end{array}$ & $\begin{array}{l}58 \\
58\end{array}$ & $\begin{array}{r}1.7-52 \\
1.1-4.2\end{array}$ & $\begin{array}{l}4.4 \\
2.5\end{array}$ & $\begin{array}{l}.10-0.75 \\
.04-0.18\end{array}$ & $\begin{array}{l}.43 \\
.12\end{array}$ \\
\hline Continental interiors & & & & & & \\
\hline 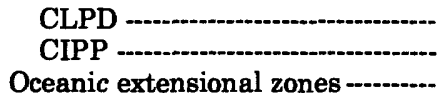 & $\begin{array}{c}20-210 \\
3-150 \\
89-200\end{array}$ & $\begin{array}{r}95 \\
55 \\
148\end{array}$ & $\begin{array}{l}2.4-27 \\
.55-4.9 \\
2.0-6.0\end{array}$ & $\begin{array}{l}5.1 \\
1.5 \\
3.6\end{array}$ & $\begin{array}{l}.05-0.56 \\
.01-0.24 \\
.32-6.8\end{array}$ & $\begin{array}{l}.20 \\
.04 \\
.48\end{array}$ \\
\hline
\end{tabular}

${ }^{+} \mathrm{N}$ indicates chondrite normalized value

negative Eu anomalies, and (3) increasing ranges within groups.

Data for rock-glass pairs indicate slight enrichment of $\mathrm{Ce}$ and $\mathrm{Yb}$ in rocks with $\mathrm{SiO}_{2}$ less than 75 percent. The data for this part of the Woodson granodiorite compositional range are so scattered that a meaningful trend cannot be drawn. At the

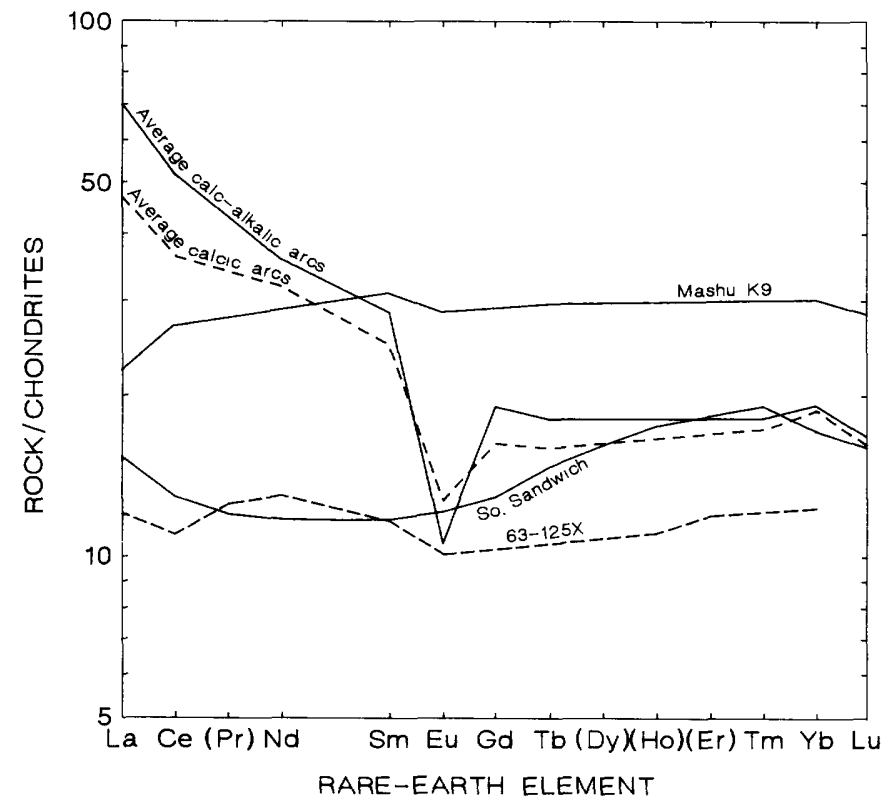

Figure 62.-Chondrite-normalized rare-earth-element patterns for rhyolites of island arcs. Data sources: South Sandwich pumice (app. II, No. 220); Mashu K9, dacite, Mashu Volcano, Hokkaido (Masuda and others, 1975); 63-125X, alkali-poor dacite, Louisehoj Formation, St. Thomas (Donnelly and Rogers, 1980, fig. 5). Averages of obsidians from island arcs (table 8). Chondrite rare-earth-element values from Haskin and others (1968). Rare-earth elements in parentheses are not used in construction of curves, owing to lack of data.
high-SiO end, $\mathrm{Ce}$ is depleted rapidly with increasing fractionation. Ce depletion is also shown in the Okushiri glass (Nos. 186, 187). In high-SiO ${ }_{2}$ CLPD rocks, LREE depletion is probably achieved by fractionation of accessory phases such as monazite and allanite (see Miller and Mittlefehldt, 1982; Mittlefehldt and Miller, 1983, for review).

Analyses of the rock-glass pairs and the Woodson rocks show slight depletion of $\mathrm{Eu}$ in the residual liquids of rocks with $\mathrm{SiO}_{2}$ less than 75 percent but very strong depletion in more $\mathrm{SiO}_{2}$-rich rocks. The Eu depletion presumably reflects plagioclase control, either during crystal fractionation or as a residual phase during melting of the source rocks.

CIPP has a striking and characteristic effect on REE distribution. The LREE are down-elements and the HREE up-elements, the cross-over point being between $\mathrm{Nd}$ and $\mathrm{Sm}$ (fig. 63). Eu is highly depleted. The chondrite-normalized patterns thus tend toward being dagger-shaped, flat with a substantial negative $\mathrm{Eu}$ anomaly. The $\mathrm{Ce} / \mathrm{Yb}$ ratios are notably lower than in CLPD rocks of the same rhyolite group. In individual CIPP systems, the magnitude of the Eu anomaly increases strongly and almost linearly with decreasing $\mathrm{Ce} / \mathrm{Yb}$ ratio (Hildreth, 1981, fig. 8). The relation between $\mathrm{Ce} / \mathrm{Yb}$ and $\mathrm{Eu} / \mathrm{Eu}^{*}$ in CIPP obsidians is scattered because of within-group variations in REE abundances, but is still positive (fig. 64).

Within-group variations in the REE are substantial; at constant $\mathrm{SiO}_{2}, \mathrm{Ce}$ and $\mathrm{Yb}$ can vary by a factor of 4-5 in CLPD rocks. In a gross way, the LREE are highest in those rocks with relatively high $\mathrm{FeO}_{t}, \mathrm{Zr}$, and $\mathrm{Hf}$, such as the Yellowstone obsidians and rhyolites of oceanic extensional zones. The HREE from Tb-Lu do not show this affiliation, their strongest correlations $(r>0.60)$ being with $\mathrm{Nb}, \mathrm{Ta}, \mathrm{Be}, \mathrm{F}, \mathrm{Sn}$, and $\mathrm{Zn}$. The correlation with those elements (table 


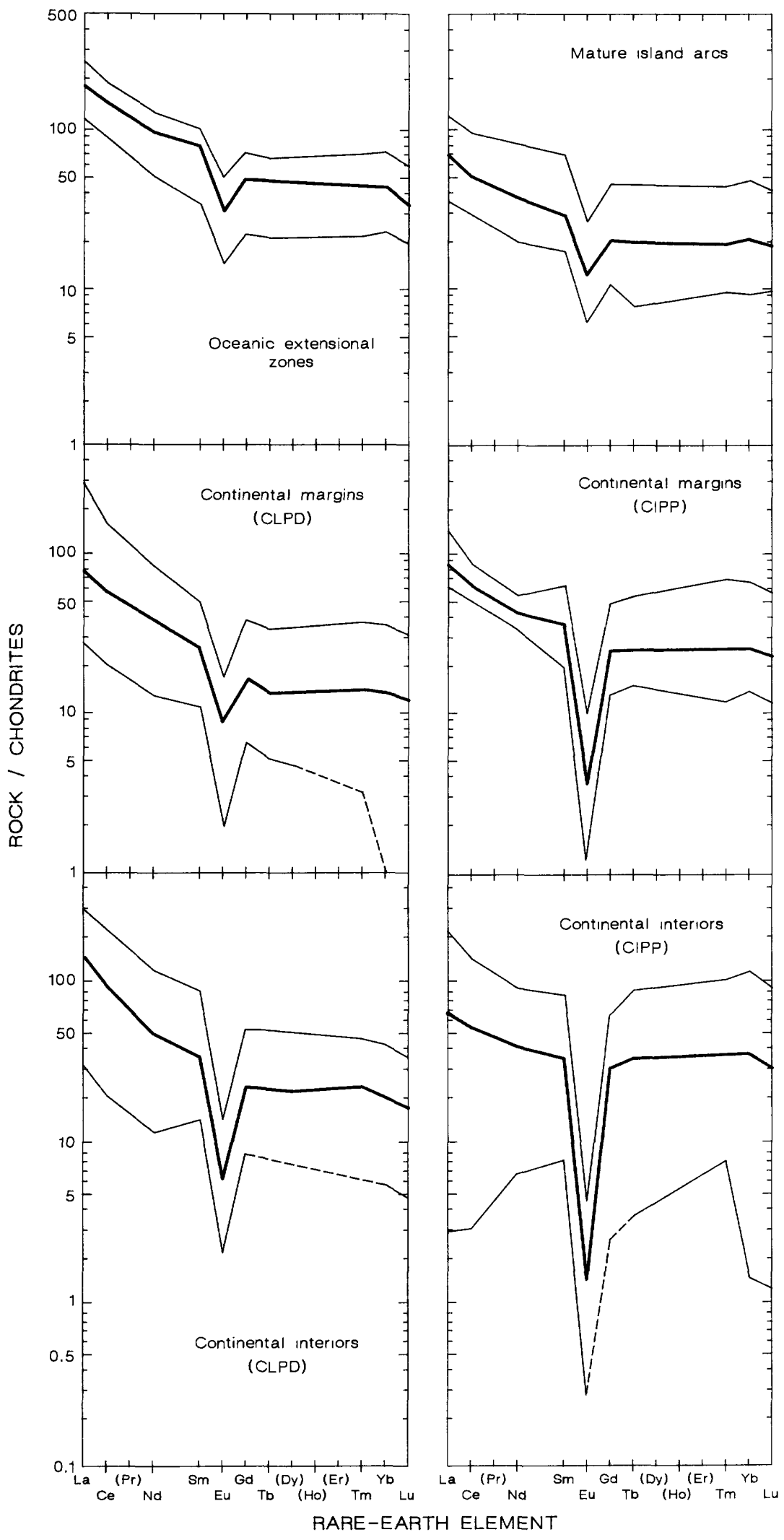

FIGURE 63.-Chondrite-normalized rare-earth-element (REE) patterns for obsidians of various obsidian groups (dashed where uncertain). Range is indicated by lighter lines and average by heavier line in each case. Dashed lines indicate uncertainty. Chondrite REE values from Haskin and others (1968). 
16) reflects the fact that they are all up-elements during CIPP, perhaps indicating a control by $F$ complexing.

The large within-group variations of the REE leads to extensive overlap of between-group abundances, such that it is difficult to ascribe individual specimens or groups of specimens to a rhyolite group on this basis alone. The chondrite-normalized patterns are rather distinctive, however, and as REE are relatively stable during crystallization and secondary hydration of silicic rocks, the patterns may well be of use in defining the tectonic setting of such rocks and (or) the genetic mechanisms operative on them.

\section{SUMMARY OF GEOCHEMICAL BEHAVIOR}

The foregoing discussion revealed that the distribution of each element in the subalkalic silicic obsidians is controlled by a combination of genetic and source-rock effects. Table 17 presents an attempt to quantify some of these effects. Between-group and within-group differences are estimated on $\mathrm{SiO}_{2}$ normalized bases. The crystal-liquid and CIPP terms crudely refer to amounts of change of abundance of each element related to each mechanism.

The discussion has also suggested that the elements can be broadly divided into three groups:

1. $\mathrm{Al}_{2} \mathrm{O}, \mathrm{MgO}, \mathrm{CaO}, \mathrm{TiO}_{2}, \mathrm{P}_{2} \mathrm{O}_{5}, \mathrm{Co}, \mathrm{Sc}$, and $\mathrm{Sr}$, each showing strong $(r>0.60)$ positive correlations with each other and negative correlations with $\mathrm{SiO}_{2}$, $\mathrm{K}_{2} \mathrm{O}$, and $\mathrm{Rb}$. These elements are all modestly to strongly fractionated during crystal-liquid processes

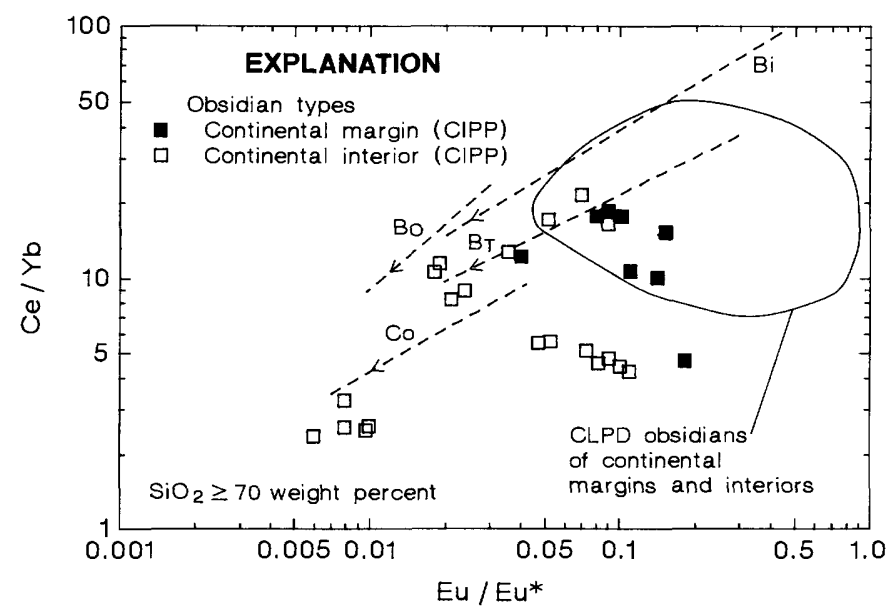

FiguRe 64.-Ratio of $\mathrm{Eu} / \mathrm{Eu}^{*}$ versus ratio of $\mathrm{Ce} / \mathrm{Yb}$ for CIPP obsidians. $\mathrm{Eu}^{*}$ is $\mathrm{Eu}$ value predicted from a smooth $\mathrm{REE}$ pattern, and $\mathrm{Eu} / \mathrm{Eu}^{*}$ is a measure of $\mathrm{Eu}$ anomaly. Data sources are same as for figure 5. Dashed lines represent CIPP systems: Bishop Tuff, Bi (Hildreth, 1981); Bandelier Tuff, Otowi, $B_{o}$, and Tshirege, $B_{T}$ Members (R.L. Smith, unpub. data); Coso Range, Co (Bacon and others, 1981). Arrows indicate direction of liquid fractionation.

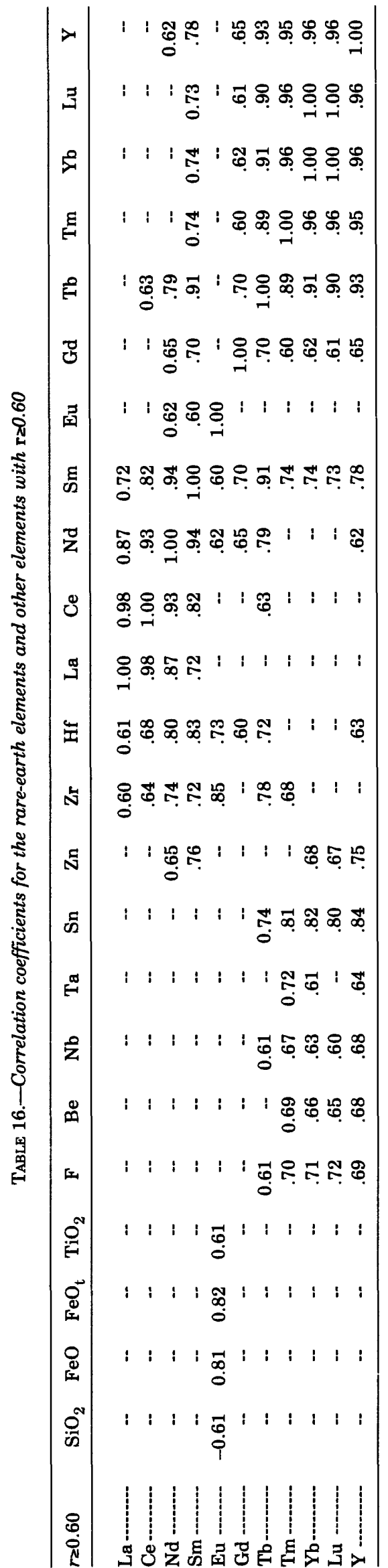


TABLE 17.-Attempt to isolate, for each element, those factors causing compositional variations in the obsidians, on a $\mathrm{SiO}_{2}-$ normalized basis

[Question marks denote uncertainty, usually due to quality of analytical data. Abbreviations: PIA, primitive island arcs; C-MIA, calcic obsidians of mature island arcs; C-A-MIA, calc-alkalic obsidians of mature island arcs; CM, continental margins; CI, continental interiors; $\mathrm{OE}$, oceanic extensional zones]

\begin{tabular}{|c|c|c|c|c|c|}
\hline Element & $\begin{array}{c}\text { Total } \\
\text { concentration } \\
\text { range }\end{array}$ & $\begin{array}{l}\text { Maximum } \\
\text { range } \\
\text { within-group }\end{array}$ & $\begin{array}{l}\text { Variation } \\
\text { due to } \\
\text { tectonic setting }\end{array}$ & $\begin{array}{l}\text { Variation } \\
\text { related to } \\
\text { CLPD }\end{array}$ & $\begin{array}{l}\text { Variation } \\
\text { related to } \\
\text { CIPP }\end{array}$ \\
\hline $\mathrm{Al}_{2} \mathrm{O}_{3} \ldots$ & 0.4 & 0.1 & $\mathrm{PLA}+\mathrm{OE}<\mathrm{MIA}+\mathrm{CM}+\mathrm{CI}$ & Slight & Slight \\
\hline $\mathrm{FeO}_{\mathrm{t}}$ & $\times 10$ & $\times 3-4$ & $\mathrm{PLA}+\mathrm{OE}>\mathrm{C}-\mathrm{MIA}>\mathrm{C}-\mathrm{A}-\mathrm{MIA}+\mathrm{CM}+\mathrm{CI}$ & Slight & Modest \\
\hline MgO -........ & $\times 10^{3}$ & $x<10$ & $\mathrm{PLA}+\mathrm{C}-\mathrm{MIA}>\mathrm{CM}+\mathrm{CI}$ & Very strong & Very strong \\
\hline $\mathrm{CaO}$ & $\times 30$ & $\times 2-3$ & $\mathrm{PLA}+\mathrm{MIA}>\mathrm{CM}+\mathrm{CI}$ & Very strong & Very strong \\
\hline $\mathrm{Na}_{2} \mathrm{O}$ & $\times 2$ & $\times 2$ & Little & Modest & Strong \\
\hline $\mathrm{K}_{2} \mathrm{O} \ldots \ldots$ & $\times 5$ & $\times 1.5-2$ & $\mathrm{PIA}<\mathrm{MIA}<\mathrm{CM}+\mathrm{CI}$ & Modest & Slight \\
\hline $\mathrm{TiO}_{2}$ & $\times 45$ & $x 4$ & $\mathrm{MIA}>\mathrm{CM}+\mathrm{Cl}$ & Strong & Strong \\
\hline $\mathrm{P}_{2} \mathrm{O}_{5}$ & $10^{2}$ & $\times 10$ & Modest strong & Strong & \\
\hline MnO -........ & $\times 10$ & $5-10$ & None & Modest $\rightarrow$ strong & Strong \\
\hline Cl--..-.-.-.-- & $\times 10$ & $\times 3$ & $\mathrm{OE}>\mathrm{MIA}>\mathrm{CM}+\mathrm{CI}$ & Modest & Modest \\
\hline F - - & $\times 30$ & $\times 3$ & $\mathrm{OE}>\mathrm{CI}>\mathrm{CM}+\mathrm{MIA}$ & Modest & Modest $\rightarrow$ very strong \\
\hline $\mathrm{Ba}$ & $\times 10^{3}$ & $\times 2$ & $\mathrm{PIA}<\mathrm{C}-\mathrm{MIA}<\mathrm{C}-\mathrm{A}-\mathrm{MIA}<\mathrm{CM}<\mathrm{CI}$ & Low & Very strong \\
\hline Co - -..-.-.-- & $\times 40$ & $?$ & None? & Strong & Strong \\
\hline Cs - -.......... & $\times 20$ & $8-9$ & $\mathrm{PIA} ?<\mathrm{MIA}+\mathrm{CM}+\mathrm{CI}<\mathrm{OE}$ & Modest & Strong \\
\hline $\mathrm{Nb}, \mathrm{Ta} \ldots$ & $\times 400$ & $\times 2$ & $\mathrm{PIA}<\mathrm{MIA}<\mathrm{CM}<\mathrm{CI}$ & Slight & Strong \\
\hline $\mathrm{Pb}$ & $\times 25$ & $\times 2-3$ & $\mathrm{IA}<\mathrm{CM}+\mathrm{MIA}+\mathrm{CI}$ & Modest & Strong \\
\hline Rb - - -......... & $\times 75$ & $\times 2$ & $\mathrm{PIA}<\mathrm{MIA}+\mathrm{CM}<\mathrm{CI}$ & Modest & Strong \\
\hline $\mathrm{Sb}$ & $\times 10$ & $?$ & $\mathrm{OE}+\mathrm{CI}<\mathrm{CM}+\mathrm{MIA} ?$ & $?$ & Modest $\rightarrow$ strong? \\
\hline Sc -........- & $\times 20$ & $\times 4$ & $\mathrm{MIA}>\mathrm{CM}+\mathrm{CI}$ & Strong & Modest \\
\hline Sr - & $\times 10^{3}$ & $\times 3-4$ & $\mathrm{PIA}<\mathrm{MIA}+\mathrm{CM}<\mathrm{CI}$ & Strong & Very strong \\
\hline Th, U -...-.-- & $\times 80$ & $\times 3-4$ & $\mathrm{PIA}<\mathrm{C}-\mathrm{MIA}<\mathrm{C}-\mathrm{A}-\mathrm{MIA}<\mathrm{CM}<\mathrm{CI}$ & Modest & Strong \\
\hline Zn -...-....... & $\times 35$ & $\times 4$ & $\mathrm{OE}>\mathrm{MIA}+\mathrm{CM}+\mathrm{CI}$ & Modest & Modest \\
\hline \multirow[t]{2}{*}{ Zr, Hf -...-... } & $\times 40$ & $\times 4$ & $\mathrm{Zr}: \mathrm{OE}>\mathrm{MIA}+\mathrm{CM}+\mathrm{CI}$ & Modest & Modest \\
\hline & & & Hf: $\mathrm{OE}>\mathrm{CI}>\mathrm{CM}+\mathrm{MIA}$ & Modest & \\
\hline LREE --..-- & $\times 10$ & $\times 7$ & $\mathrm{PIA}<\mathrm{C}-\mathrm{MIA}<\mathrm{C}-\mathrm{A}-\mathrm{MIA}<\mathrm{CM}<\mathrm{CI}<\mathrm{OE}$ & Modest $\rightarrow$ strong & Strong \\
\hline Eu - - & $\times 10$ & $\times 6$ & $\mathrm{MIA}>\mathrm{CM}>\mathrm{CI}$ & Strong & Strong \\
\hline HREE --..-.-- & $\times 20$ & $\times 6$ & $\mathrm{MIA}+\mathrm{CM}<\mathrm{CI}+\mathrm{OE}$ & Modest & Strong \\
\hline
\end{tabular}

and are, with the possible exception of Sc, downelements in CIPP systems.

2. Be, Sn, Li, W, Rb, Th, U, Pb, Nb, Ta, HREE, Y, and $F, \pm Z n$. These elements are all concentrated in residual liquids during crystal-liquid processes, are enriched in continental-interior rhyolites, as opposed to subduction-related rhyolites, and are up-elements in CIPP systems. This similarity has led to correlations greater than 0.60 between most pairs. The role of $\mathrm{F}$ may be especially important in this group. For example, the average $\mathrm{Be} / \mathrm{F}$ and $\mathrm{Sn} / \mathrm{F}$ ratios for each of the main rhyolite groups (excluding primitive island arcs, for which no data are available) lie within the narrow limits $0.0043 \pm 0.0008$ and $0.0044 \pm 0.0006$, respectively. A possible interpretation is that $\mathrm{Be}$ and Sn contents are directly related to the contents of $F$ in the magma, perhaps as a result of complexing, independently of the degree of crustal maturity.

(3) $\mathrm{FeO}_{t}, \mathrm{Na}_{2} \mathrm{O}, \mathrm{Cl}, \mathrm{Hf}, \mathrm{Zr}, \mathrm{LREE}$, and $\mathrm{Eu}, \pm \mathrm{Zn}$. Some of the correlation coefficients in this group are less than 0.60 , but, for each element, the highest correlations shown are usually for other members of the group. $\mathrm{Na}_{2} \mathrm{O}, \mathrm{Cl}, \mathrm{Hf}$, and $\mathrm{Zn}$ are usually up-elements, and the LREE and Eu down-elements, in CIPP subalkalic systems, whereas $\mathrm{FeO}_{\mathrm{t}}$ and $\mathrm{Zr}$ show controls by CIPP and crystal-liquid processes. Such dissimilar behavior contributes to the lowering of the values of the correlation coefficient. The most significant correlations between the members of this group are found in base-level compositions, and the controlling factor may be the presence of $\mathrm{Cl}$ acting as a ligand in halide complexes. 


\section{REFERENCES CITED}

Anderson, C.A., 1933, Volcanic history of Glass Mountain, northern California: American Journal of Science, v. 26, p. $485-506$.

1936, Volcanic history of the Clear Lake area, California: Geological Society of America Bulletin, v. 47, p. 629-664.

Aramaki, Shigeo, 1963, Geology of Asama Volcano: Tokyo University Faculty of Science Journal, Section II, v. 14, p. 229443.

Aramaki, Shigeo, and Haramura, Hiroshi, 1966, Leaching of $\mathrm{Na}_{2} \mathrm{O}$ from volcanic glasses during hydration: Journal of the Geological Society of Japan, v. 72, p. 69-73 [in Japanese, with English abstract].

Aruscavage, P.J., and Campbell, E.Y., 1978, Spectrophotometric determinations of tungsten in rocks by using zinc-dithiol: U.S. Geological Survey Journal of Research, 6, p. 697-699. 1981, Molybdenum content of 16 U.S. Geological Survey Standard Rocks: Geostandards Newsletter, vol. V, no. 2, p. 171-173.

Bacon, C.R., Kurasawa, Hajime, Delevaux, M.H., Kistler, R.W., and Doe, B.R., 1984, Lead and strontium isotopic evidence for crustal interaction and compositional zonation in the source regions of Pleistocene basaltic and rhyolitic magmas of the Coso volcanic field, California: Contributions to Mineralogy and Petrology, v. 85, p. 366-375.

Bacon, C.R., Macdonald, R., Smith, R.L., and Baedecker, P.A., 1981, Pleistocene high-silica rhyolites of the Coso volcanic field, Inyo County, California: Journal of Geophysical Research, v. 86, p. 10223-10241.

Bacon, C.R., and Metz, Jenny, 1984, Magmatic inclusions in rhyolites, contaminated basalts, and compositional zonation beneath the Coso volcanic field, California: Contributions to Mineralogy and Petrology, v. 85, p. 346-365.

Bailey, D.K., 1970, Volatile flux, heat-focusing and the generation of magma: Geological Journal Special Issue No. 2, p. $177-186$.

1974, Melting in the deep crust, in Sørensen, Henning, ed., The alkaline rocks: New York, John Wiley, p. 436-442.

-1980, Volcanism, Earth degassing and replenished lithosphere mantle: Philosophical Transactions of the Royal Society of London, ser. A, v. 297, p. 309-322.

Bailey, D.K., and Macdonald, R., 1970, Petrochemical variations among mildly peralkaline (comendite) obsidians from the oceans and continents: Contributions to Mineralogy and Petrology, v. 28, p. 340-351.

-1975 , Fluorine and chlorine in peralkaline liquids and the need for magma generation in an open system: Mineralogical Magazine, v. 40, p. 405-414.

Bailey, R.A., Dalrymple, G.B., and Lanphere, M.A., 1976, Volcanism, structure and geochronology of Long Valley caldera, Mono County, California: Journal of Geophysical Research, v. 81, p. $725-744$.

Baker, B.H., and McBirney, A.R., 1985, Liquid fractionation. Part III: Geochemistry of zoned magmas and the compositional effects of liquid fractionation: Journal of Volcanology and Geothermal Research, v. 24, p. 55-81.

Baker, P.E., 1972, Volcanism at destructive plate margins: Journal of Earth Science, Leeds, v. 8, p. 183-195.

1978, The South Sandwich Islands. III. Petrology of the volcanic rocks: British Antarctic Survey Scientific Report No. 93, p. $1-34$.

-1982, Evolution and classification of orogenic volcanic rocks, in Thorpe, R.S., ed., Andesites: Chichester, Wiley and Sons, p. 11-23.
Baldanza, B., Faraone, D., and Giaquinto, S., 1973, Isola di Vulcano: il complesso riolitico di Monte Lentia: Periodico di Mineralogia, v. 42, p. 113-172.

Barberi, F., Innocenti, F., Ferrara, G., Keller, J., and Villari, L., 1974, Evolution of Eolian arc volcanism, southern Tyrrhenian Sea: Earth and Plantetary Science Letters, v. 21, p. 269-276.

Barker, Fred, 1979, Trondhjemite: definition, environment and hypotheses of origin, in Barker, Fred, ed., Trondhjemites, dacites, and related rocks: Amsterdam, Elsevier, p. 1-12.

Barnes, V.E., Edwards, George, McLaughlin, W.A., Friedman, Irving, and Joensuu, Oiva, 1970, Macusanite occurrence, age, and composition, Macusani, Peru: Geological Society of America Bulletin, v. 81, p. 1539-1546.

Bateman, P.C., and Chappell, B.W., 1979, Crystallization, fractionation, and solidification of the Tuolumne Intrusive Series, Yosemite National Park, California: Geological Society of America Bulletin, v. 90, p. 465-482.

Belluomini, G., and Taddeucci, A., 1970, Studi sulle ossidiane italiane. I. Contenuto e composizione isotopica dell' uranio e del torio: Periodico di Mineralogia, v. 39, p. 387-395.

Belluomini, G., and Taddeucci, A., 1971, Studi sulle ossidiane italiane. III. Elementi minori: Periodico di Mineralogia, v. 40, p. $11-40$.

Bemmelen, R.W. van, and Rutten, M.G., 1955, Table Mountains of Northern Iceland: Leiden, E.J. Brill, $217 \mathrm{p}$.

Blattner, Peter, and Reid, Frank, 1982, The origin of lavas and ignimbrites of the Taupo Volcanic Zone, New Zealand, in the light of oxygen isotope data: Geochimica et Cosmochimica Acta, v. 46, p. 1417-1429.

Bowen, N.L., 1935, "Ferrosilite" as a natural mineral: American Journal of Science, 5 th Series, v. 30, p. 481-494.

Bowman, H.R., Asaro, F., and Perlman, I., 1973, On the uniformity of composition in obsidians and evidence for magmatic mixing: Journal of Geology, v. 81, p. 312-327.

Brown, G.C., 1979, The changing pattern of batholith emplacement during Earth history, in Atherton, M.P., and Tarney, John, eds., Origin of granite batholiths: Geochemical evidence: Orpington, Shiva Publishing, p. 106-115.

Brown, G.C., 1982, Calc-alkaline intrusive rocks: Their diversity, evolution, and relation to volcanic arcs, in Thorpe, R.S., ed., Andesites: Chichester, Wiley and Sons, p. 437-461.

Brown, G.C., Thorpe, R.S., and Webb, P.C., 1984, The geochemical characteristics of granitoids in contrasting arcs and comments on magma sources: Journal of the Geological Society of London, v. 141, p. 411-426.

Bryan, W.B., 1968, Low-potash dacite drift pumice from the Coral Sea: Geological Magazine, v. 105, p. 431-439.

1971, Coral Sea drift pumice stranded on Eua Island, Tonga, in 1969: Geological Society of America Bulletin, v. 82 , p. $2799-2812$.

- 1979, Low- $\mathrm{K}_{2} \mathrm{O}$ dacite from the Tonga-Kermadec island arc: Petrography, chemistry, and petrogenesis, in Barker, Fred, ed., Trondhjemites, dacites, and related rocks: Amsterdam, Elsevier, p. 581-600.

Byers, F.M., Jr., 1959, Geology of Umnak and Bogoslof Islands, Aleutian Islands, Alaska: U.S. Geological Survey Bulletin 1028-L, p. 267-369.

Cameron, Maryellen, Bagby, W.C., and Cameron, K.L., 1980, Petrogenesis of voluminous mid-Tertiary ignimbrites of the Sierra Madre Occidental, Chihuahua, Mexico: Contributions to Mineralogy and Petrology, v. 74, p. 271-284.

Campbell, E.Y., and Aruscavage, P.J., 1982, Molybdenum and tungsten contents of five CRPE and eight ANRT geochemical reference materials: Geostandards Newsletter, v. 6, no. 2, p. 229-231. 
Campbell, E.Y., and Simon, F.O., 1978. Atomic-absorption determination of beryllium in geological materials by use of electrothermal atomization. Talanta, v. 25, p. 251-255.

Cann, J.R., and Renfrew, Colin, 1964, The characterization of obsidian and its application to the Mediterranean region: Proceedings of the Prehistoric Society, v. 30, p. 111-133.

Carmichael, I.S.E., 1962, A note on the composition of some natural acid glasses: Geological Magazine, v. 99, p. 253264.

1967, The iron-titanium oxides of salic volcanic rocks and their associated ferromagnesian silicates: Contributions to Mineralogy and Petrology, v. 14, p. 36-64.

Cawthorn, R.G., Strong, D.F., and Brown, P.A., 1976, Origin of corundum-normative intrusive and extrusive magmas: $\mathrm{Na}$ ture, v. 259, p. 102-104.

Challis, G.A., 1971, Chemical analyses of New Zealand rocks and minerals with CIPW norms and petrographic descriptions: 1917-57. Part 1. Igneous and pyroclastic rocks: Geological Survey of New Zealand Bulletin 84, $178 \mathrm{p}$.

Chayes, Felix, 1970, On the occurrence of corundum in the norms of the common volcanic rocks: Carnegie Institution of Washington Yearbook 68, p. 179-182.

Christiansen, R.L., and Lipman, P.W., 1972, Cenozoic volcanism and plate tectonic evolution of the Western United States. II. Late Cenozoic: Philosophical Transactions of the Royal Society of London, ser. A, v. 271, p. 249-284.

Church, S.E., and Tilton, G.R., 1973, Lead and strontium isotopic studies in the Cascade Mountains: Bearing on andesite genesis: Geological Society of America Bulletin, v. 84, p. 431-454.

Coleman, P.J., 1975, On island arcs: Earth Science Reviews, v. 11, p. $47-80$.

Condie, K.C., and Hayslip, D.L., 1975, Young bimodal volcanism at Medicine Lake volcanic center, northern California: Geochimica et Cosmochimica Acta, v. 39, p. 1165-1178.

Condomines, M., Grönvold, K., Hooker, P.J., Muehlenbachs, K., O'Nions, R.K., Oskarsson, N., and Oxburgh, E.R., 1983, Helium, oxygen, strontium and neodymium isotopic relationships in Icelandic volcanics: Earth and Planetary Science Letters, v. 66, p. 125-136.

Coulon, Christian, and Thorpe, R.S., 1981, Role of continental crust in petrogenesis of orogenic volcanic associations: Tectonophysics, v. 77, p. 79-93.

Creasey, S.C., and Krieger, M.H., 1978, Galiuro Volcanics, Pinal, Graham, and Cochise Counties, Arizona: U.S. Geological Survey Journal of Research, v. 6, p. 115-131.

Crecraft, H.R., Nash, W.P., Evans, S.H., Jr., 1981, Late Cenozoic volcanism at Twin Peaks, Utah. Part 1. Geology and petrology: Journal of Geophysical Research, v. 86, p. 10303-10320.

DePaolo, D.J., and Farmer, G.L., 1984, Isotopic data bearing on the origin of Mesozoic and Tertiary granitic rocks in the Western United States: Philosophical Transactions of the Royal Society of London, ser. A, v. 310, p. 743-753.

DePaolo, D.J., and Johnson, R.W., 1979, Magma genesis in the New Britain island-arc: Constraints from $\mathrm{Nd}$ and $\mathrm{Sr}$ isotopes and trace-element patterns: Contributions to Mineralogy and Petrology, v. 70, p. 367-379.

Diller, J.S., and Patton, H.B., 1902, The geology and petrography of Crater Lake National Park: U.S. Geological Survey Professional Paper 3, $167 \mathrm{p}$.

Doe, B.R., 1967, The bearing of lead isotopes on the source of granitic magma: Journal of Petrology, v. 7, p. 51-83.

1968, Lead and strontium isotopic studies of Cenozoic volcanic rocks in the Rocky Mountain region-A summary: Colorado School of Mines Quarterly, v. 63, p. 149-174.
Doe, B.R., and Delevaux, M.H., 1973, Variations in lead-isotopic compositions in Mesozoic granitic rocks of California: A preliminary investigation: Geological Society of America Bulletin, v. 84, p. 3513-3526.

Doe, B.R., Hedge, C.E., and White, D.E., 1966, Preliminary investigation of the source of lead and strontium in deep geothermal brines underlying the Salton Sea geothermal area: Economic Geology, v. 61, p. 462-483.

Doe, B.R., Leeman, W.P., Christiansen, R.L., and Hedge, C.E., 1982 , Lead and strontium isotopes and related trace elements as genetic tracers in the upper Cenozoic rhyolitebasalt association of the Yellowstone Plateau volcanic field: Journal of Geophysical Research, v. 87, p. 4785-4806.

Doe, B.R., and Zartman, R.E., 1982, Plumbotectonics of Japan: Some evidence for a rejuvenated craton: Mining Geology, v. 32, p. 285-289.

Donnelly, T.W., and Rogers, J.J.W., 1980, Igneous series in island arcs: The northeastern Caribbean compared with worldwide island-arc assemblages: Bulletin Volcanologique, v. 43, p. 347-382.

Dunbar, N.W:, and Kyle, P.R., 1986, $\mathrm{H}_{2} \mathrm{O}$ and $\mathrm{Cl}$ contents, and temperature of Taupo Volcanic Zone rhyolitic magmas: International Volcanological Congress, New Zealand, February 1986, Abstracts, p. 148.

Eichelberger, J.C., and Westrich, H.R., 1983, Behavior of water in rhyolitic magma at shallow depth: Eos, v. 64, p. 338.

Ewart, A., 1979, A review of the mineralogy and chemistry of Tertiary-Recent dacitic, latitic, rhyolitic, and related sialic volcanic rocks, in Barker, Fred, ed., Trondhjemites, dacites and related rocks: Amsterdam, Elsevier, p. 13-121.

Ewart, A., Brothers, R.N., and Mateen, A., 1977, An outline of the geology and geochemistry, and the possible petrogenetic evolution of the volcanic rocks of the Tonga-Kermadec-New Zealand island arc: Journal of Volcanology and Geothermal Research, v. 2, p. 205-250.

Ewart, A., Bryan, W.B., and Gill, J.B., 1973, Mineralogy and geochemistry of the younger volcanic islands of Tonga, S.W. Pacific: Journal of Petrology, v. 14, p. 429-465.

Ewart, A., and LeMaitre, R.W., 1980, Some regional compositional differences within Tertiary-Recent orogenic magmas: Chemical Geology, v. 30, p. 257-283.

Ewart, A., and Stipp, J.J., 1968, Petrogenesis of the volcanic rocks of the central North Island, New Zealand, as indicated by a study of ${ }^{87} \mathrm{Sr} /{ }^{86} \mathrm{Sr}$ ratios, and $\mathrm{Sr}, \mathrm{Rb}, \mathrm{K}, \mathrm{U}$ and $\mathrm{Th}$ abundances: Geochimica et Cosmochimica Acta, v. 32, p. 699-735.

Ewart, A., Taylor, S.R., and Capp, A.C., 1968, Trace and minor element geochemistry of the rhyolitic volcanic rocks, central North Island, New Zealand. Total rock and residual liquid data: Contributions to Mineralogy and Petrology, v. 18, p. 76-104.

Fenner, C.N., 1923, The origin and mode of emplacement of the great tuff deposit of the Valley of Ten Thousand Smokes: National Geographic Society, Contributed Technical papers (Katmai Series), no. 1, 74 p.

Flanagan, F.J., ed., 1976, Description and analyses of eight new USGS rock standards: U.S. Geological Survey Professional Paper 840, $192 \mathrm{p}$.

Friedman, Irving, and Long, William, 1976, Hydration rate of obsidian: Science, v. 191, p. 347-352.

Friedman, Irving, Long, William, and Smith, R.L., 1963, Viscosity and water content of rhyolite glass: Journal of Geophysical Research, v. 68, p. 6523-6535.

Friedman, Irving, and O'Neil, J.R., 1978, Hydrogen, in Wedepohl, K.H., ed., Handbook of Geochemistry, v. II/5: Berlin, SpringerVerlag, p. IE1-IE4. 
Friedman, Irving, and Smith, R.L., 1958, The deuterium content of water in some volcanic glasses: Geochimica et Cosmochimica Acta, v. 15, p. 218-228.

Fuge, R., 1976, The automated colorimetric determination of fluorine and chlorine in geological samples: Chemical Geology, v. 17, p. $37-43$.

Gale, N.H., 1981, Mediterranean obsidian source characterization by strontium isotope analysis: Archaeometry, v. 23, p. 41-51.

Gass, I.G., Harris, P.G., and Holdgate, M.W., 1963, Pumice eruption in the area of the South Sandwich Islands: Geological Magazine, v. 100, p. 321-330.

Georgiades, A.N., 1956, Research on Greek obsidians: Praktika tis Akademias Athinon, v. 31, p. 150-163 [in Greek, with French summary].

Gill, James, 1981, Orogenic andesites and plate tectonics: Berlin, Springer-Verlag, 390 p.

Gill, J.B., and Stork, A.L., 1979, Miocene low-K dacites and trondhjemites of Fiji, in Barker, Fred, ed., Trondhjemites, dacites, and related rocks: Amsterdam, Elsevier, p. 629-649.

Gordus, A.A., Wright, G.A., and Griffin, J.B., 1968, Obsidian sources characterized by neutron-activation analysis: Science, v. 161, p. 382-384.

Gorshkov, G.S., 1970, Volcanism and the upper mantle. Investigations in the Kurile Island Arc: New York, Plenum Press, 385 p.

Grange, L.I., 1937, The geology of the Rotorua-Taupo subdivision: New Zealand Geological Survey Bulletin 37, p. 1-138.

Green, Jack, 1965, Selection of rock standards for lunar research: New York Academy of Sciences Annals, v. 123, p. 1123-1147.

Greenland, L.P., and Campbell, E.Y., 1974, Spectrophotometric determination of niobium in rocks: U.S. Geological Survey Journal of Research, v. 2, n. 3, p. 353-355.

Griffin, J.B., Gordus, A.A., and Wright, G.A., 1969, Identification of the sources of Hopewellian obsidian in the Middle West: American Antiquity, v. 34, p. 1-14.

Halliday, A.N., Fallick, A.E., Hutchinson, J., and Hildreth, W., 1984, $\mathrm{A} \mathrm{Nd}, \mathrm{Sr}$ and $\mathrm{O}$ isotopic investigation into the causes of chemical and isotopic zonation in the Bishop Tuff, California: Earth and Planetary Science Letters, v. 68, p. 379391.

Hamilton, Warren, 1963, Petrology of rhyolite and basalt, northwestern Yellowstone Plateau: U.S. Geological Survey Professional Paper 475-C, p. C78-C81.

Haskin, L.A., Haskin, M.A., Frey, F.A., and Wildeman, T.R., 1968, Relative and absolute terrestrial abundances of the rare earths, in Ahrens, L.R., ed., Origin and distribution of the elements: Oxford, Pergamon, p. 889-912.

Hedge, C.E., and Peterman, Z.E., 1974, Strontium: 38B. Isotopes in nature, in Wedepohl, K.H., ed., Handbook of geochemistry: Berling, Springer-Verlag, v. II/4, p. 38B1-38B14.

Heizer, R.F., Williams, Howel, and Graham, J.A., 1965, Notes on Mesoamerican obsidians and their significance in archaeological studies: University of California Archaeological Research Facility Contribution No. 1, p. 94-103.

Herrmann, A.G., 1970, Yttrium and lanthanides, in Wedepohl, K.H., ed., Handbook of geochemistry: Berlin, SpringerVerlag, v. II/5.

Higgins, M.W., 1973, Petrology of Newberry Volcano, central Oregon: Geological Society of America Bulletin, v. 84, p. 455488.

Hildreth, E.W., 1977, The magma chamber of the Bishop Tuff: Gradients in temperature, pressure and composition: Berkeley, University of California, $\mathrm{Ph} . \mathrm{D}$. thesis, $328 \mathrm{p}$.

1979, The Bishop Tuff: Evidence for the origin of compositional zonation in silicic magma chambers, in Chapin, C.E., and Elston, W.E., eds., Ash-flow tuffs: Geological Society of America Special Paper 180, p. 43-75.

1981, Gradients in silicic magma chambers: Implications for lithospheric magmatism: Journal of Geophysical Research, v. 86, p. 10153-10192.

Hill, U.T., 1959, Photometric determination of aluminum in steel: Analytical Chemistry, v. 31, p. 429-431.

Homma, F., and Mukae, M., 1938, Preliminary report on the geological structure of the central cones of Aso Volcano: Volcanological Society of Japan Bulletin, v. 4, p. 45-76.

Huang, W.H., and Johns, W.D., 1967, Simultaneous determination of fluorine and chlorine in silicate rocks by a rapid spectrophotometric method: Analytica Chimica Acta, v. 37, p. 508-515.

Ingram, B.L., 1970, Determination of fluorine in silicate rocks without separation of aluminum using a specific ion electrode: Analytical Chemistry, v. 42, no. 14, p. 1825-1827.

Isshiki, Naoki, 1963, Petrology of Hachijo-Jima volcano group, Seven Izu Islands, Japan: Tokyo University Faculty of Science Journal, v. 15, p. 91-134.

Jack, R.N., 1971, The source of obsidian artifacts in northern Arizona: Plateau, v. 43, p. 103-114.

Jack, R.N., and Carmichael, I.S.E., 1969, The chemical "fingerprinting" of acid volcanic rocks: California Division of Mines and Geology Special Report 100, p. 17-32.

Jakes, P., and Gill, J.B., 1970, Rare earth elements and the island arc tholeiitic series: Earth and Planetary Science Letters, v. 9, p. 17-28.

Jakes, P., and White, A.J.R., 1972, Major and trace element abundances in volcanic rocks of orogenic areas: Geological Society of America Bulletin, v. 83, p. 29-40.

James, R.S., and Hamilton, D.L., 1969, Phase relations in the system Ab-Or-An-Q at 1 kilobar water vapor pressure: Contributions to Mineralogy and Petrology, v. 21, p. 111-141.

Jezek, P.A., and Noble, D.C., 1978, Natural hydration and ion exchange of obsidian: An electron microprobe study: American Mineralogist, v. 63, p. 266-273.

Johnson, R.W., and Arculus, R.J., 1978, Volcanic rocks of the Witu Islands, Papua New Guinea: The origin of magmas above the deepest part of the New Britain Benioff zone: Bulletin Volcanologique, v. 41, p. 609-655.

Johnson, R.W., Smith, I.E.M., and Taylor, S.R., 1978, Hot-spot volcanism in St. Andrew Strait, Papua New Guinea: Geochemistry of a Quaternary bimodal rock suite: BMR Journal of Australian Geology and Geophysics, v. 3, p. 55-69.

Katsui, Yoshio, 1959, Chemical compositions of Quaternary volcanic rocks of Hokkaido: Geological Commission of Hokkaido Bulletin 38, p. 27-47 [in Japanese].

Katsui, Yoshio, Oba, Y., Ando, S., Nishimura, S., Masuda, Y., Kurasawa, H., and Fujimaki, H., 1978, Petrochemistry of the Quaternary volcanic rocks of Hokkaido, north Japan: Hokkaido University Faculty of Science Journal, ser. IV, v. 18 , p. $449-484$.

Katz, Amitai, and Grossman, Lawrence, 1976, Intercalibration of 17 standard silicates for 14 elements by instrumental neutron activation analysis: U.S. Geological Survey Professional Paper 840, p. 49-57.

Kawano, Yoshinori, 1950, Natural glasses in Japan: Geological Survey of Japan Report 134, p. 1-29.

Keller, Jörg, 1980, The island of Vulcano: Rendiconti Societá Italiana di Mineralogia e Petrologia, v. 36, p. 369-414.

Keller, Jörg, 1982, Mediterranean island arcs, in Thorpe, R.S., ed., Andesites: Chichester, Wiley and Sons, p. 307-325.

Klemic, Harry, Gottfried, David, Cooper, Margaret, and Marsh, S.P., 1973, Zirconium and hafnium, in Brobst, D.A., and 
Pratt, W.P., eds., United States mineral resources: U.S. Geological Survey Professional Paper 820, p. 713-722.

Kôzu, Shukusuke, 1929, Thermal studies of obsidian, pitchstone, and perlite from Japan: Science Reports of Tôhoku Imperial University, ser. III, v. 3, p. 225-238.

Kuno, Hisashi, 1966, Lateral variation of basalt magma type across continental margins and island arcs: Bulletin Volcanologique, v. 29, p. 195-222.

Kurasawa, Hajima, 1959, Petrology and chemistry of the Amagi volcanic rocks, Izu peninsula, Japan: Earth Science, v. 44, p. 1-18 [in Japanese, with English summary].

Laidley, R.A., and McKay, D.S., 1971, Geochemical examination of obsidians from Newberry caldera, Oregon: Contributions to Mineralogy and Petrology, v. 30, p. 336-342.

Leeman, W.P., 1979, Partitioning of $\mathrm{Pb}$ between volcanic glass and coexisting sanidine and plagioclase feldspars: Geochimica et Cosmochimica Acta, v. 43, p. 171-175.

Lesher, C.E., Walker, D., Candela, P., and Hays, J.F., 1982, Soret fractionation of natural silicate melts of intermediate to silicic composition: Geological Society of America Abstracts with Programs, v. 14, p. 545.

Lipman, P.W., 1965, Chemical comparison of glassy and crystalline volcanic rocks: U.S. Geological Survey Bulletin 1201-D, p. D1-D24.

Lipman, P.W., 1975, Evolution of the Platoro caldera complex and related volcanic rocks, southeastern San Juan Mountain, Colorado: U.S. Geological Survey Professional Paper 852, 128 p.

Lipman, P.W., Christiansen, R.L., and Van Alstine, R.E., 1968, Retention of alkalis by calc-alkalic rhyolites during crystallization and hydration: American Mineralogist, v. 54, p. 286291.

Lipman, P.W., Doe, B.R., Hedge, C.E., and Steven, T.A., 1978, Petrologic evolution of the San Juan volcanic field, southwestern Colorado: $\mathrm{Pb}$ and $\mathrm{Sr}$ isotope evidence: Geological Society of America Bulletin, v. 89, p. 59-82.

Lipman, P.W., and Friedman, Irving, 1975, Interaction of meteoric water with magma: An oxygen-isotope study of ash-flow sheets from southern Nevada: Geological Society of America Bulletin, v. 86, p. 695-702.

Lipman, P.W., Rowley, P.D., Mehnert, H.H., Evans, S.H., Jr., Nash, W.P., and Brown, F.H., 1978, Pleistocene rhyolite of the Mineral Mountains, Utah-Geothermal and archaeological significance: U.S. Geological Survey Journal of Research, v. 6, p. 133-147.

Lofgren, Gary, 1971, Experimentally produced devitrification textures in natural rhyolite glass: Geological Society of America Bulletin, v. 82, p. 111-124.

Lowder, G.G., and Carmichael, I.S.E., 1970, The volcanoes and caldera of Talasea, New Britain: Geology and petrology: Geological Society of America Bulletin, v. 81, p. 17-38.

Macdonald, R., and Bailey, D.K., 1973, The chemistry of the peralkaline oversaturated obsidians: U.S. Geological Survey Professional Paper 440-N-1, 37 p.

Macdonald, R., Bailey, D.K., and Sutherland, D.S., 1970, Oversaturated peralkaline glassy trachytes from Kenya: Journal of Petrology, v. 11, p. 507-517.

MacKenzie, D.E., and Chappell, B.W., 1972, Shoshonite and calcalkaline lavas from the Highlands of Papua New Guinea: Contributions to Mineralogy and Petrology, v. 35, p. 50-62.

Mahood, G.A., 1981a, Chemical evolution of a Pleistocene rhyolitic center: Sierra la Primavera, Jalisco, Mexico: Contributions to Mineralogy and Petrology, v. 77, p. 129-149.

- 1981b, A summary of the geology and petrology of the Sierra La Primavera, Mexico: Journal of Geophysical Research, v. 86, p. 10137-10152.
Mahood, G.A., and Hildreth, E.W., 1983, Large partition coefficients for trace elements in high-silica rhyolites: Geochimica et Cosmochimica Acta, v. 47, p. 11-30.

Martin, Rudolf, and de Sitter-Koomans, C.M., 1955, Pseudotectites from Colombia and Peru: Leidse Geologische Mededelingen, v. 20 , p. $151-164$.

Masuda, Yasuyuki, Nishimura, Susumu, Ikeda, Takashi, and Katsui, Yoshio, 1975, Rare-earth and trace elements in the Quaternary volcanic rocks of Hokkaido, Japan: Chemical Geology, v. 15, p. 251-271.

McBirney, A.R., 1968, Petrochemistry of the Cascade andesite volcanoes: Oregon Department of Geology and Mineral Industries Bulletin 62, p. 101-107.

Melson, W.G., Jarosewich, E., and Lundquist, C.A., 1970, Volcanic eruption at Metis Shoal, Tonga, 1967-1968. Description and petrology: Smithsonian Contributions to the Earth Sciences 4, $18 \mathrm{p}$.

Michael, P.J., 1983, Chemical differentiation of the Bishop Tuff and other high-silica magmas through crystallization processes: Geology, v. 11, p. 31-34.

Miller, C.F., and Mittlefehldt, D.W., 1982, Light rare earth element depletion in felsic magmas: Geology, v. 10, p. 129-133.

-1984, Extreme fractionation in felsic magma chambers: a product of liquid-state diffusion or fractional crystallization?: Earth and Planetary Science Letters, v. 68, p. 151-158.

Minami, Eiiti, and Matsui, Yoshito, 1960, Composition of the main chemical components in the rocks from Hotoke-iwa volcanic body of Mt. Asama: Earthquake Research Institute Bulletin, v. 38, p. 291-305.

Mittlefehldt, D.W., and Miller, C.F., 1983, Geochemistry of the Sweetwater Wash pluton, California: Implications for "anomalous" trace element behavior during differentiation of felsic magmas: Geochimica et Cosmochimica Acta, v. 47, p. 109-124.

Miyashiro, Akiho, 1974, Volcanic rock series in island arcs and active continental margins: American Journal of Science, v. 274 , p. $321-355$.

Muehlenbachs, K., 1973, The oxygen isotope geochemistry of siliceous volcanic rocks from Iceland: Carnegie Institution of Washington Yearbook 72, p. 593-597.

Newman, S., Stolper, E., and Epstein, S., 1985, Variations in hydrogen isotopic ratios of obsidians erupted 1400 A.D. at Mono Craters, California: Eos, v. 66, p. 391.

Noble, D.C., 1967, Sodium, potassium, and ferrous iron contents of some secondarily hydrated natural silicic glasses: American Mineralogist, v. 52, p. 280-286.

Noble, D.C., and Hedge, C.E., $1969,{ }^{87} \mathrm{Sr} /{ }^{86} \mathrm{Sr}$ variations within individual ash-flow sheets: U.S. Geological Survey Professional Paper 650-C, p. C133-C139.

Noble, D.C., Hedge, C.E., McKee, E.H., and Korringa, M.K., 1973, Reconnaissance study of the strontium isotopic composition of Cenozoic volcanic rocks in the northwestern Great Basin: Geological Society of America Bulletin, v. 84, p. 1393-1406.

Noble, D.C., Korringa, M.K., Hedge, C.E., and Riddle, G.O., 1972, Highly differentiated subalkaline rhyolite from Glass Mountain, Mono County, California: Geological Society of America Bulletin, v. 83, p. 1179-1184.

Noble, D.C., Rigot, W.L., and Bowman, H.R., 1979, Rare-earthelement content of some highly differentiated ash-flow tuffs and lavas, in Chapin, C.E., and Elston, W.E., eds., Ash-flow tuffs: Geological Society of America Special Paper 180, p. 77-85.

Noble, D.C., Rose, W.I., and Zielinski, R.A., 1980, Uranium contents of glassy and devitrified andesites and dacites, Mount Mazama, Oregon: Economic Geology, v. 75, p. 127-129. 
Noble, D.C., Smith, V.C., and Peck, L.C., 1967, Loss of halogens from crystallized and glassy silicic volcanic rocks: Geochimica et Cosmochimica Acta, v. 31, p. 215-223.

Noe-Nygaard, Arne, 1952, A group of liparite occurrences in Vatnajökull, Iceland: Folia Geographica Danica, v. 1, p. 1-59.

O'Neil, J.R., and Taylor, B.E., 1985, Degassing of Obsidian Dome magma: Hydrogen and oxygen isotope studies in the Inyo Dome chain, Long Valley area, California: Eos, v. 66, p. 387.

O'Nions, R.K., and Grönvold, K., 1973, Petrogenetic relationships of acid and basic rocks in Iceland: Sr-isotopes and rare-earth elements in late and post-glacial volcanics: Earth and Planetary Science Letters, v. 19, p. 397-409.

Ono, Koji, 1962, Chemical composition of volcanic rocks in Japan: Geological Survey of Japan, 441 p.

Ostapenko, V.F., Fedorchenko, V.I., and Shilov, V.N., 1967, Pumices, ignimbrites, and rhyolites from the Great Kurile Arc: Bulletin Volcanologique, v. 30, p. 81-92.

Oversby, V.M., and Ewart, A., 1972, Lead isotopic compositions of Tonga-Kermadec volcanics and their petrogenetic significance: Contributions to Mineralogy and Petrology, v. 37, p. 181-210.

Page, R.W., and Johnson, R.W., 1974, Strontium isotope ratios of Quaternary volcanic rocks from Papua New Guinea: Lithos, v. 7, p. 91-100.

Parker, R.L., and Fleischer, Michael, 1968, Geochemistry of niobium and tantalum: U.S. Geological Survey Professional Paper 612, $43 \mathrm{p}$.

Peacock, M.A., 1931, Classification of igneous rock series: Journal of Geology, v. 39, p. 54-67.

Pearce, J.A., 1982, Trace element characteristics of lavas from destructive plate boundaries, in Thorpe, R.S., ed., Andesites: New York, John Wiley, p. 525-548.

-1983, The role of sub-continental lithosphere in magma genesis at destructive plate margins, in Hawkesworth, C.J., and Norry, M.J., eds., Continental basalts and mantle xenoliths: Nantwich, Shiva Publications, p. 230-249.

Pearce, J.A., and Gale, G.H., 1977, Identification of oredeposition environment from trace-element geochemistry of associated igneous host rocks, in Volcanic processes in ore genesis: Geological Society of London Special Publication No. 7, p. 14-24.

Pearce, J.A., Harris, N.B.W., and Tindle, A.G., 1984, Trace element discrimination diagrams for the tectonic interpretation of granitic rocks: Journal of Petrology, v. 25, p. 956-983.

Peccerillo, A., and Taylor, S.R., 1976, Geochemistry of Eocene calc-alkaline volcanic rocks from the Kastamonu area, northern Turkey: Contributions to Mineralogy and Petrology, v. 58, p. $63-81$.

Peck, D.L., 1980, Geologic map of the Merced Peak quadrangle, central Sierra Nevada, California: U.S. Geological Survey Geologic Quadrangle Map GQ-1531 (scale 1:62,500).

Peterman, Z.E., Carmichael, I.S.E., and Smith, A.L., 1970a, ${ }^{87} \mathrm{Sr} /{ }^{86} \mathrm{Sr}$ ratios of Quaternary lavas of the Cascade Range, northern California: Geological Society of America Bulletin, v. 81, p. 311-318.

Peterman, Z.E., Lowder, G.C., and Carmichael, I.S.E., 1970b, ${ }^{87} \mathrm{Sr} /{ }^{86} \mathrm{Sr}$ ratios of the Talasea series, New Britain, Territory of New Guinea: Geological Society of America Bulletin, v. 81 , p. $39-40$.

Petro, W.L., Vogel, T.A., and Wilband, J.T., 1979, Majorelement chemistry of plutonic rock suites from compressional and extensional plate boundaries: Chemical Geology, v. 26, p. 217-235.

Phair, George, and Gottfried, David, 1964, The Colorado Front Range, Colorado, U.S.A., as a uranium and thorium prov- ince, in Adams, J.A.S., and Lowder, W.M., eds., The natural radiation environment: Chicago, University of Chicago Press, p. 7-38.

Pichler, Hans, and Zeil, Werner, 1972, The Cenozoic rhyoliteandesite association of the Chilean Andes: Bulletin Volcanologique, v. 35, p. 424-452.

Pitcher, W.S., 1979, The nature, ascent and emplacement of granite magmas: Journal of the Geological Society of London, v. 136 , p. $627-662$.

Powers, H.A., 1932, The lavas of the Modoc Lava Bed quadrangle, California: American Mineralogist, v. 17, p. 253294.

Prinz, Martin, 1968, Geochemistry of basaltic rocks: Trace elements, in Hess, H.H., and Poldervaart, Aarie, eds., Basalts: The Poldervaart treatise on rocks of basaltic composition. Volume I: New York, Wiley-Interscience, p. 271-323.

Pushkar, P., McBirney, A.R., and Kudo, A.M., 1972, The isotopic composition of strontium in Central American ignimbrites: Bulletin Volcanologique, v. 35, p. 265-294.

Renfrew, Colin, Cann, J.R., and Dixon, J.E., 1965, Obsidian in the Aegean: Annual of the British School at Athens, no. 60, p. 225-247.

Renfrew, Colin, Dixon, J.E., and Cann, J.R., 1966, Obsidian and early cultural contact in the Near East: Proceedings of the Prehistoric Society, v. 32, p. 30-72.

-1968, Further analysis of Near Eastern obsidians: Proceedings of the Prehistoric Society, v. 34, p. 319-331.

Rigg, T., and Wagenbauer, H.A., 1961, Spectrophotometric determination of titanium in silicate rocks: Analytical Chemistry, v. 33, p. 1347-1349.

Robinson, P.T., 1972, Petrology of the potassic Silver Peak volcanic center, western Nevada: Geological Society of America Bulletin, v. 83, p. 1693-1708.

Robinson, P.T., Elders, W.A., and Muffler, L.J.P., 1976, Quaternary volcanism in the Salton Sea geothermal field, Imperial Valley, California: Geological Society of America Bulletin, v. 87 , p. $347-360$.

Rogers, J.J.W., and Adams, J.A.S., 1969, Thorium, in Wedepohl, K.H., ed., Handbook of Geochemistry: Berling, SpringerVerlag, v. II/5.

Rosholt, J.N., Prijana, and Noble, D.C., 1971, Mobility of uranium and thorium in glassy and crystallized silicic volcanic rocks: Economic Geology, v. 66, p. 1061-1069.

Ross, C.S., and Smith, R.L., 1955, Water and other volatiles in volcanic glasses: American Mineralogist, v. 40, p. 10711089.

Rutherford, N.F., 1978, Fission-track age and trace element geochemistry of some Minden Rhyolite obsidians: New Zealand Journal of Geology and Geophysics, v. 21, p. 443-448.

Salát, Jan, and Oncáková, Petronella, 1964, Perlity, ich vyskyt, petrochémia a prakticke pouzitie: Bratislava, Vydavatelstvo Slovenskej Akadémie Vied, 147 p. [in Czechoslovakian, with German summary].

Saunders, A.D., Tarney, John, Marsh, N.G., and Wood, D.A., 1980, Ophiolites as ocean crust or marginal basin crust: A geochemical approach: Proceedings of the International Symposium, Cyprus, 1979, p. 193-204.

Schwarz, L.J., and Rowe, J.J., 1976, The determination of antimony, hafnium, and tantalum in the new USGS standard rocks: U.S. Geological Survey Professional Paper 840, p. 67-69.

Shand, S.J., 1949, Eruptive rocks: London, Thomas Murby and Co., $488 \mathrm{p}$.

Shapiro, L., and Brannock, W.W., 1955, Rapid determination of water in silicate rocks: Analytical Chemistry, v. 27, p. 560562 . 
Shapiro, L., and Brannock, W.W., 1962, Rapid analysis of silicate, carbonate and phosphate rocks: U.S. Geological Survey Bulletin 1144-A, 56 p.

Shaw, D.M., 1968, A review of K-Rb fractionation trends by covariance analysis: Geochimica et Cosmochimica Acta, v. 32, p. 573-601.

Shaw, H.R., Smith, R.L., and Hildreth, W., 1976, Thermogravitational mechanisms for chemical variations in zoned magma chambers [abs.]: Geological Society of America Abstracts with Programs, v. 8, p. 1102.

Shepherd, E.S., 1938, The gases in rocks and some related problems: American Journal of Science, 5th series, v. 35A, p. 311-351.

Shuto, Kenji, and Yashima, Ryuichi, 1974, Sr isotopic compositions of some Ryozen volcanic rocks from the northeastern part of Fukushima Prefecture: Journal of the Japanese Association of Mineralogists, Petrologists and Economic Geologists, v. 69 , p. $373-380$.

Sigurdsson, Haraldur, and Sparks, R.S.J., 1981, Petrology of rhyolitic and mixed magma ejecta from the 1875 eruption of Askja, Iceland: Journal of Petrology, v. 22, p. 41-84.

Smith, A.L., Roobol, M.J., and Gunn, B.M., 1980, The Lesser Antilles-A discussion of the island arc magmatism: Bulletin Volcanologique, v. 43, p. 287-302.

Smith, I.E.M., and Johnson, R.W., 1981, Contrasting rhyolite suites in the late Cenozoic of Papua New Guinea: Journal of Geophysical Research, v. 86, p. 10257-10272.

Smith, I.E.M., Ward, G.K., and Ambrose, W.R., 1977, Geographic distribution and the characterization of volcanic glasses in Oceania: Archaeology and Physical Anthropology in Oceania, v. 12, p. 173-201.

Smith, R.L., 1979, Ash-flow magmatism, in Chapin, C.E., and Elston, W.E., eds., Ash-flow tuffs: Geological Society of America Special Paper 180, p. 5-27.

Smith, R.L., and Bailey, R.A., 1966, The Bandelier Tuff: a study of ash-flow eruption cycles from zoned magma chambers: Bulletin Volcanologique, v. 29, p. 83-104.

Smith, R.L., and Macdonald, R., 1979, Rhyolitic volcanism and its relationship to granitic plutonism [abs.]: Geological Society of America Abstracts with Programs, v. 11, p. 520.

Sparks, R.S.J., Sigurdsson, Haraldur, and Wilson, Lionel, 1977, Magma mixing: A mechanism for triggering acid explosive eruptions: Nature, v. 267, p. 315-318.

Steiner, A., 1963, Crystallization behavior and origin of the acidic ignimbrite and rhyolite magma in the North Island of New Zealand: Bulletin Volcanologique, v. 25, p. 217-241.

Stevenson, D.P., Stross, F.H., and Heizer, R.F., 1971, An evaluation of $\mathrm{x}$-ray fluorescence analysis as a method for correlating obsidian artifacts with source location: Archaeometry, v. 13, p. 17-25.

Stewart, D.B., 1979, The formation of siliceous potassic glassy rocks, in Yoder, H.S., Jr., ed., The evolution of the igneous rocks: Princeton, Princeton University Press, p. 339-350.

Stuckless, J.S., and O'Neil, J.R., 1973, Petrogenesis of the Superstition-Superior volcanic area as inferred from strontium- and oxygen-isotope studies: Geological Society of America Bulletin, v. 84, p. 1987-1998.

Szadeczky-Kardoss, E., Pesty, L., Kliburszky, B., Bardossy, G., and Simo, B., 1964, Complex experimental petrologic investigations on the interchange of rocks and magma: Acta Geologica Acad. Sci. Hungaricae, v. 8, p. 71-82.

Tanida, Katsutoshi, 1961, A study of salic effusive rocks: Science Reports of Tohoku University, ser. 3, v. 7, p. 47-100.

Tanner, J.T., and Ehmann, W.D., 1967, The abundance of antimony in meteorites, tektites and rocks by neutron activa- tion analysis: Geochimica et Cosmochimica Acta, v. 31, p. 2007-2026.

Tatlock, D.B., Flanagan, F.J., Bastron, Harry, Berman, Sol, and Sutton, A.L., Jr., 1976, Rhyolite, RGM-1, from Glass Mountain, California, in Flanagan, F.J., ed., Description and analysis of eight new USGS rock standards: U.S. Geological Survey Professional Paper 840, p. 11-14.

Taylor, B.E., Eichelberger, J.C., and Westrich, H.R., 1983, Hydrogen isotopic evidence of rhyolitic magma degassing during shallow intrusion and eruption: Nature, v. 306, p. 541-545.

Taylor, H.P., Jr., 1968, The oxygen isotope geochemistry of igneous rocks: Contributions to Mineralogy and Petrology, v. 19, p. 1-71.

Taylor, H.P., Jr., and Forester, R.W., 1971, Low $-{ }^{18} \mathrm{O}$ igneous rocks from the intrusive complexes of Skye, Mull, and Ardnamurchan, western Scotland: Journal of Petrology, v. 12, p. 465-497.

Tchoua, Félix, 1970, Découverte d'obsidienne dans le Mont Manengouba (Cameroun): Annales de la Faculté des Sciences du Cameroun, no. 4, p. 23-30.

Thorpe, R.S., ed., 1982, Andesites: orogenic andesites and related rocks: New York, John Wiley, 724 p.

Tilling, R.I., and Gottfried, D., 1969, Distribution of thorium, uranium, and potassium in igneous rocks of the Boulder Batholith region, Montana, and its bearing on radiogenic heat production and heat flow: U.S. Geological Survey Professional Paper 614-E, 29 p.

Tomita, T., 1935, On the chemical compositions of the Cenozoic alkaline suite of the circum-Japan Sea region: Shanghai Scientific Institute Journal, sec. II, v. 1, p. 227-306.

Truesdell, A.H., 1962, Study of natural glasses through their behavior as membrane electrodes: Nature, v. 194, p. 77-79.

1966, Ion-exchange constants of natural glasses by the electrode method: American Mineralogist, v. 51, p. 110-122.

Tsuya, H., 1929, Volcanoes of Kôzu-shima: Tokyo University Earthquake Research Institute Bulletin, v. 7, p. 269-334. 1933, Petrology of some lavas of volcano Asama, Sinano province, Japan: Tokyo University Earthquake Research Institute Bulletin, v. 11, p. 575-594.

1937, On the geology of the Huzi volcanic zone, with special reference to the geology and petrology of Idu and the southern islands: Tokyo University Earthquake Institute Bulletin, v. 15, p. 215-357.

Uchimizu, M., 1966, Geology and petrology of alkali rocks from Dogo, Iki Islands: Tokyo University Faculty of Science Journal, sec. II, v. 16, p. 85-159.

Vendl, Aladar, 1927, Die typen der ungarischen rhyolithe: Neues Jahrbuch $f$. Mineralogie Geologie Paläontologie BB, v. 55A, p. 183.

Vlodavetz, V.I., and Piip, B.I., 1959, Catalogue of the active volcanoes of the world including Solfatara fields. Part 8. Kamchatka and continental areas of Asia: Naples, International Association of Volcanology and Chemistry of the Earth's Interior, $110 \mathrm{p}$.

von Platen, H., 1965, Kristallisation granitischer Schmelzen: Beitrage Mineralogie und Petrographie, v. 11, p. 334-381.

Walker, D., Lesher, C.E., and Hays, J.F., 1981, Soret separation of lunar liquid: Proceedings of the Lunar and Planetary Sciences, v. 1213, p. 991-999.

Walsh, J.N., Beckinsale, R.D., Skelhorn, R.R., and Thorpe, R.S., 1979 , Geochemistry and petrogenesis of Tertiary granitic rocks from the Island of Mull, northwest Scotland: Contributions to Mineralogy and Petrology, v. 71, p. 99-116.

Washington, H.S., 1917, Chemical analyses of igneous rocks: U.S. Geological Survey Professional Paper 99, 1201 p. 
1920, The rhyolites of Lipari: American Journal of Science, 4 th series, v. 50 , p. $446-462$.

Weaver, S.D., Saunders, A.D., Pankhurst, R.J., and Tarney, J., 1979, A geochemical study of magmatism associated with the initial stages of back-arc spreading: Contributions to Mineralogy and Petrology, v. 68, p. 151-169.

Welke, H., Moorbath, S., Cumming, G.L., and Sigurdsson, H., 1968, Lead isotope studies on igneous rocks from Iceland: Earth and Planetary Science Letters, v. 4, p. 221-231.

Westrich, H.R., Stockman, H.W., and Taylor, B.E., 1985, Volatile content of Obsidian Dome and the Inyo Dike: Eos, v. 66, p. 387.

Whitehead, D., and Malik, S.A., 1975, Determination of ferrous and total iron in silicate rocks by automated colorimetry: Analytical Chemistry, v. 47, p. 554-556.

-1976, Automated colorimetric determination of phosphorous in silicate rocks in the presence of silicon: Analyst, v. 101, p. $485-490$

Whitehead, D., and Thomas, J.E., 1985, Use of a nebulizer in pyrohydrolytic decomposition of silicate materials for determination of fluorine and chlorine: Analytical Chemistry, v. 57, p. 2421-2423.

Williams, Howel, 1935, Newberry Volcano of central Oregon: Geological Society of America Bulletin, v. 46, p. 253-304.

1942, The geology of Crater Lake National Park, Oregon, with a reconnaissance of the Cascade Range southward to Mount Shasta: Carnegie Institution of Washington Publication $540,162 \mathrm{p}$.

Wood, D.A., 1980, The application of a Th-Hf-Ta diagram to problems of tectonomagmatic classification and to establishing the nature of crustal contamination of basaltic lavas of the British Tertiary Volcanic Province: Earth and Planetary Science Letters, v. 50, p. 11-30.

Wood, D.A., Joron, J.L., and Treuil, M., 1979, A reappraisal of the use of trace elements to classify and discriminate be- tween magma series erupted in different tectonic settings: Earth and Planetary Science Letters, v. 45, p. 326-336.

Wood, D.A., Joron, J.L., Treuil, M., Norry, M.J., and Tarney, J., 1979, Elemental and $\mathrm{Sr}$ isotope variations in basic lavas from Iceland and the surrounding ocean floor. The nature of mantle source inhomogeneities: Contributions to Mineralogy and Petrology, v. 70, p. 319-339.

Wright, F.E., 1915, Obsidian from Hrafntinnuhryggur, Iceland: Its lithophysae and surface markings: Geological Society of America Bulletin, v. 26, p. 255-286.

Wright, G.A., and Gordus, A.A., 1969, Source areas for obsidian recovered at Munhata, Beisamoun, Hazorea, and El-Khiam: Israel Exploration Journal, v. 19, p. 79-88.

Yagi, Kenzo, 1953, Rocent activity of Usu Volcano, Japan, with special reference to the formation of Syowa Sinzan: Transactions of the American Geophysical Union, v. 34, p. 449556.

Yajima, Toshihiko, Higuchi, Hideo, and Nagasawa, Hiroshi, 1972, Variation of rare earth concentrations in pigeonitic and hypersthenic rock series from Izu-Hakone region, Japan: Contributions to Mineralogy and Petrology, v. 35, p. 235-244.

Zartman, R.E., 1974, Lead isotope provinces in the cordillera of the western United States, and their geologic significance: Economic Geology, v. 69, p. 792-805.

Zielinski, R.A., 1978, Uranium abundances and distribution in associated glassy and crystalline rhyolites of the Western United States: Geological Society of America Bulletin, v. 89, p. 409-414.

Zielinski, R.A., Lipman, P.W., and Millard, H.T., 1977, Minorelement abundances in obsidian, perlite, and felsite of calcalkalic rhyolites: American Mineralogist, v. 62, p. 426-437.

Zies, E.G., 1929, The Valley of Ten Thousand Smokes: National Geographic Society, Contributed Technical Papers, v. 1, no. 4, 79 p. 
APPENDIXES I-VII 
APPENDIX 1.-Chemical analyses of subalkalic silicic obsidians

\begin{tabular}{|c|c|c|c|c|c|c|c|c|c|c|c|}
\hline \multirow{2}{*}{$\begin{array}{l}\text { Country/State-... } \\
\text { Volcanic field/region--- }\end{array}$} & \multicolumn{7}{|c|}{ ALASKA } & \multicolumn{4}{|c|}{ OREGON } \\
\hline & \multicolumn{2}{|c|}{ Umnak Is land } & \multirow{2}{*}{$\frac{\text { Katma i }}{\text { Novarupta }}$} & \multicolumn{3}{|c|}{ Wrangell Mountains } & \multirow{2}{*}{$\begin{array}{c}\begin{array}{c}\text { Koyukuk } \\
\text { Valley }\end{array} \\
\begin{array}{c}\text { Indian } \\
\text { River }\end{array}\end{array}$} & & ee Sis & & Crater Lake \\
\hline Locality-_._- & SW. Umnak & Okmok & & Capital & Mountain & $\begin{array}{l}\text { Ptarmigan } \\
\text { Lake }\end{array}$ & & & th Sis & & The Watchman \\
\hline $\begin{array}{l}\text { Specimen } \\
\text { Collection No. (RLS-) }\end{array}$ & $\begin{array}{c}1 \\
190\end{array}$ & $\begin{array}{r}2 \\
56\end{array}$ & $\begin{array}{c}3 \\
214\end{array}$ & $\begin{array}{r}4 \\
39\end{array}$ & $\begin{array}{c}5 \\
196\end{array}$ & $\begin{array}{r}6 \\
45\end{array}$ & $\begin{array}{r}7 \\
46\end{array}$ & $\begin{array}{c}8 \\
187\end{array}$ & $\begin{array}{c}9 \\
189\end{array}$ & $\begin{array}{r}10 \\
199\end{array}$ & $\begin{array}{c}11 \\
8-3 \mathrm{AV}\end{array}$ \\
\hline
\end{tabular}

Chemical analyses (weight percent)

\begin{tabular}{|c|c|c|c|c|c|c|c|c|c|c|c|}
\hline $\begin{array}{l}\mathrm{SiO}_{2} \mathrm{O}_{2} \\
\mathrm{Al}_{2} \mathrm{O}_{3} \\
\mathrm{Fe}_{2} \mathrm{O}_{2} \\
\mathrm{Fe}_{2} \mathrm{O}_{3} \\
\mathrm{Mg} 0\end{array}$ & $\begin{array}{r}76.1 \\
12.71 \\
.23 \\
.93 \\
.15 \\
1.04 \\
3.59 \\
3.91 \\
.42 \\
.13 \\
.01 \\
.05 \\
.09 \\
.09 \\
.03 \\
.03\end{array}$ & $\begin{array}{r}73.1 \\
13.33 \\
.62 \\
2.06 \\
.08 \\
1.23 \\
4.68 \\
3.88 \\
.05 \\
.18 \\
.02 \\
.10 \\
.19 \\
.18 \\
.06 \\
.06\end{array}$ & $\begin{array}{r}75.9 \\
12.55 \\
.72 \\
.93 \\
.34 \\
1.16 \\
4.32 \\
2.94 \\
.14 \\
.21 \\
.02 \\
.07 \\
.10 \\
.08 \\
.08 \\
.06\end{array}$ & $\begin{array}{r}71.0 \\
15.13 \\
.82 \\
.91 \\
.38 \\
1.29 \\
5.27 \\
3.68 \\
.15 \\
.34 \\
.07 \\
.11 \\
.05 \\
.03 \\
.06 \\
.05\end{array}$ & $\begin{array}{r}71.6 \\
15.37 \\
.70 \\
.82 \\
.35 \\
1.24 \\
5.26 \\
3.61 \\
.11 \\
.31 \\
.05 \\
.12 \\
.04 \\
-.- \\
.05 \\
--.\end{array}$ & $\begin{array}{r}75.4 \\
13.22 \\
.56 \\
.65 \\
.20 \\
.84 \\
4.32 \\
4.18 \\
.11 \\
.21 \\
.03 \\
.05 \\
.10 \\
.09 \\
.04 \\
.04\end{array}$ & $\begin{array}{r}77.3 \\
12.41 \\
.44 \\
.26 \\
.04 \\
.39 \\
4.05 \\
4.52 \\
.06 \\
.10 \\
.01 \\
.07 \\
.08 \\
.06 \\
.12 \\
.11\end{array}$ & $\begin{array}{r}72.6 \\
14.21 \\
.84 \\
1.31 \\
.53 \\
1.97 \\
4.69 \\
3.08 \\
.25 \\
.34 \\
.05 \\
.07 \\
.06 \\
.05 \\
.03 \\
.03\end{array}$ & $\begin{array}{r}72.8 \\
14.34 \\
.76 \\
1.41 \\
.55 \\
1.90 \\
4.64 \\
3.02 \\
.12 \\
.34 \\
.05 \\
.07 \\
.05 \\
.06 \\
.03 \\
.03\end{array}$ & $\begin{array}{r}73.1 \\
14.02 \\
.46 \\
1.30 \\
.39 \\
1.58 \\
4.54 \\
3.20 \\
.08 \\
.31 \\
.04 \\
.05 \\
.07 \\
--.04 \\
.-\end{array}$ & $\begin{array}{r}66.8 \\
16.13 \\
.54 \\
3.00 \\
1.33 \\
3.57 \\
4.84 \\
2.32 \\
.51 \\
.64 \\
.11 \\
.08 \\
.07 \\
-. \\
.06 \\
--\end{array}$ \\
\hline $\begin{array}{l}\text { Subtotal } \\
\text { Less } 0=(F, C l)_{2}\end{array}$ & $\begin{array}{r}99.39 \\
.03\end{array}$ & $\begin{array}{r}99.58 \\
.07\end{array}$ & $\begin{array}{r}99.46 \\
.05\end{array}$ & $\begin{array}{r}99.25 \\
.03\end{array}$ & $\begin{array}{r}99.63 \\
.03\end{array}$ & $\begin{array}{r}99.91 \\
.04\end{array}$ & $\begin{array}{r}99.84 \\
.06\end{array}$ & $\begin{array}{r}100.03 \\
.02\end{array}$ & $\begin{array}{r}100.09 \\
.02\end{array}$ & $\begin{array}{r}99.18 \\
.03\end{array}$ & $\begin{array}{r}100.00 \\
.04\end{array}$ \\
\hline Total- & 99.36 & 99.51 & 99.41 & 99.22 & 99.60 & 99.87 & 99.78 & 100.01 & 100.07 & 99.15 & 99.96 \\
\hline $\mathrm{Fe}_{\mathrm{t}} \mathrm{t}^{1}$ & 1.14 & 2.62 & 1.58 & 1.65 & 1.45 & 1.15 & .66 & 2.07 & 2.09 & 1.71 & 3.49 \\
\hline $\left.\mathrm{Fe} 0 /\left(\mathrm{Fe} 0+\mathrm{Fe}_{2}{ }_{3}\right)^{1}\right)^{1} \ldots$ & .80 & .77 & .56 & .53 & .54 & .54 & .37 & .61 & .65 & .74 & .85 \\
\hline $\mathrm{Na}_{2} \mathrm{O} / \mathrm{K}_{2} \mathrm{O}^{\mathrm{l}} \ldots$ & .92 & 1.21 & 1.47 & 1.43 & 1.46 & 1.03 & .90 & 1.52 & 1.54 & 1.42 & 2.09 \\
\hline$\left(\mathrm{Na}_{2} \mathrm{O}+\mathrm{K}_{2} \mathrm{O}\right) / \mathrm{Al}_{2} \mathrm{O}_{3}{ }^{2}-\ldots$ & .80 & .89 & .82 & .84 & .82 & .88 & .93 & .78 & .76 & .78 & .65 \\
\hline$\left(\mathrm{CaO}+\mathrm{Na}_{2} \mathrm{O}+\mathrm{K}_{2} \mathrm{O}\right) / \mathrm{Al}_{2} \mathrm{O}_{3}{ }^{2}---$ & .95 & 1.06 & .99 & .99 & .96 & 1.00 & .99 & 1.03 & 1.00 & .98 & 1.05 \\
\hline $\mathrm{CaO} /\left(\mathrm{Na}_{2} \mathrm{O}+\mathrm{K}_{2} \mathrm{O}\right)^{1} \ldots$ & .14 & .14 & .16 & .14 & .14 & .10 & .05 & .25 & .25 & .20 & .50 \\
\hline $\mathrm{Cl} / \mathrm{F}^{1+}$ & 3.3 & 3.2 & 1.4 & .79 & .83 & 2.5 & .60 & 1.9 & 2.1 & 1.9 & 1.2 \\
\hline
\end{tabular}

CIPW norms

\begin{tabular}{|c|c|c|c|c|c|c|c|c|c|c|c|}
\hline Q- & 37.63 & 27.54 & 36.48 & 23.07 & 24.00 & 32.15 & 35.69 & 28,35 & 28.84 & 30.17 & 19.01 \\
\hline or & 23.37 & 23.09 & $\begin{array}{l}30.40 \\
17.52\end{array}$ & 22.00 & $\begin{array}{l}4.00 \\
21.46\end{array}$ & $\begin{array}{l}3.10 \\
24.79\end{array}$ & $\begin{array}{r}3.09 \\
26.82\end{array}$ & $\begin{array}{l}28.35 \\
18.26\end{array}$ & $\begin{array}{l}20.04 \\
17.87\end{array}$ & 19.10 & 13.01 \\
\hline ab--.--a-d & 30.73 & 39.89 & 36.86 & 45.04 & 44.76 & 36.68 & 34.41 & 39.81 & 39.31 & 38.81 & 41.22 \\
\hline an & 5.15 & 3.93 & 5.67 & 6.00 & 5.86 & 3.99 & 1.88 & 8.65 & 9.11 & 7.65 & 15.53 \\
\hline $\mathrm{C}-1-1$ & .71 & -- & .20 & .30 & .68 & .13 & .17 & -- & .10 & .31 & -- \\
\hline ac---_-_-_.-. & -. & -- & $\ldots$ & -- & -- & -- & -- & -. & -. & -- & -- \\
\hline ns $-\cdots$ & -- & .- & _- & .. & -- & -- & -.- & _- & -- & -- & -- \\
\hline wo ? & -- & .87 & -- & -- & -- & -- & -- & .34 & - & -- & .65 \\
\hline $\begin{array}{l}\text { wo } \\
\text { en }\end{array}$ & -. & .06 & .. & .- & - & $\ldots$ & .- & .34 & - & -- & .29 \\
\hline fs & -- & .00 & 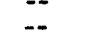 & -. & -- & -- & -- & .17 & $-\overline{-}$ & $\overline{--}$ - + r +1 & .09 \\
\hline en ? he- & .38 & .14 & .85 & .96 & .88 & .50 & .10 & 1.15 & 1.37 & .98 & 3.04 \\
\hline fs $\}$ hy-- & 1.41 & 2.27 & .90 & .64 & .64 & .48 & .08 & 1.12 & 1.53 & 1.60 & 3.82 \\
\hline$m t-1$ & .34 & .91 & 1.05 & 1.20 & 1.02 & .82 & .64 & 1.22 & 1.10 & .67 & .79 \\
\hline i 1 b & .25 & .34 & .40 & .65 & .59 & .40 & .19 & .65 & .65 & .60 & 1.22 \\
\hline & .02 & .05 & .05 & .16 & .12 & .07 & .02 & .012 & -0 & .09 & .26 \\
\hline
\end{tabular}




\begin{tabular}{|c|c|c|c|c|c|c|c|c|c|c|c|}
\hline & 1 & 2 & 3 & 4 & 5 & 6 & 7 & 8 & 9 & 10 & 11 \\
\hline \multicolumn{12}{|c|}{ Trace elements (ppm) } \\
\hline 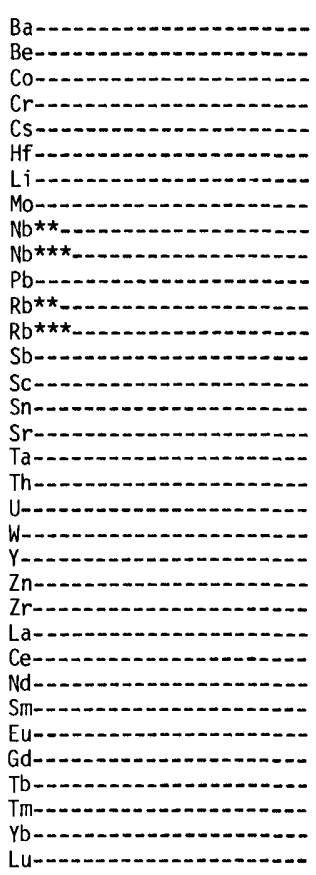 & $\begin{array}{c}925 . \\
1.6 \\
.9 \\
<2.0 \\
11.4 \\
3.4 \\
68 . \\
2.3 \\
5.2 \\
6 . \\
22 . \\
162 . \\
170 . \\
2.3 \\
2.0 \\
3.4 \\
105 . \\
.55 \\
15.5 \\
7.2 \\
2.2 \\
21 . \\
20 . \\
100 . \\
21 . \\
38 . \\
17 . \\
3.0 \\
.40 \\
<3.0 \\
<.30 \\
.27 \\
1.7 \\
.27\end{array}$ & $\begin{array}{c}1285 . \\
3.2 \\
.5 \\
<7.0 \\
6.9 \\
10.9 \\
44 . \\
4.2 \\
13 . \\
16 . \\
44 . \\
96 . \\
100 . \\
1.7 \\
6.4 \\
3.6 \\
97 . \\
1.03 \\
10.1 \\
4.5 \\
2.0 \\
85 . \\
108 . \\
420 . \\
37 . \\
79 . \\
46 . \\
11.8 \\
1.65 \\
10.5 \\
2.0 \\
1.3 \\
8.9 \\
1.30\end{array}$ & $\begin{array}{c}952 . \\
1.6 \\
1.6 \\
1.6 \\
2.3 \\
4.9 \\
35 . \\
2.5 \\
5.3 \\
5 . \\
9 . \\
64 . \\
66 . \\
1.2 \\
8.4 \\
1.0 \\
86 . \\
.44 \\
5.0 \\
2.1 \\
1.3 \\
48 . \\
31 . \\
157 . \\
19 . \\
39 . \\
20 . \\
5.6 \\
.78 \\
6.1 \\
1.14 \\
.55 \\
4.6 \\
.67\end{array}$ & $\begin{array}{c}1085 . \\
2.5 \\
.4 \\
1.7 \\
1.8 \\
7.5 \\
29 . \\
5.0 \\
19 . \\
17 . \\
30 . \\
93 . \\
105 . \\
.7 \\
2.4 \\
1.3 \\
305 . \\
1.24 \\
11.6 \\
4.1 \\
.74 \\
24 . \\
52 . \\
360 . \\
38 . \\
71 . \\
30 . \\
5.5 \\
1.11 \\
3.8 \\
.62 \\
.37 \\
2.6 \\
.38\end{array}$ & $\begin{array}{c}1070 . \\
--.4 \\
<2.0 \\
2.3 \\
7.6 \\
-- \\
-- \\
--. \\
19 . \\
97 . \\
100 . \\
.8 \\
2.6 \\
--. \\
255 . \\
1.37 \\
12.5 \\
4.1 \\
-- \\
32 . \\
56 . \\
286 . \\
43 . \\
78 . \\
33 . \\
5.7 \\
1.07 \\
3.7 \\
.72 \\
.45 \\
2.8 \\
.43\end{array}$ & $\begin{array}{c}670 . \\
2.2 \\
.9 \\
<5.0 \\
3.0 \\
4.2 \\
36 . \\
4.9 \\
14 . \\
13 . \\
15 . \\
109 . \\
100 . \\
.7 \\
2.3 \\
1.0 \\
100 . \\
1.30 \\
11.8 \\
5.6 \\
1.1 \\
14 . \\
30 . \\
157 . \\
25 . \\
36 . \\
16 . \\
3.0 \\
.38 \\
1.8 \\
.39 \\
.26 \\
2.0 \\
.30\end{array}$ & $\begin{array}{c}33 . \\
5.4 \\
<.3 \\
<4.0 \\
3.4 \\
4.3 \\
47 . \\
8.2 \\
30 . \\
34 . \\
39 . \\
169 . \\
170 . \\
1.1 \\
1.8 \\
2.5 \\
2 . \\
2.40 \\
40.1 \\
14.4 \\
1.9 \\
30 . \\
31 . \\
106 . \\
30 . \\
47 . \\
14 . \\
3.0 \\
.14 \\
2.9 \\
.59 \\
.44 \\
3.9 \\
.59\end{array}$ & $\begin{array}{c}835 . \\
1.5 \\
3.0 \\
2.0 \\
3.0 \\
4.7 \\
30 . \\
2.8 \\
13 . \\
12 . \\
21 . \\
76 . \\
84 . \\
.5 . \\
3.8 \\
1.5 \\
255 . \\
.82 \\
7.3 \\
3.0 \\
1.1 \\
23 . \\
41 . \\
171 . \\
21 . \\
39 . \\
17 . \\
2.9 \\
.63 \\
2.9 \\
.41 \\
.33 \\
1.8 \\
.29\end{array}$ & $\begin{array}{c}815 . \\
1.4 \\
3.1 \\
2.2 \\
2.8 \\
4.5 \\
32 . \\
2.8 \\
11 . \\
10 . \\
18 . \\
70 . \\
79 . \\
<.8 \\
3.8 \\
1.5 \\
250 . \\
.89 \\
7.4 \\
3.2 \\
1.3 \\
25 . \\
37 . \\
178 . \\
21 . \\
39 . \\
17 . \\
2.9 \\
.62 \\
2.6 \\
.43 \\
.21 \\
1.8 \\
.29\end{array}$ & $\begin{array}{c}980 . \\
-- \\
2.2 \\
<3.0 \\
2.9 \\
4.8 \\
-- \\
-- \\
-- \\
12 . \\
12 . \\
74 . \\
77 . \\
.6 \\
3.8 \\
-- \\
215 . \\
.96 \\
8.3 \\
3.3 \\
-- \\
23 . \\
34 . \\
183 . \\
22 . \\
40 . \\
17 . \\
3.4 \\
.63 \\
3.5 \\
.43 \\
.26 \\
2.0 \\
.33\end{array}$ & $\begin{array}{c}685 . \\
1 \overline{-} \\
11.2^{3} \\
153.0^{3} \\
3.2 \\
5.9 \\
-- \\
-- \\
7 . \\
7 . \\
12 . \\
52 . \\
53 . \\
1.4 \\
9.0 \\
-- \\
444 . \\
2.41^{3} \\
5.4 \\
2.3 \\
-- \\
25 . \\
42 . \\
218 . \\
21 . \\
43 . \\
24 . \\
4.8 \\
1.04 \\
4.6 \\
.55 \\
.36 \\
2.6 \\
.36\end{array}$ \\
\hline $\begin{array}{l}\mathrm{Nb} / \mathrm{Ta}- \\
\mathrm{K} / \mathrm{Rb}- \\
\mathrm{Rb} / \mathrm{Sr} \\
\mathrm{Ca} / \mathrm{Sr}- \\
\mathrm{Th} / \mathrm{U}- \\
\mathrm{Zr} / \mathrm{Hf}- \\
\mathrm{Ce} / \mathrm{Yb}- \\
\mathrm{Eu} / \mathrm{Eu}{ }^{\mathrm{N}} \mathrm{-}\end{array}$ & $\begin{array}{c}10.2 \\
191 . \\
1.6 \\
71.0 \\
2.2 \\
29 . \\
22.4 \\
--\end{array}$ & $\begin{array}{c}14.1 \\
322 . \\
1.0 \\
91.0 \\
2.2 \\
39 . \\
8.9 \\
.46\end{array}$ & $\begin{array}{c}11.7 \\
370 . \\
.77 \\
112 . \\
2.4 \\
32 . \\
8.5 \\
.41\end{array}$ & $\begin{array}{l}14.5 \\
290 . \\
.34 \\
35 . \\
2.8 \\
48 . \\
27.3 \\
.75\end{array}$ & $\begin{array}{c}300 . \\
.39 \\
35 . \\
3.1 \\
38 . \\
27.9 \\
.72\end{array}$ & $\begin{array}{c}10.4 \\
347 . \\
1.0 \\
70 . \\
2.1 \\
37 . \\
18.0 \\
.50\end{array}$ & $\begin{array}{c}13.3 \\
221 . \\
85 . \\
1394 . \\
2.8 \\
25 . \\
12.1 \\
.14\end{array}$ & $\begin{array}{c}15.2 \\
304 . \\
.33 \\
55 . \\
2.4 \\
36 . \\
21.7 \\
.67\end{array}$ & $\begin{array}{l}11.8 \\
317 . \\
.32 \\
54 . \\
2.3 \\
40 . \\
21.7 \\
.69\end{array}$ & $\begin{array}{l}12.5 \\
345 . \\
.36 \\
53 . \\
2.5 \\
38.0 \\
20.0 \\
.57\end{array}$ & $\begin{array}{l}36 \overline{3 .} \\
.12 \\
58 . \\
2.4 \\
37 . \\
16.5 \\
.68\end{array}$ \\
\hline
\end{tabular}

See footnotes at end of table. 


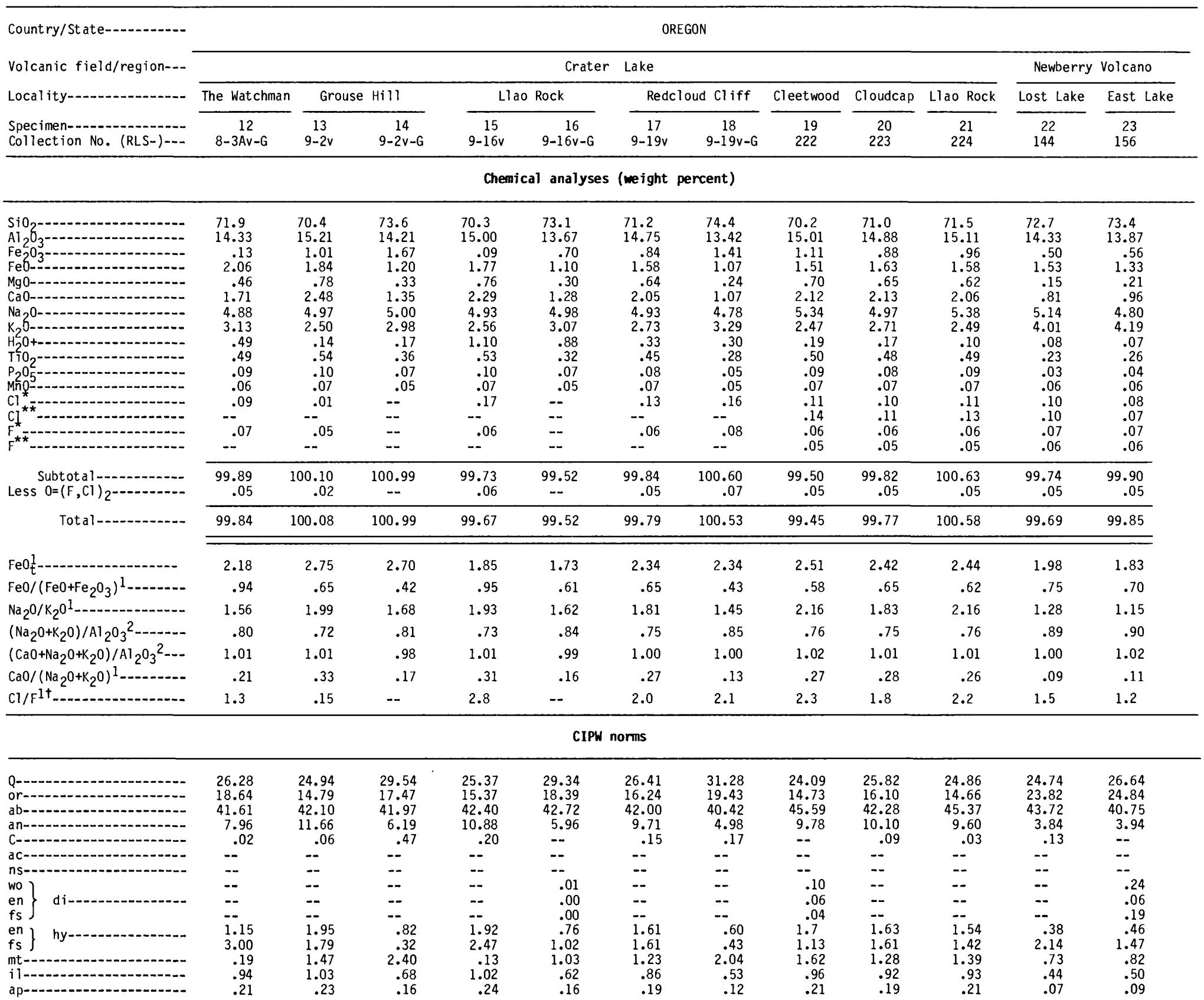




\begin{tabular}{|c|c|c|c|c|c|c|c|c|c|c|c|c|}
\hline & 12 & 13 & 14 & 15 & 16 & 17 & 18 & 19 & 20 & 21 & 22 & 23 \\
\hline \multicolumn{13}{|c|}{ Trace elements (ppm) } \\
\hline 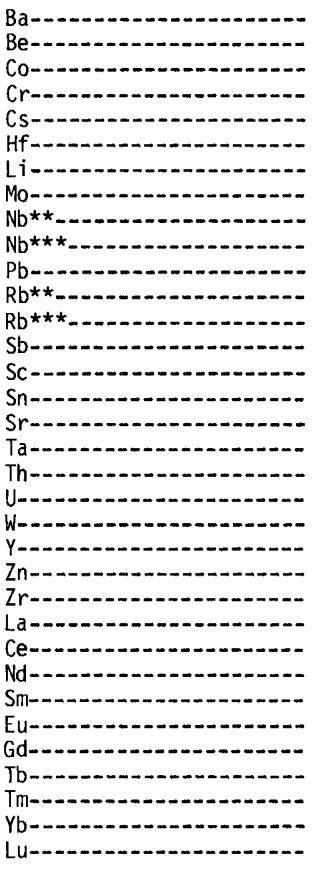 & $\begin{array}{c}847 . \\
\overline{6 .} .^{3} \\
92.3 \\
4.4 \\
7.5 \\
-- \\
-- \\
-- \\
9 . \\
14 . \\
60 . \\
72 . \\
1.9 \\
6.1 \\
-- \\
248 . \\
32.33 \\
7.0 \\
3.3 \\
32 . \\
39 . \\
285 . \\
24 . \\
52 . \\
28 . \\
5.6 \\
.93 \\
5.6 \\
.80 \\
.37 \\
3.1 \\
.44\end{array}$ & $\begin{array}{c}790 . \\
\overline{4.5} \\
-- \\
1.8 \\
5.7 \\
-- \\
-- \\
-. \\
8 . \\
12 . \\
61 . \\
60 . \\
.8 \\
7.7 \\
-. \\
344 . \\
.56 \\
5.6 \\
2.6 \\
22 . \\
31 . \\
217 . \\
18 . \\
35 . \\
20 . \\
4.2 \\
.96 \\
4.1 \\
.58 \\
.40 \\
2.3 \\
.36\end{array}$ & $\begin{array}{c}786 . \\
\ddot{2.1} \\
1.3 \\
2.1 \\
6.4 \\
-- \\
-. \\
-- \\
9 . \\
14 . \\
67 . \\
75 . \\
-- \\
5.4 \\
-- \\
205 . \\
.55 \\
6.6 \\
3.3 \\
-- \\
23 . \\
26 . \\
232 . \\
17 . \\
33 . \\
18 . \\
4.3 \\
.89 \\
4.1 \\
.52 \\
.45 \\
2.4 \\
.36\end{array}$ & $\begin{array}{c}748 . \\
\ddot{4.3} \\
2.2 \\
4.0 \\
6.1 \\
-- \\
-- \\
-. \\
8 . \\
13 . \\
61 . \\
63 . \\
.9 \\
7.5 \\
-. \\
327 . \\
.61 \\
6.0 \\
2.9 \\
28 . \\
35 . \\
225 . \\
22 . \\
45 . \\
26 . \\
5.6 \\
.99 \\
4.8 \\
.70 \\
.54 \\
2.7 \\
.40\end{array}$ & $\begin{array}{c}802 . \\
-. \\
1.9 \\
<2.0 \\
4.7 \\
6.8 \\
-- \\
-- \\
-- \\
8 . \\
14 . \\
76 . \\
80 . \\
-- \\
5.4 \\
-- \\
195 . \\
.59 \\
7.3 \\
3.6 \\
30 . \\
35 . \\
236 . \\
25 . \\
49 . \\
27 . \\
5.5 \\
.86 \\
5.2 \\
.66 \\
.55 \\
2.9 \\
.42\end{array}$ & $\begin{array}{c}798 . \\
\overline{3.8} \\
-- \\
4.1 \\
6.4 \\
-- \\
-- \\
-- \\
9 . \\
16 . \\
67 . \\
70 . \\
0.9 \\
6.9 \\
-- \\
300 . \\
.54 \\
6.4 \\
3.3 \\
27 . \\
36 . \\
226 . \\
22 . \\
45 . \\
26 . \\
5.2 \\
.92 \\
5.6 \\
.65 \\
.43 \\
2.7 \\
.40\end{array}$ & $\begin{array}{c}817 . \\
-. \\
1.6 \\
2.0 \\
5.0 \\
5.9 \\
-- \\
-- \\
-- \\
8 . \\
18 . \\
79 . \\
84 . \\
0.9 \\
4.4 \\
-- \\
158 . \\
.57 \\
7.4 \\
3.3 \\
30 . \\
30 . \\
214 . \\
25 . \\
49 . \\
25 . \\
5.4 \\
.74 \\
5.0 \\
.75 \\
.45 \\
2.8 \\
.42\end{array}$ & $\begin{array}{c}782 . \\
3.3 \\
3.8 \\
2.5 \\
3.1 \\
5.8 \\
28 . \\
1.6 \\
6.8 \\
8 . \\
13 . \\
56 . \\
52 . \\
1.2 \\
6.6 \\
1.1 \\
402 . \\
.52 \\
4.9 \\
2.3 \\
.60 \\
24 . \\
42 . \\
220 . \\
22 . \\
42 . \\
22 . \\
4.6 \\
.93 \\
4.3 \\
.69 \\
.31 \\
2.3 \\
.34\end{array}$ & $\begin{array}{c}821 . \\
2.0 \\
4.0 \\
3.0 \\
4.1 \\
6.5 \\
35 . \\
1.8 \\
6.8 \\
8 . \\
11 . \\
71 . \\
65 . \\
-. \\
7.4 \\
1.6 \\
291 . \\
.60 \\
6.1 \\
3.0 \\
.66 \\
27 . \\
34 . \\
233 . \\
22 . \\
45 . \\
27 . \\
5.4 \\
.97 \\
5.3 \\
.82 \\
.38 \\
2.7 \\
.39\end{array}$ & $\begin{array}{c}820 . \\
2.0 \\
3.4 \\
1.1 \\
3.4 \\
5.9 \\
35 . \\
1.6 \\
6.4 \\
8 . \\
13 . \\
60 . \\
56 . \\
. . \\
6.5 \\
1.2 \\
326 . \\
.50 \\
5.1 \\
2.5 \\
.50 \\
25 . \\
43 . \\
228 . \\
21 . \\
43 . \\
23 . \\
4.8 \\
.94 \\
4.5 \\
.73 \\
.35 \\
2.7 \\
.36\end{array}$ & $\begin{array}{c}895 . \\
2.9 \\
0.8 \\
<5.0 \\
5.0 \\
8.6 \\
43 . \\
3.9 \\
19 . \\
22 . \\
17 . \\
111 . \\
122 . \\
<0.5 \\
5.5 \\
4.0 \\
50 . \\
1.82 \\
11.2 \\
4.9 \\
1.7 \\
50 . \\
48 . \\
337 . \\
32 . \\
64 . \\
28 . \\
7.1 \\
.79 \\
5.6 \\
.90 \\
.89 \\
4.9 \\
.72\end{array}$ & $\begin{array}{c}910 . \\
2.9 \\
1.4 \\
2.3 \\
5.1 \\
7.5 \\
47 . \\
3.3 \\
19 . \\
20 . \\
28 . \\
150 . \\
136 . \\
0.4 \\
4.9 \\
4.3 \\
75 . \\
1.46 \\
11.9 \\
4.2 \\
2.1 \\
49 . \\
46 . \\
280 . \\
30 . \\
64 . \\
25 . \\
6.5 \\
.75 \\
5.6 \\
1.08 \\
.78 \\
4.6 \\
.62\end{array}$ \\
\hline 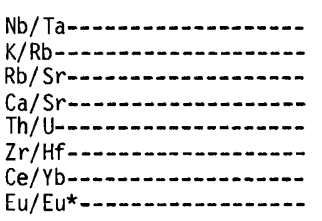 & $\begin{array}{l}36 \overline{1 .} \\
.29 \\
49 . \\
2.1 \\
38 . \\
16.8 \\
.51\end{array}$ & $\begin{array}{c}14.3 \\
346 . \\
.17 \\
52 . \\
2.2 \\
38 . \\
15.2 \\
.71\end{array}$ & $\begin{array}{l}16.4 \\
330 . \\
.37 \\
47 . \\
2.0 \\
36 . \\
13.8 \\
.64\end{array}$ & $\begin{array}{l}13.1 \\
337 . \\
.19 \\
50 . \\
2.1 \\
37 . \\
16.7 \\
.59\end{array}$ & $\begin{array}{l}13.6 \\
319 . \\
.41 \\
47.0 \\
2.0 \\
35 . \\
16.9 \\
.50\end{array}$ & $\begin{array}{l}16.7 \\
324 . \\
. .23 \\
49.8 \\
1.9 \\
35 . \\
16.7 \\
.60\end{array}$ & $\begin{array}{c}14.0 \\
325 . \\
.53 \\
48 . \\
2.2 \\
36 . \\
17.5 \\
.44\end{array}$ & $\begin{array}{l}14.2 \\
394 . \\
.13 \\
38 . \\
2.1 \\
38 . \\
18.3 \\
.64\end{array}$ & $\begin{array}{l}12.3 \\
346 . \\
.22 \\
52 . \\
2.0 \\
36 . \\
16.7 \\
.56\end{array}$ & $\begin{array}{l}14.4 \\
369 . \\
.17 \\
45 . \\
2.0 \\
39 . \\
15.9 \\
.62\end{array}$ & $\begin{array}{c}11.3 \\
273 . \\
2.4 \\
116 . \\
2.3 \\
39 . \\
13.1 \\
.38\end{array}$ & $\begin{array}{c}13.4 \\
256 . \\
1.8 \\
92 . \\
2.8 \\
37 . \\
13.9 \\
.38\end{array}$ \\
\hline
\end{tabular}

See footnotes at end of table. 


\begin{tabular}{|c|c|c|c|c|c|c|c|c|c|c|c|}
\hline \multirow{3}{*}{ 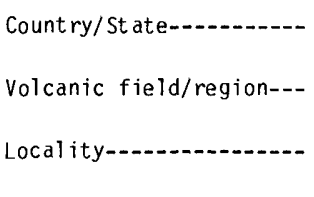 } & \multicolumn{11}{|c|}{ OREGON } \\
\hline & \multicolumn{11}{|c|}{ Southeast Oregon } \\
\hline & East Butte & $\begin{array}{l}\text { Quartz } \\
\text { Mountain }\end{array}$ & $\begin{array}{l}\text { Cougar } \\
\text { Mountain }\end{array}$ & $\begin{array}{l}\text { Glass } \\
\text { Buttes }\end{array}$ & Riley & $\begin{array}{l}\text { Horse } \\
\text { Mountain }\end{array}$ & $\begin{array}{l}\text { Drewes } \\
\text { Ranch }\end{array}$ & $\begin{array}{l}\text { Tucker } \\
\text { Hil1 }\end{array}$ & $\begin{array}{l}\text { McComb } \\
\text { Butte }\end{array}$ & $\begin{array}{l}\text { Orijana } \\
\text { Canyon }\end{array}$ & $\begin{array}{l}\text { Beatys } \\
\text { Butte }\end{array}$ \\
\hline $\begin{array}{l}\text { Specimen-1 } \\
\text { Collection No. (RLS-) }\end{array}$ & $\begin{array}{r}24 \\
159\end{array}$ & $\begin{array}{r}25 \\
157\end{array}$ & $\begin{array}{r}26 \\
162\end{array}$ & $\begin{array}{r}27 \\
158\end{array}$ & $\begin{array}{r}28 \\
154\end{array}$ & $\begin{array}{l}29 \\
54\end{array}$ & $\begin{array}{r}30 \\
163\end{array}$ & $\begin{array}{r}31 \\
161\end{array}$ & $\begin{array}{r}32 \\
155\end{array}$ & $\begin{array}{r}33 \\
164\end{array}$ & $\begin{array}{r}34 \\
160\end{array}$ \\
\hline \multicolumn{12}{|c|}{ Chemical analyses (weight percent) } \\
\hline 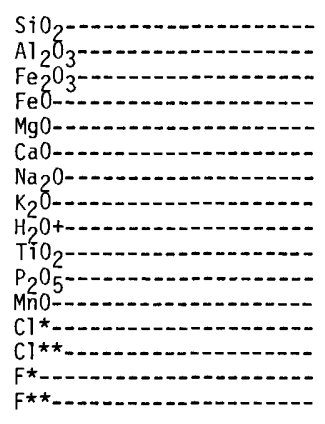 & $\begin{array}{l}74.9 \\
13.71 \\
.46 \\
1.22 \\
.05 \\
1.00 \\
4.57 \\
3.74 \\
.14 \\
.12 \\
.01 \\
.05 \\
.06 \\
.05 \\
.05 \\
.05\end{array}$ & $\begin{array}{r}74.3 \\
13.34 \\
.35 \\
1.17 \\
.05 \\
.84 \\
4.55 \\
4.03 \\
.09 \\
.12 \\
.01 \\
.05 \\
.07 \\
.06 \\
.07 \\
.06\end{array}$ & $\begin{array}{r}77.3 \\
12.66 \\
.37 \\
.75 \\
.03 \\
.64 \\
4.34 \\
3.65 \\
.09 \\
.07 \\
.01 \\
.05 \\
.06 \\
.05 \\
.06 \\
.02\end{array}$ & $\begin{array}{r}76.6 \\
13.11 \\
.28 \\
.60 \\
.09 \\
.85 \\
3.90 \\
4.28 \\
.11 \\
.12 \\
.02 \\
.05 \\
.03 \\
.02 \\
.04 \\
.03\end{array}$ & $\begin{array}{r}73.8 \\
13.23 \\
.71 \\
1.55 \\
.08 \\
.50 \\
4.99 \\
4.60 \\
.07 \\
.23 \\
.02 \\
.10 \\
.09 \\
.07 \\
.07 \\
.07\end{array}$ & $\begin{array}{c}76.4 \\
10.82 \\
1.23 \\
1.52 \\
<.005 \\
.17 \\
4.74 \\
4.48 \\
.08 \\
.18 \\
.01 \\
.08 \\
.10 \\
.09 \\
.09 \\
.09\end{array}$ & $\begin{array}{l}76.3 \\
12.64 \\
.30 \\
.41 \\
.03 \\
.49 \\
4.04 \\
4.46 \\
.19 \\
.06 \\
.01 \\
.07 \\
.04 \\
.04 \\
.04 \\
.03\end{array}$ & $\begin{array}{r}76.7 \\
13.23 \\
.15 \\
.50 \\
.05 \\
.78 \\
4.02 \\
4.48 \\
.09 \\
.06 \\
.01 \\
.07 \\
.04 \\
.04 \\
.11 \\
.10\end{array}$ & $\begin{array}{l}76.3 \\
13.30 \\
.18 \\
.41 \\
.05 \\
.91 \\
3.95 \\
4.57 \\
.11 \\
.06 \\
.01 \\
.07 \\
.02 \\
.04 \\
.04 \\
.03\end{array}$ & $\begin{array}{r}76.9 \\
11.92 \\
.45 \\
.41 \\
.04 \\
.27 \\
3.82 \\
4.95 \\
.13 \\
.13 \\
.01 \\
.09 \\
.06 \\
.05 \\
.09 \\
.08\end{array}$ & $\begin{array}{r}74.0 \\
13.78 \\
.36 \\
.77 \\
.15 \\
1.16 \\
3.71 \\
4.93 \\
.11 \\
.17 \\
.03 \\
.06 \\
.03 \\
.02 \\
.02 \\
.02\end{array}$ \\
\hline $\begin{array}{l}\text { Subtotal } 1-. . . \\
\text { Less } 0=(F, C l)_{2}\end{array}$ & $\begin{array}{r}100.08 \\
.03 \\
\end{array}$ & $\begin{array}{r}99.04 \\
.04 \\
\end{array}$ & $\begin{array}{r}100.08 \\
.04 \\
\end{array}$ & $\begin{array}{r}100.08 \\
.02 \\
\end{array}$ & $\begin{array}{r}100.03 \\
.05 \\
\end{array}$ & $\begin{array}{r}99.90 \\
.06 \\
\end{array}$ & $\begin{array}{r}99.08 \\
.03 \\
\end{array}$ & $\begin{array}{r}100.29 \\
.05 \\
\end{array}$ & $\begin{array}{r}99.99 \\
.02 \\
\end{array}$ & $\begin{array}{r}99.27 \\
.05 \\
\end{array}$ & $\begin{array}{r}99.28 \\
.02 \\
\end{array}$ \\
\hline Total---------.-- & 100.05 & 99.00 & 100.04 & 100.06 & 99.98 & 99.84 & 99.05 & 100.24 & 99.97 & 99.22 & 99.26 \\
\hline $\mathrm{Fe}_{\mathrm{t}}^{1}-$ & 1.63 & 1.49 & 1.08 & 0.85 & 2.19 & 2.63 & 0.68 & 0.64 & 0.57 & 0.82 & 1.09 \\
\hline $\mathrm{Fe} 0 /\left(\mathrm{Fe} 0+\mathrm{Fe}_{2} \mathrm{O}_{3}\right)^{1} \ldots$ & .73 & .77 & .67 & .68 & .69 & .55 & .58 & .77 & .69 & .48 & .68 \\
\hline $\mathrm{Na}_{2} \mathrm{O} / \mathrm{K}_{2} \mathrm{O}^{\mathrm{l}} \ldots$ & 1.22 & 1.13 & 1.19 & .91 & 1.08 & 1.06 & .91 & .90 & .86 & .77 & .75 \\
\hline$\left(\mathrm{Na}_{2} \mathrm{O}+\mathrm{K}_{2} \mathrm{O}\right) / \mathrm{Al}_{2} \mathrm{O}_{3}{ }^{2} \cdots$ & .84 & .89 & .88 & .84 & 1.00 & 1.17 & .91 & .87 & .86 & .97 & .83 \\
\hline$\left(\mathrm{CaO}+\mathrm{Na}_{2} \mathrm{O}+\mathrm{K}_{2} \mathrm{O}\right) / \mathrm{Al}_{2} \mathrm{O}_{3}{ }^{2}-\cdots$ & .98 & 1.00 & .97 & .96 & 1.06 & 1.20 & .98 & .97 & .98 & 1.01 & .98 \\
\hline $\mathrm{CaO} /\left(\mathrm{Na}_{2} \mathrm{O}+\mathrm{K}_{2} \mathrm{O}\right)^{1}$ & .12 & .10 & .08 & .10 & .05 & .02 & .06 & .09 & .11 & .03 & .13 \\
\hline $\mathrm{Cl} / \mathrm{F}^{1+} \mathrm{H}^{2}$ & 1.1 & 1.0 & .83 & .61 & 1.1 & 1.1 & 1.0 & .38 & .74 & .65 & 1.2 \\
\hline \multicolumn{12}{|c|}{ CIPW norms } \\
\hline 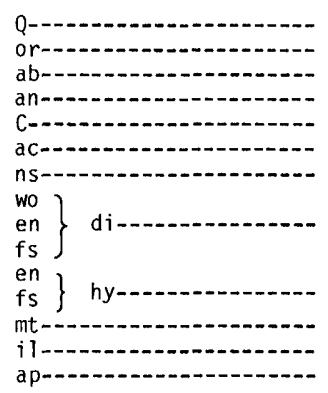 & $\begin{array}{c}31.07 \\
22.14 \\
38.74 \\
4.90 \\
.35 \\
-.- \\
-- \\
-- \\
-- \\
-.13 \\
.136 \\
.67 \\
.23 \\
.02\end{array}$ & $\begin{array}{c}30.13 \\
24.10 \\
38.97 \\
4.12 \\
-- \\
-- \\
-- \\
.01 \\
.00 \\
.01 \\
.13 \\
1.76 \\
.51 \\
.23 \\
.02\end{array}$ & $\begin{array}{c}36.27 \\
21.60 \\
36.77 \\
3.11 \\
.43 \\
-. \\
-- \\
-- \\
-- \\
-. \\
.08 \\
1.05 \\
.54 \\
.13 \\
.02\end{array}$ & $\begin{array}{c}35.32 \\
25.32 \\
33.03 \\
4.09 \\
.57 \\
-- \\
-- \\
-- \\
-- \\
-- \\
.22 \\
.77 \\
.41 \\
.23 \\
.05\end{array}$ & $\begin{array}{l}25.63 \\
27.23 \\
42.30 \\
.12 \\
-- \\
-. \\
-- \\
.94 \\
.09 \\
.94 \\
.11 \\
1.13 \\
1.03 \\
.44 \\
.05\end{array}$ & $\begin{array}{l}34.43 \\
26.57 \\
30.83 \\
-- \\
-- \\
3.57 \\
1.25 \\
.33 \\
.00 \\
.37 \\
.00 \\
2.28 \\
.00 \\
.34 \\
.02\end{array}$ & $\begin{array}{c}34.84 \\
26.67 \\
34.60 \\
2.39 \\
.30 \\
-- \\
-- \\
-- \\
-- \\
-.08 \\
.54 \\
.44 \\
.12 \\
.02\end{array}$ & $\begin{array}{c}34.06 \\
26.46 \\
34.00 \\
3.80 \\
.37 \\
-- \\
-- \\
-\therefore \\
-- \\
-- \\
.12 \\
.83 \\
.22 \\
.11 \\
.02\end{array}$ & $\begin{array}{c}33.30 \\
27.24 \\
33.54 \\
4.17 \\
-- \\
-- \\
- \\
.12 \\
.01 \\
.12 \\
.12 \\
.53 \\
.22 \\
.15 \\
.02\end{array}$ & $\begin{array}{l}35.44 \\
29.55 \\
32.65 \\
.77 \\
-- \\
-- \\
-- \\
.22 \\
.05 \\
.18 \\
.05 \\
.16 \\
.66 \\
.25 \\
.02\end{array}$ & $\begin{array}{c}30.77 \\
29.39 \\
31.67 \\
5.61 \\
.31 \\
-. \\
-- \\
-- \\
-. \\
-- \\
.38 \\
.96 \\
.53 \\
.33 \\
.07\end{array}$ \\
\hline
\end{tabular}




\begin{tabular}{|c|c|c|c|c|c|c|c|c|c|c|c|}
\hline & 24 & 25 & 26 & 27 & 28 & 29 & 30 & 31 & 32 & 33 & 34 \\
\hline \multicolumn{12}{|c|}{ Trace elements (ppm) } \\
\hline 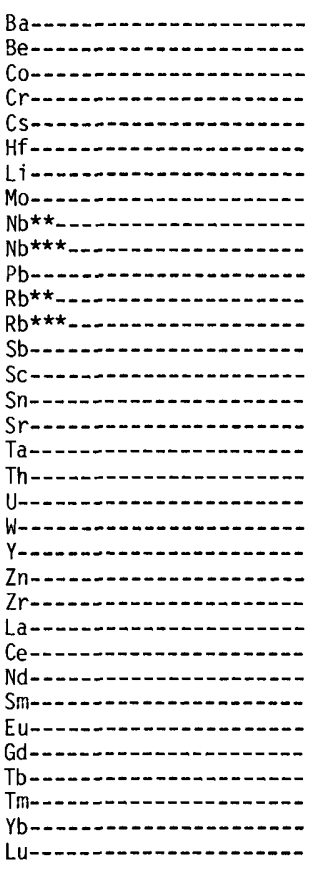 & $\begin{aligned} 950 . \\
2.5 \\
.3 \\
<5.0 \\
5.8 \\
5.9 \\
60 . \\
2.1 \\
13 . \\
11 . \\
26 . \\
122 . \\
127 . \\
.6 \\
4.7 \\
3.9 \\
80 . \\
.95 \\
10.5 \\
4.0 \\
1.6 \\
52 . \\
62 . \\
188 . \\
27 . \\
55 . \\
25 . \\
6.6 \\
.75 \\
5.5 \\
1.09 \\
.74 \\
4.8 \\
.66\end{aligned}$ & $\begin{array}{r}995 . \\
2.6 \\
.4 \\
<4.0 \\
6.2 \\
5.5 \\
68 . \\
2.2 \\
11 . \\
12 . \\
21 . \\
128 . \\
132 . \\
.6 \\
3.6 \\
4.3 \\
70 . \\
1.07 \\
11.5 \\
4.4 \\
1.8 \\
48 . \\
56 . \\
168 . \\
27 . \\
56 . \\
23 . \\
6.4 \\
.65 \\
5.3 \\
1.13 \\
.74 \\
4.7 \\
.65\end{array}$ & $\begin{array}{c}1250 . \\
2.2 \\
.1 \\
<4.0 \\
3.7 \\
4.6 \\
42 . \\
3.2 \\
10 . \\
10 . \\
19 . \\
92 . \\
103 . \\
.4 \\
3.9 \\
2.7 \\
40 . \\
.95 \\
6.9 \\
2.8 \\
1.3 \\
61 . \\
64 . \\
112 . \\
18 . \\
42 . \\
20 . \\
6.4 \\
.68 \\
6.6 \\
1.21 \\
.84 \\
5.7 \\
.76\end{array}$ & $\begin{array}{c}1370 . \\
1.3 \\
.3 \\
44.0 \\
3.4 \\
3.4 \\
36 . \\
3.0 \\
11 . \\
8 . \\
21 . \\
97 . \\
102 . \\
.2 \\
2.7 \\
1.4 \\
73 . \\
.76 \\
8.4 \\
3.2 \\
1.1 \\
27 . \\
20 . \\
88 . \\
27 . \\
49 . \\
18 . \\
3.7 \\
.54 \\
3.7 \\
.69 \\
.41 \\
2.8 \\
.41\end{array}$ & $\begin{array}{c}1200 . \\
3.4 \\
.4 \\
<5.0 \\
4.8 \\
11.5 \\
37 . \\
4.5 \\
24 . \\
30 . \\
21 . \\
116 . \\
110 . \\
.5 \\
6.6 \\
3.2 \\
10 . \\
1.65 \\
9.0 \\
3.4 \\
2.0 \\
80 . \\
89 . \\
447 . \\
36 . \\
78 . \\
35 . \\
9.0 \\
1.00 \\
7.3 \\
1.53 \\
1.10 \\
6.9 \\
.98\end{array}$ & $\begin{array}{c}42 . \\
4.7 \\
<.4 \\
<7.0 \\
5.6 \\
15.0 \\
44 . \\
5.5 \\
39 . \\
37 . \\
32 . \\
114 . \\
140 . \\
2.2 \\
.53 \\
4.0 \\
2 . \\
2.36 \\
12.5 \\
4.9 \\
1.7 \\
120 . \\
195 . \\
710 . \\
62 . \\
124 . \\
70 . \\
15.5 \\
1.16 \\
14.1 \\
2.71 \\
1.74 \\
11.6 \\
1.65\end{array}$ & $\begin{array}{c}31 . \\
3.1 \\
.1 \\
\langle 4.0 \\
4.3 \\
3.5 \\
46 . \\
4.1 \\
12 . \\
-- \\
26 . \\
127 . \\
133 . \\
.4 \\
3.0 \\
1.4 \\
9 . \\
1.24 \\
10.8 \\
4.8 \\
1.4 \\
27 . \\
24 . \\
66 . \\
16 . \\
33 . \\
14 . \\
4.3 \\
.13 \\
3.5 \\
.70 \\
.43 \\
3.0 \\
.44\end{array}$ & $\begin{array}{c}305 . \\
3.3 \\
.2 \\
<4.0 \\
4.4 \\
3.0 \\
49 . \\
6.5 \\
9.6 \\
8 . \\
19 . \\
108 . \\
110 . \\
<.5 \\
2.4 \\
2.9 \\
50 . \\
1.19 \\
7.8 \\
4.2 \\
1.4 \\
29 . \\
27 . \\
52 . \\
13 . \\
25 . \\
9 . \\
3.3 \\
.30 \\
2.9 \\
.58 \\
.39 \\
2.7 \\
.38\end{array}$ & $\begin{array}{c}380 . \\
3.3 \\
.1 \\
<3.0 \\
4.3 \\
2.9 \\
59 . \\
3.1 \\
12 . \\
11 . \\
30 . \\
91 . \\
102 . \\
.3 \\
2.2 \\
1.1 \\
80 . \\
1.33 \\
6.3 \\
3.8 \\
1.3 \\
28 . \\
21 . \\
65 . \\
9 . \\
18 . \\
8 . \\
2.1 \\
.34 \\
1.8 \\
.53 \\
.27 \\
2.4 \\
.34\end{array}$ & $\begin{array}{c}13 . \\
4.4 \\
<.2 \\
3.5 \\
4.7 \\
6.7 \\
75 . \\
7.1 \\
36 . \\
38 . \\
19 . \\
141 . \\
130 . \\
1.2 \\
3.8 \\
4.0 \\
2 . \\
2.62 \\
9.8 \\
5.1 \\
2.5 \\
108 . \\
95 . \\
149 . \\
20 . \\
55 . \\
30 . \\
10.5 \\
.61 \\
10.8 \\
2.25 \\
1.82 \\
11.7 \\
1.66\end{array}$ & $\begin{array}{c}985 . \\
2.0 \\
.9 \\
<3.0 \\
2.8 \\
4.0 \\
40 . \\
4.0 \\
14 . \\
17 . \\
19 . \\
122 . \\
125 . \\
.4 \\
1.8 \\
.7 \\
173 . \\
1.08 \\
7.2 \\
3.0 \\
.7 \\
12 . \\
24 . \\
146 . \\
23 . \\
38 . \\
11 . \\
2.3 \\
.42 \\
1.9 \\
.36 \\
.23 \\
1.4 \\
.21\end{array}$ \\
\hline 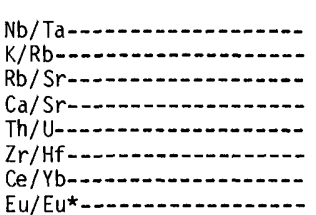 & $\begin{array}{l}12.6 \\
244 . \\
15.9 \\
89 . \\
2.6 \\
32 . \\
11.5 \\
.38\end{array}$ & $\begin{array}{c}10.8 \\
253 . \\
1.9 \\
86 . \\
2.6 \\
31 . \\
11.9 \\
.34\end{array}$ & $\begin{aligned} 10.5 \\
294 . \\
2.6 \\
114 . \\
2.5 \\
24 . \\
7.4 \\
.32\end{aligned}$ & $\begin{array}{c}12.5 \\
348 . \\
1.4 \\
83 . \\
2.6 \\
26 . \\
17.5 \\
.45\end{array}$ & $\begin{array}{l}16.4 \\
347 . \\
11.0 \\
357 . \\
2.7 \\
39 . \\
11.3 \\
.38\end{array}$ & $\begin{array}{l}16.1 \\
266 . \\
70.0 \\
608 . \\
2.6 \\
47 . \\
10.7 \\
.24\end{array}$ & $\begin{array}{l}9.7 \\
278 . \\
14.8 \\
389 . \\
2.3 \\
19 . \\
11.0 \\
.10\end{array}$ & $\begin{array}{c}7.4 \\
338.4 \\
2.2 \\
112 . \\
1.9 \\
17 . \\
9.3 \\
.30\end{array}$ & $\begin{array}{c}8.7 \\
372 . \\
1.3 \\
81 . \\
1.7 \\
22 . \\
7.5 \\
.54\end{array}$ & $\begin{array}{c}14.1 \\
316 . \\
65.0 \\
965 . \\
1.9 \\
22 . \\
4.7 \\
.18\end{array}$ & $\begin{array}{c}14.4 \\
327 . \\
.72 \\
48 . \\
2.4 \\
37 . \\
27.1 \\
.61\end{array}$ \\
\hline
\end{tabular}

See footnotes at end of table. 
APPENDIX I.-Chemical analyses of subalkalic silicic obsidians-Continued

\begin{tabular}{|c|c|c|c|c|c|c|c|c|c|c|c|c|}
\hline Country/State-.........-. & \multicolumn{12}{|c|}{ CALIFORNIA } \\
\hline Volcanic field/region--- & \multicolumn{5}{|c|}{ Warner Mountains } & \multicolumn{4}{|c|}{ Medicine Lake Highlands } & \multirow{3}{*}{$\begin{array}{c}\begin{array}{c}\text { Sonoma } \\
\text { Volcanic Field }\end{array} \\
\begin{array}{c}\text { Napa Glass } \\
\text { Mountain }\end{array} \\
44 \\
43\end{array}$} & \multicolumn{2}{|c|}{$\begin{array}{l}\text { Clear Lake } \\
\text { Volcanic Field }\end{array}$} \\
\hline Local ity-.....-.-. & \multicolumn{2}{|c|}{ Sugar Hill } & \multicolumn{2}{|c|}{ Buck Mountain } & \multirow{2}{*}{$\frac{\begin{array}{l}\text { Boyd } \\
\text { Creek }\end{array}}{\frac{39}{44}}$} & \multirow{2}{*}{$\begin{array}{c}\begin{array}{c}\text { Grasshopper } \\
\text { Flat }\end{array} \\
40 \\
142\end{array}$} & \multirow{2}{*}{$\begin{array}{c}\begin{array}{c}\text { Little Glass } \\
\text { Mountain }\end{array} \\
41 \\
143\end{array}$} & \multicolumn{2}{|c|}{$\begin{array}{l}\text { Big Glass } \\
\text { Mountain }\end{array}$} & & \multirow{2}{*}{$\begin{array}{r}\begin{array}{r}\text { Bonanza } \\
\text { Springs }\end{array} \\
45 \\
153\end{array}$} & \multirow{2}{*}{$\begin{array}{c}\begin{array}{c}\text { Camel Back } \\
\text { Ridge }\end{array} \\
46 \\
149\end{array}$} \\
\hline $\begin{array}{l}\text { Specimen- } \\
\text { Collection No. (RLS-) }\end{array}$ & $\begin{array}{l}35 \\
51\end{array}$ & $\begin{array}{l}36 \\
52\end{array}$ & $\begin{array}{l}37 \\
40\end{array}$ & $\begin{array}{l}38 \\
41\end{array}$ & & & & $\begin{array}{r}42 \\
141\end{array}$ & $\begin{array}{c}43 \\
\text { RGM-1 }\end{array}$ & & & \\
\hline \multicolumn{13}{|c|}{ Chemical analyses (weight percent) } \\
\hline 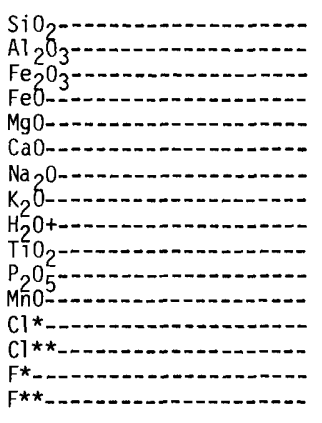 & $\begin{array}{r}76.5 \\
12.67 \\
.38 \\
.55 \\
.10 \\
.67 \\
3.65 \\
4.77 \\
.11 \\
.13 \\
.02 \\
.05 \\
.04 \\
.03 \\
.03 \\
.03\end{array}$ & $\begin{array}{r}73.0 \\
14.37 \\
.50 \\
.70 \\
.13 \\
.71 \\
4.63 \\
4.91 \\
.15 \\
.21 \\
.02 \\
.08 \\
.10 \\
.08 \\
.04 \\
.04\end{array}$ & $\begin{array}{r}75.8 \\
13.27 \\
.37 \\
.38 \\
.08 \\
.81 \\
3.98 \\
4.54 \\
.17 \\
.09 \\
.01 \\
.06 \\
.05 \\
.03 \\
.03 \\
.02\end{array}$ & $\begin{array}{r}75.7 \\
13.16 \\
.37 \\
.39 \\
.08 \\
.82 \\
3.96 \\
4.49 \\
.04 \\
.10 \\
.01 \\
.06 \\
.04 \\
.03 \\
.03 \\
.02\end{array}$ & $\begin{array}{r}75.7 \\
13.35 \\
.40 \\
.39 \\
.07 \\
.80 \\
3.87 \\
4.59 \\
.09 \\
.09 \\
.02 \\
.06 \\
.04 \\
.03 \\
.03 \\
.02\end{array}$ & $\begin{array}{r}75.2 \\
13.34 \\
.40 \\
.86 \\
.19 \\
.85 \\
3.97 \\
4.57 \\
.08 \\
.22 \\
.03 \\
.04 \\
.06 \\
.06 \\
.05 \\
.04\end{array}$ & $\begin{array}{r}74.0 \\
14.02 \\
.42 \\
1.25 \\
.26 \\
1.21 \\
4.06 \\
4.34 \\
.08 \\
.28 \\
.05 \\
.04 \\
.06 \\
.06 \\
.04 \\
.03\end{array}$ & $\begin{array}{r}73.3 \\
13.99 \\
.41 \\
1.29 \\
.26 \\
1.23 \\
4.12 \\
4.33 \\
.08 \\
.29 \\
.05 \\
.04 \\
.05 \\
.06 \\
.04 \\
.04\end{array}$ & $\begin{array}{r}73.44 \\
13.74 \\
.50 \\
1.24 \\
.29 \\
1.18 \\
4.18 \\
4.34 \\
.34 \\
.27 \\
.05 \\
.04 \\
.07 \\
.06 \\
.04 \\
.04\end{array}$ & $\begin{array}{r}76.3 \\
12.62 \\
.51 \\
.71 \\
.01 \\
.37 \\
4.31 \\
4.50 \\
.22 \\
.08 \\
.01 \\
.03 \\
.07 \\
.06 \\
.07 \\
.06\end{array}$ & $\begin{array}{r}75.1 \\
13.23 \\
.18 \\
1.09 \\
.08 \\
.90 \\
3.79 \\
4.33 \\
.07 \\
.09 \\
.02 \\
.04 \\
.06 \\
.05 \\
.07 \\
.07\end{array}$ & $\begin{array}{r}75.7 \\
13.10 \\
.19 \\
1.12 \\
.19 \\
1.00 \\
3.43 \\
4.67 \\
.11 \\
.26 \\
.03 \\
.03 \\
.04 \\
.04 \\
.07 \\
.06\end{array}$ \\
\hline $\begin{array}{l}\text { Subtotal } \\
\text { Less } 0=(F, C 1)_{2}\end{array}$ & $\begin{array}{r}99.67 \\
.02\end{array}$ & $\begin{array}{r}99.54 \\
.04\end{array}$ & $\begin{array}{r}99.63 \\
.02\end{array}$ & $\begin{array}{r}99.25 \\
.02\end{array}$ & $\begin{array}{r}99.50 \\
.02\end{array}$ & $\begin{array}{r}99.86 \\
.03\end{array}$ & $\begin{array}{r}100.11 \\
.03\end{array}$ & $\begin{array}{r}99.49 \\
.03\end{array}$ & $\begin{array}{r}99.72 \\
.03\end{array}$ & $\begin{array}{r}99.81 \\
.04\end{array}$ & $\begin{array}{r}99.05 \\
.04\end{array}$ & $\begin{array}{r}99.94 \\
.04\end{array}$ \\
\hline 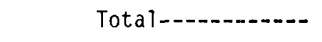 & 99.65 & 99.50 & 99.61 & 99.23 & 99.48 & 99.83 & 100.08 & 99.46 & 99.69 & 99.77 & 99.01 & 99.90 \\
\hline $\mathrm{Fe}_{\mathrm{t}} \mathrm{l}-$ & .90 & 1.15 & .71 & .72 & .75 & 1.22 & 1.63 & 1.66 & 1.69 & 1.17 & 1.25 & 1.29 \\
\hline $\mathrm{Fe} 0 /\left(\mathrm{Fe} 0+\mathrm{Fe}_{2} \mathrm{O}_{3}\right)^{1}-\ldots$ & .59 & .58 & .51 & .51 & .49 & .68 & .75 & .76 & .71 & .58 & .86 & .85 \\
\hline $\mathrm{Na}_{2} \mathrm{O} / \mathrm{K}_{2} \mathrm{O}^{\mathrm{l}} \ldots$ & .77 & .94 & .88 & .88 & .84 & .87 & .94 & .95 & .96 & .96 & .88 & .73 \\
\hline$\left(\mathrm{Na}_{2} \mathrm{O}+\mathrm{K}_{2} \mathrm{O}\right) / \mathrm{Al}_{2} \mathrm{O}_{3}{ }^{2}$ & .88 & .90 & .86 & .86 & .85 & .86 & .81 & .82 & .84 & .95 & .83 & .82 \\
\hline$\left(\mathrm{CaO}+\mathrm{Na}_{2} \mathrm{O}+\mathrm{K}_{2} \mathrm{O}\right) / \mathrm{Al}_{2} \mathrm{O}_{3}{ }^{2}-\cdot$ & .98 & .99 & .97 & .98 & .96 & .98 & .97 & .98 & 1.00 & 1.00 & .95 & .95 \\
\hline $\mathrm{CaO} /\left(\mathrm{Na}_{2} \mathrm{O}+\mathrm{K}_{2} \mathrm{O}\right)^{1}$ & .08 & .07 & .10 & .10 & .10 & .10 & .14 & .15 & .14 & .04 & .11 & .12 \\
\hline $\mathrm{Cl} / \mathrm{F}^{\mathrm{it}} \mathrm{L}_{-}$ & 1.3 & 2.3 & 1.5 & 1.4 & 1.4 & 1.4 & 1.6 & 1.4 & 1.6 & 1.0 & .76 & .61 \\
\hline \multicolumn{13}{|c|}{ CIPH norms } \\
\hline Q & 35.41 & 25.50 & 33.49 & 33.76 & 33.93 & 32.27 & 30.25 & 29.35 & 29.23 & 33.04 & 34.08 & 34.94 \\
\hline or- & 28.33 & 29.23 & 26.99 & 26.76 & 27.30 & 27.10 & 25.66 & 25.77 & 25.84 & 26.74 & 25.89 & 27.67 \\
\hline$a b-\ldots$ & 31.04 & 39.47 & 33.88 & 33.80 & 32.96 & 33.70 & 34.38 & 35.11 & 35.63 & 36.67 & 32.44 & 29.11 \\
\hline an-1-n & 3.21 & 3.42 & 3.98 & 4.04 & 3.86 & 4.03 & 5.68 & 5.82 & 5.57 & 1.78 & 4.39 & 4.78 \\
\hline C-1-1 & .33 & .20 & .36 & .32 & .61 & .39 & .56 & .41 & .14 & .01 & .73 & .66 \\
\hline ac- & -- & -- & -- & -- & -- & -- & -- & -- & -- & -- & -- & -- \\
\hline ns-1-n & -- & -- & -- & -- & -- & -- & -- & -- & -- & -- & -- & -- \\
\hline wo ? & -- & -- & -- & -- & -- & -- & -- & -- & -- & $\cdots$ & -- & -- \\
\hline en $\}$ di-n.............. & -- & -- & -- & -- & -- & -- & -- & $\cdots$ & -- & -- & -- & -- \\
\hline & $-{ }_{25}$ & $\cdots_{33}$ & -- & $-{ }^{2}$ & -- & -- & -- & -- & --73 & - & & -- \\
\hline $\left.\begin{array}{l}\text { en } \\
\text { fs }\end{array}\right\}$ hy-n. & $\begin{array}{l}.25 \\
.58\end{array}$ & $\begin{array}{l}.33 \\
.68\end{array}$ & $\begin{array}{l}.20 \\
.36\end{array}$ & $\begin{array}{l}.20 \\
.36\end{array}$ & $\begin{array}{l}.18 \\
.35\end{array}$ & $\begin{array}{l}.48 \\
.96\end{array}$ & $\begin{array}{r}.65 \\
1.56\end{array}$ & $\begin{array}{r}.65 \\
1.64\end{array}$ & $\begin{array}{r}.73 \\
1.50\end{array}$ & $\begin{array}{l}.03 \\
.81\end{array}$ & $\begin{array}{l}.20 \\
1.80\end{array}$ & $\begin{array}{r}.48 \\
1.53\end{array}$ \\
\hline$m t-1+1-1$ & .55 & .73 & .54 & .54 & .58 & .58 & .61 & .60 & .73 & .74 & .26 & .28 \\
\hline i $17--\ldots$ & .25 & .40 & .17 & .19 & .17 & .42 & .53 & .56 & .52 & .15 & .17 & .50 \\
\hline ар-1- & .05 & .05 & .02 & .02 & .05 & .07 & .12 & .12 & .12 & .02 & .05 & .07 \\
\hline
\end{tabular}




\begin{tabular}{|c|c|c|c|c|c|c|c|c|c|c|c|c|}
\hline & 35 & 36 & 37 & 38 & 39 & 40 & 41 & 42 & 43 & 44 & 45 & 46 \\
\hline \multicolumn{13}{|c|}{ Trace elements (ppm) } \\
\hline 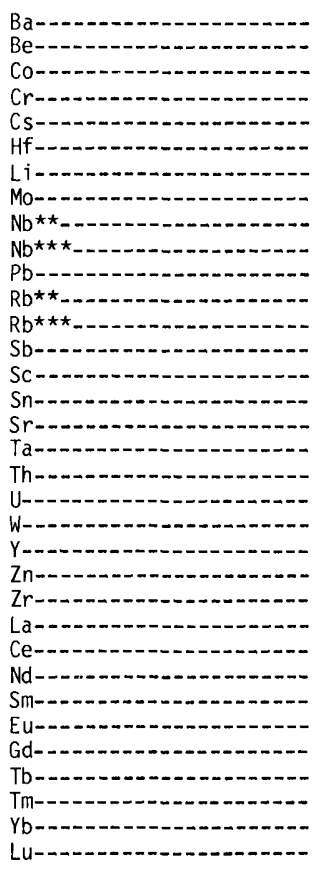 & $\begin{array}{c}680 . \\
2.6 \\
.5 \\
<6.0 \\
3.2 \\
3.5 \\
32 . \\
4.4 \\
16 . \\
17 . \\
18 . \\
119 . \\
135 . \\
1.1 \\
2.5 \\
1.7 \\
50 . \\
1.45 \\
14.5 \\
5.6 \\
1.1 \\
16 . \\
22 . \\
122 . \\
27 . \\
48 . \\
17 . \\
3.2 \\
.36 \\
2.9 \\
.46 \\
.33 \\
2.6 \\
.37\end{array}$ & $\begin{array}{c}1340 . \\
3.0 \\
.4 \\
<7.0 \\
2.1 \\
5.5 \\
25 . \\
4.6 \\
18 . \\
18 . \\
27 . \\
102 . \\
118 . \\
.4 \\
4.2 \\
1.8 \\
63 . \\
1.17 \\
10.2 \\
3.8 \\
1.5 \\
26 . \\
37 . \\
262 . \\
35 . \\
63 . \\
24 . \\
4.7 \\
.80 \\
3.2 \\
.70 \\
.56 \\
3.0 \\
.45\end{array}$ & $\begin{array}{c}635 . \\
3.0 \\
.2 \\
<5.0 \\
2.4 \\
3.1 \\
42 . \\
4.4 \\
15 . \\
16 . \\
27 . \\
104 . \\
122 . \\
.4 \\
1.7 \\
1.2 \\
70 . \\
1.16 \\
9.8 \\
4.1 \\
.80 \\
12 . \\
23 . \\
100 . \\
23 . \\
36 . \\
13 . \\
2.7 \\
.37 \\
1.9 \\
.38 \\
.26 \\
1.9 \\
.29\end{array}$ & $\begin{array}{r}745 . \\
2.7 \\
.2 \\
<5.0 \\
3.0 \\
3.7 \\
41 . \\
4.2 \\
14 . \\
16 . \\
32 . \\
121 . \\
120 . \\
.6 \\
2.0 \\
1.0 \\
70 . \\
1.50 \\
11.7 \\
4.7 \\
.78 \\
21 . \\
25 . \\
100 . \\
30 . \\
51 . \\
17 . \\
3.4 \\
.50 \\
2.5 \\
.37 \\
.36 \\
2.2 \\
.34\end{array}$ & $\begin{array}{c}690 . \\
2.8 \\
.2 \\
<4.0 \\
2.6 \\
3.2 \\
42 . \\
4.5 \\
15 . \\
16 . \\
34 . \\
111 . \\
115 . \\
<.7 \\
1.8 \\
1.4 \\
70 . \\
1.16 \\
10.1 \\
4.1 \\
.84 \\
20 . \\
20 . \\
101 . \\
25 . \\
37 . \\
13 . \\
2.8 \\
.33 \\
1.7 \\
.39 \\
.23 \\
1.9 \\
.29\end{array}$ & $\begin{array}{c}790 . \\
2.5 \\
1.2 \\
<4.0 \\
7.8 \\
5.0 \\
52 . \\
3.8 \\
9.2 \\
7 . \\
22 . \\
146 . \\
142 . \\
1.5 \\
3.6 \\
3.0 \\
72 . \\
1.09 \\
13.9 \\
6.2 \\
1.6 \\
20 . \\
25 . \\
170 . \\
25 . \\
50 . \\
20 . \\
5.1 \\
.41 \\
3.7 \\
.68 \\
.56 \\
3.2 \\
.47\end{array}$ & $\begin{array}{c}850 . \\
2.6 \\
1.9 \\
<5.0 \\
10.1 \\
5.6 \\
64 . \\
2.9 \\
9.6 \\
-- \\
18 . \\
155 . \\
155 . \\
.6 \\
4.3 \\
3.0 \\
115 . \\
1.10 \\
14.9 \\
6.7 \\
1.4 \\
25 . \\
32 . \\
208 . \\
24 . \\
46 . \\
17 . \\
4.5 \\
.57 \\
3.8 \\
.68 \\
.40 \\
2.5 \\
.39\end{array}$ & $\begin{array}{c}885 . \\
2.7 \\
2.1 \\
<5.0 \\
10.5 \\
5.7 \\
61 . \\
2.8 \\
9.1 \\
9 . \\
22 . \\
147 . \\
156 . \\
.7 \\
4.5 \\
3.7 \\
115 . \\
1.00 \\
14.8 \\
6.5 \\
2.1 \\
23 . \\
30 . \\
206 . \\
23 . \\
44 . \\
17 . \\
4.8 \\
.58 \\
3.6 \\
.76 \\
.46 \\
2.6 \\
.39\end{array}$ & $\begin{array}{c}810 . \\
-- \\
1.9 \\
3.3 \\
9.7 \\
5.7 \\
-- \\
-- \\
9.4 \\
10 . \\
22 . \\
148 . \\
154 . \\
1.2 \\
4.36 \\
-- \\
115 . \\
1.03 \\
14.6 \\
5.9 \\
-- \\
28 . \\
28 . \\
212 . \\
24 . \\
45 . \\
20 . \\
4.3 \\
.59 \\
4.0 \\
.62 \\
.39 \\
2.5 \\
.39\end{array}$ & $\begin{array}{c}415 . \\
3.7 \\
<.3 \\
<5.0 \\
13.5 \\
6.4 \\
110 . \\
1.7 \\
13 . \\
16 . \\
49 . \\
175 . \\
200 . \\
1.3 \\
2.4 \\
5.8 \\
5 . \\
1.02 \\
17.1 \\
7.0 \\
2.2 \\
37 . \\
62 . \\
260 . \\
30 . \\
47 . \\
24 . \\
6.1 \\
.18 \\
4.3 \\
1.04 \\
.57 \\
4.4 \\
.61\end{array}$ & $\begin{array}{c}1200 . \\
2.5 \\
.7 \\
1.6 \\
9.7 \\
3.9 \\
69 . \\
.58 \\
11 . \\
14 . \\
27 . \\
154 . \\
157 . \\
.7 \\
5.7 \\
2.7 \\
97 . \\
.97 \\
15.6 \\
5.6 \\
2.7 \\
28 . \\
42 . \\
102 . \\
31 . \\
66 . \\
28 . \\
5.5 \\
.37 \\
6.0 \\
1.06 \\
.35 \\
2.8 \\
.36\end{array}$ & $\begin{array}{c}655 . \\
2.3 \\
1.4 \\
2.3 \\
14.8 \\
5.5 \\
75 . \\
.75 \\
14 . \\
14 . \\
21 . \\
201 . \\
210 . \\
1.2 \\
4.6 \\
5.7 \\
73 . \\
1.31 \\
21.7 \\
6.8 \\
3.5 \\
33 . \\
24 . \\
136 . \\
31 . \\
64 . \\
25 . \\
5.2 \\
.33 \\
5.0 \\
.96 \\
.56 \\
3.5 \\
.46\end{array}$ \\
\hline $\begin{array}{l}\mathrm{Nb} / \mathrm{Ta}- \\
\mathrm{K} / \mathrm{Rb}- \\
\mathrm{Rb} / \mathrm{Sr} \\
\mathrm{Ca} / \mathrm{Sr} \\
\mathrm{Th} / \mathrm{U} \\
\mathrm{Zr} / \mathrm{Hf} \\
\mathrm{Ce} / \mathrm{Yb} \\
\mathrm{Eu} / \mathrm{Eu} \mathrm{C}^{*}\end{array}$ & $\begin{array}{c}11.4 \\
293 . \\
2.7 \\
96 . \\
2.6 \\
35 . \\
18.5 \\
.39\end{array}$ & $\begin{array}{c}15.4 \\
345 . \\
1.9 \\
81 . \\
2.7 \\
48 . \\
21.0 \\
.63\end{array}$ & $\begin{array}{c}13.4 \\
309 . \\
1.7 \\
83 . \\
2.4 \\
32 . \\
19.0 \\
.51\end{array}$ & $\begin{array}{l}10.0 \\
311 . \\
1.7 \\
84 . \\
2.5 \\
27 . \\
23.2 \\
.58\end{array}$ & $\begin{array}{c}13.4 \\
331 . \\
1.6 \\
82 . \\
2.4 \\
32 . \\
19.5 \\
.46\end{array}$ & $\begin{array}{c}7.4 \\
267 . \\
2.0 \\
84 . \\
2.2 \\
34 . \\
15.6 \\
.32\end{array}$ & $\begin{array}{c}8.7 \\
232 . \\
1.4 \\
75 . \\
2.2 \\
37.4 \\
18.4 \\
.42\end{array}$ & $\begin{array}{c}9.1 \\
230 . \\
1.4 \\
76 . \\
2.3 \\
36 . \\
16.9 \\
.42\end{array}$ & $\begin{array}{c}9.4 \\
234 . \\
1.3 \\
73 . \\
2.5 \\
37 . \\
18.0 \\
.43\end{array}$ & $\begin{array}{l}14.2 \\
187 . \\
40 . \\
529 . \\
2.4 \\
41 . \\
10.7 \\
.11\end{array}$ & $\begin{array}{c}12.9 \\
229 . \\
6.2 \\
66 . \\
2.8 \\
26 . \\
23.6 \\
.20\end{array}$ & $\begin{array}{c}10.7 \\
185 . \\
2.9 \\
98 . \\
3.2 \\
25 . \\
18.3 \\
.20\end{array}$ \\
\hline
\end{tabular}

See footnotes at end of table. 
APPENDIX I.-Chemical analyses of subalkalic silicic obsidians-Continued

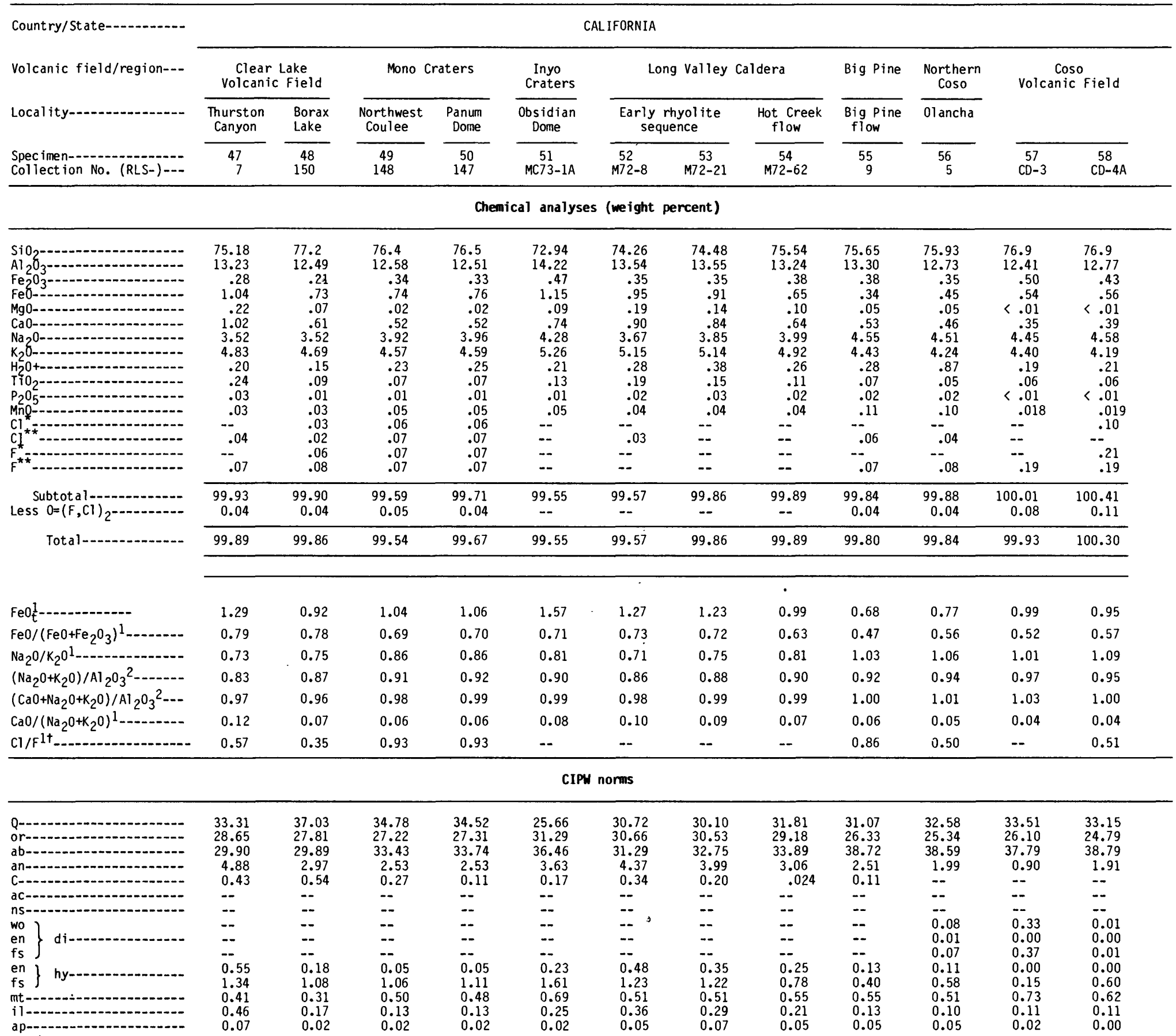




\begin{tabular}{|c|c|c|c|c|c|c|c|c|c|c|c|c|}
\hline & 47 & 48 & 49 & 50 & 51 & 52 & 53 & 54 & 55 & 56 & 57 & 58 \\
\hline \multicolumn{13}{|c|}{ Trace elements (ppm) } \\
\hline 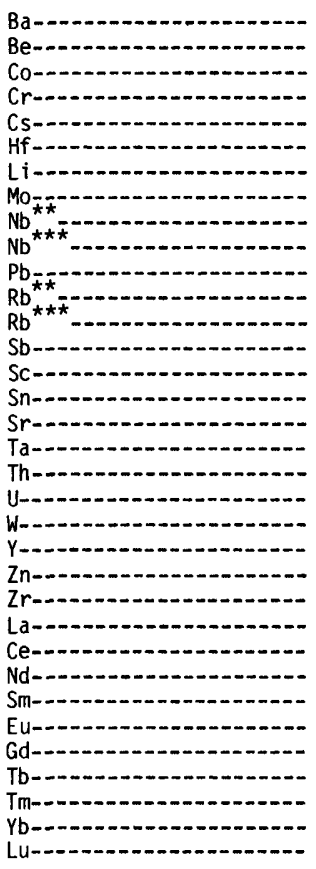 & $\begin{array}{c}649 . \\
2.5 \\
1.3 \\
1.1 \\
14.0 \\
5.3 \\
81 . \\
0.61 \\
12 . \\
14 . \\
20 . \\
193 . \\
223 . \\
0.7 \\
4.3 \\
6.0 \\
72 . \\
1.21 \\
22.2 \\
7.3 \\
3.5 \\
45 . \\
25 . \\
173 . \\
31 . \\
55 . \\
26 . \\
5.6 \\
0.30 \\
4.4 \\
0.86 \\
0.37 \\
3.3 \\
0.48\end{array}$ & $\begin{array}{c}60 . \\
3.1 \\
0.4 \\
2.1 \\
14.0 \\
3.6 \\
95 . \\
0.96 \\
16 . \\
18 . \\
25 . \\
218 . \\
227 . \\
0.8 \\
4.1 \\
7.9 \\
9 . \\
1.25 \\
15.6 \\
6.6 \\
3.3 \\
47 . \\
34 . \\
78 . \\
21 . \\
48 . \\
24 . \\
5.6 \\
0.08 \\
6.1 \\
1.19 \\
0.59 \\
3.9 \\
0.51\end{array}$ & $\begin{array}{c}20 . \\
3.8 \\
0.2 \\
1.7 \\
5.2 \\
4.2 \\
42 . \\
2.5 \\
23 . \\
28 . \\
28 . \\
175 . \\
190 . \\
0.8 \\
1.8 \\
3.1 \\
7 . \\
1.95 \\
18.7 \\
5.2 \\
2.1 \\
28 . \\
36 . \\
103 . \\
23 . \\
48 . \\
22 . \\
5.1 \\
0.13 \\
4.5 \\
0.73 \\
0.32 \\
2.7 \\
0.37\end{array}$ & $\begin{array}{c}<50 . \\
3.8 \\
0.2 \\
<4.0 \\
5.3 \\
4.3 \\
42 . \\
2.6 \\
22 . \\
25 . \\
21 . \\
178 . \\
193 . \\
0.9 \\
1.9 \\
3.1 \\
8 . \\
1.97 \\
18.9 \\
5.2 \\
2.2 \\
26 . \\
41 . \\
105 . \\
24 . \\
52 . \\
19 . \\
4.4 \\
0.13 \\
4.9 \\
0.75 \\
0.45 \\
2.8 \\
0.39\end{array}$ & 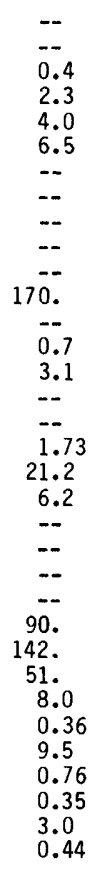 & $\begin{array}{c}-- \\
-- \\
0.8 \\
1.7 \\
4.7 \\
4.8 \\
-- \\
-- \\
-- \\
-- \\
\overline{-} \\
148 . \\
-- \\
0.9 \\
2.1 \\
-- \\
-- \\
1.34 \\
15.8 \\
5.2 \\
-- \\
-- \\
-- \\
\ddot{-} \\
42 . \\
64 . \\
23 . \\
3.4 \\
0.43 \\
4.7 \\
0.37 \\
0.14 \\
1.7 \\
0.27\end{array}$ & $\begin{array}{c}-- \\
-- \\
0.6 \\
1.9 \\
4.7 \\
4.9 \\
-- \\
-- \\
-- \\
-- \\
143 . \\
\overline{-} \\
1.0 \\
2.1 \\
-- \\
\overline{1 .} \\
16.0 \\
5.5 \\
-- \\
-- \\
-- \\
\overline{-} \\
43 . \\
68 . \\
24 . \\
3.6 \\
0.40 \\
5.4 \\
0.41 \\
0.21 \\
1.8 \\
0.28\end{array}$ & 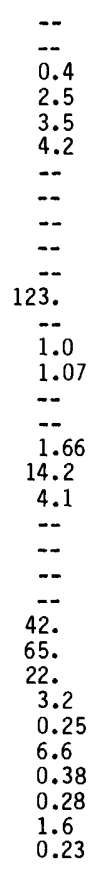 & $\begin{array}{c}12 . \\
7.3 \\
<0.3 \\
1.6 \\
4.4 \\
4.2 \\
64 . \\
5.3 \\
40 . \\
50 . \\
30 . \\
208 . \\
206 . \\
1.4 \\
3.3 \\
3.0 \\
8 . \\
3.80 \\
21.8 \\
7.2 \\
2.4 \\
40 . \\
38 . \\
73 . \\
11 . \\
28 . \\
13 . \\
4.0 \\
0.31 \\
4.0 \\
0.71 \\
0.39 \\
3.1 \\
0.46\end{array}$ & $\begin{array}{c}9 . \\
9.1 \\
<0.4 \\
<5.0 \\
9.0 \\
4.3 \\
110 . \\
2.0 \\
45 . \\
59 . \\
32 . \\
265 . \\
278 . \\
2.7 \\
2.0 \\
5.7 \\
4 . \\
6.55 \\
26.8 \\
9.3 \\
2.7 \\
54 . \\
39 . \\
83 . \\
9 . \\
22 . \\
9 . \\
3.7 \\
0.06 \\
4.2 \\
0.72 \\
<0.30 \\
4.0 \\
0.58\end{array}$ & $\begin{array}{c}8 . \\
\ddot{-} .1 \\
0.1 \\
0.0 \\
7.0 \\
6.0 \\
-- \\
-- \\
-- \\
75 . \\
34 . \\
297 . \\
330 . \\
0.9 \\
0.99 \\
-- \\
2.8 \\
7.00 \\
34.3 \\
12.3 \\
-- \\
-- \\
55 . \\
105 . \\
16 . \\
40 . \\
25 . \\
6.9 \\
0.02 \\
-- \\
1.67 \\
1.03 \\
7.5 \\
0.99\end{array}$ & $\begin{array}{c}5.4 \\
11 . \\
0.1 \\
<0.7 \\
7.1 \\
6.1 \\
180 . \\
-- \\
7- \\
71 . \\
38 . \\
313 . \\
325 . \\
0.9 \\
0.99 \\
11 . \\
3.2 \\
6.66 \\
34.3 \\
12.5 \\
7-. \\
72 . \\
59 . \\
105 . \\
16 . \\
39 . \\
21 . \\
6.8 \\
0.02 \\
7-- \\
1.60 \\
1.05 \\
7.4 \\
1.07\end{array}$ \\
\hline 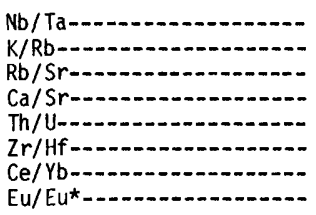 & $\begin{array}{c}10.7 \\
180 . \\
3.1 \\
101 . \\
3.1 \\
33 . \\
16.7 \\
0.19\end{array}$ & $\begin{array}{c}13.6 \\
172 . \\
25.2 \\
484 . \\
2.4 \\
22 . \\
12.3 \\
0.04\end{array}$ & $\begin{array}{c}13.1 \\
200 . \\
27.1 \\
531 . \\
3.6 \\
25 . \\
17.8 \\
0.08\end{array}$ & $\begin{array}{c}11.9 \\
197 . \\
24.1 \\
465 . \\
3.6 \\
24 . \\
18.6 \\
0.09\end{array}$ & $\begin{array}{c}-- \\
25 \overline{7} \\
-- \\
\overline{3.4} \\
\overline{--} \\
0.3 \\
0.13\end{array}$ & $\begin{array}{c}\overline{--} \\
\overline{--} \\
\overline{3.2} \\
\overline{--} \\
37.7 \\
0.33\end{array}$ & $\begin{array}{c}298 . \\
-- \\
\overline{-.} \\
2.9 \\
37.8 \\
0.28\end{array}$ & $\begin{array}{c}332 . \\
-- \\
\overline{--} \\
3.5 \\
\overline{--} \\
0.6 \\
0.17\end{array}$ & $\begin{array}{c}11.8 \\
179 . \\
25.8 \\
474 . \\
3.0 \\
17.0 \\
9.0 \\
0.24\end{array}$ & $\begin{array}{c}7.9 \\
127 . \\
69.5 \\
822 . \\
2.9 \\
19 . \\
5.5 \\
0.05\end{array}$ & $\begin{array}{l}10.7 \\
111 . \\
118 . \\
893 . \\
2.8 \\
18 . \\
5.3 \\
0.01\end{array}$ & $\begin{array}{l}10.7 \\
107 . \\
102 . \\
871 . \\
2.7 \\
17 . \\
5.3 \\
0.01\end{array}$ \\
\hline
\end{tabular}

See footnotes at end of table. 
APPENDIX I.-Chemical analyses of subalkalic silicic obsidians-Continued

\begin{tabular}{|c|c|c|c|c|c|c|c|c|c|c|c|c|}
\hline \multirow{3}{*}{$\begin{array}{l}\text { Country/State-1- } \\
\text { Volcanic field/region--- } \\
\text { Specimen-- } \\
\text { Collection No. (RLS-)--. }\end{array}$} & \multicolumn{12}{|c|}{ CALIFORNIA } \\
\hline & \multicolumn{12}{|c|}{ Coso Volcanic Field } \\
\hline & $\begin{array}{c}59 \\
C D-5\end{array}$ & $\begin{array}{c}60 \\
\mathrm{CD}-17\end{array}$ & $\begin{array}{c}61 \\
C D-22\end{array}$ & $\begin{array}{c}62 \\
\text { CD-7 }\end{array}$ & $\begin{array}{c}63 \\
\text { CD-20 }\end{array}$ & $\begin{array}{c}64 \\
\mathrm{CD}-23\end{array}$ & $\begin{array}{c}65 \\
C D-30\end{array}$ & $\begin{array}{c}66 \\
C D-33\end{array}$ & $\begin{array}{c}67 \\
C D-8\end{array}$ & $\begin{array}{c}68 \\
\text { CD-12 }\end{array}$ & $\begin{array}{c}69 \\
\text { CD-14 }\end{array}$ & $\begin{array}{c}70 \\
C D-18\end{array}$ \\
\hline \multicolumn{13}{|c|}{ Chemical analyses (weight percent) } \\
\hline 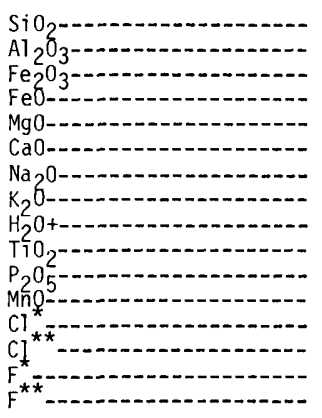 & $\begin{array}{r}76.6 \\
12.41 \\
0.40 \\
0.58 \\
<0.01 \\
0.35 \\
4.52 \\
4.15 \\
0.29 \\
0.07 \\
0.03 \\
0.019 \\
0.10 \\
-- \\
0.20 \\
0.19\end{array}$ & $\begin{array}{c}76.2 \\
12.57 \\
0.40 \\
0.53 \\
<0.02 \\
0.39 \\
4.31 \\
4.50 \\
0.22 \\
0.06 \\
0.01 \\
0.017 \\
0.06 \\
-- \\
0.27 \\
0.17\end{array}$ & $\begin{array}{l}76.9 \\
12.39 \\
0.64 \\
0.39 \\
0.02 \\
0.35 \\
4.55 \\
4.18 \\
0.08 \\
0.06 \\
0.02 \\
0.020 \\
-- \\
-- \\
-- \\
0.18\end{array}$ & $\begin{array}{c}76.9 \\
12.68 \\
0.40 \\
0.44 \\
<0.01 \\
0.32 \\
4.58 \\
4.30 \\
0.14 \\
0.05 \\
<0.01 \\
0.020 \\
0.05 \\
-.-25 \\
0.25 \\
0.25\end{array}$ & $\begin{array}{l}76.2 \\
12.56 \\
0.56 \\
0.44 \\
0.02 \\
0.43 \\
4.07 \\
4.87 \\
0.51 \\
0.09 \\
<0.01 \\
0.019 \\
-- \\
-- \\
-- \\
0.11\end{array}$ & $\begin{array}{c}76.4 \\
12.56 \\
0.35 \\
0.60 \\
0.02 \\
0.44 \\
4.32 \\
4.58 \\
0.28 \\
0.09 \\
<0.01 \\
0.016 \\
0.07 \\
--. \\
0.16 \\
0.14\end{array}$ & $\begin{array}{l}76.5 \\
12.57 \\
0.31 \\
0.65 \\
0.02 \\
0.42 \\
4.32 \\
4.58 \\
0.37 \\
0.07 \\
0.01 \\
0.018 \\
0.08 \\
-- \\
0.11 \\
0.12\end{array}$ & $\begin{array}{c}76.7 \\
12.45 \\
0.40 \\
0.63 \\
0.02 \\
0.41 \\
4.34 \\
4.61 \\
0.19 \\
0.09 \\
<0.01 \\
0.016 \\
0.07 \\
-.0 .11 \\
0.11 \\
0.12\end{array}$ & $\begin{array}{l}77.0 \\
12.06 \\
0.38 \\
0.57 \\
0.02 \\
0.31 \\
4.44 \\
4.41 \\
0.23 \\
0.06 \\
<0.01 \\
0.021 \\
-- \\
-- \\
-- \\
0.13\end{array}$ & $\begin{array}{c}76.6 \\
12.42 \\
0.69 \\
0.30 \\
<0.01 \\
0.36 \\
4.36 \\
4.24 \\
0.38 \\
0.08 \\
<0.01 \\
0.021 \\
0.06 \\
-- \\
0.16 \\
0.13\end{array}$ & $\begin{array}{c}77.0 \\
12.54 \\
0.43 \\
0.50 \\
0.03 \\
0.38 \\
4.32 \\
4.37 \\
0.27 \\
0.04 \\
<0.01 \\
0.023 \\
-- \\
-. \\
-0.12 \\
0.12\end{array}$ & $\begin{array}{c}76.8 \\
12.41 \\
0.28 \\
0.55 \\
0.03 \\
0.42 \\
4.40 \\
4.38 \\
0.22 \\
0.07 \\
<0.01 \\
0.018 \\
0.08 \\
-- \\
0.14 \\
0.13\end{array}$ \\
\hline $\begin{array}{l}\text { Subtotal } \\
\text { Less } 0=(\mathrm{F}, \mathrm{Cl})_{2}\end{array}$ & $\begin{array}{r}99.72 \\
0.10 \\
\end{array}$ & $\begin{array}{r}99.51 \\
0.11 \\
\end{array}$ & $\begin{array}{r}99.78 \\
0.08 \\
\end{array}$ & $\begin{array}{r}100.13 \\
0.12 \\
\end{array}$ & $\begin{array}{r}99.88 \\
0.05\end{array}$ & $\begin{array}{r}99.88 \\
0.08 \\
\end{array}$ & $\begin{array}{r}100.04 \\
0.07 \\
\end{array}$ & $\begin{array}{r}100.05 \\
0.06 \\
\end{array}$ & $\begin{array}{r}99.63 \\
0.05\end{array}$ & $\begin{array}{r}99.80 \\
0.08\end{array}$ & $\begin{array}{r}100.02 \\
0.05\end{array}$ & $\begin{array}{r}99.80 \\
0.08\end{array}$ \\
\hline 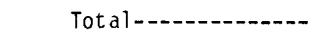 & 99.62 & 99.40 & 99.70 & 100.01 & 99.83 & 99.80 & 99.97 & 99.99 & 99.58 & 99.72 & 99.97 & 99.72 \\
\hline $\mathrm{Fe}_{\mathrm{t}}^{1}-$ & 0.94 & 0.89 & 0.97 & 0.80 & 0.94 & 0.92 & 0.93 & 0.99 & 0.91 & 0.92 & 0.89 & 0.80 \\
\hline $\mathrm{Fe} 0 /\left(\mathrm{Fe} 0+\mathrm{Fe}_{2} \mathrm{O}_{3}\right)^{1} \ldots$ & 0.59 & 0.57 & 0.38 & 0.52 & 0.44 & 0.63 & 0.68 & 0.61 & 0.67 & 0.30 & 0.54 & 0.66 \\
\hline $\mathrm{Na}_{2} \mathrm{O}^{\prime} \mathrm{K}_{2} \mathrm{O}^{\mathrm{l}}$ & 1.09 & 0.96 & 1.09 & 1.07 & 0.84 & 0.94 & 0.94 & 0.94 & 1.01 & 1.03 & 0.99 & 1.01 \\
\hline$\left(\mathrm{Na}_{2} \mathrm{O}+\mathrm{K}_{2} \mathrm{O}\right) / \mathrm{Al}_{2}{ }_{2}{ }_{3}^{2}-\cdots$ & 0.96 & 0.95 & 0.97 & 0.96 & 0.95 & 0.96 & 0.96 & 0.97 & 1.00 & 0.95 & 0.94 & 0.97 \\
\hline$\left(\mathrm{Ca} O+\mathrm{Na}_{2} \mathrm{O}+\mathrm{K}_{2} \mathrm{O}\right) / \mathrm{Al}_{2} \mathrm{O}_{3}{ }^{2}-\cdots$ & 1.01 & 1.01 & 1.02 & 1.01 & 1.02 & 1.02 & 1.02 & 1.03 & 1.05 & 1.00 & 1.00 & 1.03 \\
\hline $\mathrm{CaO} /\left(\mathrm{Na}_{2} \mathrm{O}+\mathrm{K}_{2} \mathrm{O}\right)^{1} \ldots$ & 0.04 & 0.04 & 0.04 & 0.04 & 0.05 & 0.05 & 0.05 & 0.05 & 0.04 & 0.04 & 0.04 & 0.05 \\
\hline $\mathrm{Cl}_{/} \mathrm{F}^{1+}{ }_{-}$ & 0.49 & 0.26 & -- & 0.20 & -- & 0.45 & 0.68 & 0.56 & -- & 0.41 & -- & 0.56 \\
\hline \multicolumn{13}{|c|}{ CIPW nortis } \\
\hline 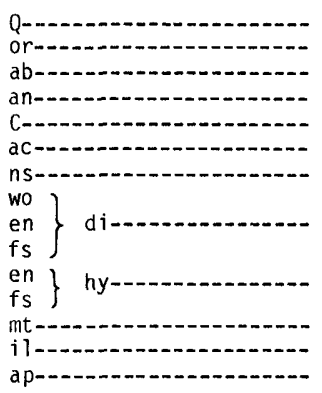 & $\begin{array}{l}33.81 \\
24.74 \\
38.58 \\
1.33 \\
-- \\
-- \\
-- \\
0.09 \\
0.00 \\
0.11 \\
0.00 \\
0.56 \\
0.59 \\
0.13 \\
0.07\end{array}$ & $\begin{array}{l}33.20 \\
26.86 \\
36.84 \\
1.68 \\
(4) \\
-- \\
-- \\
0.09 \\
0.00 \\
0.09 \\
0.02 \\
0.49 \\
0.59 \\
0.12 \\
0.02\end{array}$ & $\begin{array}{l}33.94 \\
24.82 \\
38.69 \\
1.04 \\
-- \\
-- \\
-- \\
0.17 \\
0.05 \\
0.13 \\
-- \\
-- \\
0.93 \\
0.12 \\
0.05\end{array}$ & $\begin{array}{l}33.08 \\
25.49 \\
38.88 \\
1.35 \\
-- \\
-- \\
-- \\
0.10 \\
0.00 \\
0.12 \\
0.00 \\
0.32 \\
0.58 \\
0.10 \\
--\end{array}$ & $\begin{array}{l}33.19 \\
28.99 \\
34.70 \\
1.63 \\
-- \\
-- \\
-- \\
0.22 \\
0.04 \\
0.19 \\
0.01 \\
0.04 \\
0.82 \\
0.17 \\
---\end{array}$ & $\begin{array}{l}32.84 \\
27.23 \\
36.78 \\
1.36 \\
-- \\
-- \\
-- \\
0.35 \\
0.03 \\
0.36 \\
0.02 \\
0.34 \\
0.51 \\
0.17 \\
--\end{array}$ & $\begin{array}{l}32.86 \\
27.21 \\
36.75 \\
1.39 \\
-- \\
-- \\
-- \\
0.27 \\
0.02 \\
0.28 \\
0.03 \\
0.58 \\
0.45 \\
0.13 \\
0.02\end{array}$ & $\begin{array}{l}32.94 \\
27.33 \\
36.85 \\
0.88 \\
-- \\
-- \\
-- \\
0.49 \\
0.04 \\
0.51 \\
0.02 \\
0.21 \\
0.58 \\
0.17 \\
0.00\end{array}$ & $\begin{array}{l}33.89 \\
26.25 \\
37.76 \\
-- \\
--.08 \\
0.08 \\
-- \\
0.65 \\
0.05 \\
0.67 \\
0.00 \\
0.03 \\
0.52 \\
0.12 \\
0.00\end{array}$ & $\begin{array}{l}34.56 \\
25.29 \\
37.24 \\
1.80 \\
-- \\
-- \\
-- \\
-- \\
-- \\
- \\
- \\
0.81 \\
0.15 \\
0.00\end{array}$ & $\begin{array}{c}34.17 \\
25.92 \\
36.69 \\
1.89 \\
0.01 \\
-- \\
-- \\
-- \\
-- \\
-- \\
0.08 \\
0.54 \\
0.63 \\
0.08 \\
0.00\end{array}$ & $\begin{array}{c}33.59 \\
26.05 \\
37.47 \\
1.18 \\
-- \\
-. \\
-- \\
0.38 \\
0.04 \\
0.048 \\
0.04 \\
0.33 \\
0.41 \\
0.13 \\
0.00\end{array}$ \\
\hline
\end{tabular}




\begin{tabular}{|c|c|c|c|c|c|c|c|c|c|c|c|c|}
\hline & 59 & 60 & 61 & 62 & 63 & 64 & 65 & 66 & 67 & 68 & 69 & 70 \\
\hline \multicolumn{13}{|c|}{ Trace elements (ppm) } \\
\hline Ba--..- & 6.0 & -- & 6. & $<2$. & -- & 32. & -- & 55. & -- & - & -- & -- \\
\hline $\mathrm{Be}-\mathrm{C}-\mathrm{C}-\mathrm{B}$ & -- & -- & -- & 13. & -- & 8.9 & -- & 6.5 & -- & -- & -- & -- \\
\hline Co-1-2 & 0.1 & 0.2 & 0.1 & 0.1 & 0.2 & 0.2 & 0.3 & 0.2 & 0.1 & 0.1 & 0.1 & 0.1 \\
\hline $\mathrm{Cr}-\ldots$ & $<1.1$ & $<1.0$ & $<1.3$ & $<0.5$ & $<1.2$ & $<1.6$ & 0.4 & $<1.7$ & $<1.3$ & $<1.1$ & $<1.1$ & $<1.1$ \\
\hline Cs-................ & 6.9 & 7.2 & 7.2 & 9.2 & 6.7 & 6.5 & 4.5 & 4.4 & 5.8 & 6.0 & 6.2 & 6.3 \\
\hline 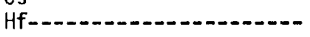 & 5.7 & 5.9 & 5.9 & 6.2 & 5.1 & 5.3 & 5.6 & 5.1 & 4.9 & 5.0 & 4.9 & 5.1 \\
\hline 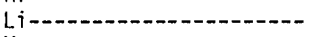 & 120. & -- & -- & 150. & -- & 89. &.- & 76. & -- &.- & -- & $\cdots$ \\
\hline Mo $=---1$ & -- & -- & -- & -- & -- & -- & -- & -- & -- & -- & -- & -- \\
\hline 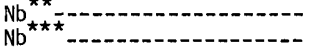 & $7 \overline{7}$ & $8 \overline{0}$ & $7 \overline{8}$ & $8 \overline{8}$ & $\overline{--}$ & $57^{--}$ & $52^{--}$ & 10 & 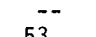 & $\overline{7}$ & $50^{--}$ & -- \\
\hline $\begin{array}{l}N D \\
P b\end{array}$ & 31. & $\begin{array}{l}80 . \\
39 .\end{array}$ & 33. & $\begin{array}{l}88 . \\
36 .\end{array}$ & $2 \overline{1}$. & 31. & 23. & 29. & 53. & 47. & 50 & 51. \\
\hline $\mathrm{Rb}^{\bar{x} \bar{x}-\bar{x}}$ & 295. & 302. & 312. & 353. & 285. & 258. & 205. & 201. & 222. & 229. & $232^{\circ}$ & $\begin{array}{r}30 . \\
236 .\end{array}$ \\
\hline $\mathrm{Rb}^{\star \star \star}-$ & 315. & 335. & 320. & 370. & 270 . & 270. & 195. & 210. & 250. & 235 . & 230. & 240. \\
\hline $\mathrm{Sb}-\ldots$ & 1.2 & 1.0 & 1.0 & 1.3 & 0.9 & 1.0 & 0.8 & 0.6 & 0.9 & 0.9 & 1.0 & 1.0 \\
\hline Sc-... & 0.97 & 0.95 & 1.00 & 0.87 & 0.76 & 0.80 & 0.90 & 0.85 & 0.50 & 0.51 & 0.55 & 0.53 \\
\hline Sn- & $-\overline{2}$ & -- & $\because-$ & 13. & -- & 9.6 & $\ldots$ & 6.7 & -- & -- & - & -- \\
\hline & 3.7 & $\bar{z}-\bar{a}$ & 2.2 & 1.4 & -- & 6.8 & -- & 10.2 & -- & -- & -- & -- \\
\hline 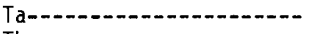 & 6.97 & 7.54 & 7.00 & 8.99 & 6.33 & 5.52 & 4.29 & 4.02 & 5.16 & 5.43 & 5.48 & 5.81 \\
\hline Th- - & 34.7 & 34.7 & 34.8 & 42.1 & 32.5 & 31.6 & 26.3 & 25.3 & 28.4 & 29.2 & 29.0 & 29.9 \\
\hline U U-1 & 13.4 & 15.4 & 11.2 & 16.7 & 14.8 & 9.3 & 8.1 & 7.8 & 12.1 & 12.9 & 12.8 & 13.6 \\
\hline W-1-20-1) & -- & -- & -- & -- & - & -- & -- & -- & & & -- & -- \\
\hline 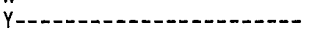 & 76. & 70. & 75. & -- & -- & - & 47. & 47. & 59. & 55. & 62. & 57. \\
\hline $\mathrm{Zn}-\cdots$ & 53. & 57. & 57. & 53. & 43. & 44. & 49. & 45. & 44. & 44. & 45. & 46. \\
\hline $\mathrm{Zr}=-$. & 100. & 100. & 100. & 100. & 115. & 110. & 140. & 135. & 95. & 90. & 95. & 90. \\
\hline La-..- & 16. & 16. & 17. & 13. & 30. & 32. & 44. & 41. & 17. & 17. & 17. & 19. \\
\hline Ce--..- & 38. & 37. & 40. & 32. & 56. & 61. & 78. & 74. & 36. & 37. & 37. & 38. \\
\hline $\mathrm{Nd}-1-1-1$ & 23. & 25. & 23. & 22. & 33. & 27. & 34. & 31. & 21. & 25. & 23. & 27. \\
\hline 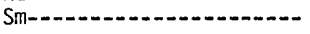 & 7.0 & 6.6 & 7.0 & 6.9 & 5.9 & 6.2 & 6.7 & 6.6 & 4.8 & 4.9 & 4.9 & 5.0 \\
\hline Еu- & $<0.03$ & $<0.03$ & 0.04 & $<0.03$ & 0.11 & 0.09 & 0.13 & 0.15 & 0.07 & 0.06 & 0.08 & 0.08 \\
\hline Gd-20-1 & -- & -- & -- & -. & -- & -- & -- & -- & - & -- & -- & \\
\hline $\mathrm{Tb}-\cdots$ & 1.57 & 1.63 & 1.58 & 1.83 & 1.28 & 1.20 & 1.12 & 1.06 & 1.06 & 1.06 & 1.20 & 1.11 \\
\hline TM- & 1.10 & 1.10 & 1.11 & 1.32 & 0.92 & 0.80 & 0.64 & 0.72 & 0.75 & 0.81 & 0.76 & 0.82 \\
\hline 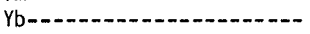 & 7.2 & 7.3 & 7.4 & 9.0 & 5.9 & 6.1 & 5.2 & 4.9 & 5.5 & 5.6 & 5.5 & 5.7 \\
\hline Lu-- & 0.99 & 0.97 & 0.98 & 1.20 & 0.80 & 0.82 & 0.67 & 0.62 & 0.72 & 0.77 & 0.75 & 0.77 \\
\hline $\mathrm{Nb} / \mathrm{Ta}$ & 11.1 & 10.6 & 11.1 & 9.8 & -- & 10.3 & 12.1 & 12.2 & 10.3 & 8.7 & 9.1 & 8.8 \\
\hline $\mathrm{K} / \mathrm{Rb}-\ldots$ & 109. & 112. & 108. & 96. & 150. & 141. & 195. & 182. & 146. & 150. & 158. & 151. \\
\hline $\mathrm{Rb} / \mathrm{Sr}-.$. & 85.1 & 1120 & 146. & 264. & -- & 39.7 & -- & 20.6 & 140 & & 100 & 1010 \\
\hline $\mathrm{Ca} / \mathrm{Sr}-$ & 6.8 & -- & 1137. & 1634. & -- & 463. & -- & 287. & - & -- & -- & -- \\
\hline Th/U-...- & 2.6 & 2.3 & 3.1 & 2.5 & 2.2 & 3.4 & 3.3 & 3.2 & 2.4 & 2.3 & 2.3 & 2.2 \\
\hline $\mathrm{Zr} / \mathrm{HF}$ & 18. & 17. & 17. & 16. & 23. & 21. & 25. & 26. & 19. & 18. & 19. & 18. \\
\hline $\begin{array}{l}\text { Ce/Yb- } \\
\text { Eu/Eü }\end{array}$ & $\begin{array}{l}5.3 \\
--\end{array}$ & $\begin{array}{l}5.1 \\
--\end{array}$ & $\begin{array}{l}5.4 \\
0.02\end{array}$ & $\begin{array}{l}3.6 \\
--\end{array}$ & $\begin{array}{l}9.5 \\
0.05\end{array}$ & 10.0 & $\begin{array}{c}15.0 \\
0.06\end{array}$ & $\begin{array}{r}15.1 \\
0.08\end{array}$ & 6.6 & 6.6 & 6.7 & $\begin{array}{l}6.7 \\
0.05\end{array}$ \\
\hline
\end{tabular}

See footnotes at end of table. 
APPENDIX I.-Chemical analyses of subalkalic silicic obsidians-Continued

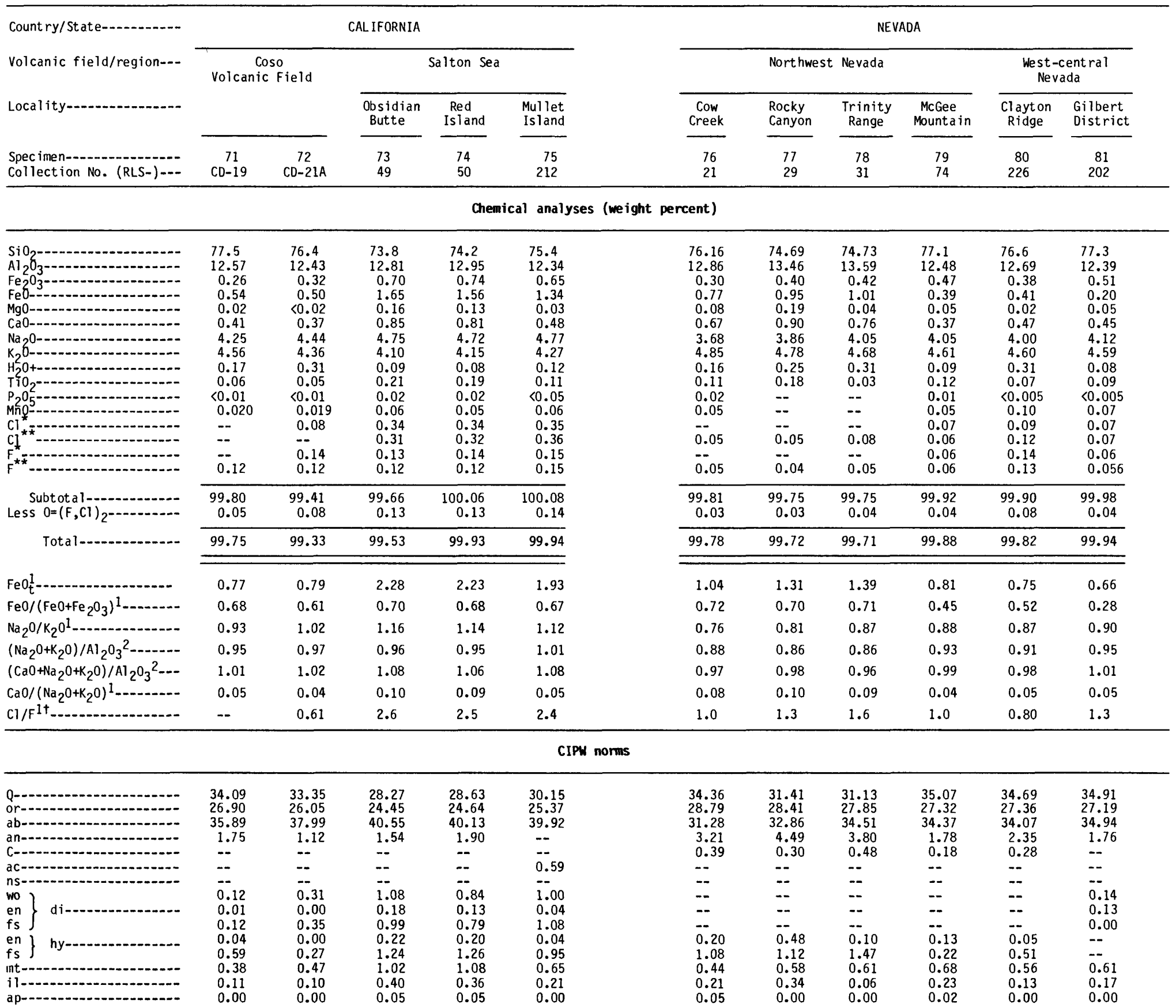




\begin{tabular}{|c|c|c|c|c|c|c|c|c|c|c|c|}
\hline & 71 & 72 & 73 & 74 & 75 & 76 & 77 & 78 & 79 & 80 & 81 \\
\hline \multicolumn{12}{|c|}{ Trace elements ( $p p m)$} \\
\hline 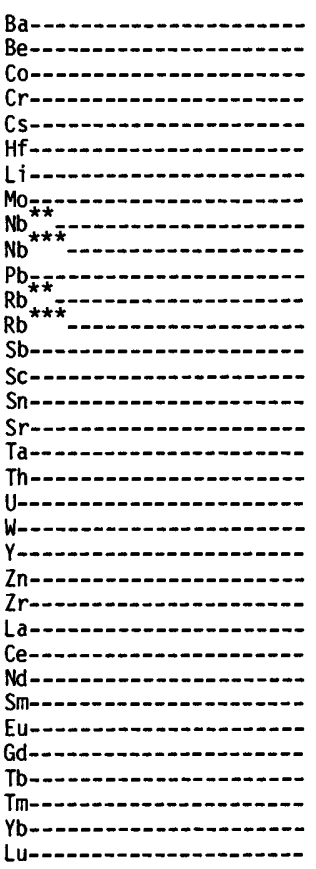 & $\begin{array}{c}-- \\
\ddot{0.1} \\
<1.2 \\
6.1 \\
5.0 \\
-- \\
-- \\
\overline{--} \\
55 . \\
32 . \\
234 . \\
245 . \\
0.8 \\
0.52 \\
-- \\
-- \\
5.83 \\
29.8 \\
14.4 \\
-- \\
\overline{-} \\
45 . \\
95 . \\
17 . \\
36 . \\
20 . \\
5.0 \\
0.07 \\
-- \\
1.11 \\
0.86 \\
5.2 \\
0.73\end{array}$ & $\begin{array}{c}12.8 \\
7.9 \\
0.1 \\
<1.1 \\
6.2 \\
5.1 \\
92 . \\
-- \\
52 . \\
52 . \\
27 . \\
232 . \\
255 . \\
0.9 \\
0.53 \\
8.3 \\
4.8 \\
5.76 \\
29.8 \\
14.3 \\
60 . \\
43 . \\
90 . \\
19 . \\
38 . \\
24 . \\
5.0 \\
0.07 \\
\overline{1 .} \\
0.12 \\
5.3 \\
0.75\end{array}$ & $\begin{array}{c}515 . \\
5.8 \\
1.4 \\
<8.0 \\
4.0 \\
11.8 \\
60 . \\
3.2 \\
28 . \\
32 . \\
13 . \\
133 . \\
135 . \\
0.6 \\
3.1 \\
8.3 \\
25 . \\
2.48 \\
20.8 \\
5.7 \\
1.2 \\
115 . \\
68 . \\
395 . \\
54 . \\
122 . \\
66 . \\
15.0 \\
1.54 \\
14.1 \\
2.98 \\
1.96 \\
13.6 \\
1.87\end{array}$ & $\begin{array}{c}490 . \\
5.8 \\
1.4 \\
<8.0 \\
4.0 \\
11.7 \\
61 . \\
3.1 \\
29 . \\
33 . \\
16 . \\
130 . \\
145 . \\
0.6 \\
2.9 \\
8.2 \\
25 . \\
2.38 \\
20.2 \\
5.2 \\
1.3 \\
130 . \\
60 . \\
395 . \\
54 . \\
115 . \\
64 . \\
14.2 \\
1.43 \\
13.0 \\
3.00 \\
1.81 \\
12.3 \\
1.80\end{array}$ & $\begin{array}{c}400 . \\
7.1 \\
0.3 \\
<2.0 \\
4.5 \\
11.9 \\
81 . \\
3.3 \\
37 . \\
40 . \\
18 . \\
146 . \\
155 . \\
0.6 \\
2.0 \\
12 . \\
7 . \\
3.25 \\
22.3 \\
7.5 \\
1.1 \\
155 . \\
73 . \\
286 . \\
68 . \\
143 . \\
79 . \\
18.2 \\
1.26 \\
19.1 \\
3.51 \\
2.25 \\
17.2 \\
2.26\end{array}$ & $\begin{array}{c}434 . \\
3.1 \\
0.3 \\
\langle 5.0 \\
8.5 \\
3.5 \\
56 . \\
3.0 \\
14 . \\
16 . \\
25 . \\
176 . \\
202 . \\
0.4 \\
2.8 \\
2.8 \\
54 . \\
1.29 \\
19.1 \\
7.9 \\
1.8 \\
34 . \\
32 . \\
94 . \\
31 . \\
59 . \\
24 . \\
4.7 \\
0.28 \\
3.6 \\
0.59 \\
0.29 \\
2.6 \\
0.37\end{array}$ & $\begin{array}{c}1050 . \\
2.4 \\
0.7 \\
<5.0 \\
6.6 \\
4.6 \\
46 . \\
3.5 \\
12 . \\
13 . \\
25 . \\
166 . \\
164 . \\
0.4 \\
2.8 \\
11.9 \\
127 . \\
1.13 \\
15.2 \\
6.7 \\
1.4 \\
29 . \\
30 . \\
147 \\
37 . \\
69 . \\
26 . \\
4.7 \\
0.50 \\
3.4 \\
0.59 \\
0.35 \\
2.2 \\
0.32\end{array}$ & $\begin{array}{c}801 . \\
3.1 \\
0.1 \\
10.7 \\
7.1 \\
3.2 \\
38 . \\
2.3 \\
12 . \\
15 . \\
24 . \\
172 . \\
182 . \\
0.6 \\
1.3 \\
2.7 \\
97 . \\
1.19 \\
13.7 \\
5.1 \\
1.5 \\
8 . \\
66 . \\
72 . \\
24 . \\
46 . \\
19 . \\
4.3 \\
0.42 \\
2.4 \\
0.31 \\
0.36 \\
0.2 \\
<0.08\end{array}$ & $\begin{array}{c}130 . \\
5.5 \\
0.3 \\
1.9 \\
7.3 \\
4.9 \\
44 . \\
8.1 \\
27 . \\
25 . \\
17 . \\
221 . \\
212 . \\
1.2 \\
1.6 \\
3.4 \\
18 . \\
2.95 \\
24.9 \\
13.2 \\
3.9 \\
27 . \\
38 . \\
153 . \\
40 . \\
71 . \\
29 . \\
6.6 \\
0.26 \\
4.6 \\
0.98 \\
0.53 \\
4.6 \\
0.67\end{array}$ & $\begin{array}{c}<50 . \\
7.3 \\
0.1 \\
1.9 \\
8.8 \\
4.6 \\
170 . \\
4.6 \\
36 . \\
45 . \\
34 . \\
325 . \\
322 . \\
2.2 \\
3.0 \\
2.9 \\
<1 . \\
3.83 \\
29.5 \\
9.9 \\
2.8 \\
52 . \\
34 . \\
100 . \\
16 . \\
38 . \\
22 . \\
7.6 \\
0.05 \\
6.8 \\
1.17 \\
0.62 \\
4.6 \\
0.64\end{array}$ & $\begin{array}{c}23 . \\
5.3 \\
0.1 \\
<2.0 \\
8.6 \\
4.3 \\
56 . \\
5.7 \\
35 . \\
39 . \\
26 . \\
218 . \\
215 . \\
<0.9 \\
1.5 \\
2.8 \\
8 . \\
3.29 \\
31.1 \\
10.5 \\
2.9 \\
24 . \\
20 . \\
79 . \\
36 . \\
61 . \\
20 . \\
3.3 \\
0.18 \\
4.8 \\
<0.40 \\
0.39 \\
2.8 \\
0.43\end{array}$ \\
\hline 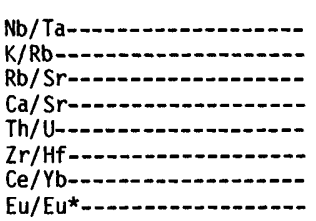 & $\begin{array}{c}9.4 \\
155 . \\
-- \\
-- \\
2.1 \\
19 . \\
6.9 \\
0.04\end{array}$ & $\begin{array}{c}9.0 \\
142 . \\
53.1 \\
551 . \\
2.1 \\
18 . \\
7.2 \\
0.04\end{array}$ & $\begin{array}{c}12.1 \\
252 . \\
5.4 \\
243 . \\
3.7 \\
34 . \\
9.0 \\
0.32\end{array}$ & $\begin{array}{c}13.0 \\
238 . \\
5.8 \\
232 . \\
3.9 \\
34 . \\
9.4 \\
0.32\end{array}$ & $\begin{array}{c}11.9 \\
229 . \\
22.1 \\
490 . \\
3.0 \\
24 . \\
8.3 \\
0.20\end{array}$ & $\begin{array}{c}11.6 \\
199 . \\
3.7 \\
89 . \\
2.4 \\
27 . \\
22.7 \\
0.21\end{array}$ & $\begin{array}{c}11.1 \\
242 . \\
1.3 \\
51 . \\
2.3 \\
32 . \\
31.4 \\
0.38\end{array}$ & $\begin{array}{c}11.3 \\
213 . \\
1.9 \\
56 . \\
2.7 \\
23 . \\
23.0 \\
0.41\end{array}$ & $\begin{array}{c}8.8 \\
181 . \\
11.8 \\
147 . \\
1.9 \\
31.9 \\
15.4 \\
0.15\end{array}$ & $\begin{array}{c}10.6 \\
119 . \\
-- \\
-- \\
3.0 \\
26 . \\
8.3 \\
0.02\end{array}$ & $\begin{array}{c}11.3 \\
177 . \\
26.9 \\
402 . \\
3.0 \\
18 . \\
21.8 \\
0.14\end{array}$ \\
\hline
\end{tabular}

See footnotes at end of table. 
APPENDIX I.-Chemical analyses of subalkalic silicic obsidians-Continued

\begin{tabular}{|c|c|c|c|c|c|c|c|c|c|c|}
\hline \multirow{3}{*}{$\begin{array}{l}\text { Country/State--..- } \\
\text { Volcanic field/region--- } \\
\text { Locality- }\end{array}$} & \multirow{3}{*}{$\begin{array}{l}\text { NEVADA } \\
\begin{array}{c}\text { Timber } \\
\text { Mounta a in }\end{array} \\
\text { Shoshone } \\
\text { Mounta in }\end{array}$} & \multicolumn{6}{|c|}{ IDAHO } & \multicolumn{3}{|c|}{ WYOMING } \\
\hline & & \multicolumn{3}{|c|}{ Snake River Plain } & \multicolumn{3}{|c|}{ Blackfoot Volcanic Field } & \multicolumn{3}{|c|}{ Yellowstone Volcanic Field } \\
\hline & & $\begin{array}{l}\text { Big Southern } \\
\text { Butte }\end{array}$ & $\begin{array}{l}\text { Ammon } \\
\text { quadrangle }\end{array}$ & $\begin{array}{l}\text { American } \\
\text { Falls }\end{array}$ & $\begin{array}{l}\text { Middle } \\
\text { Cone }\end{array}$ & $\begin{array}{l}\text { North } \\
\text { Cone }\end{array}$ & $\begin{array}{c}\text { China } \\
\text { Hat }\end{array}$ & $\begin{array}{l}\text { Mount } \\
\text { Everts }\end{array}$ & $\begin{array}{l}\text { Gibbon } \\
\text { River }\end{array}$ & $\begin{array}{l}\text { Summit } \\
\text { Lake }\end{array}$ \\
\hline $\begin{array}{l}\text { Specinen- } \\
\text { Collection No. (RLS-)-- }\end{array}$ & $\begin{array}{l}82 \\
14\end{array}$ & $\begin{array}{l}83 \\
75\end{array}$ & $\begin{array}{r}84 \\
151\end{array}$ & $\begin{array}{r}85 \\
152\end{array}$ & $\begin{array}{r}86 \\
185\end{array}$ & $\begin{array}{r}87 \\
188\end{array}$ & $\begin{array}{r}88 \\
191\end{array}$ & $\begin{array}{l}89 \\
--\end{array}$ & $\begin{array}{r}90 \\
267\end{array}$ & $\begin{array}{r}91 \\
268\end{array}$ \\
\hline \multicolumn{11}{|c|}{ Chemical analyses (weight percent) } \\
\hline 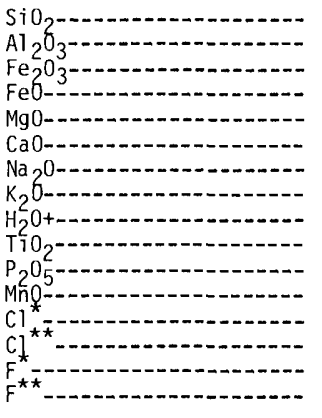 & $\begin{array}{r}74.25 \\
13.50 \\
0.44 \\
0.86 \\
0.18 \\
0.68 \\
4.00 \\
5.33 \\
0.26 \\
0.22 \\
0.03 \\
0.04 \\
-- \\
0.05 \\
-- \\
--\end{array}$ & $\begin{array}{l}75.4 \\
12.38 \\
0.58 \\
1.04 \\
<0.005 \\
0.48 \\
4.29 \\
4.61 \\
0.14 \\
0.09 \\
<0.005 \\
0.04 \\
0.18 \\
0.22 \\
0.30 \\
0.33\end{array}$ & $\begin{array}{l}76.1 \\
12.18 \\
0.45 \\
1.30 \\
0.07 \\
0.54 \\
3.54 \\
5.03 \\
0.11 \\
0.23 \\
0.02 \\
0.05 \\
0.08 \\
0.07 \\
0.12 \\
0.12\end{array}$ & $\begin{array}{l}75.9 \\
12.10 \\
0.47 \\
0.79 \\
0.09 \\
0.52 \\
3.46 \\
5.12 \\
0.04 \\
0.23 \\
0.01 \\
0.05 \\
0.09 \\
0.09 \\
0.13 \\
0.13\end{array}$ & $\begin{array}{r}75.9 \\
12.53 \\
0.40 \\
0.50 \\
0.02 \\
0.54 \\
4.20 \\
4.51 \\
0.39 \\
0.06 \\
0.01 \\
0.07 \\
0.14 \\
0.14 \\
0.32 \\
0.35\end{array}$ & $\begin{array}{r}76.2 \\
12.47 \\
0.44 \\
0.47 \\
0.02 \\
0.53 \\
4.16 \\
4.34 \\
0.31 \\
0.06 \\
0.01 \\
0.06 \\
0.14 \\
0.14 \\
0.32 \\
0.34\end{array}$ & $\begin{array}{r}76.5 \\
12.51 \\
0.39 \\
0.51 \\
0.02 \\
0.52 \\
4.12 \\
4.53 \\
0.23 \\
0.06 \\
0.01 \\
0.07 \\
0.14 \\
0.15 \\
0.34 \\
0.34\end{array}$ & $\begin{array}{r}75.83 \\
12.42 \\
0.94 \\
0.63 \\
0.00 \\
0.52 \\
3.70 \\
5.08 \\
0.25 \\
0.10 \\
0.00 \\
0.04 \\
-- \\
0.06 \\
-- \\
0.15\end{array}$ & $\begin{array}{r}76.59 \\
12.25 \\
0.50 \\
0.72 \\
0.00 \\
0.38 \\
4.01 \\
4.78 \\
0.17 \\
0.07 \\
0.01 \\
0.03 \\
-- \\
0.11 \\
-- \\
0.26\end{array}$ & $\begin{array}{r}76.51 \\
12.05 \\
0.47 \\
1.11 \\
0.01 \\
0.42 \\
3.65 \\
5.10 \\
0.23 \\
0.13 \\
0.01 \\
0.04 \\
-.- \\
0.08 \\
-0.18 \\
0.01\end{array}$ \\
\hline $\begin{array}{l}\text { Subtotal } \\
\text { Less } 0=(F, C 1)_{2}\end{array}$ & $\begin{array}{r}99.84 \\
0.01\end{array}$ & $\begin{array}{r}99.57 \\
0.18\end{array}$ & $\begin{array}{r}99.82 \\
0.07\end{array}$ & $\begin{array}{r}99.00 \\
0.07\end{array}$ & $\begin{array}{r}99.61 \\
0.19\end{array}$ & $\begin{array}{r}99.54 \\
0.17\end{array}$ & $\begin{array}{r}99.96 \\
0.18\end{array}$ & $\begin{array}{r}99.72 \\
0.08\end{array}$ & $\begin{array}{r}99.88 \\
0.13\end{array}$ & $\begin{array}{r}99.99 \\
0.09\end{array}$ \\
\hline 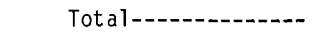 & 99.83 & 99.39 & 99.75 & 98.93 & 99.42 & 99.37 & 99.78 & 99.64 & 99.75 & 99.90 \\
\hline $\mathrm{FeO}_{\mathrm{t}}^{1}-\mathrm{-}^{-}$ & 1.26 & 1.56 & 1.71 & 1.21 & 0.86 & 0.87 & 0.86 & 1.48 & 1.17 & 1.53 \\
\hline $\mathrm{Fe} 0 /\left(\mathrm{Fe} 0+\mathrm{Fe}_{2} \mathrm{O}_{3}\right)^{1} \ldots$ & 0.66 & 0.64 & 0.74 & 0.63 & 0.56 & 0.52 & 0.57 & 0.40 & 0.59 & 0.70 \\
\hline $\mathrm{Na}_{2} \mathrm{O} / \mathrm{K}_{2} \mathrm{O}^{\mathrm{l}-}$ & 0.75 & 0.93 & 0.70 & 0.68 & 0.93 & 0.96 & 0.91 & 0.73 & 0.84 & 0.72 \\
\hline$\left(\mathrm{Na}_{2} \mathrm{O}+\mathrm{K}_{2} \mathrm{O}\right) / \mathrm{Al}_{2} \mathrm{O}_{3}{ }^{2} \cdots$ & 0.91 & 0.97 & 0.92 & 0.93 & 0.94 & 0.93 & 0.93 & 0.93 & 0.96 & 0.96 \\
\hline$\left(\mathrm{CaO}+\mathrm{Na}_{2} \mathrm{O}+\mathrm{K}_{2} \mathrm{O}\right) / \mathrm{Al}_{2} \mathrm{O}_{3}{ }^{2}-$. & 1.01 & 1.04 & 1.01 & 1.01 & 1.02 & 1.00 & 1.01 & 1.01 & 1.02 & 1.02 \\
\hline $\mathrm{CaO} /\left(\mathrm{Na}_{2} \mathrm{O}+\mathrm{K}_{2} \mathrm{O}\right)^{1}$ & 0.07 & 0.05 & 0.06 & 0.06 & 0.06 & 0.06 & 0.06 & 0.06 & 0.04 & 0.05 \\
\hline $\mathrm{Cl} / \mathrm{F}^{1+}+\ldots$ & -- & 0.63 & 0.61 & 0.72 & 0.42 & 0.42 & 0.42 & 0.40 & 0.42 & 0.44 \\
\hline \multicolumn{11}{|c|}{ CIPW norms } \\
\hline Q & 28.67 & 31.82 & 34.45 & 35.08 & 33.32 & 34.46 & 34.10 & 33.94 & 34.14 & 34.49 \\
\hline or-- & 31.65 & 27.54 & 29.87 & 30.64 & 26.99 & 25.97 & 26.97 & 30.24 & 28.43 & 30.29 \\
\hline$a b-\ldots$ & 34.01 & 36.70 & 30.10 & 29.65 & 35.99 & 35.64 & 35.13 & 31.54 & 34.16 & 31.04 \\
\hline an-w-non & 3.16 & 0.92 & 2.50 & 2.39 & 2.04 & 2.57 & 2.28 & 2.30 & 1.32 & 1.44 \\
\hline 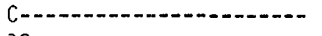 & -- & -- & -- & -- & -- & -- & -- & -- & -- & -- \\
\hline ac- & -- & -- & -- & -- & -- & -- & -- & -- & -- & -- \\
\hline $\begin{array}{l}\text { wo } \\
\text { wo }\end{array}$ & $\overline{0.02}$ & $\overline{0.62}$ & $\overline{0.03}$ & $\ddot{0.06}$ & 0.25 & $\overline{0 .} 01$ & $\overline{0.11}$ & $\overline{0 .} 13$ & $\overline{0 .}-22$ & $\overrightarrow{0.25}$ \\
\hline en $\}$ di-n. & 0.01 & 0.00 & 0.00 & 0.02 & 0.02 & 0.01 & 0.01 & 0.00 & 0.00 & 0.00 \\
\hline fs J & 0.01 & 0.71 & 0.03 & 0.05 & 0.26 & 0.01 & 0.11 & 0.14 & 0.24 & 0.27 \\
\hline en , hy-..-.......... & 0.45 & 0.00 & 0.17 & 0.21 & 0.03 & 0.05 & 0.04 & 0.00 & 0.00 & 0.02 \\
\hline fs $\}$ ny-n & 0.92 & 0.67 & 1.71 & 0.73 & 0.37 & 0.51 & 0.54 & 0.15 & 0.61 & 1.25 \\
\hline mt -2 & 0.64 & 0.85 & 0.66 & 0.69 & 0.59 & 0.65 & 0.57 & 1.37 & 0.73 & 0.69 \\
\hline i门-11- & 0.42 & 0.17 & 0.44 & 0.44 & 0.12 & 0.12 & 0.12 & 0.19 & 0.13 & 0.25 \\
\hline ap- & 0.07 & 0.00 & 0.05 & 0.02 & 0.02 & 0.02 & 0.02 & 0.00 & 0.02 & 0.02 \\
\hline
\end{tabular}




\begin{tabular}{|c|c|c|c|c|c|c|c|c|c|c|}
\hline & 82 & 83 & 84 & 85 & 86 & 87 & 88 & 89 & 90 & 91 \\
\hline \multicolumn{11}{|c|}{ Trace elements (ppm) } \\
\hline 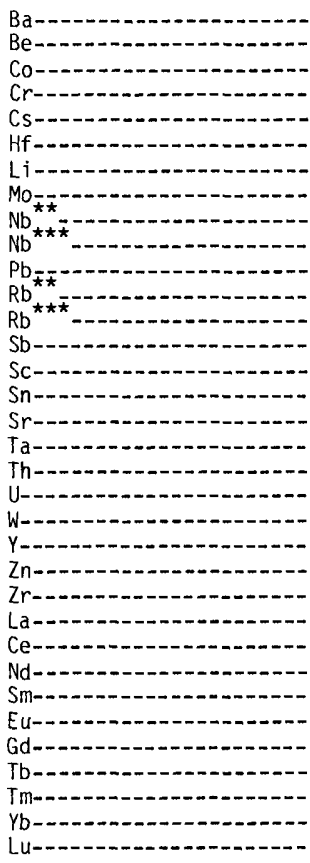 & $\begin{array}{l}651 . \\
3.9 \\
0.9 \\
1.9 \\
4.6 \\
5.7 \\
54 . \\
3.5 \\
26 . \\
32 . \\
27 . \\
186 . \\
206 . \\
0.4 \\
2.4 \\
3.5 \\
90 . \\
2.32 \\
28.2 \\
5.8 \\
2.6 \\
33 . \\
29 . \\
211 . \\
61 . \\
99 . \\
35 . \\
6.0 \\
0.53 \\
4.6 \\
0.62 \\
0.34 \\
2.6 \\
0.40\end{array}$ & $\begin{array}{c}<50 . \\
23 . \\
<0.4 \\
<7.0 \\
4.4 \\
14.5 \\
99 . \\
4.1 \\
270 . \\
305 . \\
101 . \\
296 . \\
299 . \\
0.5 \\
0.12 \\
18 . \\
<5 . \\
21.68 \\
20.7 \\
11.0 \\
4.7 \\
245 . \\
282 . \\
338 . \\
72 . \\
132 . \\
51 . \\
15.6 \\
0.27 \\
16.6 \\
4.26 \\
3.22 \\
23.6 \\
3.04\end{array}$ & $\begin{array}{r}970 . \\
3.9 \\
0.6 \\
<4.0 \\
3.1 \\
10.6 \\
34 . \\
4.8 \\
51 . \\
63 . \\
32 . \\
175 . \\
175 . \\
0.2 \\
3.0 \\
5.7 \\
18 . \\
3.87 \\
25.2 \\
6.7 \\
2.5 \\
69 . \\
65 . \\
330 . \\
84 . \\
159 . \\
60 . \\
13.1 \\
0.98 \\
10.1 \\
2.17 \\
0.83 \\
6.1 \\
0.85\end{array}$ & $\begin{array}{c}975 . \\
3.6 \\
0.6 \\
2.0 \\
4.0 \\
7.5 \\
35 . \\
4.8 \\
48 . \\
52 . \\
26 . \\
197 . \\
195 . \\
0.4 \\
1.9 \\
4.7 \\
20 . \\
3.31 \\
25.9 \\
6.9 \\
3.4 \\
59 . \\
54 . \\
224 . \\
76 . \\
147 . \\
53 . \\
9.6 \\
0.97 \\
10.3 \\
1.85 \\
0.91 \\
6.0 \\
0.80\end{array}$ & $\begin{array}{c}9 . \\
15 . \\
0.2 \\
<2.0 \\
18.6 \\
6.6 \\
100 . \\
2.8 \\
90 . \\
94 . \\
40 . \\
473 . \\
460 . \\
0.5 \\
2.2 \\
16 . \\
0.3 \\
10.9 \\
49.1 \\
35.1 \\
4.8 \\
173 . \\
51 . \\
106 . \\
17 . \\
45 . \\
30 . \\
10.1 \\
0.04 \\
13.9 \\
2.56 \\
2.40 \\
17.4 \\
2.41\end{array}$ & $\begin{array}{c}3 . \\
13 . \\
<0.4 \\
33.0 \\
17.4 \\
6.1 \\
97 . \\
2.9 \\
82 . \\
82 . \\
42 . \\
45 . \\
455 . \\
0.3 \\
2.1 \\
16 . \\
0.7 \\
9.94 \\
50.1 \\
33.6 \\
4.3 \\
177 . \\
50 . \\
110 . \\
15 . \\
43 . \\
28 . \\
9.6 \\
0.04 \\
16.1 \\
2.40 \\
2.41 \\
16.9 \\
2.29\end{array}$ & $\begin{array}{c}2 . \\
14 . \\
<0.4 \\
<3.0 \\
19.1 \\
6.5 \\
98 . \\
3.0 \\
77 . \\
81 . \\
33 . \\
491 . \\
440 . \\
<0.9 \\
2.3 \\
16 . \\
0.6 \\
11.10 \\
52.7 \\
35.0 \\
5.0 \\
175 . \\
48 . \\
104 . \\
21 . \\
59 . \\
35 . \\
10.3 \\
0.03 \\
14.9 \\
2.01 \\
2.55 \\
17.8 \\
2.48\end{array}$ & $\begin{array}{c}-- \\
-- \\
0.2 \\
<20.0 \\
4.0 \\
8.3 \\
-- \\
-- \\
-- \\
-- \\
-- \\
228 . \\
-- \\
<3 . \\
1.6 \\
-- \\
-- \\
4.87 \\
32.2 \\
8.6 \\
-- \\
-- \\
-- \\
-- \\
94 . \\
179 . \\
71 . \\
15.9 \\
0.61 \\
13.2 \\
2.44 \\
1.16 \\
8.0 \\
1.07\end{array}$ & $\begin{array}{c}21 . \\
\overline{0 .} \\
<5.0 \\
6.8 \\
8.4 \\
-- \\
-- \\
54 . \\
67 . \\
41 . \\
295 . \\
300 . \\
0.4 \\
0.91 \\
-. \\
1.5 \\
5.07 \\
36.2 \\
10.0 \\
110 . \\
99 . \\
165 . \\
43 . \\
96 . \\
44 . \\
13.3 \\
0.07 \\
11.4 \\
2.76 \\
1.36 \\
9.1 \\
1.20\end{array}$ & \begin{tabular}{c}
67. \\
\hdashline 0.3 \\
$<7.0$ \\
4.1 \\
9.3 \\
-- \\
\hdashline- \\
58. \\
71. \\
32. \\
206. \\
214. \\
$<2.0$ \\
1.3 \\
$\ddot{1.8}$ \\
4.90 \\
28.8 \\
7.9 \\
.- \\
93. \\
101. \\
270. \\
92. \\
176. \\
66. \\
15.8 \\
0.46 \\
12.0 \\
2.39 \\
1.34 \\
8.0 \\
1.05
\end{tabular} \\
\hline $\begin{array}{l}\mathrm{Nb} / \mathrm{Ta} \\
\mathrm{K} / \mathrm{Rb} \\
\mathrm{Rb} / \mathrm{Sr} \\
\mathrm{Ca} / \mathrm{Sr} \\
\mathrm{Th} / \mathrm{U} \\
\mathrm{Zr} / \mathrm{Hf} \\
\mathrm{Ce} / \mathrm{Yb} \\
\mathrm{Eu} / \mathrm{Eu}{ }^{*}\end{array}$ & $\begin{array}{c}12.5 \\
215 . \\
22.9 \\
54.9 \\
4.9 \\
37 . \\
38.1 \\
0.31\end{array}$ & $\begin{array}{c}13.3 \\
128 . \\
-- \\
\overline{1.9} \\
23 . \\
5.6 \\
0.05\end{array}$ & $\begin{array}{c}14.7 \\
239 . \\
9.7 \\
214 . \\
3.8 \\
31 . \\
26.1 \\
0.26\end{array}$ & $\begin{array}{c}15.1 \\
218 . \\
9.8 \\
186 . \\
3.8 \\
30 . \\
24.5 \\
0.30\end{array}$ & $\begin{array}{c}8.4 \\
81 . \\
1533 . \\
12863 . \\
1.4 \\
16 . \\
2.6 \\
0.01\end{array}$ & $\begin{array}{c}8.3 \\
79 . \\
650 . \\
5411 . \\
1.5 \\
18 . \\
2.5 \\
0.01\end{array}$ & $\begin{array}{c}7.1 \\
85 . \\
733 . \\
6193 . \\
1.5 \\
16 . \\
3.3 \\
0.01\end{array}$ & $\begin{array}{c}18 \overline{.} \\
-- \\
\overline{3.7} \\
\overline{-} \\
22.4 \\
0.13\end{array}$ & $\begin{array}{c}11.9 \\
135 . \\
200 . \\
1811 . \\
3.6 \\
20 . \\
10.6 \\
0.02\end{array}$ & $\begin{array}{c}13.2 \\
205 . \\
119 . \\
1668 . \\
3.7 \\
29 . \\
22.0 \\
0.10\end{array}$ \\
\hline
\end{tabular}

See footnotes at end of table. 
APPENDIX I.-Chemical analyses of subalkalic silicic obsidians-Continued

\begin{tabular}{|c|c|c|c|c|c|c|c|c|c|c|c|}
\hline \multirow{3}{*}{$\begin{array}{l}\text { Country/State- } \\
\text { Volcanic field/region-. } \\
\text { Local ity-... }\end{array}$} & \multicolumn{3}{|c|}{ WYOMING } & \multicolumn{8}{|c|}{ UTAH } \\
\hline & \multicolumn{3}{|c|}{ Yellowstone Volcanic Field } & \multirow[b]{2}{*}{$\begin{array}{l}\text { Wildcat } \\
\text { Hills }\end{array}$} & \multirow[b]{2}{*}{$\begin{array}{c}\text { White } \\
\text { Mountain }\end{array}$} & \multicolumn{3}{|c|}{ Twin Peaks Volcanic Field } & \multicolumn{3}{|c|}{ Mineral Mountains } \\
\hline & $\begin{array}{c}\text { Elephant } \\
\text { Back }\end{array}$ & $\begin{array}{l}\text { Crystal } \\
\text { Spring }\end{array}$ & $\begin{array}{l}\text { Obsidian } \\
\text { Cliff }\end{array}$ & & & Rhy & of $\mathrm{Cu}$ & Mine & Bai & dge & $\begin{array}{l}\text { North } \\
\text { dome }\end{array}$ \\
\hline $\begin{array}{l}\text { Specimen- } \\
\text { collection No. (RLS-) }\end{array}$ & $\begin{array}{r}92 \\
269\end{array}$ & $\begin{array}{r}93 \\
270\end{array}$ & $\begin{array}{r}94 \\
271\end{array}$ & $\begin{array}{r}95 \\
106\end{array}$ & $\begin{array}{r}96 \\
116\end{array}$ & $\begin{array}{r}97 \\
103\end{array}$ & $\begin{array}{r}98 \\
104\end{array}$ & $\begin{array}{r}99 \\
105\end{array}$ & $\begin{array}{l}100 \\
136\end{array}$ & $\begin{array}{l}101 \\
137\end{array}$ & $\begin{array}{l}102 \\
138\end{array}$ \\
\hline
\end{tabular}

Chemical analyses (weight percent)

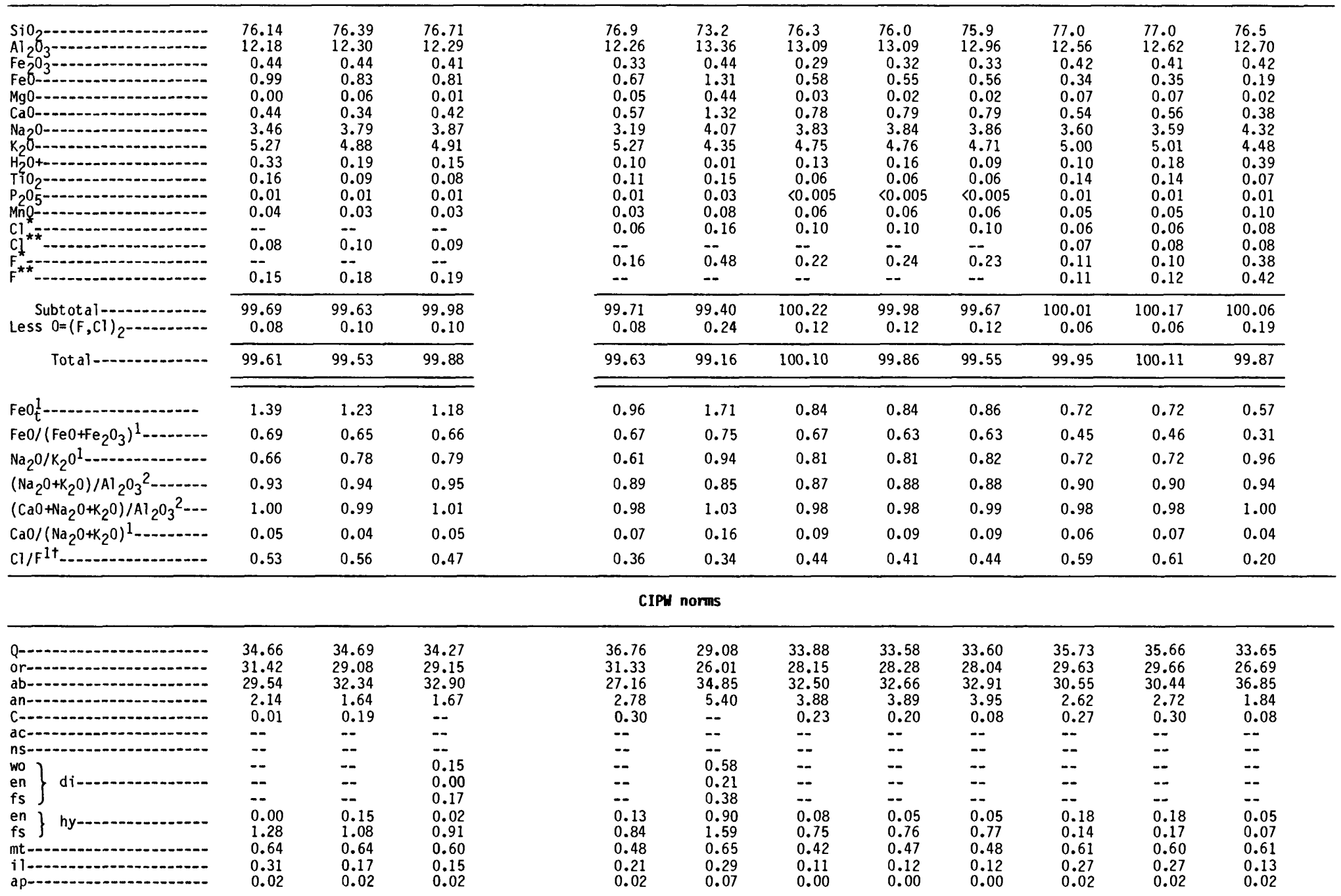




\begin{tabular}{|c|c|c|c|c|c|c|c|c|c|c|c|}
\hline & 92 & 93 & 94 & 95 & 96 & 97 & 98 & 99 & 100 & 101 & 102 \\
\hline \multicolumn{12}{|c|}{ Trace elements (ppm) } \\
\hline 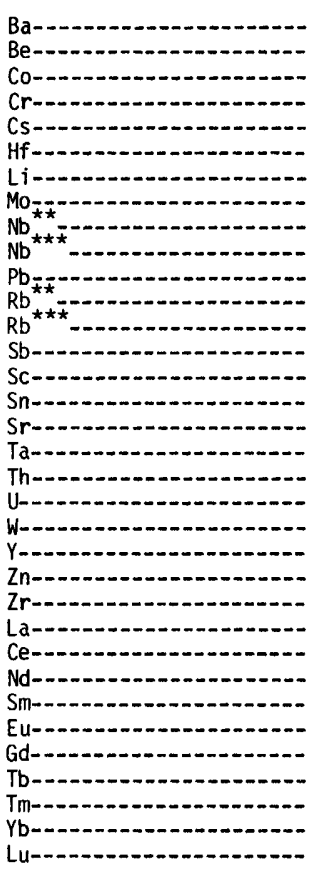 & $\begin{array}{c}240 . \\
\overline{0.4} \\
<8.0 \\
4.2 \\
8.6 \\
-- \\
-- \\
51 . \\
60 . \\
34 . \\
191 . \\
203 . \\
0.5 \\
2.3 \\
-- \\
11 . \\
4.55 \\
30.1 \\
7.9 \\
7-. \\
74 . \\
63 . \\
233 . \\
95 . \\
185 . \\
70 . \\
14.9 \\
0.70 \\
11.2 \\
2.15 \\
1.27 \\
6.6 \\
0.91\end{array}$ & $\begin{array}{c}38 . \\
-- \\
0.6 \\
<9.0 \\
4.7 \\
7.2 \\
-- \\
-- \\
42 . \\
51 . \\
39 . \\
199 . \\
254 . \\
0.4 \\
1.3 \\
-- \\
3.3 \\
3.45 \\
29.6 \\
6.4 \\
--. \\
89 . \\
83 . \\
175 . \\
61 . \\
120 . \\
45 . \\
12.1 \\
0.16 \\
9.7 \\
2.13 \\
1.24 \\
6.7 \\
0.94\end{array}$ & $\begin{array}{c}34 . \\
0 . .3 \\
0.3 \\
13 . \\
5.3 \\
7.6 \\
-z \\
7 \overline{-} \\
54 . \\
39 . \\
222 \\
259 . \\
0.6 \\
1.1 \\
\overline{1 .} \\
3.7 \\
26.4 \\
7.3 \\
7-. \\
92 . \\
83 . \\
177 . \\
56.8 \\
118.0 \\
56.9 \\
12.3 \\
0.18 \\
9.3 \\
1.8 \\
0.9 \\
7.1 \\
0.91\end{array}$ & $\begin{array}{c}105 . \\
5.3 \\
0.5 \\
<4.0 \\
4.1 \\
4.9 \\
52 . \\
4.6 \\
29 . \\
36 . \\
50 . \\
240 . \\
243 . \\
0.2 \\
1.7 \\
5.8 \\
12 . \\
3.47 \\
45.6 \\
8.9 \\
3.2 \\
55 . \\
27 . \\
128 . \\
69 . \\
125 . \\
44 . \\
9.4 \\
0.28 \\
7.9 \\
1.53 \\
1.13 \\
7.9 \\
1.10\end{array}$ & $\begin{array}{c}<50 . \\
7.0 \\
2.9 \\
9.0 \\
5.2 \\
6.0 \\
78 . \\
2.1 \\
36 . \\
35 . \\
48 . \\
291 . \\
284 . \\
0.3 \\
2.6 \\
8.7 \\
20 . \\
3.97 \\
33.6 \\
10.9 \\
4.4 \\
115 . \\
70 . \\
126 . \\
18 . \\
46 . \\
24 . \\
8.3 \\
0.31 \\
8.1 \\
1.82 \\
2.05 \\
12.8 \\
2.07\end{array}$ & $\begin{array}{c}<50 . \\
4.9 \\
0.2 \\
<4.0 \\
4.7 \\
4.7 \\
66 . \\
2.8 \\
34 . \\
-. \\
55 . \\
267 . \\
268 . \\
0.3 \\
1.8 \\
4.7 \\
8 . \\
2.92 \\
27.9 \\
7.1 \\
3.9 \\
48 . \\
39 . \\
100 . \\
12 . \\
34 . \\
20 . \\
6.2 \\
0.20 \\
6.2 \\
1.12 \\
0.99 \\
7.6 \\
1.05\end{array}$ & $\begin{array}{c}<50 . \\
4.6 \\
0.2 \\
<3.0 \\
4.8 \\
4.6 \\
67 . \\
2.5 \\
37 . \\
-. \\
52 . \\
263 . \\
278 . \\
0.3 \\
1.8 \\
4.9 \\
<5 . \\
3.00 \\
27.9 \\
7.2 \\
3.5 \\
41 . \\
40 . \\
100 . \\
12 . \\
32 . \\
20 . \\
6.2 \\
0.20 \\
5.2 \\
1.13 \\
1.08 \\
7.5 \\
1.07\end{array}$ & $\begin{array}{c}<50 . \\
4.6 \\
0.2 \\
<3.0 \\
4.7 \\
4.6 \\
67 . \\
2.8 \\
36 . \\
-- \\
44 . \\
274 . \\
261 . \\
0.2 \\
1.8 \\
4.7 \\
7 . \\
2.90 \\
27.7 \\
7.1 \\
3.6 \\
48 . \\
33 . \\
102 . \\
12 . \\
33 . \\
18 . \\
6.2 \\
0.20 \\
5.6 \\
1.12 \\
1.05 \\
7.6 \\
1.07\end{array}$ & $\begin{array}{c}165 . \\
4.2 \\
0.3 \\
<4.0 \\
3.5 \\
4.1 \\
61 . \\
4.3 \\
26 . \\
30 . \\
25 . \\
195 . \\
200 . \\
0.1 \\
2.3 \\
1.7 \\
37 . \\
2.04 \\
22.1 \\
6.2 \\
2.4 \\
21 . \\
24 . \\
100 . \\
47 . \\
83 . \\
23 . \\
4.1 \\
0.33 \\
3.4 \\
0.43 \\
0.36 \\
2.5 \\
0.42\end{array}$ & $\begin{array}{c}180 . \\
4.0 \\
0.3 \\
<4.0 \\
3.4 \\
4.1 \\
57 . \\
4.5 \\
25 . \\
30 . \\
26 . \\
187 . \\
205 . \\
<0.3 \\
2.2 \\
1.7 \\
40 . \\
1.97 \\
21.7 \\
6.2 \\
1.9 \\
18 . \\
35 . \\
97 . \\
47 . \\
82 . \\
23 . \\
4.0 \\
0.33 \\
2.6 \\
0.44 \\
0.35 \\
2.5 \\
0.42\end{array}$ & $\begin{array}{c}<50 . \\
9.6 \\
0.1 \\
<4.0 \\
7.0 \\
5.6 \\
110 . \\
5.9 \\
54 . \\
56 . \\
29 . \\
346 . \\
360 . \\
0.3 \\
3.6 \\
3.6 \\
<5 . \\
3.57 \\
39.3 \\
11.6 \\
3.6 \\
32 . \\
50 . \\
88 . \\
29 . \\
49 . \\
11 . \\
1.5 \\
0.02 \\
<2.0 \\
<0.20 \\
0.42 \\
3.8 \\
0.70\end{array}$ \\
\hline $\begin{array}{l}\mathrm{Nb} / \mathrm{Ta}-\mathrm{d} \\
\mathrm{K} / \mathrm{Rb} \\
\mathrm{Rb} / \mathrm{Sr}- \\
\mathrm{Ca} / \mathrm{Sr}-\end{array}$ & $\begin{array}{c}12.4 \\
229 . \\
18.1 \\
281 . \\
3.8 \\
27 . \\
28.0 \\
0.17\end{array}$ & $\begin{array}{l}13.5 \\
203 . \\
77.0 \\
736 . \\
4.6 \\
24 . \\
17.9 \\
0.05\end{array}$ & $\begin{array}{c}13.2 \\
177 . \\
202 . \\
2729 . \\
3.6 \\
36 . \\
16.6 \\
0.05\end{array}$ & $\begin{array}{c}9.4 \\
180 . \\
20.3 \\
340 . \\
5.1 \\
26 . \\
15.8 \\
0.10\end{array}$ & $\begin{array}{c}8.9 \\
127 . \\
14.2 \\
472 . \\
3.1 \\
21 . \\
3.6 \\
0.12\end{array}$ & $\begin{array}{c}11.6 \\
147 . \\
33.5 \\
697 . \\
3.9 \\
21 . \\
4.5 \\
0.10\end{array}$ & $\begin{array}{c}12.3 \\
142 . \\
-- \\
\overline{3.9} \\
22 . \\
4.3 \\
0.11\end{array}$ & $\begin{array}{c}12.4 \\
150 . \\
37.3 \\
807 . \\
3.9 \\
22.9 \\
4.3 \\
0.10\end{array}$ & $\begin{array}{c}13.7 \\
208 . \\
5.4 \\
104 . \\
3.6 \\
24 . \\
33.2 \\
0.27\end{array}$ & $\begin{array}{c}14.0 \\
203 . \\
5.1 \\
100 . \\
3.5 \\
24 . \\
32.8 \\
0.31\end{array}$ & $\begin{array}{c}15.4 \\
103 . \\
-- \\
-- \\
3.4 \\
16 . \\
12.9 \\
0.04\end{array}$ \\
\hline
\end{tabular}

See footnotes at end of table. 
APPENDIX I.-Chemical analyses of subalkalic silicic obsidians-Continued

\begin{tabular}{|c|c|c|c|c|c|c|c|c|c|}
\hline \multirow{3}{*}{$\begin{array}{l}\text { Country/State-- } \\
\text { Volcanic field/region--- } \\
\text { Local ity-a- }\end{array}$} & \multirow{3}{*}{ 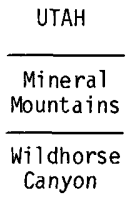 } & \multicolumn{2}{|c|}{ COLORADO } & \multicolumn{4}{|c|}{ ARIZONA } & \multirow{2}{*}{\multicolumn{2}{|c|}{$\frac{\text { NEW MEXICO }}{\text { Taos Plateau }}$}} \\
\hline & & \multirow{2}{*}{$\frac{\begin{array}{c}\text { Nathrop } \\
\text { Field }\end{array}}{\begin{array}{c}\text { Bald } \\
\text { Mountain }\end{array}}$} & \multirow{2}{*}{$\begin{array}{l}\begin{array}{l}\text { San Juan } \\
\text { Mountains }\end{array} \\
\begin{array}{l}\text { Beaver } \\
\text { Creek }\end{array}\end{array}$} & \multirow{2}{*}{$\begin{array}{l}\text { Superior } \\
\begin{array}{c}\text { Queen } \\
\text { Creek }\end{array}\end{array}$} & \multicolumn{3}{|c|}{ San Francisco Mountains } & & \\
\hline & & & & & $\begin{array}{l}\text { Government } \\
\text { Mountain }\end{array}$ & $\begin{array}{l}\text { Sitgreaves } \\
\text { southeast }\end{array}$ & $\begin{array}{l}\text { R.S. } \\
\text { Hiti }\end{array}$ & \multicolumn{2}{|c|}{ Cerros No Agua } \\
\hline $\begin{array}{l}\text { Specimen- } \\
\text { Collection No. (RLS-) -. }\end{array}$ & $\begin{array}{l}103 \\
139\end{array}$ & $\begin{array}{r}104 \\
33\end{array}$ & $\begin{array}{c}105 \\
65 L-161-A\end{array}$ & $\begin{array}{r}106 \\
35\end{array}$ & $\begin{array}{r}107 \\
48\end{array}$ & $\begin{array}{r}108 \\
53\end{array}$ & $\begin{array}{r}109 \\
47\end{array}$ & $\begin{array}{r}110 \\
27\end{array}$ & $\begin{array}{c}111 \\
66 \mathrm{~L}-23-\mathrm{A}\end{array}$ \\
\hline \multicolumn{10}{|c|}{ Chemical analyses (weight percent) } \\
\hline $\begin{array}{l}\mathrm{SiO}_{2} \\
\mathrm{Al}_{2} \mathrm{O}_{3} \\
\mathrm{Fe}_{2} \mathrm{O}_{3} \\
\mathrm{Fe}^{\mathrm{M} 0} \mathrm{O}_{2} \\
\mathrm{MgO}\end{array}$ & $\begin{array}{l}76.6 \\
12.51 \\
0.39 \\
0.36 \\
0.07 \\
0.54 \\
3.55 \\
4.83 \\
0.11 \\
0.14 \\
0.01 \\
0.05 \\
0.07 \\
0.07 \\
0.11 \\
0.12\end{array}$ & $\begin{array}{r}76.57 \\
12.78 \\
0.35 \\
0.33 \\
0.05 \\
0.45 \\
4.31 \\
4.54 \\
0.22 \\
0.08 \\
0.00 \\
0.10 \\
-- \\
0.070 \\
-- \\
0.180\end{array}$ & $\begin{array}{l}76.2 \\
13.1 \\
0.32 \\
0.44 \\
0.15 \\
0.69 \\
4.1 \\
4.8 \\
0.16 \\
0.11 \\
0.02 \\
0.14 \\
-. \\
0.09 \\
-- \\
0.13\end{array}$ & $\begin{array}{r}76.66 \\
12.68 \\
0.35 \\
0.36 \\
0.09 \\
0.48 \\
4.05 \\
4.61 \\
0.11 \\
0.11 \\
0.01 \\
0.08 \\
-- \\
0.07 \\
-- \\
0.05\end{array}$ & $\begin{array}{l}75.1 \\
13.86 \\
0.36 \\
0.55 \\
0.03 \\
0.77 \\
4.48 \\
4.23 \\
0.17 \\
0.02 \\
0.01 \\
0.08 \\
0.06 \\
0.04 \\
0.08 \\
0.07\end{array}$ & $\begin{array}{l}75.1 \\
13.39 \\
0.51 \\
0.48 \\
<0.005 \\
0.39 \\
4.65 \\
4.63 \\
0.08 \\
0.02 \\
0.005 \\
0.06 \\
0.04 \\
0.04 \\
0.42 \\
0.44\end{array}$ & $\begin{array}{l}75.2 \\
13.29 \\
0.51 \\
0.51 \\
<0.005 \\
0.36 \\
5.07 \\
4.14 \\
0.02 \\
0.02 \\
0.005 \\
0.06 \\
0.04 \\
0.03 \\
0.41 \\
0.43\end{array}$ & $\begin{array}{l}75.6 \\
13.26 \\
0.36 \\
0.28 \\
0.05 \\
0.67 \\
4.17 \\
4.56 \\
0.15 \\
0.06 \\
<0.005 \\
0.09 \\
0.08 \\
-.-09 \\
0.09\end{array}$ & $\begin{array}{r}76.35 \\
12.34 \\
0.47 \\
0.60 \\
0.03 \\
0.38 \\
4.29 \\
4.39 \\
0.91 \\
0.09 \\
0.02 \\
0.06 \\
-- \\
0.06 \\
-- \\
0.19\end{array}$ \\
\hline $\begin{array}{l}\text { Subtotal } \\
\text { Less } 0=(F, C 1)_{2}\end{array}$ & $\begin{array}{r}99.35 \\
0.06\end{array}$ & $\begin{array}{r}100.03 \\
0.09\end{array}$ & $\begin{array}{r}100.45 \\
0.08\end{array}$ & $\begin{array}{r}99.71 \\
0.04\end{array}$ & $\begin{array}{r}99.79 \\
0.04\end{array}$ & $\begin{array}{r}99.78 \\
0.19\end{array}$ & $\begin{array}{r}99.64 \\
0.08\end{array}$ & $\begin{array}{r}99.41 \\
0.06\end{array}$ & $\begin{array}{r}100.18 \\
0.09\end{array}$ \\
\hline Total-_-_. & 99.29 & 99.94 & 100.37 & 99.67 & 99.75 & 99.59 & 99.46 & 99.35 & 100.09 \\
\hline $\mathrm{Fe}_{\mathrm{t}}^{1} \ldots$ & 0.71 & 0.65 & 0.73 & 0.68 & 0.87 & 0.94 & 0.97 & 0.60 & 1.02 \\
\hline $\mathrm{FeO} /\left(\mathrm{Fe} 0+\mathrm{Fe}_{2} \mathrm{O}_{3}\right)^{1}-\ldots$ & 0.48 & 0.48 & 0.58 & 0.51 & 0.60 & 0.48 & 0.50 & 0.44 & 0.56 \\
\hline $\mathrm{Na}_{2} \mathrm{O} / \mathrm{K}_{2} \mathrm{O}^{1}$ & 0.74 & 0.95 & 0.85 & 0.88 & 1.06 & 1.00 & 1.23 & 0.91 & 0.98 \\
\hline$\left(\mathrm{Na}_{2} \mathrm{O}+\mathrm{K}_{2} \mathrm{O}\right) / \mathrm{Al}_{2} \mathrm{O}_{3}{ }^{2}-\ldots$ & 0.89 & 0.94 & 0.91 & 0.92 & 0.86 & 0.95 & 0.96 & 0.89 & 0.96 \\
\hline$\left(\mathrm{CaO}+\mathrm{Na}_{2} \mathrm{O}+\mathrm{K}_{2} \mathrm{O}\right) / \mathrm{Al}_{2} \mathrm{O}_{3}{ }^{2}-$. & 0.96 & 1.00 & 1.01 & 0.99 & 0.96 & 1.00 & 1.01 & 0.98 & 1.01 \\
\hline $\mathrm{CaO} /\left(\mathrm{Na}_{2} \mathrm{O}+\mathrm{K}_{2} \mathrm{O}\right)^{1}$ & 0.06 & 0.05 & 0.08 & 0.06 & 0.09 & 0.04 & 0.04 & 0.08 & 0.04 \\
\hline $\mathrm{Cl} / \mathrm{F}^{1+}+$ & 0.61 & 0.39 & 0.69 & 1.4 & 0.68 & 0.09 & 0.09 & 0.87 & 0.32 \\
\hline \multicolumn{10}{|c|}{ CIPW norms } \\
\hline Q- & 36.49 & 33.09 & 32.06 & 34.35 & 30.97 & 29.51 & 29.19 & 32.55 & 33.88 \\
\hline or - & 28.82 & 26.95 & 28.35 & 27.38 & 25.12 & 27.57 & 24.67 & 27.19 & 26.20 \\
\hline ab-o-nos & 30.33 & 36.63 & 34.67 & 34.45 & 38.10 & 39.65 & 43.26 & 35.61 & 36.66 \\
\hline an-1-nons & 2.64 & 2.13 & 3.16 & 2.33 & 3.77 & 1.88 & 1.29 & 3.35 & 1.46 \\
\hline 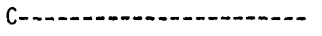 & 0.49 & -- & - & 0.18 & 0.54 & 0.00 & -- & 0.25 & -- \\
\hline ac--ons & -- & -- & -- & -- & -- & -- & -- & -- & -- \\
\hline 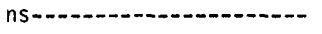 & -- & -- & -- & -- & -- & -- & -- & $-\cdot$ & -- \\
\hline & -- & 0.05 & 0.05 & -- & -- & -- & 0.19 & -- & 0.13 \\
\hline en $\}$ di-n & -- & 0.01 & 0.02 & -- & -- & -- & 0.00 & -- & 0.01 \\
\hline fs $\int$ in & -- & 0.04 & 0.03 & -- & -- & -- & 0.21 & -- & 0.13 \\
\hline en & 0.18 & 0.11 & 0.35 & 0.23 & 0.08 & 0.00 & 0.00 & 0.13 & 0.06 \\
\hline fs $\}$ my & 0.20 & 0.33 & 0.59 & 0.34 & 0.83 & 0.54 & 0.39 & 0.29 & 0.56 \\
\hline $\mathrm{mt}-\mathrm{-r}$ & 0.57 & 0.51 & 0.46 & 0.51 & 0.53 & 0.75 & 0.75 & 0.53 & 0.69 \\
\hline †† - & 0.27 & 0.15 & 0.21 & 0.21 & 0.04 & 0.04 & 0.04 & 0.12 & 0.17 \\
\hline ap & 0.02 & 0.00 & 0.05 & 0.02 & 0.02 & 0.02 & 0.02 & 0.00 & 0.05 \\
\hline
\end{tabular}




\begin{tabular}{|c|c|c|c|c|c|c|c|c|c|}
\hline & 103 & 104 & 105 & 106 & 107 & 108 & 109 & 110 & 111 \\
\hline \multicolumn{10}{|c|}{ Trace elements (ppm) } \\
\hline 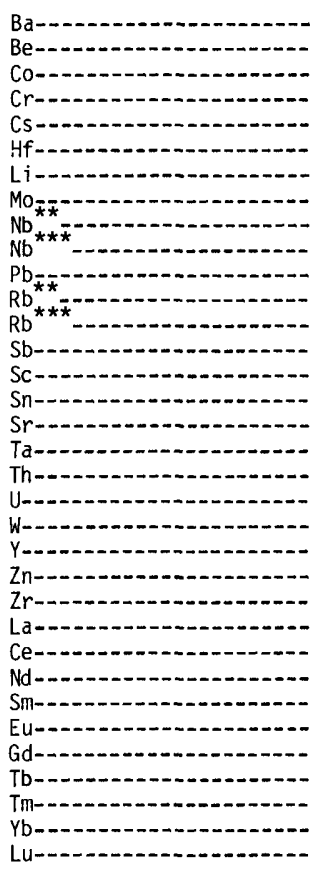 & $\begin{array}{l}190 . \\
4.0 \\
0.3 \\
<4.0 \\
3.5 \\
4.2 \\
55 . \\
4.6 \\
26 . \\
23 . \\
23 . \\
181 . \\
200 . \\
<0.4 \\
2.2 \\
1.8 \\
40 . \\
1.98 \\
23.3 \\
6.2 \\
1.5 \\
20 . \\
22 . \\
98 . \\
46 . \\
82 . \\
22 . \\
3.8 \\
0.35 \\
3.7 \\
0.44 \\
0.34 \\
2.6 \\
0.43\end{array}$ & $\begin{array}{l}<50 . \\
7.6 \\
0.1 \\
<6.0 \\
7.2 \\
4.0 \\
90 . \\
3.3 \\
49 . \\
\ddot{7 .} . \\
318 . \\
332 . \\
0.5 \\
3.9 \\
3.6 \\
<5.0 \\
4.93 \\
37.7 \\
18.0 \\
2.2 \\
36 . \\
42 . \\
61 . \\
19 . \\
45 . \\
19 . \\
5.8 \\
0.14 \\
4.2 \\
0.76 \\
0.91 \\
2.7 \\
0.48\end{array}$ & $\begin{array}{c}18 . \\
6 . \\
0.2 \\
12 . \\
7.8 \\
4.8 \\
77 . \\
9 . \\
50 . \\
\overline{19 .} \\
225 . \\
-. \\
1.1 \\
1.5 \\
-0.7 \\
8.7 \\
22.8 \\
10.8 \\
-- \\
-- \\
-- \\
207 . \\
33.5 \\
52.5 \\
19.3 \\
2.7 \\
0.20 \\
2.2 \\
0.3 \\
1.2 \\
1.1 \\
0.15\end{array}$ & $\begin{array}{c}193 . \\
2.8 \\
0.1 \\
<4.0 \\
2.0 \\
3.2 \\
36 . \\
2.3 \\
27 . \\
36 . \\
24 . \\
141 . \\
129 . \\
0.2 \\
2.8 \\
1.5 \\
15 . \\
2.13 \\
13.7 \\
3.6 \\
1.6 \\
32 . \\
35 . \\
80 . \\
29 . \\
59 . \\
22 . \\
5.1 \\
0.47 \\
3.6 \\
0.68 \\
0.32 \\
2.4 \\
0.34\end{array}$ & $\begin{array}{c}295 . \\
4.6 \\
0.2 \\
<4.0 \\
2.4 \\
3.4 \\
73 . \\
2.4 \\
44 . \\
45 . \\
34 . \\
118 . \\
103 . \\
0.7 \\
1.4 \\
3.5 \\
75 . \\
5.69 \\
10.3 \\
5.2 \\
2.3 \\
14 . \\
50 . \\
78 . \\
10 . \\
18 . \\
7 . \\
2.7 \\
0.30 \\
2.6 \\
0.50 \\
<0.20 \\
1.7 \\
0.24\end{array}$ & $\begin{array}{c}4 . \\
20 . \\
<0.4 \\
<5.0 \\
8.6 \\
8.6 \\
550 . \\
1.4 \\
224 . \\
258 . \\
87 . \\
351 . \\
392 . \\
1.4 \\
0.26 \\
15.0 \\
1.0 \\
22.39 \\
41.4 \\
12.9 \\
2.1 \\
102 . \\
147 . \\
163 . \\
9 . \\
20 . \\
13 . \\
5.3 \\
0.02 \\
6.7 \\
1.51 \\
<0.30 \\
8.3 \\
1.16\end{array}$ & $\begin{array}{c}5 . \\
21 . \\
<0.4 \\
<4.0 \\
9.3 \\
9.5 \\
200 . \\
1.4 \\
240 . \\
252 . \\
82 . \\
389 . \\
367 . \\
1.9 \\
0.30 \\
11.0 \\
1.0 \\
29.41 \\
47.2 \\
17.1 \\
1.5 \\
105 . \\
140 . \\
163 . \\
10 . \\
24 . \\
16 . \\
6.9 \\
0.02 \\
8.2 \\
1.72 \\
<0.40 \\
9.2 \\
1.28\end{array}$ & $\begin{array}{c}130 . \\
\ddot{0 .} \\
0.2 \\
1.1 \\
2.1 \\
3.3 \\
-- \\
\ddot{2} . \\
39 . \\
22 . \\
140 . \\
135 . \\
0.4 \\
3.0 \\
-- \\
35 . \\
3.05 \\
10.2 \\
3.5 \\
-- \\
28 . \\
30 . \\
58 . \\
13 . \\
26 . \\
12 . \\
2.6 \\
0.34 \\
3.0 \\
0.48 \\
0.30 \\
2.5 \\
0.39\end{array}$ & $\begin{array}{c}1 . \\
9 . \\
0.09 \\
9 . \\
6.8 \\
5.9 \\
133 . \\
3 . \\
110 . \\
--. \\
50 . \\
280 . \\
--. \\
1.1 \\
7.69 \\
-- \\
2.5 \\
8.1 \\
24.3 \\
8.3 \\
-- \\
-- \\
--. \\
190 . \\
10.6 \\
27.6 \\
18.9 \\
5.9 \\
0.14 \\
4.6 \\
1.2 \\
0.7 \\
6.0 \\
0.67\end{array}$ \\
\hline $\begin{array}{l}\mathrm{Nb} / \mathrm{Ta}- \\
\mathrm{K} / \mathrm{Rb}- \\
\mathrm{Rb} / \mathrm{Sr}- \\
\mathrm{Ca} / \mathrm{Sr} \\
\mathrm{Th} / \mathrm{U}- \\
\mathrm{Zr} / \mathrm{Hf} \\
\mathrm{Ce} / \mathrm{Yb}- \\
\mathrm{Eu} / \mathrm{Eu}\end{array}$ & $\begin{array}{c}12.4 \\
200 . \\
5.0 \\
97 . \\
3.8 \\
23 . \\
31.5 \\
0.29\end{array}$ & $\begin{array}{c}9.9 \\
114 . \\
-- \\
-- \\
2.1 \\
15 . \\
16.7 \\
0.09\end{array}$ & $\begin{array}{r}14.7 \\
171 . \\
25.9 \\
567 . \\
2.1 \\
43 . \\
47.7 \\
0.25\end{array}$ & $\begin{array}{c}14.8 \\
297 . \\
8.6 \\
229 . \\
3.8 \\
25 . \\
24.6 \\
0.34\end{array}$ & $\begin{array}{c}7.8 \\
341.8 \\
1.4 \\
73 . \\
2.0 \\
23 . \\
10.6 \\
0.35\end{array}$ & $\begin{array}{c}10.8 \\
98 . \\
392 . \\
2187 . \\
3.2 \\
19 . \\
2.4 \\
0.01\end{array}$ & $\begin{array}{l}8.4 \\
94 . \\
367 . \\
2573 . \\
2.8 \\
17 . \\
2.6 \\
0.01\end{array}$ & $\begin{array}{c}11.6 \\
280 . \\
3.9 \\
137 . \\
2.9 \\
18 . \\
10.4 \\
0.37\end{array}$ & $\begin{array}{c}13.6 \\
126 . \\
112 . \\
1086 . \\
2.9 \\
32 . \\
4.6 \\
0.08\end{array}$ \\
\hline
\end{tabular}

See footnotes at end of table. 


\begin{tabular}{|c|c|c|c|c|c|c|c|c|c|c|c|}
\hline \multirow{4}{*}{ 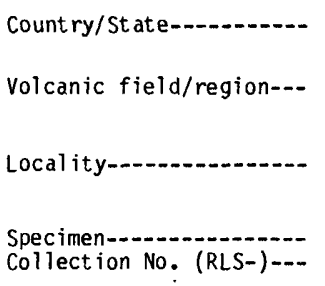 } & \multicolumn{11}{|c|}{ NEW MEXICO } \\
\hline & \multicolumn{10}{|c|}{ Jemez Mountains Volcanic Field } & \multirow{3}{*}{$\begin{array}{c}\begin{array}{c}\text { Sout hwest } \\
\text { New Mexico }\end{array} \\
\begin{array}{c}\text { Big Lue } \\
\text { Mountains }\end{array} \\
122 \\
102\end{array}$} \\
\hline & \multicolumn{2}{|c|}{$\begin{array}{l}\text { Canovas Canyon } \\
\text { Rhyolite }\end{array}$} & \multicolumn{3}{|c|}{ El Rechuelos Rhyolite } & \multicolumn{2}{|c|}{$\begin{array}{l}\text { Cerro Toledo } \\
\text { Rhyol ite }\end{array}$} & \multicolumn{3}{|c|}{ Valles Rhyolite } & \\
\hline & $\begin{array}{l}112 \\
200\end{array}$ & $\begin{array}{r}113 \\
15\end{array}$ & $\begin{array}{r}114 \\
25\end{array}$ & $\begin{array}{r}115 \\
73\end{array}$ & $\begin{array}{l}116 \\
194\end{array}$ & $\begin{array}{r}117 \\
17\end{array}$ & $\begin{array}{r}118 \\
72\end{array}$ & $\begin{array}{c}119 \\
76-61\end{array}$ & $\begin{array}{c}120 \\
\text { Posos }\end{array}$ & $\begin{array}{c}121 \\
76-79\end{array}$ & \\
\hline \multicolumn{12}{|c|}{ Chemical analyses (meight percent) } \\
\hline $\begin{array}{l}\mathrm{SiO}_{2}- \\
\mathrm{Al}_{2} \mathrm{O}_{3} \\
\mathrm{Fe}_{2} \mathrm{O}_{3} \\
\mathrm{Fe}^{\mathrm{M} O} \mathrm{O}\end{array}$ & $\begin{array}{l}76.4 \\
12.74 \\
0.39 \\
0.30 \\
0.06 \\
0.43 \\
4.31 \\
4.55 \\
0.18 \\
0.11 \\
0.01 \\
0.07 \\
0.06 \\
0.06 \\
0.03 \\
0.03\end{array}$ & $\begin{array}{r}76.36 \\
12.67 \\
0.33 \\
0.43 \\
0.09 \\
0.47 \\
3.56 \\
5.40 \\
0.23 \\
0.10 \\
0.01 \\
0.06 \\
--.07 \\
0.07 \\
-0.03\end{array}$ & $\begin{array}{r}76.74 \\
12.73 \\
0.33 \\
0.38 \\
0.07 \\
0.45 \\
3.85 \\
4.94 \\
0.14 \\
0.08 \\
0.01 \\
0.07 \\
-- \\
0.07 \\
-0.03\end{array}$ & $\begin{array}{l}77.0 \\
12.77 \\
0.29 \\
0.24 \\
0.05 \\
0.47 \\
3.91 \\
4.71 \\
0.23 \\
0.08 \\
0.01 \\
0.06 \\
0.06 \\
0.04 \\
0.03 \\
0.03\end{array}$ & $\begin{array}{l}76.9 \\
12.82 \\
0.24 \\
0.32 \\
0.05 \\
0.42 \\
4.23 \\
4.49 \\
0.14 \\
0.07 \\
0.01 \\
0.07 \\
0.04 \\
0.04 \\
0.05 \\
0.05\end{array}$ & $\begin{array}{r}76.37 \\
12.14 \\
0.50 \\
0.64 \\
0.04 \\
0.26 \\
4.39 \\
4.41 \\
0.61 \\
0.07 \\
0.00 \\
0.08 \\
-- \\
0.17 \\
-- \\
0.14\end{array}$ & $\begin{array}{c}76.6 \\
12.12 \\
0.50 \\
0.53 \\
0.02 \\
0.31 \\
4.30 \\
4.34 \\
0.32 \\
0.08 \\
<0.005 \\
0.06 \\
0.15 \\
0.13 \\
0.13 \\
--\end{array}$ & $\begin{array}{r}75.68 \\
12.78 \\
0.50 \\
0.54 \\
0.05 \\
0.37 \\
4.38 \\
4.73 \\
0.30 \\
0.13 \\
<0.01 \\
.0 .06 \\
-0.10 \\
--.09 \\
0.09\end{array}$ & $\begin{array}{r}76.49 \\
12.59 \\
0.45 \\
0.64 \\
0.06 \\
0.31 \\
4.34 \\
4.59 \\
0.14 \\
0.10 \\
0.01 \\
0.06 \\
-- \\
-- \\
--\end{array}$ & $\begin{array}{c}73.16 \\
13.42 \\
0.99 \\
0.99 \\
0.66 \\
1.61 \\
3.92 \\
4.20 \\
0.30 \\
0.30 \\
0.09 \\
0.06 \\
-- \\
-- \\
-- \\
--\end{array}$ & $\begin{array}{r}76.6 \\
12.69 \\
0.35 \\
0.58 \\
0.04 \\
0.58 \\
3.80 \\
4.73 \\
0.09 \\
0.07 \\
0.01 \\
0.06 \\
0.06 \\
-- \\
0.05 \\
--\end{array}$ \\
\hline $\begin{array}{l}\text { Subtotal } \\
\text { Less } 0=(F, C 1)_{2}-\end{array}$ & $\begin{array}{r}99.64 \\
0.03\end{array}$ & $\begin{array}{r}99.81 \\
0.03\end{array}$ & $\begin{array}{r}99.89 \\
0.03\end{array}$ & $\begin{array}{r}99.90 \\
0.03\end{array}$ & $\begin{array}{r}99.85 \\
0.03\end{array}$ & $\begin{array}{r}99.82 \\
0.10\end{array}$ & $\begin{array}{r}99.45 \\
0.09\end{array}$ & $\begin{array}{r}99.71 \\
0.06\end{array}$ & $\begin{array}{c}99.78 \\
--\end{array}$ & $\begin{array}{l}99.70 \\
--\end{array}$ & $\begin{array}{r}99.71 \\
0.04\end{array}$ \\
\hline Total-_-_...- & 99.61 & 99.78 & 99.86 & 99.57 & 99.82 & 99.72 & 99.36 & 99.65 & 99.78 & 99.70 & 99.67 \\
\hline $\mathrm{Fe}_{\mathrm{t}}^{1} \ldots$ & 0.65 & 0.73 & 0.68 & 0.50 & 0.54 & 1.09 & 0.98 & 0.99 & 1.05 & 1.88 & 0.89 \\
\hline $\mathrm{Fe} 0 /\left(\mathrm{Fe} 0+\mathrm{Fe}_{2} \mathrm{O}_{3}\right)^{1} \ldots$ & 0.43 & 0.57 & 0.54 & 0.45 & 0.57 & 0.56 & 0.51 & 0.52 & 0.59 & 0.50 & 0.62 \\
\hline $\mathrm{Na}_{2} \mathrm{O} / \mathrm{K}_{2} \mathrm{O}^{\mathrm{l}}$ & 0.95 & 0.66 & 0.78 & 0.83 & 0.94 & 1.00 & 0.99 & 0.93 & 0.95 & 0.93 & 0.80 \\
\hline$\left(\mathrm{Na}_{2} \mathrm{O}+\mathrm{K}_{2} \mathrm{O}\right) / \mathrm{Al}_{2} \mathrm{O}_{3}{ }^{2} \ldots$ & 0.94 & 0.92 & 0.92 & 0.90 & 0.92 & 0.99 & 0.97 & 0.97 & 0.96 & 0.82 & 0.90 \\
\hline$\left(\mathrm{CaO}+\mathrm{Na}_{2} \mathrm{O}+\mathrm{K}_{2} \mathrm{O}\right) / \mathrm{Al}_{2} \mathrm{O}_{3}{ }^{2}-$ & 0.99 & 0.99 & 0.98 & 0.97 & 0.98 & 1.03 & 1.02 & 1.02 & 1.01 & 1.04 & 0.98 \\
\hline $\mathrm{CaO} /\left(\mathrm{Na}_{2} \mathrm{O}+\mathrm{K}_{2} \mathrm{O}\right)^{1}$ & 0.05 & 0.05 & 0.05 & 0.05 & 0.05 & 0.03 & 0.04 & 0.04 & 0.03 & 0.20 & 0.07 \\
\hline $\mathrm{Cl} / \mathrm{F}^{1+}+\mathrm{C}_{-}$ & 2.3 & 2.3 & .2 .3 & 1.5 & 0.85 & 1.2 & 1.1 & 1.1 & -- & -- & 1.1 \\
\hline \multicolumn{12}{|c|}{ CIPW norms } \\
\hline 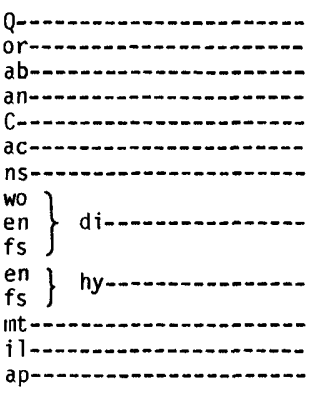 & $\begin{array}{l}33.08 \\
27.06 \\
3.70 \\
1.99 \\
--. \\
- \\
-. \\
0.04 \\
0.02 \\
0.02 \\
0.13 \\
0.16 \\
0.57 \\
0.21 \\
0.02\end{array}$ & $\begin{array}{l}33.84 \\
32.08 \\
30.28 \\
2.28 \\
0.14 \\
-- \\
-- \\
-- \\
-- \\
0 . \\
0.23 \\
0.47 \\
0.48 \\
0.19 \\
0.02\end{array}$ & $\begin{array}{l}34.39 \\
29.32 \\
32.72 \\
2.24 \\
0.23 \\
- \\
-- \\
\therefore- \\
- \\
- \\
0.18 \\
0.29 \\
0.48 \\
0.15 \\
0.00\end{array}$ & $\begin{array}{l}35.24 \\
27.95 \\
33.22 \\
2.28 \\
0.41 \\
-- \\
-- \\
-- \\
-- \\
- \\
0.13 \\
0.18 \\
0.42 \\
0.15 \\
0.02\end{array}$ & $\begin{array}{l}34.11 \\
26.63 \\
35.93 \\
2.03 \\
0.26 \\
-- \\
- \\
- \\
- \\
- \\
0.13 \\
0.41 \\
0.35 \\
0.13 \\
0.02\end{array}$ & $\begin{array}{l}33.54 \\
26.35 \\
37.56 \\
0.40 \\
-- \\
-- \\
-- \\
0.38 \\
0.05 \\
0.37 \\
0.06 \\
0.44 \\
0.73 \\
0.13 \\
0.00\end{array}$ & $\begin{array}{c}34.56 \\
25.94 \\
36.81 \\
0.96 \\
-- \\
- \\
- \\
0.25 \\
0.02 \\
0.25 \\
0.03 \\
0.30 \\
0.73 \\
0.15 \\
0.00\end{array}$ & $\begin{array}{l}31.39 \\
28.17 \\
37.35 \\
1.25 \\
-- \\
- \\
\ddot{0 .} \\
0.25 \\
0.06 \\
0.21 \\
0.07 \\
0.27 \\
0.73 \\
0.25 \\
0.00\end{array}$ & $\begin{array}{c}32.77 \\
27.22 \\
36.86 \\
1.32 \\
-- \\
- \\
-- \\
0.07 \\
0.01 \\
0.06 \\
0.14 \\
0.69 \\
0.66 \\
0.19 \\
0.02\end{array}$ & $\begin{array}{l}30.18 \\
24.97 \\
33.37 \\
6.66 \\
-- \\
-- \\
-- \\
0.33 \\
0.22 \\
0.08 \\
1.43 \\
0.54 \\
1.44 \\
0.57 \\
0.21\end{array}$ & $\begin{array}{c}34.94 \\
28.10 \\
32.33 \\
2.83 \\
0.29 \\
-- \\
-\therefore \\
-\therefore \\
-- \\
0.10 \\
0.82 \\
0.44 \\
0.13 \\
0.02\end{array}$ \\
\hline
\end{tabular}




\begin{tabular}{|c|c|c|c|c|c|c|c|c|c|c|c|}
\hline & 112 & 113 & 114 & 115 & 116 & 117 & 118 & 119 & 120 & 121 & 122 \\
\hline \multicolumn{12}{|c|}{ Trace elements (ppm) } \\
\hline 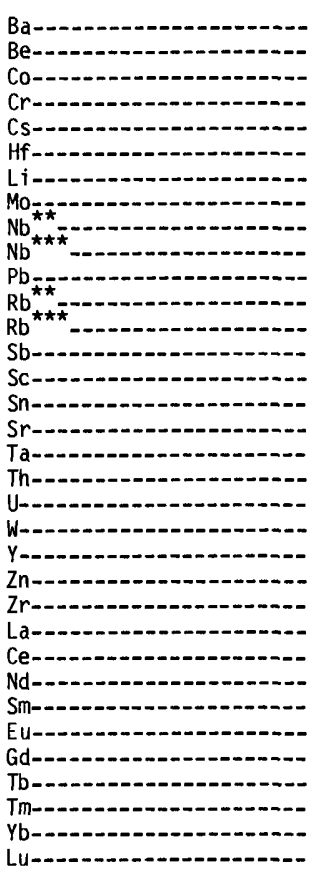 & $\begin{array}{c}337 . \\
3.8 \\
0.2 \\
<2.0 \\
4.0 \\
3.3 \\
45 . \\
5.7 \\
53 . \\
54 . \\
25 . \\
109 . \\
120 . \\
<0.7 \\
1.9 \\
1.8 \\
35 . \\
4.78 \\
23.2 \\
8.3 \\
2.3 \\
27 . \\
23 . \\
88 . \\
31 . \\
52 . \\
17 . \\
3.2 \\
0.36 \\
<3.0 \\
<0.30 \\
<0.30 \\
2.2 \\
0.33\end{array}$ & $\begin{array}{r}330 . \\
3.7 \\
0.2 \\
<4.0 \\
4.0 \\
3.3 \\
45 . \\
5.2 \\
51 . \\
59 . \\
22 . \\
117 . \\
118 . \\
<2.0 \\
2.0 \\
1.3 \\
34 . \\
4.70 \\
24.5 \\
8.0 \\
1.6 \\
31 . \\
20 . \\
85 . \\
30 . \\
54 . \\
17 . \\
3.5 \\
0.38 \\
2.9 \\
0.45 \\
<0.20 \\
2.4 \\
0.35\end{array}$ & $\begin{array}{c}8.0 \\
3.4 \\
0.1 \\
<5.0 \\
4.6 \\
3.0 \\
66 . \\
3.9 \\
40 . \\
54 . \\
23 . \\
157 . \\
156 . \\
0.3 \\
2.9 \\
1.6 \\
5 . \\
5.00 \\
18.3 \\
9.9 \\
1.9 \\
29 . \\
23 . \\
55 . \\
18 . \\
39 . \\
15 . \\
3.7 \\
0.18 \\
3.5 \\
0.59 \\
0.91 \\
2.1 \\
0.32\end{array}$ & $\begin{array}{c}<50 . \\
3.7 \\
<0.3 \\
1.7 \\
4.1 \\
3.0 \\
84 . \\
3.3 \\
40 . \\
43 . \\
41 . \\
153 . \\
152 . \\
<0.7 \\
2.7 \\
1.5 \\
<5 . \\
5.08 \\
17.0 \\
10.8 \\
2.3 \\
17 . \\
20 . \\
67 . \\
19 . \\
37 . \\
16 . \\
3.8 \\
0.16 \\
2.8 \\
0.56 \\
0.29 \\
2.2 \\
0.31\end{array}$ & $\begin{array}{c}11.0 \\
3.3 \\
0.1 \\
<3.0 \\
4.5 \\
2.9 \\
63 . \\
4.4 \\
45 . \\
47 . \\
24 . \\
152 . \\
155 . \\
<0.8 \\
2.8 \\
2.0 \\
4 . \\
4.85 \\
17.5 \\
8.5 \\
2.5 \\
28 . \\
18 . \\
52 . \\
18 . \\
37 . \\
16 . \\
3.3 \\
0.16 \\
3.0 \\
<0.40 \\
<0.30 \\
2.2 \\
0.32\end{array}$ & $\begin{array}{c}<50 . \\
6.9 \\
0.1 \\
<5.0 \\
5.4 \\
7.4 \\
64 . \\
9.9 \\
96 . \\
107 . \\
29 . \\
189 . \\
206 . \\
0.4 \\
1.0 \\
5.3 \\
<5 . \\
6.74 \\
22.9 \\
7.5 \\
6.6 \\
82 . \\
86 . \\
152 . \\
34 . \\
71 . \\
27 . \\
7.6 \\
<0.30 \\
6.4 \\
1.54 \\
0.55 \\
6.6 \\
0.87\end{array}$ & $\begin{array}{c}<50 . \\
7.6 \\
<0.3 \\
<5.0 \\
6.2 \\
7.2 \\
61 . \\
8.9 \\
87 . \\
96 . \\
46 . \\
202 . \\
206 . \\
<0.8 \\
1.1 \\
5.0 \\
<5 . \\
7.85 \\
23.7 \\
10.3 \\
6.0 \\
60 . \\
94 . \\
202 . \\
36 . \\
71 . \\
30 . \\
8.3 \\
0.05 \\
7.6 \\
1.58 \\
0.92 \\
6.2 \\
0.90\end{array}$ & $\begin{array}{c}34 . \\
3.5 \\
0.2 \\
1.0 \\
4.5 \\
6.6 \\
44 . \\
5.9 \\
58 . \\
60 . \\
29 . \\
140 . \\
150 . \\
0.3 \\
1.7 \\
2.0 \\
3.2 \\
3.75 \\
17.3 \\
5.5 \\
2.9 \\
48 . \\
58 . \\
187 . \\
48 . \\
93 . \\
33 . \\
7.3 \\
0.26 \\
5.5 \\
1.07 \\
0.65 \\
4.3 \\
0.59\end{array}$ & $\begin{array}{c}42 . \\
-- \\
0.3 \\
4.0 \\
5.0 \\
6.2 \\
-- \\
-- \\
-. \\
59 . \\
31 . \\
155 . \\
163 . \\
0.3 \\
1.5 \\
-- \\
4.7 \\
3.92 \\
17.7 \\
6.8 \\
-- \\
49 . \\
61 . \\
171 . \\
53 . \\
92 . \\
41 . \\
7.8 \\
0.23 \\
9.4 \\
1.18 \\
0.77 \\
4.8 \\
0.65\end{array}$ & $\begin{array}{c}586 . \\
3.4 \\
3.7 \\
13.2 \\
4.5 \\
4.8 \\
57 . \\
4.1 \\
39 . \\
43 . \\
21 . \\
151 . \\
151 . \\
0.3 \\
3.71 \\
5.6 \\
202 . \\
3.55 \\
21.1 \\
6.9 \\
3.0 \\
31 . \\
22 . \\
135 . \\
39 . \\
69 . \\
25 . \\
4.1 \\
0.47 \\
4.1 \\
0.67 \\
0.56 \\
3.4 \\
0.49\end{array}$ & $\begin{array}{c}85 . \\
4.0 \\
0.3 \\
<4.0 \\
7.2 \\
4.3 \\
52 . \\
3.2 \\
32 . \\
32 . \\
39 . \\
228 . \\
240 . \\
0.5 \\
2.2 \\
3.3 \\
10 . \\
2.95 \\
31.3 \\
6.6 \\
2.6 \\
31 . \\
36 . \\
111 . \\
30 . \\
59 . \\
28 . \\
5.9 \\
0.20 \\
<4.0 \\
0.98 \\
0.67 \\
4.9 \\
0.70\end{array}$ \\
\hline 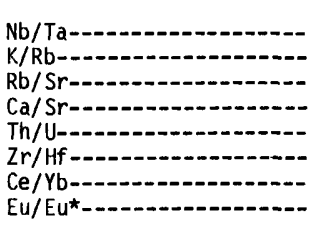 & $\begin{array}{c}11.2 \\
315 . \\
3.4 \\
88 . \\
2.8 \\
27 . \\
23.6 \\
--\end{array}$ & $\begin{array}{c}11.7 \\
380 . \\
3.5 \\
99 . \\
3.1 \\
26 . \\
22.5 \\
0.37\end{array}$ & $\begin{array}{c}9.4 \\
263 . \\
31.2 \\
643 . \\
1.9 \\
18 . \\
18.6 \\
0.15\end{array}$ & $\begin{array}{c}8.2 \\
257 . \\
-- \\
\ddot{1.6} \\
22 . \\
16.8 \\
0.15\end{array}$ & $\begin{array}{c}9.5 \\
240 . \\
38.8 \\
751 . \\
2.1 \\
18 . \\
16.8 \\
0.16\end{array}$ & $\begin{array}{c}15.1 \\
178 . \\
-- \\
\overline{3.1} \\
21 . \\
10.8 \\
--\end{array}$ & $\begin{array}{c}11.7 \\
175 . \\
-- \\
-- \\
2.3 \\
28 . \\
11.5 \\
0.02\end{array}$ & $\begin{array}{c}15.7 \\
262 . \\
46.9 \\
826 . \\
3.2 \\
28 . \\
28.3 \\
0.14\end{array}$ & $\begin{array}{l}15.1 \\
234 . \\
34.7 \\
47.2 \\
2.6 \\
28 . \\
19.2 \\
0.08\end{array}$ & $\begin{array}{c}11.6 \\
231 . \\
0.75 \\
57 . \\
3.1 \\
28 . \\
20.3 \\
0.36\end{array}$ & $\begin{array}{c}10.9 \\
164 . \\
24.0 \\
415 . \\
4.7 \\
26 . \\
12.0 \\
0.11\end{array}$ \\
\hline
\end{tabular}

See footnotes at end of table. 


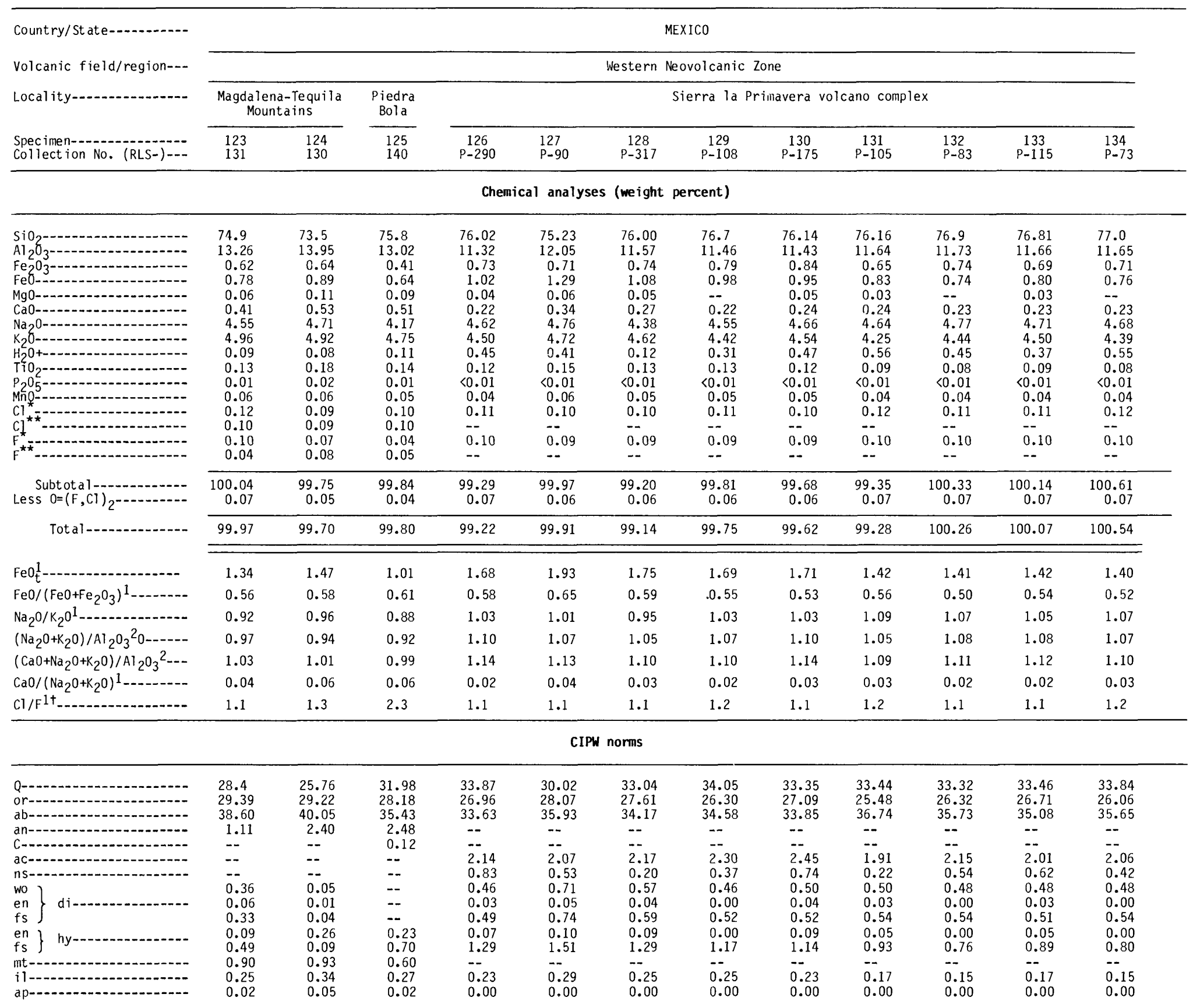




\begin{tabular}{|c|c|c|c|c|c|c|c|c|c|c|c|c|}
\hline & 123 & 124 & 125 & 126 & 127 & 128 & 129 & 130 & 131 & 132 & 133 & 134 \\
\hline \multicolumn{13}{|c|}{ Trace elements (ppm) } \\
\hline 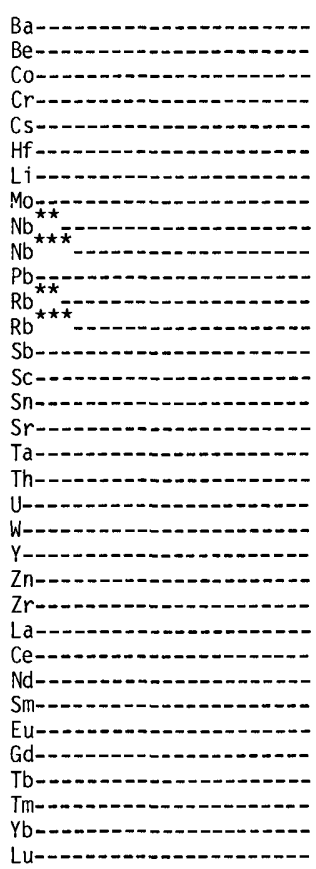 & $\begin{array}{c}70 . \\
5.3 \\
0.2 \\
<4.0 \\
3.7 \\
7.9 \\
36 . \\
7.6 \\
38 . \\
51 . \\
25 . \\
153 . \\
160 . \\
0.7 \\
2.3 \\
4.5 \\
7 . \\
3.16 \\
14.6 \\
5.3 \\
2.7 \\
49 . \\
70 . \\
242 . \\
52 . \\
103 . \\
43 . \\
8.4 \\
0.17 \\
6.7 \\
1.36 \\
0.74 \\
4.8 \\
0.67\end{array}$ & $\begin{array}{c}430 . \\
4.3 \\
0.4 \\
<4.0 \\
3.2 \\
7.6 \\
32 . \\
6.3 \\
30 . \\
41 . \\
22 . \\
127 . \\
135 . \\
0.8 \\
3.2 \\
3.7 \\
26 . \\
2.48 \\
12.1 \\
4.2 \\
1.4 \\
39 . \\
44 . \\
279 . \\
43 . \\
84 . \\
33 . \\
6.4 \\
0.38 \\
4.9 \\
1.08 \\
0.74 \\
3.8 \\
0.55\end{array}$ & $\begin{array}{c}310 . \\
3.7 \\
0.5 \\
2.3 \\
5.4 \\
5.0 \\
36 . \\
6.6 \\
20 . \\
16 . \\
17 . \\
156 . \\
154 . \\
0.6 \\
2.2 \\
2.6 \\
33 . \\
1.93 \\
17.2 \\
7.1 \\
1.8 \\
22 . \\
32 . \\
146 . \\
32 . \\
60 . \\
25 . \\
4.6 \\
0.22 \\
3.6 \\
0.67 \\
0.40 \\
2.7 \\
0.41\end{array}$ & $\begin{array}{c}<50 . \\
-- \\
-- \\
3.2 \\
14.5 \\
-- \\
-- \\
65 . \\
61 . \\
-- \\
160 . \\
0.4 \\
0.63 \\
-- \\
-- \\
4.31 \\
18.3 \\
7.6 \\
-- \\
51 . \\
116 . \\
500 . \\
55 . \\
122 . \\
50 . \\
10.6 \\
0.09 \\
9.7 \\
1.57 \\
0.95 \\
5.9 \\
0.88\end{array}$ & $\begin{array}{c}<50 . \\
-- \\
-- \\
-- \\
3.0 \\
14.6 \\
-- \\
-- \\
-- \\
64 . \\
18 . \\
-- \\
162 . \\
<0.9 \\
1.79 \\
-- \\
-- \\
3.69 \\
16.8 \\
5.4 \\
-- \\
52 . \\
104 . \\
616 . \\
76 . \\
162 . \\
64 . \\
11.6 \\
0.10 \\
9.5 \\
1.54 \\
0.87 \\
6.0 \\
0.94\end{array}$ & $\begin{array}{c}<50 . \\
-- \\
-- \\
-- \\
3.6 \\
13.2 \\
-- \\
-- \\
70 . \\
24 . \\
-- \\
170 . \\
0.4 \\
0.98 \\
-- \\
-- \\
3.84 \\
18.9 \\
6.9 \\
-- \\
75 . \\
105 . \\
521 . \\
66 . \\
134 . \\
54 . \\
10.8 \\
0.06 \\
9.3 \\
1.62 \\
0.83 \\
5.9 \\
0.85\end{array}$ & $\begin{array}{c}<50 . \\
-- \\
-- \\
-- \\
3.4 \\
14.0 \\
-- \\
-- \\
-- \\
60 . \\
25 . \\
-- \\
157 . \\
0.3 \\
0.67 \\
-- \\
-- \\
3.74 \\
17.5 \\
6.3 \\
-- \\
50 . \\
112 . \\
548 . \\
56 . \\
122 . \\
48 . \\
10.3 \\
0.09 \\
8.9 \\
1.53 \\
0.82 \\
5.9 \\
0.84\end{array}$ & $\begin{array}{c}<50 . \\
-- \\
0.2 \\
-- \\
3.2 \\
14.5 \\
-- \\
-- \\
-. \\
62 . \\
28 . \\
-- \\
162 . \\
0.4 \\
0.74 \\
-- \\
-- \\
3.87 \\
17.9 \\
5.8 \\
-. \\
54 . \\
103 . \\
568 . \\
60 . \\
130 . \\
51 . \\
10.6 \\
0.09 \\
9.4 \\
1.53 \\
0.83 \\
6.0 \\
0.88\end{array}$ & $\begin{array}{c}<50 . \\
-- \\
-- \\
-- \\
3.4 \\
11.2 \\
-- \\
-- \\
\overline{-} \\
85 . \\
25 . \\
-- \\
170 . \\
0.7 \\
0.70 \\
-- \\
-- \\
-- \\
16.6 \\
5.6 \\
-- \\
49 . \\
108 . \\
373 . \\
38 . \\
88 . \\
35 . \\
8.4 \\
0.06 \\
8.0 \\
1.35 \\
-- \\
5.5 \\
0.80\end{array}$ & $\begin{array}{c}<50 . \\
-- \\
0.3 \\
-- \\
3.5 \\
11.3 \\
-- \\
-- \\
-- \\
74 . \\
18 . \\
-- \\
177 . \\
0.6 \\
0.70 \\
-- \\
-- \\
3.76 \\
17.1 \\
6.1 \\
-- \\
49 . \\
102 . \\
381 . \\
39 . \\
92 . \\
37 . \\
8.7 \\
0.06 \\
8.2 \\
1.37 \\
0.80 \\
5.8 \\
0.84\end{array}$ & $\begin{array}{c}<50 . \\
\overline{0 .} \\
0.5 \\
3.6 \\
11.2 \\
\overline{--} \\
6.0 \\
\overline{--} \\
51 . \\
16 . \\
-- \\
165 . \\
0.4 \\
0.71 \\
-- \\
-- \\
3.56 \\
17.2 \\
5.4 \\
\overline{-} \\
50 . \\
96 . \\
375 . \\
40 . \\
91 . \\
40 . \\
8.4 \\
0.07 \\
\overline{1 .} \\
\overline{1 .-37} \\
\overline{5 .-} \\
0.79\end{array}$ & $\begin{array}{c}<50 . \\
-- \\
<0.5 \\
-- \\
3.7 \\
11.4 \\
-- \\
-- \\
-- \\
69 . \\
31 . \\
-- \\
165 . \\
<0.8 \\
0.69 \\
-- \\
-- \\
3.57 \\
16.6 \\
5.6 \\
-- \\
49 . \\
95 . \\
382 . \\
40 . \\
90 . \\
39 . \\
8.5 \\
0.06 \\
8.3 \\
1.34 \\
0.80 \\
5.7 \\
0.83\end{array}$ \\
\hline 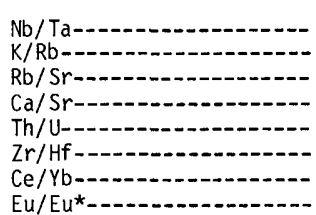 & $\begin{array}{c}14.1 \\
257 . \\
22.9 \\
419 . \\
2.8 \\
31 . \\
21.5 \\
0.07\end{array}$ & $\begin{array}{c}14.3 \\
303 . \\
5.2 \\
146 . \\
2.9 \\
37 . \\
22.1 \\
0.21\end{array}$ & $\begin{array}{c}9.3 \\
256 . \\
4.7 \\
111 . \\
2.4 \\
29 . \\
22.2 \\
0.17\end{array}$ & $\begin{array}{c}15.1 \\
233 . \\
-- \\
-- \\
2.4 \\
34 . \\
20.7 \\
0.03\end{array}$ & $\begin{array}{c}17.3 \\
242 . \\
-- \\
-- \\
3.1 \\
42 . \\
27.0 \\
0.03\end{array}$ & $\begin{array}{c}18.2 \\
226 . \\
-- \\
-- \\
2.7 \\
39 . \\
22.7 \\
0.02\end{array}$ & $\begin{array}{c}16.0 \\
234 . \\
-- \\
-- \\
2.8 \\
39 . \\
20.7 \\
0.03\end{array}$ & $\begin{array}{c}16.0 \\
233 . \\
-- \\
-- \\
3.1 \\
39 . \\
21.7 \\
0.03\end{array}$ & $\begin{array}{c}208 . \\
-- \\
\overline{--} \\
3.0 \\
33 . \\
16.0 \\
0.02\end{array}$ & $\begin{array}{c}19.7 \\
208 . \\
-- \\
-- \\
2.8 \\
34 . \\
15.9 \\
0.02\end{array}$ & $\begin{array}{c}14.3 \\
226 . \\
-- \\
-- \\
3.2 \\
33 . \\
15.7 \\
0.03\end{array}$ & $\begin{array}{c}19.3 \\
221 . \\
-\therefore \\
-- \\
3.0 \\
34 . \\
15.8 \\
0.02\end{array}$ \\
\hline
\end{tabular}

See footnotes at end of table. 
APPENDIX I.-Chemical analyses of subalkalic silicic obsidians-Continued

\begin{tabular}{|c|c|c|c|c|c|c|c|c|c|c|c|c|}
\hline \multirow{4}{*}{$\begin{array}{l}\text { Country/State- } \\
\text { Volcanic field/region-- } \\
\text { Local ity- } \\
\text { Specimen- } \\
\text { Collect ion No. (RLS-) }\end{array}$} & \multicolumn{12}{|c|}{ MEXICO } \\
\hline & \multicolumn{3}{|c|}{ Western Neovolcanic Zone } & \multicolumn{4}{|c|}{ Central Neovolcanic Zone } & \multicolumn{5}{|c|}{ Eastern Neovolcanic Zone } \\
\hline & \multicolumn{3}{|c|}{$\begin{array}{l}\text { Sierra la Primavera } \\
\text { volcano complex }\end{array}$} & \multicolumn{4}{|c|}{ Los Azufres Region } & \multicolumn{3}{|c|}{ Los Humeros } & \multicolumn{2}{|c|}{$\begin{array}{l}\text { Las Derrumbadas } \\
\text { Region }\end{array}$} \\
\hline & $\begin{array}{r}135 \\
P-40\end{array}$ & $\begin{array}{r}136 \\
P-67\end{array}$ & $\begin{array}{r}137 \\
P-15\end{array}$ & $\begin{array}{l}138 \\
274\end{array}$ & $\begin{array}{l}139 \\
275\end{array}$ & $\begin{array}{l}140 \\
276\end{array}$ & $\begin{array}{l}141 \\
273\end{array}$ & $\begin{array}{l}142 \\
280\end{array}$ & $\begin{array}{l}143 \\
277\end{array}$ & $\begin{array}{l}144 \\
278\end{array}$ & $\begin{array}{l}145 \\
279\end{array}$ & $\begin{array}{l}146 \\
125\end{array}$ \\
\hline \multicolumn{13}{|c|}{ Chemical analyses (weight percent) } \\
\hline 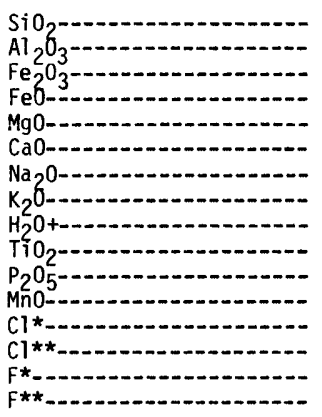 & $\begin{array}{l}76.3 \\
11.67 \\
0.66 \\
0.81 \\
-- \\
0.23 \\
4.62 \\
4.39 \\
0.47 \\
0.08 \\
<0.01 \\
0.04 \\
0.12 \\
-- \\
0.10 \\
--\end{array}$ & $\begin{array}{r}76.82 \\
11.65 \\
0.65 \\
0.81 \\
0.03 \\
0.23 \\
4.65 \\
4.39 \\
0.51 \\
0.08 \\
<0.01 \\
0.04 \\
0.12 \\
-- \\
0.10 \\
--\end{array}$ & $\begin{array}{r}76.67 \\
11.82 \\
0.56 \\
0.67 \\
0.02 \\
0.30 \\
4.47 \\
4.43 \\
0.88 \\
0.06 \\
<0.01 \\
0.04 \\
0.13 \\
-- \\
0.10 \\
--\end{array}$ & $\begin{array}{r}77.3 \\
12.58 \\
0.43 \\
0.55 \\
0.02 \\
0.39 \\
3.95 \\
4.67 \\
0.14 \\
0.07 \\
0.01 \\
0.04 \\
0.05 \\
0.07 \\
0.08 \\
0.07\end{array}$ & $\begin{array}{l}76.7 \\
12.50 \\
0.41 \\
0.59 \\
0.02 \\
0.36 \\
3.83 \\
4.57 \\
0.24 \\
0.07 \\
0.01 \\
0.03 \\
0.05 \\
0.06 \\
0.06 \\
0.06\end{array}$ & $\begin{array}{l}76.8 \\
12.43 \\
0.44 \\
0.61 \\
0.03 \\
0.43 \\
3.87 \\
4.62 \\
0.18 \\
0.08 \\
0.01 \\
0.05 \\
0.03 \\
0.04 \\
0.06 \\
0.05\end{array}$ & $\begin{array}{l}76.9 \\
12.62 \\
0.52 \\
0.48 \\
0.02 \\
0.39 \\
4.06 \\
4.49 \\
0.16 \\
0.07 \\
0.01 \\
0.04 \\
0.08 \\
0.11 \\
0.07 \\
0.06\end{array}$ & $\begin{array}{l}75.7 \\
12.34 \\
0.57 \\
0.58 \\
0.03 \\
0.35 \\
4.20 \\
4.66 \\
0.33 \\
0.10 \\
0.01 \\
0.03 \\
0.11 \\
0.14 \\
0.07 \\
0.06\end{array}$ & $\begin{array}{l}76.7 \\
12.48 \\
0.47 \\
0.45 \\
0.04 \\
0.31 \\
4.02 \\
4.53 \\
0.18 \\
0.11 \\
0.01 \\
0.05 \\
0.07 \\
0.09 \\
0.06 \\
0.05\end{array}$ & $\begin{array}{c}70.6 \\
14.63 \\
0.84 \\
1.06 \\
0.20 \\
0.69 \\
4.98 \\
4.91 \\
0.30 \\
0.30 \\
0.04 \\
0.06 \\
0.10 \\
0.12 \\
0.07 \\
0.05\end{array}$ & $\begin{array}{c}73.8 \\
13.99 \\
0.32 \\
0.73 \\
0.02 \\
0.60 \\
4.37 \\
4.17 \\
0.82 \\
0.03 \\
0.05 \\
0.05 \\
0.05 \\
0.06 \\
0.06 \\
0.05\end{array}$ & $\begin{array}{r}74.2 \\
14.04 \\
0.09 \\
0.52 \\
0.03 \\
0.48 \\
4.42 \\
4.15 \\
0.98 \\
0.02 \\
0.04 \\
0.12 \\
0.05 \\
0.01 \\
0.08 \\
0.08\end{array}$ \\
\hline $\begin{array}{l}\text { Subtotal } \\
\text { Less } 0=(F, C l)_{2}\end{array}$ & $\begin{array}{r}99.49 \\
0.07\end{array}$ & $\begin{array}{r}100.08 \\
0.07\end{array}$ & $\begin{array}{r}100.15 \\
0.07 \\
\end{array}$ & $\begin{array}{r}100.29 \\
0.05 \\
\end{array}$ & $\begin{array}{r}99.45 \\
0.04 \\
\end{array}$ & $\begin{array}{r}99.64 \\
0.03\end{array}$ & $\begin{array}{r}99.92 \\
0.05\end{array}$ & $\begin{array}{r}99.09 \\
0.06\end{array}$ & $\begin{array}{r}99.48 \\
0.04\end{array}$ & $\begin{array}{r}98.78 \\
0.05\end{array}$ & $\begin{array}{r}99.06 \\
0.03\end{array}$ & $\begin{array}{r}99.22 \\
0.05\end{array}$ \\
\hline 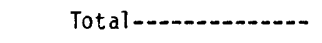 & 99.42 & 100.01 & 100.08 & 100.24 & 99.41 & 99.61 & 99.87 & 99.03 & 99.44 & 98.73 & 99.03 & 99.17 \\
\hline $\mathrm{Fe} 001-\ldots$ & 1.40 & 1.40 & 1.17 & 0.94 & 0.96 & 1.01 & 0.95 & 1.09 & 0.87 & 1.82 & 1.02 & 0.60 \\
\hline $\mathrm{Fe} 0 /\left(\mathrm{Fe} 0+\mathrm{Fe}_{2} \mathrm{O}_{3}\right)^{1} \ldots \ldots$ & 0.55 & 0.55 & 0.54 & 0.56 & 0.59 & 0.58 & 0.48 & 0.50 & 0.49 & 0.56 & 0.70 & 0.84 \\
\hline $\mathrm{Na}_{2} \mathrm{O} / \mathrm{K}_{2} \mathrm{O}^{1}$ & 1.05 & 1.06 & 1.01 & 0.85 & 0.84 & 0.84 & 0.90 & 0.90 & 0.89 & 1.01 & 1.05 & 1.07 \\
\hline$\left(\mathrm{Na}_{2} \mathrm{O}+\mathrm{K}_{2} \mathrm{O}\right) / \mathrm{Al}_{2} \mathrm{O}_{3}{ }^{2}$ & 1.06 & 1.06 & 1.03 & 0.92 & 0.90 & 0.91 & 0.91 & 0.97 & 0.92 & 0.92 & 0.84 & 0.84 \\
\hline$\left(\mathrm{CaO}+\mathrm{Na}_{2} \mathrm{O}+\mathrm{K}_{2} \mathrm{O}\right) / \mathrm{Al}_{2} \mathrm{O}_{3}{ }^{2} \cdots$ & 1.09 & 1.10 & 1.07 & 0.97 & 0.95 & 0.98 & 0.97 & 1.02 & 0.97 & 1.01 & 0.92 & 0.91 \\
\hline $\mathrm{CaO} /\left(\mathrm{Na}_{2} \mathrm{O}+\mathrm{K}_{2} \mathrm{O}\right)^{1}$ & 0.03 & 0.03 & 0.03 & 0.05 & 0.04 & 0.05 & 0.05 & 0.04 & 0.04 & 0.07 & 0.07 & 0.06 \\
\hline $\mathrm{Cl} / \mathrm{F}^{1+} \mathrm{C}^{2}$ & 1.2 & 1.2 & 1.3 & 0.83 & 0.85 & 0.70 & 1.4 & 2.0 & 1.4 & 1.9 & 1.0 & 0.56 \\
\hline \multicolumn{13}{|c|}{ CIPW norms } \\
\hline Q- & 33.39 & 33.73 & 33.54 & 35.33 & 36.18 & 35.57 & 35.22 & 33.06 & 35.42 & 21.16 & 31.32 & 31.75 \\
\hline or & 26.26 & 26.11 & 26.43 & 27.59 & 27.25 & 27.47 & 26.64 & 27.94 & 26.99 & 29.51 & 25.11 & 24.99 \\
\hline$a b--1-1$ & 36.02 & 35.72 & 36.49 & 33.42 & 32.71 & 32.95 & 34.49 & 36.06 & 34.30 & 42.86 & 37.68 & 38.12 \\
\hline an-1-1- & -- & - & -- & 1.87 & 1.74 & 2.08 & 1.8 & 1.07 & 1.49 & 3.12 & 2.70 & 2.16 \\
\hline 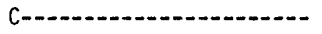 & -- & $\cdots$ & -- & 0.34 & 0.63 & 0.61 & 0.40 & $=$ & 0.43 & -- & 1.34 & 1.53 \\
\hline ac- & 1.93 & 1.89 & 1.50 & -- & -- & -- & -- & -- & -- & -- & -- & -- \\
\hline ns--nons & 0.32 & 0.41 & -- & -- & -- & -- & -- & -- & -- & -- & -- & -- \\
\hline & 0.48 & 0.48 & 0.63 & -- & -- & -- & -- & 0.26 & -- & 0.04 & -- & -- \\
\hline en $\}$ di-n & 0.00 & 0.03 & 0.03 & -- & -- & -- & -- & 0.04 & -- & 0.02 & -- & -- \\
\hline fs $\int$ arding & 0.55 & 0.51 & 0.68 & -- & -- & -- & -- & 0.25 & -- & 0.03 & -- & -- \\
\hline en $\}$ hy- & 0.00 & 0.05 & 0.02 & 0.05 & 0.05 & 0.08 & 0.05 & 0.04 & 0.10 & 0.49 & 0.05 & 0.08 \\
\hline $\begin{array}{l}\text { fs } \\
\text { mt }\end{array}$ & $\begin{array}{l}0.90 \\
--\end{array}$ & $\begin{array}{l}0.93 \\
--\end{array}$ & $\begin{array}{l}0.50 \\
0.07\end{array}$ & $\begin{array}{l}0.61 \\
0.62\end{array}$ & $\begin{array}{l}0.69 \\
--\end{array}$ & $\begin{array}{l}0.72 \\
0.64\end{array}$ & $\begin{array}{l}0.41 \\
0.76\end{array}$ & $\begin{array}{l}0.25 \\
0.84\end{array}$ & $\begin{array}{l}0.35 \\
0.69\end{array}$ & $\begin{array}{l}0.86 \\
1.24\end{array}$ & $\begin{array}{l}1.14 \\
0.47\end{array}$ & $\begin{array}{l}1.11 \\
0.13\end{array}$ \\
\hline$i 1-20$ & $\overrightarrow{0.15}$ & 0.15 & 0.12 & 0.13 & 0.13 & $\begin{array}{l}0.04 \\
0.15\end{array}$ & 0.13 & $\begin{array}{l}0.04 \\
0.19\end{array}$ & 0.21 & $\begin{array}{l}1 .<4 \\
0.58\end{array}$ & $\begin{array}{l}0.41 \\
0.06\end{array}$ & 0.04 \\
\hline & & 0.00 & 0.00 & 0.02 & 0.02 & 0.02 & 0.02 & 0.02 & 0.02 & 0.09 & 0.12 & 0.09 \\
\hline
\end{tabular}




\begin{tabular}{|c|c|c|c|c|c|c|c|c|c|c|c|c|}
\hline & 135 & 136 & 137 & 138 & 139 & 140 & $14 \mathrm{i}$ & 142 & 143 & 144 & 345 & 146 \\
\hline \multicolumn{13}{|c|}{ Trace elements (ppm) } \\
\hline $\begin{array}{l}\mathrm{Ba}--- \\
\mathrm{Be}--\end{array}$ & $<50$. & $<50$. & $<50$. & 75. & 95. & 210 & b. & 126. & 430. & 673. & 1040 & 10. \\
\hline $\begin{array}{l}\text { Be--.- } \\
\text { Co-..- }\end{array}$ & $<0.2$ & $\ddot{0.5}$ & $\ddot{0}$ & 2.1 & 2.2 & 2.0 & 2.6 & 3.7 & 2.6 & 2.3 & 1.8 & 5.1 \\
\hline C & $<0.2$ & 0.5 & 0.2 & 0.3 & 0.3 & 0.4 & 0.2 & 0.3 & 0.3 & 1.5 & $<0.03$ & 0.1 \\
\hline Cr--10-1 & $\overline{3.6}$ & $\overline{3} 5$ & $\ddot{a}$ & $\ddot{-a}$ & $-\overline{-}$ & -- & -- & -- & -- & -- & -- & $<4.0$ \\
\hline Cs-.....- & 3.6 & 3.5 & 4.4 & 13.1 & 7.7 & 6.6 & 8.9 & 4.0 & 3.3 & 5.2 & 5.2 & 10.6 \\
\hline Hf-D-W & 11.4 & 11.2 & 8.8 & 5.2 & 3.6 & 4.0 & 4.1 & 5.1 & 4.1 & 9.0 & 2.3 & 2.1 \\
\hline Li-n......... & -- & -- & -- & 61. & 51. & 47. & 61. & 44. & 36.0 & 35. & 42. & 88. \\
\hline Mo-n- & -- & -- & -- & 2.1 & 2.0 & 2.8 & 3.0 & 5.0 & 5.4 & 8.6 & 1.6 & 0.68 \\
\hline $\mathrm{Nb}^{\star \star \star \ldots}$ & 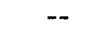 & -. & - & 16. & 13. & 13. & 20. & 19. & 15. & 20. & 13. & 19. \\
\hline$N b^{\star \star *} \ldots$ & 65. & 64. & 67. & 19. & 15. & 14. & 23. & 20. & 19. & 20. & 16. & 20. \\
\hline $\mathrm{Pb}-\ldots$ & 25. & 24. & 15. & 20. & 21. & 20. & 22. & 20. & 19. & 16. & 20. & 20. \\
\hline $\mathrm{Rb}^{\star *}$ & -- & $\ddot{-}$ & -- & 262. & 162. & 145. & 173. & 151. & 119. & 145. & 122. & 190. \\
\hline $\mathrm{Rb}^{\star \star *}$ & 165. & 166. & 193. & 193. & 171. & 152 & 173. & 160. & 129. & 152. & 128. & 210 \\
\hline $\mathrm{Sb}$ & $<0.6$ & 0.9 & 0.6 & --- & $\ddot{2} 57$ & $\ddot{z}$ & -- & $=-76$ & $=-$ & $=-$ & -- & 0.8 \\
\hline 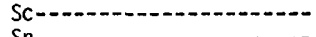 & 0.68 & 0.69 & 1.09 & 3.76 & 2.57 & 2.55 & 2.69 & 2.76 & 2.49 & 3.03 & 1.03 & 3.7 \\
\hline Sn--...-. & -- & -- & -- & 4.2 & 4.8 & 4.0 & 6.0 & 7.0 & 2.6 & 3.5 & 2.8 & 2.4 \\
\hline Sr-...- & -- & -- & - & 5. & 7. & 15. & $<1$. & 5. & 17. & 55. & 111. & 7. \\
\hline Ta----- & 3.70 & 3.44 & 3.37 & 2.94 & 1.58 & 1.37 & 2.00 & 2.14 & 1.70 & 1.71 & 1.33 & 2.57 \\
\hline Th-..... & 16.5 & 15.9 & 19.4 & 24.1 & 15.4 & 14.6 & 15.9 & 23.3 & 18.2 & $19.7^{\circ}$ & 4.2 & 5.8 \\
\hline U-......- & 5.9 & 5.9 & 6.4 & 8.9 & 4.7 & 4.2 & 5.5 & 6.7 & 5.1 & 6.4 & 3.6 & 6.4 \\
\hline$W-\ldots$ & 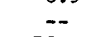 & o & -- & 1.7 & 1.4 & 1.2 & 1.4 & 1.9 & 1.3 & 1.6 & 1.0 & 1.e \\
\hline 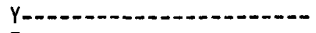 & 52. & 50. & 47. & 35. & 31. & 28. & 37. & 38. & 29. & 31. & 8. & 25. \\
\hline$Z n-1, \ldots$ & 104. & 98. & 83. & 32. & 27. & 29. & 40. & 31. & 21. & 32. & 56. & 50 . \\
\hline Zr-or- & 367. & 377. & 226. & 100 & 100. & 120. & 113. & 150. & 124. & 367. & 54. & 22. \\
\hline 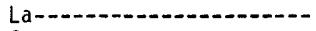 & 39. & 38. & 35. & 31. & 27. & 39. & 24. & 43. & 37. & 38. & 13. & 5. \\
\hline $\mathrm{Ce}-\ldots$ & 93. & 87. & 78. & 62. & 55. & 72. & 47. & 79. & 67. & 70. & 24. & 14. \\
\hline $\mathrm{Nd}-\mathrm{-O}$ & 39. & 38. & 35. & 26. & 25. & 27. & 21. & 28. & 25. & 25. & 10. & 7. \\
\hline Sm- & 8.3 & 8.4 & 7.9 & 7.7 & 5.2 & 5.4 & 5.2 & 6.4 & 5.0 & 5.6 & 3.0 & 2.4 \\
\hline 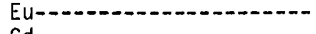 & 0.05 & 0.06 & 0.03 & 0.13 & 0.13 & 0.20 & 0.09 & 0.19 & 0.31 & 0.57 & 0.51 & 0.06 \\
\hline Gd-1-1 & 7.8 & 7.5 & 6.8 & 8.8 & 6.1 & 6.6 & 6.3 & 7.1 & 5.3 & 5.7 & 2.6 & 2.6 \\
\hline Tb-1. & 1.33 & 1.35 & 1.24 & 1.22 & 0.71 & 0.66 & 0.86 & 0.86 & 0.62 & 0.75 & 0.27 & 0.47 \\
\hline Tm--10- & 0.81 & 0.77 & 0.72 & 0.49 & 0.33 & 0.33 & 0.58 & 0.57 & 0.44 & 0.49 & $<0.08$ & 0.05 \\
\hline Yb-10- & 5.6 & 5.5 & 5.4 & 3.9 & 2.6 & 2.3 & 3.2 & 3.9 & 2.8 & 3.1 & 0.2 & 2.7 \\
\hline Lu-........-................ & 0.82 & 0.79 & 0.78 & 0.56 & 0.36 & 0.33 & 0.44 & 0.53 & 0.41 & 0.47 & 0.02 & 0.36 \\
\hline $\mathrm{Nb} / \mathrm{Ta}$ & 17.6 & 18.6 & 19.9 & 6.0 & 8.9 & 9.9 & 10.8 & 9.1 & 10.0 & 11.7 & 10.9 & 7.6 \\
\hline K/Rb--- & 221. & 220. & 191. & 201. & 222. & 252. & 215. & 242. & 292. & 268 & 270 & 164. \\
\hline $\mathrm{Rb} / \mathrm{S} \mathrm{B}$ & -- & -- & -- & 39. & 24. & 10.1 & 87. & 32.0 & 7.6 & 2.8 & 1.2 & 30. \\
\hline $\mathrm{Ca} / \mathrm{Sr}-\cdots$ & $\because 0$ & $\ddot{z}$ & $\overline{3} 0$ & 557. & 368. & 205. & 1394. & 500. & 130 & 90. & 39. & 490. \\
\hline Th/J---- & 2.8 & 2.7 & 3.0 & 2.7 & 2.3 & 3.5 & 2.9 & 3.5 & 3.6 & 3.1 & 1.2 & 0.91 \\
\hline $\mathrm{Zr} / \mathrm{Hf}-\cdots-$ & 32. & 34. & 26. & 19. & 28. & 30. & 28. & 29. & 30. & 41. & 23. & 11. \\
\hline $\mathrm{Ce} / \mathrm{Yb}$ & 16.6 & 15.8 & 14.4 & 15.9 & 21.2 & 31.3 & 14.7 & 20.3 & 23.9 & 22.6 & 120 & 5.2 \\
\hline $\mathrm{Eu} / \mathrm{Eu}^{*}-\cdots$ & 0.02 & 0.02 & 0.01 & 0.05 & 0.07 & 0.10 & 0.05 & 0.09 & 0.19 & 0.31 & 0.56 & 0.07 \\
\hline
\end{tabular}

See footnotes at end of table. 
APPENDIX I.-Chemical analyses of subalkalic silicic obsidians-Continued

\begin{tabular}{|c|c|c|c|c|c|c|c|c|}
\hline Country/St at e---------- & \multicolumn{5}{|c|}{ MEXICO } & \multicolumn{2}{|c|}{ GUATEMALA } & \multirow{3}{*}{$\begin{array}{l}\text { COLOMBIA } \\
\\
\text { Popayan }\end{array}$} \\
\hline Volcanic Field/Region-.- & \multicolumn{5}{|c|}{ Eastern Neovolcanic Zone } & \multirow[b]{2}{*}{ El Fiscal } & \multirow[b]{2}{*}{$\begin{array}{l}\text { Cerro } \\
\text { Ixtepequa }\end{array}$} & \\
\hline Locality--.-- & $\begin{array}{l}\text { Las } \\
\text { Derrumbadas }\end{array}$ & & Tulancins & & Zacualtipan & & & \\
\hline $\begin{array}{l}\text { Specimen- } \\
\text { Collection No. (RLS-)-- }\end{array}$ & $\begin{array}{l}147 \\
126\end{array}$ & $\begin{array}{l}148 \\
127\end{array}$ & $\begin{array}{l}149 \\
128\end{array}$ & $\begin{array}{l}150 \\
132\end{array}$ & $\begin{array}{l}151 \\
129\end{array}$ & $\begin{array}{l}152 \\
134\end{array}$ & $\begin{array}{l}153 \\
135\end{array}$ & $\begin{array}{l}154 \\
133\end{array}$ \\
\hline \multicolumn{9}{|c|}{ Chemical analyses (weight percent) } \\
\hline 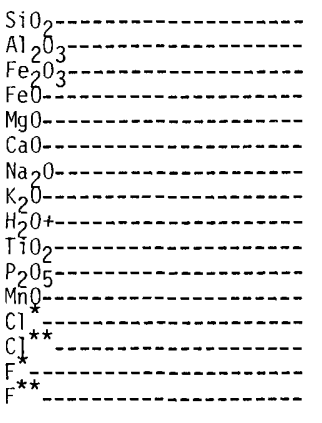 & $\begin{array}{l}74.6 \\
14.08 \\
0.11 \\
0.52 \\
0.03 \\
0.48 \\
4.39 \\
4.16 \\
0.76 \\
0.02 \\
0.05 \\
0.13 \\
0.05 \\
0.01 \\
0.08 \\
0.08\end{array}$ & $\begin{array}{l}74.3 \\
12.44 \\
0.75 \\
1.74 \\
<0.005 \\
0.51 \\
4.80 \\
4.38 \\
0.08 \\
0.20 \\
0.01 \\
0.05 \\
0.15 \\
0.13 \\
0.13 \\
0.14\end{array}$ & $\begin{array}{l}75.0 \\
11.25 \\
1.83 \\
0.45 \\
0.05 \\
0.10 \\
5.15 \\
4.44 \\
0.08 \\
0.20 \\
0.01 \\
0.15 \\
0.19 \\
0.19 \\
0.22 \\
0.24\end{array}$ & $\begin{array}{l}75.7 \\
11.44 \\
1.86 \\
0.45 \\
0.05 \\
0.12 \\
5.25 \\
4.53 \\
0.07 \\
0.21 \\
0.01 \\
0.15 \\
0.18 \\
0.19 \\
0.23 \\
0.19\end{array}$ & $\begin{array}{l}74.8 \\
12.85 \\
0.39 \\
1.09 \\
0.13 \\
0.67 \\
3.44 \\
5.34 \\
0.09 \\
0.23 \\
0.03 \\
0.02 \\
0.07 \\
0.06 \\
0.11 \\
0.12\end{array}$ & $\begin{array}{l}75.5 \\
13.63 \\
0.51 \\
0.32 \\
0.14 \\
0.97 \\
4.11 \\
4.05 \\
0.10 \\
0.14 \\
0.02 \\
0.09 \\
0.06 \\
0.06 \\
0.02 \\
0.02\end{array}$ & $\begin{array}{l}74.5 \\
13.80 \\
0.41 \\
0.81 \\
0.24 \\
1.18 \\
3.95 \\
4.24 \\
0.10 \\
0.22 \\
0.04 \\
0.06 \\
0.07 \\
0.07 \\
0.02 \\
0.01\end{array}$ & $\begin{array}{l}76.1 \\
13.82 \\
0.10 \\
0.49 \\
0.12 \\
0.71 \\
4.25 \\
3.68 \\
0.09 \\
0.09 \\
0.08 \\
0.10 \\
0.03 \\
0.04 \\
0.03 \\
0.01\end{array}$ \\
\hline $\begin{array}{l}\text { Subtotal } \\
\text { Less } 0=(\mathrm{F}, \mathrm{Cl})_{2}\end{array}$ & $\begin{array}{r}99.48 \\
0.05\end{array}$ & $\begin{array}{r}99.53 \\
0.09\end{array}$ & $\begin{array}{r}99.13 \\
0.14\end{array}$ & $\begin{array}{r}100.23 \\
0.13\end{array}$ & $\begin{array}{r}99.26 \\
0.06\end{array}$ & $\begin{array}{r}99.66 \\
0.02\end{array}$ & $\begin{array}{r}99.63 \\
0.02\end{array}$ & $\begin{array}{r}99.70 \\
0.02\end{array}$ \\
\hline Total-a.........- & 99.43 & 99.44 & 98.99 & 100.10 & 99.20 & 99.64 & 99.61 & 99.68 \\
\hline $\mathrm{Fe}_{\mathrm{t}} \mathrm{t}_{\mathrm{t}}$ & 0.53 & 2.42 & 2.10 & 2.13 & 1.44 & 0.78 & 1.18 & 0.58 \\
\hline $\mathrm{Fe} 0 /\left(\mathrm{Fe} 0+\mathrm{Fe}_{2} \mathrm{O}_{3}\right)^{1} \ldots$ & 0.83 & 0.70 & 0.20 & 0.19 & 0.74 & .0 .39 & 0.66 & 0.83 \\
\hline $\mathrm{Na}_{2} \mathrm{O} / \mathrm{K}_{2} \mathrm{O}^{1} \ldots \ldots$ & 1.06 & 1.10 & 1.16 & 1.16 & 0.64 & 1.01 & 0.93 & 1.15 \\
\hline$\left(\mathrm{Na}_{2} \mathrm{O}+\mathrm{K}_{2} \mathrm{O}\right) / \mathrm{Al}_{2} \mathrm{O}_{3}{ }^{2}-\cdots$ & 0.83 & 1.02 & 1.18 & 1.18 & 0.89 & 0.82 & 0.80 & 0.79 \\
\hline$\left(\mathrm{CaO}+\mathrm{Na}_{2} \mathrm{O}+\mathrm{K}_{2} \mathrm{O}\right) / \mathrm{Al}_{2} \mathrm{O}_{3}{ }^{2} \ldots$ & 0.90 & 1.09 & 1.20 & 1.20 & 0.98 & 0.95 & 0.96 & 0.89 \\
\hline $\mathrm{CaO} /\left(\mathrm{Na}_{2} \mathrm{O}+\mathrm{K}_{2} \mathrm{O}\right)^{1} \ldots$ & 0.06 & 0.06 & 0.01 & 0.01 & 0.08 & 0.12 & 0.14 & 0.09 \\
\hline $\mathrm{Cl} / \mathrm{F}^{1 \dagger}$ & 0.68 & 1.0 & 0.82 & 0.88 & 0.60 & 2.9 & 3.9 & 1.0 \\
\hline \multicolumn{9}{|c|}{ CIPW norms } \\
\hline 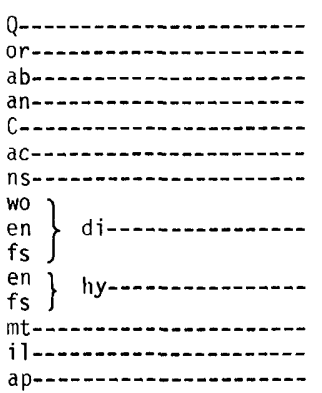 & $\begin{array}{l}32.18 \\
24.94 \\
3.69 \\
2.08 \\
1.63 \\
-- \\
-- \\
-- \\
-- \\
-- \\
0.08 \\
1.09 \\
0.16 \\
0.04 \\
0.12\end{array}$ & $\begin{array}{l}28.37 \\
26.10 \\
39.93 \\
-- \\
-- \\
0.90 \\
-- \\
1.04 \\
0.00 \\
1.18 \\
0.00 \\
1.44 \\
0.65 \\
0.38 \\
0.02\end{array}$ & $\begin{array}{l}31.88 \\
26.60 \\
33.61 \\
-- \\
-- \\
5.37 \\
1.04 \\
0.18 \\
0.03 \\
0.17 \\
0.10 \\
0.62 \\
-- \\
0.39 \\
0.02\end{array}$ & $\begin{array}{l}31.45 \\
26.83 \\
33.70 \\
-- \\
--. \\
5.39 \\
1.10 \\
0.22 \\
0.03 \\
0.21 \\
0.09 \\
0.55 \\
-- \\
0.40 \\
0.02\end{array}$ & $\begin{array}{l}32.53 \\
31.88 \\
29.41 \\
3.16 \\
0.27 \\
-- \\
-- \\
-- \\
-- \\
-- \\
0.33 \\
1.35 \\
0.57 \\
0.44 \\
0.07\end{array}$ & $\begin{array}{l}33.99 \\
24.06 \\
34.96 \\
4.71 \\
0.77 \\
-- \\
-- \\
-- \\
-- \\
-- \\
0.35 \\
0.10 \\
0.74 \\
0.27 \\
0.05\end{array}$ & $\begin{array}{l}32.29 \\
25.19 \\
33.61 \\
5.62 \\
0.67 \\
-- \\
-- \\
-- \\
-- \\
-- \\
0.60 \\
0.90 \\
0.60 \\
0.42 \\
0.09\end{array}$ & $\begin{array}{l}35.60 \\
21.85 \\
36.13 \\
3.01 \\
1.75 \\
-- \\
-- \\
-- \\
-- \\
-- \\
0.30 \\
0.86 \\
0.15 \\
0.17 \\
0.19\end{array}$ \\
\hline
\end{tabular}




\begin{tabular}{|c|c|c|c|c|c|c|c|c|}
\hline & 147 & 148 & 149 & 150 & 151 & 152 & 153 & 154 \\
\hline \multicolumn{9}{|c|}{ Trace elements (ppm) } \\
\hline 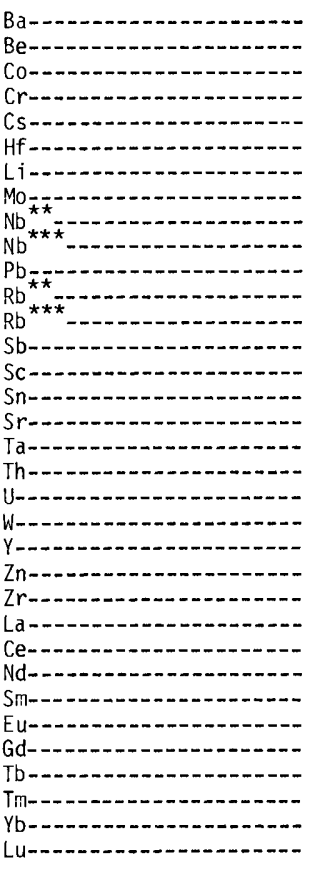 & $\begin{array}{l}9 . \\
5.6 \\
0.1 \\
1.3 \\
11.0 \\
2.2 \\
92 . \\
.64 \\
20 . \\
20 . \\
27 . \\
193 . \\
217 . \\
0.6 \\
3.8 \\
3.1 \\
8 . \\
2.62 \\
5.1 \\
6.3 \\
1.4 \\
25 . \\
50 . \\
22 . \\
5 . \\
12 . \\
4 . \\
2.4 \\
0.07 \\
2.4 \\
0.45 \\
0.25 \\
2.5 \\
0.34\end{array}$ & $\begin{array}{c}885 . \\
5.8 \\
<0.2 \\
3.4 \\
5.9 \\
17.0 \\
63 . \\
5.8 \\
45 . \\
49 . \\
20 . \\
119 . \\
141 . \\
1.7 \\
0.77 \\
6.1 \\
16 . \\
2.79 \\
12.6 \\
3.4 \\
1.5 \\
95 . \\
204 . \\
683 . \\
77 . \\
160 . \\
77 . \\
15.5 \\
1.64 \\
13.4 \\
2.64 \\
1.36 \\
9.4 \\
1.24\end{array}$ & $\begin{array}{c}11 . \\
10.0 \\
<0.2 \\
<5.0 \\
4.1 \\
25.2 \\
68 . \\
5.9 \\
86 . \\
84 . \\
23 . \\
195 . \\
209 . \\
0.3 \\
3.2 \\
7.1 \\
3 . \\
5.66 \\
19.3 \\
5.9 \\
2.1 \\
124 . \\
218 . \\
943 . \\
40 . \\
92 . \\
36 . \\
9.3 \\
1.52 \\
10.3 \\
2.43 \\
1.76 \\
12.6 \\
1.77\end{array}$ & $\begin{array}{c}8 . \\
10.0 \\
<0.2 \\
<5.0 \\
4.1 \\
24.4 \\
71 . \\
6.6 \\
83 . \\
88 . \\
26 . \\
190 . \\
205 . \\
0.3 \\
3.1 \\
6.2 \\
2 . \\
5.59 \\
18.0 \\
6.4 \\
1.6 \\
115 . \\
233 . \\
928 . \\
39 . \\
91 . \\
32 . \\
11.0 \\
1.44 \\
9.9 \\
2.30 \\
1.71 \\
12.5 \\
1.81\end{array}$ & $\begin{array}{c}305 . \\
6.2 \\
1.2 \\
<5.0 \\
15.7 \\
6.9 \\
82 . \\
3.6 \\
19 . \\
24 . \\
24 . \\
283 . \\
296 . \\
1.0 \\
3.1 \\
9.4 \\
40 . \\
2.23 \\
36.5 \\
9.0 \\
2.4 \\
47 . \\
27 . \\
212 . \\
56 . \\
110 . \\
38 . \\
8.8 \\
0.46 \\
7.4 \\
1.26 \\
0.82 \\
4.8 \\
0.68\end{array}$ & $\begin{array}{c}950 . \\
2.1 \\
0.2 \\
<4.0 \\
7.3 \\
3.0 \\
71 . \\
2.2 \\
10 . \\
12 . \\
22 . \\
144 . \\
157 . \\
0.7 \\
1.6 \\
1.8 \\
157 . \\
1.12 \\
10.1 \\
4.7 \\
2.0 \\
17 . \\
34 . \\
89 . \\
25 . \\
46 . \\
19 . \\
3.3 \\
0.54 \\
2.7 \\
0.43 \\
0.18 \\
1.9 \\
0.29\end{array}$ & $\begin{array}{c}1090 . \\
1.8 \\
0.9 \\
<3.0 \\
2.7 \\
3.9 \\
39.9 \\
2.9 \\
10 . \\
11 . \\
20 . \\
96 . \\
103 . \\
<0.3 \\
1.8 \\
1.3 \\
157 . \\
0.89 \\
6.5 \\
2.8 \\
1.1 \\
14 . \\
22 . \\
148 . \\
24 . \\
42 . \\
13 . \\
2.9 \\
0.50 \\
2.2 \\
0.40 \\
0.30 \\
1.8 \\
0.28\end{array}$ & $\begin{array}{c}1440 . \\
2.2 \\
0.2 \\
1.2 \\
3.8 \\
1.9 \\
43 . \\
2.3 \\
15 . \\
21 . \\
22 . \\
117 . \\
120 . \\
0.3 \\
1.4 \\
1.2 \\
135 . \\
1.33 \\
6.8 \\
4.8 \\
2.3 \\
14 . \\
40 . \\
40 . \\
11 . \\
22 . \\
0 . \\
2.0 \\
0.37 \\
1.6 \\
0.32 \\
<0.10 \\
0.9 \\
0.15\end{array}$ \\
\hline 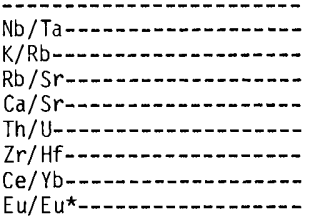 & $\begin{array}{c}7.6 \\
159 . \\
27.1 \\
429 . \\
0.81 \\
10 . \\
4.8 \\
0.09\end{array}$ & $\begin{array}{r}16.9 \\
258 . \\
8.8 \\
228 . \\
3.7 \\
40 . \\
17.0 \\
0.35\end{array}$ & $\begin{array}{c}15.2 \\
176 . \\
69.7 \\
238 . \\
3.3 \\
37 . \\
7.3 \\
0.48\end{array}$ & $\begin{array}{l}14.9 \\
183 . \\
103 . \\
429 . \\
2.8 \\
38 . \\
7.3 \\
0.38\end{array}$ & $\begin{array}{c}9.6 \\
150 . \\
7.4 \\
120 . \\
4.1 \\
31.9 \\
22.9 \\
0.18\end{array}$ & $\begin{array}{r}9.8 \\
214 . \\
1.0 \\
44.2 \\
2.2 \\
30 . \\
24.2 \\
0.56\end{array}$ & $\begin{array}{c}11.8 \\
342 . \\
0.66 \\
53.7 \\
2.3 \\
38 . \\
23.3 \\
0.60\end{array}$ & $\begin{array}{l}13.5 \\
255 \\
0.89 \\
37.6 \\
1.4 \\
21.4 \\
24.4 \\
0.64\end{array}$ \\
\hline
\end{tabular}

See footnotes at end of table. 
APPENDIX I.-Chemical analyses of subalkalic silicic obsidians-Continued

\begin{tabular}{|c|c|c|c|c|c|c|c|c|c|}
\hline Country/St ate--..-...-.- & \multicolumn{4}{|c|}{ ECUADOR } & \multicolumn{2}{|c|}{ PERU } & \multirow{4}{*}{$\frac{\frac{\text { BOLIVIA }}{\text { S. Bolivia }}}{\frac{}{\text { unknown }}}$} & \multirow{2}{*}{\multicolumn{2}{|c|}{$\frac{\text { CHILE }}{\text { Central }}$}} \\
\hline Volcanic field/region--- & \multirow{3}{*}{$\begin{array}{c}\begin{array}{c}\text { Caldera } \\
\text { Chacana }\end{array} \\
155 \\
146\end{array}$} & \multicolumn{3}{|c|}{ Galapagos Islands } & \multirow{3}{*}{$\begin{array}{c}\text { unknown } \\
\begin{array}{c}159 \\
206\end{array}\end{array}$} & \multirow{3}{*}{$\begin{array}{c}\text { Macusani } \\
\begin{array}{l}160 \\
215\end{array}\end{array}$} & & & \\
\hline Local ity--.-.-... & & & Al cedo & & & & & \multicolumn{2}{|c|}{$\begin{array}{l}\text { Volcan Laguna } \\
\text { del Maule }\end{array}$} \\
\hline $\begin{array}{l}\text { Specimen- } \\
\text { Collection No. (RLS-) }\end{array}$ & & $\begin{array}{l}156 \\
186\end{array}$ & $\begin{array}{l}157 \\
192\end{array}$ & $\begin{array}{l}158 \\
193\end{array}$ & & & & $\begin{array}{l}162 \\
203\end{array}$ & $\begin{array}{l}163 \\
204\end{array}$ \\
\hline \multicolumn{10}{|c|}{ Chemical analyses (weight percent) } \\
\hline 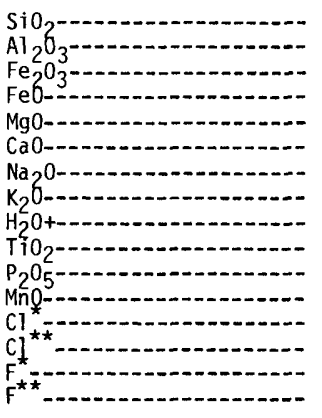 & $\begin{array}{l}77.2 \\
12.84 \\
0.20 \\
0.35 \\
0.07 \\
0.58 \\
3.65 \\
4.59 \\
0.06 \\
0.10 \\
0.01 \\
0.05 \\
0.03 \\
0.03 \\
0.03 \\
0.02\end{array}$ & $\begin{array}{l}70.6 \\
13.33 \\
1.34 \\
3.00 \\
0.28 \\
1.52 \\
5.73 \\
2.85 \\
0.20 \\
0.41 \\
0.04 \\
0.16 \\
0.10 \\
0.09 \\
0.09 \\
0.10\end{array}$ & $\begin{array}{l}70.6 \\
13.17 \\
1.01 \\
3.88 \\
0.18 \\
1.73 \\
5.73 \\
2.66 \\
0.18 \\
0.41 \\
0.03 \\
0.18 \\
0.10 \\
0.10 \\
0.10 \\
0.09\end{array}$ & $\begin{array}{l}71.0 \\
13.36 \\
1.10 \\
2.83 \\
0.24 \\
1.23 \\
5.93 \\
3.01 \\
0.14 \\
0.37 \\
0.03 \\
0.14 \\
0.10 \\
0.12 \\
0.10 \\
0.09\end{array}$ & $\begin{array}{r}76.2 \\
13.25 \\
0.30 \\
0.34 \\
0.08 \\
0.60 \\
4.29 \\
4.30 \\
0.12 \\
0.10 \\
0.01 \\
0.08 \\
0.05 \\
0.05 \\
0.03 \\
0.02\end{array}$ & $\begin{array}{l}72.6 \\
15.65 \\
0.11 \\
0.45 \\
0.01 \\
0.18 \\
4.20 \\
3.60 \\
0.29 \\
0.04 \\
0.42 \\
0.09 \\
0.05 \\
0.04 \\
1.37 \\
1.35\end{array}$ & $\begin{array}{l}74.5 \\
13.86 \\
0.65 \\
0.87 \\
0.19 \\
1.10 \\
3.57 \\
4.79 \\
0.20 \\
0.21 \\
0.03 \\
0.08 \\
0.12 \\
0.09 \\
0.11 \\
0.10\end{array}$ & $\begin{array}{l}75.9 \\
12.77 \\
0.43 \\
0.48 \\
0.12 \\
0.67 \\
4.17 \\
4.56 \\
0.15 \\
0.17 \\
0.01 \\
0.07 \\
0.11 \\
0.10 \\
0.03 \\
0.03\end{array}$ & $\begin{array}{l}73.7 \\
14.20 \\
0.55 \\
0.62 \\
0.23 \\
0.87 \\
5.15 \\
3.93 \\
0.20 \\
0.25 \\
0.03 \\
0.09 \\
0.10 \\
0.12 \\
0.04 \\
0.04\end{array}$ \\
\hline $\begin{array}{l}\text { Subtotal } \\
\text { Less } 0=\left(\mathrm{F}, \mathrm{Cl}_{2}-\right.\end{array}$ & $\begin{array}{r}99.76 \\
0.02 \\
\end{array}$ & $\begin{array}{r}99.65 \\
0.06 \\
\end{array}$ & $\begin{array}{r}99.95 \\
0.06 \\
\end{array}$ & $\begin{array}{r}99.58 \\
0.06 \\
\end{array}$ & $\begin{array}{r}99.75 \\
0.02 \\
\end{array}$ & $\begin{array}{c}99.78^{5} \\
0.58 \\
\end{array}$ & $\begin{array}{r}100.28 \\
0.07 \\
\end{array}$ & $\begin{array}{r}99.64 \\
0.04\end{array}$ & $\begin{array}{r}99.97 \\
0.04\end{array}$ \\
\hline Total- & 99.74 & 99.59 & 99.89 & 99.52 & 99.73 & $99.20^{5}$ & $\overline{100.21}$ & 99.60 & 99.93 \\
\hline $\mathrm{Fe}_{\mathrm{t}} \mathrm{l}$ & 0.53 & 4.21 & 4.79 & 3.82 & 0.61 & 0.55 & 1.46 & 0.87 & 1.12 \\
\hline $\mathrm{Fe} 0 /\left(\mathrm{Fe} 0+\mathrm{Fe}_{2} \mathrm{O}_{3}\right)^{1}-\ldots$ & 0.64 & 0.69 & 0.79 & 0.72 & 0.53 & 0.80 & 0.57 & 0.53 & 0.53 \\
\hline $\mathrm{Na}_{2} \mathrm{O} / \mathrm{K}_{2} \mathrm{O}^{1}$ & 0.80 & 2.01 & 2.15 & 1.97 & 1.00 & 1.17 & 0.75 & 0.91 & 1.31 \\
\hline$\left(\mathrm{Na}_{2} \mathrm{O}+\mathrm{K}_{2} \mathrm{O}\right) / \mathrm{Al}_{2} \mathrm{O}_{3}{ }^{2} \ldots$ & 0.85 & 0.94 & 0.93 & 0.98 & 0.88 & 0.69 & 0.80 & 0.92 & 0.90 \\
\hline$\left(\mathrm{CaO}+\mathrm{Na}_{2} \mathrm{O}+\mathrm{K}_{2} \mathrm{O}\right) / \mathrm{Al}_{2} \mathrm{O}_{3}{ }^{2}-\cdots$ & 0.94 & 1.15 & 1.17 & 1.14 & 0.97 & 0.71 & 0.94 & 1.02 & 1.01 \\
\hline $\mathrm{CaO} /\left(\mathrm{Na}_{2} \mathrm{O}+\mathrm{K}_{2} \mathrm{O}\right)^{1}$ & 0.07 & 0.18 & 0.21 & 0.14 & 0.07 & 0.02 & 0.13 & 0.08 & 0.10 \\
\hline $\mathrm{Cl} / \mathrm{F}^{1 \dagger}$ & 1.2 & 1.0 & 1.0 & 1.2 & 2.0 & 0.03 & 1.2 & 3.7 & 2.3 \\
\hline \multicolumn{10}{|c|}{ CIPW norms } \\
\hline $\begin{array}{l}\text { Q } \\
\text { or } \\
\text { abn } \\
\text { an } \\
\text { acs } \\
\text { ns } \\
\text { wo } \\
\text { en } \\
\text { fs } \\
\text { en } \\
\text { fs } \\
\text { mt } \\
\text { il } \\
\text { ap }\end{array}$ & $\begin{array}{l}37.03 \\
27.22 \\
31.0 \\
2.82 \\
0.84 \\
-- \\
-- \\
-- \\
\overline{-} \\
\overline{0.18} \\
0.41 \\
0.29 \\
0.19 \\
0.02\end{array}$ & $\begin{array}{l}22.22 \\
16.97 \\
48.85 \\
2.25 \\
-- \\
-\therefore \\
-- \\
2.12 \\
0.34 \\
1.96 \\
0.36 \\
2.09 \\
1.96 \\
0.78 \\
0.09\end{array}$ & $\begin{array}{l}21.89 \\
15.79 \\
48.69 \\
2.37 \\
-- \\
-- \\
- \\
2.53 \\
0.20 \\
2.61 \\
0.25 \\
3.36 \\
1.47 \\
0.78 \\
0.07\end{array}$ & $\begin{array}{l}21.52 \\
17.92 \\
50.56 \\
0.95 \\
-- \\
-- \\
-. \\
2.09 \\
0.30 \\
1.98 \\
0.30 \\
1.99 \\
1.61 \\
0.71 \\
0.07\end{array}$ & $\begin{array}{l}33.40 \\
25.53 \\
36.47 \\
2.92 \\
0.47 \\
-- \\
-- \\
-- \\
-- \\
0 . \\
0.20 \\
0.36 \\
0.44 \\
0.19 \\
0.02\end{array}$ & $\begin{array}{l}34.92 \\
21.85 \\
36.51 \\
0.00 \\
4.98 \\
-. \\
-- \\
-- \\
- \\
0 . \\
0.03 \\
0.86 \\
0.16 \\
0.08 \\
0.33\end{array}$ & $\begin{array}{l}32.50 \\
28.35 \\
34.25 \\
5.27 \\
0.88 \\
-- \\
-- \\
- \\
- \\
0.47 \\
0.86 \\
0.94 \\
0.40 \\
0.07\end{array}$ & $\begin{array}{c}32.78 \\
27.12 \\
35.52 \\
2.68 \\
-- \\
-- \\
-- \\
0.25 \\
0.11 \\
0.14 \\
0.19 \\
0.24 \\
0.63 \\
0.33 \\
0.02\end{array}$ & $\begin{array}{l}26.50 \\
23.31 \\
43.74 \\
4.04 \\
-. \\
-- \\
-. \\
0.04 \\
0.02 \\
0.02 \\
0.55 \\
0.42 \\
0.80 \\
0.48 \\
0.07\end{array}$ \\
\hline
\end{tabular}




\begin{tabular}{|c|c|c|c|c|c|c|c|c|c|}
\hline & 155 & 156 & 157 & 158 & 159 & 160 & 161 & 162 & 163 \\
\hline \multicolumn{10}{|c|}{ Trace elements (ppm) } \\
\hline 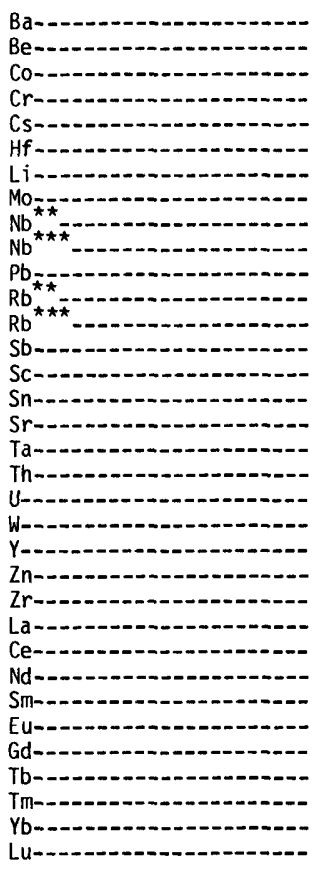 & $\begin{array}{c}900 . \\
1.8 \\
0.1 \\
<4.0 \\
10.4 \\
2.3 \\
57.0 \\
3.5 \\
13 . \\
13 . \\
15 . \\
165 . \\
170 . \\
1.5 \\
1.3 \\
0.7 \\
88 . \\
1.40 \\
19.0 \\
8.3 \\
2.6 \\
8 . \\
21 . \\
52 . \\
17 . \\
32 . \\
12 . \\
2.6 \\
0.25 \\
2.6 \\
0.24 \\
<0.10 \\
0.9 \\
0.12\end{array}$ & $\begin{array}{c}400 . \\
5.0 \\
1.2 \\
<2.0 \\
0.8 \\
20.0 \\
24 . \\
5.7 \\
74 . \\
74 . \\
16 . \\
65 . \\
71 . \\
<1.0 \\
6.1 \\
5.3 \\
120 . \\
4.96 \\
9.2 \\
2.6 \\
1.8 \\
101 . \\
170 . \\
850 . \\
61 . \\
133 . \\
69 . \\
16.2 \\
2.94 \\
16.8 \\
2.33 \\
1.60 \\
9.0 \\
1.25\end{array}$ & $\begin{array}{c}410 . \\
5.0 \\
0.8 \\
<2.0 \\
0.9 \\
21.8 \\
25 . \\
5.2 \\
74 . \\
76 . \\
10 . \\
62 . \\
62 . \\
<2.0 \\
7.2 \\
6.8 \\
128 . \\
5.35 \\
9.4 \\
2.3 \\
1.9 \\
114 . \\
156 . \\
860 . \\
64 . \\
135 . \\
68 . \\
17.9 \\
3.29 \\
16.7 \\
2.57 \\
1.68 \\
9.9 \\
1.38\end{array}$ & $\begin{array}{c}435 . \\
5.2 \\
1.5 \\
0.6 \\
1.0 \\
21.3 \\
28 . \\
6.0 \\
79 . \\
83 . \\
10 . \\
50 . \\
71 . \\
<1.0 \\
4.7 \\
8.4 \\
90 . \\
5.64 \\
10.4 \\
2.8 \\
2.1 \\
108 . \\
142 . \\
840 . \\
66 . \\
136 . \\
73 . \\
17.5 \\
2.81 \\
16.7 \\
2.76 \\
1.50 \\
10.0 \\
1.35\end{array}$ & $\begin{array}{c}625 . \\
2.7 \\
0.2 \\
<2.0 \\
6.8 \\
3.0 \\
44 . \\
2.4 \\
16 . \\
16 . \\
20 . \\
165 . \\
183 . \\
0.5 \\
2.0 \\
1.4 \\
85 . \\
1.78 \\
18.0 \\
7.9 \\
1.7 \\
19 . \\
33 . \\
67 . \\
22 . \\
39 . \\
14 . \\
2.7 \\
0.36 \\
<3.0 \\
<0.40 \\
0.28 \\
1.3 \\
0.21\end{array}$ & $\begin{array}{c}<50 . \\
32 . \\
3.1 \\
<4.0 \\
503 . \\
1.3 \\
3400 . \\
0.26 \\
52 . \\
60 . \\
31 . \\
1100 . \\
1174 . \\
3.9 \\
2.3 \\
250 . \\
1 . \\
22.10 \\
1.3 \\
16.9 \\
76 . \\
31 . \\
106 . \\
28 . \\
1 . \\
3 . \\
<20 . \\
1.5 \\
<0.04 \\
<3.0 \\
0.17 \\
<0.30 \\
0.3 \\
0.04\end{array}$ & $\begin{array}{c}675 . \\
3.4 \\
0.2 \\
-- \\
10.6 \\
6.1 \\
160 . \\
3.8 \\
23 . \\
28 . \\
29 . \\
221 . \\
216 . \\
1.3 \\
4.2 \\
1.7 \\
152 . \\
2.34 \\
21.9 \\
8.1 \\
4.1 \\
43 . \\
64 . \\
211 . \\
47 . \\
91 . \\
41 . \\
9.9 \\
1.16 \\
8.4 \\
1.16 \\
0.43 \\
3.2 \\
0.44\end{array}$ & $\begin{array}{c}700 . \\
2.4 \\
0.5 \\
<2.0 \\
8.3 \\
4.0 \\
43 . \\
3.4 \\
11 . \\
11 . \\
22 . \\
201 . \\
195 . \\
0.5 \\
2.2 \\
1.8 \\
62 . \\
1.32 \\
26.6 \\
7.3 \\
1.7 \\
22 . \\
16 . \\
108 . \\
36 . \\
66 . \\
23 . \\
3.7 \\
0.43 \\
<3.0 \\
<0.40 \\
0.34 \\
2.0 \\
0.31\end{array}$ & $\begin{array}{c}750 . \\
2.5 \\
0.2 \\
<2.0 \\
4.4 \\
5.3 \\
32 . \\
3.7 \\
11 . \\
15 . \\
22 . \\
162 . \\
170 . \\
<0.8 \\
2.3 \\
2.1 \\
120 . \\
1.28 \\
21.0 \\
5.9 \\
1.9 \\
20 . \\
36 . \\
174 . \\
36 . \\
67 . \\
25 . \\
4.4 \\
0.69 \\
3.9 \\
<0.40 \\
0.38 \\
2.1 \\
0.33\end{array}$ \\
\hline 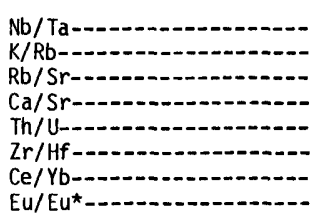 & $\begin{array}{r}9.3 \\
224 . \\
1.9 \\
47.1 \\
2.3 \\
23 . \\
35.6 \\
0.32\end{array}$ & $\begin{array}{l}14.9 \\
333 . \\
0.59 \\
90.5 \\
3.5 \\
43 . \\
14.8 \\
0.55\end{array}$ & $\begin{array}{c}14.0 \\
356 . \\
0.48 \\
96.6 . \\
4.1 \\
39 . \\
13.6 \\
0.59\end{array}$ & $\begin{array}{c}14.4 \\
352 . \\
0.79 \\
97.7 \\
3.7 \\
39 . \\
13.6 \\
0.47\end{array}$ & $\begin{array}{l}9.0 \\
195 . \\
22 . \\
50 . \\
2.3 \\
22 . \\
30.0 \\
--\end{array}$ & $\begin{array}{c}2.5 \\
25 . \\
1174 . \\
1286 . \\
0.1 \\
22 . \\
10.0 \\
--\end{array}$ & $\begin{array}{c}10.9 \\
184 . \\
1.4 \\
52 . \\
2.7 \\
35 . \\
28.4 \\
0.40\end{array}$ & $\begin{array}{c}8.3 \\
194 . \\
3.2 \\
77 . \\
3.6 \\
27 . \\
33.0 \\
. .\end{array}$ & $\begin{array}{c}10.2 \\
192 . \\
1.4 . \\
52 . \\
3.6 \\
33 . \\
31.9 \\
0.51\end{array}$ \\
\hline
\end{tabular}

See footnotes at end of table. 
APPENDIX I.-Chemical analyses of subalkalic silicic obsidians-Continued

\begin{tabular}{|c|c|c|c|c|c|c|c|c|c|c|}
\hline Country/State---.-.-.- & \multicolumn{3}{|c|}{ CHILE } & \multirow{2}{*}{ 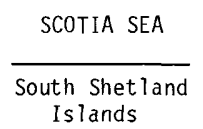 } & \multicolumn{6}{|c|}{ ICELAND } \\
\hline Volcanic field/region--- & \multicolumn{3}{|c|}{ Central Chile } & & \multirow[b]{2}{*}{$\begin{array}{l}\text { Ljósu- } \\
\text { fjôl1 } \\
\end{array}$} & & & \multirow[b]{2}{*}{$\begin{array}{l}\text { Kerling- } \\
\text { arfjoil }\end{array}$} & \multicolumn{2}{|c|}{$\begin{array}{c}\text { Torfajökull } \\
\text { Volcanic Complex }\end{array}$} \\
\hline Locality-- & \multicolumn{3}{|c|}{ Volcan Laguna del Maule } & $\begin{array}{l}\text { Decept ion } \\
\text { Island }\end{array}$ & & Pres & akur & & $\begin{array}{l}\text { Hrafntinn- } \\
\text { uhraun }\end{array}$ & Laugahraun \\
\hline $\begin{array}{l}\text { Specimen- } \\
\text { Collect ion No. (RLS-)--- }\end{array}$ & $\begin{array}{l}164 \\
205\end{array}$ & $\begin{array}{l}165 \\
220\end{array}$ & $\begin{array}{l}166 \\
221\end{array}$ & $\begin{array}{l}167 \\
213\end{array}$ & $\begin{array}{l}168 \\
180\end{array}$ & $\begin{array}{c}169 \\
1\end{array}$ & $\begin{array}{r}170 \\
11\end{array}$ & $\begin{array}{r}171 \\
42\end{array}$ & $\begin{array}{l}172 \\
177\end{array}$ & $\begin{array}{l}173 \\
178\end{array}$ \\
\hline
\end{tabular}

Chemical analyses (weight percent)

\begin{tabular}{|c|c|c|c|c|c|c|c|c|c|c|}
\hline $\begin{array}{l}\mathrm{SiO}_{2} \mathrm{O}_{2} \\
\mathrm{Al}_{2} \mathrm{O}_{3} \\
\mathrm{Fe}_{2} \mathrm{O}_{3} \\
\mathrm{Fe}\end{array}$ & $\begin{array}{r}75.0 \\
13.28 \\
0.52 \\
0.43 \\
0.14 \\
0.70 \\
4.53 \\
4.17 \\
0.12 \\
0.18 \\
0.01 \\
0.09 \\
0.11 \\
0.11 \\
0.03 \\
0.03\end{array}$ & $\begin{array}{r}74.6 \\
14.12 \\
0.53 \\
0.54 \\
0.20 \\
0.73 \\
4.88 \\
3.90 \\
0.21 \\
0.23 \\
0.03 \\
0.10 \\
0.13 \\
0.18 \\
0.04 \\
0.04\end{array}$ & $\begin{array}{l}74.5 \\
14.17 \\
0.54 \\
0.58 \\
0.21 \\
0.75 \\
4.87 \\
3.90 \\
0.21 \\
0.25 \\
0.04 \\
0.10 \\
0.11 \\
0.13 \\
0.04 \\
0.04\end{array}$ & $\begin{array}{r}67.8 \\
14.98 \\
0.97 \\
3.36 \\
0.70 \\
1.92 \\
6.87 \\
1.82 \\
0.12 \\
0.74 \\
0.09 \\
0.20 \\
0.16 \\
0.16 \\
0.06 \\
0.03\end{array}$ & $\begin{array}{r}74.3 \\
12.01 \\
0.88 \\
1.46 \\
0.00 \\
0.32 \\
5.36 \\
4.58 \\
0.23 \\
0.15 \\
0.00 \\
0.08 \\
0.17 \\
0.17 \\
0.34 \\
0.32\end{array}$ & $\begin{array}{r}76.73 \\
12.26 \\
0.45 \\
1.15 \\
0.10 \\
1.08 \\
4.29 \\
3.32 \\
0.22 \\
0.11 \\
0.01 \\
0.05 \\
-0.05 \\
--.13 \\
0.13\end{array}$ & $\begin{array}{r}76.94 \\
12.26 \\
0.33 \\
1.10 \\
0.00 \\
0.93 \\
4.28 \\
3.45 \\
0.24 \\
0.10 \\
0.01 \\
0.04 \\
-- \\
0.04 \\
--.13 \\
0.13\end{array}$ & $\begin{array}{r}73.2 \\
13.17 \\
0.74 \\
1.61 \\
0.13 \\
0.96 \\
4.88 \\
3.78 \\
0.16 \\
0.20 \\
0.02 \\
0.08 \\
0.12 \\
0.12 \\
0.20 \\
0.17\end{array}$ & $\begin{array}{l}70.0 \\
14.58 \\
0.74 \\
2.01 \\
0.26 \\
1.16 \\
5.47 \\
4.43 \\
0.12 \\
0.33 \\
0.04 \\
0.08 \\
0.16 \\
--.20 \\
0 .-\end{array}$ & $\begin{array}{c}69.5 \\
14.36 \\
1.01 \\
2.03 \\
0.26 \\
1.18 \\
5.51 \\
4.21 \\
0.59 \\
0.34 \\
0.04 \\
0.10 \\
0.12 \\
---19 \\
---\end{array}$ \\
\hline $\begin{array}{l}\text { Subtotal al } \\
\text { Less } 0=(F, C 1)_{2}\end{array}$ & $\begin{array}{r}99.31 \\
0.04\end{array}$ & $\begin{array}{r}100.27 \\
0.05\end{array}$ & $\begin{array}{r}100.28 \\
0.05\end{array}$ & $\begin{array}{r}99.77 \\
0.05\end{array}$ & $\begin{array}{r}99.87 \\
0.18\end{array}$ & $\begin{array}{r}99.95 \\
0.07\end{array}$ & $\begin{array}{r}99.85 \\
0.06\end{array}$ & $\begin{array}{r}99.23 \\
0.11\end{array}$ & $\begin{array}{r}99.58 \\
0.12\end{array}$ & $\begin{array}{r}99.44 \\
0.11\end{array}$ \\
\hline Total- & 99.27 & 100.22 & 100.23 & 99.72 & 99.69 & 99.88 & 99.79 & 99.12 & 99.46 & 99.33 \\
\hline $\mathrm{FeO}_{\mathrm{t}}^{1}$ & 0.90 & 1.02 & 1.07 & 4.23 & 2.25 & 1.56 & 1.40 & 2.28 & 2.68 & 2.94 \\
\hline $\mathrm{Fe} 0 /\left(\mathrm{Fe} 0+\mathrm{Fe}_{2} \mathrm{O}_{3}\right)^{1}-\ldots$ & 0.45 & 0.50 & 0.52 & 0.78 & 0.62 & 0.72 & 0.77 & 0.69 & 0.73 & 0.67 \\
\hline $\mathrm{Na}_{2} \mathrm{O} / \mathrm{K}_{2} \mathrm{O}^{1}$ & 1.09 & 1.25 & 1.25 & 3.77 & 1.17 & 1.29 & 1.24 & 1.29 & 1.23 & 1.31 \\
\hline$\left(\mathrm{Na}_{2} \mathrm{O}+\mathrm{K}_{2} \mathrm{O}\right) / \mathrm{Al}_{2} \mathrm{O}_{3}{ }^{2}$ & 0.90 & 0.87 & 0.86 & 0.89 & 1.15 & 0.87 & 0.88 & 0.92 & 0.95 & 0.95 \\
\hline$\left(\mathrm{CaO}+\mathrm{Na}_{2} \mathrm{O}+\mathrm{K}_{2} \mathrm{O}\right) / \mathrm{Al}_{2} \mathrm{O}_{3}{ }^{2}-\cdots$ & 1.00 & 0.96 & 0.96 & 1.12 & 1.20 & 1.03 & 1.02 & 1.05 & 1.09 & 1.10 \\
\hline $\mathrm{CaO} /\left(\mathrm{Na}_{2} \mathrm{O}+\mathrm{K}_{2} \mathrm{O}\right)^{1}$ & 0.08 & 0.08 & 0.09 & 0.22 & 0.03 & 0.14 & 0.12 & 0.11 & 0.12 & 0.12 \\
\hline $\mathrm{Cl} / \mathrm{F}^{1+}+\ldots$ & 3.8 & 3.7 & 2.9 & 3.7 & 0.51 & 0.38 & 0.31 & 0.65 & 0.78 & 0.63 \\
\hline \multicolumn{11}{|c|}{ CIPW norms } \\
\hline 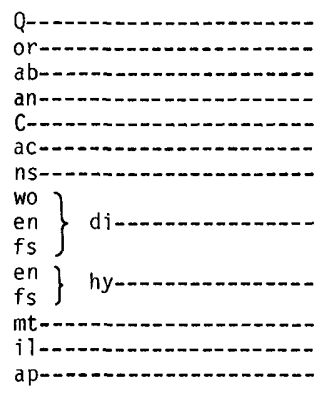 & $\begin{array}{l}31.20 \\
24.88 \\
38.70 \\
3.44 \\
0.07 \\
-- \\
-- \\
-- \\
-- \\
0.35 \\
0.23 \\
0.76 \\
0.35 \\
0.02\end{array}$ & $\begin{array}{l}29.39 \\
23.08 \\
41.35 \\
3.43 \\
0.62 \\
-- \\
-- \\
\cdots \\
\cdots \\
-- \\
0.50 \\
0.36 \\
0.77 \\
0.44 \\
0.07\end{array}$ & $\begin{array}{l}29.29 \\
23.07 \\
41.25 \\
3.46 \\
0.67 \\
-- \\
-- \\
-- \\
-- \\
-- \\
0.52 \\
0.39 \\
0.78 \\
0.48 \\
0.09\end{array}$ & $\begin{array}{l}14.92 \\
10.82 \\
58.45 \\
4.69 \\
-- \\
-- \\
-- \\
1.80 \\
0.52 \\
1.35 \\
1.23 \\
3.19 \\
1.41 \\
1.43 \\
0.21\end{array}$ & $\begin{array}{l}28.53 \\
27.30 \\
36.59 \\
-- \\
-- \\
2.57 \\
1.45 \\
0.67 \\
0.00 \\
0.76 \\
0.00 \\
1.85 \\
0.00 \\
0.29 \\
0.00\end{array}$ & $\begin{array}{l}36.24 \\
19.71 \\
36.47 \\
4.41 \\
-- \\
-- \\
-. \\
0.38 \\
0.05 \\
0.36 \\
0.20 \\
1.30 \\
0.66 \\
0.21 \\
0.02\end{array}$ & $\begin{array}{l}36.43 \\
20.50 \\
36.42 \\
4.07 \\
-- \\
-- \\
\ddot{0 .} \\
0.00 \\
0.02 \\
0.00 \\
1.43 \\
0.48 \\
0.19 \\
0.02\end{array}$ & $\begin{array}{l}27.89 \\
22.62 \\
41.81 \\
2.90 \\
-- \\
-- \\
-- \\
0.75 \\
0.11 \\
0.71 \\
0.22 \\
1.48 \\
1.09 \\
0.39 \\
0.05\end{array}$ & $\begin{array}{l}18.13 \\
26.42 \\
46.71 \\
2.17 \\
-- \\
-. \\
1 . \\
1.41 \\
0.29 \\
1.22 \\
0.36 \\
1.49 \\
1.08 \\
0.63 \\
0.09\end{array}$ & $\begin{array}{l}18.43 \\
25.25 \\
47.32 \\
2.05 \\
-- \\
-- \\
-- \\
1.52 \\
0.33 \\
1.29 \\
0.33 \\
1.27 \\
1.49 \\
0.66 \\
0.09\end{array}$ \\
\hline
\end{tabular}




\begin{tabular}{|c|c|c|c|c|c|c|c|c|c|c|}
\hline & 164 & 165 & 166 & 167 & 168 & 169 & 170 & 171 & 172 & 173 \\
\hline \multicolumn{11}{|c|}{ Trace elements (ppm) } \\
\hline 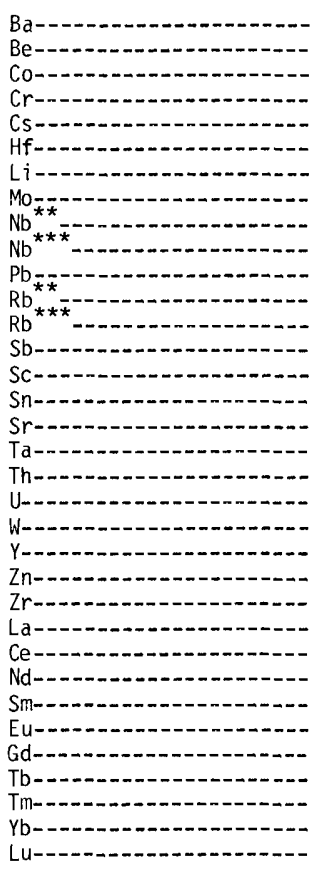 & $\begin{array}{c}680 . \\
2.6 \\
0.3 \\
<3.0 \\
5.8 \\
4.2 \\
38 . \\
4.2 \\
12 . \\
12 . \\
23 . \\
182 . \\
188 . \\
<0.8 \\
2.5 \\
1.6 \\
80 . \\
1.18 \\
24.0 \\
6.7 \\
2.0 \\
25 . \\
29 . \\
122 . \\
35 . \\
58 . \\
21 . \\
3.8 \\
0.51 \\
3.3 \\
<0.4 \\
0.37 \\
1.9 \\
0.28\end{array}$ & $\begin{array}{c}724 . \\
2.9 \\
0.3 \\
1.2 \\
4.5 \\
4.9 \\
34 . \\
4.0 \\
11 . \\
13 . \\
19 . \\
165 . \\
163 . \\
0.8 \\
2.3 \\
1.2 \\
99 . \\
1.18 \\
20.0 \\
5.8 \\
1.8 \\
24 . \\
36 . \\
174 . \\
35 . \\
64 . \\
26 . \\
5.0 \\
0.69 \\
3.8 \\
0.42 \\
0.30 \\
2.2 \\
0.30\end{array}$ & $\begin{array}{c}739 . \\
2.8 \\
0.3 \\
1.9 \\
4.5 \\
5.0 \\
28 . \\
3.8 \\
11 . \\
13 . \\
16 . \\
165 . \\
161 . \\
1.5 \\
2.3 \\
1.1 \\
110 . \\
1.17 \\
20.6 \\
6.0 \\
1.8 \\
23 . \\
36 . \\
190 . \\
34 . \\
63 . \\
24 . \\
4.8 \\
0.68 \\
4.2 \\
0.41 \\
0.31 \\
2.2 \\
0.31\end{array}$ & $\begin{array}{r}287 . \\
3.0 \\
2.5 \\
<4.0 \\
2.0 \\
11.9 \\
28 . \\
2.6 \\
16 . \\
14 . \\
14 . \\
24 . \\
36 . \\
<2.0 \\
10.7 \\
3.5 \\
140 . \\
1.26 \\
5.0 \\
1.2 \\
0.94 \\
73 . \\
100 . \\
500 . \\
29 . \\
65 . \\
39 . \\
10.1 \\
2.05 \\
10.0 \\
1.59 \\
0.98 \\
7.5 \\
1.11\end{array}$ & $\begin{array}{c}<50 . \\
7.1 \\
<0.2 \\
3.9 \\
2.0 \\
22.1 \\
36 . \\
6.2 \\
-- \\
235 . \\
13 . \\
172 . \\
166 . \\
0.5 \\
0.43 \\
5.6 \\
<5 . \\
17.30 \\
20.1 \\
7.0 \\
3.3 \\
115 . \\
179 . \\
903 . \\
100 . \\
199 . \\
83 . \\
19.8 \\
0.70 \\
14.7 \\
3.12 \\
1.38 \\
11.2 \\
1.57\end{array}$ & $\begin{array}{c}685 . \\
4.2 \\
0.5 \\
0.9 \\
1.0 \\
8.1 \\
38 . \\
3.2 \\
60 . \\
69 . \\
19 . \\
82 . \\
86 . \\
<0.9 \\
2.1 \\
7.0 \\
73 . \\
4.46 \\
12.8 \\
3.5 \\
1.8 \\
115 . \\
109 . \\
185 . \\
61 . \\
124 . \\
62 . \\
14.1 \\
2.27 \\
13.0 \\
2.53 \\
1.36 \\
9.7 \\
1.29\end{array}$ & $\begin{array}{c}-- \\
-- \\
<0.4 \\
<7.0 \\
1.0 \\
7.9 \\
-- \\
-- \\
-- \\
-- \\
-- \\
82 . \\
-- \\
0.6 \\
1.7 \\
-- \\
-- \\
4.54 \\
12.3 \\
3.3 \\
-- \\
-- \\
-- \\
-- \\
56 . \\
107 . \\
56 . \\
13.9 \\
2.05 \\
11.6 \\
2.59 \\
1.33 \\
9.5 \\
1.26\end{array}$ & $\begin{array}{c}880 . \\
4.9 \\
1.1 \\
<7.0 \\
0.9 \\
10.5 \\
28 . \\
5.1 \\
130 . \\
132 . \\
14 . \\
76 . \\
110 . \\
<0.7 \\
1.3 \\
7.6 \\
57 . \\
8.52 \\
10.9 \\
3.7 \\
2.0 \\
128 . \\
140 . \\
480 . \\
70 . \\
157 . \\
66 . \\
15.8 \\
2.31 \\
12.7 \\
2.43 \\
1.38 \\
8.3 \\
1.16\end{array}$ & $\begin{array}{c}545 . \\
-- \\
1.7 \\
0.4 \\
1.2 \\
16.0 \\
-- \\
-- \\
-- \\
126 . \\
14 . \\
117 . \\
113 . \\
0.3 \\
2.5 \\
-- \\
80 . \\
8.15 \\
17.0 \\
5.1 \\
-- \\
64 . \\
110 . \\
681 . \\
95 . \\
169 . \\
63 . \\
14.3 \\
1.61 \\
9.9 \\
1.38 \\
0.84 \\
6.4 \\
0.88\end{array}$ & $\begin{array}{c}545 . \\
13.6 \\
13.6 \\
4.0 \\
1.0 \\
16.8 \\
-- \\
-- \\
- \\
129 . \\
15 . \\
111 . \\
108 . \\
0.4 \\
2.8 \\
10 . \\
100 . \\
8.11 \\
15.9 \\
4.9 \\
6-- \\
65 . \\
110 . \\
731 . \\
91 . \\
167 . \\
67 . \\
14.2 \\
1.83 \\
9.1 \\
1.98 \\
1.06 \\
6.4 \\
0.88\end{array}$ \\
\hline $\begin{array}{l}\mathrm{Nb} / \mathrm{Ta}- \\
\mathrm{K} / \mathrm{Rb} \mathrm{S} \\
\mathrm{Rb} / \mathrm{Sr}- \\
\mathrm{C} / \mathrm{Sr} \\
\mathrm{Th} / \mathrm{U}- \\
\mathrm{Zr} / \mathrm{Hf} \\
\mathrm{Ce} / \mathrm{Yb}- \\
\mathrm{Eu} / \mathrm{Eu}\end{array}$ & $\begin{array}{c}10.2 \\
184 . \\
2.4 \\
63 . \\
3.6 \\
29 . \\
30.5 \\
0.44\end{array}$ & $\begin{array}{c}10.2 \\
199 . \\
1.7 \\
53 . \\
3.5 \\
36 . \\
29.1 \\
0.49\end{array}$ & $\begin{array}{c}10.3 \\
201 . \\
1.5 \\
49 . \\
3.4 \\
38 . \\
29 . \\
0.47\end{array}$ & $\begin{array}{c}11.9 \\
420 . \\
0.26 \\
98 . \\
4.2 \\
42 . \\
8.7 \\
0.63\end{array}$ & $\begin{array}{c}13.6 \\
229 . \\
-- \\
-- \\
2.9 \\
41 . \\
17.8 \\
0.14\end{array}$ & $\begin{array}{c}14.5 \\
320 . \\
1.2 \\
106 . \\
3.7 \\
23 . \\
12.8 \\
0.50\end{array}$ & $\begin{array}{c}-- \\
-- \\
-- \\
-- \\
3.7 \\
-- \\
11.3 \\
0.50\end{array}$ & $\begin{array}{c}15.4 \\
285 . \\
1.9 \\
120 . \\
3.0 \\
46 . \\
18.9 \\
0.50\end{array}$ & $\begin{array}{c}15.5 \\
325 . \\
1.4 \\
104 . \\
3.3 \\
43 . \\
26.4 \\
0.41\end{array}$ & $\begin{array}{c}15.9 \\
324 . \\
1.1 \\
84 . \\
3.2 \\
44 . \\
26.1 \\
0.50\end{array}$ \\
\hline
\end{tabular}

See footnotes at end of table. 
APPENDIX I.-Chemical analyses of subalkalic silicic obsidians-Continued

\begin{tabular}{|c|c|c|c|c|c|c|c|c|c|}
\hline \multirow{4}{*}{$\begin{array}{l}\text { Country/State-1. } \\
\text { Volcanic field/region-- } \\
\text { Locality- } \\
\text { Specimen- } \\
\text { Collect ion No. (RLS-) }\end{array}$} & \multicolumn{5}{|c|}{ ICELAND } & \multicolumn{4}{|c|}{ ITALY } \\
\hline & \multirow{2}{*}{$\begin{array}{c}\begin{array}{c}\text { Torfajökull } \\
\text { Volcanic } \\
\text { Complex }\end{array} \\
\begin{array}{c}\text { Domadals- } \\
\text { hraun }\end{array}\end{array}$} & \multirow{2}{*}{$\begin{array}{l}\text { Hrafnt inn- } \\
\text { uhryggur }\end{array}$} & \multirow[b]{2}{*}{$\begin{array}{r}\text { Askja } \\
1875\end{array}$} & & & \multirow{2}{*}{$\begin{array}{c}\text { Sardinia } \\
\begin{array}{c}\text { Mount } \\
\text { Arci }\end{array}\end{array}$} & \multicolumn{2}{|c|}{$\begin{array}{l}\text { Lipari } \\
\text { Island }\end{array}$} & \multirow{2}{*}{$\begin{array}{c}\text { Vulcano } \\
\begin{array}{r}1739 ? \\
\text { flow }\end{array}\end{array}$} \\
\hline & & & & \multicolumn{2}{|c|}{ Oraefajökulı } & & $\begin{array}{l}\text { Roche } \\
\text { Rosse }\end{array}$ & $\begin{array}{l}\text { Mount } \\
\text { Pelato }\end{array}$ & \\
\hline & $\begin{array}{l}174 \\
176\end{array}$ & $\begin{array}{r}175 \\
37\end{array}$ & $\begin{array}{r}176 \\
61\end{array}$ & $\begin{array}{r}177 \\
68\end{array}$ & $\begin{array}{r}178 \\
57\end{array}$ & $\begin{array}{l}179 \\
209\end{array}$ & $\begin{array}{r}180 \\
65\end{array}$ & $\begin{array}{l}181 \\
210\end{array}$ & $\begin{array}{l}182 \\
197\end{array}$ \\
\hline \multicolumn{10}{|c|}{ Chemical analyses (weight percent) } \\
\hline $\begin{array}{l}\mathrm{SiO}_{2} \mathrm{O}_{2} \\
\mathrm{Al}_{2} \mathrm{O}_{3} \\
\mathrm{Fe}_{2} \mathrm{O}_{3} \\
\mathrm{Fe} \mathrm{O}_{3} \\
\mathrm{Mg0}\end{array}$ & $\begin{array}{l}70.1 \\
14.59 \\
0.78 \\
2.16 \\
0.25 \\
1.14 \\
5.45 \\
4.38 \\
0.08 \\
0.32 \\
0.04 \\
0.08 \\
0.15 \\
-- \\
0.19 \\
--\end{array}$ & $\begin{array}{l}74.9 \\
12.17 \\
0.74 \\
2.49 \\
0.08 \\
1.67 \\
4.42 \\
2.70 \\
0.15 \\
0.25 \\
0.02 \\
0.11 \\
0.06 \\
0.05 \\
0.10 \\
0.09\end{array}$ & $\begin{array}{l}72.1 \\
12.77 \\
1.11 \\
2.84 \\
0.73 \\
2.69 \\
4.08 \\
2.30 \\
0.05 \\
0.92 \\
0.19 \\
0.11 \\
0.03 \\
0.02 \\
0.05 \\
0.05\end{array}$ & $\begin{array}{r}73.2 \\
13.34 \\
0.80 \\
1.54 \\
0.09 \\
0.80 \\
5.10 \\
4.11 \\
0.06 \\
0.18 \\
0.02 \\
0.07 \\
0.17 \\
0.17 \\
0.14 \\
0.13\end{array}$ & $\begin{array}{l}73.2 \\
13.00 \\
0.67 \\
1.49 \\
0.01 \\
0.76 \\
5.13 \\
3.84 \\
0.05 \\
0.17 \\
0.01 \\
0.07 \\
0.19 \\
0.17 \\
0.15 \\
0.15\end{array}$ & $\begin{array}{l}74.3 \\
13.86 \\
0.30 \\
1.33 \\
0.21 \\
0.70 \\
3.50 \\
5.05 \\
0.13 \\
0.26 \\
0.07 \\
0.07 \\
0.12 \\
-- \\
0.15 \\
-.-\end{array}$ & $\begin{array}{r}74.7 \\
13.13 \\
0.47 \\
1.16 \\
0.04 \\
0.87 \\
4.23 \\
5.05 \\
0.14 \\
0.08 \\
0.01 \\
0.12 \\
0.34 \\
0.35 \\
0.15 \\
0.13\end{array}$ & $\begin{array}{l}74.6 \\
13.24 \\
0.43 \\
1.21 \\
0.04 \\
0.61 \\
4.16 \\
4.92 \\
0.12 \\
0.09 \\
0.01 \\
0.08 \\
0.30 \\
-- \\
0.15 \\
--\end{array}$ & $\begin{array}{l}73.2 \\
13.49 \\
0.60 \\
1.33 \\
0.12 \\
0.87 \\
4.21 \\
5.08 \\
0.14 \\
0.11 \\
0.01 \\
0.09 \\
0.31 \\
-- \\
0.15 \\
--\end{array}$ \\
\hline $\begin{array}{l}\text { Subtotal } \\
\text { Less } 0=(F, C 1)_{2}-\end{array}$ & $\begin{array}{r}99.71 \\
0.11\end{array}$ & $\begin{array}{r}99.85 \\
0.05\end{array}$ & $\begin{array}{r}99.97 \\
0.03\end{array}$ & $\begin{array}{r}99.62 \\
0.10\end{array}$ & $\begin{array}{r}98.73 \\
0.10\end{array}$ & $\begin{array}{r}100.05 \\
0.09\end{array}$ & $\begin{array}{r}100.48 \\
0.14\end{array}$ & $\begin{array}{r}99.96 \\
0.13\end{array}$ & $\begin{array}{r}99.71 \\
0.13\end{array}$ \\
\hline Total- & 99.60. & 99.80 & 99.94 & 99.52 & 99.63 & 99.96 & 100.34 & 99.83 & 99.58 \\
\hline $\mathrm{Fe}_{\mathrm{t}} \mathrm{t}_{-}$ & 2.86 & 3.16 & 3.85 & 2.26 & 2.14 & 1.60 & 1.58 & 1.60 & 1.87 \\
\hline $\mathrm{Fe} 0 /\left(\mathrm{Fe} 0+\mathrm{Fe}_{2} \mathrm{O}_{3}\right)^{1} \ldots$ & 0.73 & 0.77 & 0.72 & 0.66 & 0.69 & 0.82 & 0.71 & 0.74 & 0.69 \\
\hline $\mathrm{Na}_{2} \mathrm{O} / \mathrm{K}_{2} \mathrm{O}^{1} \ldots$ & 1.24 & 1.64 & 1.77 & 1.24 & 1.34 & 0.69 & 0.84 & 0.85 & 0.83 \\
\hline$\left(\mathrm{Na}_{2} \mathrm{O}+\mathrm{K}_{2} \mathrm{O}\right) / \mathrm{Al}_{2} \mathrm{O}_{3}{ }^{2} \ldots$ & 0.94 & 0.84 & 0.72 & 0.96 & 0.97 & 0.81 & 0.95 & 0.92 & 0.92 \\
\hline$\left(\mathrm{CaO}+\mathrm{Na}_{2} \mathrm{O}+\mathrm{K}_{2} \mathrm{O}\right) / \mathrm{Al}_{2} \mathrm{O}_{3}{ }^{2} \ldots$ & 1.08 & 1.09 & 1.10 & 1.07 & 1.08 & 0.90 & 1.10 & 1.00 & 1.04 \\
\hline $\mathrm{CaO} /\left(\mathrm{Na}_{2} \mathrm{O}+\mathrm{K}_{2} \mathrm{O}\right)^{1} \ldots$ & 0.12 & 0.23 & 0.42 & 0.09 & 0.08 & 0.08 & 0.09 & 0.07 & 0.09 \\
\hline $\mathrm{Cl} / \mathrm{F}^{1+} \mathrm{C}_{-}$ & 0.78 & 0.59 & 0.55 & 1.2 & 1.2 & 0.78 & 2.5 & 2.1 & 2.1 \\
\hline \multicolumn{10}{|c|}{ CIPH norms } \\
\hline $\begin{array}{l}\text { Q } \\
\text { or } \\
\text { abn } \\
\text { an } \\
\text { acs } \\
\text { wo } \\
\text { en } \\
\text { fs } \\
\text { en } \\
\text { f } \\
\text { mt } \\
i 1 \\
\text { ap }\end{array}$ & $\begin{array}{c}18.37 \\
26.07 \\
46.45 \\
2.43 \\
-- \\
-. \\
-- \\
1.26 \\
0.24 \\
1.12 \\
0.39 \\
1.85 \\
1.14 \\
0.61 \\
0.09\end{array}$ & $\begin{array}{l}34.26 \\
16.03 \\
37.57 \\
5.42 \\
-. \\
-. \\
-. \\
1.16 \\
0.07 \\
1.23 \\
0.14 \\
2.54 \\
1.08 \\
0.48 \\
0.05\end{array}$ & $\begin{array}{l}32.45 \\
13.61 \\
34.58 \\
9.75 \\
-- \\
-- \\
-- \\
0.99 \\
0.38 \\
0.62 \\
1.44 \\
2.36 \\
1.61 \\
1.75 \\
0.44\end{array}$ & $\begin{array}{c}25.83 \\
24.47 \\
43.48 \\
1.38 \\
-- \\
-- \\
-- \\
1.04 \\
0.12 \\
1.03 \\
0.11 \\
0.99 \\
1.17 \\
0.34 \\
0.05\end{array}$ & $\begin{array}{l}27.13 \\
23.07 \\
44.14 \\
1.12 \\
-- \\
-- \\
-- \\
1.10 \\
0.02 \\
1.23 \\
0.01 \\
0.83 \\
0.99 \\
0.33 \\
0.02\end{array}$ & $\begin{array}{l}32.25 \\
29.95 \\
29.72 \\
3.03 \\
1.54 \\
-- \\
-- \\
-- \\
-- \\
0.53 \\
1.90 \\
0.44 \\
0.50 \\
0.16\end{array}$ & $\begin{array}{l}28.38 \\
30.02 \\
35.64 \\
1.95 \\
-. \\
- \\
- \\
1.04 \\
0.06 \\
1.11 \\
0.04 \\
0.74 \\
0.70 \\
0.15 \\
0.02\end{array}$ & $\begin{array}{l}29.57 \\
29.25 \\
35.42 \\
2.94 \\
-- \\
- \\
- \\
0.02 \\
0.00 \\
0.02 \\
0.10 \\
1.86 \\
0.63 \\
0.17 \\
0.02\end{array}$ & $\begin{array}{l}26.91 \\
30.29 \\
35.94 \\
2.93 \\
-- \\
-. \\
-- \\
0.57 \\
0.08 \\
0.53 \\
0.22 \\
1.42 \\
0.88 \\
0.21 \\
0.02\end{array}$ \\
\hline
\end{tabular}




\begin{tabular}{|c|c|c|c|c|c|c|c|c|c|}
\hline & 174 & 175 & 176 & 177 & 178 & 179 & 180 & 181 & 182 \\
\hline \multicolumn{10}{|c|}{ Trace elements ( $\mathrm{ppm}$ ) } \\
\hline 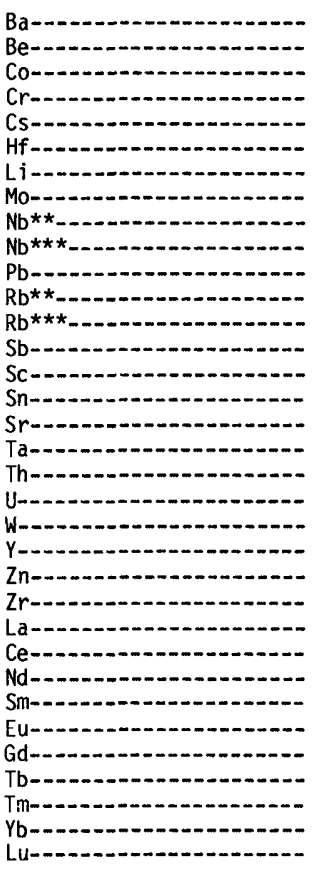 & $\begin{array}{c}585 . \\
-- \\
1.7 \\
3.8 \\
1.1 \\
16.4 \\
-- \\
-- \\
-- \\
118 . \\
16 . \\
107 . \\
114 . \\
0.4 \\
2.6 \\
\\
85 . \\
7.76 \\
16.2 \\
5.2 \\
62 . \\
110 . \\
699 . \\
91 . \\
165 . \\
61 . \\
13.3 \\
1.57 \\
9.1 \\
1.90 \\
0.84 \\
6.3 \\
0.84\end{array}$ & $\begin{array}{c}615 . \\
3.1 \\
0.7 \\
<9.0 \\
0.7 \\
12.8 \\
31 . \\
3.3 \\
54 . \\
58 . \\
10 . \\
59 . \\
69 . \\
<0.9 \\
4.6 \\
6.1 \\
97 . \\
3.67 \\
7.5 \\
2.1 \\
1.0 \\
108 . \\
132 . \\
565 . \\
56 . \\
101 . \\
63 . \\
14.4 \\
2.26 \\
11.0 \\
2.60 \\
1.16 \\
9.7 \\
1.41\end{array}$ & $\begin{array}{c}400 . \\
1.9 \\
4.0 \\
<9.0 \\
<2.0 \\
9.2 \\
23 . \\
2.3 \\
37 . \\
31 . \\
11 . \\
60 . \\
64 . \\
<0.8 \\
11.1 \\
3.9 \\
116 . \\
2.58 \\
7.3 \\
2.3 \\
0.94 \\
57 . \\
75 . \\
406 . \\
41 . \\
82 . \\
39 . \\
9.7 \\
2.01 \\
8.6 \\
1.50 \\
1.48 \\
6.1 \\
0.93\end{array}$ & $\begin{array}{c}795 . \\
5.0 \\
0.7 \\
<6.0 \\
1.0 \\
12.4 \\
33 . \\
5.0 \\
69 . \\
75 . \\
17 . \\
102 . \\
103 . \\
0.4 \\
2.4 \\
7.7 \\
40 . \\
6.19 \\
13.8 \\
4.1 \\
2.0 \\
93 . \\
107 . \\
472 . \\
85 . \\
159 . \\
76 . \\
16.5 \\
1.97 \\
13.1 \\
2.74 \\
1.29 \\
8.5 \\
1.23\end{array}$ & $\begin{array}{c}820 . \\
5.2 \\
<0.4 \\
<6.0 \\
1.0 \\
12.6 \\
35 . \\
5.0 \\
74 . \\
78 . \\
16 . \\
91 . \\
101 . \\
0.4 \\
1.5 \\
5.4 \\
55 . \\
5.85 \\
12.8 \\
3.1 \\
2.1 \\
116 . \\
135 . \\
493 . \\
87 . \\
176 . \\
78 . \\
17.7 \\
2.59 \\
15.6 \\
1.78 \\
1.41 \\
9.2 \\
1.28\end{array}$ & $\begin{array}{c}337 . \\
-- \\
1.3 \\
1.3 \\
4.0 \\
4.2 \\
-- \\
-- \\
-- \\
48 . \\
30 . \\
241 . \\
260 . \\
0.5 \\
4.1 \\
-- \\
67 . \\
3.59 \\
20.1 \\
5.6 \\
-- \\
42 . \\
86 . \\
120 . \\
33 . \\
71 . \\
33 . \\
8.0 \\
0.53 \\
6.3 \\
1.08 \\
0.39 \\
2.5 \\
0.34\end{array}$ & $\begin{array}{c}<50 . \\
8.1 \\
0.4 \\
1.1 \\
16.5 \\
6.6 \\
88 . \\
5.9 \\
32 . \\
30 . \\
46 . \\
313 . \\
319 . \\
1.2 \\
1.1 \\
5.5 \\
20 . \\
3.00 \\
55.7 \\
18.5 \\
4.3 \\
32 . \\
61 . \\
192 . \\
66 . \\
126 . \\
47 . \\
9.2 \\
0.14 \\
8.2 \\
1.21 \\
0.66 \\
4.7 \\
0.70\end{array}$ & $\begin{array}{c}65 . \\
\ddot{0.6} \\
<0.9 \\
17.0 \\
6.6 \\
-- \\
-- \\
\ddot{-} \\
50 . \\
22 . \\
317 . \\
297 . \\
1.5 \\
1.2 \\
-- \\
12 . \\
2.97 \\
55.3 \\
16.6 \\
-- \\
64 . \\
50 . \\
171 . \\
71 . \\
118 . \\
48 . \\
9.2 \\
0.15 \\
10.2 \\
<0.4 \\
0.70 \\
4.7 \\
0.71\end{array}$ & $\begin{array}{c}105 . \\
-- \\
1.2 \\
1.6 \\
18.0 \\
7.1 \\
-- \\
-- \\
\ddot{y} . \\
44 . \\
26 . \\
328 . \\
300 . \\
1.9 \\
1.6 \\
-- \\
43 . \\
2.94 \\
59.9 \\
17.3 \\
5 \overline{6} . \\
54 . \\
198 . \\
81 . \\
137 . \\
49 . \\
9.6 \\
0.22 \\
9.6 \\
<0.4 \\
0.89 \\
4.9 \\
0.71\end{array}$ \\
\hline 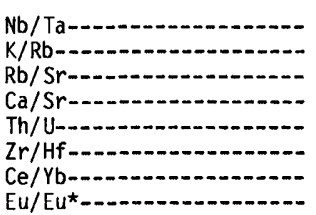 & $\begin{array}{c}15.2 \\
320 . \\
1.3 \\
96 . \\
3.1 \\
43 . \\
26.2 \\
0.45\end{array}$ & $\begin{array}{c}15.3 \\
324 . \\
0.71 \\
123 . \\
3.5 \\
44 . \\
10.4 \\
0.56\end{array}$ & $\begin{array}{c}13.2 \\
298 . \\
0.55 \\
166 . \\
3.2 \\
44 . \\
13.4 \\
0.68\end{array}$ & $\begin{array}{c}11.6 \\
331 . \\
2.6 \\
143 . \\
3.4 \\
38 . \\
18.7 \\
0.41\end{array}$ & $\begin{array}{c}13.0 \\
316 . \\
1.8 \\
99 . \\
4.1 \\
39 . \\
19.1 \\
0.48\end{array}$ & $\begin{array}{c}13.4 \\
161 . \\
3.9 \\
75 . \\
3.6 \\
29 . \\
28.4 \\
0.23\end{array}$ & $\begin{array}{c}10.3 \\
130 . \\
16.0 \\
311 . \\
3.0 \\
29 . \\
26.8 \\
0.05\end{array}$ & $\begin{array}{c}16.8 \\
138 . \\
24.8 \\
363 . \\
3.3 \\
26 . \\
25.1 \\
0.05\end{array}$ & $\begin{array}{c}15.0 \\
141.0 \\
7.0 \\
145 . \\
3.5 \\
28 . \\
28.0 \\
0.07\end{array}$ \\
\hline
\end{tabular}

See footnotes at end of table. 
APPENDIX I.-Chemical analyses of subalkalic silicic obsidians-Continued

\begin{tabular}{|c|c|c|c|c|c|c|c|c|c|c|}
\hline Country/St ate--.-.-.-.- & \multicolumn{2}{|c|}{ TURKEY } & U.S.S.R & \multicolumn{7}{|c|}{ JAPAN } \\
\hline Volcanic field/region--- & $\begin{array}{l}\text { Cappa- } \\
\text { docia }\end{array}$ & Armenia & Armenia & \multicolumn{2}{|c|}{ Hokkaido } & $\begin{array}{l}\text { Nagano } \\
\text { Prefecture }\end{array}$ & $\begin{array}{l}\text { Shizuoka } \\
\text { Prefecture }\end{array}$ & $\begin{array}{l}\text { Izu } \\
\text { Islands }\end{array}$ & $\begin{array}{l}\text { Saga } \\
\text { Prefecture }\end{array}$ & $\begin{array}{l}\text { Kumamoto } \\
\text { Prefecture }\end{array}$ \\
\hline Locality-1.- & Kocadag & $\begin{array}{c}\text { Sulphan } \\
\text { Dag } \\
\end{array}$ & Erevan & Okushiri & Island & $\begin{array}{r}\text { Wada-Toge } \\
\text { Rhyol ite } \\
\end{array}$ & Amagi & $\begin{array}{l}\text { Kozu- } \\
\text { Shima } \\
\end{array}$ & Arita & Aso \\
\hline $\begin{array}{l}\text { Specimen-1 } \\
\text { Collect ion No. (RLS-)-- }\end{array}$ & $\begin{array}{r}183 \\
67\end{array}$ & $\begin{array}{r}184 \\
66\end{array}$ & $\begin{array}{l}185 \\
211\end{array}$ & $\begin{array}{l}186 \\
168\end{array}$ & $\begin{array}{l}187 \\
198\end{array}$ & $\begin{array}{l}188 \\
145\end{array}$ & $\begin{array}{l}189 \\
165\end{array}$ & $\begin{array}{r}190 \\
38\end{array}$ & $\begin{array}{l}191 \\
166\end{array}$ & $\begin{array}{l}192 \\
167\end{array}$ \\
\hline
\end{tabular}

Chemical analyses (weight percent)

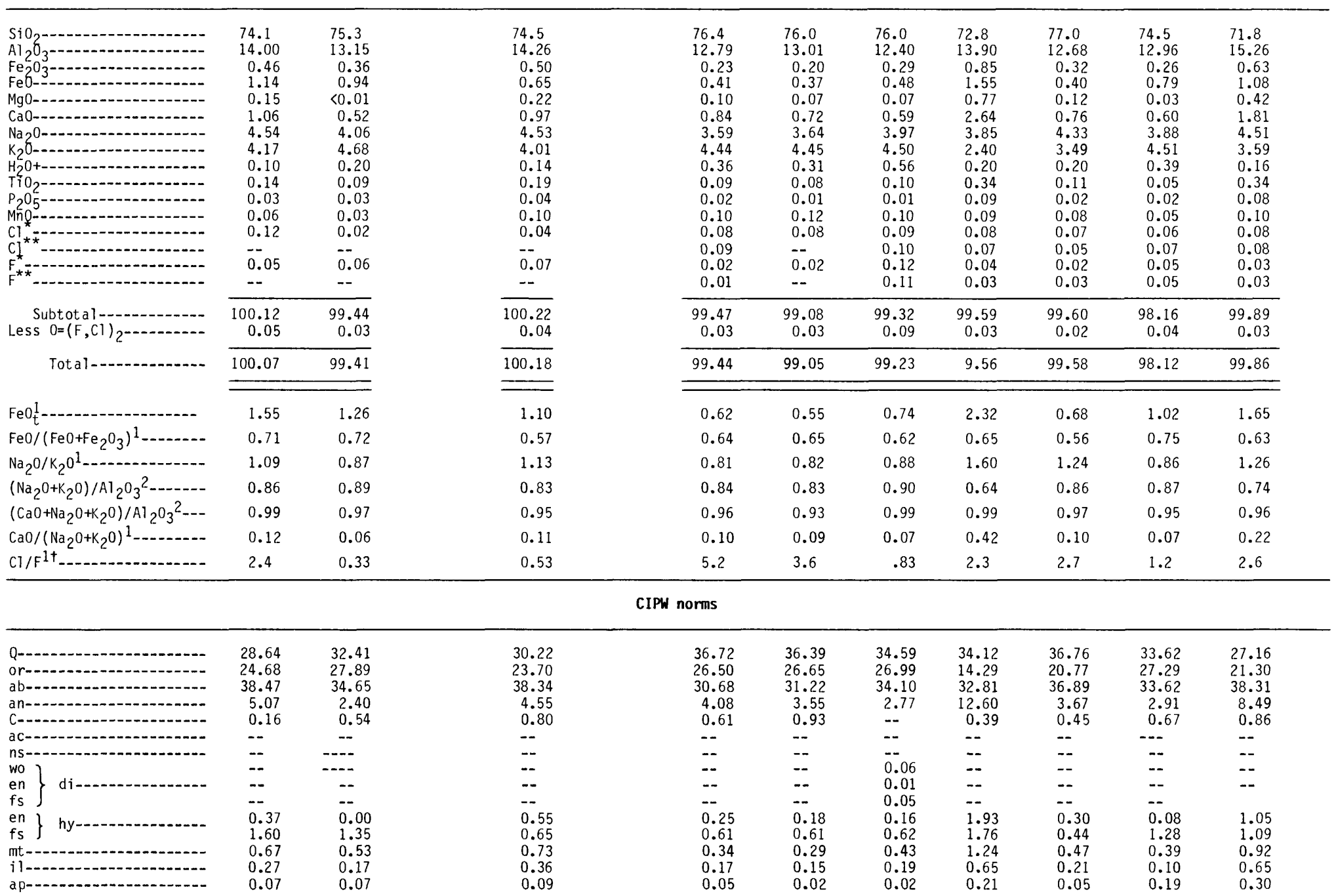




\begin{tabular}{|c|c|c|c|c|c|c|c|c|c|c|}
\hline & 183 & 184 & 185 & 186 & 187 & 188 & 189 & 190 & 191 & 192 \\
\hline \multicolumn{11}{|c|}{ Trace elements (ppm) } \\
\hline 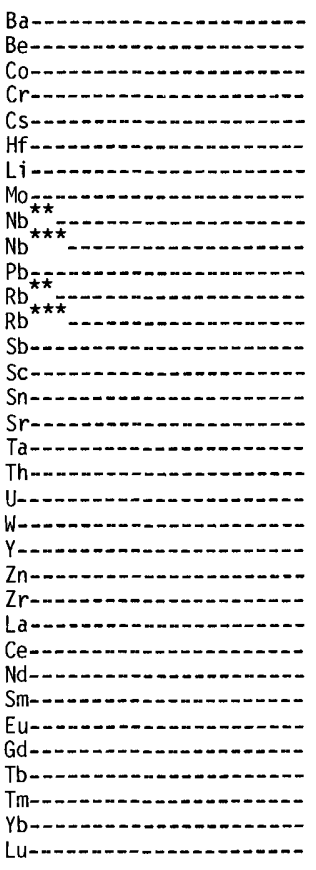 & $\begin{array}{c}498 . \\
4.1 \\
0.6 \\
<5.0 \\
6.8 \\
4.8 \\
49 . \\
3.2 \\
-- \\
43 . \\
30 . \\
167 . \\
161 . \\
0.7 \\
1.3 \\
2.2 \\
110 . \\
2.28 \\
26.4 \\
8.1 \\
3.5 \\
19 . \\
54 . \\
197 . \\
35 . \\
61 . \\
21 . \\
3.9 \\
0.54 \\
3.8 \\
0.63 \\
0.37 \\
2.9 \\
0.43\end{array}$ & $\begin{array}{r}475 . \\
3.0 \\
0.4 \\
<6.0 \\
5.3 \\
3.8 \\
58 . \\
2.7 \\
21 . \\
25 . \\
165 . \\
164 . \\
0.8 \\
3.2 \\
3.2 \\
16 . \\
1.17 \\
17.9 \\
5.7 \\
2.1 \\
27 . \\
39 . \\
133 . \\
34 . \\
64 . \\
30 . \\
6.2 \\
0.49 \\
5.2 \\
0.92 \\
0.61 \\
3.2 \\
0.47\end{array}$ & 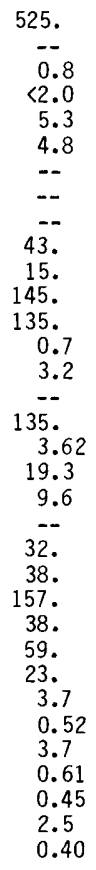 & $\begin{array}{c}915 . \\
1.8 \\
0.2 \\
<2.0 \\
11.6 \\
2.0 \\
36 . \\
1.2 \\
8.8 \\
10 . \\
13 . \\
196 . \\
200 . \\
0.2 \\
2.0 \\
0.5 \\
133 . \\
0.82 \\
17.7 \\
4.6 \\
1.5 \\
15 . \\
8 . \\
39 . \\
24 . \\
43 . \\
14 . \\
3.4 \\
0.45 \\
3.0 \\
0.38 \\
0.26 \\
2.1 \\
0.34\end{array}$ & $\begin{array}{c}950 . \\
-- \\
0.3 \\
<2.0 \\
12.7 \\
2.0 \\
-. \\
-- \\
10 . \\
15 . \\
201 . \\
200 . \\
0.4 \\
2.0 \\
-- \\
110 . \\
0.96 \\
19.8 \\
5.6 \\
-- \\
27 . \\
10 . \\
40 . \\
23 . \\
40 . \\
16 . \\
2.9 \\
0.42 \\
<4.0 \\
<0.3 \\
0.44 \\
2.2 \\
0.35\end{array}$ & $\begin{array}{c}55 . \\
3.3 \\
0.3 \\
<5.0 \\
21.1 \\
4.7 \\
60 . \\
2.7 \\
17 . \\
20 . \\
23 . \\
259 . \\
270 . \\
1.3 \\
5.2 \\
3.3 \\
20 . \\
1.88 \\
26.4 \\
7.6 \\
2.7 \\
44 . \\
30 . \\
81 . \\
19 . \\
47 . \\
24 . \\
6.3 \\
0.22 \\
6.1 \\
1.10 \\
0.76 \\
4.7 \\
0.65\end{array}$ & $\begin{array}{c}510 . \\
0.98 \\
3.8 \\
2.2 \\
2.5 \\
3.2 \\
23 . \\
2.2 \\
5.8 \\
6 . \\
19 . \\
55 . \\
51 . \\
0.3 \\
6.2 \\
0.8 \\
262 . \\
0.41 \\
4.1 \\
1.4 \\
0.76 \\
20 . \\
25 . \\
112 . \\
15 . \\
28 . \\
14 . \\
2.9 \\
0.65 \\
2.5 \\
0.32 \\
0.30 \\
1.9 \\
0.30\end{array}$ & $\begin{array}{c}665 . \\
1.5 \\
0.3 \\
<6.0 \\
2.8 \\
2.6 \\
27 . \\
1.2 \\
8 . \\
10 . \\
11 . \\
77 . \\
80 . \\
<0.9 \\
3.6 \\
1.6 \\
65 . \\
0.90 \\
5.9 \\
2.1 \\
1.3 \\
25 . \\
16 . \\
78 . \\
22 . \\
40 . \\
20 . \\
4.0 \\
0.54 \\
3.4 \\
0.70 \\
0.47 \\
3.1 \\
0.50\end{array}$ & $\begin{array}{c}225 . \\
3.7 \\
0.2 \\
2.8 . \\
11.3 \\
2.7 \\
79 . \\
1.2 \\
19 . \\
21 . \\
25 . \\
176 . \\
193 . \\
0.6 \\
1.8 \\
6.8 \\
40 . \\
2.47 \\
15.2 \\
4.2 \\
3.5 \\
26 . \\
38 . \\
52 . \\
23 . \\
41 . \\
15 . \\
3.3 \\
0.17 \\
3.1 \\
0.62 \\
0.38 \\
2.3 \\
0.32\end{array}$ & $\begin{array}{c}710 . \\
2.0 \\
0.7 \\
<2.0 \\
6.1 \\
5.6 \\
43 . \\
2.6 \\
14 . \\
12 . \\
21 . \\
118 . \\
135 . \\
0.4 \\
1.9 \\
1.2 \\
290 . \\
1.03 \\
11.6 \\
2.8 \\
1.9 \\
18 . \\
44 . \\
218 . \\
29 . \\
54 . \\
21 . \\
3.7 \\
0.83 \\
3.0 \\
0.49 \\
0.36 \\
2.2 \\
0.35\end{array}$ \\
\hline 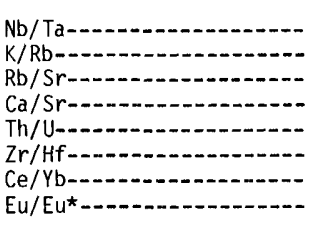 & $\begin{array}{r}18.9 \\
215 . \\
1.5 \\
69 . \\
3.3 \\
41 . \\
21.0 \\
0.44\end{array}$ & $\begin{array}{c}18.0 \\
237.0 \\
10.3 \\
232 . \\
3.1 \\
35 . \\
20.0 \\
0.26\end{array}$ & $\begin{array}{r}11.9 \\
247 . \\
1.0 \\
51.0 \\
2.0 \\
33 . \\
23.6 \\
0.43\end{array}$ & $\begin{array}{c}11.5 \\
184 . \\
1.5 \\
45 . \\
3.9 \\
20 . \\
20.5 \\
0.44\end{array}$ & $\begin{array}{c}10.4 \\
185 . \\
1.8 \\
47 . \\
3.5 \\
20 . \\
18.2 \\
--\end{array}$ & $\begin{array}{c}9.8 \\
138 . \\
13.5 \\
211 . \\
3.5 \\
17.2 \\
10.0 \\
0.14\end{array}$ & $\begin{array}{c}14.4 \\
391 . \\
0.19 \\
72 . \\
2.9 \\
35 . \\
14.7 \\
0.75\end{array}$ & $\begin{array}{c}10.0 \\
363 . \\
1.2 \\
84 . \\
2.9 \\
30 . \\
12.9 \\
0.45\end{array}$ & $\begin{array}{c}8.1 \\
194 . \\
4.8 \\
107 . \\
3.6 \\
19 . \\
17.8 \\
0.10\end{array}$ & $\begin{array}{c}12.6 \\
221 . \\
0.47 \\
45 . \\
4.1 \\
39 . \\
24.5 \\
0.78\end{array}$ \\
\hline
\end{tabular}

See footnotes at end of table. 
APPENDIX I.-Chemical analyses of subalkalic silicic obsidians-Continued

\begin{tabular}{|c|c|c|c|c|c|c|c|c|c|c|}
\hline Country/State-1- & \multicolumn{3}{|c|}{ JAPAN } & \multicolumn{7}{|c|}{ INDONESIA } \\
\hline Volcanic field/region--- & $\begin{array}{l}\text { Kagoshima } \\
\text { Prefecture }\end{array}$ & $\begin{array}{l}\text { Miyagi } \\
\text { Prefecture }\end{array}$ & $\begin{array}{l}\text { Shizuoka } \\
\text { Prefect ure }\end{array}$ & $\begin{array}{l}\text { South } \\
\text { Sumatra }\end{array}$ & Krakatau & & & Java & & \\
\hline Local ity- & Io Jima & Narugo & Atami & $\begin{array}{l}\text { South Kenak } \\
\text { Besar }\end{array}$ & $\begin{array}{c}\text { Gununy } \\
\text { Krakatau }\end{array}$ & $\begin{array}{l}\text { Gunung } \\
\text { Ki araberes }\end{array}$ & Nagrek & Samarang & Nagrek & $\begin{array}{c}\text { Daradjat- } \\
\text { Pasir } \\
\text { Kiamis }\end{array}$ \\
\hline $\begin{array}{l}\text { Specimen- } \\
\text { Collection No. (RLS-)-- }\end{array}$ & $\begin{array}{l}193 \\
169\end{array}$ & $\begin{array}{l}194 \\
207\end{array}$ & $\begin{array}{l}195 \\
208\end{array}$ & $\begin{array}{l}196 \\
111\end{array}$ & $\begin{array}{l}197 \\
110\end{array}$ & $\begin{array}{l}198 \\
108\end{array}$ & $\begin{array}{l}199 \\
107\end{array}$ & $\begin{array}{l}200 \\
114\end{array}$ & $\begin{array}{l}201 \\
113\end{array}$ & $\begin{array}{l}202 \\
109\end{array}$ \\
\hline
\end{tabular}

Chemical analyses (weight percent)

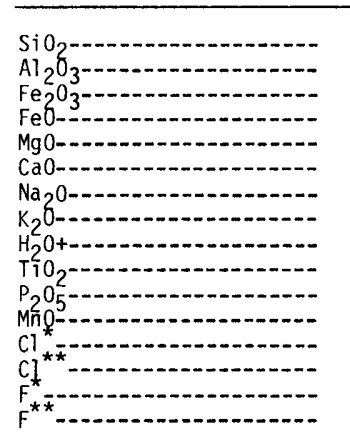

\begin{tabular}{ccc}
72.2 & 72.1 & 77.2 \\
13.50 & 14.35 & 12.33 \\
0.82 & 0.04 & 0.46 \\
2.46 & 2.09 & 1.21 \\
0.63 & 0.87 & 0.20 \\
2.63 & 3.17 & 1.55 \\
4.05 & 4.43 & 4.41 \\
2.61 & 1.17 & 1.81 \\
0.16 & 0.14 & 0.12 \\
0.66 & 0.44 & 0.21 \\
0.13 & 0.05 & 0.03 \\
0.10 & 0.12 & 0.08 \\
0.08 & 0.07 & 0.14 \\
0.08 & --.04 & -- \\
0.05 & 0.04 & -- \\
0.05 & -- & - \\
\hline 100.08 & 99.08 & 99.80 \\
0.04 & 0.03 & 0.05 \\
\hline 100.04 & 99.05 & 99.75 \\
\hline
\end{tabular}

$\mathrm{FeO}_{\mathrm{t}}^{1}-$

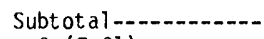
su $0=(F, C 1)_{2}-\cdots-\cdots-\cdot-$

Total-

$\overline{3.20 \quad 2.13 \quad 1.62}$

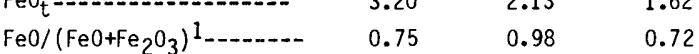

$\mathrm{Na}, \mathrm{O} / \mathrm{K}_{2} \mathrm{O}^{1}$

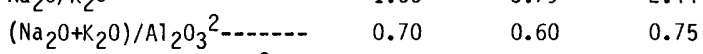

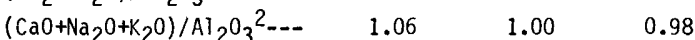

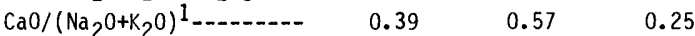

\begin{tabular}{|c|}
\hline $1+$ \\
\hline
\end{tabular}

\begin{tabular}{|c|c|c|c|c|c|c|}
\hline 76.5 & 69.1 & 77.1 & 76.7 & 76.4 & 77.1 & 76.4 \\
\hline 13.62 & 14.86 & 12.38 & 12.32 & 12.88 & 12.37 & 12.92 \\
\hline 0.17 & 1.05 & 0.30 & 0.29 & 0.33 & 0.31 & 0.33 \\
\hline 0.62 & 2.29 & 0.72 & 0.86 & 0.96 & 0.73 & 0.95 \\
\hline 0.10 & 0.82 & 0.11 & 0.09 & 0.13 & 0.11 & 0.13 \\
\hline 0.66 & 3.05 & 1.00 & 0.77 & 1.12 & 1.00 & 1.18 \\
\hline 4.36 & 4.86 & 3.48 & 3.39 & 3.73 & 3.70 & 3.79 \\
\hline 3.41 & 2.18 & 3.94 & 4.78 & 3.89 & 3.95 & 3.90 \\
\hline 0.11 & 0.12 & 0.36 & 0.08 & 0.10 & 0.05 & 0.10 \\
\hline 0.07 & 0.72 & 0.12 & 0.11 & 0.15 & 0.12 & 0.15 \\
\hline 0.05 & 0.16 & 0.01 & 0.01 & 0.02 & 0.01 & 0.01 \\
\hline 0.13 & 0.14 & 0.04 & 0.04 & 0.05 & 0.05 & 0.05 \\
\hline 0.07 & 0.17 & 0.11 & 0.15 & 0.11 & 0.10 & 0.11 \\
\hline-- & -- & -- & -- & -- & -- & -- \\
\hline 0.03 & 0.07 & 0.04 & 0.07 & 0.06 & 0.03 & 0.06 \\
\hline-- & -- & -- & -- & -- & -- & - \\
\hline $\begin{array}{r}99.90 \\
0.03\end{array}$ & $\begin{array}{r}99.59 \\
0.07\end{array}$ & $\begin{array}{r}99.70 \\
0.04\end{array}$ & $\begin{array}{r}99.66 \\
0.06\end{array}$ & $\begin{array}{r}99.93 \\
0.05\end{array}$ & $\begin{array}{r}99.63 \\
0.04\end{array}$ & $\begin{array}{r}100.08 \\
0.05\end{array}$ \\
\hline 99.87 & 99.52 & 99.66 & 99.60 & 99.88 & 99.59 & 100.03 \\
\hline 0.77 & 3.23 & 0.99 & 1.13 & 1.26 & 1.01 & 1.25 \\
\hline 0.78 & 0.69 & 0.71 & 0.75 & 0.74 & 0.70 & 0.74 \\
\hline 1.28 & 2.23 & 0.88 & 0.71 & 0.96 & 0.94 & 0.97 \\
\hline 0.80 & 0.70 & 0.81 & 0.87 & 0.80 & 0.84 & 0.81 \\
\hline 0.89 & 1.07 & 0.95 & 0.99 & 0.96 & 0.99 & 0.97 \\
\hline 0.08 & 0.43 & 0.13 & 0.09 & 0.15 & 0.13 & 0.15 \\
\hline 2.2 & 2.3 & 3.1 & 2.3 & 1.8 & 2.9 & 1.9 \\
\hline
\end{tabular}

CIPW norms

\begin{tabular}{|c|c|c|c|c|c|c|c|c|c|c|}
\hline 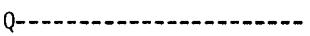 & 31.45 & 32.79 & 40.55 & 36.27 & 24.66 & 39.38 & 36.61 & & 37.95 & 36.21 \\
\hline or & 15.46 & 7.00 & 10.75 & 20.21 & 12.98 & 23.47 & 28.43 & 23.07 & 23.47 & 23.09 \\
\hline 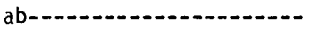 & 34.34 & 37.93 & 37.51 & 37.01 & 41.44 & 29.68 & 28.87 & 31.67 & 31.48 & 32.13 \\
\hline an-1-n & 10.97 & 15.58 & 7.53 & 2.96 & 12.39 & 4.94 & 3.78 & 5.44 & 4.92 & 5.80 \\
\hline 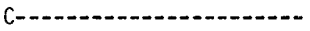 & -- & 0.15 & 0.37 & 1.68 & - & 0.60 & 0.20 & 0.55 & 0.22 & 0.34 \\
\hline 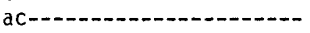 & -- & -- & - & -. & -- & -- & -- & -- & - & $(6)$ \\
\hline ns-..- & -- & -- & -- & -- & -. & -- & -- & -. & -- & -- \\
\hline wo ? & 0.52 & -- & -- & -- & 0.75 & -. & -- & -- & -. & -- \\
\hline en $\}$ di- & 0.19 & -- & -- & -- & 0.34 & -- & -- & -- & -- & -- \\
\hline fs $\int$ & 0.35 & -- & -- & -- & 0.41 & -- & -- & -. & -- & -- \\
\hline en t hy-. & 1.39 & 2.19 & 0.50 & 0.25 & 1.72 & 0.28 & 0.23 & 0.33 & 0.28 & 0.32 \\
\hline fs $\}$ & 2.59 & 3.34 & 1.65 & 1.13 & 2.02 & 0.96 & 1.24 & 1.34 & 0.99 & 1.32 \\
\hline 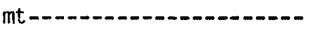 & 1.19 & 0.06 & 0.67 & 0.25 & 1.53 & 0.44 & 0.42 & 0.48 & 0.45 & 0.48 \\
\hline 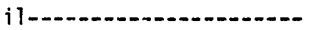 & 1.26 & 0.85 & 0.40 & 0.13 & 1.38 & 0.23 & 0.21 & 0.29 & 0.23 & 0.29 \\
\hline ap-1-n & 0.30 & 0.12 & 0.07 & 0.12 & 0.37 & 0.02 & 0.02 & 0.05 & 0.02 & 0.02 \\
\hline
\end{tabular}




\begin{tabular}{|c|c|c|c|c|c|c|c|c|c|c|}
\hline & 193 & 194 & 195 & 196 & 197 & 198 & 199 & 200 & 201 & 202 \\
\hline \multicolumn{11}{|c|}{ Trace elements (ppm) } \\
\hline 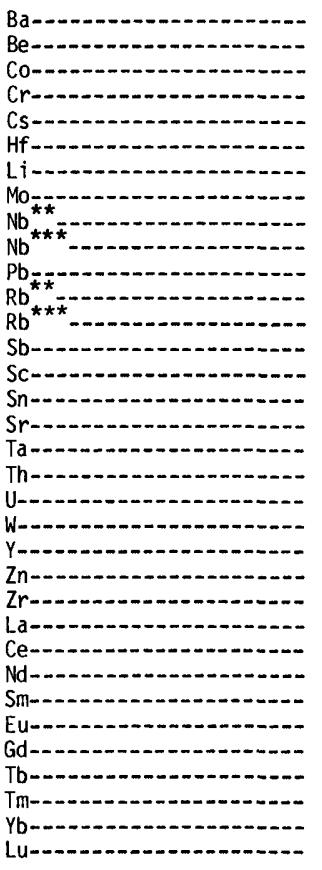 & $\begin{array}{c}460 . \\
1.3 \\
3.0 \\
2.0 \\
3.0 \\
5.1 \\
23 . \\
2.9 \\
6.2 \\
6 . \\
21 . \\
74 . \\
75 . \\
0.5 \\
11.7 \\
1.7 \\
178 . \\
0.50 \\
6.6 \\
1.6 \\
1.1 \\
35 . \\
60 . \\
180 . \\
19 . \\
39 . \\
21 . \\
5.3 \\
1.01 \\
3.6 \\
0.90 \\
0.49 \\
3.9 \\
0.55\end{array}$ & $\begin{array}{c}495 . \\
\ddot{4.6} \\
<4.0 \\
1.4 \\
3.7 \\
-- \\
-. \\
-. \\
\ddot{11 .} \\
28 . \\
23 . \\
<2.0 \\
12.1 \\
-- \\
205 . \\
0.52 \\
2.9 \\
<3.0 \\
34 . \\
37 . \\
108 . \\
12 . \\
26 . \\
16 . \\
3.7 \\
0.90 \\
4.2 \\
0.67 \\
0.49 \\
3.7 \\
0.56\end{array}$ & $\begin{array}{c}620 . \\
\ddot{1.2} \\
<3.0 \\
2.5 \\
5.0 \\
-- \\
-. \\
-- \\
\ddot{11 .} \\
27 . \\
30 . \\
0.8 \\
7.5 \\
-- \\
150 . \\
0.30 \\
2.1 \\
1.5 \\
-- \\
41 . \\
32 . \\
156 . \\
11 . \\
25 . \\
19 . \\
4.2 \\
0.79 \\
4.2 \\
0.72 \\
0.59 \\
3.9 \\
0.60\end{array}$ & $\begin{array}{c}655 . \\
2.3 \\
0.2 \\
<4.0 \\
3.5 \\
2.1 \\
33 . \\
1.3 \\
9.6 \\
10 . \\
20 . \\
95 . \\
97 . \\
0.3 \\
2.1 \\
1.0 \\
80 . \\
0.70 \\
7.2 \\
2.7 \\
1.2 \\
17 . \\
28 . \\
70 . \\
15 . \\
28 . \\
11 . \\
2.8 \\
0.37 \\
3.2 \\
0.46 \\
0.37 \\
2.3 \\
0.31\end{array}$ & $\begin{array}{c}405 . \\
1.7 \\
2.7 \\
<6.0 \\
2.3 \\
6.2 \\
21 . \\
3.5 \\
8 . \\
-. \\
12 . \\
59 . \\
58 . \\
0.3 \\
13.6 \\
1.8 \\
220 . \\
0.41 \\
7.6 \\
1.4 \\
0.85 \\
50 . \\
58 . \\
294 . \\
25 . \\
53 . \\
32 . \\
8.3 \\
1.66 \\
6.5 \\
1.24 \\
0.87 \\
5.1 \\
0.77\end{array}$ & $\begin{array}{c}570 . \\
1.5 \\
0.6 \\
<4.0 \\
9.1 \\
3.4 \\
34 . \\
2.4 \\
10 . \\
9 . \\
15 . \\
161 . \\
156 . \\
0.9 \\
1.7 \\
2.1 \\
85 . \\
0.79 \\
18.7 \\
3.7 \\
3.2 \\
10 . \\
20 . \\
106 . \\
26 . \\
44 . \\
19 . \\
3.2 \\
0.41 \\
<3.0 \\
0.41 \\
0.34 \\
2.4 \\
0.37\end{array}$ & $\begin{array}{c}392 . \\
1.5 \\
0.7 \\
<5.0 \\
11.8 \\
4.8 \\
38 . \\
3.3 \\
8 . \\
8 . \\
18 . \\
203 . \\
197 . \\
0.8 \\
3.4 \\
3.5 \\
37 . \\
0.75 \\
24.8 \\
5.6 \\
3.0 \\
55 . \\
19 . \\
123 . \\
32 . \\
65 . \\
28 . \\
7.2 \\
0.44 \\
6.5 \\
1.12 \\
0.73 \\
5.0 \\
0.71\end{array}$ & $\begin{array}{c}565 . \\
1.7 \\
0.8 \\
<5.0 \\
11.9 \\
5.0 \\
37 . \\
2.1 \\
9.6 \\
34 . \\
177 . \\
193 . \\
0.7 \\
4.6 \\
2.3 \\
90 . \\
0.64 \\
19.5 \\
4.9 \\
2.6 \\
25 . \\
29 . \\
168 . \\
26 . \\
52 . \\
22 . \\
5.7 \\
0.67 \\
2.7 \\
0.83 \\
0.50 \\
3.6 \\
0.50\end{array}$ & $\begin{array}{c}590 . \\
1.5 \\
0.6 \\
<4.0 \\
9.5 \\
3.2 \\
35 . \\
2.1 \\
11 . \\
-. \\
33 . \\
157 . \\
153 . \\
0.8 \\
1.7 \\
1.4 \\
85 . \\
0.83 \\
19.8 \\
4.2 \\
2.6 \\
12 . \\
15 . \\
104 . \\
26 . \\
46 . \\
17 . \\
3.4 \\
0.41 \\
2.7 \\
0.43 \\
0.37 \\
2.4 \\
0.36\end{array}$ & $\begin{array}{c}560 . \\
1.5 \\
0.7 \\
<5.0 \\
10.0 \\
4.8 \\
37 . \\
2.3 \\
7.2 \\
9 . \\
25 . \\
183 \\
175 . \\
0.7 \\
4.4 \\
2.5 \\
95 . \\
0.56 \\
16.4 \\
4.3 \\
2.9 \\
30 . \\
24 . \\
173 . \\
27 . \\
52 . \\
19 . \\
5.7 \\
0.66 \\
4.9 \\
0.72 \\
0.42 \\
3.7 \\
0.52\end{array}$ \\
\hline 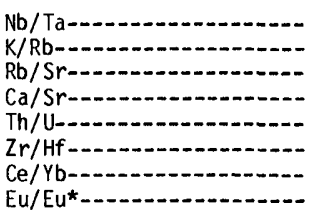 & $\begin{array}{c}12.2 \\
289 . \\
0.42 \\
106 . \\
4.1 \\
35 . \\
10.0 \\
0.70\end{array}$ & $\begin{array}{l}42 \overline{-} \\
0.11 \\
111 . \\
5.6 \\
29 . \\
7.0 \\
0.71\end{array}$ & $\begin{array}{l}50 \overline{1 .} \\
0.20 \\
74 . \\
1.4 \\
31.4 \\
6.4 \\
0.58\end{array}$ & $\begin{array}{c}14.0 \\
292 . \\
1.2 \\
59 . \\
2.7 \\
33 . \\
12.2 \\
0.38\end{array}$ & $\begin{array}{l}19.5 \\
312 . \\
0.26 \\
99 . \\
5.3 \\
47 . \\
10.4 \\
0.70\end{array}$ & $\begin{array}{c}12.0 \\
210 . \\
1.8 \\
84 . \\
5.1 \\
31 . \\
18.3 \\
0.45\end{array}$ & $\begin{array}{c}10.7 \\
201 . \\
5.3 \\
149 . \\
4.5 \\
26 . \\
13.0 \\
0.20\end{array}$ & $\begin{array}{c}15.0 \\
167 . \\
2.1 \\
89 . \\
4.0 \\
34.0 \\
14.4 \\
0.53\end{array}$ & $\begin{array}{l}13.3 \\
214 . \\
1.8 \\
84 . \\
4.7 \\
33 . \\
19.2 \\
0.42\end{array}$ & $\begin{array}{c}14.5 \\
185 . \\
1.8 \\
89 . \\
3.8 \\
36 . \\
14.1 \\
0.38\end{array}$ \\
\hline
\end{tabular}

See footnotes at end of table. 


\begin{tabular}{|c|c|c|c|c|c|c|c|c|}
\hline \multirow{4}{*}{$\begin{array}{l}\text { Country/State- } \\
\text { Volcanic field/region--- } \\
\text { Locality-....... } \\
\text { Specimen-- } \\
\text { Collection No. (RLS-)--- }\end{array}$} & \multicolumn{8}{|c|}{ INDONESIA } \\
\hline & \multicolumn{2}{|c|}{ Celebes } & \multicolumn{6}{|c|}{ Halmahera } \\
\hline & \multirow{2}{*}{$\begin{array}{c}\begin{array}{c}\text { Kp. } \\
\text { Tataaran }\end{array} \\
203 \\
101\end{array}$} & \multirow{2}{*}{$\begin{array}{c}\begin{array}{c}\text { Pasokan } \\
\text { (Belang) }\end{array} \\
204 \\
112\end{array}$} & \multirow{2}{*}{$\begin{array}{c}\begin{array}{c}\text { Mount } \\
\text { Todoku }\end{array} \\
205 \\
170\end{array}$} & \multirow{2}{*}{$\begin{array}{c}\begin{array}{c}\text { Mount Rano } \\
\text { (west) }\end{array} \\
206 \\
171\end{array}$} & \multirow{2}{*}{$\begin{array}{c}\begin{array}{c}\text { Mount } \\
\text { Popolodio }\end{array} \\
207 \\
172\end{array}$} & \multirow{2}{*}{$\begin{array}{c}\begin{array}{c}\text { Mount } \\
\text { Al on }\end{array} \\
208 \\
173\end{array}$} & \multicolumn{2}{|c|}{$\begin{array}{l}\text { Mount Rano } \\
\text { (southwest) }\end{array}$} \\
\hline & & & & & & & $\begin{array}{l}209 \\
174\end{array}$ & $\begin{array}{l}210 \\
195\end{array}$ \\
\hline \multicolumn{9}{|c|}{ Chemical analyses (weight percent) } \\
\hline 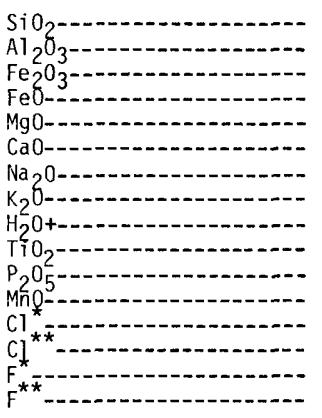 & $\begin{array}{l}75.9 \\
12.89 \\
0.47 \\
1.30 \\
0.15 \\
1.19 \\
4.43 \\
3.15 \\
0.05 \\
0.22 \\
0.02 \\
0.07 \\
0.14 \\
-- \\
0.06 \\
--\end{array}$ & $\begin{array}{l}76.3 \\
12.96 \\
0.44 \\
1.35 \\
0.16 \\
1.23 \\
4.43 \\
3.09 \\
0.11 \\
0.22 \\
0.02 \\
0.08 \\
0.12 \\
-- \\
0.06 \\
--\end{array}$ & $\begin{array}{l}72.5 \\
13.60 \\
0.77 \\
1.86 \\
0.57 \\
1.89 \\
4.47 \\
3.26 \\
0.19 \\
0.31 \\
0.04 \\
0.10 \\
0.12 \\
0.12 \\
0.06 \\
0.06\end{array}$ & $\begin{array}{l}73.5 \\
13.73 \\
0.59 \\
1.55 \\
0.25 \\
1.38 \\
4.60 \\
3.34 \\
0.20 \\
0.31 \\
0.04 \\
0.10 \\
0.15 \\
0.12 \\
0.08 \\
0.06\end{array}$ & $\begin{array}{l}69.1 \\
15.56 \\
1.08 \\
2.04 \\
0.83 \\
2.91 \\
4.65 \\
2.60 \\
0.18 \\
0.47 \\
0.13 \\
0.12 \\
0.14 \\
0.10 \\
0.08 \\
0.06\end{array}$ & $\begin{array}{l}74.1 \\
13.34 \\
0.46 \\
1.36 \\
0.17 \\
1.37 \\
4.53 \\
3.52 \\
0.20 \\
0.24 \\
0.03 \\
0.09 \\
0.13 \\
.14 \\
0.07 \\
0.07\end{array}$ & $\begin{array}{l}72.9 \\
13.55 \\
0.49 \\
1.56 \\
0.25 \\
1.42 \\
4.63 \\
3.32 \\
0.20 \\
0.32 \\
0.04 \\
0.10 \\
0.12 \\
0.13 \\
0.07 \\
0.07\end{array}$ & $\begin{array}{l}74.2 \\
13.60 \\
0.56 \\
1.30 \\
0.21 \\
1.10 \\
4.78 \\
3.48 \\
0.17 \\
0.26 \\
0.02 \\
0.10 \\
0.13 . \\
-- \\
0.08 \\
--\end{array}$ \\
\hline $\begin{array}{l}\text { Subtotal } \\
\text { Less } 0=(\mathrm{F}, \mathrm{Cl})_{2}\end{array}$ & $\begin{array}{r}100.04 \\
0.06\end{array}$ & $\begin{array}{r}100.57 \\
0.05\end{array}$ & $\begin{array}{r}99.74 \\
0.05\end{array}$ & $\begin{array}{r}99.80 \\
0.06\end{array}$ & $\begin{array}{r}99.86 \\
0.06\end{array}$ & $\begin{array}{r}99.61 \\
0.06\end{array}$ & $\begin{array}{r}98.97 \\
0.06\end{array}$ & $\begin{array}{r}99.99 \\
0.06\end{array}$ \\
\hline 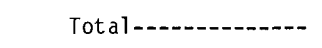 & 99.98 & $\overline{100.52}$ & 99.69 & 99.74 & 99.80 & 99.55 & 98.91 & 99.93 \\
\hline $\mathrm{Fe}_{\mathrm{t}} \mathrm{l}_{\mathrm{t}}$ & 1.72 & 1.75 & 2.56 & 2.08 & 3.01 & 1.77 & 2.00 & 1.80 \\
\hline $\mathrm{Fe} 0 /\left(\mathrm{Fe} 0+\mathrm{Fe}_{2} \mathrm{O}_{3}\right)^{1} \ldots$ & 0.73 & 0.75 & 0.71 & 0.72 & 0.65 & 0.75 & 0.76 & 0.70 \\
\hline $\mathrm{Na}_{2} \mathrm{O} / \mathrm{K}_{2} \mathrm{O}^{1} \ldots$ & 1.41 & 1.43 & 1.37 & 1.38 & 1.79 & 1.29 & 1.39 & 1.37 \\
\hline$\left(\mathrm{Na}_{2} \mathrm{O}+\mathrm{K}_{2} \mathrm{O}\right) / \mathrm{Al}_{2} \mathrm{O}_{3}{ }^{2}-\ldots$ & 0.83 & 0.82 & 0.80 & 0.81 & 0.67 & 0.83 & 0.80 & 0.86 \\
\hline$\left(\mathrm{CaO}+\mathrm{Na}_{2} \mathrm{O}+\mathrm{K}_{2} \mathrm{O}\right) / \mathrm{Al}_{2} \mathrm{O}_{3}{ }^{2}-$. & 1.00 & 0.99 & 1.05 & 1.00 & 1.01 & 1.02 & 0.98 & 1.00 \\
\hline $\mathrm{CaO} /\left(\mathrm{Na}_{2} \mathrm{O}+\mathrm{K}_{2} \mathrm{O}\right)^{1}-\ldots$ & 0.16 & 0.16 & 0.24 & 0.17 & 0.40 & 0.17 & 0.18 & 0.13 \\
\hline $\mathrm{Cl} / \mathrm{F}^{1+}+\ldots$ & 2.4 & 2.2 & 2.0 & 1.9 & 1.8 & 2.0 & 1.9 & 1.6 \\
\hline \multicolumn{9}{|c|}{ CIPW norms } \\
\hline 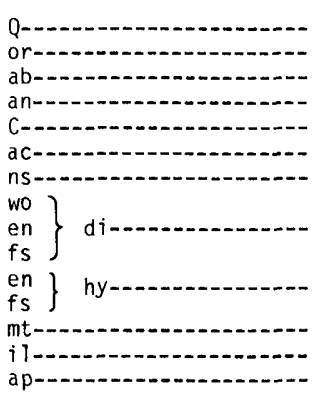 & $\begin{array}{l}34.63 \\
18.65 \\
37.56 \\
5.79 \\
0.08 \\
-- \\
-- \\
-- \\
-- \\
-- \\
0.37 \\
1.77 \\
0.68 \\
0.42 \\
0.05\end{array}$ & $\begin{array}{l}34.93 \\
18.21 \\
37.38 \\
5.96 \\
0.14 \\
-- \\
-- \\
-- \\
-- \\
-- \\
0.40 \\
1.90 \\
0.64 \\
0.42 \\
0.05\end{array}$ & $\begin{array}{l}28.67 \\
19.39 \\
38.06 \\
7.46 \\
-- \\
-- \\
-- \\
0.71 \\
0.27 \\
0.46 \\
1.16 \\
2.01 \\
1.12 \\
0.59 \\
0.09\end{array}$ & $\begin{array}{l}30.00 \\
19.86 \\
39.16 \\
6.63 \\
0.14 \\
-- \\
-- \\
-- \\
-- \\
-- \\
0.63 \\
2.05 \\
0.86 \\
0.59 \\
0.09\end{array}$ & $\begin{array}{l}24.07 \\
15.44 \\
39.55 \\
13.66 \\
0.12 \\
-- \\
-- \\
-- \\
-- \\
-- \\
2.08 \\
2.13 \\
1.57 \\
0.90 \\
0.30\end{array}$ & $\begin{array}{l}30.76 \\
20.97 \\
38.64 \\
5.72 \\
-- \\
-- \\
-- \\
0.39 \\
0.08 \\
0.34 \\
0.35 \\
1.56 \\
0.67 \\
0.46 \\
0.07\end{array}$ & $\begin{array}{l}29.50 \\
19.90 \\
39.74 \\
6.48 \\
-- \\
-- \\
- \\
0.17 \\
0.04 \\
0.14 \\
0.59 \\
2.01 \\
0.72 \\
0.62 \\
0.09\end{array}$ & $\begin{array}{l}29.82 \\
20.65 \\
40.61 \\
5.35 \\
0.02 \\
-- \\
-- \\
-- \\
-- \\
0.53 \\
1.69 \\
0.82 \\
0.50 \\
0.05\end{array}$ \\
\hline
\end{tabular}




\begin{tabular}{|c|c|c|c|c|c|c|c|c|}
\hline & 203 & 204 & 205 & 206 & 207 & 208 & 209 & 210 \\
\hline \multicolumn{9}{|c|}{ Trace elements (ppm) } \\
\hline 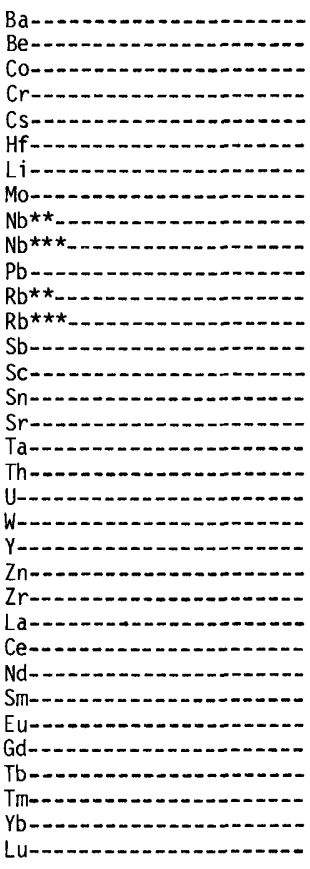 & $\begin{array}{c}475 . \\
1.3 \\
0.9 \\
<6.0 \\
4.0 \\
6.1 \\
25 . \\
2.5 \\
7 . \\
5 . \\
6 . \\
88 . \\
78 . \\
0.4 \\
8.2 \\
1.9 \\
90 . \\
0.44 \\
6.5 \\
0.7 \\
1.1 \\
50 . \\
40 . \\
262 . \\
17 . \\
39 . \\
24 . \\
6.0 \\
0.91 \\
5.9 \\
1.08 \\
0.69 \\
5.0 \\
0.76\end{array}$ & $\begin{array}{c}430 . \\
1.2 \\
1.0 \\
<5.0 \\
4.0 \\
6.2 \\
25 . \\
2.3 \\
9.2 \\
-. \\
16 . \\
77 . \\
76 . \\
<0.5 \\
8.1 \\
1.6 \\
85 . \\
0.48 \\
6.5 \\
1.5 \\
0.90 \\
49 . \\
37 . \\
262 . \\
17 . \\
38 . \\
22 . \\
6.1 \\
0.87 \\
5.6 \\
1.09 \\
0.78 \\
4.9 \\
0.75\end{array}$ & $\begin{array}{c}520 . \\
1.5 \\
3.3 \\
2.2 \\
4.4 \\
6.3 \\
34 . \\
2.0 \\
7.2 \\
7 . \\
19 . \\
68 . \\
72 . \\
0.7 \\
12.4 \\
1.7 \\
122 . \\
0.33 \\
5.4 \\
1.5 \\
1.3 \\
47 . \\
52 . \\
227 . \\
19 . \\
43 . \\
26 . \\
6.5 \\
1.06 \\
5.9 \\
1.16 \\
0.75 \\
5.3 \\
0.76\end{array}$ & $\begin{array}{c}550 . \\
1.4 \\
1.2 \\
<4.0 \\
4.5 \\
6.6 \\
35 . \\
2.1 \\
4.5 \\
6 . \\
28 . \\
76 . \\
70 . \\
0.6 \\
10.8 \\
1.8 \\
133 . \\
0.28 \\
5.5 \\
1.6 \\
1.4 \\
49 . \\
53 . \\
242 . \\
20 . \\
45 . \\
27 . \\
6.6 \\
1.14 \\
6.1 \\
1.24 \\
0.75 \\
5.3 \\
0.79\end{array}$ & $\begin{array}{c}465 . \\
1.3 \\
3.6 \\
<4.0 \\
3.6 \\
5.0 \\
30 . \\
1.4 \\
4.8 \\
5 . \\
17 . \\
58 . \\
65 . \\
0.5 \\
12.0 \\
1.7 \\
240 . \\
0.26 \\
4.3 \\
1.3 \\
1.3 \\
45 . \\
54 . \\
175 . \\
17 . \\
38 . \\
20 . \\
5.8 \\
1.20 \\
5.8 \\
0.89 \\
0.57 \\
4.4 \\
0.64\end{array}$ & $\begin{array}{c}540 . \\
1.4 \\
0.7 \\
1.1 \\
4.7 \\
6.6 \\
36 . \\
2.0 \\
5.2 \\
7 . \\
17 . \\
71 . \\
85 . \\
0.5 \\
10.3 \\
2.2 \\
110 . \\
0.30 \\
5.9 \\
1.7 \\
1.4 \\
57 . \\
57 . \\
216 . \\
20 . \\
45 . \\
29 . \\
6.9 \\
1.06 \\
6.1 \\
1.00 \\
0.78 \\
5.5 \\
0.78\end{array}$ & $\begin{array}{c}530 . \\
1.4 \\
1.2 \\
1.1 \\
4.7 \\
6.8 \\
35 . \\
2.0 \\
6 . \\
5 . \\
20 . \\
76 . \\
85 . \\
0.7 \\
10.9 \\
2.1 \\
140 . \\
0.34 \\
5.5 \\
1.7 \\
1.5 \\
52 . \\
51 . \\
235 . \\
20 . \\
45 . \\
24 . \\
6.9 \\
1.20 \\
5.7 \\
1.09 \\
0.77 \\
5.6 \\
0.79\end{array}$ & $\begin{array}{c}525 . \\
\overline{1.0} \\
<3.0 \\
5.1 \\
6.9 \\
-- \\
-- \\
-- \\
-- \\
18 . \\
74 . \\
82 . \\
1.0 \\
10.5 \\
-- \\
105 . \\
0.41 \\
6.2 \\
1.4 \\
-- \\
58 . \\
62 . \\
243 . \\
21 . \\
47 . \\
29 . \\
6.8 \\
1.07 \\
7.7 \\
1.27 \\
0.74 \\
5.8 \\
0.84\end{array}$ \\
\hline 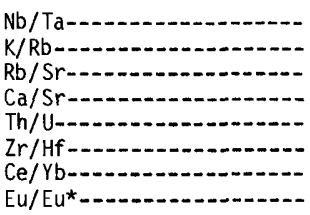 & $\begin{array}{l}13.6 \\
335 . \\
0.87 \\
95 . \\
9.1 \\
43 . \\
7.8 \\
0.47\end{array}$ & $\begin{array}{c}19.2 \\
338 . \\
0.89 \\
103 . \\
4.3 \\
42 . \\
7.8 \\
0.46\end{array}$ & $\begin{array}{l}21.5 \\
376 . \\
0.59 \\
111 . \\
3.6 \\
36 . \\
8.1 \\
0.53\end{array}$ & $\begin{array}{c}18.9 \\
396 . \\
0.53 \\
74 . \\
3.4 \\
37 . \\
8.5 \\
0.55\end{array}$ & $\begin{array}{c}18.9 \\
332 . \\
0.27 \\
87 . \\
3.3 \\
35 . \\
8.6 \\
0.60\end{array}$ & $\begin{array}{l}20.3 \\
344 . \\
0.77 \\
89 . \\
3.5 \\
33 . \\
8.2 \\
0.51\end{array}$ & $\begin{array}{c}16.2 \\
324 . \\
0.61 \\
73 . \\
3.2 \\
35 . \\
8.0 \\
0.59\end{array}$ & $\begin{array}{l}-- \\
352 . \\
0.78 \\
75 . \\
4.4 \\
35 . \\
8.1 \\
0.46\end{array}$ \\
\hline
\end{tabular}

See footnotes at end of table. 
APPENDIX I.-Chemical analyses of subalkalic silicic obsidians-Continued

\begin{tabular}{|c|c|c|c|c|c|c|c|}
\hline \multirow{4}{*}{$\begin{array}{l}\text { Country/State- } \\
\text { Volcanic field/region-- } \\
\text { Locality-. } \\
\text { Specimen-1 } \\
\text { Collection No. (RLS-) }\end{array}$} & \multicolumn{4}{|c|}{ PAPUA NEW GUINEA } & NEW BRITAIN & \multicolumn{2}{|c|}{ NEW ZEALAND } \\
\hline & \multicolumn{4}{|c|}{ Admiralty Islands } & \multirow[b]{2}{*}{ Talasea } & & \\
\hline & $\begin{array}{r}\text { Tuluman } \\
\text { Island }\end{array}$ & Lou & 1 and & $\begin{array}{l}\text { Pam Lin } \\
\text { Island }\end{array}$ & & & \\
\hline & $\begin{array}{r}211 \\
70\end{array}$ & $\begin{array}{r}212 \\
62\end{array}$ & $\begin{array}{r}213 \\
58\end{array}$ & $\begin{array}{r}214 \\
64\end{array}$ & $\begin{array}{r}215 \\
60\end{array}$ & $\begin{array}{c}216 \\
3\end{array}$ & $\begin{array}{r}217 \\
71\end{array}$ \\
\hline \multicolumn{8}{|c|}{ Chemical analyses (weight percent) } \\
\hline 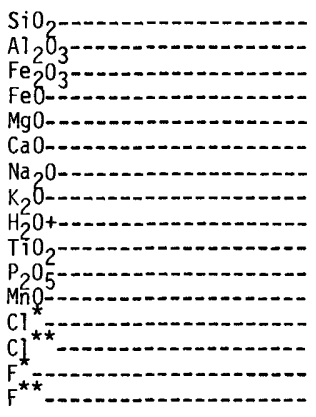 & $\begin{array}{r}69.47 \\
13.90 \\
0.90 \\
2.62 \\
0.49 \\
1.89 \\
5.38 \\
3.21 \\
0.06 \\
0.45 \\
0.13 \\
0.10 \\
0.37 \\
0.35 \\
0.14 \\
0.13\end{array}$ & $\begin{array}{r}71.80 \\
13.90 \\
0.27 \\
1.81 \\
0.45 \\
1.26 \\
4.95 \\
4.45 \\
0.04 \\
0.29 \\
0.04 \\
0.06 \\
0.38 \\
0.34 \\
0.12 \\
0.11\end{array}$ & $\begin{array}{r}73.55 \\
13.58 \\
0.48 \\
1.44 \\
0.38 \\
1.01 \\
4.84 \\
4.11 \\
0.21 \\
0.26 \\
0.03 \\
0.07 \\
0.32 \\
0.28 \\
0.11 \\
0.11\end{array}$ & $\begin{array}{r}73.63 \\
13.32 \\
0.52 \\
1.39 \\
0.29 \\
0.85 \\
4.74 \\
4.22 \\
0.28 \\
0.22 \\
0.02 \\
0.06 \\
0.31 \\
0.30 \\
0.13 \\
0.12\end{array}$ & $\begin{array}{r}76.0 \\
12.73 \\
0.53 \\
0.64 \\
0.21 \\
1.20 \\
3.93 \\
3.78 \\
0.08 \\
0.24 \\
0.03 \\
0.06 \\
0.15 \\
0.14 \\
0.05 \\
0.05\end{array}$ & $\begin{array}{r}76.97 \\
12.25 \\
0.39 \\
0.81 \\
0.15 \\
0.90 \\
3.89 \\
3.89 \\
0.22 \\
0.14 \\
0.03 \\
0.05 \\
-.- \\
0.14 \\
-. \\
0.04\end{array}$ & $\begin{array}{r}76.8 \\
12.58 \\
0.49 \\
0.82 \\
0.15 \\
1.09 \\
4.04 \\
3.47 \\
0.07 \\
0.19 \\
0.02 \\
0.04 \\
0.12 \\
0.09 \\
0.03 \\
0.03\end{array}$ \\
\hline $\begin{array}{l}\text { Subtotal } \\
\text { Less } 0=(F, C 1)_{2}\end{array}$ & $\begin{array}{l}99.10^{7} \\
0.14\end{array}$ & $\begin{array}{r}99.80 \\
0.13\end{array}$ & $\begin{array}{r}100.37 \\
0.12\end{array}$ & $\begin{array}{r}99.97 \\
0.12\end{array}$ & $\begin{array}{r}99.62 \\
0.05\end{array}$ & $\begin{array}{r}99.87 \\
0.05\end{array}$ & $\begin{array}{r}99.90 \\
0.04\end{array}$ \\
\hline Total- & $99.06^{7}$ & 99.67 & 100.25 & 99.85 & 99.57 & 99.82 & 99.86 \\
\hline $\mathrm{Fe} 0 \mathrm{t}_{\mathrm{t}}^{1}-\ldots$ & 3.43 & 2.05 & 1.87 & 1.86 & 1.12 & 1.16 & 1.26 \\
\hline $\mathrm{Fe} 0 /\left(\mathrm{Fe} 0+\mathrm{Fe}_{2} \mathrm{O}_{3}\right)^{1} \ldots$ & 0.74 & 0.87 & 0.75 & 0.73 & 0.55 & 0.68 & 0.63 \\
\hline $\mathrm{Na}_{2} \mathrm{O} / \mathrm{K}_{2} \mathrm{O}^{1}$ & 1.68 & 1.11 & 1.18 & 1.12 & 1.04 & 1.00 & 1.16 \\
\hline$\left(\mathrm{Na}_{2} \mathrm{O}+\mathrm{K}_{2} \mathrm{O}\right) / \mathrm{Al}_{2} \mathrm{O}_{3}{ }^{2}$ & 0.89 & 0.93 & 0.91 & 0.93 & 0.83 & 0.87 & 0.83 \\
\hline$\left(\mathrm{CaO}+\mathrm{Na}_{2}{ }^{\left.\mathrm{O}+\mathrm{K}_{2} \mathrm{O}\right) / \mathrm{Al}_{2} \mathrm{O}_{3}{ }^{2}-\cdots}\right.$ & 1.13 & 1.10 & 1.05 & 1.05 & 1.00 & 1.00 & -- \\
\hline $\mathrm{CaO} /\left(\mathrm{Na}_{2} \mathrm{O}+\mathrm{K}_{2} \mathrm{O}\right)^{1}$ & 0.22 & 0.13 & 0.11 & 0.09 & 0.16 & 0.12 & 0.15 \\
\hline $\mathrm{Cl} / \mathrm{F}^{1+}+\ldots$ & 2.7 & 3.0 & 2.6 & 2.5 & 3.0 & 3.5 & 3.4 \\
\hline \multicolumn{8}{|c|}{ CIPW norms } \\
\hline 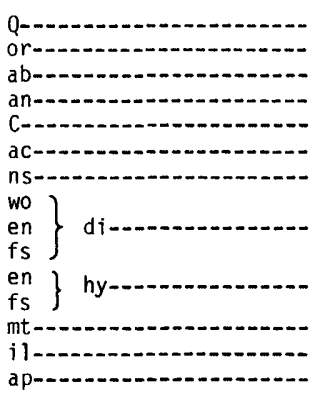 & $\begin{array}{l}21.10 \\
19.25 \\
4.20 \\
4.36 \\
-- \\
-- \\
-- \\
1.79 \\
0.49 \\
1.40 \\
0.75 \\
2.17 \\
1.32 \\
0.87 \\
0.31\end{array}$ & $\begin{array}{l}22.38 \\
26.49 \\
42.19 \\
2.58 \\
-- \\
-- \\
-- \\
1.44 \\
0.44 \\
1.06 \\
0.69 \\
1.69 \\
0.39 \\
0.56 \\
0.09\end{array}$ & $\begin{array}{l}25.55 \\
24.35 \\
41.06 \\
3.20 \\
-- \\
-- \\
-- \\
0.68 \\
0.23 \\
0.47 \\
0.72 \\
1.48 \\
0.70 \\
0.50 \\
0.07\end{array}$ & $\begin{array}{l}27.38 \\
25.12 \\
40.41 \\
2.63 \\
-- \\
-- \\
-- \\
0.62 \\
0.18 \\
0.47 \\
0.55 \\
1.42 \\
0.76 \\
0.42 \\
0.05\end{array}$ & $\begin{array}{c}35.90 \\
22.48 \\
33.47 \\
5.80 \\
0.06 \\
-- \\
-- \\
- \\
- \\
-- \\
0.53 \\
0.46 \\
0.77 \\
0.46 \\
0.07\end{array}$ & $\begin{array}{c}37.12 \\
23.11 \\
33.09 \\
4.29 \\
0.08 \\
-- \\
-- \\
-- \\
- \\
- \\
0.38 \\
1.03 \\
0.57 \\
0.27 \\
0.07\end{array}$ & $\begin{array}{l}37.24 \\
20.57 \\
34.29 \\
5.29 \\
0.25 \\
-- \\
-- \\
-- \\
-- \\
-- \\
0.38 \\
0.86 \\
0.71 \\
0.36 \\
0.05\end{array}$ \\
\hline
\end{tabular}




\begin{tabular}{llllllll}
\hline 211 & 212 & 213 & 214 & 215 & 216 & 217 \\
\hline & & Trace elements (ppm) & \\
\hline
\end{tabular}

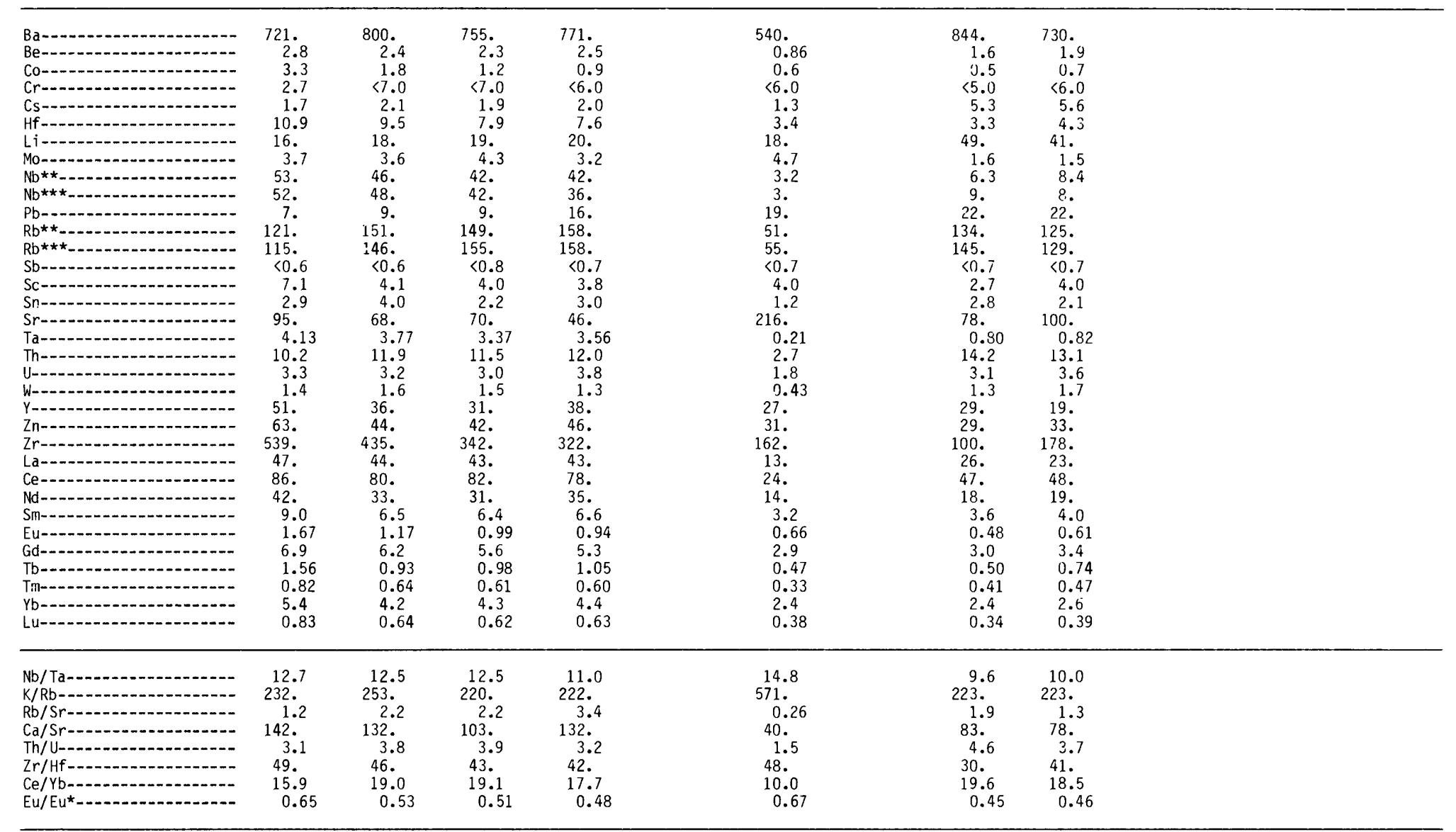

$\begin{array}{cl}\text { *Analyses performed by the University of Reading. } & 1 \text { By weight. } \\ \star \star \text { Analyses performed by the U.S. Geological Survey. } & 2 \text { Molecular. }\end{array}$

$\star \star *$ Analyses performed by the U.S. Geological Survey.
$\star * \star$ Analyses performed by the University of Lancaster.

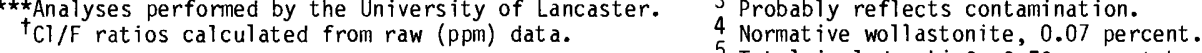

--, not determined.

5 Total includes $L i{ }^{0}, 0.73$ percent by weight.
6 Normative wollastonite $(0.05$ percent) and hematite $(0.09$ percent).

7 Total includes $\mathrm{H}_{2} \mathrm{O}-, 0.10$ percent by weight. 
APPENDIX I.-Sample localities

\section{NORTH AMERICA}

\section{UNITED STATES OF AMERICA}

\section{ALASKA}

Umnak Island Volcanic Field

1 (190) Microvesicular obsidian, cracked, slightly hydrated, lava dome, southwest Umnak Island, Aleutian Islands, Alaska. Lat $53^{\circ} 10.14^{\prime}$ N., long $168^{\circ} 24.85^{\prime} \mathrm{W}$. Collected by R.L. Smith and T.P. Miller. Same locality as that studied by Byers (1959, table 2, No. 32 (major element analysis), and table 3 , No. 32 (modal analysis)).

2 (56) Obsidian agglutinate lava, northwest slope of Somma I of Okmok caldera, northwest Umnak Island, Aleutian Islands, Alaska. Lat $53^{\circ} 29.02^{\prime}$ N., long $168^{\circ} 9.18^{\prime}$ W. Collected by R.L. Smith and T.P. Miller. Same locality as that studied by Byers (1959, table 2, No. 19 (major element analyses) and table 3, No. 19 (modal analysis)). See also table 15, sample No. 242 this study.

\section{Katmai Volganic Field}

3 (214) Microvesicular obsidian, lava dome, Novarupta, Valley of Ten Thousand Smokes, Alaska. Lat $58^{\circ} 16.57^{\prime} \mathrm{N}$., long $155^{\circ} 9.41^{\prime} \mathrm{W}$. Supplied by Wes Hildreth.

\section{Wrangell Mountains Volcanic Firld}

4 (39) Porphyritic obsidian, strongly annealed, lava flow, southeast slope of Capital Mountains, northwestern Wrangell Mountains, Alaska. Lat $62^{\circ} 24.01^{\prime}$ N., long $144^{\circ} 2.26^{\prime}$ W. Collected by R.L. Smith.

5 (196) Glass separate of sample 4 (39).

6 (45) Obsidian, Apache tear, lava flow, west side of Ptarmigan Lake, eastern Wrangell Mountains, Alaska. Lat $141^{\circ} 11.67^{\prime}$ W., long $61^{\circ} 51.96^{\prime} \mathrm{N}$. Collected by R.L. Smith and D.H. Richter.

\section{INDIAN Rrver}

7 (46) Obsidian, Apache tear. Residual litter from rhyolite lava flow, drainage divide between Indian and Little Indian rivers, Koyukuk River valley, $29 \mathrm{~km}$ southeast of Hughes, Alaska. Lat $65^{\circ} 49^{\prime}$ N., long $154^{\circ} 00^{\prime}$ W. Supplied by W.W. Patton, Jr. and T.P. Miller. This obsidian is in all probability the same as that studied by Ross and Smith (1955) from "Norwikakat River," Alaska, U.S. National Museum No. 6384. We have never been able to find this locality on a map.

\section{OREGON}

SOUTH Sister

8 (187) Porphyritic microvesicular obsidian, lava from southernmost vent of Holocene chain of vents, south flank of South Sister, Cascade Range, Deschutes County, Oregon. Lat $44^{\circ} 2.03^{\prime}$ N., long $121^{\circ} 45.33^{\prime}$ W. Collected by R.L. Smith and H.R. Shaw.

9 (189) Porphyritic microvesicular obsidian, early lobe of lava from northern-most vent of Holocene chain of vents, southeast flank of South Sister, Cascade Range, Deschutes County, Oregon. Lat $44^{\circ} 4.32^{\prime}$ N., long $121^{\circ} 44.77^{\prime}$ W. Collected by R.L. Smith and H.R. Shaw.

10 (199) Glass separate of sample 9 (189).

\section{Crater Lake Volcanic Field}

11 (8-3Av) Porphyritic dacite glass, The Watchman, Crater Lake, Klamath Courty, Oregon. Lat $42^{\circ} 56.62^{\prime}$ N., long $122^{\circ} 10.61^{\prime}$ W. Supplied by Donald C. Noble.

12 (8-3Av-G) Rhyolitic glass separate from sample 11 (8-3Av). Supplied by Donald C. Noble.

13 (9-2v) Porphyritic obsidian, Grouse Hill, Crater Lake, Klamath County, Oregon. Lat $42^{\circ} 59.46^{\prime}$ N., long $122^{\circ} 7.32^{\prime}$ W. Supplied by Donald C. Noble.

14 (9-2v-G) Glass separate from sample $13(9-2 v)$. Supplied by Donald C. Noble.

15 (9-16v) Porphyritic obsidian, Llao Rock, Crater Lake, Klamath County, Oregon. Lat $42^{\circ} 58.78^{\prime}$ N., long $122^{\circ} 7.32^{\prime}$ W. Supplied by Donald C. Noble.

$16(9-16 v-G)$ Glass separate from sample 15 (9-16v). Supplied by Donald C. Noble.

17 (9-19v) Porphyritic obsidian, lava, Redcloud Cliff, Klamath County, Crater Lake, Oregon. Lat $42^{\circ} 56.76^{\prime}$ N., long $122^{\circ} 2.74^{\prime}$ W. Supplied by Donald C. Noble.
$18(9-19 v-G)$ Glass separate from sample $17(9-19 v)$. Supplied by Donald C. Noble.

19 (222) Porphyritic obsidian, Cleetwood lava flow, Crater Lake, Oregon. Lat $42^{\circ} 58.76^{\prime}$ N., long $122^{\circ} 4.39^{\prime}$ W. Supplied by Charles R. Bacon, No. $79 \mathrm{C} 160$.

20 (223) Porphyritic obsidian, lava, Cloudcap, Crater Lake, Oregon. Lat $42^{\circ} 56.01^{\prime} \mathrm{N}$., long $122^{\circ} 2.47$ W. Supplied by Charles R. Bacon, No. 79C161.

21 (224) Porphyritic obsidian, lava, Llao Rock flow Crater Lake, Oregon. Lat $42^{\circ} 58.35^{\prime} \mathrm{N}$., long $122^{\circ} 8.6^{\prime} \mathrm{W}$. Supplied by Charles R. Bacon, No. $79 \mathrm{C} 153$.

\section{Newberky Volcanic Field}

22 (144) Obsidian, Lost Lake, Big Obsidian flow, Newberry Caldera, Deschutes County, Oregon. Lat $43^{\circ} 42.3^{\prime} \mathrm{N}$., long $121^{\circ} 14.56^{\prime} \mathrm{W}$. Collected by R.L. Smith.

23 (156) Obsidian, East Lake, southwest obsidian flow, Newberry Caldera, Deschutes County, Oregon. Lat $43^{\circ} 42.84^{\prime} \mathrm{N}$., long $121^{\circ} 13.81^{\prime} \mathrm{W}$. Collected by R.L. Smith.

\section{Southeast Oregon Volcanic Area}

24 (159) Obsidian, lava dome, East Butte, Deschutes County, Oregon. Lat $43^{\circ} 40.14^{\prime}$ N., long $120^{\circ} 58.33^{\prime}$ W. Collected by R.L. Smith and G.W. Walker.

25 (157) Obsidian, lava dome, Quartz Mountain, Deschutes County, Oregon. Lat $43^{\circ} 38.11^{\prime} \mathrm{N}$., long $120^{\circ} 53.7^{\prime} \mathrm{W}$. Collected by R.L. Smith and G.W. Walker.

26 (162) Obsidian, lava dome, Cougar Mountain, Lake County, Oregon. Lat $43^{\circ} 24.46^{\prime}$ N., long $120^{\circ} 53.33^{\prime}$ W. Collected by R.L. Smith and G.W. Walker.

27 (158) Obsidian, lava dome, northwest cluster of Glass Buttes, Lake County, Oregon. Lat $43^{\circ} 33.38^{\prime} \mathrm{N}$., long $120^{\circ} 1.85$ ' W. Collected by R.L. Smith and G.W. Walker.

28 (154) Obsidian, lava flow, roadcut on U.S. Highway 395, 4.6 miles south of U.S. Highway 20, near Riley, Lake County, Oregon. Lat $43^{\circ} 29.05^{\prime}$ N., long $119^{\circ} 32.22^{\prime} \mathrm{W}$. Collected by R.L. Smith and G.W. Walker.

29 (54) Obsidian, residual block from lava flow, Horse Mountain, Lake County, Oregon. Lat $43^{\circ} 8.24^{\prime} \mathrm{N}$., long $120^{\circ} 10.37^{\prime} \mathrm{W}$. Collected by R.L. Smith and G.W. Walker. 
30 (163) Obsidian, lava, southwest base of Razorback Ridge, Drewes Ranch, Lake County, Oregon. Lat $42^{\circ} 16.62^{\prime}$ N., long $120^{\circ} 42.29^{\prime}$ W. Collected by R.L. Smith and G.W. Walker.

31 (161) Obsidian, Apache tear, lava dome, east side of Tucker Hill, Lake County, Oregon. Lat $42^{\circ} 35.27^{\prime}$ N., long $120^{\circ} 25.27^{\prime}$ W. Collected by R.L. Smith and G.W. Walker.

32 (155) Obsidian, Apache tears, lava dome, McComb Butte, Lake County, Oregon. Lat $42^{\circ} 35.14^{\prime}$ N., long $120^{\circ} 37.13^{\prime} \mathrm{W}$. Collected by R.L. Smith and G.W. Walker.

33 (164) Obsidian, welded tuff, lithophysal cooling unit, mouth of Orijana Canyon, Poker Jim Ridge, northern Hart Mountain, Harney County, Oregon. Lat $42^{\circ} 48.51^{\prime}$ N., long $119^{\circ} 29.63^{\prime}$ W. Collected by R.L. Smith and G.W. Walker.

34 (160) Obsidian, cobble in alluvial fan, eroded from nearby lavas, northwest base of Beatys Butte, Harney County, Oregon. Lat $42^{\circ} 25^{\prime}$ N., long $119^{\circ} 22.13^{\prime}$ W. Collected by R.L. Smith and G.W. Walker

\section{CALIFORNIA}

\section{Warner Mountains Volcanic Area}

35 (51) Obsidian, lava dome, west side of Sugar Hill near lookout tower, Warner Mountains. Modoc County, California. Lat $41^{\circ} 48.11^{\prime}$ N., long $120^{\circ} 19.70^{\prime}$ W. Collected by R.L. Smith and W.A. Duffield.

36 (52) Porphyritic obsidian, lava flow, residual block on erosion surface, southeast flank of Sugar Hill, Warner Mountains, Modoc County, California. Lat $41^{\circ} 47.03^{\prime}$ N., long $120^{\circ} 18.80^{\prime} \mathrm{W}$. Collected by R.L. Smith and W.A. Duffield.

37 (40) Obsidian, lava, northwest flank of Buck Mountain, Warner Mountains, Modoc County, California. Lat $41^{\circ} 45^{\prime}$ N., long $120^{\circ} 18.25^{\prime}$ W. Collected by R.L. Smith and W.A. Duffield.

38 (41) Obsidian, lava, north flank of Buck Mountain, Warner Mountains, Modoc County, California. Lat $41^{\circ} 43.78^{\prime}$ N., long $120^{\circ} 16.81^{\prime} \mathrm{W}$. Collected by R.L. Smith and W.A. Duffield.

39 (44) Obsidian, lava, block from residual litter on eroded top of flow, east flank of Buck Mountain near head of Boyd Creek. Warner Mountain escarpment, Modoc County, California. Lat $41^{\circ} 42.57^{\prime}$ N., long $120^{\circ} 15.36^{\prime} \mathrm{W}$. Collected by R.L. Smith and W.A. Duffield.
Medicine Lake Highiands Volcanic Field

40 (142) Obsidian, lava, residual block on eroded flow, Grasshopper Flat, Medicine Lake Highlands, Modoc County, California. Lat $41^{\circ} 31.35$ ' N., long $121^{\circ} 42.40^{\prime}$ W. Collected by R.L. Smith.

41 (143) Obsidian, lava flow, Little Glass Mountain, Medicine Lake Highlands, Modoc County, California. Lat $41^{\circ} 34.59^{\prime}$ N., long $121^{\circ} 40.6^{\prime}$ W. Collected by R.L. Smith and I. Friedman.

42 (141) Obsidian, lava flow, rhyolitic part, middle of flow, Big Glass Mountain, Medicine Lake Highlands, Modoc County, California. Lat $41^{\circ} 37.43^{\prime}$ N., long $121^{\circ} 27.66^{\prime}$ W. Collected by R.L. Smith and I. Friedman.

43 (RGM-1) Obsidian, lava flow, Big Glass Mountain, Medicine Lake Highlands, Modoc County, California. U.S. Geological Survey Chemical Rock Standard RGM-1. Tatlock and others (1976, p. 11). Supplied by F.J. Flanagan.

\section{Sonoma Volcanic Fieid}

44 (43) Obsidian, block from roadcut in lava dome, Napa Glass Mountain, Napa County, California. Lat $38^{\circ} 31.76^{\prime}$ N., long $122^{\circ} 29.14 '$ W. Collected by R.L. Smith.

\section{Cuear Lake Volcanic Field}

45 (153) Obsidian, clast in tuff, rhyolite of Bonanza Springs, Loch Lomond, Lake County, California. Lat $38^{\circ} 51.55^{\prime}$ N., long $122^{\circ} 43.27^{\prime}$ W. Supplied by B.C. Hearn.

46 (149) Obsidian, lava flow, Camel Back Ridge, rhyolite of Thurston Creek, Lake County, California. Lat $38^{\circ} 54.19^{\prime}$ N., long $122^{\circ} 47.34^{\prime}$ W. Collected by R.L. Smith and B.C. Hearn.

47 (7) Obsidian, lava flow, rhyolite of Thurston Creek, Manning Flat, Lake County, California. Lat $38^{\circ} 55.41^{\prime}$ N., long $122^{\circ} 41.82^{\prime}$ W. Collected by R.L. Smith and I. Friedman. Major element analyst: Ellen S. Daniels, Denver RAL, USGS. Analysis previously unpublished.

48 (150) Obsidian, lava dome, rhyolite of Borax Lake, Clear Lake Park, Lake County, California. Lat $38^{\circ} 58.13^{\prime}$ N., long $122^{\circ} 38.7^{\prime}$ W. Supplied by B.C. Hearn.

\section{Mono-Inyo Volcanic Field}

49 (148) Obsidian, lava flow, Northwest Coulee, Mono Craters, Mono County, California. Lat $37^{\circ} 54.46^{\prime}$
N., long $119^{\circ} 2.13^{\prime}$ W. Collected by R.L. Smith and I. Friedman.

50 (147) Obsidian, lava dome, Panum Dome, Mono Craters, Mono County, California. Lat $37^{\circ} 55.88^{\prime}$ N., long $119^{\circ} 2.47^{\prime}$ W. Collected by R.L. Smith and I. Friedman.

51 (MC73-1A) Obsidian, lava dome, Obsidian Dome, Inyo Craters chain, Mono County, California. Lat $37^{\circ} 46^{\prime}$ N., long $119^{\circ} 01^{\prime}$ W. Supplied by R.A. Bailey.

52 (M72-8) Obsidian, lava dome, "early rhyolite" sequence, Long Valley Caldera, Mono County, California. Lat $37^{\circ} 40^{\prime}$ N., long $118^{\circ} 00^{\prime} \mathrm{W}$. Supplied by R.A. Bailey.

53 (M72-21) Obsidian, lava dome, "early rhyolite" sequence, Long Valley Caldera, Mono County, California. Lat $37^{\circ} 41^{\prime}$ N., long $118^{\circ} 53^{\prime}$ W. Supplied by R.A. Bailey.

54 (M72-62) Sparsely porphyritic obsidian, Hot Creek lava flow, moat rhyolite sequence, Long Valley Caldera, Mono County, California. Lat $37^{\circ} 38^{\prime}$ N., long $118^{\circ} 50^{\prime}$ W. Supplied by R.A. Bailey.

\section{Big Pine Volcanic Field}

55 (9) Obsidian, lava flow, 7 miles south of Big Pine, Inyo County, California. Lat $37^{\circ} 3.38^{\prime}$ N., long $118^{\circ} 17.87^{\prime} \mathrm{W}$. Collected by R.L. Smith and I. Friedman. Major element analyst: Ellen S. Daniels, Denver RAL, USGS. Analysis previously unpublished.

\section{Northern Coso Mountains}

56 (5) Obsidian, Apache tears, intrusive margin of dome, northern end of the Coso Mountains, about 10 miles northeast of Olancha, Inyo County, California. Lat $36^{\circ} 20.54^{\prime}$ N., long $117^{\circ} 50.61^{\prime} \mathrm{W}$. Collected by R.L. Smith and I. Friedman. Major element analyst: Ellen S. Daniels, Denver RAL, USGS. Analysis previously unpublished.

\section{Coso Volcanic Field}

57 (CD-3) Spherulitic obsidian, lava dome, Coso Volcanic Field, Inyo County, California. Lat $36^{\circ} 4.97^{\prime}$ N., long $117^{\circ} 51.71^{\prime}$ W. Collected by R.L. Smith and W.A. Duffield. Bacon and others (1981, sample No. 13).

58 (CD-4A) Lithophysal obsidian, lava dome, Coso Volcanic Field, Inyo County, California. Lat 
$36^{\circ} 4.86^{\prime}$ N., long $117^{\circ} 51.08^{\prime}$ W. Collected by R.L. Smith and W.A. Duffield. Bacon and others (1981, sample No. 10).

59 (CD-5) Spherulitic obsidian, lava dome, Coso Volcanic Field, Inyo County, California. Lat $36^{\circ} 4.73^{\prime}$ N., long $117^{\circ} 51.44^{\prime}$ W. Collected by R.L. Smith and W.A. Duffield. Bacon and others (1981, sample No. 14)

60 (CD-17) Obsidian, lava dome. Coso Volcanic Field Inyo County, California. Lat $36^{\circ} 3.07^{\prime}$ N., long $117^{\circ} 49.13^{\prime}$ W. Collected by R.L. Smith and W.A. Duffield. Bacon and others (1981, sample No. 15)

61 (CD-22) Obsidian, lava dome, Coso Volcanic Field, Inyo County, California. Lat $36^{\circ} 1.89^{\prime}$ N., long $117^{\circ} 50.46^{\prime}$ W. Collected by R.L. Smith and W.A. Duffield. Bacon and others (1981, sample No. 19).

62 (CD-7) Obsidian, lava dome, Coso Volcanic Field, Inyo County, California. Lat $36^{\circ} 6.15^{\prime}$ N., long $117^{\circ} 48.21^{\prime}$ W. Collected by R.L. Smith and W.A. Duffield. Bacon and others (1981, sample No. 5).

63 (CD-20) Obsidian, Apache tears, lava dome, Coso Volcanic Field, Inyo County, California. Lat $36^{\circ} 2.48^{\prime}$ N., long $117^{\circ} 48.58^{\prime}$ W. Collected by R.L. Smith and W.A. Duffield. Bacon and others (1981, sample No. 16).

64 (CD-23) Obsidian, lava flow, Coso Volcanic Field, Inyo County, California. Lat $36^{\circ} 1.32^{\prime} \mathrm{N}$., long $117^{\circ} 49.46^{\prime}$ W. Collected by R.L. Smith and W.A. Duffield. Bacon and others (1981, sample No. 20).

65 (CD-30) Scoriaceous obsidian, lava flow, Coso Volcanic Field, Inyo County, California. Lat $35^{\circ} 59.76^{\prime}$ N., long $117^{\circ} 48.5^{\prime} \mathrm{W}$. Collected by R.L. Smith and W.A. Duffield. Bacon and others (1981, sample No. 24).

66 (CD-33) Spherulitic obsidian, lava dome, Coso Volcanic Field, Inyo County, California. Lat $35^{\circ} 59.39^{\prime}$ N., long $117^{\circ} 48.94^{\prime}$ W. Collected by R.L. Smith and W.A. Duffield. Bacon and others (1981, sample No. 25).

67 (CD-8) Obsidian, lava dome, Coso Volcanic Field, Inyo County, California. Lat $36^{\circ} 5.54^{\prime}$ N., long $117^{\circ} 47.29^{\prime}$ W. Collected by R.L. Smith and W.A. Duffield. Bacon and others (1981, sample No. 4).

68 (CD-12) Lithophysal obsidian, lava dome, Cactu Peak, Coso Volcanic Field, Inyo County, California. Lat $36^{\circ} 4.73^{\prime}$ N., long $117^{\circ} 49.21^{\prime} \mathrm{W}$. Collected by R.L. Smith and W.A. Duffield. Bacon and others (1981, sample No. 6).

69 (CD-14) Obsidian, lava dome, Coso Volcanic Field, Inyo County, California. Lat $36^{\circ} 3.92^{\prime} \mathrm{N}$., long $117^{\circ} 49.75^{\prime}$ W. Collected by R.L. Smith and W.A. Duffield. Bacon and others (1981, sample No. 27).
70 (CD-18) Obsidian, lava dome, Coso Volcanic Field, Inyo County, California. Lat $36^{\circ} 3.01^{\prime}$ N., long $117^{\circ} 48.95^{\prime}$ W. Collected by R.L. Smith and W.A. Duffield. Bacon and others (1981, sample No. 17)

71 (CD-19) Obsidian, Apache tears, lava dome, Coso Volcanic Field, Inyo County, California. Lat $36^{\circ} 2.77^{\prime}$ N., long $117^{\circ} 48.36^{\prime} \mathrm{W}$. Collected by R.L. Smith and W.A. Duffield. Bacon and others (1981, sample No. 18).

72 (CD-21A) Obsidian, lava flow, Sugarloaf Mountain Coso Volcanic Field, Inyo County, California. Lat $36^{\circ} 1.49^{\prime} \mathrm{N}$., long $117^{\circ} 49.05^{\prime} \mathrm{W}$. Collected by R.L. Smith and W.A. Duffield. Bacon and others (1981, sample No. 26).

\section{Salton Sea Volcanic Field}

73 (49) Obsidian, lava dome, Obsidian Butte, Salton Sea, Imperial County, California. Lat $33^{\circ} 10.14$ N., long $115^{\circ} 38.23^{\prime}$ W. Collected by R.L. Smith and L.J.P. Muffler.

74 (50) Obsidian, lava dome, Red Island, Salton Sea Imperial County, California. Lat $33^{\circ} 11.89^{\prime} \mathrm{N}$., long $115^{\circ} 36.61^{\prime}$ W. Collected by R.L. Smith and L.J.P. Muffler

75 (212) Obsidian, lava dome, Mullet Island, Salton Sea, Imperial County, California. Lat $33^{\circ} 13.51$ N., long $115^{\circ} 36.45^{\prime}$ W. Supplied by K.J. Murata.

\section{NEVADA}

\section{Pershing Count}

76 (21) Obsidian, Apache tear, residual in perlite near head of Cow Creek, north end of Seven Troughs Range, Pershing County, Nevada. Lat $40^{\circ} 35.68^{\prime} \mathrm{N}$., long $118^{\circ} 46.43^{\prime} \mathrm{W}$. Collected by R.L. Smith and D.B. Tatlock. Major element analyst: Elaine L. Munson, Denver RAL, USGS. Analysis previously unpublished.

77 (29) Obsidian, Apache tear, residual in perlite, miles southeast of Rabbit Hole, Pershing County, Nevada. Lat $40^{\circ} 38.24^{\prime}$ N., long $118^{\circ} 39.82^{\prime} \mathrm{W}$. Collected by R.L. Smith and D.B. Tatlock. Major element analyst: Elaine L. Munson, Denver RAL, USGS. Analysis previously unpublished.

78 (31) Obsidian, Apache tear, residual in perlite U.S. Gypsum perlite mine, Trinity Range, 8 miles northwest of Lovelock, Pershing County, Nevada. Lat $40^{\circ} 17.3^{\prime} \mathrm{N}$., long $118^{\circ} 33.53^{\prime} \mathrm{W}$. Collected by R.L. Smith and D.B. Tatlock. Major element analyst: Elaine L. Munson, Denver RAL, USGS. Analysis previously unpublished.

79 (74) Obsidian, residual litter on distal part of eroded lava flow from McGee Mountain. Nevada Highway 120, Humboldt County, Nevada. La $41^{\circ} 54.32^{\prime}$ N., long $118^{\circ} 58.83^{\prime}$ W. Collected by R.L. Smith and H.R. Shaw.

\section{Esmeraida County}

80 (226) Obsidian, cobble in alluvial fan, from unknown source in Clayton Ridge, Esmeralda County, Nevada. Lat $37^{\circ} 39^{\prime}$ N., long $117^{\circ} 33^{\prime}$ W. Supplied by J.R. Davis.

81 (202) Obsidian, Apache tear, residual in perlite, basal glass of lava flow, northeast end of Monte Cristo Range, Esmeralda County, Nevada. Lat $38^{\circ} 13.78^{\prime}$ N., long $117^{\circ} 36.51^{\prime}$ W. Supplied by M.L. Silberman.

\section{Timber Mountain Volcanic Field}

82 (14) Obsidian, Apache tears, residual in perlite basal glass of lava flow, rhyolite of Shoshone Mountain, Nevada Test Site, Nye County, Nevada. Lat $37^{\circ} 1.08^{\prime} \mathrm{N}$, long $116^{\circ} 18.14^{\prime} \mathrm{W}$. Collected by R.L. Smith and P.P. Orkild. Major element analyst: Ellen S. Daniels, Denver RAL, USGS. Analysis previously unpublished.

\section{IDAHO}

\section{S nake River Plain}

83 (75) Obsidian, erosional litter from lava dome south side of Big Southern Butte, Butte County, Idaho. Lat $43^{\circ} 23.11^{\prime} \mathrm{N}$., long $113^{\circ} 0.56^{\prime} \mathrm{W}$. Collected by R.L. Smith and R.G. Luedke.

84 (151) Obsidian, welded tuff, archetype deposit, near Ammon, Bonneville County, Idaho. Lat $43^{\circ} 23.51^{\prime}$ N., long $111^{\circ} 51.48^{\prime}$ W. Collected by C.S. Ross and R.L. Smith.

85 (152) Obsidian, welded tuff, Walcott Tuff, Snake River Canyon below American Falls, Power County, Idaho. Lat $42^{\circ} 46.62^{\prime}$ N., long $112^{\circ} 52.41^{\prime}$ W. Collected by R.L. Smith.

\section{Blackfoot Volcanic Field}

86 (185) Porphyritic obsidian, incipiently spherulitic lava dome, southwest side of Middle Cone, Blackfoot Lava Field, Caribou County, Idaho.

\section{.}


Lat $42^{\circ} 49.32^{\prime} \mathrm{N}$, long $111^{\circ} 36.04^{\prime} \mathrm{W}$. Collected by R.L. Smith and R.G. Luedke.

87 (188) Porphyritic obsidian, incipiently spherulitic, lava dome, southwest side of North Cone, Blackfoot Lava Field, Caribou County, Idaho. Lat $42^{\circ} 50^{\prime} \mathrm{N}$., long $111^{\circ} 34.94^{\prime} \mathrm{W}$. Collected by R.L. Smith and R.G. Luedke.

88 (191) Porphyritic obsidian, incipiently spherulitic, lava dome, north side of China Hat, Blackfoot Lava Field, Caribou County, Idaho. Lat $42^{\circ} 48.92^{\prime}$ N., long $111^{\circ} 36.31^{\prime} \mathrm{W}$. Collected by R.L. Smith and R.G. Luedke.

\section{WYOMING}

\section{Yeulowstone Volcanic Field}

89 (7YC-288A) Apache tears from densely fused airfall tuff, just below base of ash-flow tuff of Member A, Huckleberry Ridge Tuff, Island Park Caldera, Yellowstone National Park, Wyoming. Sample from bluff on south rim of Mt. Everts about $1.4 \mathrm{~km}$ northwest of Undine. Lat $44^{\circ} 57.5^{\prime}$ N., long $110^{\circ} 39.36^{\prime}$ W. Supplied by R.L. Christiansen. Sparse phenocrysts.

90 (267) Obsidian, rhyolite of Gibbon River flow, from low plateau about $2 \mathrm{~km}$ southeast of Norris Geyser Basin. Yellowstone National Park, Wyoming. Lat $44^{\circ} 42.77^{\prime} \mathrm{N}$., long $110^{\circ} 42.15^{\prime} \mathrm{W}$. Supplied by R.L. Christiansen. No. 65YR-7. Sparse phenocrysts.

91 (268) Obsidian, phenocrystic, rhyolite of Summit Lake flow, from top of bluffs on west side of Black Sand Basin (Upper Geyser Basin), Yellowstone National Park, Wyoming. Lat $44^{\circ} 27.57^{\prime}$ N., long $110^{\circ} 52.03^{\prime}$ W. Supplied by R.L. Christiansen. No. 6YC-73.

92 (269) Obsidian, phenocrystic, rhyolite of Elephant Back flow, from Elephant Back about $2 \mathrm{~km}$ northwest of Fishing Bridge, Yellowstone National Park, Wyoming. Lat $44^{\circ} 34.73^{\prime}$ N., long $110^{\circ} 24.49^{\prime}$ W. Supplied by R.L. Christiansen. No. $8 \mathrm{YC}-374 \mathrm{C}$

93 (270) Obsidian, rhyolite of Crystal Spring flow, from $350 \mathrm{~m}$ northeast of Obsidian Lake, Yellowstone National Park, Wyoming. Lat $44^{\circ} 50.74^{\prime}$ N., long $110^{\circ} 42.53^{\prime} \mathrm{W}$. Supplied by R.L. Christiansen. No. 8YC-396A.

94 (271) Obsidian, rhyolite of Obsidian Cliff flow, from near mouth of dry gully, about $0.6 \mathrm{~km}$ east of Lake of the Woods, Yellowstone National Park, Wyoming. Lat $44^{\circ} 28.24^{\prime}$ N., long $110^{\circ} 42.44^{\prime}$ W.
Lipman and others (1969, table 1 , No. 15) Zielinski and others (1977, table 1). Our sample supplied by R.L. Christiansen. No. 6YC-64.

\section{UTAH}

95 (106) Obsidian, Apache tears, residual litter from lava flow on south side of Wildcat Hills, Box Elder County, Utah. Lat $41^{\circ} 49.46^{\prime}$ N., long $113^{\circ} 1.81^{\prime}$ W. Collected by R.L. Smith and R.G. Luedke.

96 (116) Snowflake obsidian, strongly annealed, lava dome, White Mountain, Millard County, Utah. Lat $38^{\circ} 54.86^{\prime}$ N., long $112^{\circ} 29.83^{\prime}$ W. Collected by R.L. Smith and R.G. Luedke.

\section{Twin Peaks Volcanic Field}

97 (103) Obsidian, lava, east of South Twin Peak, residual in perlite, rhyolite of Cudahy Mine, Twin Peak Volcanic Field, Millard County, Utah. Lat $38^{\circ} 44.86^{\prime}$ N., long $112^{\circ} 44.48^{\prime} \mathrm{W}$. Collected by R.L. Smith and H.R. Shaw.

98 (104) Obsidian, northwest lava flow, blocks from breccia, rhyolite of Cudahy Mine, Twin Peaks Volcanic Field, Millard County, Utah. Lat $38^{\circ} 46.35^{\prime}$ N., long $112^{\circ} 49.83^{\prime}$ W. Collected by R.L. Smith and H.R. Shaw.

99 (105) Obsidian, alluvial blocks from southwest lava flow, rhyolite of Cudahy Mine, Twin Peaks Volcanic Field, Millard County, Utah. Lat $38^{\circ} 43.51^{\prime}$ N., long $112^{\circ} 49.48^{\prime} \mathrm{W}$. Collected by R.L. Smith and H.R. Shaw.

\section{Mineral Mountains Volcanic Fifld}

100 (136) Obsidian, lava flow, nose of Bailey Ridge flow, Mineral Mountains, Beaver County, Utah. Lat $38^{\circ} 29.05^{\prime} \mathrm{N}$., long $112^{\circ} 49.74^{\prime} \mathrm{W}$. Collected by R.L. Smith and W.P. Nash.

101 (137) Obsidian, lava flow, northeast side of Bailey Ridge flow, Mineral Mountains, Beaver County, Utah. Lat $38^{\circ} 29.19^{\prime}$ N., long $112^{\circ} 49.05^{\prime}$ W Collected by R.L. Smith and W.P. Nash.

102 (138) Porphyritic obsidian, clast from air-fall deposit, residual litter on granite ridge crest near northernmost rhyolite dome, northern Mineral Mountains, Beaver County, Utah. Lat $38^{\circ} 31.08^{\prime}$ N., long $112^{\circ} 47.93^{\prime}$ W. Collected by R.L. Smith and W.P. Nash.

103 (139) Obsidian, lava flow, nose of Wildhorse Canyon flow, Mineral Mountains, Beaver
County, Utah. Lat $38^{\circ} 26.49^{\prime}$ N., long $112^{\circ} 50.86^{\prime}$ W. Collected by R.L. Smith and W.P. Nash.

\section{COLORADO}

NATHROP AREA

104 (33) Obsidian, Apache tears, lava dome (rhyolite of Nathrop), Bald Mountain, near Nathrop, Chaffee County, Colorado. Lat $38^{\circ} 47.03^{\prime}$ N., long $106^{\circ} 1.72^{\prime}$ W. Collected by R.L. Smith and R.E. Van Alstine. Major element analyst: Elaine L. Munson, Denver RAL, USGS. Partial analysis and mode published in Lipman and others (1968, table 1, No. 11); remainder of analysis previously unpublished.

105 (65L-161-A) Obsidian, Apache tears, basal glass of lava dome, Beaver Creek, San Juan Mountains, Rio Grande County, Colorado. Lat $37^{\circ} 34.46^{\prime}$ N., long $106^{\circ} 39.61^{\prime} \mathrm{W}$. Supplied by P.W. Lipman. Major element analysis and mode from Lipman (1975, table 11, No. 11) except $\mathrm{H}_{2} \mathrm{O}^{+}, \mathrm{H}_{2} \mathrm{O}, \mathrm{Cl}$, and $\mathrm{F}$, taken from Lipman and others (1968 table 1, No. 1). Minor elements from Zielinski and others (1977, table 1).

\section{ARIZONA}

SUPERIOR

106 (35) Obsidian, Apache tears (archetype deposit), lava, Queen Creek near the Old Pinal Townsite, Pinal County, Arizona. Lat $33^{\circ} 17^{\prime}$ N., long $11^{\circ} 8.5^{\prime}$ W. Collected by R.L. Smith and D.W. Peterson. Major element analyst: Paula M. Bushman, Denver RAL, USGS. Analysis previously unpublished.

\section{San Francisco Mountains Volcanic Fitld}

107 (48) Obsidian, block from lava dome, Government Mountain, San Francisco Volcanic Field, Coconino County, Arizona. Lat $35^{\circ} 20.68^{\prime} \mathrm{N}$., long $111^{\circ} 54.4^{\prime}$ W. Collected by R.L. Smith and H.R. Shaw.

108 (53) Obsidian, annealed relict mass in spherulitic domain, lava dome, southeast unit of Sitgreaves cluster, San Francisco Volcanic Field, Coconino County, Arizona. Lat $35^{\circ} 20^{\prime}$ N., long $111^{\circ} 58.35$ W. Collected by R.L. Smith and H.R. Shaw.

109 (47) Obsidian, lava dome. R. S. Hill, outlier of Sitgreaves cluster, San Francisco Volcanic 
Field, Coconino County, Arizona. Lat $35^{\circ} 21.62^{\prime}$ N., long $111^{\circ} 57.53^{\prime} \mathrm{W}$. Collected by R.L. Smith and H.R. Shaw.

\section{NEW MEXICO}

\section{Taos Plateau Volcanic Fielo}

110 (27) Obsidian, Apache tears, lava dome. Cerros No Agua, Taos County, New Mexico. Lat $36^{\circ} 45.68^{\prime}$ N., long $105^{\circ} 56.97^{\circ} \mathrm{W}$. Collected by C.S. Ross and R.L. Smith. An analysis of perlite associated with this obsidian is shown as sample 218 (28).

111 (66L-23-A) Obsidian, Apache tears, lava dome. Cerros No Agua, Taos County, New Mexico. Lat $36^{\circ} 45.68^{\prime}$ N., long $105^{\circ} 56.97^{\prime}$ W. Supplied by P.W. Lipman. This sample, studied by Lipman and others (1969, table 1, No. 5) and by Zielinski and others (1977), is clearly different chemically from our sample 110 (27) collected by Ross and Smith and studied by them (1955 p. 1081, table 1, No. 5a) and by Friedman and Smith (1958, p. 224, table 1, No. 36-3). The latitude and longitude given here are the same as for our sample 110 and are probably slightly incorrect.

\section{Jemez Mountains Volcanic Field}

112 (200) Obsidian, Apache tears, lava flow, Canovas Canyon Rhyolite, southern Jemez Mountains, Sandoval County, New Mexico. Lat $35^{\circ} 40.14^{\prime}$ N. long $106^{\circ} 34.08^{\prime}$ W. Collected by R.L. Smith and R.A. Bailey.

113 (15) Obsidian, Apache tears, lava flow, Canova Canyon Rhyolite, southern Jemez Mountains, Sandoval County, New Mexico. Lat $35^{\circ} 41.76^{\circ}$ N., long $106^{\circ} 34.5^{\prime}$ W. Collected by C.S. Ross and R.L. Smith. Major element analyst: Elaine L. Munson, Denver RAL, USGS. Analysis previously unpublished.

114 (25) Obsidian, Apache tears, lava dome, E Rechuelos Rhyolite, northern Jemez Mountains, Rio Arriba County, New Mexico. Lat $36^{\circ} 3.92^{\prime}$ N., long $106^{\circ} 25.5^{\prime}$ W. Collected by R.L. Smith. Major element analyst: Elaine L. Munson, Denver RAL, USGS. Analysis previously unpublished.

115 (73) Obsidian, annealed mini-columns, lava dome carapace, El Rechuelos Rhyolite, northern Jemez Mountains, Rio Arriba County, New
Mexico. Lat $36^{\circ} 2.97^{\prime}$ N., longitude $106^{\circ} 25.33^{\prime}$ W. Collected by R.L. Smith and R.A. Bailey.

116 (194) Obsidian, cobble from alluvial deposit, from lava dome, El Rechuelos Rhyolite, northern Jemez Mountains, Rio Arriba County, New Mexico. Lat $36^{\circ} 7.97^{\prime}$ N., long $106^{\circ} 25.33^{\prime} \mathrm{W}$. Collected by R.L. Smith.

117 (17) Obsidian, block from hot avalanche deposit from lava dome, Cerro Toledo Rhyolite Obsidian Ridge, east-central Jemez Mountains, Sandoval County, New Mexico. Lat $35^{\circ} 48.6^{\prime} \mathrm{N}$. long $106^{\circ} 24.5^{\prime} \mathrm{W}$. Collected by C.S. Ross and R.L. Smith. Major element analyst: Elaine L. Munson, Denver RAL, USGS. Analysis previously unpublished.

118 (72) Obsidian, block (clast) eroded from vent tuffs, Cerro Toledo Rhyolite, Santa Clara Canyon, north-central Jemez Mountains, Rio Arriba County, New Mexico. Lat $36^{\circ} 0.27^{\prime}$ N., long $106^{\circ} 25.67^{\prime}$ W. Collected by R.L. Smith.

119 (76-61) Obsidian, block, lava dome, Valles Rhyolite, top of Cerro del Medio, Valles Caldera, Sandoval County, New Mexico. Lat $35^{\circ} 54.32^{\prime}$ N., long $106^{\circ} 26.92^{\prime}$ W. Collected by R.L. Smith. Major element analyst: Vertie C. Smith, Denver RAL, USGS. Analysis previously unpublished.

120 (Posos) Obsidian, lithophysal block, alluvial from lava flow, Valles Rhyolite northwest flank Cerro del Medio, Valles Caldera, Sandoval County, New Mexico. Lat $35^{\circ} 56.22^{\prime}$ N., long $106^{\circ} 26.83^{\prime}$ W. Collected by C.S. Ross and R.L. Smith. This obsidian has long been used as a reference standard and may well have been used for a greater variety of measurements than any other obsidian. The locality has been referred to by many names by many authors: Los Posos, Posos, San Antonio, Puerto de Abrigo, Valles Caldera, and simply Jemez Mountains or New Mexico. The locality once supplied spectacular lithophysae containing cristobalite, alkali feldspar, fayalite, and magnetite, but over-collecting has made choice samples scarce. Major element analyst: Vertie C. Smith, Denver RAL, USGS. Analysis previously unpublished.

121 (76-79) Porphyritic obsidian, incipient hydration on cracks, lava flow, Valles Rhyolite, Banco Bonito, Valles Caldera, Sandoval County, New Mexico. Lat $35^{\circ} 50.14^{\prime} \mathrm{N}$., long $106^{\circ} 34.5^{\prime} \mathrm{W}$. Collected by R.L. Smith and R.A. Bailey. Major element analyst: Vertie C. Smith, Denver RAL, USGS. Analysis previously unpublished.
Mogollon Volcanic Area

122 (102) Obsidian, Apache tears, lava flow, Big Lue Mountains area, Grant County, New Mexico. Lat $33^{\circ} 8.11^{\prime}$ N., long $109^{\circ} 1.77^{\prime}$ W. Supplied by James C. Ratte.

\section{MEXICO}

123 (131) Obsidian, lithophysae, lava flow, $\mathrm{km} 747$, Mexico Federal Highway 15 near Magdalena Jalisco, Mexico. Lat $20^{\circ} 54.5^{\prime}$ N., long $103^{\circ} 54^{\prime}$ W. Collected by R.L. Smith.

124 (130) Obsidian, phenocrystic, lava flow, km 744 Mexico Federal Highway 15 near Magdalena, Jalisco, Mexico. Lat $20^{\circ} 54.5^{\prime}$ N., long $103^{\circ} 53.5^{\prime}$ W. Collected by R.L. Smith.

125 (140) Obsidian, Apache tear, lava flow, top of plateau south of Rio Santiago, Federal Highway 70, north of Guadalajara, Jalisco, Mexico. Lat $20^{\circ} 43^{\prime}$ N., long $103^{\circ} 17.5^{\prime}$ W. Collected by R.L. Smith.

126-137 (See table for collection numbers.) Obsidians (some microvesicular) from lava flows and domes, Sierra la Primavera volcano complex, Jalisco, Mexico. Approx lat $20^{\circ} 35^{\prime}$ N., approx long $103^{\circ} 32^{\prime} \mathrm{W}$. Samples supplied by Gail Mahood. Sample localities, descriptions, and coordinates are given in Mahood (1981a, appendix 1, p. 147).

138 (274) Obsidian, residual blocks from lava flow, Jeraguero, Michoacan, Mexico. Approx la $19^{\circ} 54.5^{\prime}$ N., approx long $100^{\circ} 30.5^{\prime}$ W. Collected by R.L. Smith.

139 (275) Obsidian, blocks in lava flow, roadside quarry, Zinapécuaro, Michoacan, Mexico. La $19^{\circ} 50.5^{\prime}$ N., long $100^{\circ} 50^{\prime}$ W. Collected by R.L. Smith.

140 (276) Obsidian, clast in coarse pyroclastic deposit, quarry east of Acámbaro, Guanajuato, Mexico. Lat $20^{\circ} 01^{\prime}$ N., long $100^{\circ} 39^{\prime}$ W. Collected by R.L. Smith.

141 (273) Obsidian, porphyritic block in lava flow, roadcut Los Azufres, Cerro San Andres, Michoacan, Mexico. Approx lat $19^{\circ} 49^{\prime} \mathrm{N}$ approx long $100^{\circ} 41^{\prime}$ W. Collected by R.L. Smith.

142 (280) Obsidian, clast in ash flow, Punte Carretara, Los Humeros volcanic complex, Vera Cruz, Mexico. Lat $19^{\circ} 42^{\prime} \mathrm{N}$., long $97^{\circ} 15.5^{\prime} \mathrm{W}$. Collected by R.L. Smith and C. Yáñez.

143 (277) Obsidian, lava flow, Oyameles Rhyolite, west wall of Los Potreros Caldera, Los Humeros 
volcanic complex, Puebla, Mexico. Lat $19^{\circ} 43^{\prime} \mathrm{N}$., long $97^{\circ} 30.5^{\prime} \mathrm{W}$. Collected by R.L. Smith and C. Yáñez.

144 (278) Obsidian porphyritic, rhyolite lava of Cueva Ahumada, Los Potreros Caldera, Los Humeros volcanic complex, Puebla, Mexico. Lat $19^{\circ} 40^{\prime} \mathrm{N}$., long $97^{\circ} 27^{\prime} \mathrm{W}$. Collected by R.L. Smith and C. Yáñez.

145 (279) Obsidian, microvesicular clast, rhyolitic maar deposit, El Xalapazquillo, southeast of Las Derrumbadas, Puebla, Mexico. Lat $19^{\circ} 14^{\prime}$ N., long $97^{\circ} 26^{\prime}$ W. Collected by R.L. Smith and C. Yáñez.

146 (125) Obsidian, phenocrystic, exact provenance uncertain. This obsidian was collected in 1950 by the late Carl Fries, Jr., and labeled by him, Xalapazquillo, Puebla, Mexico. The obsidian, together with many textural variants (pumice, scoria, and so forth), was sent along with obsidian from other localities to C.S. Ross, and studied by Ross and Smith (1955), and was considered unusual by them because of its high $\mathrm{H}_{2} \mathrm{O}$ content and peculiar physical properties. After the death of Fries, several unsuccessful attempts were made to relocate this source. Part of the problem may involve the term Xalapazquillo as a proper place name. Maps of the region show many "Xalapazco's" and "Xalapazquillo's" applied to maars, most of which are associated with basalts. However in 1980 , Smith was guided to a rhyolitic Xalapazquillo by C. Yáñez who was mapping in the Las Derrumbadas area. A sample collected at that time is included in our present study and is listed as No. 145 (279) above. This sample is also a high-water obsidian and, although it shows strong chemical similarities to 146 (125) and 147 (126), it is clearly a different glass. The true source for the Fries samples remains uncertain, although the chemical signatures indicate a strong provincial relation between the two sources.

147 (126) Obsidian. A second sample similar to 146 (125) from the same locality.

148 (127) Obsidian, highway cut between $\mathrm{km} 145$ and 146 about $5 \mathrm{~km} \mathrm{~N}$.-NE. of Tulancingo, Hidalgo, Mexico (Tuxpan Highway). Lat $20^{\circ} 6.5^{\prime}$ N., long $98^{\circ} 20.5^{\prime}$ W. Supplied by C. Fries, Jr., 1959.

149 (128) Obsidian, from Las Minitas about $4 \mathrm{~km}$ east of Rancho Guajolote, Hidalgo, Mexico. Approx lat $20^{\circ} 08^{\prime}$ N., long $98^{\circ} 38^{\prime} \mathrm{W}$. Supplied by C. Fries, Jr., 1959.

150 (132) Obsidian, from Tulancingo, Hidalgo, Mexico. Specific locality uncertain, but probably related to 149 (128) by their chemical similarity. Supplied by C. Fries, Jr., 1959.

151 (129) Obsidian, from road metal pit near Zacualtipán, near junction with road to Huayacocotla, Hidalgo, Mexico. Lat $20^{\circ} 37^{\prime}$ N., long $98^{\circ} 37.5^{\prime}$ W. Supplied by C. Fries, Jr., 1959.

\section{CENTRAL AMERICA}

\section{GUATEMALA}

152 (134) Obsidian, El Fiscal, Guatemala. Approx lat $14^{\circ} 44^{\prime}$ N., approx long $90^{\circ} 21.3^{\prime} \mathrm{W}$. Supplied by Alexander R. McBirney, No. G-637.

153 (135) Obsidian, Cerro Ixtepequa, Guatemala Approx lat $14^{\circ} 24.5^{\prime} \mathrm{N}$., aproximate long $89^{\circ} 59.5^{\prime}$ W. Supplied by Alexander R. McBirney, No. G664.

\section{SOUTH AMERICA}

\section{COLOMBIA}

154 (133) Obsidian, phenocrystic, microvesicular, welded breccia, lava near Popayan, Colombia. Approx lat $2^{\circ} 25^{\prime}$ N., approx long $76^{\circ} 32^{\prime} \mathrm{W}$. Supplied by I. Friedman.

\section{ECUADOR}

155 (146) Obsidian, lava flow, Caldera Chacana, Pintag, Provincia de Pichincha, near Volcan Antisana, Ecuador. Approx lat $0^{\circ} 30^{\prime}$ S., approx long $78^{\circ} 12^{\prime}$ W. Supplied by M.L. (Pete) Hall. No. 38-18.

\section{ECUADOR (GALAPAGOS ISLANDS )}

156 (186) Obsidian, phenocrystic, agglutinate lava flow on southwest floor of Alcedo caldera, Isla Isabela, Galapagos Islands, Ecuador. Lat $0^{\circ} 26.4^{\prime}$ S., long $91^{\circ} 7.3^{\prime}$ W. Supplied by Keith A. Howard.

157 (192) Obsidian, phenocrystic, probably agglutinated precaldera lava on southeast rim of Alcedo caldera, Isla Isabela, Galapagos Islands, Ecuador. Lat $0^{\circ} 26.1^{\prime}$ S., long $91^{\circ} 5.2^{\prime}$ W. Supplied by Keith A. Howard.

158 (193) Obsidian, phenocrystic, agglutinate, post(?)caldera lava flow on southwest flank of Alcedo volcano, Isla Isabela, Galapagos Islands, Ecuador. Lat $0^{\circ} 30.8^{\prime}$ S., long $91^{\circ} 7.8^{\prime}$ W. Supplied by Keith A. Howard.
PERU

159 (206) Obsidian, specific locality unknown. Supplied by G.E. Ericksen.

160 (215) Obsidian, float cobble, collected near Macusani. Lat $14^{\circ} 4^{\prime} \mathrm{S}$., long $70^{\circ} 27^{\prime}$ W. Supplied by P.A. Jezek.

\section{CHILE (BOLIVIA?)}

161 (225) Obsidian, block of densely welded breccia found in a mining camp near Chiguana, Bolivia, by Keith A. Howard and sent to R.L. Smith as a probable Andean obsidian. Further research by Smith on samples not considered in this compendium suggests that this obsidian is almost certainly from Chile. It is chemically indistinguishable from obsidians from the region of the Jarellon caldera near the three corners of Bolivia, Chile, and Argentina. Lat $22^{\circ} 55^{\prime} \mathrm{S}$. and long $67^{\circ} 26^{\prime} \mathrm{W}$.

162 (203) Obsidian, dome lava, Laguna del Maule area central Chile. Lat $36^{\circ} 02^{\prime} \mathrm{S}$., long $70^{\circ} 26^{\prime} \mathrm{W}$. Supplied by Francisco Munizaga (sample FM68) by courtesy of G.E. Ericksen.

163 (204) Obsidian, dome lava, Laguna del Maule area central Chile. Lat $36^{\circ} 02^{\prime} \mathrm{S}$., long $70^{\circ} 26^{\prime} \mathrm{W}$. Supplied by Francisco Munizaga (sample FM67A) by courtesy of G.E. Ericksen.

164 (205) Obsidian, lava flow, Laguna del Maule, central Chile. Lat $36^{\circ} 0.5^{\prime} \mathrm{S}$., long $70^{\circ} 34.5^{\prime} \mathrm{W}$. Supplied by Francisco Munizaga (sample FM13) by courtesy of G.E. Ericksen.

165 (220) Obsidian, lava flow, Laguna del Maule, central Chile. Lat $36^{\circ} 05.5^{\prime} \mathrm{S}$., long $70^{\circ} 31^{\prime} \mathrm{W}$. Supplied by Francisco Munizaga (sample FM 78) by courtesy of G.E. Ericksen.

166 (221) Obsidian, lava flow, Laguna del Maule, central Chile. Lat $36^{\circ} 08^{\prime} \mathrm{S}$, long $70^{\circ} 27^{\prime} \mathrm{W}$. Supplied by Francisco Munizaga (sample FM 81) by courtesy of G.E. Ericksen.

\section{ANTARCTICA}

\section{SOUTH SHETLAND ISLANDS}

167 (213) Obsidian, lava block, Ross Hill, Deception Island. Lat $62^{\circ} 56^{\prime}$ S., long $60^{\circ} 34^{\prime}$ W. Supplied by P.E. Baker 


\section{EUROPE}

\section{ICELAND}

168 (180) Obsidian, upper Quaternary dome lava, Botna-skyrtunna, Ljósufjöll central volcano, western Iceland. Lat $64^{\circ} 56^{\prime}$ N., long $22^{\circ} 34^{\prime} \mathrm{W}$. Supplied by H. Sigurdsson. Major element analysis in Bailey and Macdonald (1970, table 1, No. 7, No. 491)

169 (1) Obsidian, phenocrystic, Apache tears, dome lava, Prestahnukur, southwest base of Geitlandsjökull, Iceland. Lat $63^{\circ} 45.31^{\prime}$ N., long $20^{\circ} 42^{\prime}$ W. Collected by R.L. Smith and Tomas Trygvasson. D/H data by Friedman and Smith (1958), ${ }^{16} \mathrm{O} /{ }^{18} \mathrm{O}$ data by Muelenbachs (1973). Major element analyst: Ellen S. Daniels, Denver RAL, USGS. Analysis previously unpublished.

170 (11) Obsidian, another sample from Prestahnukur, Iceland. Same locality as 169 (1) but smaller Apache tears and darker glass. Major element analyst: Ellen S. Daniels, Denver RAL, USGS. Analysis previously unpublished.

171 (42) Obsidian, residual boulder litter from rhyolitic volcano, hot spring area near headwaters of major north-flowing stream, Kerlingarfjöll, southwest of the Hofsjökull, central Iceland. Lat $63^{\circ} 51.84^{\prime}$ N., long $19^{\circ} 15.16^{\prime}$ W. Collected by R.L. Smith and Tomas Trygvasson.

172 (177) Obsidian, Holocene lava flow, Hrafntinnuhraun, Torfajökull central volcano, south Iceland. Lat $63^{\circ} 58^{\prime} \mathrm{N}$., long $19^{\circ} 16^{\prime} \mathrm{W}$. Supplied by H. Sigurdsson, No. 426.

173 (178) Obsidian, Holocene lava flow, Laugahraun, Torfajökull central volcano, south Iceland. Lat $63^{\circ} 59^{\prime} \mathrm{N}$, long $19^{\circ} 06^{\prime}$ W. Supplied by $\mathrm{H}$ Sigurdsson, No. 462

174 (176) Obsidian, Holocene lava flow, Domadalshraun, Torfajökull central volcano, south Iceland. Lat $64^{\circ} 02^{\prime} \mathrm{N}$., long $19^{\circ} 07^{\prime} \mathrm{W}$. Supplied by H. Sigurdsson, No. 424

175 (37) Obsidian, dome lava, dikelike ridge, Hrafntinnuhryggur, Krafla, northeast Iceland. Lat $65^{\circ} 6.04^{\prime}$ N., long $16^{\circ} 43.37^{\prime}$ W. Collected by R.L. Smith and I. Friedman.

176 (61) Obsidian, agglutinate mantle, vulcanian phase of 1875 eruption of Askja volcano Iceland. Lat $65^{\circ} 2^{\prime} \mathrm{N}$., long $16^{\circ} 42^{\prime} \mathrm{W}$. Supplied by R.S.J. Sparks, No. As 238.
177 (68) Obsidian, Hof rhyolite dome, Oraefi central volcano, southeastern Iceland. Lat $63^{\circ} 56^{\prime}$ N., long $16^{\circ} 44^{\prime}$ W. Supplied by R.S.J. Sparks, No. Or 1.

178 (57) Obsidian, summit caldera domes, Oraefi central volcano, southeastern Iceland. Lat $63^{\circ} 57^{\prime}$ N., long $16^{\circ} 44^{\prime}$ W. Supplied by R.S.J. Sparks, No. Or 2.

\section{ITALY}

179 (209) Obsidian, southeast of Capanna, MTE, Arci, Sardinia, Italy. Approx lat $39^{\circ} 45^{\prime}$ N., approx long $8^{\circ} 35^{\prime}$ E. Supplied by Smithsonian Institution, USNM No. 99252 . Courtesy of W.G. Melson, curator.

180 (65) Obsidian, Roche Rosse lava flow, Lipari Island, Italy. Lat $38^{\circ} 30^{\prime} \mathrm{N}$., long $14^{\circ} 56^{\prime} \mathrm{E}$. Supplied by W.F. Price.

181 (210) Obsidian, Mount Pelato lava, Lipari Island, Italy. Lat $38^{\circ} 30^{\prime} \mathrm{N}$., long $14^{\circ} 56^{\prime} \mathrm{E}$. Supplied by Smithsonian Institution, USNM No. 113108-1. Courtesy of W.G. Melson, curator.

182 (197) Obsidian, lava flow of $1739(?)$, Vulcano, Italy. Highly contaminated with more mafic inclusions. This sample was handpicked to separate the glassy part from the xenoliths. Lat $38^{\circ} 24.5^{\prime} \mathrm{S}$., long $14^{\circ} 58^{\prime} \mathrm{E}$. Supplied by D. Swanson.

\section{TURKEY}

183 (67) Obsidian, flow or dome, Kocadag massif Ismir-Karaburun area, west Turkey. Lat $38^{\circ} 22^{\prime}$ N., long $26^{\circ} 36^{\prime}$ E. Supplied by L. Villari and D.K. Bailey, No. U57.

184 (66) Obsidian, lava flow, northern slope of Sulphan Dag volcano, Lake Van, Armenia, Turkey, Lat $38^{\circ} 56^{\prime} \mathrm{N}$, long $42^{\circ} 48^{\prime}$ E. Supplied by L. Villari and D.K. Bailey, No. Ag 31 .

\section{FORMER SOVIET ARMENIA}

185 (211) Obsidian, probably residual in perlitic lava flow. Location reported as between Erevan and Deliganes (perhaps Dilizhan-RLS), Russian Armenia. Obsidian localities are known along this road southwest of Lake Sevan from volcanoes Gutansar and Atis. Lat (approx) $40^{\circ} 25.91^{\prime}$ N., long (approx) $44^{\circ} 42$ ' E. Supplied by Smithsonian Institution, USNM No. 52092 . Courtesy of W.G. Melson, curator.

\section{JAPAN}

186 (168) Obsidian, porphyritic, Okushiri Island, west of Hokkaido, Japan. Lat $42^{\circ} 10^{\prime}$ N., long $139^{\circ} 30^{\prime}$ E. Supplied by K. Mimura and M. Hata, No. MH-OKI.

187 (198) Glass separate from 186 (168).

188 (145) Obsidian, Wada-Toge Rhyolite, Wada Pass, Nagano Prefecture, Honshu, Japan. Lat $36^{\circ} 09^{\prime}$ N., long $138^{\circ} 8.67^{\prime}$ E. Supplied by K. Mimura, No. WD-2.

189 (165) Obsidian, Kawago-daira lava, Amagi volcano Izu Peninsula, Honshu, Japan. Lat $34^{\circ} 50^{\prime}$ N., long $139^{\circ} 01^{\prime} \mathrm{E}$. Supplied by K. Ono and K. Mimura, JGS Cat. No. R10641.

190 (38) Obsidian, phenocrystic biotite rhyolite, dome lava, Kozu-Shima, Izu Islands, Japan. Lat $34^{\circ} 13^{\prime}$ N., long $139^{\circ} 09^{\prime} \mathrm{E}$. Supplied by the Geological Survey of Japan, Courtesy of N. Isshiki, No. NI600728071.

191 (166) Obsidian, Apache tears, Arita, Saga Prefecture, Kyushu, Japan. Lat $33^{\circ} 13^{\prime}$ N., long $129^{\circ} 55^{\prime}$ E. Supplied by K. Ono and K. Mimura, JGS Cat. No. R11461.

192 (167) Obsidian, Sakanashi rhyolite, Aso caldera Kumamoto Prefecture, Kyushu, Japan. Lat $32^{\circ} 55$ N., long $131^{\circ} 9^{\prime}$ E. Supplied by K. Ono, No. 64AS85.

193 (169) Obsidian, Nagahama rhyolite, Io Jima Island, Kikai caldera, Kagoshima Prefecture, Ryukyu Islands, Japan. Lat $30^{\circ} 47^{\prime} \mathrm{N}$., long $130^{\circ} 18^{\prime} \mathrm{E}$ Supplied by K. Ono, No. 78IO186-3.

194 (207) Obsidian, Ogatake, Narugo volcano, Miyag Prefecture, Honshu, Japan. Lat $38^{\circ} 44^{\prime}$ N., long $140^{\circ} 43^{\prime}$ E. Supplied by the Smithsonian Institution, USNM No. 108980(LIST 53071301). Courtesy of W.G. Melson, curator.

195 (208) Obsidian, Kamitaga, Atami, east coast of Izu Peninsula, Shizuoka Prefecture, Honshu, Japan. Lat $35^{\circ} 05^{\prime}$ N., long $139^{\circ} 05^{\prime}$ E. Supplied by the Smithsonian Institution, USNM No. 108954 Courtesy of W.G. Melson, curator.

\section{INDONESIA}

\section{SUMATRA}

196 (111) Obsidian, occurrence uncertain, South Kenak Besar (Djambi), South Sumatra. Possibly Bukit Besar, lat $2^{\circ} 38^{\prime}$ S., long $101^{\circ} 45^{\prime}$ E. Supplied by M.T. Zen, No. S 9412 . 


\section{KRAKATAU}

197 (110) Obsidian, clast from 1883 eruption of Krakatau, northwest slope of Gunung Krakatau, Indonesia. Lat $6^{\circ} 09^{\prime}$ S., long $105^{\circ} 25.5 '$ E. Supplied by M.T. Zen, No. S 976.

\section{JAVA}

198 (108) Obsidian, occurrence uncertain, Gunung Kiaraberes, Bogor, western Java. Lat $6^{\circ} 43^{\prime} \mathrm{S}$., long $106^{\circ} 41^{\prime}$ E. Supplied by M.T. Zen, No. I long $106^{\circ} 41^{\prime}$ E. Supplied by M.T. Zen, No. 929.

199 (107) Obsidian, occurrence uncertain, Nagrek, western Java. Latitude and longitude uncertain. Supplied by M.T. Zen.

200 (114) Obsidian, occurrence uncertain, Samarang (Garut), western Java. Lat $7^{\circ} 13.09^{\prime}$ S., long $107^{\circ} 50.45^{\prime}$ E. Supplied by M.T. Zen, No. T.A.43.

201 (113) Obsidian, occurrence uncertain, Nagrek, western Java. Latitude and longitude uncertain. Supplied by M.T. Zen. This sample is geochemically virtually identical to sample 198 (108) and very different from 199 (107), also listed as from Nagrek. We think the stable element geochemical signatures are diagnostic within the limits of analytical error. Sample 198 (108) appears to be well located. However sample labels can be transposed, especially with multiple handling and especially in museum collections. The samples are probably from the same locality.

202 (109) Obsidian, occurrence uncertain, cone between Daradjat-Pasir Kiamis, Tjitjalengka, western Java. Lat $7^{\circ} 13.64^{\prime}$ S., long $107^{\circ} 45.82^{\prime}$ E. Supplied by M.T. Zen, No. 11530. This sample seems specifically located, but the locality is much closer to Samarang (Garut) than to Tjitjalengka and there seems little question, chemically, that 200 (114) and 202 (109) are closely related.

\section{CELEBES}

203 (101) Obsidian, occurrence uncertain, Kp. Tataäran (Tomohon) near Manado, Celebes (Sulawesi),
Indonesia. Lat $1^{\circ} 16.5^{\prime} \mathrm{N}$., long $124^{\circ} 52.42^{\prime} \mathrm{E}$. Supplied by P.A. Jezek.

204 (112) Obsidian, occurrence uncertain, PasokanMenado(sic), Celebes (Sulawesi), Indonesia. The sample has a geochemical signature virtually identical to 203 (101). They are no doubt from the same or very closely related rock units. Supplied by M.T. Zen, No. 51/21965.

\section{HALMAHERA}

205 (170) Porphyritic obsidian, lava, coast west of Mount Todoku, northern Halmahera, Indonesia. Lat $1^{\circ} 14^{\prime}$ N., long $127^{\circ} 24^{\prime}$ E. Supplied by P.A. Jezek, No. NH29.

206 (171) Obsidian, porphyritic, lava, near coast west of Mount Rano, northern Halmahera, Indonesia. Lat $1^{\circ} 15.5^{\prime} \mathrm{N}$., long $127^{\circ} 26^{\prime} \mathrm{E}$. Supplied by P.A. Jezek, No. NH 31 .

207 (172) Obsidian, porphyritic, lava flow, Mount Popolodio, northern Halmahera, Indonesia. Lat $1^{\circ} 21^{\prime}$ N., long $127^{\circ} 30.5^{\prime}$ E. Supplied by P.A. Jezek, No. NH 51.

208 (173) Obsidian, porphyritic, lava, southwest slope of Mount Alon, northern Halmahera, Indonesia. Lat $1^{\circ} 20^{\prime} \mathrm{N}$., long $127^{\circ} 29^{\prime} \mathrm{E}$. Supplied by P.A. Jezek, No. NH51.

209 (174) Obsidian, porphyritic, lava, from southwestern wall of Mount Rano caldera, northern Halmahera, Indonesia. Lat $1^{\circ} 15^{\prime} \mathrm{N}$., long $127^{\circ} 27.6^{\prime}$ E. Supplied by P.A. Jezek, No. NH 58.

210 (195) Glass separate from 209 (174). Prophyritic obsidian, lava, from southwestern wall of Mount Rano caldera, northern Halmahera, Indonesia. Lat $1^{\circ} 15^{\prime} \mathrm{N}$, long $127^{\circ} 27.6^{\prime} \mathrm{E}$. Supplied by P.A. Jezek, No. NH 58.

\section{PAPUA NEW GUINEA}

\section{ADMIRALTY ISLANDS}

211 (70) Glassy lava, partly crystalline, base of flow making up part of cones 2 and 4 , southern coast of Tuluman Island, Papua New Guinea Lat $2^{\circ} 26.67^{\prime}$ S., long $147^{\circ} 18.5^{\prime}$ E. Supplied by
R.W. Johnson. Major element analyses in Johnson and others (1978, table 1, No. 25NG0011), except $\mathrm{F}$ and $\mathrm{Cl}$ analyses, which were done for this study.

212 (62) Glassy lava, partly crystalline, flow of center 8 , directly west of high point marking center 8 , southwestern coast of Lou Island, Papua New Guinea. Lat $2^{\circ} 24.83^{\prime}$ S., long $147^{\circ} 18.5^{\prime} \mathrm{E}$. Supplied by R.W. Johnson. Major element analyses in Johnson and others (1978, table 1, No. 25NG0005), except $\mathrm{F}$ and $\mathrm{Cl}$ analyses, which were done for this study.

213 (58) Glassy lava, partly crystalline, flow of center $3,1.7 \mathrm{~km}$ east of Baun village, southeast coast of Lou Island, Papua New Guinea. Lat $2^{\circ} 24^{\prime}$ S., long $147^{\circ} 21.33^{\prime}$ E. Supplied by R.W. Johnson. Major element analysis in Johnson and others (1978, table 1, No. 25NG0025), except $\mathrm{F}$ and $\mathrm{Cl}$ analyses, which were done for this study.

214 (64) Glassy lava, partly crystalline, flow, western coast of Pam Lin Island, Papua New Guinea. Lat $2^{\circ} 29.17^{\prime}$ S., long $147^{\circ} 20.17^{\prime}$ E. Supplied by R.W. Johnson. Major element analysis in Johnson and others (1978, table 1, No. 25NG0059), except $\mathrm{F}$ and $\mathrm{Cl}$ analyses, which were done for this study.

\section{NEW BRITAIN}

215 (60) Obsidian, Garua Harbor area, Talasea, New Britain. Lat $5^{\circ} 18.33^{\prime} \mathrm{S}$., long $150^{\circ} 01.33^{\prime} \mathrm{E}$. Supplied by R.W. Johnson.

\section{NEW ZEALAND}

216 (3) Obsidian, phenocrystic, lava flow, Ongaroto, North Island, New Zealand. Lat $38^{\circ} 23^{\prime}$ S., long $175^{\circ} 56^{\prime}$ E. Supplied by R.A. Bailey. Major element analyst: Ellen S. Daniels, Denver RAL, USGS. Analysis previously unpublished.

217 (71) Obsidian, Tauhara "dacite" flow, quarry, 8 $\mathrm{km}$ east of northeast corner of Lake Taupo, North Island, New Zealand. Lat $38^{\circ} 45^{\prime}$ S., long $176^{\circ} 9^{\prime}$ E. Supplied by P.E. Baker, No. NZ17. 
APPENDIX II.-Chemical analyses of secondarily hydrated subalkaline silicic obsidians

\begin{tabular}{|c|c|c|c|c|c|c|c|c|c|}
\hline Country/St ate- & NEW & $x I C 0$ & SOUTH SEAS & \multicolumn{6}{|c|}{ ICELAND } \\
\hline Volcanic field/region-.- & $\begin{array}{l}\text { Taos } \\
\text { Plateau }\end{array}$ & $\begin{array}{l}\text { Mount } \\
\text { Taylor }\end{array}$ & $\begin{array}{l}\text { South Sandwich } \\
\text { Islands }\end{array}$ & \multirow{2}{*}{\multicolumn{2}{|c|}{ Ulfarsfellsna }} & \multicolumn{3}{|c|}{ Husafell } & $\begin{array}{l}\text { Kerling- } \\
\text { arfjoli }\end{array}$ \\
\hline Locality-- & $\begin{array}{l}\text { Cerros } \\
\text { No Agua }\end{array}$ & $\begin{array}{l}\text { Grants } \\
\text { Ridge }\end{array}$ & $\begin{array}{l}\text { North } \\
\text { S.S.I. } 1962\end{array}$ & & & $\begin{array}{l}\text { Baejargil } \\
\text { stream }\end{array}$ & \multicolumn{2}{|c|}{$\begin{array}{c}\text { Reydarfell } \\
\text { dome }\end{array}$} & $\begin{array}{l}\text { Lodmundar } \\
\text { Mounta in }\end{array}$ \\
\hline $\begin{array}{l}\text { Specimen-1- } \\
\text { Collection No. (RLS-) }\end{array}$ & $\begin{array}{r}218 \\
28\end{array}$ & $\begin{array}{l}219 \\
201\end{array}$ & $\begin{array}{l}220 \\
261\end{array}$ & $\begin{array}{l}221 \\
179\end{array}$ & $\begin{array}{l}222 \\
181\end{array}$ & $\begin{array}{r}223 \\
63\end{array}$ & $\begin{array}{r}224 \\
59\end{array}$ & $\begin{array}{r}225 \\
69\end{array}$ & $\begin{array}{l}226 \\
175\end{array}$ \\
\hline
\end{tabular}

Chemical analyses (weight percent)

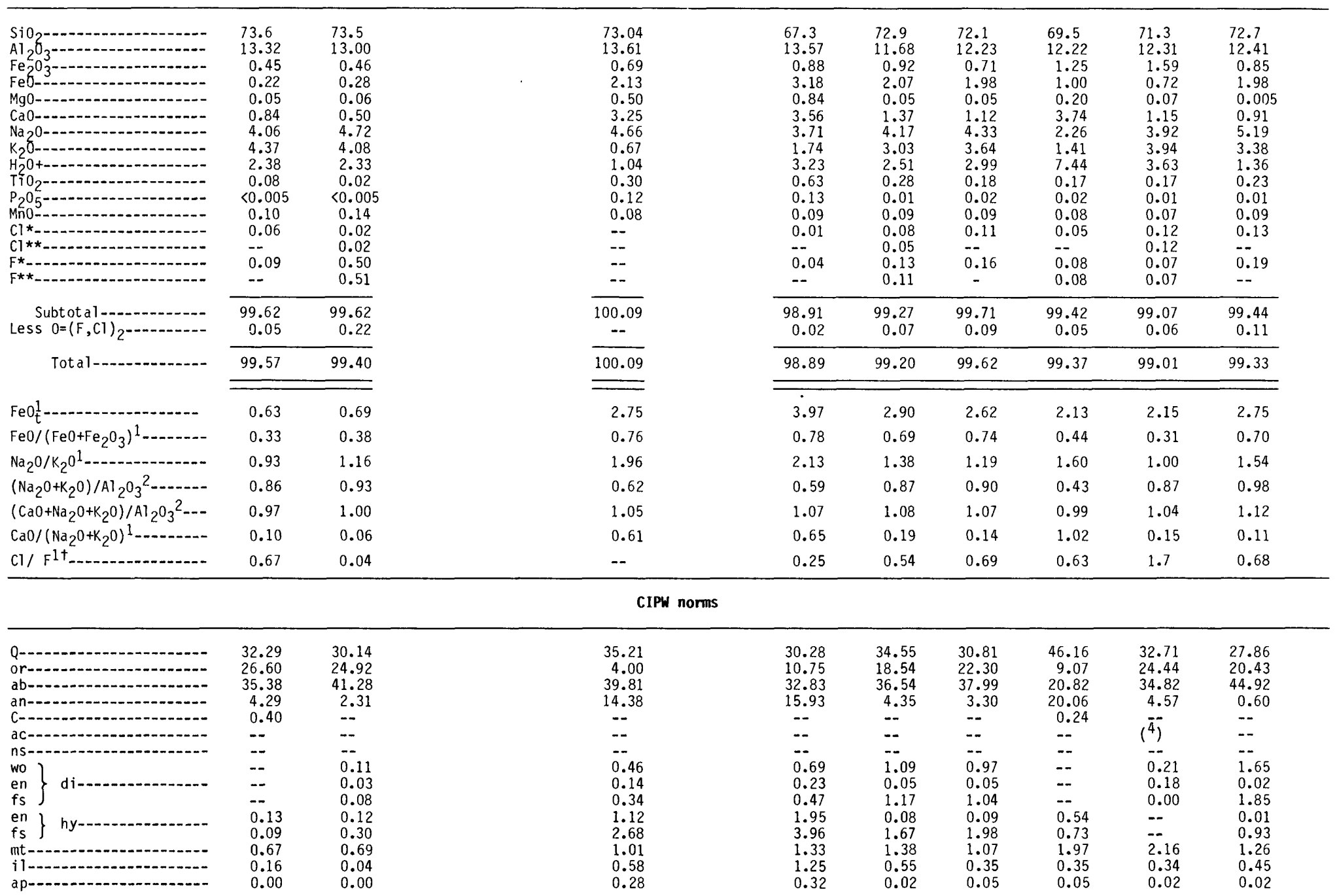




\begin{tabular}{llllllll}
\hline 218 & 219 & 220 & 221 & 222 & 223 & 224 & 225 \\
\hline
\end{tabular}

Trace elements (ppm)

\begin{tabular}{|c|c|c|c|c|c|c|c|c|c|}
\hline $\mathrm{Ba}-(-1,-1$ & 130. & 4. & 119. & 335. & 515. & 677. & 480. & 677. & 840 . \\
\hline & -- & 21. & -- & -- & 4.4 & -- & 4.4 & 4.3 & - \\
\hline Co & 0.2 & $<0.4$ & 2.8 & $22.0^{3}$ & $12.8^{3}$ & 0.2 & 0.3 & 0.3 & $21.0^{3}$ \\
\hline $\mathrm{Cr}-1-1-1$ & 1.0 & $<3.0$ & $<4.0$ & 3.8 & $<4.0$ & $<6.0$ & 2.9 & $<6.0$ & 5.8 \\
\hline Cs $-1-1$ & 2.2 & 14.2 & 0.5 & 0.3 & 0.7 & 1.0 & 6.3 & 1.4 & 0.9 \\
\hline HF-- & 3.3 & 8.0 & 3.0 & 6.9 & 18.5 & 13.0 & 9.8 & 10.3 & 18.3 \\
\hline Lí--1-O- & -- & 53. & -- & -- & 10. & -- & 5. & 8. & -- \\
\hline Mo--1 & -- & 1.2 & -- & -- & 3.7 & -- & 3.7 & 4.3 & -- \\
\hline$N b * *_{-}$ & -- & 170. & 0.6 & -- & -- & -- & 66. & 63. & -- \\
\hline $\mathrm{Nb} * * *_{2}$ & 39. & 190. & $<2.0$ & 14. & 90. & 97. & 69. & 78. & 151. \\
\hline $\mathrm{Pb}-\cdots$ & 19. & 40. & 9. & 5. & 26. & 15. & 23. & 10. & 13. \\
\hline $\mathrm{Rb}^{\star *}$ & 132. & 519. & 14. & 35. & 62. & 85. & 65. & 117. & 78. \\
\hline $\mathrm{Rb}^{\star * * *}$ & 135. & 500 & 13. & 33. & 60. & 83. & 64. & 121. & 83. \\
\hline Sb-1-2-1 & 0.4 & 1.5 & $<2.0$ & $<0.5$ & 0.3 & 0.5 & 0.7 & $<0.8$ & 0.3 \\
\hline Sc-- & 3.0 & 2.2 & 10.2 & 7.9 & 1.6 & 3.3 & 4.5 & 4.7 & 0.57 \\
\hline Sn-1-n & -- & 28. & -- & -- & 7.9 & -- & 6.8 & 4.9 & -- \\
\hline Sr- & 40. & 50 & $110 \cdot$ & 225. & 110 & 92. & 110 & 390. & \\
\hline Th & $\begin{array}{l}3.03 \\
9.9\end{array}$ & $\begin{array}{l}30.50 \\
23.2\end{array}$ & 0.1 & $\begin{array}{l}1.13 \\
6.6\end{array}$ & 9.4 & $\begin{array}{l}6.56 \\
12.6\end{array}$ & $\begin{array}{l}4.86 \\
12.1\end{array}$ & $\begin{array}{r}5.48 \\
12.9\end{array}$ & $\begin{array}{r}9.62 \\
11.3\end{array}$ \\
\hline U & 3.4 & 8.1 & $<3.0$ & 1.8 & 3.0 & 3.5 & 3.6 & 4.1 & $\begin{array}{r}11.3 \\
3.3\end{array}$ \\
\hline - & & 3.3 & -- & --0 & 3.0 & 3.0 & $\begin{array}{l}3.0 \\
1.4\end{array}$ & 1.6 & 3.3 \\
\hline 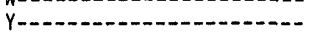 & 27. & 92. & 33. & 30. & 194. & 104. & 72.4 & 67. & 143. \\
\hline $\mathrm{Zn}-\cdots$ & 38. & 157. & 43. & 60. & 193. & 131. & 84. & 45. & 228. \\
\hline $\ln -$ & 53. & 95. & 107. & 332. & 700. & 522. & 382. & 377. & 753. \\
\hline La--.-- & 13. & 7. & 5. & 39. & 80. & 85. & 72. & 74. & 96. \\
\hline 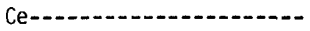 & 25. & 18. & 11. & 69. & 172 . & 163. & 140. & 140. & 192. \\
\hline Nd- & 12. & 12. & 7. & 23. & 90. & 79. & 64. & 69. & 90. \\
\hline - n-n & 2.7 & 3.9 & 2.8 & 5.7 & 26.0 & 17.1 & 13.1 & 14.2 & 22.0 \\
\hline -............... & 0.36 & 0.05 & 0.77 & 1.31 & 4.44 & 2.80 & 2.12 & 2.27 & 3.50 \\
\hline Gd-...... & 2.9 & 4.3 & 3.0 & 4.5 & 21.9 & 14.2 & 10.2 & 11.1 & 16.5 \\
\hline $\mathrm{Tb}$ & 0.46 & $<0.81$ & 0.71 & 0.63 & 4.94 & 2.71 & 2.07 & 2.20 & 3.56 \\
\hline 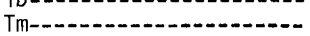 & $<0.20$ & 0.50 & 0.57 & 0.56 & 3.07 & 1.27 & 0.94 & 1.12 & 1.79 \\
\hline Yb- & 2.5 & 7.8 & 3.4 & 3.2 & 18.0 & 9.4 & 7.14 & 7.0 & 12.6 \\
\hline Lu- & 0.37 & 1.19 & 0.53 & 0.47 & 2.49 & 1.28 & 0.96 & 1.02 & 1.67 \\
\hline $\mathrm{Nb} / \mathrm{Ta}-\mathrm{-}$ & 12.9 & 5.9 & -- & 8.1 & 12.8 & 14.8 & 13.9 & 12.9 & 15.7 \\
\hline $\mathrm{K} / \mathrm{Rb}-\cdots$ & 269. & 68. & 428. & 438. & 419. & 364. & 183. & 270. & 338. \\
\hline $\mathrm{Rb} / \mathrm{Sr}$ & 3.4 & 100 & 0.12 & 0.15 & 0.55 & 0.90 & 0.58 & 0.31 & 1.1 \\
\hline $\mathrm{Ca} / \mathrm{Sr}-\ldots$ & 150. & 715. & 211 & 113. & 89. & 87. & 24.3 & 21.1 & 87. \\
\hline Th/U & 2.9 & 2.9 & -. & 3.7 & 3.1 & 3.6 & 3.3 & 3.1 & 3.4 \\
\hline $\mathrm{Zr} / \mathrm{Hf}-\mathrm{H}_{-}$ & 16. & 12. & 36. & 48. & 38. & 40. & 39. & 37. & 41. \\
\hline $\mathrm{Ce} / \mathrm{Yb}--$ & 10.0 & 2.3 & 3.2 & 21.6 & 9.6 & 17.3 & 19.7 & 20.0 & 15.2 \\
\hline $\mathrm{Eu} / \mathrm{Eu}^{*}$ & 0.40 & 0.04 & 0.82 & 0.70 & 0.58 & 0.56 & 0.56 & 0.55 & 0.56 \\
\hline $\begin{array}{l}\text { *Analyses performed } \\
\text { *Analyses performed } \\
\star \star \star A \text { Analyses performed } \\
+ \text { Cl } / F \text { ratios calcul }\end{array}$ & $\begin{array}{l}\text { the U. } \\
\text { the Un } \\
\text { from }\end{array}$ & $\begin{array}{l}\text { sity of Reading. } \\
\text { eological Survey. } \\
\text { sity of Lancaster. } \\
\text { (ppm) data. }\end{array}$ & $\begin{array}{l}\text { weight } \\
\text { ecular } \\
\text { bably } \\
\text { mative }\end{array}$ & \multicolumn{6}{|c|}{--, not determined } \\
\hline
\end{tabular}


APPENDIX II.-Sample localities, miscellaneous, mostly hydrated glasses

\section{NORTH AMERICA}

\section{UNITED STATES OF AMERICA}

\section{NEW MEXICO}

218 (28) Perlite associated with sample 110 (28), lava dome, Cerros No Agua, Taos County, New Mexico. Lat $36^{\circ} 45.68^{\prime}$ N., long $105^{\circ} 56.97^{\prime} \mathrm{W}$. Collected by C.S. Ross and R.L. Smith.

219 (201) Perlitic glass, possible clast, from pumice quarry, northeast end of Grants Ridge, 8 miles northeast of Grants, Valencia County, New Mexico. Lat $35^{\circ} 12.82^{\prime}$ N., long $107^{\circ} 44.5^{\prime} \mathrm{W}$. Collected by R.L. Smith.

\section{ANTARCTICA}

\section{SOUTH SANDWICH ISLANDS}

220 (261) Glassy pumice, block in pumice raft, collected by H.M.S. Protector, 15 March, 1962, northeast of Zavodovski Island, South Sandwich Islands. Probably erupted from seamount. Lat $55^{\circ} 55^{\prime} \mathrm{S}$., long $28^{\circ} 6^{\prime} \mathrm{W}$. Major element analysis in Gass and others (1963, table 1). Supplied by I.G. Gass.

\section{EUROPE \\ ICELAND}

221 (179) Rhyolitic glass, clast in silicic tuff, Ulfarsfellsna, Snaefellsnes. Upper Tertiary or lower Quaternary formation, west Iceland. Lat $64^{\circ} 58.5^{\prime} \mathrm{N}$., long $22^{\circ} 37^{\prime} \mathrm{W}$. Supplied by H. Sigurdsson, No. 477 .
222 (181) Rhyolitic glass, lower Quaternary flow, Ulfarsfellsna, west Iceland. Lat $64^{\circ} 58.5^{\prime}$ N., lon $22^{\circ} 37^{\prime}$ W. Supplied by H. Sigurdsson, No. 493.

223 (63) Rhyolitic glass, margin of dike cutting ashflow tuff of first silicic phase, but older than second silicic phase, Baejargil stream, Husafel central volcano (Tertiary), west Iceland. Lat $64^{\circ} 41^{\prime}$ N., long $20^{\circ} 54^{\prime}$ W. Supplied by R.S.J. Sparks, No. H1.

224 (59) Rhyolitic glass, Reydarfell lava dome, third silicic phase, Husafell central volcano (Tertiary) west Iceland. Lat $64^{\circ} 41^{\prime} \mathrm{N}$., long $20^{\circ} 55^{\prime} \mathrm{W}$. Supplied by R.S.J. Sparks, No. H2.

225 (69) Rhyolitic glass, large fiamma in densely welded vitrophyre, third silicic phase, underlying Reydarfell dome, Husafell central volcano (Tertiary), west Iceland. Lat $64^{\circ} 41^{\prime}$ N., long $22^{\circ} 55^{\prime}$ W. Supplied by R.S.J. Sparks, No. H3.

226 (175) Obsidian, Lodmundar Mountain (late Quaternary), Kerlingarfjöll central volcano, central Iceland. Lat $64^{\circ} 39^{\prime} \mathrm{N}$., long $19^{\circ} 13^{\prime} \mathrm{W}$. Supplied by H. Sigurdsson, No. 418. 
APPENDIX III.-Compilation of published major-element analyses of subalkaline silicic glasses

\begin{tabular}{|c|c|c|c|c|c|c|c|c|c|c|}
\hline Country/State-............. & \multicolumn{2}{|c|}{ ALASKA } & \multicolumn{8}{|c|}{ OREGON } \\
\hline Volcanic field/region--- & \multirow{2}{*}{$\frac{\begin{array}{c}\text { Umnak } \\
\text { Is land }\end{array}}{\begin{array}{c}\text { Northeast } \\
\text { Umnak }\end{array}}$} & \multirow{2}{*}{$\begin{array}{l}\text { Katmai } \\
\text { Novarupta }\end{array}$} & $\begin{array}{c}\text { Three } \\
\text { Sisters }\end{array}$ & \multicolumn{2}{|c|}{ Crater Lake } & \multicolumn{5}{|c|}{ Newberry Volcano } \\
\hline Locality- & & & $\begin{array}{l}\text { South } \\
\text { Sister }\end{array}$ & $\begin{array}{c}\text { Grouse } \\
\mathrm{Hill}\end{array}$ & $\begin{array}{l}\text { Llao } \\
\text { Rock }\end{array}$ & $\begin{array}{l}\text { East } \\
\text { Lake }\end{array}$ & & & & \\
\hline Specimen-1-nsto- & 242 & 244 & 245 & 246 & 247 & 248 & 249 & 250 & 251 & 252 \\
\hline
\end{tabular}

Chemical analyses (weight percent)

\begin{tabular}{|c|c|c|c|c|c|c|c|c|c|c|c|}
\hline $\begin{array}{l}\mathrm{SiO}_{2} \mathrm{O}_{2} \\
\mathrm{Al}_{2} \mathrm{O}_{3} \\
\mathrm{Fe}_{2} \mathrm{O}_{3} \\
\mathrm{Fe} 0 \\
\mathrm{Mg} 0 \mathrm{O}\end{array}$ & $\begin{array}{r}72.36 \\
13.75 \\
0.59 \\
2.33 \\
0.09 \\
1.53 \\
4.64 \\
4.16 \\
0.27 \\
0.03 \\
0.21 \\
0.06 \\
0.09 \\
--\end{array}$ & $\begin{array}{r}74.75 \\
13.01 \\
0.82 \\
1.43 \\
0.70 \\
2.12 \\
4.32 \\
2.62 \\
0.20 \\
0.05 \\
0.28 \\
0.09 \\
0.05 \\
0.11 \\
-.\end{array}$ & $\begin{array}{r}77.04 \\
12.30 \\
0.43 \\
0.97 \\
0.04 \\
1.03 \\
4.56 \\
3.12 \\
0.18 \\
0.03 \\
0.18 \\
0.04 \\
0.04 \\
0.15 \\
-.\end{array}$ & $\begin{array}{r}71.94 \\
14.31 \\
0.61 \\
1.77 \\
0.41 \\
1.75 \\
4.69 \\
3.00 \\
0.48 \\
0.16 \\
0.40 \\
0.07 \\
0.05 \\
--\end{array}$ & $\begin{array}{r}70.30 \\
14.52 \\
0.37 \\
2.56 \\
0.93 \\
2.94 \\
4.86 \\
2.66 \\
0.33 \\
0.14 \\
0.44 \\
0.09 \\
\text { tr } \\
-- \\
--\end{array}$ & $\begin{array}{r}70.77 \\
14.83 \\
1.35 \\
1.25 \\
0.64 \\
2.12 \\
5.07 \\
2.68 \\
0.33 \\
0.07 \\
0.38 \\
0.13 \\
\operatorname{tr} \\
0.11 \\
.-\end{array}$ & $\begin{array}{l}72.5 \\
14.3 \\
0.33 \\
1.7 \\
0.33 \\
1.1 \\
4.6 \\
4.1 \\
0.43 \\
0.03 \\
0.23 \\
0.10 \\
0.05 \\
--.\end{array}$ & $\begin{array}{l}72.8 \\
13.9 \\
0.67 \\
1.3 \\
0.21 \\
1.4 \\
4.5 \\
4.1 \\
0.45 \\
0.05 \\
0.22 \\
0.02 \\
0.06 \\
--\end{array}$ & $\begin{array}{c}72.35 \\
13.98 \\
0.60 \\
1.78 \\
0.30 \\
1.30 \\
5.04 \\
3.92 \\
0.45 \\
0.05 \\
0.25 \\
\text { tr } \\
\text { nil } \\
-- \\
--\end{array}$ & $\begin{array}{l}72.8 \\
14.6 \\
0.77 \\
1.3 \\
0.34 \\
1.1 \\
4.3 \\
4.0 \\
0.43 \\
0.00 \\
0.24 \\
0.10 \\
0.04 \\
---\end{array}$ & $\begin{array}{l}72.9 \\
14.0 \\
0.77 \\
1.3 \\
0.28 \\
1.0 \\
4.6 \\
4.2 \\
0.51 \\
0.02 \\
0.21 \\
0.09 \\
0.06 \\
-- \\
--\end{array}$ \\
\hline $\begin{array}{l}\text { Subtotal } \\
\text { Less } 0=(F, C l)_{2}\end{array}$ & $\begin{array}{l}100.11 \\
--\end{array}$ & $\begin{array}{r}100.55 \\
0.02 \\
\end{array}$ & $\begin{array}{r}100.11 \\
0.03\end{array}$ & $\begin{array}{l}99.64 \\
--\end{array}$ & $\begin{array}{l}100.14 \\
--\end{array}$ & $\begin{array}{r}99.73 \\
0.02\end{array}$ & $\begin{array}{l}99.80 \\
--\end{array}$ & $\begin{array}{l}99.68 \\
--\end{array}$ & 100.02 & 100.02 & 99.94 \\
\hline Total-_......... & 100.11 & 100.53 & 100.08 & 99.64 & 100.14 & 99.71 & 99.80 & 99.68 & 100.02 & 100.02 & 99.94 \\
\hline $\mathrm{Fe}_{\mathrm{t}}^{1}$ & 2.86 & 2.17 & 1.36 & 2.32 & 2.89 & 2.47 & 2.00 & 1.90 & 2.32 & 1.99 & 1.99 \\
\hline $\mathrm{Fe} 0 /\left(\mathrm{Fe} 0+\mathrm{Fe}_{2} \mathrm{O}_{3}\right)^{1}$ & 0.80 & 0.64 & 0.69 & 0.74 & 0.87 & 0.48 & 0.84 & 0.66 & 0.75 & 0.63 & 0.63 \\
\hline $\mathrm{Na}_{2} \mathrm{O} / \mathrm{K}_{2} \mathrm{O}^{1}$ & 1.12 & 1.65 & 1.46 & 1.56 & 1.83 & 1.89 & 1.12 & 1.10 & 1.29 & 1.08 & 1.10 \\
\hline$\left(\mathrm{Na}_{2} \mathrm{O}+\mathrm{K}_{2} \mathrm{O}\right) / \mathrm{Al}_{2} \mathrm{O}_{3}{ }^{2}$ & 0.88 & 0.76 & 0.88 & 0.75 & 0.75 & 0.76 & 0.84 & 0.85 & 0.90 & 0.78 & 0.87 \\
\hline$\left(\mathrm{CaO}+\mathrm{Na}_{2} \mathrm{O}+\mathrm{K}_{2} \mathrm{O}\right) / \mathrm{Al}_{2} \mathrm{O}_{3}{ }^{2}--$ & 1.09 & 1.06 & 1.04 & 0.99 & 1.12 & 1.02 & 0.98 & 1.04 & 1.07 & 0.92 & 0.99 \\
\hline $\mathrm{CaO} /\left(\mathrm{Na}_{2} \mathrm{O}+\mathrm{K}_{2} \mathrm{O}\right)^{1}$ & 0.17 & 0.31 & 0.13 & 0.23 & 0.39 & 0.27 & 0.13 & 0.16 & 0.15 & 0.13 & 0.11 \\
\hline $\mathrm{Cl} / \mathrm{F}^{1}-$ & -- & $\cdots$ & -- & -- & -- & -- & -- & -- & -- & -- & -- \\
\hline \multicolumn{12}{|c|}{ CIPH norms } \\
\hline $\begin{array}{l}\text { or } \\
\text { abo } \\
\text { an } \\
\text { an } \\
\text { fs } \\
\text { en } \\
\text { fs } \\
\text { mi } \\
\text { mi }\end{array}$ di & $\begin{array}{l}25.21 \\
24.63 \\
39.34 \\
4.41 \\
-. . \\
1.17 \\
0.08 \\
1.23 \\
0.15 \\
2.39 \\
0.86 \\
0.40 \\
0.14\end{array}$ & $\begin{array}{r}33.82 \\
15.45 \\
36.49 \\
8.35 \\
0 .- \\
0.65 \\
0.33 \\
0.30 \\
1.41 \\
1.28 \\
1.19 \\
0.53 \\
0.21\end{array}$ & $\begin{array}{r}36.17 \\
18.48 \\
38.68 \\
3.89 \\
-. \\
0.41 \\
0.03 \\
0.42 \\
0.07 \\
0.79 \\
0.63 \\
0.34 \\
0.09 \\
. .\end{array}$ & $\begin{array}{l}28.31 \\
17.91 \\
40.09 \\
8.31 \\
0.34 \\
-- \\
-- \\
-- \\
1.03 \\
2.20 \\
0.89 \\
0.77 \\
0.16 \\
--\end{array}$ & $\begin{array}{l}23.70 \\
15.77 \\
41.26 \\
9.98 \\
-. .70 \\
1.70 \\
0.67 \\
1.05 \\
1.66 \\
2.63 \\
0.54 \\
0.84 \\
0.21 \\
. .-\end{array}$ & $\begin{array}{l}25.84 \\
15.96 \\
43.24 \\
9.74 \\
0.05 \\
-- \\
-- \\
-- \\
1.61 \\
0.56 \\
1.97 \\
0.73 \\
0.30 \\
---\end{array}$ & $\begin{array}{l}26.49 \\
24.39 \\
39.18 \\
4.84 \\
0.54 \\
-- \\
-- \\
-- \\
0.83 \\
2.58 \\
0.48 \\
0.44 \\
0.23 \\
--.\end{array}$ & $\begin{array}{r}27.44 \\
24.43 \\
38.39 \\
5.67 \\
-.- \\
0.50 \\
0.13 \\
0.40 \\
0.40 \\
1.20 \\
0.98 \\
0.42 \\
0.05 \\
--.\end{array}$ & $\begin{array}{r}24.38 \\
23.28 \\
42.85 \\
3.96 \\
-- \\
1.05 \\
0.27 \\
0.84 \\
0.48 \\
1.53 \\
0.87 \\
0.48 \\
0.00 \\
.-\end{array}$ & $\begin{array}{c}29.37 \\
23.73 \\
36.54 \\
4.82 \\
1.44 \\
-- \\
-- \\
- \\
0.85 \\
1.44 \\
1.12 \\
0.46 \\
0.23\end{array}$ & $\begin{array}{c}27.23 \\
24.97 \\
39.16 \\
4.40 \\
0.29 \\
-- \\
-- \\
-- \\
0.70 \\
1.53 \\
1.12 \\
0.40 \\
0.21 \\
--\end{array}$ \\
\hline
\end{tabular}

See footnotes at end of table. 
APPENDIX III.-Compilation of published major-element analyses of subalkaline silicic glasses-Continued

\begin{tabular}{|c|c|c|c|c|c|c|c|c|c|c|c|}
\hline Country/State-.......-..- & \multicolumn{9}{|c|}{ OREGON } & \multirow{2}{*}{\multicolumn{2}{|c|}{$\begin{array}{c}\text { CALIFORNIA } \\
\begin{array}{c}\text { Medicine Lake } \\
\text { Highlands }\end{array}\end{array}$}} \\
\hline Volcanic field/region--- & \multicolumn{9}{|c|}{ Newberry Volcano } & & \\
\hline Locality---- & \multicolumn{2}{|c|}{$\begin{array}{l}\text { Pumice Cone } \\
\text { flow }\end{array}$} & \multicolumn{2}{|c|}{ North flow } & \multicolumn{5}{|c|}{ "Big Obsidian Flow" } & \multicolumn{2}{|c|}{$\begin{array}{l}\text { Massive } \\
\text { lava group }\end{array}$} \\
\hline Specimen----- & 253 & 254 & 255 & 256 & 257 & 258 & 259 & 260 & 261 & 262 & 263 \\
\hline \multicolumn{12}{|c|}{ Chemical analyses (weight percent) } \\
\hline 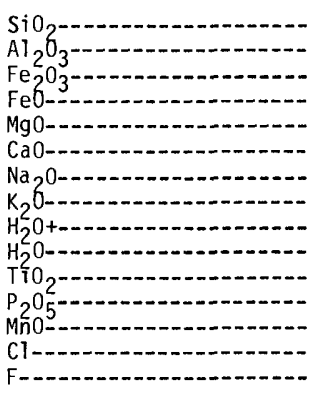 & $\begin{array}{l}72.8 \\
14.6 \\
0.44 \\
1.6 \\
0.25 \\
1.0 \\
4.2 \\
3.8 \\
0.76 \\
0.14 \\
0.21 \\
0.09 \\
0.05 \\
--.\end{array}$ & $\begin{array}{l}72.9 \\
14.1 \\
0.66 \\
1.4 \\
0.27 \\
0.98 \\
4.6 \\
4.2 \\
0.58 \\
0.02 \\
0.22 \\
0.10 \\
0.05 \\
-- \\
--\end{array}$ & $\begin{array}{l}72.9 \\
13.9 \\
0.56 \\
1.4 \\
0.24 \\
1.6 \\
4.4 \\
4.1 \\
0.42 \\
0.06 \\
0.23 \\
0.02 \\
0.12 \\
-.-\end{array}$ & $\begin{array}{l}73.1 \\
14.0 \\
0.33 \\
1.7 \\
0.28 \\
0.99 \\
4.6 \\
4.2 \\
0.45 \\
0.00 \\
0.21 \\
0.09 \\
0.05 \\
-. \\
-.\end{array}$ & $\begin{array}{r}72.22 \\
14.41 \\
0.50 \\
1.62 \\
0.18 \\
0.84 \\
5.28 \\
4.01 \\
0.12 \\
0.01 \\
0.23 \\
0.03 \\
0.06 \\
---\end{array}$ & $\begin{array}{l}72.4 \\
14.4 \\
0.64 \\
1.6 \\
0.18 \\
0.87 \\
4.9 \\
4.1 \\
0.50 \\
0.06 \\
0.22 \\
0.09 \\
0.06 \\
-- \\
--\end{array}$ & $\begin{array}{l}72.6 \\
14.4 \\
0.64 \\
1.6 \\
0.24 \\
0.92 \\
4.7 \\
3.9 \\
0.63 \\
0.03 \\
0.20 \\
0.09 \\
0.05 \\
--.\end{array}$ & $\begin{array}{r}73.40 \\
14.20 \\
0.24 \\
1.76 \\
0.18 \\
1.35 \\
4.15 \\
4.10 \\
0.40 \\
0.10 \\
0.20 \\
\operatorname{tr} \\
\operatorname{tr} \\
-- \\
--\end{array}$ & $\begin{array}{l}72.8 \\
14.4 \\
0.54 \\
1.5 \\
0.04 \\
0.84 \\
4.9 \\
4.0 \\
0.20 \\
0.10 \\
0.23 \\
0.03 \\
0.07 \\
-- \\
--\end{array}$ & $\begin{array}{l}71.50 \\
14.66 \\
0.33 \\
2.28 \\
0.44 \\
1.50 \\
4.53 \\
4.07 \\
0.20 \\
\mathrm{tr} \\
0.22 \\
\mathrm{nii} \\
\mathrm{tr} \\
--\end{array}$ & $\begin{array}{c}74.10 \\
13.33 \\
\text { tr. } \\
1.68 \\
0.38 \\
1.45 \\
3.86 \\
4.50 \\
0.29 \\
0.05 \\
0.20 \\
\mathrm{nil}^{2} \\
\mathrm{tr} \\
-- \\
--\end{array}$ \\
\hline $\begin{array}{l}\text { Subtotal } \\
\text { Less } 0=(F, C 1){ }_{2}\end{array}$ & 99.94 & 100.08 & 99.95 & 100.00 & 99.51 & 100.02 & $\begin{array}{c}100.00 \\
--\end{array}$ & 100.08 & 99.65 & $\begin{array}{l}99.73 \\
--\end{array}$ & $\begin{array}{l}99.84 \\
--\end{array}$ \\
\hline 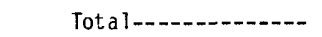 & 99.94 & 100.08 & 99.95 & 100.00 & 99.51 & 100.02 & 100.00 & 100.08 & 99.65 & 99.73 & 99.84 \\
\hline $\mathrm{FeO}_{\mathrm{t}}^{1}-$ & 2.00 & 1.99 & 1.90 & 2.00 & 2.07 & 2.18 & 2.18 & 1.98 & 1.99 & 2.58 & 1.68 \\
\hline $\mathrm{Fe} 0 /\left(\mathrm{Fe} 0+\mathrm{Fe}_{2} \mathrm{O}_{3}\right)^{1} \ldots$ & 0.78 & 0.68 & 0.71 & 0.63 & 0.76 & 0.71 & .0 .71 & 0.88 & 0.74 & 0.87 & - \\
\hline $\mathrm{Na}_{2} \mathrm{O} / \mathrm{K}_{2} \mathrm{O}^{\mathrm{l}}$ & 1.11 & 1.10 & 1.07 & 1.10 & 1.32 & 1.20 & 1.21 & 1.01 & 1.23 & 1.11 & 0.86 \\
\hline$\left(\mathrm{Na}_{2} \mathrm{O}+\mathrm{K}_{2} \mathrm{O}\right) / \mathrm{Al}_{2} \mathrm{O}_{3}{ }^{2}$ & 0.76 & 0.86 & 0.84 & 0.87 & 0.90 & 0.87 & 0.83 & 0.80 & 0.86 & 0.81 & 0.84 \\
\hline$\left(\mathrm{CaO}+\mathrm{Na}_{2} \mathrm{O}+\mathrm{K}_{2} \mathrm{O}\right) / \mathrm{Al}_{2} \mathrm{O}_{3}{ }^{2}-\cdots$ & 0.89 & 0.99 & 1.05 & 0.99 & 1.01 & 0.98 & 0.95 & 0.97 & 0.97 & 1.00 & 1.04 \\
\hline $\mathrm{CaO} /\left(\mathrm{Na}_{2} \mathrm{O}+\mathrm{K}_{2} \mathrm{O}\right)^{1} \ldots$ & 0.13 & 0.11 & 0.19 & 0.11 & 0.09 & 0.10 & 0.11 & 0.16 & 0.09 & 0.17 & 0.17 \\
\hline $\mathrm{Cl} / \mathrm{F}^{1}-\ldots$ & -- & -- & -- & -- & -- & -- & -- & -- & -- & -- & -- \\
\hline \multicolumn{12}{|c|}{ CIPU norms } \\
\hline Q- & 30.81 & 27.19 & 27.52 & 26.93 & 23.32 & 25.48 & 27.45 & 29.30 & 26.45 & 24.20 & 29.96 \\
\hline or-a & 22.67 & 24.95 & 24.36 & 24.93 & 23.84 & 24.36 & 23.20 & 24.33 & 23.79 & 24.16 & 26.73 \\
\hline ab- & 35.88 & 39.13 & 37.43 & 39.10 & 44.96 & 41.69 & 40.03 & 35.26 & 41.73 & 38.51 & 32.83 \\
\hline an & 4.42 & 4.23 & 6.10 & 4.34 & 3.80 & 3.75 & 4.00 & 6.73 & 4.00 & 7.48 & 5.79 \\
\hline C- & 1.99 & 0.45 & -- & 0.30 & -- & 0.54 & 1.00 & 0.48 & 0.56 & 0.08 & -- \\
\hline & - & -- & 0.73 & -- & 0.08 & -- & - &.- & -- & -- & 0.60 \\
\hline en din...... & -- & -- & 0.18 & -- & 0.02 & -- & -- & -- & -- & -- & 0.16 \\
\hline & -- & -- & 0.59 & -- & 0.07 & -- & -- & -- & -- & -- & 0.47 \\
\hline en f hy- & 0.63 & 0.68 & 0.42 & 0.70 & 0.44 & 0.45 & 0.60 & 0.45 & 0.10 & 1.10 & 0.79 \\
\hline fs \} ny-n. & 2.34 & 1.76 & 1.37 & 2.61 & 2.23 & 2.17 & 2.19 & 2.72 & 2.07 & 3.57 & 2.30 \\
\hline mt-n- & 0.64 & 0.96 & 0.82 & 0.48 & 0.73 & 0.93 & 0.93 & 0.35 & 0.79 & 0.48 & 0.00 \\
\hline i $1-0$ & 0.40 & 0.42 & 0.44 & 0.40 & 0.44 & 0.42 & 0.38 & 0.38 & 0.44 & 0.42 & 0.38 \\
\hline 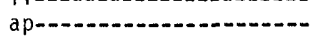 & 0.21 & 0.23 & 0.05 & 0.21 & 0.07 & 0.21 & 0.21 & 0.00 & 0.07 & 0.00 & 0.00 \\
\hline other & -- & -- & $-\infty$ & -- & -- & -- & -- & -- & -- & -- & -- \\
\hline
\end{tabular}

See footnotes at end of table. 
APPENDIX III.-Compilation of published major-element analyses of subalkaline silicic glasses-Continued

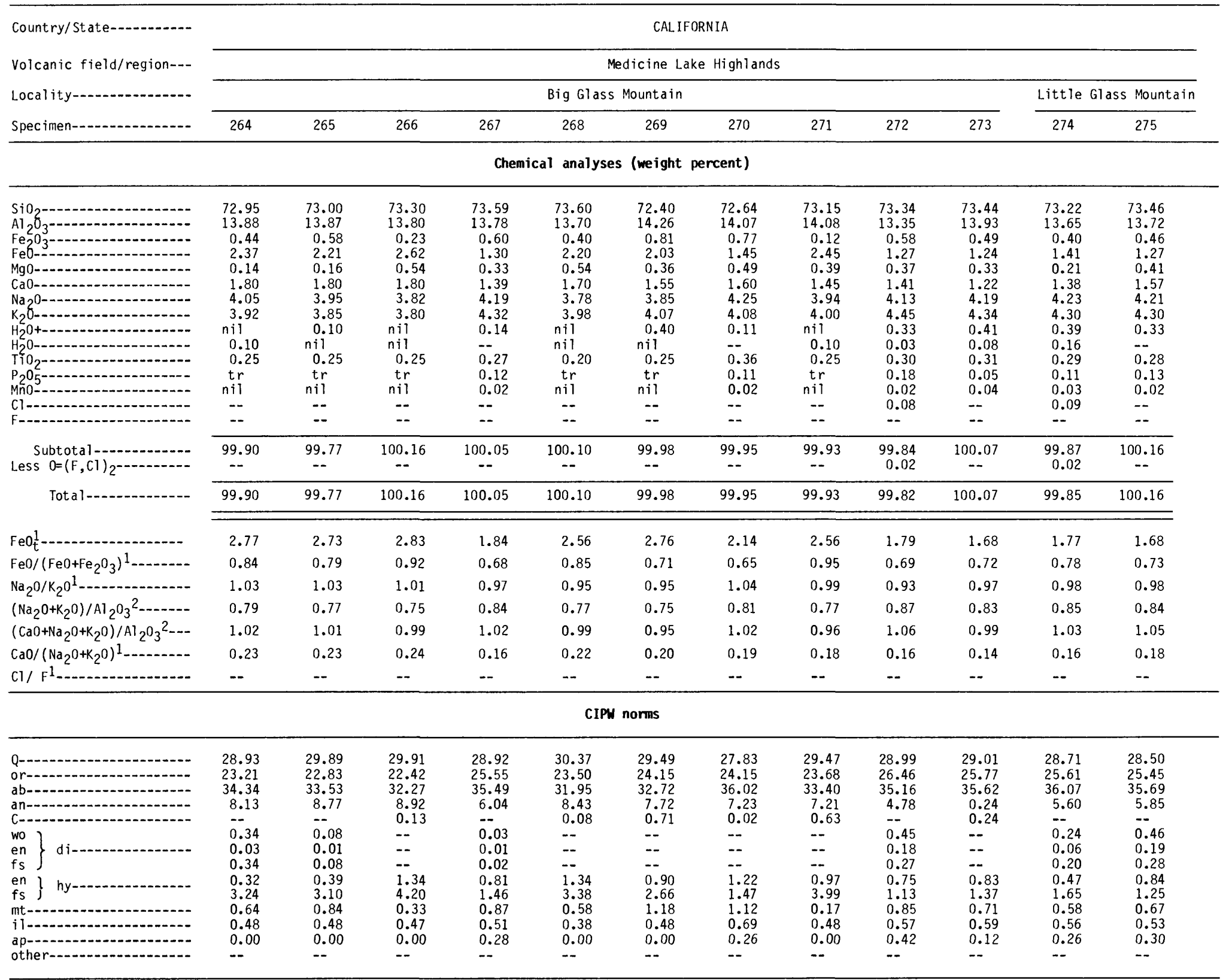

See footnotes at end of table. 


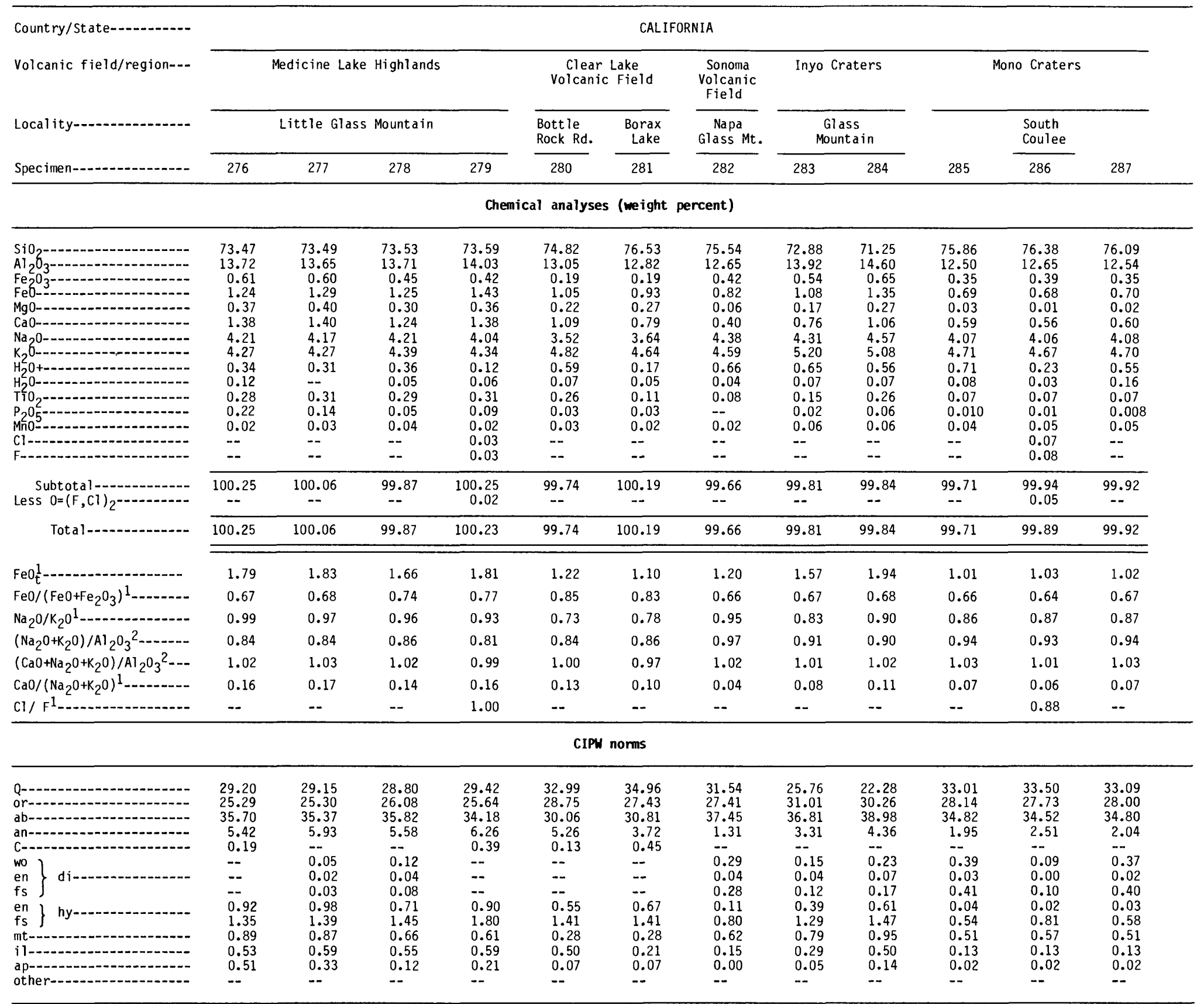

See footnotes at end of tabie. 
APPENDIX III.-Compilation of published major-element analyses of subalkaline silicic glasses-Continued

\begin{tabular}{|c|c|c|c|c|c|c|c|c|c|c|}
\hline \multirow{4}{*}{$\begin{array}{l}\text { Country/State--1.-. } \\
\text { Volcanic field/region--- } \\
\text { Locality-- } \\
\text { Specimen- }\end{array}$} & \multicolumn{3}{|c|}{ CALIFORNIA } & \multicolumn{3}{|c|}{ NEVADA } & \multicolumn{4}{|c|}{ WYOMING } \\
\hline & \multirow{3}{*}{$\begin{array}{c}\begin{array}{c}\text { Mono } \\
\text { Craters }\end{array} \\
288\end{array}$} & \multicolumn{2}{|c|}{$\begin{array}{l}\text { Long Valley } \\
\text { Complex }\end{array}$} & \multirow{3}{*}{$\begin{array}{c}\begin{array}{c}\text { Silver Peak } \\
\text { Volcanic } \\
\text { Center }\end{array} \\
291\end{array}$} & \multicolumn{2}{|c|}{ South Nevada } & \multicolumn{4}{|c|}{ Yellowstone Volcanic Complex } \\
\hline & & \multicolumn{2}{|c|}{ Glass Mountain } & & \multirow{2}{*}{$\begin{array}{c}\begin{array}{c}\text { Shoshone } \\
\text { Mountain }\end{array} \\
292\end{array}$} & \multirow{2}{*}{$\begin{array}{c}\begin{array}{c}\text { Obsidian } \\
\text { Butte }\end{array} \\
293\end{array}$} & \multirow{2}{*}{$\begin{array}{c}\begin{array}{c}\text { Lava Creek } \\
\text { Tuff }\end{array} \\
294\end{array}$} & \multicolumn{2}{|c|}{ West Yellowstone } & \multirow{2}{*}{$\begin{array}{r}\begin{array}{r}\text { Spring } \\
\text { Creek }\end{array} \\
297\end{array}$} \\
\hline & & 289 & 290 & & & & & 295 & 296 & \\
\hline \multicolumn{11}{|c|}{ Chemical analyses (weight percent) } \\
\hline 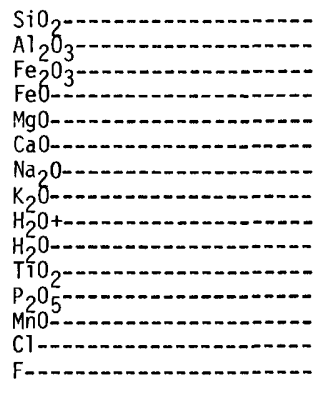 & $\begin{array}{l}76.21 \\
12.58 \\
0.30 \\
0.73 \\
0.03 \\
0.61 \\
4.05 \\
4.72 \\
0.39 \\
0.13 \\
0.07 \\
0.008 \\
0.04 \\
-- \\
--\end{array}$ & $\begin{array}{r}77.05 \\
12.58 \\
0.31 \\
0.45 \\
0.03 \\
0.44 \\
3.96 \\
4.68 \\
0.17 \\
0.02 \\
.07 \\
0.01 \\
0.04 \\
0.05 \\
0.08\end{array}$ & $\begin{array}{r}77.10 \\
12.53 \\
0.30 \\
0.46 \\
0.03 \\
0.45 \\
3.75 \\
4.76 \\
0.15 \\
0.02 \\
0.08 \\
0.01 \\
0.03 \\
0.05 \\
0.06\end{array}$ & $\begin{array}{r}75.96 \\
13.08 \\
0.39 \\
0.45 \\
0.13 \\
0.71 \\
3.87 \\
4.69 \\
0.22 \\
0.01 \\
0.12 \\
0.02 \\
0.06 \\
-- \\
--\end{array}$ & $\begin{array}{r}74.24 \\
13.46 \\
0.38 \\
0.92 \\
0.17 \\
0.67 \\
3.97 \\
5.33 \\
0.24 \\
0.04 \\
0.22 \\
0.02 \\
0.04 \\
0.05 \\
0.08\end{array}$ & $\begin{array}{r}75.53 \\
12.98 \\
0.37 \\
0.72 \\
0.10 \\
0.70 \\
3.82 \\
5.16 \\
0.15 \\
0.03 \\
0.12 \\
0.02 \\
0.05 \\
0.07 \\
0.07\end{array}$ & $\begin{array}{r}75.98 \\
12.33 \\
0.55 \\
1.08 \\
0.00 \\
0.49 \\
3.69 \\
5.10 \\
0.13 \\
0.00 \\
0.13 \\
0.01 \\
0.04 \\
0.12 \\
0.14\end{array}$ & $\begin{array}{l}76.7 \\
11.9 \\
0.5 \\
1.2 \\
0.13 \\
0.38 \\
3.4 \\
5.0 \\
0.60 \\
0.14 \\
0.01 \\
0.04 \\
0.09 \\
0.14\end{array}$ & $\begin{array}{l}75.8 \\
12.0 \\
0.8 \\
1.2 \\
0.18 \\
0.57 \\
3.4 \\
4.9 \\
0.32 \\
0.20 \\
0.02 \\
0.06 \\
0.08 \\
0.14\end{array}$ & $\begin{array}{r}76.44 \\
12.09 \\
0.46 \\
1.00 \\
0.03 \\
0.45 \\
3.55 \\
5.16 \\
0.26 \\
0.02 \\
0.14 \\
0.02 \\
0.04 \\
0.08 \\
0.17\end{array}$ \\
\hline $\begin{array}{l}\text { Subtotal } \\
\text { Less } 0=(F, C l)_{2}\end{array}$ & $\begin{array}{c}99.87 \\
-- \\
\end{array}$ & $\begin{array}{r}99.94 \\
0.05 \\
\end{array}$ & $\begin{array}{r}99.78 \\
0.04 \\
\end{array}$ & $\begin{array}{l}99.71 \\
--\end{array}$ & $\begin{array}{r}99.83 \\
0.05\end{array}$ & $\begin{array}{r}99.89 \\
0.05\end{array}$ & $\begin{array}{r}99.79 \\
0.09\end{array}$ & $\begin{array}{r}100.23 \\
0.08\end{array}$ & $\begin{array}{r}99.67 \\
0.08\end{array}$ & $\begin{array}{r}99.91 \\
0.09\end{array}$ \\
\hline 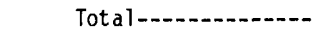 & 99.87 & 99.89 & 99.74 & 99.71 & 99.78 & 99.84 & 99.70 & 100.15 & 99.59 & 99.82 \\
\hline $\mathrm{Fe}_{\mathrm{t}}^{1}-\ldots$ & 1.00 & 0.73 & 0.73 & 0.80 & 1.26 & 1.05 & 1.58 & 1.65 & 1.92 & 1.41 \\
\hline $\mathrm{Fe} 0 /\left(\mathrm{Fe} 0+\mathrm{Fe}_{2} \mathrm{O}_{3}\right)^{1} \ldots$ & 0.71 & 0.59 & 0.61 & 0.54 & 0.71 & 0.66 & 0.66 & 0.71 & 0.60 & 0.68 \\
\hline $\mathrm{Na}_{2} \mathrm{O} / \mathrm{K}_{2} \mathrm{O}^{1} \ldots$ & 0.86 & 0.85 & 0.79 & 0.83 & 0.74 & 0.74 & 0.72 & 0.68 & 0.69 & 0.69 \\
\hline$\left(\mathrm{Na}_{2} \mathrm{O}+\mathrm{K}_{2} \mathrm{O}\right) / \mathrm{Al}_{2} \mathrm{O}_{3}{ }^{2} \ldots$ & 0.94 & 0.93 & 0.90 & 0.88 & 0.91 & 0.91 & 0.94 & 0.93 & 0.91 & 0.95 \\
\hline$\left(\mathrm{CaO}+\mathrm{Na}_{2} \mathrm{O}+\mathrm{K}_{2} \mathrm{O}\right) / \mathrm{Al}_{2} \mathrm{O}_{3}{ }^{2}---$ & 1.02 & 0.98 & 0.97 & 0.97 & 1.01 & 1.01 & 1.01 & 0.98 & 0.99 & 1.01 \\
\hline $\mathrm{CaO} /\left(\mathrm{Na}_{2} \mathrm{O}+\mathrm{K}_{2} \mathrm{O}\right)^{1}$ & 0.07 & 0.05 & 0.05 & 0.08 & 0.07 & 0.08 & 0.06 & 0.05 & 0.07 & 0.05 \\
\hline $\mathrm{Cl} / \mathrm{F}^{1}$ & -- & 0.63 & 0.83 & -- & 0.63 & 1.00 & 0.86 & 0.64 & 0.57 & 0.47 \\
\hline \multicolumn{11}{|c|}{ CIPW norms } \\
\hline Q- & 33.17 & 35.04 & 36.03 & 33.83 & 28.80 & 31.76 & 33.62 & 36.28 & 35.54 & 34.78 \\
\hline or- & 28.07 & 27.76 & 28.27 & 27.86 & 31.68 & 30.62 & 30.32 & 29.73 & 29.21 & 30.68 \\
\hline$a b+10-$ & 34.49 & 33.64 & 31.89 & 32.92 & 33.79 & 32.46 & 31.41 & 28.94 & 29.02 & 30.23 \\
\hline an-1-0. & 2.22 & 2.13 & 0.42 & 3.41 & 3.18 & 3.04 & 2.03 & 1.83 & 2.72 & 1.83 \\
\hline C-1 & - & 0.23 & 0.42 & 0.40 & -- & -- & -- & -- & 0.12 & $-\infty$ \\
\hline wo ? & 0.32 & -- & -- & -- & 0.01 & 0.13 & 0.15 & -- & -- & 0.12 \\
\hline 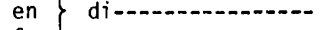 & 0.02 & -- & -- & -- & 0.00 & 0.03 & 0.00 & -- & -- & 0.01 \\
\hline fs J & 0.33 & -- & -- & - & 0.01 & 0.11 & 0.17 & -- & -- & 0.13 \\
\hline en $\}$ hy-...- & 0.05 & 0.08 & 0.08 & 0.33 & 0.42 & 0.22 & 0.00 & 0.33 & 0.45 & 0.07 \\
\hline fs $\}$ & 0.73 & 0.53 & 0.52 & 0.42 & 1.08 & 0.81 & 1.23 & 1.64 & 1.34 & 1.18 \\
\hline mt-a-n & 0.44 & 0.45 & 0.44 & 0.57 & 0.55 & 0.54 & 0.80 & 0.73 & 1.17 & 0.67 \\
\hline 门1--- & 0.13 & 0.13 & 0.15 & 0.23 & 0.42 & 0.23 & 0.25 & 0.27 & 0.38 & 0.27 \\
\hline ap- & 0.02 & 0.02 & 0.02 & 0.05 & 0.05 & 0.05 & 0.02 & 0.02 & 0.05 & 0.05 \\
\hline other- & -- & -- & -- & -- & -- & -- & -- & -- & -- & -- \\
\hline
\end{tabular}

See footnotes at end of table. 
APPENDIX III.-Compilation of published major-element analyses of subalkaline silicic glasses-Continued

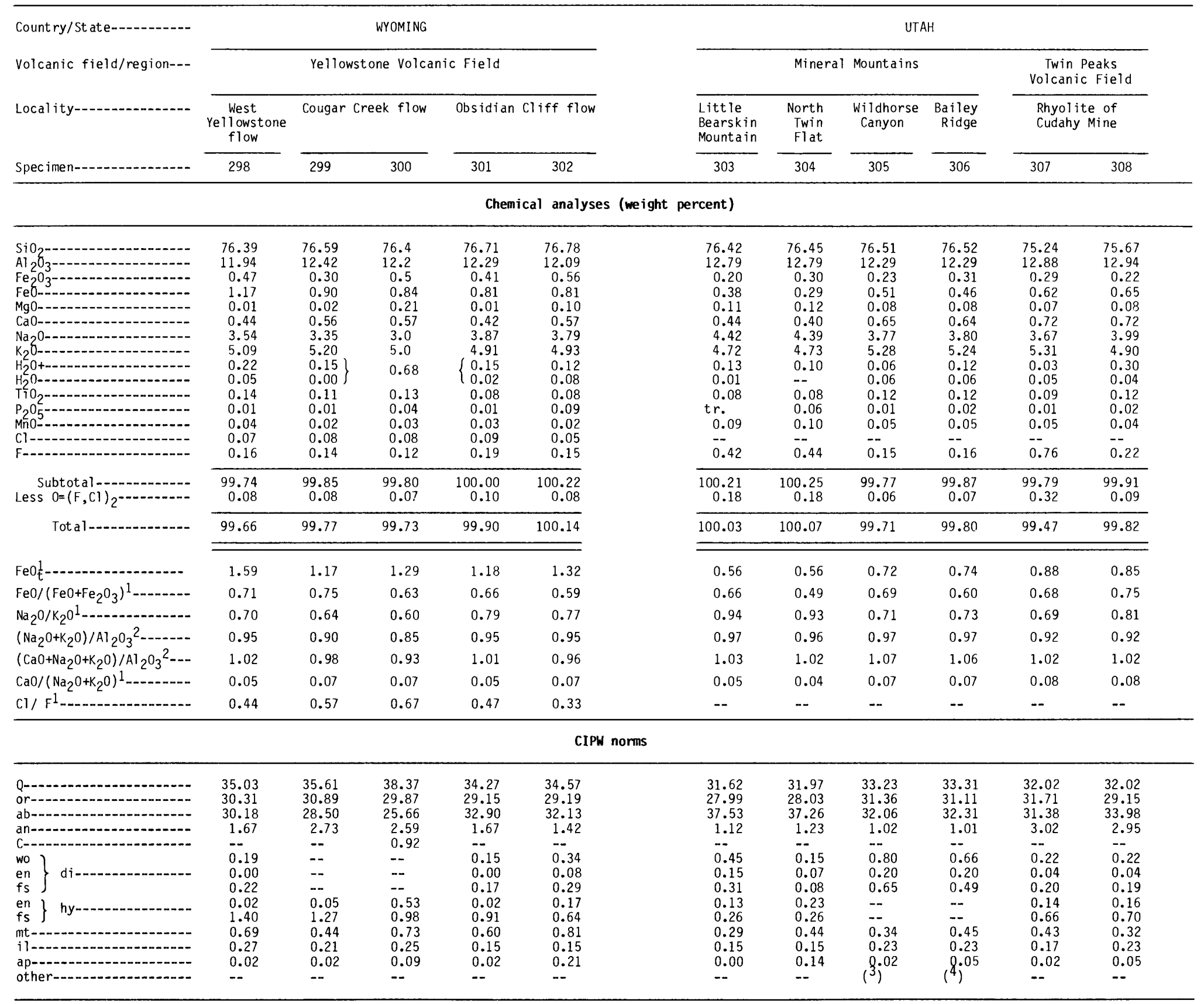

See footnotes at end of table. 
APPENDIX III.-Compilation of published major-element analyses of subalkaline silicic glasses-Continued

\begin{tabular}{|c|c|c|c|c|c|c|c|c|}
\hline \multirow{3}{*}{$\begin{array}{l}\text { Country/State-1... } \\
\text { Volcanic field/region-.- } \\
\text { Local ity- }\end{array}$} & \multirow{4}{*}{$\begin{array}{l}\frac{\text { UTAH }}{\text { Twin Peaks }} \\
\text { Volc. Field } \\
\begin{array}{l}\text { Rhyolite of } \\
\text { Cudahy Mine }\end{array} \\
309\end{array}$} & \multirow{4}{*}{$\begin{array}{c}\frac{\text { ARIZONA }}{\text { Galiuro }} \\
\text { Volcanics } \\
\text { Pinal } \\
310\end{array}$} & \multicolumn{4}{|c|}{ MEXICO } & \multicolumn{2}{|c|}{ PERU } \\
\hline & & & \multirow{3}{*}{$\frac{\frac{\text { West }}{\text { Tequila }}}{311}$} & \multicolumn{3}{|c|}{$\begin{array}{l}\text { Neovolcanic Zone } \\
\text { Central }\end{array}$} & \multirow{2}{*}{\multicolumn{2}{|c|}{ Macusani }} \\
\hline & & & & $\begin{array}{l}\text { Zinapec- } \\
\text { uaro }\end{array}$ & $\begin{array}{l}\text { Zacual- } \\
\text { tipan }\end{array}$ & $\begin{array}{l}\text { Tulan- } \\
\text { cingo }\end{array}$ & & \\
\hline Specimen--.- & & & & 312 & 313 & 314 & 315 & 316 \\
\hline \multicolumn{9}{|c|}{ Chemical analyses (weight percent) } \\
\hline 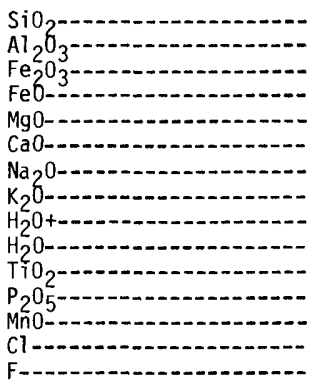 & $\begin{array}{r}75.86 \\
12.86 \\
0.21 \\
0.66 \\
0.07 \\
0.74 \\
3.93 \\
4.96 \\
0.35 \\
0.04 \\
0.11 \\
0.02 \\
0.05 \\
--.20\end{array}$ & $\begin{array}{l}74.6 \\
13.5 \\
1.3 \\
0.12 \\
0.11 \\
0.38 \\
4.2 \\
4.5 \\
0.42 \\
0.10 \\
0.21 \\
0.03 \\
0.10 \\
-- \\
--\end{array}$ & $\begin{array}{r}74.56 \\
13.15 \\
0.51 \\
1.00 \\
0.25 \\
0.66 \\
4.10 \\
5.44 \\
0.25 \\
0.06 \\
0.25 \\
0.08 \\
0.02 \\
-- \\
--\end{array}$ & $\begin{array}{r}75.43 \\
13.04 \\
0.51 \\
0.76 \\
0.15 \\
0.43 \\
4.73 \\
4.57 \\
0.51 \\
0.00 \\
0.12 \\
0.06 \\
0.02 \\
-- \\
--\end{array}$ & $\begin{array}{r}73.72 \\
13.32 \\
0.85 \\
0.76 \\
0.22 \\
0.66 \\
3.13 \\
6.60 \\
0.22 \\
0.03 \\
0.31 \\
0.09 \\
0.02 \\
-- \\
--\end{array}$ & $\begin{array}{r}73.65 \\
12.80 \\
0.60 \\
1.76 \\
0.25 \\
0.63 \\
4.28 \\
5.15 \\
0.23 \\
0.01 \\
0.29 \\
0.08 \\
0.02 \\
-- \\
--\end{array}$ & $\begin{array}{l}70.67 \\
16.12 \\
1.33 \\
0.41 \\
0.18 \\
2.07 \\
3.30 \\
5.53 \\
0.19 \\
0.18 \\
0.00 \\
0.27 \\
0.06 \\
-- \\
--\end{array}$ & $\begin{array}{l}72.8 \\
16.3 \\
0.29 \\
0.30 \\
0.00 \\
0.16 \\
4.1 \\
3.7 \\
0.70 \\
0.00 \\
0.02 \\
0.55 \\
0.06 \\
-- \\
--\end{array}$ \\
\hline $\begin{array}{l}\text { Subtotal-or } \\
\text { Less } 0=(\mathrm{F}, \mathrm{Cl})_{2}-\end{array}$ & $\begin{array}{r}100.06 \\
0.08\end{array}$ & $\begin{array}{l}99.57 \\
--\end{array}$ & 100.33 & $\begin{array}{c}100.33 \\
--\end{array}$ & 99.93 & 99.75 & $\begin{array}{c}100.31 \\
--\end{array}$ & $\overline{98.98^{6}}$ \\
\hline Total--..-- & 99.98 & 99.57 & 100.33 & 100.33 & 99.93 & 99.75 & 100.31 & $98.98^{6}$ \\
\hline $\mathrm{Fe}_{\mathrm{t}} \mathrm{t}_{-}$ & 0.85 & 1.29 & 1.46 & 1.22 & 1.53 & 2.30 & 1.61 & 0.56 \\
\hline $\mathrm{Fe} 0 /\left(\mathrm{Fe} 0+\mathrm{Fe}_{2} \mathrm{O}_{3}\right)^{1} \ldots$ & 0.76 & 0.08 & 0.66 & 0.60 & 0.47 & 0.75 & 0.24 & 0.51 \\
\hline $\mathrm{Na}_{2} \mathrm{O} / \mathrm{K}_{2} \mathrm{O}^{1} \ldots$ & 0.79 & 0.93 & 0.75 & 1.04 & 0.47 & 0.83 & 0.60 & 1.11 \\
\hline$\left(\mathrm{Na}_{2} \mathrm{O}+\mathrm{K}_{2} \mathrm{O}\right) / \mathrm{Al}_{2} \mathrm{O}_{3}{ }^{2}$ & 0.92 & 0.87 & 0.96 & 0.98 & 0.92 & 0.99 & 0.71 & 0.66 \\
\hline$\left(\mathrm{CaO}+\mathrm{Na}_{2} \mathrm{O}+\mathrm{K}_{2} \mathrm{O}\right) / \mathrm{Al}_{2} \mathrm{O}_{3}{ }^{2}-\cdots$ & 1.03 & 0.92 & 1.05 & 1.04 & 1.01 & 1.08 & 0.94 & 0.68 \\
\hline $\mathrm{CaO} /\left(\mathrm{Na}_{2} \mathrm{O}+\mathrm{K}_{2} \mathrm{O}\right)^{1} \ldots$ & 0.08 & 0.04 & 0.07 & 0.05 & 0.07 & 0.07 & 0.23 & 0.02 \\
\hline $\mathrm{Cl} / \mathrm{F}^{1}-\mathrm{C}_{1}$ & -- & -- & -- & -- & -- & -- & -- & -- \\
\hline \multicolumn{9}{|c|}{ CIPW norms } \\
\hline $\begin{array}{l}\text { Q } \\
\text { or } \\
\text { ab } \\
\text { an- } \\
\text { wo } \\
\text { en } \\
\text { fs } \\
\text { en } \\
\text { fs } \\
\text { mt } \\
\begin{array}{l}\text { i } \\
\text { ap }\end{array} \\
\text { other }\end{array}$ & $\begin{array}{c}32.28 \\
29.47 \\
33.43 \\
2.82 \\
-- \\
0.31 \\
0.05 \\
0.28 \\
0.12 \\
0.67 \\
0.31 \\
0.21 \\
0.05 \\
--.\end{array}$ & $\begin{array}{c}32.36 \\
26.85 \\
35.88 \\
1.71 \\
1.11 \\
-- \\
-- \\
-- \\
0.28 \\
0.00 \\
0.11 \\
0.40 \\
0.07 \\
--\end{array}$ & $\begin{array}{c}28.14 \\
32.14 \\
34.69 \\
1.41 \\
-- \\
0.56 \\
0.21 \\
0.36 \\
0.41 \\
0.68 \\
0.74 \\
0.48 \\
0.19 \\
--\end{array}$ & $\begin{array}{c}29.33 \\
27.05 \\
40.10 \\
0.85 \\
-- \\
0.37 \\
0.12 \\
0.26 \\
0.25 \\
0.55 \\
0.74 \\
0.23 \\
0.14 \\
--\end{array}$ & $\begin{array}{c}28.76 \\
39.13 \\
26.57 \\
2.70 \\
0.04 \\
-- \\
-- \\
-- \\
0.55 \\
0.22 \\
1.24 \\
0.59 \\
0.21 \\
--\end{array}$ & $\begin{array}{c}27.04 \\
30.58 \\
36.40 \\
0.51 \\
-- \\
0.88 \\
0.20 \\
0.74 \\
0.43 \\
1.57 \\
0.87 \\
0.55 \\
0.19 \\
--\end{array}$ & $\begin{array}{c}26.39 \\
32.70 \\
27.94 \\
8.51 \\
1.59 \\
-- \\
-- \\
-- \\
0.45 \\
0.00 \\
1.52 \\
0.00 \\
(5)^{63}\end{array}$ & $\begin{array}{c}35.22 \\
22.25 \\
35.30 \\
0.00 \\
5.65 \\
-- \\
-- \\
-- \\
0.00 \\
0.40 \\
0.43 \\
0.04 \\
0.29 \\
--\end{array}$ \\
\hline
\end{tabular}


APPENDIX III.-Compilation of published major-element analyses of subalkaline silicic glasses-Continued

\begin{tabular}{|c|c|c|c|c|c|c|c|c|c|c|c|}
\hline \multirow{4}{*}{ 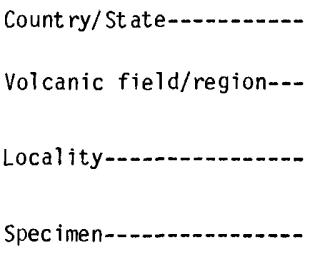 } & \multicolumn{5}{|c|}{ ICELAND } & \multicolumn{6}{|c|}{ ITALY } \\
\hline & \multirow{3}{*}{$\begin{array}{c}\text { Hrafntinn- } \\
\text { uhryggur } \\
317\end{array}$} & \multirow{2}{*}{\multicolumn{2}{|c|}{ Vatnajઇkull }} & \multirow{3}{*}{$\frac{\begin{array}{c}\text { Berufjor- } \\
\text { dur }\end{array}}{320}$} & \multirow{3}{*}{$\begin{array}{c}\text { Gaesafjolı } \\
\text { complex } \\
\begin{array}{c}\text { Little } \\
\text { Krafla }\end{array} \\
321 \\
\end{array}$} & \multirow{2}{*}{\multicolumn{4}{|c|}{$\begin{array}{c}\text { Vulcano } \\
\text { Monte Lentia }\end{array}$}} & \multicolumn{2}{|c|}{ Lipari } \\
\hline & & & & & & & & & & \multirow{2}{*}{$\frac{\begin{array}{l}\text { Forgia } \\
\text { Vecchia }\end{array}}{326}$} & \multirow{2}{*}{$\begin{array}{c}\begin{array}{r}\text { Rocche } \\
\text { Rosse }\end{array} \\
327\end{array}$} \\
\hline & & 318 & 319 & & & 322 & 323 & 324 & 325 & & \\
\hline \multicolumn{12}{|c|}{ Chemical analyses (weight percent) } \\
\hline 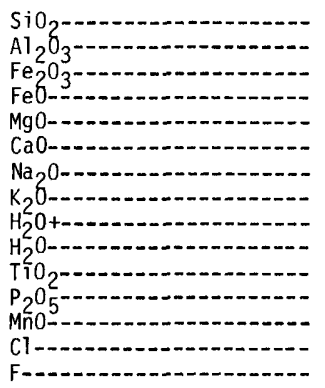 & $\begin{array}{l}75.4 \\
11.9 \\
0.7 \\
2.5 \\
0.21 \\
1.7 \\
4.4 \\
2.7 \\
0.21 \\
0.03 \\
0.27 \\
0.03 \\
0.10 \\
-. \\
--\end{array}$ & $\begin{array}{r}75.06 \\
13.84 \\
0.31 \\
1.91 \\
0.28 \\
1.62 \\
3.16 \\
3.22 \\
0.17 \\
0.06 \\
0.12 \\
\operatorname{tr} \\
\operatorname{tr} \\
-- \\
--\end{array}$ & $\begin{array}{r}73.63 \\
12.75 \\
1.33 \\
1.80 \\
\text { ni1 } \\
1.12 \\
4.96 \\
3.15 \\
0.49 \\
0.22 \\
0.24 \\
0.26 \\
0.06 \\
--.\end{array}$ & $\begin{array}{l}75.0 \\
12.4 \\
0.8 \\
1.2 \\
0.16 \\
0.92 \\
5.1 \\
3.6 \\
0.23 \\
0.04 \\
0.20 \\
0.03 \\
0.06 \\
-. \\
-.\end{array}$ & $\begin{array}{r}73.44 \\
11.82 \\
1.97 \\
1.56 \\
0.01 \\
1.74 \\
4.70 \\
3.68 \\
0.63 \\
0.14 \\
0.31 \\
0.44 \\
0.09 \\
-- \\
--\end{array}$ & $\begin{array}{l}71.37 \\
14.90 \\
1.34 \\
1.15 \\
0.36 \\
1.54 \\
4.15 \\
5.18 \\
0.27 \\
0.06 \\
-- \\
\operatorname{tr} \\
0.07 \\
-- \\
--\end{array}$ & $\begin{array}{r}71.16 \\
14.07 \\
1.80 \\
1.00 \\
0.93 \\
1.95 \\
4.08 \\
4.78 \\
0.23 \\
0.08 \\
0.20 \\
0.10 \\
0.06 \\
-- \\
--\end{array}$ & $\begin{array}{r}70.85 \\
13.70 \\
1.36 \\
1.46 \\
1.10 \\
2.32 \\
4.63 \\
4.44 \\
0.39 \\
0.02 \\
0.18 \\
0.12 \\
0.08 \\
-- \\
--\end{array}$ & $\begin{array}{r}70.69 \\
14.54 \\
0.84 \\
1.29 \\
0.74 \\
2.28 \\
4.99 \\
4.32 \\
0.26 \\
0.03 \\
0.32 \\
0.15 \\
0.05 \\
-- \\
--\end{array}$ & $\begin{array}{c}73.86 \\
12.49 \\
0.60 \\
1.40 \\
0.11 \\
0.75 \\
4.05 \\
4.81 \\
0.92 \\
0.09 \\
0.12 \\
\operatorname{tr} \\
\mathrm{tr} \\
0.26 \\
-.\end{array}$ & $\begin{array}{r}74.22 \\
12.98 \\
0.40 \\
1.60 \\
0.04 \\
0.67 \\
4.13 \\
4.97 \\
0.27 \\
0.04 \\
0.11 \\
0.14 \\
0.01 \\
0.03\end{array}$ \\
\hline $\begin{array}{l}\text { Subtotal } \\
\text { Less } 0=(F, C l)_{2}\end{array}$ & $\begin{array}{c}100.15 \\
--\end{array}$ & $\begin{array}{c}99.75 \\
--\end{array}$ & $\begin{array}{c}100.01 \\
-\end{array}$ & $\begin{array}{c}99.74 \\
-.\end{array}$ & $\begin{array}{c}100.53 \\
-.\end{array}$ & $\begin{array}{c}100.39 \\
\ldots\end{array}$ & 100.44 & $\begin{array}{c}100.65 \\
--\end{array}$ & 100.50 & $\begin{array}{r}99.46 \\
0.06\end{array}$ & $\begin{array}{r}99.61 \\
0.01\end{array}$ \\
\hline Total-an...........- & 100.15 & 99.75 & 100.01 & 99.74 & 100.53 & 100.39 & 100.44 & 100.65 & 100.50 & 99.40 & 99.60 \\
\hline $\mathrm{Fe}_{\mathrm{t}}^{1}-\ldots$ & 3.13 & 2.19 & 3.00 & 1.92 & 3.33 & 2.36 & 2.62 & 2.69 & 2.05 & 1.94 & 1.96 \\
\hline $\mathrm{Fe} 0 /\left(\mathrm{Fe} 0+\mathrm{Fe}_{2} \mathrm{O}_{3}\right)^{1}-\ldots$ & 0.78 & 0.86 & 0.58 & 0.60 & 0.44 & 0.46 & 0.36 & 0.52 & 0.61 & 0.70 & 0.80 \\
\hline $\mathrm{Na}_{2} \mathrm{O} / \mathrm{K}_{2} \mathrm{O}^{1}$ & 1.63 & 0.98 & 1.57 & 1.42 & 1.28 & 0.80 & 0.85 & 1.04 & 1.16 & 0.84 & 0.83 \\
\hline$\left(\mathrm{Na}_{2} \mathrm{O}+\mathrm{K}_{2} \mathrm{O}\right) / \mathrm{Al}_{2} \mathrm{O}_{3}{ }^{2} \ldots$ & 0.86 & 0.63 & 0.91 & 0.99 & 0.99 & 0.84 & 0.84 & 0.91 & 0.91 & 0.94 & 0.95 \\
\hline$\left(\mathrm{CaO}+\mathrm{Na}_{2} \mathrm{O}+\mathrm{K}_{2} \mathrm{O}\right) / \mathrm{Al}_{2} \mathrm{O}_{3}{ }^{2}---$ & 1.11 & 0.84 & 1.07 & 1.13 & 1.26 & 1.02 & 1.10 & 1.21 & 1.21 & 1.06 & 1.03 \\
\hline $\mathrm{CaO} /\left(\mathrm{Na}_{2} \mathrm{O}+\mathrm{K}_{2} \mathrm{O}\right)^{1-}$ & 0.24 & 0.25 & 0.14 & 0.11 & 0.21 & 0.17 & 0.22 & 0.26 & 0.24 & 0.08 & 0.07 \\
\hline $\mathrm{Cl} / \mathrm{F}^{1}-\ldots$ & -- & -- & -- & $-\cdots$ & -- & -- & -- & -- & -- & -- & -- \\
\hline \multicolumn{12}{|c|}{ CIPW norms } \\
\hline 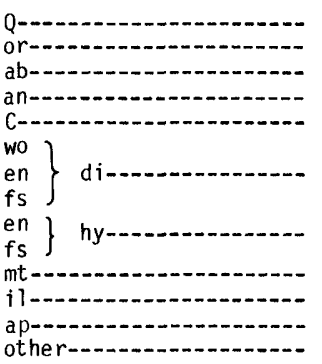 & $\begin{array}{l}34.68 \\
15.97 \\
37.27 \\
4.75 \\
-- \\
1.46 \\
0.20 \\
1.40 \\
0.33 \\
2.36 \\
1.02 \\
0.51 \\
0.07 \\
--\end{array}$ & $\begin{array}{l}39.22 \\
19.14 \\
26.90 \\
8.09 \\
2.22 \\
-- \\
-- \\
-- \\
0.70 \\
3.27 \\
0.45 \\
0.00 \\
0.00 \\
--\end{array}$ & $\begin{array}{l}30.53 \\
18.75 \\
42.27 \\
3.25 \\
-- \\
0.27 \\
0.00 \\
0.30 \\
0.00 \\
1.63 \\
0.94 \\
0.46 \\
0.61 \\
-.\end{array}$ & $\begin{array}{c}29.87 \\
21.39 \\
43.39 \\
0.31 \\
-- \\
1.64 \\
0.40 \\
1.33 \\
-- \\
\overline{1 .} \\
0.38 \\
(7)^{07}\end{array}$ & $\begin{array}{c}30.37 \\
21.80 \\
39.87 \\
0.29 \\
-- \\
0.82 \\
0.03 \\
0.90 \\
-- \\
-- \\
2.86 \\
0.59 \\
\left(\frac{1}{8}\right)^{02}\end{array}$ & $\begin{array}{r}23.24 \\
30.59 \\
35.10 \\
6.73 \\
--. \\
0.38 \\
0.17 \\
0.21 \\
0.73 \\
0.92 \\
1.94 \\
0.00 \\
0.00 \\
-.-\end{array}$ & $\begin{array}{l}24.42 \\
28.21 \\
34.48 \\
5.95 \\
-- \\
1.28 \\
1.06 \\
0.06 \\
1.26 \\
0.07 \\
2.61 \\
0.38 \\
0.23 \\
-.\end{array}$ & $\begin{array}{l}21.53 \\
26.17 \\
39.08 \\
3.48 \\
-- \\
3.02 \\
1.87 \\
0.96 \\
0.86 \\
0.44 \\
1.97 \\
0.34 \\
0.28 \\
--\end{array}$ & $\begin{array}{r}20.22 \\
25.47 \\
42.14 \\
4.51 \\
-.- \\
2.42 \\
1.39 \\
0.93 \\
0.45 \\
0.31 \\
1.22 \\
0.61 \\
0.35 \\
--\end{array}$ & $\begin{array}{c}30.25 \\
28.95 \\
34.90 \\
1.73 \\
-- \\
0.86 \\
0.12 \\
0.82 \\
0.16 \\
1.09 \\
0.89 \\
0.23 \\
0.00 \\
--\end{array}$ & $\begin{array}{c}29.22 \\
29.59 \\
35.20 \\
2.22 \\
-- \\
0.09 \\
0.00 \\
0.10 \\
0.10 \\
2.37 \\
0.58 \\
0.21 \\
0.33 \\
---\end{array}$ \\
\hline
\end{tabular}

See footnotes at end of table. 
APPENDIX III.-Compilation of published major-element analyses of subalkaline silicic glasses-Continued

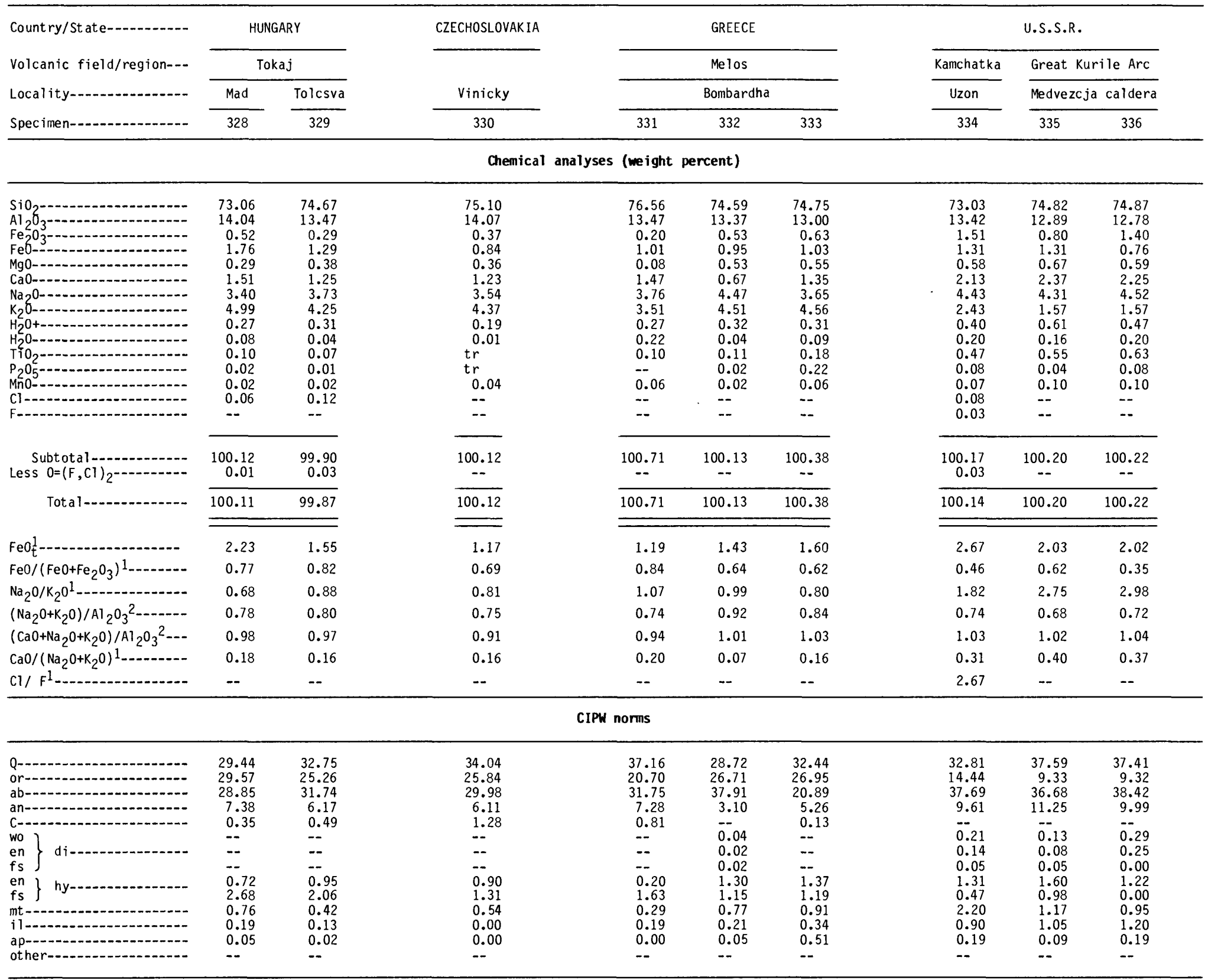

See footnotes at end of table. 


\begin{tabular}{|c|c|c|c|c|c|c|c|c|c|c|c|}
\hline \multirow{4}{*}{$\begin{array}{l}\text { Country/State- } \\
\text { Volcanic field/region--- } \\
\text { Locality- } \\
\text { Spec imen-1- }\end{array}$} & \multirow{4}{*}{$\frac{\text { CAMEROON }}{\frac{\text { Mount }}{\text { Manengouba }}}$} & \multicolumn{10}{|c|}{ JAPAN } \\
\hline & & \multicolumn{3}{|c|}{ Hokkaido } & \multicolumn{5}{|c|}{ Honshu } & \multirow{3}{*}{$\frac{\begin{array}{c}\text { Nagano } \\
\text { Prefecture }\end{array}}{\frac{\begin{array}{c}\text { Wada- } \\
\text { toge }\end{array}}{346}}$} & \multirow{3}{*}{$\begin{array}{c}\text { Huzi } \\
\text { volc. zone } \\
\begin{array}{c}\text { Kasiwa- } \\
\text { toge }\end{array} \\
347\end{array}$} \\
\hline & & \multirow{2}{*}{$\frac{\begin{array}{c}\text { Atosan- } \\
\text { upuri }\end{array}}{338}$} & \multirow{2}{*}{$\frac{\text { Tokachi }}{339}$} & \multirow{2}{*}{$\begin{array}{l}\text { Usu } \\
340\end{array}$} & \multicolumn{5}{|c|}{ Asama Volcano } & & \\
\hline & & & & & 341 & 342 & 343 & 344 & 345 & & \\
\hline \multicolumn{12}{|c|}{ Chemical analyses (weight percent) } \\
\hline 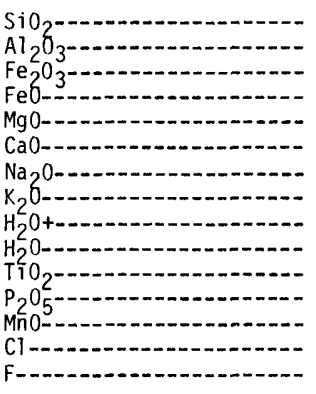 & $\begin{array}{r}72.80 \\
14.80 \\
1.58 \\
3.07 \\
0.43 \\
0.74 \\
3.36 \\
1.51 \\
0.50 \\
0.30 \\
0.32 \\
--.16 \\
0 .- \\
--\end{array}$ & $\begin{array}{r}72.64 \\
12.92 \\
1.52 \\
1.93 \\
1.14 \\
2.53 \\
4.03 \\
1.62 \\
0.61 \\
0.15 \\
0.68 \\
0.04 \\
0.07 \\
-- \\
--\end{array}$ & $\begin{array}{r}76.59 \\
12.76 \\
0.28 \\
0.98 \\
0.48 \\
1.11 \\
4.05 \\
3.47 \\
0.48 \\
0.22 \\
\operatorname{tr} \\
0.12 \\
0.04 \\
-- \\
--\end{array}$ & $\begin{array}{r}70.60 \\
15.00 \\
1.37 \\
2.49 \\
0.77 \\
3.30 \\
4.42 \\
0.98 \\
0.69 \\
0.12 \\
0.36 \\
0.21 \\
0.09 \\
-. \\
--\end{array}$ & $\begin{array}{l}73.7 \\
14.2 \\
0.39 \\
1.62 \\
0.63 \\
2.49 \\
4.47 \\
2.30 \\
0.42 \\
0.47 \\
0.09 \\
0.06 \\
-- \\
--\end{array}$ & $\begin{array}{l}73.0 \\
14.1 \\
0.65 \\
1.58 \\
0.58 \\
2.59 \\
4.12 \\
2.07 \\
0.37 \\
0.47 \\
0.09 \\
0.06 \\
-- \\
--\end{array}$ & $\begin{array}{l}72.7 \\
14.3 \\
0.42 \\
1.79 \\
0.60 \\
2.80 \\
4.19 \\
2.33 \\
0.38 \\
0.51 \\
0.09 \\
0.06 \\
-- \\
--\end{array}$ & $\begin{array}{r}72.01 \\
14.37 \\
0.73 \\
1.81 \\
0.57 \\
2.56 \\
4.35 \\
2.39 \\
0.26 \\
0.08 \\
0.41 \\
0.07 \\
0.08 \\
-. \\
--\end{array}$ & $\begin{array}{r}71.76 \\
14.20 \\
0.74 \\
1.71 \\
0.22 \\
2.94 \\
4.43 \\
2.03 \\
0.49 \\
0.73 \\
0.05 \\
0.20 \\
-- \\
--\end{array}$ & $\begin{array}{r}75.65 \\
12.81 \\
0.32 \\
0.85 \\
0.23 \\
0.56 \\
3.73 \\
4.40 \\
0.74 \\
0.13 \\
0.13 \\
0.12 \\
0.05 \\
---\end{array}$ & $\begin{array}{c}75.63 \\
12.80 \\
0.47 \\
1.95 \\
0.28 \\
2.20 \\
3.71 \\
2.35 \\
0.25 \\
0.07 \\
0.26 \\
\operatorname{tr} \\
0.06 \\
--- \\
--\end{array}$ \\
\hline $\begin{array}{l}\text { Subtotal- } \\
\text { Less } 0=(\mathrm{F}, \mathrm{Cl})_{2}\end{array}$ & 99.57 & $\begin{array}{l}99.88 \\
--\end{array}$ & $\begin{array}{c}100.58 \\
--\end{array}$ & 100.40 & $\begin{array}{c}100.84 \\
--\end{array}$ & $\begin{array}{l}99.68 \\
--\end{array}$ & $\begin{array}{c}100.17 \\
--\end{array}$ & $\begin{array}{l}99.69 \\
--\end{array}$ & 99.50 & 99.72 & 100.03 \\
\hline Total-_....... & 99.57 & 99.88 & 100.58 & 100.40 & 100.84 & 99.68 & 100.17 & 99.69 & 99.50 & 99.72 & 100.03 \\
\hline $\mathrm{Fe}_{\mathrm{t}}^{1}-\ldots$ & 4.49 & 3.30 & 1.23 & 3.72 & 1.97 & 2.17 & 2.17 & 2.47 & 2.38 & 1.14 & 2.37 \\
\hline $\mathrm{Fe} 0 /\left(\mathrm{Fe} 0+\mathrm{Fe}_{2} \mathrm{O}_{3}\right)^{1} \ldots$ & 0.66 & 0.56 & 0.78 & 0.65 & 0.81 & 0.71 & 0.81 & 0.71 & 0.70 & 0.73 & 0.81 \\
\hline $\mathrm{Na}_{2} \mathrm{O} / \mathrm{K}_{2} \mathrm{O}^{1} \ldots$ & 2.23 & 2.49 & 1.17 & 4.51 & 1.94 & 1.99 & 1.80 & 1.82 & 2.18 & 0.85 & 1.58 \\
\hline$\left(\mathrm{Na}_{2} \mathrm{O}+\mathrm{K}_{2} \mathrm{O}\right) / \mathrm{Al}_{2} \mathrm{O}_{3}{ }^{2}-\cdots$ & 0.48 & 0.65 & 0.82 & 0.56 & 0.69 & 0.64 & 0.66 & 0.68 & 0.67 & 0.85 & 0.68 \\
\hline$\left(\mathrm{CaO}+\mathrm{Na}_{2} \mathrm{O}+\mathrm{K}_{2} \mathrm{O}\right) / \mathrm{Al}_{2} \mathrm{O}_{3}{ }^{2}-\cdots$ & 0.57 & 1.01 & 0.97 & 0.96 & 1.01 & 0.97 & 1.01 & 1.00 & 1.04 & 0.93 & 0.99 \\
\hline $\mathrm{CaO} /\left(\mathrm{Na}_{2} \mathrm{O}+\mathrm{K}_{2} \mathrm{O}\right)^{1} \ldots$ & 0.15 & 0.45 & 0.15 & 0.75 & 0.37 & 0.42 & 0.43 & 0.38 & 0.46 & 0.07 & 0.36 \\
\hline $\mathrm{Cl} / \mathrm{F}^{1}-$ & -- & -- & -- & -- & -- & -- & -- & -- & -- & -- & -- \\
\hline \multicolumn{12}{|c|}{ CIPW norms } \\
\hline 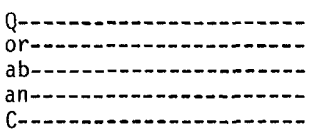 & $\begin{array}{r}43.92 \\
9.03 \\
28.79 \\
3.72 \\
6.37\end{array}$ & $\begin{array}{r}35.72 \\
9.66 \\
34.40 \\
12.40 \\
0.03\end{array}$ & $\begin{array}{r}36.29 \\
20.53 \\
34.31 \\
4.73 \\
0.61\end{array}$ & $\begin{array}{r}32.27 \\
5.82 \\
37.56 \\
15.06 \\
1.18\end{array}$ & $\begin{array}{r}31.84 \\
13.53 \\
37.57 \\
11.72 \\
0.05\end{array}$ & $\begin{array}{r}34.42 \\
12.32 \\
35.11 \\
12.35 \\
0.59\end{array}$ & $\begin{array}{r}31.83 \\
13.80 \\
35.53 \\
13.33 \\
0.01\end{array}$ & $\begin{array}{r}30.62 \\
14.22 \\
37.05 \\
12.32 \\
0.14\end{array}$ & $\begin{array}{l}31.58 \\
12.12 \\
37.86 \\
12.99 \\
--\end{array}$ & $\begin{array}{r}35.79 \\
25.30 \\
31.93 \\
2.02 \\
1.19\end{array}$ & $\begin{array}{r}38.73 \\
13.93 \\
31.48 \\
10.95 \\
0.15\end{array}$ \\
\hline $\left.\begin{array}{l}\text { wo } \\
\text { en }\end{array}\right\}$ di-................ & $=-$ & $=$ & $=$ & $=$ & $=$ & $=$ & -- & $=$ & 0.59 & -- & -- \\
\hline 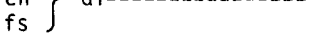 & -- & -- & - & -- & -- & $=$ & -- & -- & 0.47 & -- & $=-$ \\
\hline $\left.\begin{array}{l}\text { en } \\
\text { fs }\end{array}\right\}$ hy & $\begin{array}{l}1.08 \\
4.15\end{array}$ & $\begin{array}{l}2.86 \\
1.31\end{array}$ & $\begin{array}{l}1.20 \\
1.65\end{array}$ & $\begin{array}{l}1.93 \\
3.03\end{array}$ & $\begin{array}{l}1.56 \\
1.98\end{array}$ & $\begin{array}{l}1.46 \\
1.71\end{array}$ & $\begin{array}{l}1.50 \\
2.21\end{array}$ & $\begin{array}{l}1.43 \\
2.21\end{array}$ & $\begin{array}{l}0.40 \\
1.24\end{array}$ & $\begin{array}{l}0.58 \\
1.19\end{array}$ & $\begin{array}{l}0.70 \\
2.88\end{array}$ \\
\hline 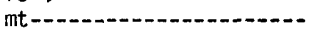 & 2.32 & 2.22 & 0.41 & $\begin{array}{l}2.05 \\
2.00-3-1\end{array}$ & $\begin{array}{l}1.90 \\
0.56\end{array}$ & 0.95 & 0.51 & 1.07 & 1.08 & 0.47 & 0.68 \\
\hline ¡|--- & 0.62 & 1.30 & 0.00 & 0.69 & 0.89 & 0.90 & 0.97 & 0.78 & 1.40 & 0.25 & 0.50 \\
\hline 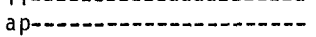 & 0.00 & 0.09 & 0.28 & 0.49 & 0.21 & 0.21 & 0.21 & 0.16 & 0.12 & 0.28 & 0.00 \\
\hline other & -- & - & -- & -- & -- & -- & -- & -- & -- & -- & -- \\
\hline
\end{tabular}


APPENDIX III.-Compilation of published major-element analyses of subalkaline silicic glasses-Continued

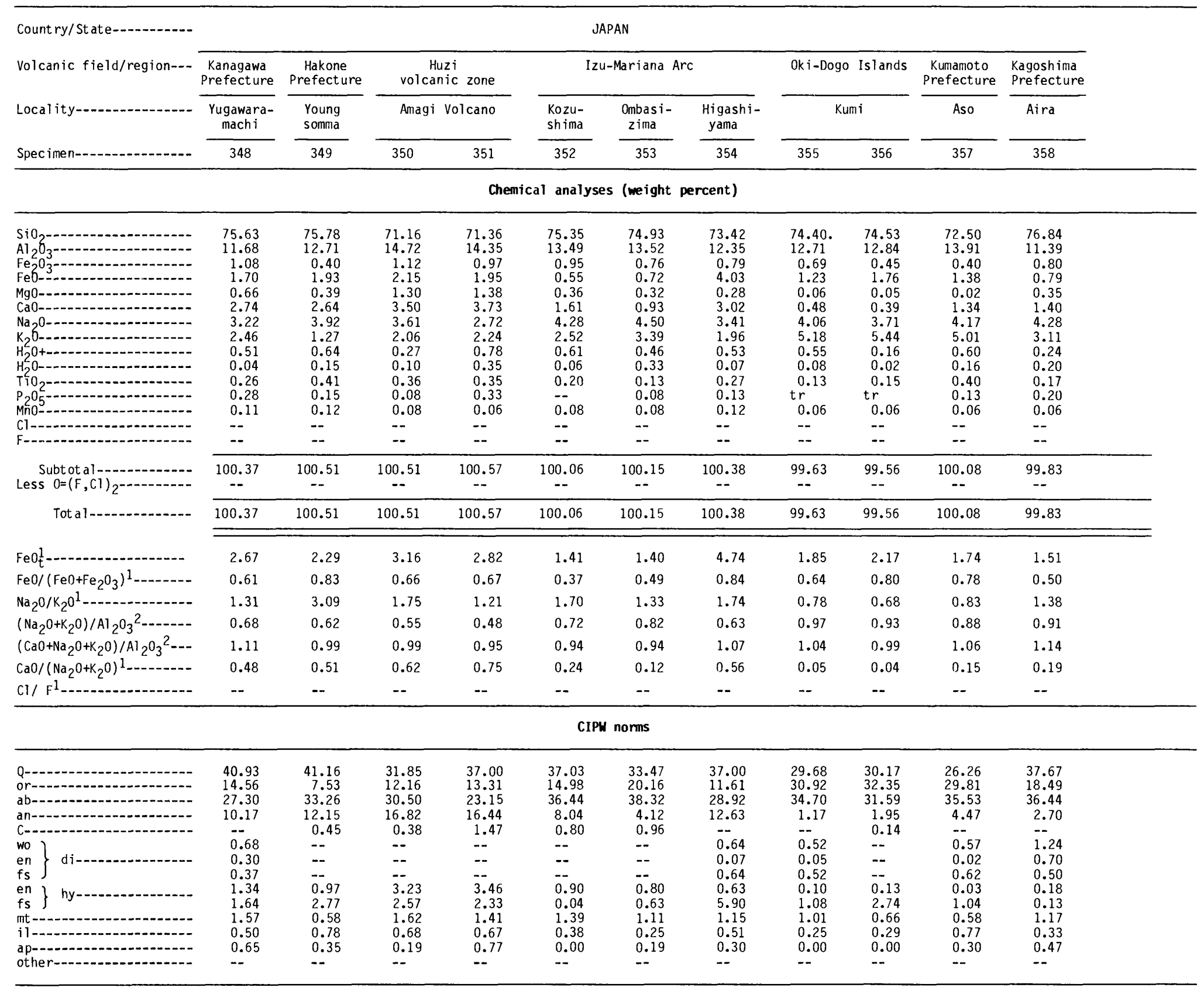


APPENDIX III.-Compilation of published major-element analyses of subalkaline silicic glasses-Continued

\begin{tabular}{|c|c|c|c|c|c|c|c|c|c|}
\hline \multirow{4}{*}{$\begin{array}{l}\text { Country/State-1 } \\
\text { Volcanic field/region- } \\
\text { Locality } \\
\text { Specimen }\end{array}$} & \multicolumn{6}{|c|}{ PAPUA NEW GUINEA } & \multirow[t]{2}{*}{ NEW BRITAIN } & \multicolumn{2}{|c|}{ NEW ZEALAND } \\
\hline & \multicolumn{2}{|c|}{ D'Entrecasteaux } & Is land & \multicolumn{2}{|c|}{ St. Andrew Strait } & \multirow{2}{*}{$\begin{array}{c}\begin{array}{c}\text { Witu } \\
\text { Islands }\end{array} \\
\begin{array}{l}\text { Garove } \\
\text { Island }\end{array}\end{array}$} & & & \\
\hline & \multicolumn{3}{|c|}{ Moresby Strait } & \multicolumn{2}{|c|}{ Lou Island } & & Talasea & $\begin{array}{c}\text { Tairua } \\
\text { River }\end{array}$ & $\begin{array}{l}\text { Fanal } \\
\text { Island }\end{array}$ \\
\hline & 359 & 360 & 361 & 362 & 363 & 364 & 365 & 366 & 367 \\
\hline \multicolumn{10}{|c|}{ Chemical analyses (weight percent) } \\
\hline 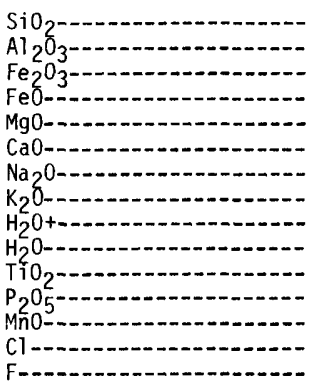 & $\begin{array}{r}72.30 \\
14.20 \\
0.38 \\
0.95 \\
0.22 \\
0.72 \\
5.19 \\
4.45 \\
0.52 \\
0.16 \\
0.26 \\
0.04 \\
0.06 \\
--\end{array}$ & $\begin{array}{r}72.77 \\
14.19 \\
0.42 \\
0.94 \\
0.22 \\
0.71 \\
5.05 \\
4.44 \\
0.41 \\
0.11 \\
0.26 \\
0.04 \\
0.05 \\
-- \\
-.\end{array}$ & $\begin{array}{r}73.66 \\
14.05 \\
0.39 \\
0.90 \\
0.18 \\
0.63 \\
5.01 \\
4.51 \\
0.38 \\
0.09 \\
0.24 \\
0.03 \\
0.04 \\
-- \\
--\end{array}$ & $\begin{array}{r}71.39 \\
13.95 \\
0.58 \\
1.88 \\
0.55 \\
1.29 \\
5.06 \\
3.93 \\
0.15 \\
0.21 \\
0.31 \\
0.04 \\
0.07 \\
-- \\
--\end{array}$ & $\begin{array}{r}71.71 \\
14.01 \\
0.43 \\
1.86 \\
0.39 \\
1.21 \\
5.04 \\
3.99 \\
0.21 \\
0.10 \\
0.30 \\
0.04 \\
0.07 \\
--\end{array}$ & $\begin{array}{l}70.3 \\
13.4 \\
0.90 \\
3.00 \\
0.73 \\
2.60 \\
5.7 \\
1.68 \\
0.11 \\
0.25 \\
0.66 \\
0.14 \\
0.15 \\
-- \\
--\end{array}$ & $\begin{array}{l}75.6 \\
12.8 \\
0.33 \\
0.84 \\
0.26 \\
1.22 \\
3.95 \\
3.85 \\
0.56 \\
0.02 \\
0.27 \\
0.03 \\
0.07 \\
-- \\
--\end{array}$ & $\begin{array}{r}76.89 \\
12.72 \\
0.43 \\
0.70 \\
0.17 \\
0.57 \\
3.48 \\
4.39 \\
0.47 \\
0.02 \\
0.08 \\
\text { nil } \\
0.07 \\
\text { tr } \\
-.-\end{array}$ & $\begin{array}{r}75.66 \\
12.86 \\
0.26 \\
1.01 \\
0.35 \\
0.97 \\
3.65 \\
4.70 \\
0.28 \\
0.07 \\
0.21 \\
0.06 \\
0.02 \\
-- \\
--\end{array}$ \\
\hline $\begin{array}{l}\text { Subtotal- } \\
\text { Less } 0=(\mathrm{F}, \mathrm{Cl})_{2}-\end{array}$ & 99.45 & $\begin{array}{c}99.61 \\
--\end{array}$ & 100.11 & 99.41 & 99.36 & $\begin{array}{c}99.62 \\
--\end{array}$ & 99.80 & $\begin{array}{l}99.99 \\
--\end{array}$ & 100.10 \\
\hline Total-a- & 99.45 & 99.61 & 100.11 & 99.41 & 99.36 & 99.62 & 99.80 & 99.99 & 100.10 \\
\hline $\mathrm{Fe}_{\mathrm{t}}^{1}-\ldots$ & 1.29 & 1.32 & 1.25 & 2.40 & 2.25 & 3.81 & 1.14 & 1.09 & 1.24 \\
\hline $\mathrm{FeO} /\left(\mathrm{Fe} 0+\mathrm{Fe}_{2} \mathrm{O}_{3}\right)^{1} \ldots$ & 0.71 & 0.73 & 0.70 & 0.76 & 0.81 & 0.77 & 0.72 & 0.62 & 0.80 \\
\hline $\mathrm{Na}_{2} \mathrm{O} / \mathrm{K}_{2} \mathrm{O}^{\mathrm{l}}$ & 1.17 & 1.14 & 1.11 & 1.29 & 1.26 & 3.39 & 1.03 & 0.79 & 0.78 \\
\hline$\left(\mathrm{Na}_{2} \mathrm{O}+\mathrm{K}_{2} \mathrm{O}\right) / \mathrm{Al}_{2} \mathrm{O}_{3}{ }^{2}$ & 0.94 & 0.92 & 0.93 & 0.90 & 0.90 & 0.84 & 0.83 & 0.82 & 0.86 \\
\hline$\left(\mathrm{CaO}+\mathrm{Na}_{2} \mathrm{O}+\mathrm{K}_{2} \mathrm{O}\right) / \mathrm{Al}_{2} \mathrm{O}_{3}{ }^{2}--\cdot$ & 1.03 & 1.02 & 1.02 & 1.07 & 1.06 & 1.19 & 1.01 & 0.90 & 1.00 \\
\hline $\mathrm{CaO} /\left(\mathrm{Na}_{2} \mathrm{O}+\mathrm{K}_{2} \mathrm{O}\right)^{1} \ldots$ & 0.07 & 0.07 & 0.07 & 0.14 & 0.13 & 0.35 & 0.16 & 0.07 & 0.12 \\
\hline $\mathrm{Cl} / \mathrm{F}^{1}$ & -- & -- & -- & -- &.- & -- & -- & -- & -- \\
\hline \multicolumn{10}{|c|}{ CIPW norms } \\
\hline Q-(- & 23.32 & 24.49 & 25.44 & 23.00 & 23.47 & 24.12 & 34.82 & 38.14 & 33.49 \\
\hline or -1 & 26.62 & 26.48 & 26.75 & 23.45 & 23.80 & 10.00 & 22.93 & 26.07 & 27.84 \\
\hline$a b--\infty$ & 44.46 & 43.12 & 42.55 & 43.23 & 43.06 & 48.59 & 33.69 & 29.60 & 30.96 \\
\hline 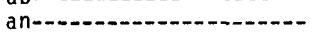 & 2.34 & 2.97 & 2.54 & 3.78 & 3.86 & 6.06 & 5.87 & 2.84 & 4.43 \\
\hline C-1 - & -- & -- & -- & -- & -- & -- & $-\infty$ & 1.21 & 0.15 \\
\hline wo ? & 0.42 & 0.14 & 0.17 & 1.01 & 0.81 & 2.51 & 0.01 & -- & -- \\
\hline en $\}$ di $\ldots . . .$. & 0.14 & 0.05 & 0.05 & 0.36 & 0.23 & 0.82 & 0.01 & -- & -- \\
\hline fs $)$ & 0.29 & 0.09 & 0.12 & 0.68 & 0.62 & 1.78 & 0.01 & -- & -- \\
\hline en $;$ hy $\ldots$ & 0.41 & 0.51 & 0.40 & 1.03 & 0.76 & 1.01 & 0.65 & 0.43 & 0.87 \\
\hline fs $\}$ hy & 0.83 & 0.96 & 0.89 & 1.94 & 2.10 & 2.21 & 0.95 & 0.93 & 1.33 \\
\hline mt-1-1 & 0.56 & 0.62 & 0.57 & 0.85 & 0.63 & 1.32 & 0.48 & 0.63 & 0.38 \\
\hline i $1-0$ & 0.50 & 0.50 & 0.46 & 0.59 & 0.58 & 1.26 & 0.52 & 0.15 & 0.40 \\
\hline ap- & 0.09 & 0.09 & 0.07 & 0.09 & 0.09 & 0.33 & 0.07 & 0.00 & 0.14 \\
\hline other & -- & -- & -- & -- & -- &.- & -- & -- & -- \\
\hline
\end{tabular}

See footnotes at end of table. 
APPENDIX III.-Compilation of published major-element analyses of subalkaline silicic glasses-Continued

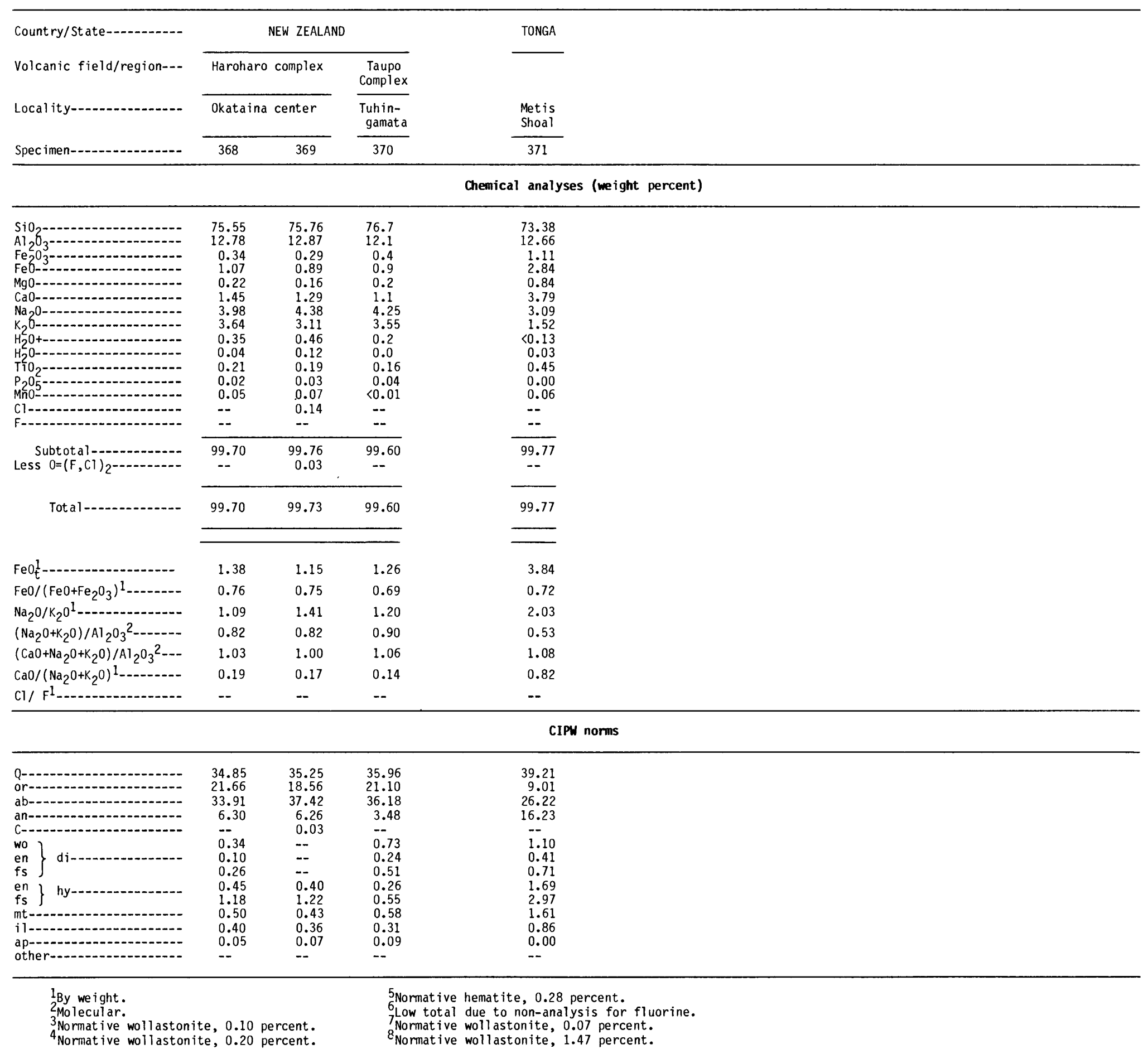


Appendix III.-Sample localities

\section{NORTH AMERICA}

\section{UNITED STATES OF AMERICA}

\section{ALASKA}

242 Rhyolitic obsidian, flow, northeastern Umnak Island. Lat $53^{\circ} 29.5^{\prime} \mathrm{N}$., long $168^{\circ} 10^{\prime} 3^{\prime \prime} \mathrm{W}$. Analyst: F.M. Byers, Jr. (Reference: Byers, 1959, table 2, No. 19, colln. 46 A By 30 a.)

243 Siliceous soda rhyolite, light band in Novarupta composite lava, Valley of Ten Thousand Smokes. Analyst: C.N. Fenner. (Reference: Fenner, 1923 p. 57 , colln. 153 c.)

244 Glassy rhyolite, Novarupta, Valley of Ten Thousand Smokes. Analyst: E.G. Zies. (Reference: Zies, 1929, p. 56, colln. Fenner No. 406.)

\section{OREGON}

245 Obsidian, north edge of Newberry flow, South Sister, at $6,800 \mathrm{ft}$ elevation. Analyst: $\mathrm{K}$. Aoki. (Reference: McBirney, 1968, table 2, No. 7 . Phenocrysts: no data.)

246 Glassy dacite, south edge of Grouse Hill dome, Crater Lake. Analyst: W.H. Herdsman. (Reference: Williams, 1942, p. 151, No. 22.)

247 Hypersthene-dacite, vitrophyric type, south edge of Llao Rock flow, Crater Lake. Analyst: H.N. Stokes. (Reference: Diller and Patton, 1902, p. 140 , No. 102.)

248 Rhyolitic obsidian, East Lake obsidian flow, Newberry Volcano. Analysts: G. Riddle, P. Elmore, G. Chloe, J. Glenn, L. Artis, H. Smith, J. Kelsey, and S. Botts. (Reference: Higgins, 1973, table 5, No. 40.)

249 Obsidian, wall obsidian in caldera pumice cone, Newberry Volcano. Analysts: same as 248. (Reference: Higgins, 1973, table 5, No. 42. Phenocrysts: not specified.)

250 Obsidian, massive, black flow on north wall of crater, Big Pumice Cone, between the lakes, Newberry Volcano. Analyst: F. Herdsman. (Reference: Williams, 1935, table, No. 10, colln. 44.)

251, 252 Obsidians, Game Hut flow, Newberry Volcono. Analysts: same as 248. (Reference:
Higgins, 1973, table 5, Nos. 48 and 49 . Phenocrysts: not specified.)

253, 254 Obsidians, Pumice Cone obsidian flow, Newberry Volcano. Analysts: same as 248 (Reference: Higgins, 1973, table 5, Nos. 50 and 51. Phenocrysts: not specified.)

255, 256 Obsidians, north obsidian flow, Newberry Volcano. Analysts: same as 248. (Reference: Higgins, 1973, table 5, Nos. 52 and 53. Phenocrysts: not specified.)

257-259 Obsidians, "Big Obsidian Flow," Newberry Volcano. Analysts: same as 248. (Reference: Higgins, 1973 , table 5 , Nos. 54,55 , and 56 . Phenocrysts: not specified.)

260 Pumiceous obsidian, plug-dome at head of "Big Obsidian Flow," Newberry Volcano. Analyst: F. Herdsman. (Reference: Williams, 1935, table, No. 11, colln. 101.)

261 Obsidian, "Big Obsidian Flow," Newberry caldera. Analyst: T. Cook. (Reference: Green, 1965, p. 1131, No. 3.)

\section{CALIFORNIA}

262 Trachytic obsidian, massive lava group, north slope Medicine Lake Highlands. Analyst: F. Herdsman. (Reference: Powers, 1932, table 1 , colln. 19044.)

263 Rhyolitic obsidian, massive lava group, south slope Medicine Lake Highlands. Analyst: F. Herdsman. (Reference: Powers, 1932, table 1, colln. 19007.)

264 Rhyolitic obsidian, near ridge of pumice breccia in rhyolite-dacite composite lava field, Glass Mountain, Medicine Lake Highlands. Analyst: F. Herdsman. (Reference: Anderson, 1933, table 1, No. 6. Phenocrysts: not specified.)

265 Rhyolitic obsidian, from dome south of Glass Mountain, Medicine Lake Highlands, representing last extrusion of lava into the rhyolite-dacite composite flow. Analyst: F. Herdsman. (Reference: Anderson, 1933, table 1, No. 7. Phenocrysts: not specified.)

266 Rhyolitic obsidian, south of ridge of pumice breccia in rhyolite-dacite composite lava field, Glass Mountain, Medicine Lake Highlands. Analyst:F. Herdsman. (Reference: Anderson 1933, table 1, No. 5. Phenocrysts:not specified.)

267 Rhyolitic obsidian, obsidian group, Big Glass Mountain, Medicine Lake Highlands. Analyst: E.S. Shepherd. (Reference: Powers, 1932, table 1, colln. 19103.)
268 Rhyolitic obsidian, associated with dacite in northeastern tongue of rhyolite-dacite composite flow, Glass Mountain, Medicine Lake Highlands. Analyst: F. Herdsman. (Reference: Anderson, 1933, table 1, No. 4. Phenocrysts: not specified.)

269 Finely vesicular rhyolitic glass, part of large dome, summit of Glass Mountain, Medicine Lake Highlands. Analyst: F. Herdsman. (Reference: Anderson, 1933, table 1, No. 10. Phenocrysts: not specified.)

270 Rhyolitic obsidian, obsidian group, fourth terrace from top, eastern slope of Big Glass Mountain, Medicine Lake Highlands. Analyst: E.S Shepherd. (Reference: Powers, 1932, table 1, colln. $19103 \mathrm{c}$.)

271 Rhyolitic obsidian, from younger obsidian flow, Glass Mountain, Medicine Lake Highlands. Analyst: F. Herdsman. (Reference: Anderson, 1933, table 1, No. 8. Phenocrysts: not specified.)

272 Rhyolitic obsidian, third terrace from top obsidian group, Big Glass Mountain, Medicine Lake Highlands. Analyst: E.S. Shepherd. (Reference: Powers, 1932, table 1, colln. 1910 b.)

273 Obsidian, Glass Mountain Medicine Lake. Analyst: I.S.E. Carmichael. (Reference: Carmichael, 1967, table 5, No. 14, colln. CAM 66.)

274-277 Obsidians, Little Glass Mountain, Medicine Lake Highlands. Analyst: E.S. Shepherd. (Reference: Shepherd, 1938, table 3. Phenocrysts: not specified.)

278 Porphyritic obsidian, Little Glass Mountain, Medicine Lake. Analyst: I.S.E. Carmichael. (Reference: Carmichael, 1967, table 5, No. 12 colln. CAM 49.)

279 Rhyolitic obsidian, obsidian group, Little Glass Mountain, Medicine Lake Highlands. Analyst: E.S. Shepherd. (Reference: Powers, 1932, table 1, colln. 19033 a, except F value-Shepherd, 1938, table 3.)

280 Obsidian, Bottle Rock Road, Clear Lake volcanic field, Lake County. Analyst: I.S.E. Carmichael (Reference: Carmichael, 1967, table 5, No. 21, colln. CAM 118.)

281 Rhyolitic obsidian, south of Borax Lake, Clear Lake volcanic field. Analyst: S. Goldich (Reference: Anderson, 1936, table 1, No. 13.Sample 13 composite and free from inclusions. Nevertheless, some of phenocrysts may, in fact, be xenocrystic from dismembered mafic inclusions.) 
282 Rhyolitic obsidian, plug underlying Little Glass Mountain, Napa County. Analyst: A.G. Loomis. (Reference: Lofgren, 1971.)

283 Porphyritic rhyolitic obsidian, Glass Mountain Inyo Craters. Analyst: I.S.E. Carmichael. (Reference: Carmichael, 1967, table 5, No. 22, colln. CAM 81.)

284 Porphyritic rhyolitic obsidian, extrusion south of Glass Mountain, Inyo Craters. Analyst: I.S.E. Carmichael. Reference: Carmichael, 1967, table 5, No. 23, colln. CAM 86 .

285 Obsidian, north of pumice mine, Mono Craters Analyst: I.S.E. Carmichael. (Reference: Carmichael, 1967, table 5, No. 17, colln. CAM 104.)

286 Aphyric obsidian, southern Coulee, Mono Craters Analysts: G. Riddle and V.C. Smith. (Reference Noble and others, 1972, table 1, No. 5, lab. D101110.)

287 Rhyolitic obsidian, circular extrusion by Route 120, Mono Craters. Analyst: I.S.E. Carmichael (Reference: Carmichael, 1967, table 5, No. 19, colln. CAM 110.)

288 Rhyolitic obsidian, flow, south of Route 120 Mono Craters. Analyst: I.S.E. Carmichael. (Reference: Carmichael, 1967, table 5, No. 18 colln. CAM 108.)

289 Aphyric obsidian, from near crest of Glass Mountain, Long Valley volcanic complex. Analysts: G. Riddle and V.C. Smith. (Reference: Noble and others, 1972, table 1, No. 1, lab D101113.)

290 Obsidian, near crest of Glass Mountain, Lon Valley volcanic complex. Analysts: G. Riddle and V.C. Smith. (Reference: Noble and others, 1972 table 1, No. 2, lab. D101114. Phenocrysts: not specified, but less than or equal to 1 percent modally.)

\section{NEVADA}

291 Rhyolitic obsidian, Silver Peak volcanic center. Analyst: U.S. Geological Survey. (Reference: Robinson, 1972, table 3, No. 0b, colln. 430160 Phenocrysts: not specified.)

292 Obsidian, core in perlite, rhyolite of Shoshone Mountain. Analysts: V.C. Smith and C.L. Parker. (Reference: Jezek and Noble, 1978, table 2, lab. D100425.)

293 Obsidian, core in perlite, rhyolite of Obsidian Butte. Analyst: V.C. Smith. (Reference: Jezek and Noble, 1978, table 4, lab. D100319.)
WYOMING

294 Obsidian, from glassy, densely welded base of member B, Lava Creek Tuff, east end of dam on Grassy Lake Reservoir, Yellowstone. Analyst: G. Riddle. (Reference: R.L. Christiansen, written commun., 1988, table 4, No. 4, lab. D101806. Phenocrysts said to include "accessory minerals.")

295 Rhyolitic obsidian, from block in obsidian breccia at top of rhyolite flow, collected along Black Canyon forest access road, $10.6 \mathrm{mi}$ west of south from West Yellowstone. Analysts: P. Elmore, I. Barlow, S. Botts, G. Chloe, and V.C. Smith (Reference: Hamilton, 1963, table, No. 11, lab. 158048.)

296 Rhyolitic obsidian, from block in breccia at top of a rhyolite flow front, $2.3 \mathrm{mi}$ south of West Yellowstone. Analysts: same as 295. (Reference: Hamilton, 1963, table, No. 9, lab. 158049.)

297 Glassy rhyolite, Spring Creek flow of Centra Plateau Member. Just west of trail to Divide Lookout, $0.8 \mathrm{~km}$ southwest of Norris Pass, Yellowstone. Analyst: G. Riddle. (Reference: R.L. Christiansen, written commun.,1988, table 4, No. 12, lab. D101812. Phenocrysts said to include "accessory minerals.")

298 Glassy rhyolite, West Yellowstone flow, Central Plateau Member. Lumbering road on west side of Madison Plateau, about $0.5 \mathrm{~km}$ south-southwest of West Yellowstone. Analyst: G. Riddle. (Reference: R.L. Christiansen, written commun.,1988, table 4, No. 15, lab. D102472. Phenocrysts said to include "accessory minerals.")

299 Glassy rhyolite, Cougar Creek flow, Roaring Mountain Member. From south side of outcrop area of flow, south of Cougar Creek, Yellowstone. Analyst: G. Riddle. (Reference: R.L. Christiansen, written commun.,1988, table 4, No. 18, lab. D101808. Phenocrysts said to include "accessory minerals.")

300 Rhyolitic obsidian, obsidian dome (hill 7085 Madison Junction quadrangle) $6.5 \mathrm{mi}$ east northeast of West Yellowstone. Analysts: same as 295. (Reference: Hamilton, 1963, table, No. 10 , lab. 158045.)

301 Glassy rhyolite, Obsidian Cliff flow, Roaring Mountain Member, Yellowstone, from $0.6 \mathrm{~km}$ east of Lake of the Woods. Analyst: G. Riddle. (Reference: R.L. Christiansen, written commun 1988, table 4, No. 19, lab. D101810.)
302 Obsidian, Obsidian Cliff, Yellowstone. Analyst: E.S. Shepherd. (Reference: Bowen, 1935, table 1, No. 3. Phenocrysts: not specified.)

\section{UTAH}

303 Obsidian, Little Bearskin Mountain dome, Mineral Mountains. Analyst: S.H. Evans, Jr. (Reference: Lipman and others, 1978, table 2, colln. MR 75-14.)

304 Obsidian, North Twin Flat Mountain dome, Mineral Mountains. Analyst: S.H. Evans, Jr. (Reference: Lipman and others, 1978, table 2, colln. MR 75-20.)

305 Obsidian, Wildhorse Canyon flow, Mineral Mountains. Analyst: S.H. Evans, Jr. (Reference: Lipman and others, 1978, table 2, colln. MR 748.)

306 Obsidian, Bailey Ridge flow, Mineral Mountains. Analyst: S.H. Evans, Jr. (Reference: Lipman and others, 1978, table 2, colln. 74-3A.)

307-309 Obsidians, rhyolite of Cudahy mine, Twin Peaks volcanic field. Analyst: not specified. (Reference: Crecraft and others, 1981, table 3 Nos. 9, 18, and 19.)

\section{ARIZONA}

310 Flow-banded rhyolite obsidian, upper rhyoliteobsidian unit, Galiuro Volcanics, Holy Joe Peak quadrangle. Analysts: P. Elmore, S. Botts, H. Smith, and D. Taylor. (Reference: Creasey and Krieger, 1978, table 2, lab. M101317W.)

\section{MEXICO}

311 Obsidian, near Tequila, on highway from Guadalajara to Tepic. Analyst: A. Obregon-Perez. (Reference: Heizer and others, 1965, table 3, No. 4. Phenocrysts: not specified.)

312 Obsidian, just south of Zinapecuaro, on highway from Zinapecuaro to Ciudad Hidalgo, Michoacan. Analyst: A. .Obregon-Perez. (Reference: Heizer and others, 1965, table 3 , No. 5. Phenocrysts: not specified.)

313 Obsidian, small cut on road from Pachuca to Zacualtipan, at turnoff east to Huayacocotla, Hidalgo. Analyst: A. Obregon-Perez. (Reference: Heizer and others, 1965, table 3, No. 3 Phenocrysts: not specified.)

314 Obsidian, exposed in cut between 145- and 146-km markers on highway from Tulancingo to Posa Rica, 
Veracruz. Analyst: A. Obregon-Perez. (Reference: Heizer and others, 1965, table 3, No. 1 . Phenocrysts: not specified.)

\section{SOUTH AMERICA}

\section{PERU}

315 Macusanite, Macusani. Analyst: C. de SitterKoomans. (Reference: Martin and de SitterKoomans, 1955, p. 158.

316 Macusanite, Macusani. Analysts: P. Elmore, S. Botts, and L. Artis. (Reference: Barnes and others, 1970, table 3, lab. 164364. Phenocrysts: not specified.)

\section{EUROPE}

\section{ICELAND}

317 Obsidian, postglacial, Hrafntinnuhryggur. Analyst: I.S.E. Carmichael. (Reference: Carmichael, 1962, table 3, No. J. Phenocrysts: not specified.)

318 Obsidian, Pálsfjall, Vatnajökull. Analyst: W.H. Herdsman. (Reference: Noe-Nygaard, 1952, table 2, No. 2.)

319 Glassy liparite, Mid-Bergvatnsá, just south of Vatnajökull. Analyst: Me. Mouritzen. (Reference: Noe-Nygaard, 1952, table 5.)

320 Obsidian pebbles, top of acid lava, Bondolfur, Berufjordur. Analyst: I.S.E. Carmichael. (Reference: Carmichael, 1962, table 3, No. N. Phenocrysts: not specified.)

321 Hypersthene hyalo-andesite (rhyolite), south flank of Little Krafla, Gaesafjöll complex. Analyst: A.C.W.C. Bot. (Reference: van Bemmelen and Rutten, 1955, table 5, colln. 309.)

\section{ITALY}

322-325 Rhyolitic obsidians, Monte Lentia, Vulcano. Analyst: not specified. (Reference: Baldanza and others, 1973, table 3, collns. L72, L70, L73, and L74, respectively. Phenocrysts: not specified.)

326 Obsidian, Forgia Vecchia, Lipari. Analyst: H.S. Washington. (Reference: Washington, 1920, table, No. 2.)

327 Obsidian, Rocche Rosse, Lipari. Analyst: H.S. Washington. (Reference: Washington, 1920, table, No. 1.)

\section{HUNGARY}

328 Grey obsidian, Mád, Tokaj. Analyst: A. Vendl. (Reference: Vendl, 1927, p. 217.)

329 Black obsidian, Tolcsva, Tilalmas, Tokaj. Analyst A. Vendl. (Reference: Vendl, 1927, p. 221.)

\section{CZECHOSLOVAKIA}

330 Obsidian, Viničky. Analyst: not known. (Reference: Salát and Oncáková, 1964, p. 50. Phenocrysts: not known.)

\section{GREECE}

331 Rhyolitic obsidian, Bombardo, Milos. Analyst: H.S. Washington. (Reference: Washington, 1920, table 4, No. 1.)

332 Obsidian, Bombardha Peninsula, Milos. Analyst: B. Simó. (Reference: Szàdeczky-Kardoss and others, 1964, table 2. Phenocrysts: not specified.)

333 Obsidian, Milos. Analyst: Th. Monrampas. (Reference: Georgiades, 1956 table 1, colln. 511. Phenocrysts: not specified.)

\section{FORMER USSR}

334 Vitreous rhyolite, eastern caldera rim, Uzon Volcano, Kamchatka. Analyst: E.A. Sverzhinskaia. (Reference: Vlodavetz and Piip, 1959, p. 53. Phenocrysts: not specified.)

335, 336 Rhyolites, extrusive dome, Medvezcja caldera Iturup Islands, Great Kurile Arc. Analyst: not known. (Reference: Ostapenko and others, 1967, table 3.)

\section{AFRICA}

\section{CAMEROON}

337 Rhyolitic obsidian, blocks, town of N'kongsamba, lower slopes of Mount Manengouba. Analyst: not stated. (Reference: Tchoua, 1970, p. 28.)

\section{ASIA \\ JAPAN}

338 Augite hypersthene dacite, Atosanupuri lava dome, Atosanupuri Volcano, Hokkaido. Analyst: Y. Katsui. (Reference: Katsui, 1958.)
339 Obsidian, Kamishihoro-machi?, Tokachi Volcano, Hokkaido. Analyst: K. Endo. (Reference: Kôzu, 1929, table 6. Phenocrysts: not specified.)

340 Hypersthene dacite, glassy part of the Ô-usu dome lava, Usu Volcano, Hokkaido. Analyst: K. Yagi. (Reference: Yagi, 1953, table 3, No. D.)

341, 342 Hypersthene-dacite obsidians, from cliff facing southwest of dry valley of Okubo-sawa at height of $\sim 1,300 \mathrm{~m}$ a.s.l., Asama Volcano, Honshu. Analyst: Y. Matsui. (Reference: Minami and Matsui, 1960, Nos. 241 and 240A respectively. See also Aramaki, 1963, table 21, Nos. 24 and 25.)

343 Hypersthene dacite, lowermost part of eastward facing cliff, about $150 \mathrm{~m}$ south of Sengataki Falls, Asama Volcano, Honshu. Analyst: Y. Matsui. (Reference: Minami and Matsui, 1960, table 4, No. 232. See also Aramaki, 1963, table 21, No. 23.)

344 Dacite obsidian, Mugenno-tani obsidian, high cliff of Hotoke-iwa (Midagajö-iwa), Asama Volcano, Honshu. Analyst: S. Tanaka. (Reference: Tsuya, 1933, table 6, No. v)

345 Hornblende-bearing hypersthene-dacite obsidian, from cliff on western bank of gorge at Sengataki, Asama Volcano, Honshu. Analyst: not known. (Reference: Aramaki, 1963, table 21, No. 12. Phenocrysts: not known.)

346 Nonporphyritic obsidian, Wada-toge, Nagano Prefecture, Honshu. Analyst: K. Tanida. (Reference: Tanida, 1961, No. 90.)

347 Two pyroxene plagioliparite, Kasiwa-toge, midway between Ito-mati and Hiyekawa, north Idu, Huzi volcanic zone, Honshu. Analyst: S. Tanaka. (Reference: Tsuya, 1937, table 7, No. 22.)

348 Augite-bearing hypersthene-dacite obsidian, Kajiya dacite, Yugawara-machi, Kanagawa Prefecture, Honshu. Analyst: M. Chiba. (Reference: Ono, 1962, No. 374. Phenocrysts: not known.)

349 Augite-bearing hypersthene-dacite obsidian, lava of young somma, Hakone Volcano, Kanagawa Prefecture, Honshu. Analyst: M. Chiba. (Reference: Ono, 1962, No. 401. Phenocrysts: not specified, but rock said to be "nearly aphyric.")

350 Olivine-bearing, two pyroxene-hornblende dacite, Iwano-yama lava, east side of Iwano-yama parasitic lava dome on northern flank (near base) of Amagi Volcano, about $3 \mathrm{~km}$ southeast of Hiyekawa, Honshu. Analyst: S. Tanaka. (Reference: Tsuya, 1937, table 17, No. 40.) 
351 Obsidian, lava of Omuro-yama volcanic group Nakaizu-machi, Amagi Volcano, Shizuoka Prefecture, Honshu. Analyst: T. Kushida (Reference: Kawano, 1950, table 7. Phenocrysts: not specified.)

352 Hypersthene plagioliparite, lava of first period, Kozu-sima Volcano, Hinmasi-hana, southwestern point of Kozu-sima Island, Izu-Mariana Arc. Analyst: S. Tanaka. (Reference: Tsuya, 1929, table 4.)

353 Aphanitic liparite, Ombasi-zima, $4 \mathrm{~km}$ southwest of Kozu-sima, Izu-Mariana Arc. Analyst: S. Tanaka. (Reference: Tsuya, 1937, table 40, No. 111.)

354 Ferroaugite-fayalite-quartz dacite obsidian fragment in pumice flow deposit(?) exposed on northwest flank of precaldera cone, Higashi-yama Volcano, Hachijo-jima volcano group, Seven Izu Islands, Izu-Mariana Arc. Analyst: H. Haramura. (Reference: Isshiki, 1963, colln. N153011301.)

355 Rhyolitic obsidian, block in ash-fall deposits of $\mathrm{Ok}$ trachyte-rhyolite group, $1.5 \mathrm{~km}$ south of Kumi, Dôgo, Oki Islands. Analyst: H. Haramura. (Reference: Uchimizu, 1966, table 15, No. 33.)

356 Anorthoclase liparite obsidian, block in ash-fall deposits of Oki trachyte-rhyolite group, south of Kumi, Goka village, Oki-Dôgo Island. Analyst: M. Teshima. (Reference: Tomita, 1935, p. 260. Phenocrysts: not specified.)

357 Two pyroxene-andesine obsidian, central zone lava, Aso Volcano, Chôyô-mura, Kumamoto Prefecture, Kyusu. Analyst: T. Oyama. (Reference: Ono, 1962 No. 770. Phenocrysts: not known.)
358 Hypersthene-hornblende plagioliparite obsidian, near Aira Volcano, Kagoshima-shi, Kyushu. Termed "clear obsidian from the Mifune rhyolite" by Aramaki and Haramura, 1966. Analyst: K. Yamaguchi. (Reference: Ono, 1962, No. 885. Phenocrysts: not specified.)

\section{INDONESIA}

\section{PAPUA NEW GUINEA}

359-361 Rhyolitic obsidians, Moresby Strait area Papua New Guinea. Analyst: not specified. (Reference: Smith and Johnson, 1981, table 3, Nos. 33-680, 33-682, and 33-683. Phenocrysts: generalized assemblage given as $\mathrm{Pl}+\mathrm{O} x \pm \mathrm{B} i \pm \mathrm{Ab} \pm \mathrm{Q}$.)

362 Glassy rhyolite flow, from center $3,700 \mathrm{~m}$ northeast of Solang village, northwestern coast of Lou Island. Analyst: I.E. Smith. (Reference: Johnson and others, 1978, table 1, colln 25NG0002.)

363 Obsidian, rhyolite lava flow of centre $8,2 \mathrm{~km}$ northwest of southern tip of Lou Island. Analyst: I.E. Smith. Reference: Johnson and others, 1978, table 1, colln. 25NG0006. Phenocrysts: not specified.

364 Rhyolite, lava flow, Garove Island, Witu Islands, Bismarck Sea. Analysts: Australian Mineral Development Laboratories. (Reference: Johnson and Arculus, 1978, table 1, No. 20, colln. 48NG0532.)
365 Rhyolitic obsidian, Garua Harbour area, Talasea, New Britain. Analyst: not specified. (Reference: Smith and Johnson, 1981, table 1, No. Gs 3/4.)

\section{NEW ZEALAND}

366 Obsidian, marekanite cores, volcanic ash beds, Tairua River. Analyst: E.J. Dunn. (Reference: Washington, 1917, p. 72. Phenocrysts: not specified.)

367 Dacite glass, stream flowing south on Fanal Island, Mokohinau Islands. Analyst: F.T. Seelye. (Reference: Challis, 1971, No. 41, colln. P10284.)

368 Obsidian, older rhyolite of Okataina center Whakapoungakau Mountain, E. Lake Rotorua. Analyst: F.T. Seelye. (Reference: Grange, 1937, p. 66, No. 3, colln. P6113.)

369 Banded spherulitic obsidian, younger rhyolite, Okataina center, south side of Lake Rotoiti, 15 chains east of turnoff to Lake Okataina. Analyst: F.T. Seelye. (Reference: Grange, 1937, p. 73, No. 2, colln. P17480.)

370 Obsidian, $7.5 \mathrm{mi}$ northwest of Taupo on west boundary of Tuhingamata. Analyst: J.A. Ritchie (Reference: Steiner, 1963, No. VII, colln. P12851.)

\section{TONGA}

371 Glass separated from dacite pumice, Metis Shoal, Tonga. Analyst: E. Jarosewich. (Reference Melson and others, 1970, table 2, No. 2.) 
APPENDIX IV.-Trace-element determinations in obsidians for which major-element analyses are not available [Values in parts per million. --, not determined; v.f., volcanic field]

\begin{tabular}{|c|c|c|c|c|c|c|c|c|c|c|c|c|c|c|c|}
\hline \multirow{3}{*}{$\begin{array}{l}\text { Country/State-- } \\
\text { Volcanic field/region--- } \\
\text { Local ity- }\end{array}$} & \multicolumn{2}{|c|}{ OREGON } & \multicolumn{2}{|c|}{ CALIFORNIA } & ARIZONA & \multicolumn{6}{|c|}{ PERU } & \multirow{3}{*}{ 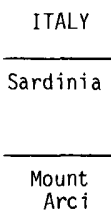 } & \multirow{3}{*}{$\begin{array}{l}\text { GREECE } \\
\text { Milos }\end{array}$} & \multirow{3}{*}{$\frac{\text { TIBET }}{}$} & \multirow{2}{*}{ 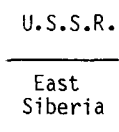 } \\
\hline & $\begin{array}{l}\text { Crater } \\
\text { Lake }\end{array}$ & \multirow{2}{*}{$\begin{array}{r}\text { Thorn } \\
\text { Lake }\end{array}$} & \multicolumn{2}{|c|}{$\begin{array}{l}\text { Northeast } \\
\text { California }\end{array}$} & \multirow{2}{*}{$\begin{array}{c}\text { San } \\
\begin{array}{c}\text { Francisco } \\
\text { v.f. }\end{array} \\
\begin{array}{c}\text { Sugar } \\
\text { Loaf }\end{array}\end{array}$} & & & & & & & & & & \\
\hline & Subaqueous & & Steele & Annie & & \multicolumn{6}{|c|}{ Macusani } & & & & arekanka \\
\hline $\begin{array}{l}\text { Specimen- } \\
\text { Collection No. (RLS-)-- }\end{array}$ & $\begin{array}{l}227 \\
260\end{array}$ & $\begin{array}{l}228 \\
258\end{array}$ & $\begin{array}{l}229 \\
251\end{array}$ & $\begin{array}{l}230 \\
257\end{array}$ & $\begin{array}{l}231 \\
259\end{array}$ & $\begin{array}{l}232 \\
119\end{array}$ & $\begin{array}{l}233 \\
120\end{array}$ & $\begin{array}{l}234 \\
121\end{array}$ & $\begin{array}{l}235 \\
122\end{array}$ & $\begin{array}{l}236 \\
123\end{array}$ & $\begin{array}{l}237 \\
124\end{array}$ & $\begin{array}{l}238 \\
255\end{array}$ & $\begin{array}{l}239 \\
254\end{array}$ & $\begin{array}{l}240 \\
256\end{array}$ & $\begin{array}{l}241 \\
253\end{array}$ \\
\hline Ba--- & 916. & 821. & 1130. & -- & 23. & -- & -- & -- & -- & -- & -- & 155. & 522. & & -- \\
\hline$-\ldots$ & & & $<0.3$ & 0.2 & $<0.2$ & -- & -- & -- & -- & -. & -- & 0.4 & 0.6 & 0.6 & 0.2 \\
\hline $\mathrm{Cr}-$ & 4.8 & 0.4 & -- & 0.7 & $<2.0$ & $<20.0$ & $<20.0$ & $<20.0$ & $<20.0$ & $<20.0$ & $<20.0$ & 0.5 & 0.5 & $<3.0$ & 0.6 \\
\hline Cs-1- & 4.8 & 6.0 & 2.5 & 2.2 & 9.9 & 507. & 523. & 539. & 530. & 528. & 545. & 4.0 & 3.7 & 85.7 & 5.8 \\
\hline Hf & 5.3 & 8.8 & 9.5 & 4.5 & 6.0 & 1.2 & 1.3 & 1.3 & 1.3 & 1.2 & 1.3 & 3.4 & 3.3 & 5.4 & 2.2 \\
\hline Nb** & $\because$ & -- & -- & -- & 119. & -- & -- & -- & -- & -- & -- & -- & -- & 22. & -- \\
\hline$N b^{\star * * *}$ & 6.5 & 20. & 21. & -- & 140. & -- & -- & -- & - & - & -- & 57. & 11. & 28. & -- \\
\hline Pb-1-1-1, & 17. & 26. & 19. & -- & 55. & -- & 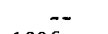 & -- & -- & -- & -- & 37. & 16. & 178 & -- \\
\hline$R_{b}^{* \star *}$ & 87. & 119. & 60. & 89. & 275. & 1166. & 1206. & 1219. & 1202. & 1181. & 1242. & 242. & 117. & 464. & 117. \\
\hline 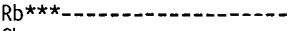 & 90. & 125. & 59. & -- & 290. & $=$ & 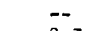 & -- & -- & & & 280. & 127. & 466. & \\
\hline Sb- & 1.1 & 1.7 & 0.8 & $-\overline{-}$ & 5.1 & 3.6 & 3.7 & 3.9 & 4.0 & 3.6 & 3.9 & 0.5 & 0.4 & 0.7 & 0.9 \\
\hline Sc-- & 5.0 & 8.6 & 10.7 & 2.7 & 4.8 & 2.4 & 2.5 & 2.5 & 2.4 & 2.4 & 2.5 & 3.8 & 1.6 & 1.1 & 2.2 \\
\hline Sr-mons & 307. & 2.0 & 0.6 & -- & 0.5 & $=$ & $\cdots$ & -- & -- & - & - & 30. & 107 & 198. & -- \\
\hline 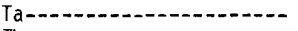 & 0.64 & 1.27 & 1.00 & 1.21 & 20.0 & 25.5 & 26.7 & 27.7 & 26.2 & 27.7 & 27.6 & 3.98 & 1.01 & 1.98 & 1.52 \\
\hline 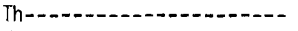 & 9.0 & 12.3 & 6.9 & 8.8 & 30.7 & 1.4 & 1.3 & 1.3 & 1.3 & 1.5 & 1.5 & 16.6 & 14.2 & 84.2 & 6.6 \\
\hline U-10-1) & 3.8 & 4.7 & 2.6 & 3.7 & 17.0 & 20.5 & 20.9 & 21.1 & 23.4 & 21.6 & 23.1 & 5.9 & 4.0 & 32.2 & 4.7 \\
\hline 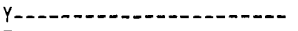 & 23. & 58. & 78. & -- & 75. & - & -- & -- & -- & -- & -- & 48. & 22. & 18. & -- \\
\hline 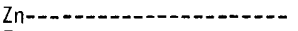 & 29. & 87. & 187. & -- & 120. & -- & - & -- & -- & - & 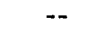 & 101. & 23. & 34. & -- \\
\hline $\mathrm{Zr}-$ & 205. & 347. & 364. & -- & 92. & -- & -. & -- & -- & - & -- & 101. & 118. & 134 & -- \\
\hline La-- & 24. & 39. & 44. & 33. & 10. & 1. & 0. & 1. & 1. & 1. & 0. & 23. & 26. & 42. & 14 \\
\hline $\mathrm{Ce}-$ & 43. & 75. & 89. & 56. & 23. & 3. & 3. & 3. & 4. & 3. & 3. & 48. & 46. & 57. & 26. \\
\hline 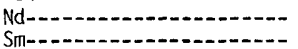 & 21. & 38. & 45. & 24. & 15. & $<30$ & $<30$. & $<30$. & $<30$. & $<30$. & $<30$. & 26. & 15. & 14. & 11. \\
\hline 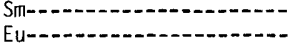 & $\begin{array}{l}4.0 \\
0.72\end{array}$ & 8.5 & 10.7 & 4.5 & 5.1 & 1.8 & 1.8 & 1.9 & 2.0 & 1.9 & 2.0 & 7.3 & 2.7 & 2.1 & 2.2 \\
\hline & 0.72 & 0.67 & 1.89 & 0.55 & $<0.03$ & $<7.0$ & $<7.0$ & $<0.0$ & $<7.0$ & $<7.0$ & $<7.0$ & 0.30 & 0.43 & 0.25 & 0.31 \\
\hline 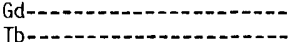 & 3.9 & 9.1 & 10.4 & 2.8 & 6.6 & $<0.70$ & $<0.70$ & $<0.70$ & $<0.60$ & $<0.70$ & $<0.70$ & 7.2 & 3.1 & $<4.0$ & 1.7 \\
\hline & 0.51 & 1.14 & 1.8 & 0.63 & 1.08 & $<0.70$ & $<0.70$ & $<0.70$ & $<0.60$ & $<0.70$ & $<0.70$ & 1.05 & $<0.20$ & $<0.30$ & 0.32 \\
\hline Trm-- & 0.37 & 0.85 & 1.1 & 0.42 & $<0.30$ & $<0.80$ & $<0.80$ & $<0.80$ & $<0.80$ & $<0.80$ & - & 0.56 & 0.50 & $<0.20$ & 0.14 \\
\hline Yb- & 2.0 & 6.0 & 8.8 & 3.2 & 6.5 & 0.5 & $<0.9$ & $<0.8$ & $<0.8$ & $<0.8$ & 0.3 & 2.8 & 2.2 & 0.4 & 1.0 \\
\hline 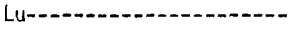 & 0.31 & 0.86 & 1.25 & 0.50 & 1.01 & $<0.10$ & $<0.20$ & $<0.20$ & $<0.10$ & $<0.20$ & $<0.20$ & 0.38 & 0.36 & 0.05 & 0.15 \\
\hline $\mathrm{Nb} / \mathrm{Ta}-\ldots$ & 10.2 & 15.7 & 21.0 & -- & 6.5 & -- & -- & -. & -. & -- & -- & 14.3 & 10.9 & 12.6 & -. \\
\hline $\mathrm{Rb} / \mathrm{Sr}-$ & 0.29 & 62.5 & 98.3 & -- & 580. & -- & -- & -- & -- & -- & -- & 9.3 & 1.2 & 2.4 & -- \\
\hline $\mathrm{Th} / \mathrm{U}$ & 2.4 & 2.6 & 2.7 & 2.4 & 1.8 & 0.07 & 0.06 & 0.06 & 0.06 & 0.07 & 0.06 & 2.8 & 3.6 & 2.6 & 1.4 \\
\hline $\mathrm{Zr} / \mathrm{Hf}-\mathrm{H}$ & 39. & 39. & 38. & -- & 15. & -- & -- & -- & -- & -- & -- & 30. & 36 . & 25. & -- \\
\hline $\mathrm{Ce} / \mathrm{Yb}-$ & 21.5 & 12.5 & 10.1 & 17.5 & 3.5 & 6.0 & -- & -- & -- & -- & 10.0 & 17.1 & 20.9 & 14.3 & 26.0 \\
\hline $\mathrm{Eu} / \mathrm{Eu}^{*}-$ & 0.56 & 0.23 & 0.56 & 0.47 & -- & -- & - & -- & -- & -- & -- & .13 & 0.45 & -. & 0.49 \\
\hline
\end{tabular}

$\star \star$ Analyses performed by the U.S. Geological Survey.
$\star * *$ Analyses performed by the University of Lancaster. 
APPEndx IV.-Sample localities

\section{NORTH AMERICA}

\section{UNITED STATES OF AMERICA}

\section{OREGON}

227 (260) Porphyritic obsidian, top of subaqueous dome east slope of Wizard Island, Crater Lake, Oregon. Lat $42^{\circ} 56.75^{\prime}$ N., long $122^{\circ} 07.75^{\prime}$ W. Supplied by C.H. Nelson.

228 (258) Obsidian, residual pebble litter on Thorn Lake alkali flat, Deschutes County, Oregon. Lat $43^{\circ} 8.78^{\prime}$ N., long $120^{\circ} 49.43^{\prime} \mathrm{W}$. These pebbles probably were first deposited as clasts in air-fall deposits from an unknown source, were rounded by wave action in ancestral Thorn Lake, were perhaps chemically pitted by alkali solution at later lake stage, and today are sand-blasted and polished by wind during the dry season. Collected by R.L. Smith and G.W. Walker.

\section{CALIFORNIA}

229 (251) Obsidian, flakes from a chipping ground for ancient artifacts and probable obsidian source. Known to archaeologists as the Steele Swamp source, NW1/4 sec. 24, T. 46 N., R. 9 E., MDBM, Modoc County, California. Lat $41^{\circ} 49.19^{\prime}$ N., long $120^{\circ} 53.67^{\prime}$ W. Supplied by W.A. Duffield.
230 (257) Obsidian, Apache tears, margin of lava dome, 1-1/4 mi northeast of Annie Lake, Modoc County, California. Lat $41^{\circ} 55.14$ ' N., long $120^{\circ} 05.06^{\prime} \mathrm{W}$. Collected by R.L. Smith and G.W. Walker.

\section{ARIZONA}

231 (259) Phenocrystic, fractured, and partly hydrated obsidian. Sugarloaf, rhyolite dome on northeast flank of San Francisco Peaks, Coconino County, Arizona. Lat $35^{\circ} 22.03^{\prime}$ N., long $111^{\circ} 36.76^{\prime}$ W. Collected by R.L. Smith and P.E. Damon.

\section{SOUTH AMERICA}

\section{PERU}

232-237 (119-124) Obsidians, 6 samples of Macusanite highly peraluminous rhyolite, Macusani, Peru. Approx. lat $14^{\circ} 4^{\prime} \mathrm{S}$, approx. long $70^{\circ} 27^{\prime} \mathrm{W}$. Glass powders supplied by P.A. Jezek.

\section{EUROPE}

ITALY

\section{SARDINIA}

238 (255) Obsidian, occurrence uncertain, Conca Cannas, MTE, Arci, Sardinia, Italy. Approx lat $39^{\circ} 45^{\prime}$ N., approx long $8^{\circ} 35^{\prime}$ E. Supplied by the
Smithsonian Institution, USNM No 99249-1. Courtesy of W.G. Melson, Curator.

\section{GREECE}

239 (254) Obsidian, occurrence uncertain, Bombardha, Milos, Greece. Lat $36^{\circ} 44^{\prime} \mathrm{N}$, long $24^{\circ} 27^{\prime} \mathrm{E}$. Supplied by the Smithsonian Institution, USNM No. 100076. Courtesy of W.G. Melson, Curator.

\section{ASIA}

\section{TIBET}

240 (256) Obsidian occurrence and source unknown. Museum label reads "From a loose stone 3 1/2 inches high found in a plain on the high plateau of Tibet. Exact locality not known." Supplied by the British Museum. Registered No. 1946, 30 Courtesy of A.R. Woolley.

\section{FORMER USSR}

\section{EASTERN SIBERIA}

241 (253) Obsidian, Apache tears ("Marekanite") Presumably from the archetypical "Marekanite" deposits on the river Marekanka, Okhotsk Siberia. Approx lat $59^{\circ} 23^{\prime}$ N., approx long $143^{\circ} 35$ E. Supplied by the British Museum Reg. No. 67438. Courtesy of A.R. Woolley. 
APPENDIx V.-Additional analyses of rhyolites of primitive island arcs

$[-$, not determined $]$

\begin{tabular}{|c|c|c|c|c|c|c|c|c|c|c|c|c|c|}
\hline 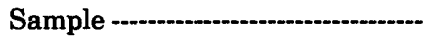 & A & $\mathbf{B}$ & C & D & $\mathbf{E}$ & $\mathbf{F}$ & $\mathbf{G}$ & $\mathbf{H}$ & $\mathbf{I}$ & $\mathbf{J}$ & $\mathbf{K}$ & $\mathbf{L}$ & $\mathbf{M}$ \\
\hline \multicolumn{14}{|c|}{ Chemical analyses (weight percent) } \\
\hline $\mathrm{SiO}_{2}$ & 70.5 & 70.7 & 70.25 & 73.60 & 73.50 & 73.04 & 70.10 & 75.1 & 77.8 & 79.4 & 70.7 & 70.3 & 71.19 \\
\hline $\mathrm{Al}_{2} \mathrm{O}_{3}$ & 13.51 & 12.5 & 12.76 & 12.29 & 11.90 & 13.61 & 14.31 & 13.5 & 11.4 & 10.4 & 15.4 & 14.9 & 15.06 \\
\hline $\mathrm{Fe}_{2} \mathrm{O}_{3}$ & 1.57 & - & 1.14 & 1.31 & .76 & .69 & - & - & - & - & - & - & - \\
\hline $\mathrm{FeO}$ & 2.17 & $5.1^{*}$ & 4.22 & 2.71 & 4.84 & 2.13 & $3.89 *$ & $2.38^{*}$ & $1.55^{*}$ & $2.24^{*}$ & $3.49^{*}$ & $4.8^{*}$ & $2.76^{*}$ \\
\hline 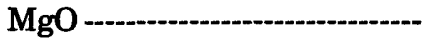 & .93 & 1.1 & 1.01 & 1.07 & .63 & .50 & .90 & .34 & .81 & .28 & .80 & 1.2 & .49 \\
\hline $\mathrm{CaO}$ & 3.66 & 4.0 & 4.61 & 3.61 & 3.80 & 3.25 & 3.46 & 2.45 & 2.50 & 1.76 & 2.41 & 4.1 & 4.01 \\
\hline $\mathrm{Na}_{2} \mathrm{O}$ & 4.55 & - & 3.10 & 3.17 & 2.81 & 4.66 & 4.88 & 4.71 & 4.01 & 4.08 & 5.33 & 4.5 & 5.25 \\
\hline $\mathrm{K}_{2} \mathrm{O}$ & .64 & 1.4 & .79 & 1.47 & .75 & .67 & .65 & .64 & 1.45 & 1.17 & .87 & .30 & .93 \\
\hline $\mathrm{H}_{2} \mathrm{O}^{+}$ & - & - & .73 & & .46 & 1.04 & - & & & & & - & - \\
\hline $\mathrm{H}_{2} \mathrm{O}^{-}$ & 1.30 & - & .05 & .13 & - & .04 & - & $1.85^{\dagger}$ & $1.66^{\dagger}$ & $2.32^{\dagger}$ & $3.25^{\dagger}$ & - & - \\
\hline $\mathrm{TiO}_{2}$ & .55 & .4 & .53 & .52 & .58 & .30 & .50 & .50 & .30 & .20 & .38 & .70 & .20 \\
\hline $\mathrm{P}_{2} \mathrm{O}_{2}$ & .12 & - & .12 & .07 & .09 & .12 & .08 & .14 & .07 & .18 & .11 & - & .13 \\
\hline MnO & .13 & .1 & .14 & .06 & - & .08 & .13 & .01 & .03 & .05 & .09 & - & .22 \\
\hline Total & 99.63 & - & 99.45 & 100.01 & 100.12 & 100.13 & - & 101.62 & 101.58 & 102.08 & 102.83 & - & - \\
\hline $\mathrm{FeO}_{\mathrm{t}}{ }^{1}$ & 3.58 & 5.1 & 5.25 & 3.89 & 5.52 & 2.75 & 3.89 & 2.38 & 1.55 & 2.24 & 3.49 & 4.8 & 2.76 \\
\hline $\mathrm{FeO} /\left(\mathrm{FeO}+\mathrm{Fe}_{2} \mathrm{O}_{3}\right)^{1}$ & .58 & - & .79 & .67 & .86 & .76 & - & - & - & - & - & - & - \\
\hline $\mathrm{Na}_{2} \mathrm{O} / \mathrm{K}_{2} \mathrm{O}^{1}$ & 7.11 & - & 3.92 & 2.16 & 3.75 & 6.96 & 7.51 & 7.36 & 2.77 & 3.49 & 6.13 & 15.0 & 5.65 \\
\hline$\left(\mathrm{Na}_{2} \mathrm{O}+\mathrm{K}_{2} \mathrm{O}\right) / \mathrm{Al}_{2} \mathrm{O}_{3}{ }^{2}$ & .61 & - & .47 & .55 & .46 & .62 & .61 & .63 & .72 & .77 & .63 & .51 & .64 \\
\hline$\left(\mathrm{CaO}+\mathrm{Na}_{2} \mathrm{O}+\mathrm{K}_{2} \mathrm{O}\right) / \mathrm{Al}_{2} \mathrm{O}_{3}{ }^{2}$ & 1.10 & - & 1.12 & 1.09 & 1.04 & 1.05 & 1.05 & .96 & 1.12 & 1.07 & .92 & 1.01 & 1.12 \\
\hline $\mathrm{CaO} /\left(\mathrm{Na}_{2} \mathrm{O}+\mathrm{K}_{2} \mathrm{O}\right)^{1}$ & .71 & - & 1.19 & .99 & 1.07 & .61 & .65 & .46 & .46 & .34 & .39 & .85 & .65 \\
\hline
\end{tabular}

Trace elements (parts per million)

\begin{tabular}{|c|c|c|c|c|c|c|c|c|c|c|c|c|c|}
\hline 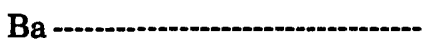 & 345 & - & - & 610 & - & 119 & 68 & 90 & 138 & 123 & 214 & 148 & - \\
\hline Co & 7 & - & - & 10 & - & 2.8 & - & - & $<5$ & $<5$ & $<5$ & 10 & - \\
\hline Cr & - & - & - & 7 & - & $<4$ & 20 & - & 3 & 3 & 2 & 5 & - \\
\hline Hf - & - & - & - & - & - & 3.0 & - & 3.0 & 2.1 & 2.9 & - & - & 一 \\
\hline $\mathrm{Nb}$ & - & 10 & - & 2.3 & - & .6 & 3 & 1.2 & 1.2 & 1.3 & - & - & - \\
\hline $\mathrm{Pb}$ & 5.1 & 10 & - & 4.24 & - & 9 & 9 & 1 & 4 & 3 & 2 & - & - \\
\hline 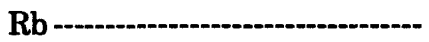 & 6.8 & 23 & - & 21 & - & 13 & 14 & 8 & 12 & 6 & 6 & 3 & 19 \\
\hline Sc - & - & - & - & 12 & - & 10.2 & - & - & 7 & 9 & 6 & 22 & - \\
\hline $\mathrm{Sr}$ & 175 & 255 & - & 130 & - & 110 & 117 & 108 & 94 & 97 & 203 & 176 & 284 \\
\hline 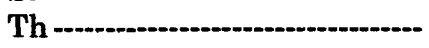 & 2.1 & 4 & - & - & - & .7 & 2 & .5 & .4 & .4 & .8 & .44 & - \\
\hline U & .84 & - & - & .39 & - & .68 & - & .4 & .4 & .4 & .5 & .31 & - \\
\hline
\end{tabular}


APPENDIX V.-Additional analyses of rhyolites of primitive island arcs-Continued

\begin{tabular}{|c|c|c|c|c|c|c|c|c|c|c|c|c|c|}
\hline Sample & $\mathbf{A}$ & B & $\mathbf{C}$ & $\mathbf{D}$ & $\mathbf{E}$ & $\mathbf{F}$ & G & $\mathbf{H}$ & I & $\mathbf{J}$ & $\mathbf{K}$ & $\mathbf{L}$ & $\mathbf{M}$ \\
\hline \multicolumn{14}{|c|}{ Trace elements-Continued } \\
\hline Y - & 41 & - & - & 25 & - & 33 & 36 & 560 & 34 & 52 & 47 & 34 & 25 \\
\hline Zn - & 84 & - & - & 46 & - & 43 & 101 & - & - & - & - & - & - \\
\hline Zr - & 84 & 51 & - & 68 & - & 107 & 178 & 177 & 142 & 119 & 162 & 54 & 196 \\
\hline $\mathrm{La}$ & 4.8 & - & - & - & - & 5 & 10 & 76 & 4.3 & 7.8 & - & - & - \\
\hline $\mathrm{Ce}$ & 14.0 & - & - & - & - & 11 & 22 & - & 12.7 & 23 & - & - & - \\
\hline Nd - & 10.5 & - & - & - & - & 7 & - & 210 & 5.8 & 17.0 & - & - & - \\
\hline $\mathrm{Sm}$ & - & - & - & - & - & 2.8 & - & 71 & 1.6 & 6.8 & - & - & - \\
\hline Eu - & - & - & - & - & - & .77 & - & 8.4 & .45 & 2.0 & - & - & - \\
\hline Gd - & - & - & - & - & - & 3.0 & - & 81 & 2.3 & 5.8 & - & - & - \\
\hline $\mathrm{Tb}$ & - & - & - & - & - & .71 & - & 12 & .37 & .89 & - & - & - \\
\hline Tm - & - & - & - & - & - & .57 & - & - & - & - & - & - & - \\
\hline Yb - & - & - & - & - & - & 3.4 & - & 27 & 1.9 & 3.0 & - & - & - \\
\hline Lu - & - & - & - & - & - & .53 & - & - & - & - & - & - & - \\
\hline K/Rb - & 781 & 505 & - & 601 & - & 428 & 385 & 664 & 1003 & 1619 & 1204 & 830 & 406 \\
\hline $\mathrm{Rb} / \mathrm{Sr}$ & .04 & .09 & - & .16 & - & .12 & .12 & .07 & .13 & .06 & .03 & .02 & .07 \\
\hline $\mathrm{Ca} / \mathrm{Sr}$ & 149 & 112 & - & 198 & - & 211 & 211 & 162 & 190 & 130 & 85 & 166 & 101 \\
\hline Th/U & 2.5 & - & - & - & - & 1.0 & - & 1.3 & 1.0 & 1.0 & 1.6 & 1.4 & - \\
\hline Zr/Hf - & - & - & - & - & - & 36 & - & 59 & 68 & 41 & - & - & - \\
\hline $\mathrm{Ce} / \mathrm{Yb}$ & - & - & - & - & - & 3.2 & - & - & 6.7 & 7.7 & - & - & - \\
\hline $\mathrm{Eu} / \mathrm{Eu}^{*}$ & - & - & - & - & - & .82 & - & .38 & .80 & .97 & - & - & - \\
\hline
\end{tabular}

†Values given are for loss on ignition.

*Total iron as $\mathrm{FeO}$.

${ }^{1}$ By weight.

${ }^{2}$ Molecular.

Sample localities and references:

A, Dacite, Curtis Island, Kermadec Islands (Ewart and others, 1977, table 2).

B, Obsidian, Tafahi Volcano, Tongan Islands (Smith and others, 1977, table 2).

C, Pumice, Eua Islands, Tonga (Bryan, 1971, table 2, No. 2).

D, Glass, 1967-68 Metis Shoal dacite, Tongan Islands (Ewart and others, 1973, table 8; Pb and U data from Oversby and Ewart, 1972; Nb value from David Gottfried, oral commun., 1980).

E, Light pumice, Herald Cays, Queensland (Bryan, 1968)

F, Pumice, South Sandwich Islands (Gass and others, 1963; this paper, spec. 220).

G, Rhyodacite, Deception Island, South Shetland Islands (Weaver and others, 1979, table 1).

H, Porphyritic obsidian clast, Undu Group, Fiji (Gill and Stork, 1979, tables 2 and 3, No. H26).

I, Lapilli tuff, Undu Group, Fiji (Gill and Stork, 1979, tables 2 and 3, No. B535).

J, Crystal tuff, Undu Group, Fiji (Gill and Stork, 1979, tables 2 and 3, No. M96)

K, Porphyritic lava, Wainimala Group, Viti Levu, Fiji (Gill and Stork, 1979, table 2, No. 856).

L, Dacite, Louisenhoj Formation, Virgin Islands, NE. Caribbean (Donnelly and Rogers, 1980, table 1).

M, Average rhyolite, The Quill, Statia, Lesser Antilles (Smith and others, 1980, table 4). 
APPENDIX VI.-Correlation matrix

\begin{tabular}{|c|c|c|c|c|c|c|c|c|c|c|c|c|c|c|c|c|}
\hline & $\mathrm{SiO}_{2}$ & $\mathrm{Al}_{2} \mathrm{O}_{3}$ & $\mathrm{Fe}_{2} \mathrm{O}_{3}$ & $\mathrm{FeO}$ & $\mathrm{MgO}$ & $\mathrm{CaO}$ & $\mathrm{Na}_{2} \mathrm{O}$ & $\mathrm{K}_{2} \mathrm{O}$ & $\mathrm{H}_{2} \mathrm{O}^{+}$ & $\mathrm{TiO}_{2}$ & $\mathrm{P}_{2} \mathrm{O}_{5}$ & $\mathrm{MnO}$ & $\mathrm{Cl}$ & $\mathbf{F}$ & $\mathrm{FeO}_{\mathrm{t}}$ & $\mathrm{Na}_{2} \mathrm{O} / \mathrm{K}_{2} \mathrm{O}$ \\
\hline $\mathrm{SiO}_{2}$ & 1.00 & -0.83 & -0.57 & -0.77 & -0.74 & -0.71 & -0.70 & 0.51 & -0.04 & -0.79 & -0.67 & -0.48 & -0.28 & 0.12 & -0.79 & -0.62 \\
\hline $\mathrm{Al}_{2} \mathrm{O}_{3} \ldots$ & -.83 & 1.00 & .31 & .41 & .66 & .61 & .57 & -.42 & .02 & .59 & .62 & .40 & .06 & -.26 & .42 & .49 \\
\hline $\mathrm{Fe}_{2} \mathrm{O}_{3}$ & -.57 & .31 & 1.00 & .54 & .47 & .42 & .56 & -.43 & -.15 & .58 & .45 & .24 & .22 & .02 & .73 & .45 \\
\hline $\mathrm{FeO}$ & -.77 & .41 & .54 & 1.00 & .61 & .72 & .56 & -.61 & -.11 & .78 & .54 & .43 & .32 & -.08 & .97 & .67 \\
\hline MgO -..-- & -.74 & .66 & .47 & .61 & 1.00 & .91 & .41 & -.71 & -.01 & .87 & .82 & .30 & .12 & -.21 & .63 & .70 \\
\hline $\mathrm{CaO}$ & -.71 & .61 & .42 & .72 & .91 & 1.00 & .35 & -.80 & -.07 & .85 & .77 & .40 & .09 & -.29 & .70 & .73 \\
\hline $\mathrm{Na}_{2} \mathrm{O}$ & -.70 & .57 & .56 & .56 & .41 & .35 & 1.00 & -.57 & .04 & .48 & .36 & .47 & .29 & .04 & .62 & .71 \\
\hline $\mathrm{K}_{2} \mathrm{O}$ & .51 & -.42 & -.43 & -.61 & -.71 & -.80 & -.57 & 1.00 & -.04 & -.67 & -.61 & -.45 & -.05 & .25 & -.62 & -.90 \\
\hline $\mathrm{H}_{2} \mathrm{O}^{+}$ & -.04 & .02 & -.15 & -.11 & -.01 & -.07 & .04 & -.04 & 1.00 & -.08 & .15 & .03 & -.04 & .04 & -.13 & .02 \\
\hline $\mathrm{TiO}_{2}$ & -.79 & .59 & .58 & .78 & .87 & .85 & .48 & -.67 & -.08 & 1.00 & .84 & .39 & .13 & -.28 & .80 & .70 \\
\hline $\mathrm{P}_{2} \mathrm{O}_{5}$ & -.67 & .62 & .45 & .54 & .82 & .77 & .36 & -.61 & .15 & .84 & 1.00 & .31 & -.02 & -.21 & .56 & .55 \\
\hline MnO̊ - - & -.48 & .40 & .24 & .43 & .30 & .40 & .47 & -.45 & .03 & .39 & .31 & 1.00 & .14 & -.15 & .42 & .52 \\
\hline Cl - -..- & -.28 & .06 & .22 & .32 & .12 & .09 & .29 & -.05 & -.04 & .13 & -.02 & .14 & 1.00 & .21 & .32 & .12 \\
\hline F - & .12 & -.26 & .02 & -.08 & -.21 & -.29 & .04 & .25 & .04 & -.28 & -.21 & -.15 & .21 & 1.00 & -.06 & -.16 \\
\hline $\mathrm{Fe}$ as $\mathrm{FeO}$ & -.79 & .42 & .73 & .97 & .63 & .70 & .62 & -.62 & -.13 & .80 & .56 & .42 & .32 & -.06 & 1.00 & .67 \\
\hline $\mathrm{Na}_{2} \mathrm{O} / \mathrm{K}_{2} \mathrm{O}$ & -.62 & .49 & .45 & .67 & .70 & .73 & .71 & -.90 & .02 & .70 & .55 & .52 & .12 & -.16 & .67 & 1.00 \\
\hline Ba -.... & -.37 & .46 & .14 & .26 & .30 & .41 & .17 & -.31 & -.14 & .34 & .28 & .11 & .03 & -.45 & .25 & .19 \\
\hline $\mathrm{Be}$ & .14 & -.24 & -.01 & -.17 & -.35 & -.38 & .13 & .23 & .15 & -.33 & -.23 & -.05 & .10 & .82 & -.14 & -.10 \\
\hline Co -....... & -.63 & .50 & .34 & .56 & .69 & .66 & .37 & -.47 & .02 & .66 & .58 & .16 & .15 & -.02 & .55 & .49 \\
\hline Cr & .13 & -.18 & -.11 & -.11 & -.11 & -.16 & -.13 & .22 & .08 & -.22 & -.17 & .01 & -.03 & .48 & -.12 & -.21 \\
\hline Cs -..- & .29 & -.23 & -.33 & -.29 & -.31 & -.29 & -.37 & .34 & .18 & -.35 & -.26 & -.14 & .08 & .22 & -.33 & -.36 \\
\hline Hf -.- & -.52 & .10 & .57 & .71 & .17 & .18 & .59 & -.21 & -.14 & .38 & .10 & .28 & .37 & .32 & .75 & .34 \\
\hline Li - & .21 & -.13 & -.17 & -.27 & -.39 & -.32 & -.05 & .25 & .13 & -.34 & -.18 & -.15 & -.13 & .58 & -.26 & -.19 \\
\hline Mo -..- & .04 & -.18 & .20 & -.08 & -.20 & -.29 & .11 & .29 & -.11 & -.04 & -.22 & .13 & .15 & .05 & -.01 & -.12 \\
\hline Nb -.......... & .05 & -.23 & .09 & -.00 & -.27 & -.31 & .20 & .19 & -.01 & -.22 & -.21 & -.05 & .12 & .72 & .03 & -.06 \\
\hline Pb - & .32 & -.29 & -.19 & -.34 & -.45 & -.41 & -.21 & .41 & -.02 & -.45 & -.33 & -.24 & -.06 & .63 & -.33 & -.35 \\
\hline Rb - & .47 & -.44 & -.32 & -.49 & -.53 & -.61 & -.32 & .59 & .13 & -.58 & -.42 & -.31 & .07 & .72 & -.49 & -.52 \\
\hline Sb -...........- & .01 & -.02 & .00 & -.02 & .02 & -.05 & .12 & -.05 & $\cdot .25$ & -.02 & -.03 & -.01 & .09 & .02 & -.02 & .07 \\
\hline Sc - - & -.51 & .36 & .33 & .63 & .65 & .72 & .32 & -.67 & .02 & .71 & .55 & .44 & .07 & -.28 & .61 & .64 \\
\hline Sn -..- & .05 & -.31 & .07 & .07 & -.24 & -.26 & .11 & .15 & .05 & -.20 & -.20 & -.20 & .20 & .76 & .08 & -.05 \\
\hline Sr - - & -.65 & .73 & .42 & .43 & .80 & .83 & .36 & -.69 & .07 & .71 & .71 & .28 & -.02 & -.40 & .46 & .59 \\
\hline Ta - & .13 & -.25 & .02 & -.11 & -.35 & -.35 & .15 & .20 & .03 & -.29 & -.22 & -.12 & .06 & .75 & -.08 & -.11 \\
\hline Th --..-..-- & .40 & -.44 & -.19 & -.38 & -.46 & -.54 & -.27 & .56 & -.01 & -.47 & -.43 & -.29 & .19 & .65 & -.36 & -.45 \\
\hline U -...-..-- & .35 & -.34 & -.20 & -.38 & -.38 & -.47 & -.17 & .41 & .09 & -.43 & -.32 & -.21 & .11 & .63 & -.37 & -.34 \\
\hline W - & .31 & -.39 & -.24 & -.22 & -.37 & -.38 & -.26 & .40 & .15 & -.35 & -.35 & -.13 & .16 & .52 & -.24 & -.36 \\
\hline Y - - & -.03 & -.30 & .20 & .26 & -.14 & -.13 & .21 & .02 & -.06 & -.06 & -.18 & .03 & .33 & .69 & .27 & .06 \\
\hline Zn & -.28 & -.04 & .35 & .47 & -.00 & .01 & .43 & -.12 & -.08 & .11 & .01 & .23 & .23 & .48 & .48 & .22 \\
\hline Zr - & -.66 & .28 & .61 & .81 & .28 & .35 & .64 & -.33 & -.17 & .54 & .22 & .38 & .36 & .06 & .83 & .43 \\
\hline La --_-_-_-_-- & -.20 & -.09 & .27 & .32 & -.10 & -.09 & .05 & .27 & -.19 & .10 & -.17 & -.02 & .34 & .14 & .34 & -.12 \\
\hline $\mathrm{Ce}$ - & -.21 & -.12 & .30 & .37 & -.10 & -.09 & .09 & .23 & -.19 & .12 & -.16 & .00 & .36 & .20 & .40 & -.08 \\
\hline Nd -...-...- & -.27 & -.13 & .40 & .52 & -.02 & .01 & .25 & .03 & -.16 & .19 & -.08 & .06 & .41 & .27 & .54 & .09 \\
\hline Sm - & -.21 & -.20 & .38 & .51 & -.06 & -.02 & .27 & -.01 & -.14 & .14 & -.09 & .08 & .37 & .42 & .53 & .11 \\
\hline Eu - & -.61 & .28 & .55 & .81 & .41 & .54 & .57 & -.55 & -.15 & .61 & .33 & .47 & .23 & -.13 & .82 & .56 \\
\hline Gd …............. & -.24 & -.10 & .39 & .39 & .08 & .06 & .29 & -.11 & -.06 & .16 & .00 & .08 & .33 & .41 & .43 & .20 \\
\hline Tb & -.03 & -.36 & .27 & .33 & -.14 & -.14 & .21 & .01 & -.11 & -.02 & -.19 & -.00 & .35 & .61 & .35 & .06 \\
\hline Tm - & .00 & -.33 & .18 & .24 & -.13 & -.13 & .17 & .02 & -.07 & -.06 & -.12 & .04 & .31 & .70 & .25 & .04 \\
\hline Yb -..- & .01 & -.33 & .19 & .22 & -.13 & -.13 & .18 & .01 & -.08 & -.07 & -.18 & -.02 & .33 & .71 & .24 & .05 \\
\hline Lu -................. & -.01 & -.32 & .20 & .24 & -.11 & -.11 & .18 & -.00 & -.10 & -.06 & -.16 & .01 & .35 & .72 & .25 & .07 \\
\hline
\end{tabular}


APPENDIX VI.-Correlation matrix-Continued

\begin{tabular}{|c|c|c|c|c|c|c|c|c|c|c|c|c|c|c|c|c|}
\hline & $\mathrm{Ba}$ & $\mathrm{Be}$ & Co & $\mathrm{Cr}$ & Cs & Hf & $\mathbf{L i}$ & Mo & $\mathrm{Nb}$ & $\mathrm{Pb}$ & $\mathbf{R b}$ & $\mathrm{Sb}$ & $\mathrm{Se}$ & Sn & $\mathrm{Sr}$ & $\mathbf{T a}$ \\
\hline $\mathrm{SiO}_{2} \ldots$ & -0.37 & 0.14 & -0.63 & 0.13 & 0.29 & -0.52 & 0.21 & 0.04 & 0.05 & 0.32 & 0.47 & 0.01 & -0.51 & 0.05 & -0.65 & 0.13 \\
\hline $\mathrm{Al}_{2} \mathrm{O}_{3}^{2}$ & .46 & -.24 & .50 & -.18 & -.23 & .10 & -.13 & -.18 & -.23 & -.29 & -.44 & -.02 & .36 & -.31 & .73 & -.25 \\
\hline $\mathrm{Fe}_{2} \mathrm{O}_{3}$ & .14 & -.01 & .34 & -.11 & -.33 & .57 & -.17 & .20 & .09 & -.19 & -.32 & .00 & .33 & .07 & .42 & .02 \\
\hline $\mathrm{FeO}$ & .26 & -.17 & .56 & -.11 & -.29 & .71 & -.27 & -.08 & -.00 & -.34 & -.49 & -.02 & .63 & .07 & .43 & -.11 \\
\hline MgO & .30 & -.35 & .69 & -.11 & -.31 & .17 & -.39 & -.20 & -.27 & -.45 & -.53 & .02 & .65 & -.24 & .80 & -.35 \\
\hline $\mathrm{CaO}$ & .41 & -.38 & .66 & -.16 & -.29 & .18 & -.32 & -.29 & -.31 & -.41 & -.61 & -.05 & .72 & -.26 & .83 & -.35 \\
\hline $\mathrm{Na}_{2} \mathrm{O}$ & .17 & .13 & .37 & -.13 & -.37 & .59 & -.05 & .11 & .20 & -.21 & -.32 & .12 & .32 & .11 & .36 & .15 \\
\hline $\mathrm{K}_{2} \mathrm{O}$ & -.31 & .23 & -.47 & .22 & .34 & -.21 & .25 & .29 & .19 & .41 & .59 & -.05 & -.67 & .15 & -.69 & .20 \\
\hline $\mathrm{H}_{2}^{2} \mathrm{O}^{+}$ & -.14 & .15 & .02 & .08 & .18 & -.14 & .13 & -.11 & -.01 & -.02 & .13 & .25 & .02 & .05 & .07 & .03 \\
\hline $\mathrm{TiO}_{2}$ & .34 & -.33 & .66 & -.22 & -.35 & .38 & -.34 & -.04 & -.22 & -.45 & -.58 & -.02 & .71 & -.20 & .71 & -.29 \\
\hline $\mathrm{P}_{2} \mathrm{O}_{5}$ & .28 & -.23 & .58 & -.17 & -.26 & .10 & -.18 & -.22 & -.21 & -.33 & -.42 & -.03 & .55 & -.20 & .71 & -.22 \\
\hline MnO & .11 & -.05 & .16 & .01 & -.14 & .28 & -.15 & .13 & -.05 & -.24 & -.31 & -.01 & .44 & -.20 & .28 & -.12 \\
\hline $\mathrm{Cl}$ & .03 & .10 & .15 & -.03 & .08 & .37 & -.13 & .15 & .12 & -.06 & .07 & .09 & .07 & .20 & -.02 & .06 \\
\hline F & -.45 & .82 & -.02 & .48 & .22 & .32 & .58 & .05 & .72 & .63 & .72 & .02 & -.28 & .76 & -.40 & .75 \\
\hline $\mathrm{Fe}$ as $\mathrm{FeO}$ & .25 & -.14 & .55 & -.12 & -.33 & .75 & -.26 & -.01 & .03 & -.33 & -.49 & -.02 & .61 & .08 & .46 & -.08 \\
\hline $\mathrm{Na}_{2} \mathrm{O} / \mathrm{K}_{2} \mathrm{O}$ & .19 & -.10 & .49 & -.21 & -.36 & .34 & -.19 & -.12 & -.06 & -.35 & -.52 & .07 & .64 & -.05 & .59 & -.11 \\
\hline Ba -.......-..- & 1.00 & -.48 & .20 & -.31 & -.25 & .03 & -.34 & -.16 & -.38 & -.38 & -.54 & -.16 & .20 & -.37 & .56 & -.40 \\
\hline $\mathrm{Be}$ & -.48 & 1.00 & -.28 & .37 & .27 & .28 & .68 & .13 & .88 & .74 & .75 & .23 & -.35 & .82 & -.43 & .91 \\
\hline Co & .20 & -.28 & 1.00 & -.01 & -.22 & .32 & -.32 & -.23 & .01 & -.35 & -.40 & .04 & .45 & -.08 & .52 & -.09 \\
\hline $\mathrm{Cr}$ & -.31 & .37 & -.01 & 1.00 & .04 & .02 & .26 & .20 & .28 & .36 & .33 & -.08 & -.17 & .18 & -.26 & .29 \\
\hline Cs - - & -.25 & .27 & -.22 & .04 & 1.00 & -.25 & .35 & -.28 & -.00 & .24 & .64 & .36 & -.17 & .37 & -.30 & .12 \\
\hline Hf & .03 & .28 & .32 & .02 & -.25 & 1.00 & -.00 & .27 & .48 & .01 & -.10 & -.00 & .18 & .44 & .02 & .36 \\
\hline Li & -.34 & .68 & -.32 & .26 & .35 & -.00 & 1.00 & -.14 & .59 & .63 & .62 & .36 & -.26 & .52 & -.30 & .65 \\
\hline Mo - - & -.16 & .013 & -.23 & .020 & -.28 & .27 & -.14 & 1.00 & .18 & -.02 & -.00 & .02 & -.25 & 0.00 & -0.22 & 0.09 \\
\hline Nb ….............. & -.38 & .88 & .01 & .28 & -.00 & .48 & .59 & .18 & 1.00 & .64 & .48 & .10 & -.35 & .72 & -.37 & .96 \\
\hline $\mathrm{Pb}$ & -.38 & .74 & -.35 & .36 & .24 & .01 & .63 & -.02 & .64 & 1.00 & .64 & .08 & -.40 & .53 & -.43 & .68 \\
\hline Rb & -.54 & .75 & -.40 & .33 & .64 & -.10 & .62 & -.00 & .48 & .64 & 1.00 & .19 & -.54 & .65 & -.60 & .57 \\
\hline 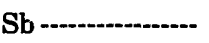 & -.16 & .23 & .04 & -.08 & .36 & -.00 & .36 & .02 & .10 & .08 & .19 & 1.00 & -.02 & .11 & -.01 & .17 \\
\hline Se - - & .20 & -.35 & .45 & -.17 & -.17 & .18 & -.26 & -.25 & -.35 & -.40 & -.54 & -.02 & 1.00 & -.25 & .46 & -.37 \\
\hline Sn - & -.37 & .82 & -.08 & .18 & .37 & .44 & .52 & .00 & .72 & .53 & .65 & .11 & -.25 & 1.00 & -.44 & .73 \\
\hline Sr & .56 & -.43 & .52 & -.26 & -.30 & .02 & -.30 & -.22 & -.37 & -.43 & -.60 & -.01 & .46 & -.44 & 1.00 & -.38 \\
\hline Ta -............. & -.40 & .91 & -.09 & .29 & .12 & .36 & .65 & .09 & .96 & .68 & .57 & .17 & -.37 & .73 & -.38 & 1.00 \\
\hline Th & -.53 & .67 & -.30 & .17 & .56 & .01 & .50 & .18 & .44 & .55 & .89 & .22 & -.53 & .59 & -.55 & .52 \\
\hline U - & -.49 & .70 & -.27 & .20 & .60 & -.05 & .44 & .13 & .43 & .47 & .84 & .20 & -.44 & .65 & -.44 & .56 \\
\hline W - & -.25 & .49 & -.29 & .14 & .49 & .06 & .27 & .25 & .37 & .47 & .67 & .03 & -.34 & .51 & -.44 & .36 \\
\hline Y - & -.25 & .68 & .02 & .27 & .10 & .63 & .26 & .12 & .68 & .40 & .38 & -.02 & -.07 & .84 & -.33 & .64 \\
\hline Zn & -.09 & .54 & .15 & .25 & -.20 & .78 & .24 & .17 & .74 & .38 & .08 & .01 & -.01 & .55 & -.12 & .61 \\
\hline Zr & .19 & .01 & .39 & -.02 & -.36 & .94 & -.19 & .25 & .25 & -.21 & -.35 & -.05 & .31 & .19 & .18 & .11 \\
\hline La -...... & -.00 & .03 & .10 & .02 & -.17 & .61 & -.24 & .41 & .28 & -.04 & -.03 & -.16 & -.18 & .20 & -.17 & .12 \\
\hline $\mathrm{Ce}$ & -.02 & .08 & .10 & .03 & -.16 & .68 & -.21 & .38 & .31 & -.02 & -.00 & -.17 & -.14 & .28 & -.19 & .16 \\
\hline Nd & -.02 & .13 & .14 & .05 & -.17 & .80 & -.15 & .26 & .34 & -.04 & -.02 & -.11 & -.01 & .40 & -.13 & .21 \\
\hline Sm - & -.10 & .30 & .13 & .08 & -.10 & .83 & -.01 & .21 & .47 & .11 & .09 & -.08 & .02 & .55 & -.22 & .36 \\
\hline Eu & .36 & -.21 & .37 & -.22 & -.47 & .73 & -.32 & .09 & .04 & -.42 & -.58 & -.15 & .45 & .00 & .36 & -.09 \\
\hline Gd - & -.08 & .34 & .16 & -.02 & .01 & .60 & .03 & .06 & .37 & .08 & .12 & .06 & .05 & .49 & .01 & .33 \\
\hline Tb & -.18 & .54 & -.01 & .08 & .01 & .72 & .16 & .16 & .61 & .31 & .29 & -.07 & -.06 & .74 & -.33 & .54 \\
\hline Tm - & -.25 & .69 & -.01 & .35 & .10 & .58 & .24 & .13 & .67 & .39 & .38 & -.09 & -.06 & .81 & -.36 & .72 \\
\hline Yb-1-_-_- & -.26 & .66 & .01 & .15 & .11 & .59 & .24 & .09 & .63 & .44 & .41 & -.06 & -.05 & .82 & -.35 & .61 \\
\hline Lu - & -.24 & .65 & .02 & .25 & .11 & .59 & .22 & .08 & .60 & .42 & .40 & -.07 & -.04 & .80 & -.33 & .59 \\
\hline
\end{tabular}


APPENDIX VI.-Correlation matrix-Continued

\begin{tabular}{|c|c|c|c|c|c|c|c|c|c|c|c|c|c|c|c|c|}
\hline & Th & $\mathbf{U}$ & $\mathbf{w}$ & $\mathbf{Y}$ & $\mathrm{Zn}$ & $\mathrm{Zr}$ & La & $\mathrm{Ce}$ & Nd & $\mathrm{Sm}$ & $\mathbf{E u}$ & Gd & $\mathrm{Tb}$ & $\mathrm{Tm}$ & $\mathrm{Yb}$ & Lu \\
\hline $\mathrm{SiO}_{2}$ & 0.40 & 0.35 & 0.31 & -0.03 & -0.28 & -0.66 & -0.20 & -0.21 & -0.27 & -0.21 & -0.61 & -0.24 & -0.03 & 0.00 & 0.01 & -0.01 \\
\hline $\mathrm{Al}_{2} \mathrm{O}_{3} \ldots$ & -.44 & -.34 & -.39 & -.30 & -.04 & .28 & -.09 & -.12 & -.13 & -.20 & .28 & -.10 & -.36 & -.33 & -.33 & -.32 \\
\hline $\mathrm{Fe}_{2}^{2} \mathrm{O}_{3}^{3}$ & -.19 & -.20 & -.24 & .20 & .35 & .61 & .27 & .30 & .40 & .38 & .55 & .39 & .27 & .18 & .19 & .20 \\
\hline $\mathrm{FeO}$ & -.38 & -.38 & -.22 & .26 & .47 & .81 & .32 & .37 & .52 & .51 & .81 & .39 & .33 & .24 & .22 & .24 \\
\hline MgO & -.46 & -.38 & -.37 & -.14 & -.00 & .28 & -.10 & -.10 & -.02 & -.06 & .41 & .08 & -.14 & -.13 & -.13 & -.11 \\
\hline $\mathrm{CaO}$ & -.54 & -.47 & -.38 & -.13 & .01 & .35 & -.09 & -.09 & .01 & -.02 & .54 & .06 & -.14 & -.13 & -.13 & -.11 \\
\hline $\mathrm{Na}_{2} \mathrm{O}$ & -.27 & -.17 & -.26 & .21 & .43 & .64 & .05 & .09 & .25 & .27 & .57 & .29 & .21 & .17 & .18 & .18 \\
\hline $\mathrm{K}_{2} \mathrm{O}$ & .56 & .41 & .40 & .02 & -.12 & -.33 & .27 & .23 & .03 & -.01 & -.55 & -.11 & .01 & .02 & .01 & -.00 \\
\hline $\mathrm{H}_{2} \mathrm{O}^{+}$ & -.01 & .09 & .15 & -.06 & -.08 & -.17 & -.19 & -.19 & -.16 & -.14 & -.15 & -.06 & -.11 & -.07 & -.08 & -.10 \\
\hline $\mathrm{TiO}_{2}$ & -.47 & -.43 & -.35 & -.06 & .11 & .54 & .10 & .12 & .19 & .14 & .61 & .16 & -.02 & -.06 & -.07 & -.06 \\
\hline $\mathrm{P}_{2} \mathrm{O}_{5}$ & -.43 & -.32 & -.35 & -.18 & .01 & .22 & -.17 & -.16 & -.08 & -.09 & .33 & .00 & -.19 & -.12 & -.18 & -.16 \\
\hline MnO & -.29 & -.21 & -.13 & .03 & .23 & .38 & -.02 & .00 & .06 & .08 & .47 & .08 & -.00 & .04 & -.02 & .01 \\
\hline Cl - & .19 & .11 & .16 & .33 & .23 & .36 & .34 & .36 & .41 & .37 & .23 & .33 & .35 & .31 & .33 & .35 \\
\hline F -... & .65 & .63 & .52 & .69 & .48 & .06 & .14 & .20 & .27 & .42 & -.13 & .41 & .61 & .70 & .71 & .72 \\
\hline $\mathrm{Fe}$ as $\mathrm{FeO}$ & -.36 & -.37 & -.24 & .27 & .48 & .83 & .34 & .40 & .54 & .53 & .82 & .43 & .35 & .25 & .24 & .25 \\
\hline $\mathrm{Na}_{2} \mathrm{O} / \mathrm{K}_{2} \mathrm{O}$ & -.45 & -.34 & -.36 & .06 & .22 & .43 & -.12 & -.08 & .09 & .11 & .56 & .20 & .06 & .04 & .05 & .07 \\
\hline Ba -................ & -.53 & -.49 & -.25 & -.25 & -.09 & .19 & -.00 & -.02 & -.02 & -.10 & .36 & -.08 & -.18 & -.25 & -.26 & -.24 \\
\hline $\mathrm{Be}$ & .67 & .70 & .49 & .68 & .54 & .01 & .03 & .08 & .13 & .30 & -.21 & .34 & .54 & .69 & .66 & .65 \\
\hline 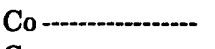 & -.30 & -.27 & -.29 & .02 & .15 & .39 & .10 & .10 & .14 & .13 & .37 & .16 & -.01 & -.01 & .01 & .02 \\
\hline 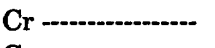 & .17 & .20 & .14 & .27 & .25 & -.02 & .02 & .03 & .05 & .08 & -.22 & -.02 & .08 & .35 & .15 & .25 \\
\hline Cs -.-.-.-- & .56 & .60 & .49 & .10 & -.20 & -.36 & -.17 & -.16 & -.17 & -.10 & -.47 & .01 & .01 & .10 & .11 & .11 \\
\hline Hf -...-...- & .01 & -.05 & .06 & .63 & .78 & .94 & .61 & .68 & .80 & .83 & .73 & .60 & .72 & .58 & .59 & .59 \\
\hline Li (-........... & .50 & .44 & .27 & .26 & .24 & -.19 & -.24 & -.21 & -.15 & -.01 & -.32 & .03 & .16 & .24 & .24 & .22 \\
\hline Mo -.......... & .18 & .13 & .25 & .12 & .17 & .25 & .41 & .38 & .26 & .21 & .09 & .06 & .16 & .13 & .09 & .08 \\
\hline $\mathrm{Nb}$ & .44 & .43 & .37 & .68 & .74 & .25 & .28 & .31 & .34 & .47 & .04 & .37 & .61 & .67 & .63 & .60 \\
\hline 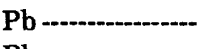 & .55 & .47 & .47 & .40 & .38 & -.21 & -.04 & -.02 & -.04 & .11 & -.42 & .08 & .31 & .39 & .44 & .42 \\
\hline Rb -....- & .89 & .84 & .67 & .38 & .08 & -.35 & -.03 & -.00 & -.02 & .09 & -.58 & .12 & .29 & .38 & .41 & .40 \\
\hline Sb - & .22 & .20 & .03 & -.02 & .01 & -.05 & -.16 & -.17 & -.11 & -.08 & -.15 & .06 & -.07 & -.09 & -.06 & -.07 \\
\hline Sc - - & -.53 & -.44 & -.34 & -.07 & -.01 & .31 & -.18 & -.14 & -.01 & .02 & .45 & .05 & -.06 & -.06 & -.05 & -.04 \\
\hline Sn -...- & .59 & .65 & .51 & .84 & .55 & .19 & .20 & .28 & .40 & .55 & .00 & .49 & .74 & .81 & .82 & .80 \\
\hline Sr -.................. & -.55 & -.44 & -.44 & -.33 & -.12 & .18 & -.17 & -.19 & -.13 & -.22 & .36 & .01 & -.33 & -.36 & -.35 & -.33 \\
\hline Ta -................. & .52 & .56 & .36 & .64 & .61 & .11 & .12 & .16 & .21 & .36 & -.09 & .33 & .54 & .72 & .61 & .59 \\
\hline Th & 1.00 & .84 & .65 & .36 & .06 & -.23 & .20 & .21 & .16 & .20 & -.45 & .21 & .34 & .36 & .39 & .39 \\
\hline U U & .84 & 1.00 & .59 & .45 & .05 & -.27 & -.04 & -.02 & .01 & .10 & -.46 & .20 & .30 & .46 & .47 & .47 \\
\hline W & .65 & .59 & 1.00 & .38 & .18 & -.12 & .13 & $\cdot .17$ & .13 & .22 & -.28 & .16 & .35 & .39 & .43 & .42 \\
\hline Y - & .36 & .45 & .38 & 1.00 & .75 & .41 & .36 & .46 & .62 & .78 & .29 & .65 & .93 & .95 & .96 & .96 \\
\hline Zn & .06 & .05 & .18 & .75 & 1.00 & .64 & .47 & .54 & .65 & .76 & .50 & .55 & .78 & .68 & .68 & .67 \\
\hline $\mathrm{Zr}$ & -.23 & -.27 & -.12 & .41 & .64 & 1.00 & .60 & .64 & .74 & .72 & .85 & .49 & .52 & .37 & .36 & .36 \\
\hline La -...-. & .20 & -.04 & .13 & .36 & .47 & .60 & 1.00 & .98 & .87 & .72 & .41 & .46 & .52 & .29 & .28 & .27 \\
\hline$\overline{\mathrm{Ce}}$ & .21 & -.02 & .17 & .46 & .54 & .64 & .98 & 1.00 & .93 & .82 & .48 & .53 & .63 & .41 & .39 & .38 \\
\hline Nd -..- & .16 & .01 & .13 & .62 & .65 & .74 & .87 & .93 & 1.00 & .94 & .62 & .65 & .79 & .57 & .56 & .55 \\
\hline Sm -.... & .20 & .10 & .22 & .78 & .76 & .72 & .72 & .82 & .94 & 1.00 & .60 & .70 & .91 & .74 & .74 & .73 \\
\hline Eu & -.45 & -.46 & -.28 & .29 & .50 & .85 & .41 & .48 & .62 & .60 & 1.00 & .42 & .43 & .28 & .25 & .26 \\
\hline Gd - & .21 & .20 & .16 & .65 & .55 & .49 & .46 & .53 & .65 & .70 & .42 & 1.00 & .70 & .60 & .62 & .61 \\
\hline Tb & .34 & .30 & .35 & .93 & .78 & .52 & .52 & .63 & .79 & .91 & .43 & .70 & 1.00 & .89 & .91 & .90 \\
\hline $\operatorname{Tm} \ldots$ & .36 & .46 & .39 & .95 & .68 & .37 & .29 & .41 & .57 & .74 & .28 & .60 & .89 & 1.00 & .96 & .96 \\
\hline Yb -...-........... & .39 & .47 & .43 & .96 & .68 & .36 & .28 & .39 & .56 & .74 & .25 & .62 & .91 & .96 & 1.00 & 1.00 \\
\hline Lu -...-. & .39 & .47 & .42 & .96 & .67 & .36 & .27 & .38 & .55 & .73 & .26 & .61 & .90 & .96 & 1.00 & 1.00 \\
\hline
\end{tabular}


APPENDIX VII.-Phenocryst assemblages and modal analyses of porphyritic obsidians

[Compositions given in appendixes I, II, III, and IV. +, mineral present but no modal data available; (?), uncertain identification; -, not recorded. All accessories < 0.1 percent. Al, allanite; ap, apatite; gr, granophyric intergrowths of quartz and alkali feldspar; po, pyrrhotite; z, zircon; s, sphene

\begin{tabular}{|c|c|c|c|c|c|c|c|c|c|}
\hline $\begin{array}{l}\text { Sample number } \\
\text { Collection number }\end{array}$ & $\begin{array}{c}1 \\
190\end{array}$ & $\begin{array}{c}2 \\
56\end{array}$ & $\begin{array}{c}3 \\
214\end{array}$ & $\begin{array}{c}4 \\
39\end{array}$ & $\begin{array}{c}6 \\
45\end{array}$ & $\begin{array}{c}8 \\
187\end{array}$ & $\begin{array}{c}9 \\
189\end{array}$ & $\begin{array}{c}11 \\
8-3 A v\end{array}$ & $\begin{array}{c}13 \\
9-2 v\end{array}$ \\
\hline \multicolumn{10}{|l|}{ Phenocrysts: } \\
\hline Quartz - & - & - & .3 & - & - & - & - & - & - \\
\hline Alkali feldspar -..... & - & - & $?$ & - & - & - & - & - & - \\
\hline Plagioclase - & 4.7 & .7 & 5.4 & 2.7 & $<.1$ & 9.6 & 6.1 & + & + \\
\hline Olivi ne -.._-_._._._. & - & $<.1$ & - & - & - & - & - & $?$ & $?$ \\
\hline Clinopyroxene --..-- & - & .4 & .4 & - & $<.1$ & - & - & + & + \\
\hline Orthopyroxene -...... & - & - & .3 & - & - & 1.3 & .8 & + & + \\
\hline Amphibole -.............. & $<.1$ & - & - & - & - & - & - & - & + \\
\hline Biotite - & .8 & - & - & .5 & - & - & - & - & - \\
\hline Fe-Ti-oxides -_._-_._-_..- & $<.1$ & - & .2 & .3 & - & $<0.1$ & $<.1$ & + & + \\
\hline Others --..-...-..-..- & $\mathbf{z} ?$ & - & ap & $\operatorname{ap}, z$ & 一 & 一 & - & - & 一 \\
\hline 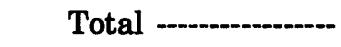 & 5.5 & 1.1 & 6.6 & 3.5 & $<.1$ & 10.9 & 6.9 & - & - \\
\hline Xenoliths - & - & $<.1$ & - & - & - & - & - & + & - \\
\hline
\end{tabular}

\begin{tabular}{|c|c|c|c|c|c|c|c|c|c|}
\hline $\begin{array}{l}\text { Sample number } \\
\text { Collection number }\end{array}$ & $\begin{array}{c}15 \\
9-16 v\end{array}$ & $\begin{array}{c}17 \\
9-19 v\end{array}$ & $\begin{array}{c}19 \\
222\end{array}$ & $\begin{array}{c}20 \\
223\end{array}$ & $\begin{array}{c}21 \\
224\end{array}$ & $\begin{array}{c}22 \\
144\end{array}$ & $\begin{array}{c}24 \\
159\end{array}$ & $\begin{array}{c}31 \\
161\end{array}$ & $\begin{array}{l}36 \\
52\end{array}$ \\
\hline \multicolumn{10}{|l|}{ Phenocrysts: } \\
\hline Quartz & - & - & - & - & - & - & - & - & - \\
\hline Alkali feldspar -.....- & - & - & - & - & - & - & - & - & - \\
\hline Plagioclase - & + & + & 7.5 & 10.0 & 6.1 & $<.1$ & 1.1 & $<.1$ & $<.1$ \\
\hline Clinopyroxene --.---- & + & + & - & .8 & .3 & $<.1$ & - & - & - \\
\hline Orthopyroxene -...-. & + & + & .8 & .4 & .6 & $<.1$ & $<.1$ & - & - \\
\hline Amphibole -............ & + & + & $<.1$ & - & - & - & - & $<.1$ & - \\
\hline Biotite - & - & - & & - & - & - & - & - & $<.1$ \\
\hline Fe-Ti-oxides -_-_-_-_- & + & + & .2 & .4 & .3 & $<.1$ & $<.1$ & - & - \\
\hline Others - & - & - & - & - & - & 一 & - & gr & - \\
\hline Total -.........- & - & - & 8.5 & 11.6 & 7.3 & $<.1$ & 1.1 & $<.1$ & $<.1$ \\
\hline Xenoliths - & + & - & 一 & - & - & - & - & - & - \\
\hline
\end{tabular}




\begin{tabular}{|c|c|c|c|c|c|c|c|c|c|}
\hline $\begin{array}{l}\text { Sample number } \\
\text { Collection number-a- }\end{array}$ & $\begin{array}{c}41 \\
143\end{array}$ & $\begin{array}{l}45 \\
53\end{array}$ & $\begin{array}{c}46 \\
149\end{array}$ & $\begin{array}{c}47 \\
7\end{array}$ & $\begin{array}{c}48 \\
150\end{array}$ & $\begin{array}{c}49 \\
148\end{array}$ & $\begin{array}{c}51 \\
\text { MC73-1A }\end{array}$ & $\begin{array}{c}53 \\
\text { M72-21 }\end{array}$ & $\begin{array}{c}54 \\
\text { M72-62 }\end{array}$ \\
\hline \multicolumn{10}{|l|}{ Phenocrysts: } \\
\hline Quartz - & - & - & - & - & - & - & - & - & - \\
\hline Alkali feldspar --..- & - & - & - & - & - & - & .2 & - & .5 \\
\hline Plagioclase --.-- & .6 & $<.1$ & .2 & .8 & $<.1$ & - & .7 & .9 & .2 \\
\hline Olivine & - & - & - & - & - & - & - & - & - \\
\hline Clinopyroxene ------- & - & - & - & - & $<.1$ & - & $<.1$ & - & - \\
\hline Orthopyroxene & .4 & - & $<.1$ & .2 & $<.1$ & - & $<.1$ & .1 & - \\
\hline Amphibole & - & - & - & - & - & - & $<.1$ & - & $<.1$ \\
\hline Biotite - & - & - & - & - & - & - & $<.1$ & $<.1$ & $<.1$ \\
\hline Fe-Ti-oxides - & $<.1$ & - & $<.1$ & $<.1$ & - & $<.1$ & $<.1$ & $<.1$ & $<.1$ \\
\hline Others - & - & - & ap & ap,z? & - & $\mathrm{z} ?$ & $\mathrm{z}$ & - & $\mathrm{z} ?$ \\
\hline Total & 1.0 & $<.1$ & .2 & 1.0 & $<.1$ & $<.1$ & .9 & 1.0 & .7 \\
\hline Xenoliths & - & - & - & - & 0.3 & - & - & - & - \\
\hline $\begin{array}{l}\text { Sample number } \\
\text { Collection number }\end{array}$ & $\begin{array}{l}57 \\
\text { CD3 }\end{array}$ & $\begin{array}{c}58 \\
\mathrm{CD} 4 \mathrm{~A}\end{array}$ & $\begin{array}{c}59 \\
\text { CD5 }\end{array}$ & $\begin{array}{c}60 \\
\text { CD17 }\end{array}$ & $\begin{array}{c}61 \\
\text { CD22 }\end{array}$ & $\begin{array}{c}62 \\
\text { CD7 }\end{array}$ & $\begin{array}{c}63 \\
\mathrm{CD} 20\end{array}$ & $\begin{array}{c}64 \\
\text { CD23 }\end{array}$ & $\begin{array}{c}65 \\
\text { CD30 }\end{array}$ \\
\hline \multicolumn{10}{|l|}{ Phenocrysts: } \\
\hline Quartz & ? & ? & ? & + & + & + & ? & ? & $?$ \\
\hline Alkali feldspar & + & + & + & + & + & + & ? & ? & ? \\
\hline Plagioclase & + & + & + & + & + & + & + & + & + \\
\hline Olivine & - & + & + & + & - & - & - & + & + \\
\hline Clinopyroxene -..---.- & + & + & + & - & + & - & - & + & + \\
\hline Orthopyroxene & + & + & + & - & + & - & - & + & + \\
\hline Amphibole - - & + & + & + & + & + & + & - & + & - \\
\hline Biotite & + & - & + & - & - & - & - & + & + \\
\hline Fe-Ti-oxides & + & + & + & + & + & + & - & + & + \\
\hline Others - - & $\begin{array}{l}\text { ap, } \\
\text { po,z }\end{array}$ & $\begin{array}{r}\text { ap, } \\
\text { po,z }\end{array}$ & $\begin{array}{r}\text { al,ap, } \\
\text { po,z }\end{array}$ & $\begin{array}{r}\text { al, } \\
\text { ap,po }\end{array}$ & $\begin{array}{r}\text { al, } \\
\text { ap,z }\end{array}$ & ap,z & - & $\begin{array}{r}\text { ap, } \\
\text { po,z }\end{array}$ & $\begin{array}{r}\text { al, } \\
\text { ap,po }\end{array}$ \\
\hline Total & .01 & .01 & .01 & 1 & 1 & 2 & .001 & .001 & .01 \\
\hline Xenoliths & - & - & - & - & - & - & - & - & - \\
\hline
\end{tabular}


APPENDIX VII.-Phenocryst assemblages and modal analyses of porphyritic obsidians-Continued

\begin{tabular}{|c|c|c|c|c|c|c|c|c|c|}
\hline $\begin{array}{l}\text { Sample number } \\
\text { Collection number }\end{array}$ & $\begin{array}{c}66 \\
\text { CD33 }\end{array}$ & $\begin{array}{c}67 \\
\text { CD8 }\end{array}$ & $\begin{array}{c}68 \\
\mathrm{CD} 12\end{array}$ & $\begin{array}{c}69 \\
\text { CD14 }\end{array}$ & $\begin{array}{c}70 \\
\text { CD18 }\end{array}$ & $\begin{array}{c}71 \\
\text { CD19 }\end{array}$ & $\begin{array}{c}72 \\
\text { CD21A }\end{array}$ & $\begin{array}{l}73 \\
49\end{array}$ & $\begin{array}{l}74 \\
50\end{array}$ \\
\hline \multicolumn{10}{|l|}{ Phenocrysts: } \\
\hline Quartz - & $?$ & + & + & + & $?$ & $?$ & $?$ & - & - \\
\hline Alkali feldspar --- & $?$ & + & + & + & $?$ & + & + & .7 & 1.4 \\
\hline Plagioclase - & + & + & + & + & $?$ & $?$ & + & 1.1 & .6 \\
\hline Olivine & + & - & + & + & + & + & - & - & $<.1$ \\
\hline Clinopyroxene --.--- & + & - & + & - & - & + & + & 0.1 & $<.1$ \\
\hline Orthopyroxene ----- & + & - & - & - & $?$ & - & + & - & - \\
\hline Amphibole - & + & + & - & + & + & + & + & $<0.1$ & $<.1$ \\
\hline Biotite - & + & - & - & + & + & + & + & - & - \\
\hline Fe-Ti-oxides -----.---- & + & + & + & + & + & + & + & $<0.1$ & $<.1$ \\
\hline \multicolumn{2}{|c|}{ Others -..........ap, } & ap & $\begin{array}{r}\text { al, } \\
\text { ap,z }\end{array}$ & al & $\begin{array}{r}\text { al, } \\
\text { ap,z }\end{array}$ & - & $\begin{array}{r}\text { al,ap, } \\
\text { po,z }\end{array}$ & $\mathbf{z} ?$ & - \\
\hline Total - & .01 & 1 & 1 & 1 & .001 & .01 & - & 1.9 & 2.0 \\
\hline Xenoliths - -............... & - & - & - & - & 0.3 & - & - & - & - \\
\hline $\begin{array}{l}\text { Sample number } \\
\text { Collection number }-. . . . . . . . . .\end{array}$ & $\begin{array}{c}84 \\
151\end{array}$ & $\begin{array}{c}85 \\
152\end{array}$ & $\begin{array}{c}86 \\
185\end{array}$ & $\begin{array}{c}87 \\
188\end{array}$ & $\begin{array}{c}88 \\
191\end{array}$ & 89 & $\begin{array}{c}90 \\
267\end{array}$ & $\begin{array}{c}91 \\
268\end{array}$ & $\begin{array}{c}92 \\
269\end{array}$ \\
\hline Phenocrysts: & & & & & & & & & \\
\hline Quartz --.-..- & $<.1$ & - & 3.5 & 1.8 & 6.2 & + & .6 & + & + \\
\hline Alkali feldspar - & .4 & .1 & 1.6 & 2.2 & 2.6 & + & .3 & + & + \\
\hline Plagioclase --..- & .3 & .1 & .9 & 1.0 & 1.3 & + & $.6 ?$ & - & - \\
\hline Olivine - & - & - & - & - & - & - & - & - & - \\
\hline Clinopyroxene --.---.- & .1 & $<.1$ & - & - & - & - & + & + & - \\
\hline Orthopyroxene ------ & .1 & $<.1$ & - & - & - & - & - & - & - \\
\hline Amphibole -............ & - & - & $<.1$ & - & $<.1$ & - & - & - & - \\
\hline Biotite -.................. & - & - & - & $<.1$ & $<.1$ & - & - & - & - \\
\hline Fe-Ti-oxides --..--...-. & $<.1$ & $<.1$ & $<.1$ & $<.1$ & $<.1$ & - & $<.1$ & + & - \\
\hline Others - - & - & $\mathbf{z} ?$ & - & - & - & - & - & - & - \\
\hline Total - & 0.9 & 0.2 & 6.0 & 5.0 & 10.1 & - & 1.5 & - & - \\
\hline Xenoliths - & - & - & - & - & - & - & - & - & - \\
\hline
\end{tabular}


APPENDIX VII.-Phenocryst assemblages and modal analyses of porphyritic obsidians-Continued

\begin{tabular}{|c|c|c|c|c|c|c|c|c|c|}
\hline $\begin{array}{l}\text { Sample number --- } \\
\text { Collection number---. }\end{array}$ & $\begin{array}{c}95 \\
106\end{array}$ & $\begin{array}{c}96 \\
116\end{array}$ & $\begin{array}{c}98 \\
104\end{array}$ & $\begin{array}{l}102 \\
138\end{array}$ & $\begin{array}{c}105 \\
65 \mathrm{~L}-161 \mathrm{~A}\end{array}$ & $\begin{array}{l}107 \\
48\end{array}$ & $\begin{array}{c}108 \\
53\end{array}$ & $\begin{array}{c}109 \\
47\end{array}$ & $\begin{array}{c}110 \\
27\end{array}$ \\
\hline \multicolumn{10}{|l|}{ Phenocrysts: } \\
\hline Quartz & .9 & .5 & - & .5 & - & - & .2 & - & - \\
\hline Alkali feldspar --_- & 1.0 & - & - & $<.1$ & - & - & .3 & - & $<.1$ \\
\hline Plagioclase - & .8 & 2.9 & $<.1$ & .4 & $<1.0$ & .3 & .4 & .6 & - \\
\hline Olivine & - & - & - & - & - & - & - & - & - \\
\hline Clinopyroxene -....-. & - & 1.8 & - & - & - & - & - & - & - \\
\hline Orthopyroxene - & - & - & - & - & - & - & - & - & - \\
\hline Amphibole & - & 4.7 & - & - & - & - & - & - & - \\
\hline Biotite & - & - & - & - & - & $<.1$ & - & - & $<.1$ \\
\hline Fe-Ti-oxides & $<.1$ & $<.1$ & - & - & - & - & $<.1$ & - & $<.1$ \\
\hline Others - & $\mathrm{z} ?$ & - & - & - & - & - & - & - & - \\
\hline Total & 2.7 & 9.9 & $<.1$ & .9 & $<1.0$ & .3 & .9 & .6 & $<.1$ \\
\hline Xenoliths & - & - & - & - & - & - & - & - & - \\
\hline Sample number & 111 & 116 & 119 & 121 & 124 & 128 & 141 & 143 & 144 \\
\hline Collection number & 66L-23-A & 194 & 76 & 76-79 & 130 & P317 & 273 & 277 & 278 \\
\hline \multicolumn{10}{|l|}{ Phenocrysts: } \\
\hline Quartz & + & $<.1$ & - & - & - & .45 & - & - & 1.7 \\
\hline Alkali feldspar & - & $<.1$ & 2.7 & 1.8 & 4.3 & .5 & - & - & .3 \\
\hline Plagioclase -- & 1.0 & $<.1$ & .3 & 3.1 & .4 & - & 1.0 & $<.1$ & .3 \\
\hline Olivine - & - & - & - & - & - & .03 & - & - & - \\
\hline Clinopyroxene -........ & - & - & - & 0.1 & - & .02 & - & - & - \\
\hline Orthopyroxene -..--.- & - & - & - & $<.1$ & - & - & - & - & .1 \\
\hline Amphibole - & - & - & - & 1.1 & - & - & - & - & - \\
\hline Biotite -... & - & - & - & .3 & - & - & - & - & - \\
\hline Fe-Ti-oxides & - & - & .2 & .3 & $<.1$ & $<.1$ & - & $<.1$ & .1 \\
\hline Others - & - & - & $\mathrm{z}$ ? & $\mathrm{z} ?$ & - & - & - & $\mathrm{z} ?$ & - \\
\hline Total …........... & 1.0 & $<.1$ & 3.2 & 6.8 & 4.7 & 1.00 & 1.0 & $<.1$ & 2.5 \\
\hline Xenoliths & - & - & - & - & - & - & - & - & - \\
\hline
\end{tabular}


APPENDIX VII.-Phenocryst assemblages and modal analyses of porphyritic obsidians-Continued

\begin{tabular}{|c|c|c|c|c|c|c|c|c|c|}
\hline $\begin{array}{l}\text { Sample number } \\
\text { Collection number }\end{array}$ & $\begin{array}{l}145 \\
279\end{array}$ & $\begin{array}{l}146 \\
125\end{array}$ & $\begin{array}{l}147 \\
126\end{array}$ & $\begin{array}{l}148 \\
127\end{array}$ & $\begin{array}{l}151 \\
129\end{array}$ & $\begin{array}{l}154 \\
133\end{array}$ & $\begin{array}{l}156 \\
186\end{array}$ & $\begin{array}{l}157 \\
192\end{array}$ & $\begin{array}{l}158 \\
193\end{array}$ \\
\hline \multicolumn{10}{|l|}{ Phenocrysts: } \\
\hline Quartz & 2.8 & - & - & - & - & - & - & - & - \\
\hline Alkali feldspar ----- & .4 & - & - & $<.1 ?$ & - & - & - & - & - \\
\hline Plagioclase & .4 & $<.1$ & 1.6 & - & - & .6 & 1.1 & 2.4 & 3.3 \\
\hline Olivine & - & - & - & - & - & - & $<.1$ & $<.1$ & $<.1$ \\
\hline Clinopyroxene -.--_- & - & - & - & - & $<.1$ & - & .1 & .3 & .2 \\
\hline Orthopyroxene & - & - & - & - & - & - & - & - & - \\
\hline Amphibole -.......... & .4 & - & - & - & - & - & - & - & - \\
\hline Biotite & .3 & - & - & - & - & .2 & - & - & - \\
\hline Fe-Ti-oxides & - & - & - & - & - & $<.1$ & $<.1$ & .1 & .2 \\
\hline Others & - & - & - & $\mathbf{z}$ & ap & - & - & - & $\mathrm{z} ?$ \\
\hline Total … & 4.3 & $<.1$ & 1.6 & $<.1$ & $<.1$ & .8 & 1.2 & 2.8 & 3.7 \\
\hline Xenoliths & - & - & - & - & - & - & - & - & 1.7 \\
\hline
\end{tabular}

\begin{tabular}{|c|c|c|c|c|c|c|c|c|c|}
\hline $\begin{array}{l}\text { Sample number } \\
\text { Collection number }\end{array}$ & $\begin{array}{l}161 \\
225\end{array}$ & $\begin{array}{l}162 \\
203\end{array}$ & $\begin{array}{l}163 \\
204\end{array}$ & $\begin{array}{l}166 \\
221\end{array}$ & $\begin{array}{l}167 \\
213\end{array}$ & $\begin{array}{l}168 \\
180\end{array}$ & $\begin{array}{c}169 \\
1\end{array}$ & $\begin{array}{c}170 \\
11\end{array}$ & $\begin{array}{c}171 \\
42\end{array}$ \\
\hline \multicolumn{10}{|l|}{ Phenocrysts: } \\
\hline Quartz - & - & - & - & - & - & - & 1.4 & + & - \\
\hline Alkali feldspar --.-- & - & - & - & - & - & 1.0 & - & - & - \\
\hline Plagioclase & - & .1 & $<.1$ & .7 & .6 & $+?$ & 1.1 & + & $<.1$ \\
\hline Olivine - & - & - & - & - & - & + & $<.1$ & + & - \\
\hline Clinopyroxene -.--.-- & - & - & - & - & .4 & + & $<.1$ & + & $<.1$ \\
\hline Orthopyroxene --..- & - & - & - & - & - & - & - & - & - \\
\hline Amphibole --.---- & - & .1 & $<.1$ & .1 & - & - & - & - & - \\
\hline Biotite - & - & - & - & - & - & - & - & - & - \\
\hline Fe-Ti-oxides --.-- & .1 & - & $<.1$ & - & $<.1$ & - & $<.1$ & + & $<.1$ \\
\hline Others - & - & ap & - & - & - & - & $\mathbf{z}$ & - & - \\
\hline Total & .1 & .2 & $<.1$ & .8 & 1.0 & $>1.0$ & 2.5 & - & $<.1$ \\
\hline Xenoliths & - & - & - & - & - & - & - & - & - \\
\hline
\end{tabular}


APPENDIX VII.-Phenocryst assemblages and modal analyses of porphyritic obsidians-Continued

\begin{tabular}{|c|c|c|c|c|c|c|c|c|c|}
\hline $\begin{array}{l}\text { Sample number } \\
\text { Collection number }\end{array}$ & $\begin{array}{l}172 \\
177\end{array}$ & $\begin{array}{l}173 \\
178\end{array}$ & $\begin{array}{l}174 \\
176\end{array}$ & $\begin{array}{c}176 \\
61\end{array}$ & $\begin{array}{c}178 \\
57\end{array}$ & $\begin{array}{l}179 \\
209\end{array}$ & $\begin{array}{c}183 \\
67\end{array}$ & $\begin{array}{c}184 \\
66\end{array}$ & $\begin{array}{l}185 \\
211\end{array}$ \\
\hline \multicolumn{10}{|l|}{ Phenocrysts: } \\
\hline Quartz & - & - & - & - & - & - & - & - & - \\
\hline Alkali feldspar ---- & - & - & - & - & - & - & - & - & - \\
\hline Plagioclase - & + & + & + & 1.5 & 1.1 & .1 & .8 & .8 & - \\
\hline Olivine - & + & - & + & - & $<.1$ & - & - & - & - \\
\hline Clinopyroxene ------- & + & + & + & .7 & $<.1$ & $<.1$ & - & $<.1$ & - \\
\hline Orthopyroxene -...-- & - & - & - & .1 & - & - & - & - & - \\
\hline Amphibole …_- & + & + & - & - & - & - & - & - & - \\
\hline Biotite - & - & - & - & - & - & $<.1$ & - & .2 & - \\
\hline Fe-Ti-oxides ---.-- & + & - & + & $<.1$ & $<.1$ & $<.1$ & $<.1$ & $<.1$ & $<.1$ \\
\hline Others - & - & - & - & - & - & - & - & - & - \\
\hline Total & - & - & - & 2.3 & 1.1 & .1 & .8 & 1.0 & $<.1$ \\
\hline Xenoliths & - & - & - & 3.5 & - & - & - & - & - \\
\hline
\end{tabular}

\begin{tabular}{|c|c|c|c|c|c|c|c|c|c|}
\hline $\begin{array}{l}\text { Sample number } \\
\text { Collection number }\end{array}$ & $\begin{array}{l}186 \\
168\end{array}$ & $\begin{array}{l}188 \\
145\end{array}$ & $\begin{array}{l}189 \\
165\end{array}$ & $\begin{array}{c}190 \\
38\end{array}$ & $\begin{array}{l}192 \\
167\end{array}$ & $\begin{array}{l}193 \\
169\end{array}$ & $\begin{array}{l}194 \\
207\end{array}$ & $\begin{array}{l}195 \\
208\end{array}$ & $\begin{array}{l}197 \\
110\end{array}$ \\
\hline \multicolumn{10}{|l|}{ Phenocrysts: } \\
\hline Quartz & 1.8 & - & - & - & - & - & - & 2.3 & - \\
\hline Alkali feldspar --.-- & - & - & - & $<.1 ?$ & - & - & - & - & - \\
\hline Plagioclase & 2.1 & $<.1$ & 2.9 & .3 & 3.3 & 7.4 & 9.2 & 2.3 & 5.5 \\
\hline Olivine - & - & - & - & - & - & - & - & - & - \\
\hline Clinopyroxene ----- & - & $<.1$ & .1 & - & - & $<.1$ & .9 & - & .2 \\
\hline Orthopyroxene & - & $<.1$ & .2 & - & - & .3 & 1.5 & $<.1$ & .8 \\
\hline Amphibole -...-...- & - & .1 & - & - & $<.1$ & - & - & $<.1$ & - \\
\hline Biotite - & 1.0 & - & - & $<.1$ & .7 & - & - & - & - \\
\hline Fe-Ti-oxides -- & $<.1$ & $<.1$ & .1 & $<.1$ & .3 & $<.1$ & $<.1$ & $<.1$ & .6 \\
\hline Others & ap & ap & - & - & ap & - & - & $\mathbf{z}$ & - \\
\hline Total …_....... & 4.9 & .1 & 3.3 & .3 & 4.3 & 7.7 & 11.6 & 5.6 & 7.1 \\
\hline Xenoliths & - & - & - & - & - & - & - & - & - \\
\hline
\end{tabular}




\section{APPENDIX VII}

APPENDIX VII.-Phenocryst assemblages and modal analyses of porphyritic obsidians-Continued

\begin{tabular}{|c|c|c|c|c|c|c|c|c|c|}
\hline $\begin{array}{l}\text { Sample number } \\
\text { Collection number }\end{array}$ & $\begin{array}{l}198 \\
108\end{array}$ & $\begin{array}{l}199 \\
107\end{array}$ & $\begin{array}{l}200 \\
114\end{array}$ & $\begin{array}{l}201 \\
113\end{array}$ & $\begin{array}{l}202 \\
109\end{array}$ & $\begin{array}{l}203 \\
101\end{array}$ & $\begin{array}{l}204 \\
112\end{array}$ & $\begin{array}{l}205 \\
170\end{array}$ & $\begin{array}{l}206 \\
171\end{array}$ \\
\hline \multicolumn{10}{|l|}{ Phenocrysts: } \\
\hline Quartz & 1.2 & - & - & 1.2 & - & - & - & - & - \\
\hline Alkali feldspar & .5 & - & - & - & .3 & - & - & - & - \\
\hline Plagioclase & .8 & .1 & .7 & 1.8 & .1 & 1.3 & .4 & 6.9 & 4.5 \\
\hline Olivine & - & - & - & - & - & - & - & $<.1$ & - \\
\hline Clinopyroxene--..--.. & - & - & $<.1$ & $<.1$ & - & .1 & - & .2 & - \\
\hline Orthopyroxene & $<.1$ & - & - & $<.1$ & - & - & $<.1$ & .3 & .3 \\
\hline Amphibole -......... & .2 & .2 & - & .3 & - & - & - & - & - \\
\hline Biotite & - & - & - & - & - & - & - & - & - \\
\hline Fe-Ti-oxides & $<.1$ & $<.1$ & .3 & $<.1$ & $<.1$ & $<.1$ & $<.1$ & $<.1$ & .2 \\
\hline Others & $\mathbf{z} ?$ & $\mathrm{z} ?$ & ap & - & $\mathrm{z} ?$ & - & - & - & - \\
\hline Total - & 2.7 & .3 & 1.0 & 3.3 & .4 & 1.4 & .4 & 7.4 & 5.0 \\
\hline Xenoliths & - & .2 & - & - & - & - & - & 2.0 & - \\
\hline
\end{tabular}

\begin{tabular}{|c|c|c|c|c|c|c|c|}
\hline $\begin{array}{l}\text { Sample number } \\
\text { Collection number }\end{array}$ & $\begin{array}{l}207 \\
172\end{array}$ & $\begin{array}{l}208 \\
173\end{array}$ & $\begin{array}{l}209 \\
174\end{array}$ & $\begin{array}{c}211 \\
70\end{array}$ & $\begin{array}{c}213 \\
58\end{array}$ & $\begin{array}{c}214 \\
64\end{array}$ & $\begin{array}{c}216 \\
3\end{array}$ \\
\hline \multicolumn{8}{|l|}{ Phenocrysts: } \\
\hline Quartz & - & - & - & - & - & - & - \\
\hline Alkali feldspar & - & - & - & - & - & - & 0.8 \\
\hline Plagioclase --. & 18.3 & 7.5 & 4.4 & $<.1$ & .4 & $<.1$ & 1.3 \\
\hline Olivine & - & - & - & - & - & $<.1$ & - \\
\hline Clinopyroxene -...... & $<.1$ & - & $<.1$ & - & - & - & - \\
\hline Orthopyroxene & 1.6 & .3 & $<.1$ & - & - & - & $<.1$ \\
\hline Amphibole & .2 & .2 & - & - & - & - & - \\
\hline Biotite & - & - & - & - & - & - & - \\
\hline Fe-Ti-oxides & .5 & $<.1$ & .2 & $<.1$ & $<.1$ & $<.1$ & .2 \\
\hline Others & - & - & - & - & $\mathrm{z} ?$ & - & $\mathrm{z} ?$ \\
\hline Total -............ & 20.6 & 8.0 & 4.6 & $<.1$ & .4 & $<.1$ & 2.3 \\
\hline Xenoliths & - & 0.3 & - & - & - & - & - \\
\hline
\end{tabular}


APPENDIX VII.-Phenocryst assemblages and modal analyses of porphyritic obsidians-Continued

\begin{tabular}{|c|c|c|c|c|c|c|c|c|c|}
\hline $\begin{array}{l}\text { Sample number } \\
\text { Collection number }-. .-\ldots-. .-\end{array}$ & $\begin{array}{l}219 \\
201\end{array}$ & $\begin{array}{l}220 \\
261\end{array}$ & $\begin{array}{l}221 \\
179\end{array}$ & $\begin{array}{l}222 \\
181\end{array}$ & $\begin{array}{c}223 \\
63\end{array}$ & $\begin{array}{c}224 \\
59\end{array}$ & $\begin{array}{c}225 \\
69\end{array}$ & $\begin{array}{l}228 \\
258\end{array}$ & $\begin{array}{l}231 \\
259\end{array}$ \\
\hline \multicolumn{10}{|l|}{ Phenocrysts: } \\
\hline Quartz & .3 & - & - & - & - & - & - & - & 2.3 \\
\hline Alkali feldspar & - & - & - & - & - & - & - & - & 3.8 \\
\hline Plagioclase & - & + & + & + & $<.1$ & .8 & .3 & $<.1$ & 3.6 \\
\hline Olivine - & - & 一 & - & - & - & - & - & - & - \\
\hline Clinopyroxene -....... & - & - & + & + & - & - & - & - & .1 \\
\hline Orthopyroxene --..- & - & + & - & - & - & - & - & - & - \\
\hline Amphibole -......... & - & - & - & - & - & - & - & - & - \\
\hline Biotite - & - & - & - & - & - & - & - & - & 0.2 \\
\hline Fe-Ti-oxides -..-.-.-- & - & + & - & - & $<.1$ & $<.1$ & $<.1$ & $<.1$ & $<.1$ \\
\hline Others & - & - & - & - & - & - & - & - & - \\
\hline Total -................ & .3 & - & - & - & $<.1$ & .8 & .3 & $<.1$ & 10.0 \\
\hline Xenoliths -................ & - & - & - & - & - & - & - & - & .9 \\
\hline
\end{tabular}

No modal information is available for specimens 227, 232-2401

\begin{tabular}{|c|c|c|c|c|c|c|c|c|c|c|}
\hline Sample number -.....-..- & 246 & 247 & 248 & 261 & 273 & 278 & 279 & 280 & 281 & 283 \\
\hline \multicolumn{11}{|l|}{ Phenocrysts: } \\
\hline Quartz & - & - & - & - & - & - & - & - & - & .1 \\
\hline Alkali feldspar -..-- & - & - & - & - & - & - & - & - & - & .1 \\
\hline Plagioclase -...-_- & 20 & + & - & 5 & - & 5.6 & + & 1.2 & + & .1 \\
\hline Olivine & - & - & - & - & - & - & - & - & - & - \\
\hline Clinopyroxene --..--..- & 2 & - & $?$ & 3 & $<.1$ & + & - & - & + & $<.1$ \\
\hline Orthopyroxene --..- & 1 & + & - & - & $<.1$ & + & + & .2 & + & $<.1$ \\
\hline Amphibole --_-_. & 2 & + & + & - & - & - & - & - & + & $<.1$ \\
\hline Biotite -................ & - & - & - & - & - & - & - & - & - & $<.1$ \\
\hline Fe-Ti-oxides -..-_..-- & 2 & + & - & 2 & $<.1$ & .1 & - & .2 & - & $<.1$ \\
\hline Others & - & ap & - & - & - & - & - & - & - & - \\
\hline Total & 27 & - & - & 10 & - & 6.3 & - & 1.6 & - & .4 \\
\hline Xenoliths & - & - & - & - & - & - & - & - & + & - \\
\hline
\end{tabular}


APPENDIX VII.-Phenocryst assemblages and modal analyses of porphyritic obsidians-Continued

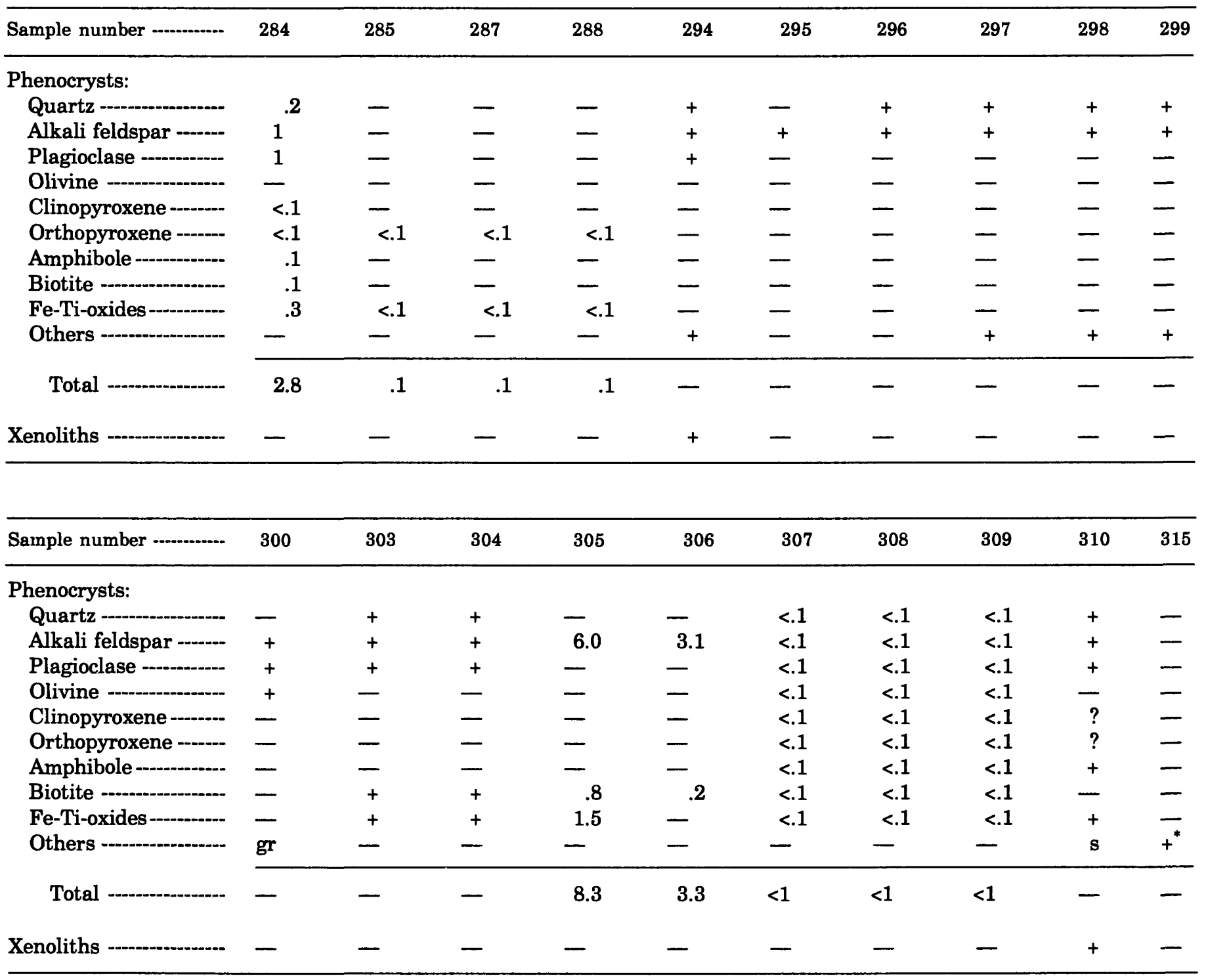

* Spec. 315 -- andalusite, zircon, sillimanite, mica and cordierite. 
APPENDIX VII.-Phenocryst assemblages and modal analyses of porphyritic obsidians-Continued

\begin{tabular}{|c|c|c|c|c|c|c|c|c|c|c|}
\hline Sample number - -...-... & 319 & 321 & 328 & 329 & 335 & 336 & 337 & 338 & 340 & 341 \\
\hline \multicolumn{11}{|l|}{ Plienocrysts: } \\
\hline Quartz & - & - & - & - & + & + & - & + & + & - \\
\hline Plagioclase --..-...-. & + & + & + & + & + & + & - & + & - & + \\
\hline Olivine - & + & - & - & - & - & - & - & - & - & - \\
\hline Clinopyroxene -...-.- & + & + & - & - & - & - & - & + & - & + \\
\hline Amphibole -........... & - & - & - & - & - & - & - & - & + & + \\
\hline Biotite - & - & - & + & + & - & - & - & - & - & + \\
\hline Fe-Ti-oxides - & - & + & $?$ & - & - & - & - & + & - & + \\
\hline Otliers & 一 & - & - & - & - & - & - & - & - & - \\
\hline Total & - & - & - & - & c.15 & c. 15 & - & - & - & $<20$ \\
\hline
\end{tabular}

\begin{tabular}{|c|c|c|c|c|c|c|c|c|c|c|}
\hline Sample number & 342 & 343 & 344 & 347 & 350 & 352 & 354 & 364 & 367 & 368 \\
\hline \multicolumn{11}{|l|}{ Phenocrysts: } \\
\hline Quartz & - & - & - & + & + & + & - & - & - & - \\
\hline Plagioclase - & + & + & 8.78 & + & + & + & + & 14 & + & + \\
\hline 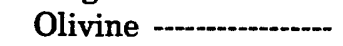 & - & - & - & - & + & - & + & - & - & - \\
\hline Clinopyroxene --.--- & + & + & .29 & + & + & - & + & + & - & - \\
\hline Amphibole - & + & + & .25 & - & + & - & - & - & - & + \\
\hline Biotite - & + & + & - & - & - & - & - & - & - & - \\
\hline Fe-Ti-oxides --..-- & + & + & .56 & + & - & - & + & $<1$ & - & - \\
\hline Others -......... & 一 & - & - & - & - & - & - & ap & - & - \\
\hline Total - & $<20$ & $<20$ & 10.1 & - & - & - & - & 15 & - & - \\
\hline
\end{tabular}

Note: Samples 290, 317, 320, 322-325, 345, 348, and 356-361 are reported as being porphyritic, but the phenocryst assemblages are not specified. 


\section{SELECTED SERIES OF U.S. GEOLOGICAL SURVEY PUBLICATIONS}

\section{Periodicals}

Earthquakes \& Volcanoes (issued bimonthly).

Preliminary Determination of Epicenters (issued monthly).

\section{Technical Books and Reports}

Professional Papers are mainly comprehensive scientific reports of wide and lasting interest and importance to professional scientists and engineers. Included are reports on the results of resource studies and of topographic, hydrologic, and geologic investigations. They also include collections of related papers addressing different aspects of a single scientific topic.

Bulletins contain significant data and interpretations that are of lasting scientific interest but are generally more limited in scope or geographic coverage than Professional Papers. They include the results of resource studies and of geologic and topographic investigations; as well as collections of short papers related to a specific topic.

Water-Supply Papers are comprehensive reports that present significant interpretive results of hydrologic investigations of wide interest to professional geologists, hydrologists, and engineers. The series covers investigations in all phases of hydrology, including hydrogeology, availability of water, quality of water, and use of water.

Circulars present administrative information or important scientific information of wide popular interest in a format designed for distribution at no cost to the public. Information is usually of short-term interest.

Water-Resources Investigations Reports are papers of an interpretive nature made available to the public outside the formal USGS publications series. Copies are reproduced on request unlike formal USGS publications, and they are also available for public inspection at depositories indicated in USGS catalogs.

Open-File Reports include unpublished manuscript reports, maps, and other material that are made available for public consultation at depositories. They are a nonpermanent form of publication that may be cited in other publications as sources of information.

\section{Maps}

Geologic Quadrangle Maps are multicolor geologic maps on topographic bases in 71/2-or 15-minute quadrangle formats (scales mainly $1: 24,000$ or $1: 62,500$ ) showing bedrock, surficial, or engineering geology. Maps generally include brief texts; some maps include structure and columnar sections only.

Geophysical Investigations Maps are on topographic or planimetric bases at various scales; they show results of surveys using geophysical techniques, such as gravity, magnetic, seismic, or radioactivity, which reflect subsurface structures that are of economic or geologic significance. Many maps include correlations with the geology.

Miscellaneous Investigations Series Maps are on planimetric or topographic bases of regular and irregular areas at various scales; they present a wide variety of format and subject matter. The series also includes 7 1/2-minute quadrangle photogeologic maps on planimetric bases which show geology as interpreted from aerial photographs. Series also includes maps of Mars and the Moon.
Coal Investigations Maps are geologic maps on topographic or planimetric bases at various scales showing bedrock or surficial geology, stratigraphy, and structural relations in certain coal-resource areas.

Oil and Gas Investigations Charts show stratigraphic information for certain oil and gas fields and other areas having petroleum potential.

Miscellaneous Field Studies Maps are multicolor or black-andwhite maps on topographic or planimetric bases on quadrangle or irregular areas at various scales. Pre-1971 maps show bedrock geology in relation to specific mining or mineral-deposit problems; post-1971 maps are primarily black-and-white maps on various subjects such as environmental studies or wildemess mineral investigations.

Hydrologic Investigations Atlases are multicolored or black-andwhite maps on topographic or planimetric bases presenting a wide range of geohydrologic data of both regular and irregular areas; principal scale is $1: 24,000$ and regional studies are at $1: 250,000$ scale or smaller.

\section{Catalogs}

Permanent catalogs, as well as some others, giving comprehensive listings of U.S. Geological Survey publications are available under the conditions indicated below from the U.S. Geological Survey, Books and Open-File Reports Section, Federal Center, Box 25425, Denver, CO 80225. (See latest Price and Availability List.)

"Publications of the Geological Survey, 1879- 1961" may be purchased by mail and over the counter in paperback book form and as a set of microfiche.

"Publications of the Geological Survey, 1962- 1970" may be purchased by mail and over the counter in paperback book form and as a set of microfiche.

"Publications of the U.S. Geological Survey, 1971- 1981" may be purchased by mail and over the counter in paperback book form (two volumes, publications listing and index) and as a set of microfiche.

Supplements for 1982, 1983, 1984, 1985, 1986, and for subsequent years since the last permanent catalog may be purchased by mail and over the counter in paperback book form.

State catalogs, "List of U.S. Geological Survey Geologic and Water-Supply Reports and Maps For (State)," may be purchased by mail and over the counter in paperback booklet form only.

"Price and Availability List of U.S. Geological Survey Publications," issued annually, is available free of charge in paperback booklet form only.

Selected copies of a monthly catalog "New Publications of the U.S. Geological Survey" available free of charge by mail or may be obtained over the counter in paperback booklet form only. Those wishing a free subscription to the monthly catalog "New Publications of the U.S. Geological Survey" should write to the U.S. Geological Survey, 582 National Center, Reston, VA 22092.

Note.--Prices of Government publications listed in older catalogs, announcements, and publications may be incorrect. Therefore, the prices charged may differ from the prices in catalogs, announcements, and publications. 
E 